\title{
Bundesrepublik Deutschland
}

Der Bundeskanzler

Bonn, den 23. März 1962

$3-42000-3456 / 61$

An den Herrn

Präsidenten des Deutschen Bundestages

Hiermit übersende ich den von der Bundesregierung beschlossenen

\section{Entwurf eines Gesetzes über Urheberrecht und verwandte Schutzrechte (Urheberrechtsgesetz)}

mit Begründung (Anlage 1). Ich bitte, die Beschlußfassung des Deutschen Bundestages herbeizuführen.

Federführend ist der Bundesminister der Justiz.

Der Bundesrat hat in seiner 240. Sitzung am 2. Februar 1962 gemäß Artikel 76 Abs. 2 des Grundgesetzes beschlossen, zu dem Entwurf - wie aus der Anlage 2 ersichtlich - Stellung zu nehmen. Im übrigen hat der Bundesrat gegen den Entwurf keine Einwendungen erhoben. Er ist der Ansicht, daß das Gesetz seiner Zustimmung bedarf.

Die Auffassung der Bundesregierung zu der Stellungnahme des Bundesrates ist in der Anlage 3 dargelegt.

Der Stellvertreter des Bundeskanzlers

\section{Ludwig Erhard}




\section{Anlage 1}

\section{Entwurf eines Gesetzes \\ über Urheberrecht und verwandte Schutzrechte}

(Urheberrechtsgesetz)

Inhaltsübersicht

ERSTER TEIL

Urheberrecht

\section{Erster Abschnitt:}

Allgemeines . . . . . . . . . . . . $\$ 1$

Zweiter Abschnitt:

Das Werk

Geschützte Werke . . . . . . . $\$ 2$

Bearbeitungen . . . . . . . . . $\$ 3$

Sammelwerke . . . . . . . . . . $\$ 4$

Amtliche Werke . . . . . . . . . $\$ 5$

Veröffentlichte und erschienene Werke . $\$ 6$

Dritter Abschnitt:

Der Urheber

Urheber . . . . . . . . . . . . $\$ 7$

Miturheber . . . . . . . . . . $\$ 8$

Urheber verbundener Werke . . . . . \$ 9

Vermutung der Urheberschaft . . . . $\$ 10$

Vierter Abschnitt:

Inhalt des Urheberrechts

1. Allgemeines . . . . . . . . . . . $\$ 11$

2. Urheberpersönlichkeitsrecht

Veröffentlichungsrecht . . . . . . $\$ 12$

Anerkennung der Urheberschaft . . . . \$13

Entstellung des Werkes . . . . . . . \$ 14

3. Verwertungsrechte

Allgemeines . . . . . . . . . . $\$ 15$

Vervielfältigungsrecht . . . . . . . $\$ 16$

Verbreitungsrecht . . . . . . . . $\$ 17$

Ausstellungsrecht . . . . . . . . . $\$ 18$

Vortrags-, Aufführungs- und Vorführungsrecht . . . . . . . . . . . § 19

Senderecht . . . . . . . . . . . $\$ 20$

Recht der Wiedergabe durch Bild- oder Tonträger . . . . . . . . . . . $\$ 21$
Recht der Wiedergabe von Funksendungen . . . . . . . . . . . \$22

Bearbeitungen und Umgestaltungen . . $\$ 23$

Freie Benutzung . . . . . . . . . $\$ 24$

4. Sonstige Rechte des Urhebers

Zugang zu Werkstücken . . . . . $\S 25$

Folgerecht . . . : . . . . . . . . $\$ 26$

Vermietung von Vervielfältigungsstücken $\$ 27$

Fünfter Abschnitt:

Rechtsverkehr im Urheberrecht

1. Rechtsnachfolge in das Urheberrecht

Vererbung des Urheberrechts . . . . . $\$ 28$

Ubertragung des Urheberrechts . . . . § 29

Rechtsnachfolger des Urhebers . . . $\$ 30$

2. Nutzungsrechte

Einräumung von Nutzungsrechten . . . $\$ 31$

Beschränkung von Nutzungsrechten . . $\$ 32$

Weiterwirkung einfacher Nutzungsrechte $\S 33$

Ubertragung von Nutzungsrechten . . \$ 34

Einräumung einfacher Nutzungsrechte . . $\$ 35$

Beteiligung des Urhebers . . . . . . $\$ 36$

Verträge über die Einräumung von Nutzungsrechten . . . . . . . . . \$37

Beiträge zu Sammlungen . . . . . . $\$ 38$

Änderungen des Werkes . . . . . . $\$ 39$

Verträge über künftige Werke . . . . $\$ 40$

Rückrufsrecht wegen Nichtausübung . . $\$ 41$

Rückrufsrecht wegen gewandelter Uberzeugung. . . . . . . . . . . . $\$ 42$

Urheber in Arbeits- oder Dienstverhältnissen . . . . . . . . . . . . $\$ 43$

Veräußerụng des Originals dès Werkes $\S 44$ Sechster Abschnitt:

Schranken des Urheberrechts

Rechtspflege und öffentliche Sicherheit . $\$ 45$

Sammlungen für Kirchen-, Schul- oder Unterrichtsgebrauch . . . . . . . $\$ 46$ 
Schulfunksendungen . . . . . . . .

Offentliche Reden . . . . . . . . . $\$ 48$

Zeitungsartikel . . . . . . . . . . $\$ 49$

Bild- und Tonberichterstattung . . . . $\$ 50$

Zitate . . . . . . . . . . . . . $\$ 51$

Vertonungsfreiheit . . . . . . . . $\$ 52$

Offentliche Wiedergabe . . . . . . . $\$ 53$

Vervielfältigung zum persönlichen Ge-

brauch . . . . . . . . . . . . $\$ 54$

Vervielfältigung zum sonstigen eigenen

Gebrauch . . . . . . . . . . . $\$ 55$

Vervielfältigung durch Sendeunternehmen $\$ 56$

Vervielfältigung durch Geschäftsbetriebe $\S 57$

Unwesentliches Beiwerk . . . . . . $\$ 58$

Katalogbilder . . . . . . . . . . $\$ 59$

Werke an öffentlichen Plätzen . . . . $\$ 60$

Bildnisse . . . . . . . . . . . . $\$ 61$

Anderungsverbot . . . . . . . . . $\S 62$

Quellenangabe . . . . . . . . $\$ 63$

Siebenter Abschnitt:

Gesetzliche Nutzungsrechte

Herstellung von Tonträgern . . . . . \$64

Funksendung . . . . . . . . . . . . $\$ 65$

Anderungsverbot; Quellenangabe . . . $\$ 66$

\section{Achter Abschnitt:}

Dauer des Urheberrechts

Allgemeines . . . . . . . . . . . $\$ 67$

Miturheber . . . . . . . . . . . $\$ 68$

Anonyme und pseudonyme Werke . . . $\$ 69$

Lieferungswerke . . . . . . . . . $\$ 70$

Lichtbildwerke . . . . . . . . . . $\$ 71$

Berechnung der Fristen . . . . . . . $\$ 72$

Neunter Abschnitt:

Urhebernachfolgevergütung

Allgemeines . . . . . . . . . . . $\$ 73$

Verbreitung von Vervielfältigungsstücken $§ \quad 74$

Ausnahmen . . . . . . . . . . . \$75

Höhe der Urhebernachfolgevergütung . . § 76

Einziehung der Urhebernachfolgevergütung . . . . . . . . . . . . $\$ 77$

Verwendung der Urhebernachfolgevergütung . . . . . . . . . . . . $\$ 78$

Errichtung des Urheberfonds . . . . . $\$ 79$

\section{ZWEITER TEIL}

Verwandte Schutzrechte

Erster Abschnitt:

Schutz bestimmter Ausgaben

Wissenschaftliche Ausgaben . . . . . $\$ 80$

Ausgaben nachgelassener Werke . . . $\$ 81$

Zweiter Abschnitt:

Schutz der Lichtbilder . . . . . . . . . $\quad$. 882

Dritter Abschnitt:

Schutz des ausübenden Künstlers

Ausübender Künstler . . . . . . . . $\$ 83$

Bildschirm- und Lautsprecherübertragung $\S 84$

Vervielfältigung . . . . . . . . $\$ 85$

Funksendung . . . . . . . . . . $\$ 86$

Offentliche Wiedergabe . . . . . $\$ 87$

Abtretung . . . . . . . . . . . $\$ 88$

Ausübende Künstler in Arbeits- oder

Dienstverhältnissen . . . . . . . $\$ 89$

Chor-, Orchester- und Bühnenaufführun-

gen . . . . . . . . . . . $\$ 90$

Schutz des Veranstalters . . . . . . $\S 91$

Dauer der Rechte . . . . . . . . $\$ 92$

Schutz gegen Entstellung . . . . . \ 93

Beschränkung der Rechte . . . . . § 94

Vierter Abschnitt:

Schutz des Herstellers von Tonträgern

Vervielfältigungs- und Verbreitungsrecht $\S 95$

Anspruch auf Beteiligung . . . . . \ 96

Fünfter Abschnitt:

Schutz des Sendeunternehmens . . . . . $\$ 97$

DRITTER TEIL

Besondere Bestimmungen für Filme

Erster Abschnitt:

Filmwerke

Recht zur Verfilmung . . . . . . $\$ 98$

Rechte am Filmwerk . . . . . . . $\$ 99$

Einschränkung der Rechte . . . . . . $\$ 100$

Rechte an Lichtbildern . . . . . . \$ $\$ 101$

Ausübende Künstler . . . . . . . . $\$ 102$

Schutz gegen Entstellung . . . . . $\$ 103$

Schutz des Filmherstellers . . . . . §104 
Zweiter Abschnitt:

Laufbilder ........... § 105

\section{VIERTER TEIL}

Gemeinsame Bestimmungen für Urheberrecht und verwandte Schutzrechte

\section{Erster Abschnitt:}

Verwertungsverbot

\section{Zweiter Abschnitt:}

Rechtsverletzungen

1. Bürgerlich-rechtliche Vorschriften; Rechtsweg

Anspruch auf Unterlassung und Schadenersatz . . . . . . . . . . . . \$107

Anspruch auf Vernichtung und ähnliche Maßnahmen . . . . . . . . \$108

Anspruch auf Uberlassung . . . . . \$109

Haftung des Inhabers eines Unternehmens . . . . . . . . . . \$110

Áusnahmen . . . . . . . . . . \$111

Verjährung . . . . . . . . . \$112

Bekanntmachung des Urteils . . . . \$113

Rechtsweg . . . . . . . . . \$114

Gerichte für Urheberrechtsstreitsachen . $\$ 115$

2. Strafrechtliche Vorschriften

Unerlaubte Verwertung urheberrechtlich geschützter Werke . . . . . . . \$116

Unzulässiges Anbringen der Urheberbezeichnung . . . . . . . . $\$ 117$

Unerlaubte Eingriffe in verwandte Schutzrechte . . . . . . . $\$ 118$

Strafantrag . . . . . . . . . . . \$119

Anspruch auf Vernichtung und ähnliche Maßnahmen . . . . . . . . $\$ 120$

Bekanntmachung des Urteils . . . . . $\$ 121$

\section{Dritter Abschnitt:}

Zwangsvollstreckung

1. Allgemeines . . . . . . . . . . §122

2. Zwangsvollstredkung wegen Geldforderungen gegen den Urheber

Urheberrecht . . . . . . . . \$123

Originale von Werken . . . . . . . $\$ 124$

3. Zwangsvollstreckung wegen Geldforderungen gegen den Rechtsnachfolger des Urhebers

Urheberrecht . . . . . . . . . .

Originale von Werken . . . . . . . \$126
Testamentsvollstrecker . . . . . . \$127

4. Zwangsvollstreckung wegen Geldforderungen gegen den Verfasser wissenschaftlicher Ausgaben und gegen den Lichtbildner . . . . . . . . . $\$ 128$

5. Zwangsvollstreckung wegen Geldforderungen in bestimmte Vorrichtungen . . $\$ 129$

\section{FUNFTER TEII}

Anwendungsbereich

Ubergangs- und Schlußbestimmungen

Erster Abschnitt:

Anwendungsbereich des Gesetzes

1. Urheberrecht

Deutsche Staatsangehörige . . . . $\$ 130$

Ausländische Staatsangehörige . . . . $\$ 131$

Staatenlose . . . . . . . . . . \$132

Ausländische Flüchtlinge . . . . . $\$ 133$

2. Verwandte Schutzrechte

Wissenschaftliche Ausgaben und Lichtbilder . . . . . . . . . . . . \$134

Schutz des ausübenden Künstlers . . . $\$ 135$

Schutz des Herstellers von Tonträgern . $\$ 136$

Schutz des Sendeunternehmens . . . $\$ 137$

Schutz des Filmherstellers . . . . . $\$ 138$

Zweiter Abschnitt:

Ubergangsbestimmungen

Werke . . . . . . . . . . . $\$ 139$

Ubersetzungen . . . . . . . . . $\$ 140$

Verträge . . . . . . . . . . . \$141

Tonträger . . . . . . . . . . . $\$ 142$

Urheber . . . . . . . . . . . \$143

Inhaber verwandter Schutzrechte . . . $\$ 144$

Vervielfältigung und Verbreitung . . . $\$ 145$

Ubertragung von Rechten . . . : . . \$146

Dritter Abschnitt:

Schlußbestimmungen

Urheberrolle . . . . . . . . . $\$ 147$

Änderung der Strafprozeßordnung . . . \$148

Anderung des Gesetzes über das am

6. September 1952 unterzeichnete

Welturheberrechtsabkommen . . . \$149

Aufgehobene Vorschriften . . . . . $\$ 150$

Geltung im Land Berlin . . . . . . . $\$ 151$

Inkrafttreten . . . . . . . . . . \$152 
Der Bundestag hat das folgende Gesetz beschlossen:

\section{ERSTER TEII}

\section{Urheberrecht}

ERSTER ABSCHNITT

Allgemeines

\section{$\S 1$}

Die Urheber von Werken der Literatur, Wissenschaft und Kunst genießen für ihre Werke Schutz nach Maßgabe dieses Gesetzes.

\section{ZWEITER ABSCHNITT}

\section{Das Werk}

\section{$\S 2$}

\section{Geschützte Werke}

(1) $\mathrm{Zu}$ den geschützten Werken der Literatur, Wissenschaft und Kunst gehören insbesondere:

1. Sprachwerke, wie Schriftwerke und Reden;

2. Werke der Musik;

3. pantomimische Werke einschließlich der Werke der Tanzkunst;

4. Werke der bildenden Künste einschließlich der Werke der Baukunst und der angewandten Kunst und Entwürfe solcher Werke;

5. Lichtbildwerke einschließlich der Werke, die ähnlich wie Lichtbildwerke geschaffen werden:

6. Filmwerke einschließlich der Werke, die ähnlich wie Filmwerke geschaffen werden;

7. Darstellungen wissenschaftlicher oder technischer Art, wie Zeichnungen, Pläne, Karten, Skizzen, Tabellen und plastische Darstellungen.

(2) Werke im Sinne dieses Gesetzes sind nur persönliche geistige Schöpfungen.

\section{$\S 3$}

\section{Bearbeitungen}

Ubersetzungen und andere Bearbeitungen eines Werkes, die persönliche geistige Schöpfungen des Bearbeiters sind, werden unbeschadet des Urheberrechts am bearbeiteten Werk wie selbständige Werke geschützt.

\section{$\S 4$}

\section{Sammelwerke}

Sammlungen von Werken oder anderen Beiträgen, die durch Auslese oder Anordnung eine persönliche geistige Schöpfung sind (Sammelwerke), werden unbeschadet des Urheberrechts an den auf- genommenen Werken wie selbständige Werke geschützt.

\section{$\S 5$}

\section{Amtliche Werke}

(1) Gesetze, Verordnungen, amtliche Erlasse und Bekanntmachungen sowie Entscheidungen und amtlich verfaßte Leitsätze zu Entscheidungen genießen keinen urheberrechtlichen Schutz.

(2) Das gleiche gilt für andere amtliche Werke, die im amtlichen Interesse zur allgemeinen Kenntnisnahme veröffentlicht worden sind, wenn die Werke nicht mit einem Vorbehalt der Rechte versehen sind. Die Bestimmungen in $\S 63$ Abs. 1 und 2 über die Quellenangabe sind entsprechend anzuwenden.

\section{$\S 6$}

\section{Veröffentlichte und erschienene Werke}

(1) Ein Werk ist veröffentlicht, wenn es mit Zustimmung des Berechtigten der Offentlichkeit zugänglich gemacht worden ist.

(2) Ein Werk ist erschienen, wenn mit Zustimmung des Berechtigten Vervielfältigungsstücke des Werkes nach ihrer Herstellung in genügender Anzahl der Offentlichkeit angeboten oder in Verkehr gebracht worden sind. Ein Werk der bildenden Künste gilt auch dann als erschienen, wenn das Original oder ein Vervielfältigungsstück des Werkes mit Zustimmung des Berechtigten bleibend öffentlich ausgestellt ist.

\section{DRITTER ABSCHNITT \\ Der Urheber \\ $\S 7$ \\ Urheber}

Urheber ist der Schöpfer des Werkes.

$$
\S 8
$$

\section{Miturheber}

(1) Haben mehrere ein Werk gemeinsam geschaffen, ohne daß sich ihre Beiträge gesondert verwerten lassen, so sind sie Miturheber des Werkes.

(2) Das Recht zur Veröffentlichung und zur Verwertung des Werkes steht den Miturhebern zur gesamten Hand zu; Anderungen des Werkes sind nur mit Einwilligung der Miturheber zulässig. Ein Miturheber darf jedoch seine Einwilligung zur Veröffentlichung, Verwertung oder Änderung nicht wider Treu und Glauben verweigern. Jeder Miturheber ist berechtigt, Ansprüche aus Verletzungen des gemeinsamen Urheberrechts geltend zu machen; er kann jedoch nur Leistung an alle Miturheber verlangen.

(3) Die Erträgnisse aus der Nutzung des Werkes gebühren den Miturhebern nach dem Verhältnis der 
Bedeutung ihrer Anteile an der Schöpfung des Werkes, wenn nichts anderes zwischen den Miturhebern vereinbart ist.

(4) Ein Miturheber kann auf seinen Anteil an den Verwertungsrechten ( $\$ 15)$ verzichten. Der Verzicht ist den anderen Miturhebern gegenüber zu erklären. Mit der Erklärung wächst der Anteil den anderen Miturhebern zu.

\section{§ 9}

Urheber verbundener Werke

Haben mehrere Urheber ihre Werke zu gemeinsamer Verwertung miteinander verbunden, so kann jeder vom anderen die Einwilligung zur Veröffentlichung, Verwertung und Anderung der verbundenen Werke verlangen, wenn die Einwilligung dem anderen nach Treu und Glauben zuzumuten ist.

\section{$\S 10$}

\section{Vermutung der Urheberschaft}

(1) Wer auf den Vervielfältigungsstücken eines erschienenen Werkes oder auf dem Original eines Werkes der bildenden Künste in der üblichen Weise als Urheber bezeichnet ist, wird bis zum Beweis des Gegenteils als Urheber des Werkes angesehen; dies gilt auch für eine Bezeichnung, die als Deckname oder Künstlerzeichen des Urhebers bekannt ist.

(2) Ist der Urheber nicht nach Absatz 1 bezeichnet, so wird vermutet, daß derjenige ermächtigt ist, die Rechte des Urhebers geltend zu machen, der auf den Vervielfältigungsstücken des Werkes als Herausgeber bezeichnet ist. Ist kein Herausgeber angegeben, so wird vermutet, daß der Verleger ermächtigt ist.

\section{VIERTER ABSCHNITT:}

\section{Inhalt des Urheberrechts}

\section{Allgemeines}

\section{$\S 11$}

Das Urheberrecht schützt den Urheber in seinen geistigen und persönlichen Beziehungen zum Werk und in der Nutzung des Werkes.

2. Urheberpersönlichkeitsrecht

\section{$\S 12$}

\section{Veröffentlichungsrecht}

(1) Der Urheber hat das Recht zu bestimmen, ob und wie sein Werk zu veröffentlichen ist.

(2) Dem Urheber ist es vorbehalten, den Inhalt seines Werkes öffentlich mitzuteilen oder zu beschreiben, solange weder das Werk noch der wesentliche Inhalt oder eine Beschreibung des Werkes mit seiner Zustimmung veröffentlicht ist.
$\S 13$

\section{Anerkennung der Urheberschaft}

Der Urheber hat das Recht auf Anerkennung seiner Urheberschaft am Werk. Er kann bestimmen, ob das Werk mit einer Urheberbezeichnung zu versehen und welche Bezeichnung zu verwenden ist.

\section{$\S 14$}

\section{Entstellung des Werkes}

Der Urheber hat das Recht, eine Entstellung oder eine andere Beeinträchtigung seines Werkes zu verbieten, die geeignet ist, seine berechtigten geistigen oder persönlichen Interessen am Werk zu gefährden.

\section{Verwertungsrechte}

\section{$\S 15$}

\section{Allgemeines}

(1) Der Urheber hat das ausschließliche Recht, sein Werk in körperlicher Form zu verwerten; das Recht umfaßt insbesondere

1. das Vervielfältigungsrecht ( $\S 16)$,

2. das Venbreitungsrecht ( $\$ 17)$,

3. das Ausstellungsrecht $(\S, 18)$.

(2) Der Urheber hat ferner das ausschlieBliche Recht, sein Werk in unkörperlicher Form öffentlich wiederzugeben (Recht der öffentlichen Wiedergabe); das Recht umfaßt insbesondere

1. das Vortrags-, Aufführungs- und Vorführungsrecht ( $\$ 19)$,

2. das Senderecht $(\S 20)$,

3. das Recht der Wiedergabe durch Bildoder Tonträger ( $\$ 21)$,

4. das Recht der Wiedergabe von Funksendungen ( $\$ 22$ ).

(3) Die Wiedergabe eines Werkes ist öffentlich, wenn sie für eine Mehrheit von Personen bestimmt ist, es sei denn, daß der Kreis dieser Personen bestimmt abgegrenzt ist und sie durch gegenseitige Beziehungen oder durch Beziehung zum Veranstalter persönlich untereinander verbunden sind.

\section{$\S 16$}

\section{Vervielfältigungsrecht}

(1) Das Vervielfältigungsrecht ist das Recht, Vervielfältigungsstücke des Werkes herzustellen, gleichviel in welchem Verfahren und in welcher Zahl.

(2) Eine Vervielfältigung ist auch die Ubertragung des Werkes auf Vorrichtungen zur wiederholbaren Wiedergabe von Bild- oder Tonfolgen (Bild- oder Tonträger), gleichviel: ob es sich um die Bild- oder Tonträger oder um die Ubertragung des Aufnahme einer Wiedergabe des Werkes auf einen 
Werkes von einem Bild- oder Tonträger auf einen anderen handelt.

\section{$\S 17$}

\section{Verbreitungsrecht}

(1) Das Verbreitungsrecht ist das Recht, das Original oder Vervielfältigungsstücke des Werkes der Offentlichkeit anzubieten oder in Verkehr zu bringen.

(2) Sind das Original oder Vervielfältigungsstücke des Werkes mit Zustimmung des zur Verbreitung im Geltungsbereich dieses Gesetzes Berechtigten im Wege der Veräußerung in Verkehr gebracht worden, so ist ihre Weiterverbreitung zulässig.

\section{$\S 18$}

\section{Ausstellungsrecht}

Das Ausstellungsrecht ist das Recht, das Original oder Vervielfältigungsstücke eines unveröffentlichten Werkes der bildenden Künste oder eines unveröffentlichten Lichtbildwerkes öffentlich zur Schau zu stellen.

\section{$\S 19$}

\section{Vortrags-, Aufführungs- und Vorführungsrecht}

(1) Das Vortragsrecht ist das Recht, ein Sprachwerk durch persönliche Darbietung öffentlich zu Gehör zu bringen.

(2) Das Aufführungsrecht ist das Recht, ein Werk der Musik durch persönliche Darbietung öffentlich zu Gehör zu bringen oder ein Werk öffentlich bühnenmäßig darzustellen.

(3) Das Vortrags- und Aufführungsrecht umfaßt das Recht, Vorträge und Aufführungen außerhalb der Veranstaltung, bei der sie stattfinden, durch Bildschirm, Lautsprecher oder ähnliche technische Einrichtungen öffentlich wahrnehmbar zu machen.

(4) Das Vorführungsrecht ist das Recht, ein Werk der bildenden Künste, ein Lichtbildwerk, ein Filmwerk oder Darstellungen wissenschaftlicher oder technischer Art durch technische Einrichtungen öffentlich wahrnehmbar zu machen. Das Vorfühnungsrecht umfaßt nicht das Recht, die Funksendung solcher Werke öffentlich wahrnehmbar zu machen $(\S \cdot 22)$.

\section{$\S 20$ \\ Senderecht}

Das Senderecht ist das Recht, das Werk durch Funk, wie Ton- und Fernsehrundfunk, Drahtfunk oder ähnliche technische Einrichtungen, der Offentlichkeit zugänglich zu machen.

\section{$\S 21$}

Recht der Wiedergabe durch Bild- oder Tonträger

Das Recht der Wiedergabe durch Bild- oder Tonträger ist das Recht, Vorträge oder Aufführungen des Werkes mittels Bild- oder Tonträger öffentlich wahrnehmbar zu machen. $\S 19$ Abs. 3 gilt entsprechend.

\section{$\S 22$}

\section{Recht der Wiedergabe von Funksendungen}

Das Recht der Wiedergabe von Funksendungen ist das Recht, Funksendungen des Werkes durch Bildschirm, Lautsprecher oder ähnliche technische Einrichtungen öffentlich wahrnehmbar zu machen. $\S 19$ Abs. 3 gilt entsprechend.

\section{$\S 23$}

\section{Bearbeitungen und Umgestaltungen}

(1) Bearbeitungen oder andere Umgestaltungen des Werkes dürfen nur mit Einwilligung des Urhebers des bearbeiteten oder umgestalteten Werkes veröffentlicht oder verwertet werden.

(2) Im Falle einer Bearbeitung oder Umgestaltung durch Verfilmung bedarf bereits die Herstellung der Bearbeitung oder Umgestaltung der Einwilligung des Urhebers.

\section{$\S 24$}

\section{Freie Benutzung}

Ein selbständiges Werk, das in freier Benutzung des Werkes eines anderen geschaffen worden ist, danf ohne Zustimmung des Urhebers des benutzten Werkes veröffentlicht und verwertet werden.

\section{Sonstige Rechtedes Urhebers}

\section{$\S 25$ \\ Zugang zu Werkstücken}

(1) Der Urheber kann vom Besitzer des Originals oder eines Vervielfältigungsstückes seines Werkes verlangen, daß er ihm das Original oder das Vervielfältigungsstück zugänglich macht, so:weit dies zur Herstellung von Vervielfältigungsstücken oder Bearbeitungen des Werkes erforderlich ist und nicht berechtigte Interessen des Besitzers entgegenstehen.

(2) Der Besitzer ist nicht verpflichtet, das Original oder das Vervielfältigungsstück dem Urheber herauszugeben.

\section{$\S 26$}

Folgerecht

(1) Wird das Original eines Werkes der bildenden Künste im geschäftlichen Verkehr weiterveräußert, so hat der Veräußerer dem Urheber einen Anteil in Höhe von eins vom Hundert des Veräußerungserlöses $z u$ entrichten. Die Verpflichtung entfällt, wenn der Veräußerungserlös weniger als fünfhundert Deutsche Mark beträgt.

(2) Der Urheber kann auf den Anteil im voraus nicht verzichten. Die Anwartschaft darauf unterliegt nicht der Zwangsvollstreckung; eine Vierfügung über die Anwartschaft ist unwirksam. 
(3) Die vorstehenden Bestimmungen sind auf Werke der Baukunst und der angewandten Kunst nicht anzuwenden.

\section{$\S 27$}

\section{Vermietung von Vervielfältigungsstücken}

(1) Werden Vervielfältigungsstücke eines Werkes, deren Weiterverbreitung nach $\S 17$ Abs. 2 zulässig ist, vermietet, so hat der Vermieter dem Urheber hierfür eine angemessene Vergütung zu gewähren, wenn die Vermietung Erwerbszwecken des Vermieters dient.

(2) Absatz 1 ist auf Vervielfältigungsstücke, die mit Zustimmung des Urhebers zum Zwecke der Vermietung hergestellt worden sind, sowie auf Vervielfältigungsstücke von Werken der Baukunst und der angewandten Kunst nicht anzuwenden.

\section{FUNFTER ABSCHNITT}

Rechtsverkehr im Urheberrechi

$$
\begin{aligned}
& \text { 1. Rechtsnachfolge } \\
& \text { in das Urheberrecht }
\end{aligned}
$$

\section{$\S 28$}

\section{Vererbung des Urheberrechts}

(1) Das Urheberrecht ist vererblich.

(2) Der Urheber kann durch letztwillige Venfügung die Ausübung des Urheberrechts einem Testamentsvollstrecker übertragen. $\S 2210$ des Bürgerlichen Gesetzbuchs ist nicht anzuwenden.

\section{$\S 29$}

\section{Ubertragung des Urheberrechts}

Das Unheberrecht kann in Erfüllung einer Verfügung von Todes wegen oder an Miterben im Wege der Erbauseinandersetzung übertragen werden. Im übrigen ist es nicht übertragbar.

$$
\S 30
$$

\section{Rechtsnachfolger des Urhebers}

Der Rechtsnachfolger des Urhebers hat die dem Urheber nach diesem Gesetz zustehenden Rechte, soweit nichts anderes bestimmt ist.

\section{Nutzungsrechte}

$$
\text { § } 31
$$

\section{Einräumung von Nutzungsrechten}

(1) Der Urheber kann einem anderen das Recht einräumen, das Werk auf einzelne oder alle Nutzungsarten zu nutzen (Nutzungsrecht). Das Nutzungsrecht kann als einfaches oder ausschließliches Recht eingeräumt werden.
(2) Das einfache Nutzungsrecht berechtigt den Inhaber, das Werk neben dem Urheber oder ande. ren Berechtigten auf die ihm erlaubte Art zu nutzen.

(3) Das ausschließliche Nutzungsrecht berechtigt den Inhaber, das Werk unter Ausschluß aller anderen Personen einschließlich des Urhebers auf die ihm erlaubte Art zu nutzen und einfache Nutzungsrechte einzuräumen. $\S 35$ bleibt unberührt.

(4) Die Einräumung von Nutzungsnechten für noch nicht bekannte Nutzungsarten sowie Verpflichtungen hierzu sind unwirksam.

$$
\S 32
$$

\section{Beschränkung von Nutzungsrechten}

Das Nutzungsrecht kann räumlich, zeitlich oder inhaltlich beschränkt eingeräumt werden.

\section{§33}

\section{Weiterwirkung einfacher Nutzungsrechte}

Ein einfaches Nutzungsrecht, das der Urheber vor Einräumung eines ausschließlichen Nutzungsrechts eingeräumt hat, bleibt gegenüber dem Inhaber des ausschließlichen Nutzungsrechts iwirksam, wenn nichts anderes zwischen dem Urheber und dem Inhaiber des einfachen Nutzungsrechts vereinbart ist.

\section{$\S 34$}

\section{Ubertragung von Nutzungsrechten}

(1) Ein Nutzungsrecht kann nur mit Zustimmung des Urhebers übertragen werden. Der Urheber darf die Zustimmung nicht wider Treu und Glauben verweigern.

(2) Werden mit dem Nutzungsrecht an einem Sammelwerk ( $\S 4$ ) Nutzungsrechte an den in das Sammelwerk aufgenommenen einzelnen Werken übertragen, so genügt die Zustimmung des Urhebers des Sammelwerkes.

(3) Ein Nutzungsrecht kann ohne Zustimmung dies Urhebers übertragen werden, wenn die Ubertragung im Rahmen der Gesamtveräußerung eines Unternehmens oder der Vieräußerung von Teilen eines Unternehmens geschieht.

(4) Abweichende Vereinbarungen zwischen dem Inhaber des Nutzungsrechts und dem Urheber sind zulässig.

(5) Ist die Ubertragung des Nutzungsrechts nach Vertrag odier kraft Gesetzes ohne Zustimmung des Urhebers zulässig, so haftet der Erwerber gesamtschuldnerisch für die Erfüllung der sich aus dem Vertrag mit dem Urheber ergebenden Verpflichtungen des Veräußerers.

\section{$\S 35$}

\section{Einräumung einfacher Nutzungsrechte}

(1) Der Inhaber eines ausschließlichen Nutzungsrechts kann einfache Nutzungsrechte nur mit $\mathrm{Zu}$ stimmung des Urhebers einräumen. Der Zustim- 
mung bedarf es nicht, wenn das ausschließliche Nutzungsrecht nur zur Wahrnehmung der Belange des Urhebers eingeräumt ist.

(2) Die Bestimmungen in $\S 34$ Abs. 1 Satz 2, Abs. 2 und Abs. 4 sind entsprechend anzuwenden.

\section{$\S 36$}

\section{Beteiligung des Urhebers}

(1) Hat der Urheber einem anderen ein Nutzungsrecht eingeräumt, ohne sich eine angemessene Beteiligung an den Erträgnissen aus der Nutzung des Werkes vorzubehalten, so kann er von dem Nutzungsberechtigten eine solche angemessene Beteiligung verlangen, wenn die Nutzungserträgnisse unter Berücksichtigung seiner gesamten Beziehungen zu dem Nutzungsberechtigten in einem auffälligen Mißverhältnis zu der für die Einräumung des Nutzungsrechts vereinbarten Vergütung stehen.

(2) Der Anspruch verjährt in zwei Jahren von dem Zeitpunkt an, in dem der Urheber von den Umständen, aus denen sich der Anspruch ergibt, Kenntnis erlangt, ohne Rücksicht auf diese Kenntnis in zehn Jahren.

(3) Auf den Anspruch kann im voraus nicht verzichtet werden. Die Anwartschaft darauf unterliegt nicht der Zwangsvollstreckung; eine Verfügung über die Anwartschaft ist unwirksam.

\section{$\S 37$}

\section{Verträge über die Einräumung von Nutzungsrechten}

(1) Räumt der Urheber einem anderen ein Nutzungsrecht am Werk ein, so verbleibt ihm im Zweifel das Recht der Einwilligung zur Veröffentlichung oder Verwertung einer Bearbeitung des Werkes.

(2) Räumt der Urheber einem anderen ein Nut- zungsrecht zur Vervielfältigung des Werkes ein, so verbleibt ihm im Zweifel das Recht, das Werk auf Bild- oder Tonträger zu übertragen.

(3) Räumt der Urheber einem anderen ein Nutzungsrecht $\mathrm{zu}$ einer öffentlichen Wiedergabe des Werkes ein, so ist dieser im Zweifel nicht berechtigt, die Wiedergabe außerhalb der Veranstaltung, für die sie bestimmt ist, durch Bildschirm, Lautsprecher oder ähnliche technische Einrichtungen öffentlich wahrnehmbar zu machen.

\section{$\S 38$}

\section{Beiträge zu Sammlungen}

(1) Gestattet der Urheber die Aufnahme des Werkes in eine periodisch erscheinende Sammlung, so erwirbt der Verleger oder Herausgeber im Zweifel ein ausschlieBliches Nutzungsrecht zur Vervielfältigung und Verbreitung. Jedoch darf der Urheber das Werk nach Ablauf eines Jahres seit Erscheinen anderweit vervielfältigen und verbreiten, wenn nichts anderes vereinbart ist.

(2) Absatz 1 Satz 2 gilt auch für einen Beitrag zu einer nicht periodisch erscheinenden Sammlung, für dessen Uberlassung dem Urheber kein Anspruch auf Vergütung zusteht.

(3) Wird der Beitrag einer Zeitung überlassen, so ist der Urheber sogleich nach Erscheinen des Beitrags berechtigt, ihn anderweit $\mathrm{zu}$ vervielfältigen und $\mathrm{zu}$ verbreiten, wenn nichts anderes vereinbart ist.

\section{$\S 39$}

\section{Anderungen des Werkes}

(1) Der Inhaber eines Nutzungsrechts darf das Werk, dessen Titel oder Urheberbezeichnung ( $\$ 10$ Abs. 1) nicht ändern, wenn nichts anderes vereinbart ist.

(2) Änderungen des Werkes und seines Titels, $\mathrm{zu}$ denen der Urheber seine Einwilligung nach Treu und Glauben nicht versagen kann, sind zulässig.

\section{$\S 40$}

\section{Verträge uber künftige Werke}

(1) Ein Vertrag, durch den sich der Urheber zur Einräumung von Nutzungsrechten an künftigen Werken verpflichtet, die überhaupt nicht näher oder nur der Gattung nach bestimmt sind, bedarf der schriftlichen Form. Er kann von beiden Vertragsteilen nach Ablauf von fünf Jahren seit dem Abschluß des Vertrages gekündigt werden. Die Kündigungsfrist beträgt sechs Monate, wenn keine kürzere Frist vereinbart ist.

(2) Auf das Kündigungsrecht kann im voraus nicht verzichtet werden. Andere vertragliche oder gesetzliche Kündigungsrechte bleiben unberührt.

(3) Wenn in Erfüllung des Vertrages Nutzungsrechte an künftigen Werken eingeräumt worden sind, wird mit Beendigung des Vertrages die Verfügung hinsichtlich der Werke unwirksam, die $\mathrm{zu}$ diesem Zeitpunkt noch nicht abgeliefert sind.

\section{$\S 41$}

\section{Rückrufsrecht wegen Nichtausübung}

(1) Ubt der Inhaber eines ausschließlichen Nutzungsrechts das Recht nicht oder nur unzureichend aus und werden dadurch berechtigte Interessen des Urhebers erheblich verletzt, so kann dieser das Nut. zungsrecht zurückrufen. Dies gilt nicht, wenn die Nichtausübung oder die unzureichende Ausübung des Nutzungsrechts überwiegend auf Umständen beruht, deren Behebung dem Urheber zuzumuten ist.

(2) Das Rückrufsrecht kann nicht vor Ablauf von zwei Jahren seit Einräumung oder Ubertragung des Nutzungsrechts oder, wenn das Werk später abgeliefert wird, seit der Ablieferung geltend gemacht werden.

(3) Der Rückruf kann erst erklärt werden, nachdem der Urheber dem Inhaber des Nutzungsrechts unter Ankündigung des Rückrufs eine angemessene Nachfrist zur zureichenden Ausübung des Nutzungsrechts bestimmt hat. Der Bestimmung der Nachfrist bedarf es nicht, wenn die Ausübung des Nutzungs- 
rechts seinem Inhaber unmöglich ist oder von ihm verweigert wird oder wenn durch die Gewährung einer Nachfrist überwiegende Interessen des Urhebers gefährdet würden.

(4) Auf das Rückrufsrecht kann im voraus nicht verzichtet werden. Seine Ausübung kann im voraus für mehr als fünf Jahre nicht ausgeschlossen werden.

(5) Mit Wirksamwerden des Rückrufs erlischt das Nutzungsrecht.

(6) Der Urheber hat den Betroffenen zu entschädigen, wenn und soweit es der Billigkeit entspricht.

(7) Rechte und Ansprüche der Beteiligten nach anderen gesetzlichen Vorschriften bleiben unberührt.

\section{$\S 42$}

\section{Rückrufsrecht wegen gewandelter Uberzeugung}

(1) Der Urheber kann ein Nutzungsrecht gegenüber dem Inhaber zurückrufen, wenn das Werk seiner Uberzeugung nicht mehr entspricht und ihm deshalb die Verwertung des Werkes nicht mehr zugemutet werden kann.

(2) Der Rechtsnachfolger des Urhebers (§ 30) kann den Rückruf nur erklären, wenn er nachweist, 'daß der Urheber vor seinem Tode zum Rückruf berechtigt gewesen wäre und an der Erklärung des Rückrufs gehindert war oder diese letztwillig verfügt hat.

(3) Auf das Rückrufsrecht kann im voraus nicht verzichtet werden. Seine Ausübung kann nicht ausgeschlossen werden.

(4) Der Urheber hat den Inhaber des Nutzungsrechts angemessen zu entschädigen. Die Entschädigung muß mindestens die Aufwendungen decken, die der Inhaber des Nutzungsrechts bis zur Erklärung des Rückrufs gemacht hat; jedoch bleiben hierbei Aufwendungen, die auf bereits gezogene Nutzungen entfallen, außer Betracht. Der Rückruf wird erst wirksam, wenn der Urheber die Aufwendungen ersetzt oder Sicherheit dafür geleistet hat. Der Inhaber des Nutzungsrechts hat dem Urheber binnen einer Frist von einem Monat nach Erklärung des Rückrufs die Aufwendungen mitzuteilen; kommt er dieser Pflicht nicht nach, so wird der Rückruf bereits mit Ablauf dieser Frist wirksam.

(5) Will der Urheber nach Rückruf das Werk wieder verwerten, so ist er verpflichtet, dem früheren Inhaber des Nutzungsrechts ein entsprechendes Nutzungsrecht $\mathrm{zu}$ angemessenen Bedingungen anzubieten.

(6) Die Bestimmungen in $\S 41$ Abs. 5 und 7 sind entsprechend anzuwenden.

\section{$\S 43$}

Urheber in Arbeits- oder Dienstverhältnissen

Die Vorschriften dieses Unterabschnitts sind auch anzuwenden, wenn der Urheber das Werk in Erfüllung seiner Verpflichtungen aus einem Arbeits- oder Dienstverhältnis geschaffen hat, soweit sich aus dem Inhalt oder idem Wesen des Arbeits- oder Dienstverhältnisses nichts anderes engibt.

\section{$\S 44$}

\section{Veräußerung des Originals des Werkes}

(1) Veräußert der Urhelber das Original des Werkes, so räumt er damit im Zweifel dem Erwwerber ein Nutzungsrecht nicht ein.

(2) Der Eigentümer des Originals eines Wierkes der bildenden Künste ist berechtigt, das Werk öffentlich auszustellen, auch wenn es noch nicht veröffentlicht ist, es sei denn, daß der Urheber dies bei der Veräußerung des Originals ausdrücklich ausgeschlossen hat.

\section{SECHSTER ABSCHNITT}

\section{Schranken des Urheberrechts}

\section{$\S 45$}

\section{Rechtspflege und öffentliche Sicherheit}

(1) Zulässig ist, einzelne Vervielfältigungsstücke von Werken zur Verwendung in Verfahren vor einem Gericht, einem Schiedsgericht oder einer Behörde herzustellen oder herstellen zu lassen.

(2) Behörden dürfen für Zwecke der Rechtspflege und der öffentlichen Sicherheit Bildnisse vervielfältigen oder vervielfältigen lassen.

(3) Soweit nach den vorstehenden Bestimmungen Werke vervielfältigt werden dürfen, ist auch ihre Verbreitung, öffentliche Ausstellung und öffentliche Wiedergabe zulässig.

\section{$\S 46$}

\section{Sammlungen für Kirchen, Schul- oder Unterrichtsgebrauch}

(1) Zulässig ist die Vervielfältigung und Verbreitung, wenn Teile von Werken, Sprachwerke oder Werke der Musik von geringem Umfang oder einzelne Werke der bildenden Künste oder einzelne Lichtbildwerke nach dem Érscheinen in eine Sammlung aufgenommen werden, die Werke einer größeren Anzahl von Urhebern vereinigt und nach ihrer Beschaftenheit nur für den Kirchen-, Schul- oder Unterrichtsgebrauch bestimmt ist. Im Eingang der Sammlung ist deutlich anzugeben, wozu sie bestimmt ist.

(2) Absatz 1 gilt für Werke der Musik, die in eine für den Musikunterricht bestimmte Sammlung aufgenommen werden, nur, wenn es sich um eine Sammlung für den Musikunterricht in allgemeinbildenden Schulen handelt.

(3) Der Urheber kann die Vervielfältigung und Verbreitung verbieten, wenn das Werk seiner Uberzeugung nicht mehr entspricht, ihm deshalb die Verwertung des Werkes nicht mehr zugemutet werden kann und er ein etwa bestehendes Nutzungs- 
recht aus diesem Grunde zurückgerufen hat ( $\$ 42)$. Die Bestimmungen in $\S 145$ Abs. 1 und 2 sind entsprechend anzuwenden.

(4) Für die Vervielfältigung und Vierbreitung ist dem Urheber eine angemessene Vergütung zu gewähren.

\section{$\S 47$}

\section{Schulfunksendungen}

(1) Schulen dürfen einzelne Vervielfältigungsstücke von Werken, die innerhalb einer Schulfunksendung gesendet werden, durch Übertragung der Werke auf Bild- oder Tonträger herstellen.

(2) Die Vervielfältigungsstücke dünfen nur für den Unterricht verwendet werden und sind spätestens ein Jahr nach der Herstellung unbrauchbar zu machen.

\section{$\S 48$}

\section{Offentliche Reden}

\section{(1) Zulässig ist}

1. die Vervielfältigung und Verbreitung von Reden über Tagesfragen in Zeitungen sowie in Zeitschriften oder an'deren Informationsblättern, die im wesentlichen den Tagesinteressen Rechnung tragen, wenn die Reden bei öffentlichen Versammlungen oder im Rundfunk gehalten worden sind, sowie die öffentliche Wiedergabe solcher Reden,

2. Idie Vervielfältigung, Verbreitung und öffentliche Wiedergabe von Reden, die bei öffentlichen Verhandlungen vor staatlichen, kommunalen oder kirchlichen Organen gehalten worden sind.

(2) Unzulässig ist jedoch die Vervielfältigung und Verbreitung der in Absatz 1 Nr. 2 bezeichneten Reden in Form einer Sammlung, die überwiegend Reden desselben Urhebers enthält.

\section{$\S 49$}

\section{Zeitungsartikel}

(1) Zulässig ist die Vervielfältigung und Verbreitung einzelner Artikel aus Zeitungen und anderen lediglich Tagesinteressen dienenden Informationsblättern in anderen Zeitungen und Informationsblättern Idieser Art sowie die öffentliche Wiedergabe solcher Artikel, wenn die Artikel politische, wirtschaftliche oder religiöse Tagesfragen betreffen und nicht mit einem Vorbehalt der Rechte versehen sind.

(2) Unbeschränkt zulässig ist die Vervielfältigung, Verbreitung und öffentliche Wiedergabe von vermischten Nachrichten tatsächlichen Inhalts und von Tagesneuigkeiten, die durch Presse oder Funk veröffentlicht worden sind; ein durch andere gesetzliche Vorschriften gewährter Schutz bleibt unberührt.

\section{$\S 50$}

\section{Bild- und Tonberichterstattung}

Zur Bild- und Tonberichterstattung über Tagesereignisse durch Funk und Film sowie in Zeitungen oder Zeitschriften, die im wesentlichen den Tagesinteressen Rechnung tragen, 'dürrfen Werke, die im Verlauf der Vorgänge, über die berichtet wird, wahrnehmbar werden, in einem durch den Zweck gebotenen Umfang vervielfältigt, verbreitet und öffentlich wiedergegeben werden.

\section{$\S 51$ \\ Zitate}

Zulässig ist die Vervielfältigung, Verbreitung und ötfentliche Wiedergabe,

1. wenn einzelne Werke nach dem Erscheinen in ein selbständiges wissenschaftliches Werk zur Erläuterung des Inhalts in einem durch diesen Zweck gebotenen Umfang aufgenommen werden,

2. wenn einzelne Stellen eines Werkes nach der Veröffentlichung in einem selbständigen Sprachwerk angeführt werden,

3. wenn einzelne Stellen eines erschienenen Werkes der Musik in einem selbständigen Werk der Musik in einem durch den Zweck gebotenen Umfang angeführt werden,

4. wenn ein Thema aus einem erschienenen Werk ider Musik in einem selbständigen Variationenwerk angeführt wird.

\section{$\S 52$}

\section{Vertonungsfreiheit}

(1) Kleine Teile einer Dichtung oder Gedichte von geringem Umfang dürfen nach ihrem Erscheinen als Text zu einem neuen Werk ider Musik in Verbindung mit diesem vervielfältigt, verbreitet und öffentlich wiedergegeben werden.

(2) Absatz 1 gilt nicht für Sprachwerke, die nur als Text zu einem Werk der Musik erschienen oder ihrer Gattung nach zur Vertonung bestimmt sind.

(3) Ohne Verbindung mit dem Werk der Musik dürfen vertonte Sprachwerke der in Absatz 1 bezeichneten Art zum Gebrauch der Hörer, die an einer Aufführung des Werkes der Musik teilnehmen, vervielfältigt und verbreitet werden.

(4) Der Urheber des vertonten Werkes hat gegen jeden, der sein Werk nach den Absätzen 1 und 3 verwertet, einen Anspruch auf angemessene Vergütung. 


\section{$\S 53$ \\ Offentliche Wiedergabe}

(1) Zulässig ist die öffentliche Wiedergabe eines erschienenen Werkes,

1. wenn die Wiedergabe keinem Erwerbszweck des Veranstalters dient, die Teilnehmer ohne Entgelt zugelassen werden und im Falle ides Vortrages oder der Aufführung des Werkes den ausübenden Künstlern ( $\S 83)$ keine besondere Vergütung gezahlt wird; jedoch hat, wenn die Veranstaltung dem Erwerbszweck eines Dritten dient, dieser dem Urheber für die Wiedergabe eine angemessene Vergütung zu gewähren;

2. wenn die Wiedergabe bei einer kirchlichen Feierlichkeit oder bei einer anderen Veranstaltung der Kirchen oder sonstigen Religionsgesellschaften des öffentlichen Rechts stattfindet; jedoch hat stets der Veranstalter dem Urheber für die Wiedergabe eine angemessene Vergütung zu gewähren, selbst wenn die in Nummer 1 aufgeführten Voraussetzungen vorliegen.

(2) Offentliche bühnenmäßige Aufführungen und Funksendungen eines Werkes sowie öffentliche Vorführungen"eines Filmwerkes sind stets nur mit Einwilligung des Berechtigten zulässig.

\section{$\S 54$}

\section{Vervielfältigung zum persönlichen Gebrauch}

(1) Zulässig ist, einzelne Vervielfältigungsstücke eines Werkes zum persönlichen Gebrauch herzustellen.

(2) Der zur Vervielfältigung Befugte darf die Vervielfältigungsstücke auch durch einen anderen herstellen lassen; doch gilt dies für die Ubertragung von Werken auf Bild- oder Tonträger und die Vervielfältigung von Werken der bildenden Künste nur, wenn es unentgeltlich geschieht.

(3) Für die Aufnahme der Vorführung oder Funksendung eines Werkes auf Bild- oder Tonträger und die Ubertragung eines Werkes von einem Bild- oder Tonträger auf einen anderen ist dem Urheber eine angemessene Vergütung zu gewähren.

(4) Die Vervielfältigungsstücke dürfen weder verbreitet noch $\mathrm{zu}$ öffentlichen Wiedergaben benutzt werden.

(5) Die Aufnahme öffentlicher Vorträge, Aufführungen oder Vorführungen eines Werkes auf Bildoder Tonträger, die Ausführung von Plänen und Entwürfen zu Werken der bildenden Künste und der Nachbau eines Werkes der Baukunst sind stets nur mit Einwilligung des Berechtigten zulässig.

\section{$\S 55$}

Vervielfältigung zum sonstigen eigenen Gebrauch

(1) Zulässig ist, einzelne Vervielfältigungsstücke eines Werkes herzustellen oder herstellen zu lassen
1. zum eigenen wissenschaftlichen Gebrauch, wenn und soweit die Vervielfältigung zu diesem Zweck geboten ist,

2. zur Aufnahme in ein eigenes Archiv, wenn und soweit die Vervielfältigung $\mathrm{zu}$ diesem Zweck geboten ist und als Vorlage für die Vervielfältigung ein eigenes Werkstück benutzt wird,

3. zur eigenen Unterrichtung über Tagesfragen, wenn es sich um ein durch Funk gesendetes Werk handelt,

4. zum sonstigen eigenen Gebrauch,

a) wenn es sich um kleine Teile eines erschienenen Werkes oder um einzelne Aufsätze handelt, die in Zeitungen oder Zeitschriften erschienen sind,

b) wenn es sich um ein vergriffenes Werk handelt und der Berechtigte nicht auffindbar ist. Ist der Berechtigte auffindbar und das Werk länger als drei Jahre vergriffen, so darf er seine Einwilligung zur Vervielfältigung nur aus wichtigem Grunde verweigern.

(2) Für die Vervielfältigung ist dem Urheber eine angemessene Vergütung zu gewähren, wenn die Vervielfältigung gewerblichen Zwecken des zur Vervielfältigung Befugten dient.

(3) Die Bestimmungen in $\S 54$ Abs. 4 und 5 sind entsprechend anzuwenden.

\section{$\S 56$}

\section{Vervielfältigung durch Sendeunternehmen}

(1) Ein Sendeunternehmen, das zur Funksendung eines Werkes berechtigt ist, darf das Werk mit eigenen Mitteln auf Bild- oder Tonträger übertragen, um diese zur Funksendung über jeden seiner Sender oder Richtstrahler je einmal zu benutzen. Die Bild- oder Tonträger sind spätestens einen Monat nach der ersten Funksendung des Werkes unbrauchbar zu machen.

(2) Bild- oder Tonträger, die außergewöhnlichen dokumentarischen Wert haben, brauchen nicht unbrauchbar gemacht zu werden, wenn sie in ein amtliches Archiv aufgenommen werden. Von der Aufnahme in das Archiv ist dèr Urheber unverzüglich zu benachrichtigen.

\section{$\S 57$}

\section{Vervielfältigung durch Geschäftsbetriebe}

In Geschäftsbetrieben, die Vorrichtungen zur Herstellung von Bild- oder Tonträgern vertreiben, dürfen Werke auf Bild- oder Tonträger übertragen werden, soweit es notwendig ist, um Kunden mit den Vorrichtungen bekanntzumachen. Die Bild- und Tonträger sind unverzüglich unbrauchbar zu machen. 


\section{$\S 58$}

\section{Unwesentliches Beiwerk}

Zulässig ist die Vervielfältigung, Verbreitung und öffentliche Wiedergabe von Werken, wenn sie als unwesentliches Beiwerk neben dem eigentlichen Gegenstand der Vervielfältigung, Verbreitung oder öffentlichen Wiedergabe erscheinen.

\section{$\S 59$}

\section{Katalogbilder}

Zulässig ist, öffentlich ausgestellte oder zur Versteigerung bestimmte Werke der bildenden Künste in Verzeichnissen, die zur Durchführung der Ausstellung oder Versteigerung vom Veranstalter herausgegeben werden, zu vervielfältigen und zu verbreiten.

\section{$\S 60$}

\section{Werke an öffentlichen Plätzen}

(1) Zulässig ist, Werke, die sich bleibend an öffentlichen Wegen, Straßen oder Plätzen befinden, mit Mitteln der Malerei oder Graphik, durch Lichtbild oder durch Film zu vervielfältigen, zu verbreiten und öffentlich wiederzugeben sowie solche Werke durch Fernsehfunk zu senden. Bei Bauwerken erstrecken sich diese Befugnisse nur auf die äußere Ansicht.

(2) Die Vervielfältigungen dürfen nicht an einem Bauwerk vorgenommen werden.

\section{$\S 61$}

\section{Bildnisse}

(1) Der Besteller eines Bildnisses oder sein Rechtsnachfolger darf es durch Lichtbild vervielfältigen oder vervielfältigen lassen. Handelt es sich bei dem Bildnis um ein Lichtbildwerk, so ist die Vervielfältigung auch auf andere Weise als durch Lichtbild zulässig. Die Vervielfältigungsstücke dürfen unentgeltlich verbreitet werden.

(2) Die gleichen Rechte stehen bei einem auf Bestellung geschaffenen Bildnis dem Abgebildeten, nach seinem Tode seinen Angehörigen zu.

(3) Angehörige im Sinne des Absatzes 2 sind der Ehegatte und die Kinder oder, wenn weder ein Ehegatte noch Kinder vorhanden sind, die Eltern.

\section{$\S 62$}

\section{Anderungsverbot}

(1) Soweit nach den Bestimmungen dieses Aibschnitts die Benutzung eines Werkes zulässig ist, dürfen Anderungen an dem Werk nicht vorgenommen werden. $\S 39$ gilt entsprechend.

(2) Soweit der Benutzungszweck es erfordert, sind Ubersetzungen und solche Änderungen des Werkes zulässig, idie nur Auszüge oder Ubertragungen in eine andere Tonart oder Stimmlage darstellen.
(3) Bei Werken der bildenden Künste und Lichtbildwerken sind Ubertragungen des Werkes in eine andere Größe und solche Anderungen zulässig, die das für ıdie Vervielfältigung angewendete Verfahren mit sich bringt.

(4) Bei Sammlungen für Kirchen-, Schul- oder Unterrichtsgebrauch ( $\$ 46)$ sind außer den nach den Absätzen 1 bis 3 erlaubten Anderungen solche Änderungen von Sprachwerken zulässig, die für den Kirchen-, Schul- oder Unterrichtsgebrauch erforderlich sind. Diese Änderungen bedürfen jedoch, solange ider Urheber lebt, seimer Einwilligung. Sie gilt als erteilt, wenn der Urheber nicht innerhalb eines Monats, nachdem ihm die beabsichtigte Anderung mitgeteilt worden ist, widerspricht.

\section{$\S 63$}

\section{Quellenangabe}

(1) Wenn ein Werk oder ein Teil eines Werkes in den Fällen des $\S 45$ Abs. 1, der $\S \S 46$ bis 48, 50 bis 52,59 und 60 vervielfältigt wird, ist stets die Quelle deutlich anzugeben, es sei denn, daß die Quelle auf dem benutzten Werkstück oder bei der benutzten Werkwiedergabe nicht angegeben worden ist.

(2) Soweit nach den Bestimmungen dieses Abschnitts die öffentliche Wiedergabe eines Werkes zulässig ist, ist die Quelle deutlich anzugeben, wenn und soweit die Verkehrssitte es erfordert.

(3) Wind ein Artikel aus einer Zeitung oder einem anderen Informationsblatt nach $\S 49$ Abs. 1 in einer anderen Zeitung oder in einem anderen Informationsblatt abgedruckt oder durch Funk gesendet, so ist stets außer dem Urheber, der in der benutzten Quelle bezeichnet ist, auch die Zeitung oder das Informationsblatt anzugeben, woraus der Artikel entnommen ist; ist dort eine andere Zeitung oder ein anderes Informationsblatt als Quelle angeführt, so ist diese Zeitung oder dieses Informationsblatt anzugeben.

\section{SIEBENTER ABSCHNITT}

\section{Gesetzliche Nutzungsrechte \\ $\S 64$ \\ Herstellung von Tonträgern}

(1) Hat ider Urheber eines Werkes der Musik einem Hersteller von Tonträgern ein Nutzungsrecht eingeräumt mit dem Inhalt, das Werk zu gewerblichen Zwecken auf Tonträger zu übertragen und diese $\mathrm{zu}$ vervielfältigen und $\mathrm{zu}$ verbreiten, so ist jeder andere Hersteller von Tonträgern, der im Geltungsbereich dieses Gesetzes seine Hauptniederlassung oder seinen Wohnsitz hat, nach Erscheinen des Werkes gleichfalls berechtigt, es auf Tonträger zu übertragen und idiese $\mathrm{zu}$ vervielfältigen und $\mathrm{zu}$ verbreiten, es sei denn, Idaß das bezeichnete Nutzungsrecht erlaubterweise von einer Verwertungsgesellschaft wahrgenommen wird. Die Berechtigung 
umfaßt nicht die Befugnis, das Werk zur Herstellung eines Tonfilms zu benutzen. $\S 46$ Abs. 3 gilt entsprechend.

(2) Einem Hersteller von Tonträgern, der seine Hauptniederlassung oder seinen Wohnsitz nicht im Geltungsbereich dieses Gesetzes hat, steht die Berechtigung nach Aibsatz $1 \mathbf{z u}$, soweit in dem Staat, in dem er seine Hauptniederlassung oder seinen Wohnsitz hat, den Herstellern von Tonträgern, die ihre Hauptniederlassung oder ihren Wohnsitz im Geltungsbereich dieses Gesetzes haben, nach einer Bekanntmachung des Bundesministers der Justiz im Bundesgesetzblatt ein entsprechendes Recht gewährt wird.

(3) Mit der Vervielfältigung darf. erst begonnen werden, wenn idie Absicht, von der Berechtigung nach Albsatz 1 Gebrauch zu machen, Idem Urheber durch eingeschriebenen Brief mitgeteilt worden ist und seit Absendung des Briefes zwei Wochen verstrichen sind. Ist der Wohnort oder Aufenthaltsort des Urhebers unbekannt, so kann die Mitteilung durch Veröffentlichung im Bundesanzeiger bewirkt werden.

(4) Die Berechtigung nach Absatz 1 wirkt nur im Geltungsbereich dieses Gesetzes und für die Ausfuhr nach Staaten, in denen das Werk keinen Schutz gegen die Uibertragung auf Tonträger genießt.

(5) Für die Vervielfältigung und Verbreitung des Wierkes nach den vorstehenden Bestimmungen ist dem Urheber eine angemessene Vergütung zu gewähren. Hat er das in Absatz 1 bezeichnete Nutzungsrecht als ausschließliches Recht eingeräumt, so ist die Vergütung dem Inhaber des ausschließlichen Nutzungsrechts zu gewähren.

(6) Auf ein Sprachwerk, das als Text mit einem Werk der Musik verbunden ist, sind die vorstehenden Bestimmungen entsprechend anzuwenden, wenn der Urheber des Sprachwerkes einem Hersteller von Tonträgern ein Nutzungsrecht eingeräumt hat mit dem Inhalt, das Sprachwerk in Verbindung mit dem Werk der Musik auf Tonträger zu übertragen und diese $\mathrm{zu}$ vervielfältigen und $\mathrm{zu}$ verbreiten.

(7) Die vorstehenden Bestimmungen sind nicht anzuwenden, wenn der Urheber das in Absatz 1 bezeichnete Nutzungsrecht lediglich für die Herstellung eines Tonfilms eingeräumt hat.

\section{$\S 65$}

\section{Funksendung}

(1) Hat der Urheber eines Sprachwerkes oder eines Werkes der Musik einem anderen ein ausschließliches Nutzungsrecht zur Funksendung des Werkes eingeräumt, so ist für die Dauer dieses Nutzungsrechts jedes Sendeunternehmen mit Sitz im Geltungsbereich dieses Gesetzes gleichfalls berechtigt, das Wenk idurch Funk zu seniden, es sei denn, daß das Nutzungsrecht erlaubterweise von einer Verwertungsgesellschaft wahrgenommen wind. Handelt es sich um ein Bühnenwerk, so umfaßt die Berechtigung nicht die Befugnis, das Werk vollständig oder Teile des Werkes derart zu senden, daß der Gang der Handlung erkennbar wird.
(2) Für die Funksendung ist dem Inhaber des ausschließlichen Nutzungsrechts eine angemessene Vergütung zu gewähren.

(3) Die vorstehenden Bestimmungen sind nicht anzuwenden, wenn der Urheber das in Absatz 1 bezeichnete Nutzungsrecht lediglich für die Funksendung eines Tonfilms eingeräumt hat.

\section{$\S 66$}

\section{Anderungsverbot; Quellenangabe}

Soweit nach den Bestimmungen dieses Abschnitts die Benutzung eines Werkes zulässig ist, sind $\S 62$ Abs. 1 und 2 und $\S 63$ Abs. 1 und 2 entsprechend anzuwenden.

\section{ACHTER ABSCHNITT}

\section{Dauer des Urheberrechts}

\section{$\S 67$}

\section{Allgemeines}

(1) Das Urheberrecht erlischt fünfzig Jahre nach dem Tode des Urhebers.

(2) Wird ein nachgelassenes Werk nach Ablauf von vierzig, aber vor Ablauf von fünfzig Jahren nach idem Tode des Urhebers veröffentlicht, so erlischt das Unheberrecht erst zehn Jahre nach der Veröffentlichung.

\section{$\S 68$}

\section{Miturheber}

Steht das Urheberrecht mehreren Miturhebern (§ 8) $\mathrm{zu}$, so erlischt es fünfzig Jiahre nach diem Tode des längstlebenden Miturhebers.

\section{$\S 69$}

\section{Anonyme und pseudonyme Werke}

(1) Ist der wahre Name oder der bekannte Deckname des Urhebers weder nach § 10 Abs. 1 noch bei einer öffenlichen Wiedergabe des Wierkes angegeben worden, so erlischt das Urheberrecht fünfzig Jahre nach der Veröffentlichung des Werkes.

(2) Die Dauer des Urheberrechts berechnet sich auch im Falle des Absatzes 1 nach den $\S \S 67$ und 68,

1. wenn innerhalb der in Absatz 1 bezeichneten Frist der wahre Name oder der bekannte Deckname des Urhebers nach § 10 Abs. 1 angegreben oder der Urheber auf andere Weise als Schöpfer des Werkes bekannt wird,

2. wenn innerhalb der in Absatz 1 bezeichneten Frist der wahre Name des Urhebens zur Eintragung in die Urheberrolle ( $\$ 147$ ) angemeldet wird,

3. wenn das Werk erst nach idem Tode des Urhebers veröffentlicht wird. 
(3) Zur Anmeldung nach Absatz 2 Nr. 2 sind der Urheber, nach seinem Tode sein Rechtsnachfolger (\$ 30) oder der Testamentsvollstrecker (\$28 Abs. 2) berechtigt.

(4) Die vorstehenden Bestimmungen sind auf Werke der bildenden Künste nicht anzuwenden.

\section{$\S 70$}

\section{Lieferungswerke}

Bei Werken, die in inhaltlich nicht abgeschlossenen Teilen (Lieferungen) veröffentlicht werden, ist in den Fällen des $\S 67$ Abs. 2 und des $\S 69$ Abs. 1 für die Berechnung der Schutzfrist der Zeitpunkt der Veröffentlichung der letzten Lieferung maßgebend.

\section{$\S 71$}

\section{Lichtbildwerke}

Das Urhelberrecht an Lichtbildwerken erlischt fünfundzwanzig Jahre nach idem Erscheinen des Werkes, jedoch bereits fünfundzwanzig Jahre nach der Herstellung, wenn das Werk innerhalb dieser Frist nicht erschienen ist.

\section{$\S 72$}

\section{Berechnung der Fristen}

Die Fristen dieses Abschnitts beginnen mit dem Ablauf ides Kalenderjahres, in dem das für den Beginn der Frist maßgebende Ereignis eingetreten ist.

\section{NEUNTER ABSCHNITT}

Urhebernachfolgevergütung

\section{$\S 73$ \\ Allgemeines}

(1) Für die öffentliche Wiedergabe eines Wierkes, Idas urheberrechtlich nicht geschützt ist, sowie für die gewerbsmäßige Verbreitung von Vervielfältignungsstücken eines solchen Werkes ist eine Vergütung (Urhebernachfolgevergütung) an den Urheberfonds ( $\$ 79)$ zu zahlen.

(2) Die Urhelbernachfolgevergütung entfällt, soweit nach den Bestimmungen des Sechsten Abschnitts die Verwertung auch bei urheberrechtlich geschützten Werken ohne Vergütung zulässig ist.

\section{$\S 74$}

\section{Verbreitung von Vervielfältigungsstủcken}

(1) Die Urhebernachfolgevergütung für die gewerbsmäßige Verbreitung von Vervielfältigungsstücken ist für jedes im Geltungsbereich dieses Gesetzes im Wiege der Veräußerung in Verkehr gebrachte Vervielfältigungsstück, jedoch nur einmal, $\mathrm{zu}$ entrichten.

(2) Für die gewerbsmäßige Verbreitung von Vervielfältigungsstücken, die vor Bekanntmachung der
Errichtung des Urheberfonds ( $\$ 79$ Abs. 2) hergestellt sind, ist eine Urhebernachfolgevergütung nicht zu entrichten.

\section{$\S 75$}

Ausnahmen

(1) Die Urhebernachfolgevengütung ist nicht zu entrichten

1. für die Verwertung von religiösen und wissenschaftlichen Wierken, von Werken zum Schulgebrauch und amtlichen Werken (§ 5) sowie von textkritischen Ausgaben von Werken,

2. für die Verwertung von wissenschaftlichen Ausgaben und Ausgaben nachgelassener Werke, die nach den $\S \S 80$ und 81 geschützt sind,

3. für die gewerbsmäßige Verbreitung von Vervielfältigungsstücken eines Werkes, deren Ladenpreis weniger als zweieinhalb Deutsche Mark beträgt.

(2) Im übrigen kann der Urheberfonds in besonıders gelagerten Ausnahmefällen auf die Urhebernachfolgevergütung verzichten.

\section{$\S 76$}

\section{Höhe der Urhebernachfolgevergütung}

(1) Die Urhebernachfolgevergütung beträgt zehn vom Hundert der Vergütung, die für die Einräumung des entsprechenden Nutzungsrechts bei Bestethen eines Urheberrechtsschutzes angemessen wäre. Für die gewerbsmäßige Verbreitung von Viervielfältigungsstücken eines Werkes beträgt die Urhebernachfolgevergütung eins vom Hundert des Ladenpreises; sie ist auf den nächstliegenden durch fünf teilbaren Pfennigbetrag jeweils nach oben oder unten abzurunden.

(2) Für die Verwertung des Werkes in einer urheberrechtlich geschützten Bearbeitung ist unibeschadet des Urheberrechts des Bearbeiters die Hälfte der nach Absatz 1 zu iberechnenden Beträge zu entrichten.

(3) Die Urhebernachfolgevergütung ist pauschal zu bemessen, wenn die Einzelabrechnung für den Verpflichteten unverhältnismäßig hohe Kosten verunsachen würde.

\section{$\S 77$}

\section{Einziehung der Urhebernachfolgevergütung}

Der Urheberfonds kann die Einziehung der Urhebernachfolgevengütung einer Verwertungsgesellschaft überlassen, die entsprechende Nutzungs rechte oder Vergütungsansprüche an urheberrechtlich greschützten W.erken wahrnimmt. In diesem Fall darf der Verwertungsgesellschaft für die Einziehung weder ein Entgelt noch Ersatz der Unkosten gewährt werden; jedoch ist, wenn die Verwertungsgesellschaft Versorgungseinrichtungen für ihre Mitglieder eingerichtet hat, ein angemessener Teil der ein- 
gezogenen Beträge diesen Versorgungseinrichtungen zur Verbesserung der Versorgung verdienter Unheber zuzuweisen.

\section{$\S 78$}

\section{Verwendung der Urhebernachfolgevergütung}

(1) Die Einnahmen aus der Urhebernachfolgevergütung sind $\mathrm{zu}$ folgenden Zwecken zu verwenden:

1. für Ehrensolde an Urheber, deren Verdienste und Lebensverhältnisse dies recht: fertigen;

2. für die Unterstützung bedürftiger Hinterbliebener verdienter Urheber;

3. für Förderungsbeihilfen an begabte Urheber.

(2) Zur Deckung von Unkosten dürfen bis zu fünf vom Hundert der Einnahmen einbehalten werden.

\section{$\S 79$}

\section{Errichtung des Urheberfonds}

(1) Der Urheberfonds ist als Stiftung des bürgerlichen Rechts zu errichten. Die Verfassung der Stiftung muß ein Organ vorsehen, in dem alle Länder vertreten sind.

(2) Der Bundesminister der Justiz macht die Errichtung des Urheberfonds im Bundesanzeiger bekannt, sobald das in Absatz 1 Satz 2 genannte Stiftungsorgan gebildet ist. Solange die Errichtung nicht bekanntgemacht ist, besteht keine Verpflichtung zur Zahlung der Urhebernachfolgevergütung.

ZWEITER TEIL

\section{Verwandte Schutzrechte}

\author{
ERSTER ABSCHNITT
}

Schutz bestimmter Ausgaben

$\S 80$

\section{Wissenschaftliche Ausgaben}

(1) Ausgaben unheberrechtlich nicht geschützter Werke oder Texte werden in entsprechender Anwendung der Vorschriften des Ersten Teils geschützt, wenn sie das Engebnis wissenschaftlich sichtender Tätigkeit darstellen und sich wesentlich von den bisher bekannten Ausgaben der Werke oder Texte unterscheiden.

(2) Das Recht steht dem Verfasser der Ausgabe zu.

(3) Das Recht erlischt zehn Jahre nach dem Erscheinen der Ausgabe, jedoch bereits zehn Jahre nach der Herstellung, wenn die Ausgabe innerhalb dieser Frist nicht erschienen ist. Die Frist ist nach $\S 72 \mathrm{zu}$ berechnen.

\section{$\S 81$}

\section{Ausgaben nachgelassener Werke}

(1) Wer ein nicht erschienenes Werk im Geltungsbereich dieses Gesetzes nach Erlöschen des Urheberrechts erscheinen läßt, hat das ausschließliche Recht, das Werk zu vervielfältigen und zu verbreiten sowie die Vervielfältigungsstücke des Werkes zur öffentlichen Wiedergabe zu benutzen. Das gleiche gilt für nicht erschienene Werke, die im Geltungsbereich dieses Gesetzes niemals geschützt waren, deren Urheber aber schon länger als fünfzig Jahre tot ist. Die $\S \S 5,15$ bis 24,27 und 45 bis 66 sind sinngemäß anzuwenden.

(2) Das Recht ist übertragbar.

(3) Das Recht erlischt zehn Jahre nach dem Erscheinen des Werkes. Die Frist ist nach $\S 72 \mathrm{zu}$ berechnen.

\section{ZWEITER ABSCHNITT \\ Schutz der Lichtbilder}

\section{$\S 82$}

(1) Auf Lichtbilder und auf Erzeugnisse, die ähnlich wie Lichtbilder hergestellt werden, sind die für Lichtbildwerke geltenden Vorschriften des Ersten Teils sinngemäß anzuwenden.

(2) Das Recht nach Absatz 1 steht dem Lichtbildner zu.

\section{DRITTER ABSCHNITT}

\section{Schutz des ausübenden Künstlers}

\section{$\S 83$}

\section{Austibender Künstler}

Ausübender Künstler im Sinne dieses Gesetzes ist, wer ein Werk vorträgt oder aufführt oder bei dem Vortrag oder der Aufführung eines Werkes künstlerisch mitwirkt.

\section{$\S 84$}

\section{Bildschirm- und Lautsprecheribbertragung}

Die Darbietung des ausübenden Künstlers darf nur mit seiner Einwilligung außerhalb der Veranstaltung, bei der sie stattfindet, durch Bildschirm, Lautsprecher oder ähnliche technische Einrichtungen öffentlich wahrnehmbar gemacht werden.

\section{$\S 85$}

\section{Vervielfältigung}

Die Darbietung des ausübenden Künstlers darf nur mit seiner Einwilligung auf Bild- oder Tonträger aufgenommen werden. Die Bild- oder Tonträger dürfen nur mit seiner Einwilligung vervielfältigt werden. 


\section{$\S 86$ \\ Funksendung}

(1) Die Darbietung des ausübenden Künstlers darf nur mit seiner Einwilligung durch Funk gesendet werden.

(2) Die Darbietung des ausübenden Künstlers, die erlaubterweise auf Bild- oder Tonträger aufgenommen worden ist, darf ohne seine Einwilligung durch Funk gesendet werden, wenn die Bild- und Tonträger erschienen sind; jedoch ist ihm hierfür eine angemessene Vergütung zu gewähren.

\section{$\S 87$ \\ Offentliche Wiedergabe}

Wird die Darbietung des ausübenden Künstlers mittels Bild- oder Tonträger oder die Funksendung seiner Darbietung öffentlich wahrnehmbar gemacht, so ist ihm hierfür eine angemessene Vergütung zu gewähren.

\section{$\S 88$ \\ Abtretung}

Der ausübende Künstler kann die nach den $\S \S 84$ bis 87 gewährten Rechte und Ansprüche an Dritte abtreten; jedoch behält er stets die Befugnis, die in den $\S \S 84,85$ und 86 Abs. 1 vorgesehene Einwilligung auch selbst zu erteilen.

\section{$\S 89$}

\section{Austubende Künstler \\ in Arbeits- oder Dienstverhältnissen}

Hat ein ausübender Künstler eine Darbietung in Erfüllung seiner Verpflichtungen aus einem Arbeitsoder Dienstverhältnis erbracht, so bestimmt sich, wenn keine besonderen Vereinbarungen getroffen sind, nach dem Wesen des Arbeits- oder Dienstverhältnisses, in welchem Umfang und unter welchen Bedingungen der Arbeitgeber oder Dienstherr die Darbietung benutzen und anderen ihre Benutzung gestatten darf.

\section{$\S 90$}

\section{Chor-, Orchester- und Bühnenaufführungen}

(1) Bei Chor-, Orchester- und Bühnenaufführungen genügt in den Fällen der $\$ \S 84,85$ und 86 Abs. 1 neben der Einwilligung der Solisten, des Dirigenten und des Regisseurs die Einwilligung der gewählten Vertreter (Vorstände) der mitwirkenden Künstlergruppen, wie Chor, Orchester, Ballett und Bühnenensemble. Hat eine Gruppe keinen Vorstand, so wird die Einwilligung der ihr angehörenden ausübenden Künstler durch die Einwilligung des Leiters der Gruppe ersetzt.

(2) Zur Geltendmachung der sich aus den $\$ \S 84$ bis 87 ergebenden Rechte mit Ausnahme der Einwilligungsrechte sind bei Chor-, Orchester- und Bühnenaufführungen für die mitwirkenden Künstlergruppen jeweils deren Vorstände und, soweit für eine Gruppe ein Vorstand nicht besteht, der Leiter dieser Gruppe allein ermächtigt. Die Ermächtigung kann auf eine Verwertungsgesellschaft übertragen werden.

\section{$\S 91$}

\section{Schutz des Veranstalters}

Wird die Darbietung des ausübenden Künstlers von einem Unternehmen veranstaltet, so bedarf es in den Fällen der $\S \S 84,85$ und 86 Abs. 1 neben der Einwilligung des ausübenden Künstlers auch der Einwilligung des Inhabers des Unternehmens.

\section{$\S 92$}

\section{Dauer der Rechte}

Ist die Darbietung des ausübenden Künstlers auf einen Bild- oder Tonträger aufgenommen worden, so erlöschen die Rechte des ausübenden Künstlers und des Veranstalters fünfundzwanzig Jahre nach dem Erscheinen des Bild- oder Tonträgers, jedoch bereits fünfundzwanzig Jahre nach der Darbietung, wenn der Bild- oder Tonträger innerhalb dieser Frist nicht erschienen ist. Die Frist ist nach $\S 72 \mathrm{zu}$ berechnen.

\section{$\S 93$}

\section{Schutz gegen Entstellung}

(1) Der ausübende Künstler hat das Recht, eine Entstellung oder eine andere Beeinträchtigung seiner Darbietung zu verbieten, die geeignet ist, sein Ansehen oder seinen Ruf als ausübender Künstler zu gefährden.

(2) Haben mehrere ausübende Künstler gemeinsam eine Darbietung erbracht, so haben sie bei der Ausübung des Rechts aufeinander angemessene Rücksicht zu nehmen.

(3) Das Recht erlischt mit dem Tode des ausübenden Künstlers, jedoch erst fünfundzwanzig Jahre nach der Darbietung, wenn der ausübende Künstler vor Ablauf dieser Frist verstorben ist; die Frist ist nach $\S 72 \mathrm{zu}$ berechnen. Nach dem Tode des ausübenden Künstlers steht das Recht seinen Angehörigen ( $\$ 61$ Abs. 3) zu.

\section{$\S 94$}

\section{Beschränkung der Rechte}

Auf die dem ausübenden Künstler und dem Veranstalter nach diesem Abschnitt zustehenden Rechte sind die Vorschriften des Sechsten Abschnitts des Ersten Teils sinngemäß anzuwenden.

\section{VIERTER ABSCHNITT}

\section{Schutz des Herstellers von Tonträgern}

\section{$\S 95$}

\section{Vervielfaltigungs- und Verbreitungsrecht}

(1) Der Hersteller eines Tonträgers hat das ausschließliche Recht, den Tonträger zu vervielfältigen und zu verbreiten. Ist der Tonträger in einem Un- 
ternehmen hergestellt worden, so gilt der Inhaber des Unternehmens als Hersteller. Das Recht entsteht nicht durch Vervielfältigung eines Tonträgers.

(2) Das Recht erlischt fünfundzwanzig Jahre nach dem Erscheinen des Tonträgers, jedoch bereits fünfundzwanzig Jahre nach der Herstellung, wenn der Tonträger innerhalb dieser Frist nicht erschienen ist. Die Frist ist nach $\S 72 \mathrm{zu}$ berechnen.

(3) Die Vorschriften des Sechsten Abschnitts des Ersten Teils sind sinngemäß anzuwenden.

(4) Ein Schutz nach anderen gesetzlichen Vorschriften bleibt unberührt.

\section{$\S 96$}

\section{Anspruch auf Beteiligung}

Wird ein erschienener Tonträger, auf den die Darbietung eines ausübenden Künstlers aufgenommen ist, zur öffentlichen Wiedergabe der Darbietung benutzt, so hat der Hersteller des Tonträgers gegen den ausübenden Künstler einen Anspruch auf angemessene Beteiligung an der Vergütung, die dieser nach $\S 86$ Abs. 2 und $\S 87$ erhält.

\section{FUNFTER ABSCHNITT}

\section{Schutz des Sendeunternehmens}

\section{$\S 97$}

(1) Das Sendeunternehmen hat das ausschließliche Recht,

1. seine Funksendung weiterzusenden,

2. zu Erwerbszwecken seine Funksendung auf Bild- oder Tonträger aufzunehmen, Lichtbilder von seiner Funksendung herzustellen sowie die Bild- oder Tonträger oder Lichtbilder zu vervielfältigen,

3. an Stellen, die der Offentlichkeit nur gegen Zahlung eines Eintrittsgelides zugänglich sind, seine Fernsehsendung öffentlich wahrnehmbar zu machen.

(2) Das Recht erlischt fünfundzwanzig Jahre nach der Funksendung. Die Frist ist nach $\S 72 \mathrm{zu}$ berechnen.

(3) Die Vorschriften des Sechsten Abschnitts des Ersten Teils sind sinngemäß anzuwenden.

DRITTER TEII

\section{Besondere Bestimmungen für Filme}

\section{ERSTER ABSCHNITT}

Filmwerke

\section{$\S 98$}

\section{Recht zur Verfilmung}

(1) Gestattet der Urheber einem anderen, sein Werk $\mathrm{zu}$ verfilmen, so liegt darin im Zweifel die
Einräumung folgender ausschließlicher Nutzungsrechte:

1. das Werk unverändert oder unter Bearbeitung oder Umgestaltung zur Herstellung eines Filmwerkes zu benutzen;

2. das Filmwerk zu vervielfältigen und $\mathrm{zu}$ verbreiten $_{i}$

3. das Filmwerk öffentlich vorzuführen, wenn es sich um ein zur Vorführung bestimmtes Filmwerk handelt;

4. das Filmwerk durch Funk zu senden, wenn es sich um ein zur Funksendung bestimmtes Filmwerk handelt;

5. Ubersetzungen und andere filmische Bearbeitungen oder Umgestaltungen des Filmwerkes in gleichem Umfang wie dieses zu verwerten.

(2) Die in Absatz 1 bezeichneten Befugnisse berechtigen im Zweifel nicht zu einer Wiederverfilmung des Werkes. Der Urheber ist im Zweifel berechtigt, sein Werk nach Ablauf von zehn Jahren nach Herstellung des Filmwerkes anderweit filmisch $\mathrm{zu}$ verwerten.

(3) Die vorstehenden Bestimmungen sind auf die in den $\S \S 80$ und 81 bezeichneten Schutzrechte entsprechend anzuwenden.

\section{$\S 99$}

\section{Rechte am Filmwerk}

(1) Wer sich zur Mitwirkung bei der Herstellung eines Filmes verpflichtet, räumt damit für den Fall daß er ein Urheberrecht am Filmwerk erwirbt, dem Filmhersteller im Zweifel das ausschließliche Recht ein, das Filmwerk sowie Ubersetzungen und andere filmische Bearbeitungen oder Umgestaltungen des Filmwerkes auf alle bekannten Nutzungsarten zu nutzen.

(2) Hat der Urheber des Filmwerkes das in Absatz 1 bezeichnete Nutzungsrecht im voraus einem Dritten eingeräumt, so behält er gleichwohl stets die Befugnis, dieses Recht beschränkt oder unbeschränkt dem Filmhersteller einzuräumen.

(3) Die Urheberrechte an den zur Herstellung des Filmwerkes benutzten Werken, wie Roman, Drehbuch und Filmmusik, bleiben unberührt.

\section{$\S 100$}

\section{Einschränkung der Rechte}

Die Bestimmungen über das Erfordernis der $\mathrm{Zu}$ stimmung des Urhebers zur Ubertragung von Nutzungsrechten ( $\S 34$ ) und zur Einräumung einfacher Nutzungsrechte ( $\$ 35$ ) sowie über das Rückrufsrecht wegen Nichtausübung ( $\S 41)$ und wegen gewandelter Uberzeugung ( $\S 42)$ gelten nicht für die in $\S 98$ Abs. 1 Nr. 2 bis 5 und $\S 99$ bezeichneten Rechte. Dem Urheber des Filmwerkes ( $\S 99$ ) stehen Ansprüche aus $\S 36$ nicht $\mathrm{zu}$. 
$\S 101$

\section{Rechte an Lichtbildern}

Die Rechte zur filmischen Verwertung der bei der Herstellung eines Filmwerkes entstehenden Lichtbilder erwirbt der Filmhersteller. Dem Lichtbildner stehen insoweit keine Rechte $\mathrm{zu}$.

\section{$\S 102$}

\section{Ausübende Künstler}

Ausübenden Künstlern, die bei der Herstellung eines Filmwerkes mitwirken oder deren Darbietungen erlaubterweise zur Herstellung eines Filmwerkes benutzt werden, stehen in Ansehung des Filmwerkes Rechte nach den $\S \S 85$ bis 87 nicht zu.

\section{$\S 103$}

\section{Schutz gegen Entstellung}

Die Urheber des Filmwerkes und der zu seiner Herstellung benutzten Werke sowie die Inhaber verwandter Schutzrechte, die bei der Herstellung des Filmwerkes mitwirken oder deren Leistungen zur Herstellung des Filmwerkes benutzt werden, können in Ansehung des Filmwerkes Rechte aus den $\S \S 14$ und 93 nur im Falle einer gröblichen Entstellung oder anderen gröblichen Beeinträchtigung ihrer Werke oder Leistungen geltend machen. Sie haben hierbei aufeinander und auf den Filmhersteller angemessene Rücksicht zu nehmen.

\section{$\S 104$}

\section{Schutz des Filmherstellers}

(1) Der Filmhersteller hat das ausschließliche Recht, den Bildträger oder Bild- und Tonträger, auf den das Filmwerk aufgenommen ist, zu vervielfältigen, zu verbreiten und zur öffentlichen Vorführung oder Funksendung zu benutzen. Der Filmhersteller hat ferner das Recht, jede Entstellung oder Kürzung des Bildträgers oder Bild- und Tonträgers zu verbieten, die geeignet ist, seine berechtigten Interessen an diesem zu gefährden.

(2) Das Recht ist übertragbar.

(3) Das Recht erlischt fünfundzwanzig Jahre nach dem Erscheinen des Bildträgers oder Bild- und Tonträgers, jedoch bereits fünfundzwanzig Jahre nach der Herstellung, wenn der Bildträger oder Bild- und Tonträger innerhalb dieser Frist nicht erschienen ist.

(4) Die Vorschriften des Sechsten Abschnitts des Ersten Teils sind sinngemäß anzuwenden.

\section{ZWEITER ABSCHNITT}

\section{Laufbilder}

\section{$\S 105$}

Die $\S \S 98,100,101,103$ und 104 sind auf Bildfolgen und Bild- und Tonfolgen, die nicht als Filmwerke geschützt sind, entsprechend anzuwenden.
VIERTER TEIL

\section{Gemeinsame Bestimmungen für Urheberrecht und verwandte Schutzrechte}

\section{ERSTER ABSCHNITT}

\section{Verwertungsverbot}

$$
\S 106
$$

(1) Rechtswidrig hergestellte Vervielfältigungsstücke dürfen weder verbreitet noch zu öffentlichen Wiedergaben benutzt werden.

(2) Rechtswidrig veranstaltete Funksendungen dürfen nicht auf Bild- oder Tonträger aufgenommen oder öffentlich wiedergegeben werden.

\section{ZWEITER ABSCHNITT}

\section{Rechtsverletzungen}

1. Bürgerlich-rechtliche

Vorschriften; Rechtsweg

\section{$\S 107$}

\section{Anspruch auf Unterlassung und Schadenersatz}

(1) Wer das Urheberrecht oder ein anderes nach diesem Gesetz geschütztes Recht widerrechtlich verletzt, kann vom Verletzten auf Beseitigung der Beeinträchtigung, bei Wiederholungsgefahr auf Unterlassung und, wenn dem Verletzer Vorsatz oder Fahrlässigkeit zur Last fällt, auch auf Schadenersatz in Anspruch genommen werden. An Stelle des Schadenersatzes kann der Verletzte die Herausgabe des Gewinns, den der Verletzer durch die Verletzung des Rechts erzielt hat, und Rechnungslegung über diesen Gewinn verlangen.

(2) Urheber, Verfasser wissenschaftlicher Ausgaben ( $(80)$, Lichtbildner ( $(82)$ und ausübende Künstler ( $(83)$ können, wenn dem Verletzer Vorsatz oder Fahrlässigkeit zur Last fällt, auch wegen des Schadens, der nicht Vermögensschaden ist, eine Entschädigung in Geld verlangen, wenn und soweit es der Billigkeit entspricht. Der Anspruch ist nicht übertragbar, es sei denn, daß er durch Vertrag anerkannt oder daß er rechtshängig geworden ist.

(3) Ansprüche aus anderen gesetzlichen Vorschriften bleiben unberührt.

\section{$\S 108$}

\section{Anspruch auf Vernichtung und ähnliche Maßnahmen}

(1) Der Verletzte kann verlangen, daß alle rechtswidrig hergestellten, rechtswidrig verbreiteten und zur rechtswidrigen Verbreitung bestimmten Vervielfältigungsstücke vernichtet werden.

(2) Der Verletzte kann ferner verlangen, daß die ausschließlich zur rechtswidrigen Herstellung von Vervielfältigungsstücken bestimmten Vorrichtun- 
gen, wie Formen, Platten, Steine, Drudkstöcke, Matrizen und Negative, unbrauchbar gemacht oder, falls dies nicht durchführbar ist, vernichtet werden.

(3) Kann der durch die Rechtsverletzung verursachte Zustand von Vervielfältigungsstücken oder Vorrichtungen auf andere Weise beseitigt werden, insbesondere dadurch, daß Anderungen als nicht vom Berechtigten herrührend gekennzeichnet werden, so kann der Verletzte nur die hierzu erforderlichen Maßnahmen verlangen.

(4) Den in den Absätzen 1 bis 3 vorgesehenen Maßnahmen sind nur die Vervielfältigungsstücke und Vorrichtungen unterworfen, die Eigentum der an der rechtswidrigen Herstellung oder Verbreitung der Vervielfältigungsstücke Beteiligten oder deren Erben sind. Diese Maßnahmen dürfen erst vollzogen werden, nachdem dem Eigentümer gegenüber rechtskräftig auf sie erkannt ist.

\section{$\S 109$}

\section{Anspruch auf Uberlassung}

(1) Statt der in $\S 108$ vorgesehenen Maßnahmen kann der Verletzte verlangen, daß ihm die Vervielfältigungsstücke und Vorrichtungen ganz oder teilweise gegen eine angemessene Vergütung überlassen werden, welche die Herstellungskosten nicht übersteigen darf.

(2) § 108 Abs. 4 gilt entsprechend.

\section{$\S 110$}

\section{Haftung des Inhabers eines Unternehmens}

Ist in einem Unternehmen von einem Arbeitnehmer oder Beauftragten ein nach diesem Gesetz geschütztes Recht widerrechtlich verletzt worden, so hat der Verletzte die Ansprüche aus den $\S \S 107$ bis 109 mit Ausnahme des Anspruchs auf Schadenersatz auch gegen den Inhaber des Unternehmens. Weitergehende Ansprüche nach anderen gesetzlichen Vorschriften bleiben unberührt.

\section{$\S 111$}

\section{Ausnahmen}

(1) Richten sich im Falle der Verletzung eines nach diesem Gesetz geschützten Rechts die Ansprüche des Verletzten auf Beseitigung oder Unterlassung ( $\$ 107$ ), auf Vernichtung oder Unbrauchbarmachung ( $\$ 108)$ oder auf Uberlassung ( $\$ 109)$ gegen eine Person, der weder Vorsatz noch Fahrlässigkeit zur Last fällt, so kann diese zur Abwendung der Ansprüche den Verletzten in Geld entschädigen, wenn ihr durch die Erfüllung der Ansprüche ein unverhältnismäßig großer Schaden entstehen würde und dem Verletzten die Abfindung in Geld zuzumuten ist. Als Entschädigung ist der Betrag zu zahlen, der im Falle einer vertraglichen Einräumung des Rechts als Vergütung angemessen gewesen wäre. Mit der Zahlung der Entschädigung gilt die Einwilligung des Verletzten zur Verwertung im üblichen Umfange als erteilt.
(2) Den in den $\S \S 108$ und 109 vorgesehenen Maßnahmen unterliegen nicht:

1. Bauwerke;

2. ausscheidbare Teile von Vervielfältigungsstücken und Vorrichtungen, deren Herstellung oder Verbreitung nicht rechtswidrig ist;

3. Vervielfältigungsstücke, die nur wegen des Fehlens oder der Beschaffenheit der Quellenangabe dem Gesetz nicht entsprechen; der Verletzte kann jedoch verlangen, daß nachträglich die Quelle angegeben oder die Quellenangabe berichtigt wird, soweit diese Maßnahmen durchführbar sind.

\section{$\S 112$}

\section{Verjährung}

(1) Der Anspruch auf Schadenersatz nach § 107 verjährt in drei Jahren von dem Zeitpunkt an, in welchem der Verletzte von dem Schaden und der Person des Ersatzpflichtigen Kenntnis erlangt, ohne Rücksicht auf diese Kenntnis in dreißig Jahren von der Begehung der Handlung an.

(2) Die Ansprüche aus den $\S 108$ und 109 unterliegen nicht der Verjährung.

\section{$\S 113$}

\section{Bekanntmachung des Urteils}

(1) Ist eine Klage auf Grund dieses Gesetzes erhoben worden, so kann im Urteil der obsiegenden Partei die Befugnis zugesprochen werden, das Urteil auf Kosten der unterliegenden Partei öffentlich bekanntzumachen, wenn sie ein berechtigtes Interesse dartut. Das Urteil darf erst nach Rechtskraft bekanntgemacht werden, wenn nicht das Gericht etwas anderes bestimmt.

(2) Art und Umfang der Bekanntmachung werden im Urteil bestimmt. Die Befugnis zur Bekanntmachung erlischt, wenn das Urteil nicht innerhalb von sechs Monaten nach Eintritt der Rechtskraft bekanntgemacht wird.

(3) Die Partei, der die Befugnis zur Bekanntmachung zusteht, kann beantragen, die unterliegende Partei zur Vorauszahlung der Bekanntmachungskosten zu verurteilen. Uber den Antrag entscheidet das Prozeßgericht erster Instanz durch Beschluß ohne mündliche Verhandlung. Vor der Entscheidung ist die unterliegende Partei zu hören.

\section{$\S 114$}

\section{Rechtsweg}

Für alle Rechtsstreitigkeiten, durch die ein Anspruch aus einem der in diesem Gesetz geregelten Rechtsverhältnisse geltend gemacht wird, (Urheberrechtsstreitsachen) ist der ordentliche Rechtsweg gegeben. Für Urheberrechtsstreitsachen aus Arbeitsoder Dienstverhältnissen, die ausschließlich Ansprüche auf Leistung einer vereinbarten Vergütung 
zum Gegenstand haben, bleiben der Rechtsweg zu den Gerichten für Arbeitssachen und der Verwaltungsrechtsweg unberührt.

\section{$\S 115$}

\section{Gerichte für Urheberrechtsstreitsachen}

(1) Die Landesregierungen werden ermächtigt, durch Rechtsverordnung Urheberrechtsstreitsachen, für die das Landgericht in erster Instanz oder in der Berufungsinstanz zuständig ist, für die Bezirke mehrerer Landgerichte einem von ihnen zuzuweisen, wenn dies der Rechtspflege dienlich ist.

(2) Die Landesregierungen werden ferner ermächtigt, die zur Zuständigkeit der Amtsgerichte gehörenden Urheberrechtsstreitsachen für die Bezirke mehrerer Amtsgerichte einem von ihnen zuzuweisen, wenn dies der Rechtspflege dienlich ist.

(3) Die Landesregierungen können die Ermächtigungen nach den Absätzen 1 und 2 auf die Landesjustizverwaltungen übertragen.

(4) Vor einem Landgericht, dem nach Absatz 1 die Urheberrechtsstreitsachen aus den Bezirken mehrerer Landgerichte zugewiesen sind, können sich die Parteien auch durch Rechtsanwälte vertreten lassen, die bei dem sonst zuständigen Landgericht zugelassen sind. Das Entsprechende gilt für die Vertretung vor dem Oberlandesgericht als Berufungsgericht.

(5) Die Mehrkosten, die einer Partei dadurch erwachsen, daß sie sich nach Absatz 4 durch einen nicht beim Prozeßgericht zugelassenen Rechtsanwalt vertreten läßt, sind nicht zu erstatten.

\section{Strafrechtliche Vorschriften}

\section{$\S 116$}

Unerlaubte Verwertung urheberrechtlich geschützter Werke

Wer in anderen als den gesetzlich zugelassenen Fällen vorsätzlich ohne Einwilligung des Berechtigten ein Werk oder eine Bearbeitung oder Umgestaltung eines Werkes vervielfältigt, verbreitet oder öffentlich wiedergibt, wird mit Geldstrafe oder mit Gefängnis bis zu einem Jahr bestraft.

\section{$\S 117$}

Unzulässiges Anbringen der Urheberbezeichnung

\section{Wer vorsätzlich}

1. auf ıdem Original eines Werkes der ibildenden Künste die Urheberbezeichnung ( $\$ 10$ Abs. 1) ohne Einwilligung des Urhebers anbringt oder ein derart bezeichnetes Original verbreitet,

2. auf einem Vervielfältigungsstück oder einer Bearbeitung eines Werkes der bildenden Künste die Urheberbezeichnung ( $\S 10$ Abs. 1) auf eine Art anbringt, die dem Vervielfältigungisstück oder der Bearbeitung den Anschein eines Originals gibt, oder ein derart bezeich- netes Vervielfältigungsstück oder eine solche Bearbeitung verbreitet,

wird mit Geldstrafe oder mit Gefängnis bis zu einem Jahr bestraft, wenn die Tat nicht in anderen Vorschriften mit schwererer Strafe bedroht ist.

\section{$\S_{118}$}

\section{Unerlaubte Eingriffe in verwandte Schutzrechte}

Wer in anderen als den gesetzlich zugelassenen Fällen vorsätzlich ohne Einwilligung des Berechtigten

1. eine wissenschaftliche Ausgabe ( $\S$ 80) oder eine Bearbeitung oder Umgestaltung einer solchen Ausgabe vervielfältigt, verbreitet oder öffentlich wiedergibt,

2. ein nachgelassenes Werk oder eine Bearbeitung oder Umgestaltung eines solchen Werkes entgegen $\S 81$ verwertet,

3. ein Lichtbild ( $\$ 82$ ) oder eine Bearbeitung oder Umgestaltung eines Lichtbildes vervielfältigt, venbreitet oder öffentlich wiedergibt,

4. die Darbietung eines ausübenden Künstlers entgegen iden $\S \S 84,85$ oder 86 Abs. 1 verwertet,

5. einen Tonträger entgegen $\S 95$ verwertet,

6. eine Funksendung entgegen $\S 97$ verwertet,

7. einen Bildträger oder Bild- und Tonträger entgegen $\S \S 104$ oder 105 in Verbindung mit $\S 104$ verwertet,

wird mit Geldstrafe oder mit Gefängnis bis zu einem Jahr bestraft.

$\S 119$

Strafantrag

Die Tat wird nur auf Antrag verfolgt. Der Antrag kann zurückgenommen werden.

\section{$\S 120$}

\section{Anspruch auf Vernichtung und ähnliche Maßnahmen}

Der Verletzte kann bei Vergehen nach den $\S \S 116$, 117 Nr. 2 und $\S 118$ die in den $\S \S 108$ und 109 bezeichneten Ansprüche nach den Vorschriften der Strafprozeßordnung über die Entschädigung des Verletzten ( $\$ \$ 403$ bis $406 \mathrm{c}$ ) geltend machen, im Verfahren vor dem Amtsgericht ohne Rücksicht auf den Wert des Streitgegenstandes. Bei diesen Vergehen ist $\S 40$ ides Strafigesetzbuchs auf die in den $\S \S 108$ und 109 genannten Gegenstände nicht anzuwenden.

\section{$\S 121$}

\section{Bekanntmachung des Urteils}

(1) Wird in den Fällen der $\S \S 116$ bis 118 auf Strafe erkannt, so kann im Urteil auf Antrag zugleich dem Verletzten die Befugnis zugesprochen werdén, die Verurteilung auf Kosten des Angeklag- 
ten öffentlich bekanntzumachen, wenn ider Verletzte ein berechtigtes Interesse an der Bekanntmachung hat. Dem Verletzten ist auf Kosten des Angeklagten eine Ausfertigung des Urteils zu erteilen. Die Befugnis zur Bekanntmachung erlischt, wenn die Verurteilung nicht innerhalb von sechs Monaten nach Eintritt der Rechtskraft bekanntgemacht wird.

(2) Auf Antrag des freigesprochenen Angeklagten kann ' das Gericht die öffentliche Bekanntmachung der Freisprechung anordnen. Die Kosten trägt im Verfahren auf erhobene Privatklage der Privatkläger, im Verfahren auf erhobene öffentliche Klage die Staatskasse, soweit die Kosten nicht nach $\S 469$ der Strafprozeßordnung dem Anzeigenden auferlegt werden.

(3) Art und Umfang der Bekanntmachung werden im Urteil bestimmt.

\section{DRITTER ABSCHNITT}

\section{Zwangsvollstreckung}

\section{Allgemeines}

\section{$\S 122$}

Die Zwangsvollstreckung in ein nach diesem Gesetz geschütztes Recht ist nach den allgemeinen Vorschriften zulässig, so.weit sich aus den $\S \S 123$ bis 129 nichts anderes ergibt.

\section{Zwangsvollstreckung wegen Geldforderungen gegen den $\mathrm{Urheber}$}

\section{$\S 123$}

\section{Urheberrecht}

Gegen iden Urheber ist die Zwangsvollstreckung wegen Geldfonderungen in das Urheberrecht nur mit seiner Einwilligung und nur insoweit zulässig, als er Nutzungsrechte einräumen kann (§31). Die Einwilligung kann nicht durch den gesetzlichen Vertreter erteilt iwerden.

\section{$\S 124$}

\section{Originale von Werken}

(1) Gegen den Urheber ist die Zwangsvollstrekkung wegen Geldforderungen in idie ihm gehörenden Originale seiner Werke nur mit seiner Einwilligung zulässig. Die Einwilligung kann nicht durch den gesetzlichen Vertreter erteilt werden.

(2) Der Einwilligung bedarf es nicht,

1. soweit die Zwangsvollstreckung in das Original des Werkes zur Durchführung der Zwangsvollstreckung in ein Nutzungsrecht am Werk notwendig ist,

2. zur Zwangsvollstreckung in ddas Original eines Werkes der Baukunst,
3. zur Zwangsvollstreckung in das Original eines anderen Werkes der bildenden Künste, wenn das Werk veröffentlicht ist.

In den Fällen der Nummern 2 und 3 darf das Original des Werkes ohne Zustimmung des Urhebers verbreitet werden.

3. Z w angsollstreckung wegen

Geldforderungen gegen den

Rechtsnachfolger des Urhebers

\section{$\S 125$}

Urheberrecht

Gegen den Rechtsnachfolger des Urhebers ( $§ 30$ ) ist die Zwangsvollstreckung wegen Geldforderungen in das Urheberrecht nur mit seiner Einwilligung und nur insoweit zulässig, al's er Nutzungsrechte einräumen kann ( $\S 31$ ). Der Einwilligung bedarf es nicht, wenn das Werk erschienen ist.

\section{$\S 126$}

\section{Originale von Werken}

(1) Gegen den Rechtsnachfolger des Urhebers (§ 30) ist die Zwangsvollstreckung wegen Geldforderungen in die ihm gehörenden Originale von Werken ides Urhebers nur mit seiner Einwilligung zulässig.

(2) Der Einwilligung bedarf es nicht

1. in den Fällen des $\S 124$ Abs. 2 Satz 1,

2. zur Zwangsvollstreckung in das Original eines Werkes, wenn das Werk erschienen ist.

$\S .124$ Abs. 2 Satz 2 gilt entsprechend.

\section{$\S 127$}

\section{Testamentsvollstrecker}

Ist nach $\S 28$ Aibs. 2 angeondnet, daß das Urheberrecht durch einen Testamentsvollstrecker ausgeübt wird, so ist die nach den $\S \S 125$ und 126 erforderliche Einwilligung durch den Testamentsvollstredker zu erteilen.

4. Zwangsvollstreckung wegen Geldforderungen gegen den

Verfasser wissenschaftlicher

Ausgaben und gegen den Lich t bildner

\section{$\S 128$}

Die $\S \S 123$ bis 127 sind sinngemäß anzuwenden

1. auf die Zwangsvollstreckung wegen Geldforderungen gegen den Verfasser wissenschaftlicher Ausgaben ( $\$ 80)$ und seinen Rechtsnachfolger,

2. auf die Zwangsvollstredkung wegen Geldforderungen gegen den Lichtbildner (§ 82) und seinen Rechtsnachfolger. 


\section{Zwangsvollstreckung wegen Geldforderungen in bestimmte Vorrichtungen}

\section{$\S 129$}

(1) Vorrichtungen, die ausschließlich zur Vervielfältigung oder Funksendung eines Werkes bestimmt sind, wie Formen, Platten, Steine, Druckstöcke, Matrizen und Negative, unterliegen der Zwangsvollstreckung wegen Geldforderungen nur, soweit der Gläubiger zur Nutzung des Werkes mittels dieser Vorrichtungen berechtigt ist.

(2) Das gleiche gilt für Vorrichtungen, die ausschließlich zur Vorführung eines Filmwerkes bestimmt sind, wie Filmstreifen und dergleichen.

(3) Die Absätze 1 und 2 sind auf die nach den §8 80 und 81 geschützten Ausgaben, die nach $\S 82$ geschützten Lichtbilder und die nach $\S 85$ Satz 2, $\S \S 95,97,104$ und 105 geschützten Bild- und Tonträger entsprechend anzuwenden.

\section{FUNFTER TEIL}

\section{Anwendungsbereich Ubergangs- und Schlußbestimmungen}

\author{
ERSTER ABSCHNITT
}

\section{Anwendungsbereich des Gesetzes}

1. Urheberrecht

\section{$\S 130$}

\section{Deutsche Staatsangehörige}

(1) Deutsche Staatsangehörige genießen den urheberrechtlichen Schutz für alle ihre Werke, gleichviel, ob und wo die Werke erschienen sind. Ist ein Werk von Miturhebern ( $\S 8)$ geschaffen, so genügt es, wenn ein Miturheber deutscher Staatsangehöriger ist.

(2) Deutschen Staatsangehörigen stehen Deutsche im Sinne des Artikels 116 Abs. 1 des Grundgesetzes gleich, die nicht die deutsche Staatsangehörigkeit besitzen.

\section{$\S 131$}

\section{Ausländische Staatsangehörige}

(1) Ausländische Staatsangehörige genießen den urheberrechtlichen Schutz für ihre im Geltungsbereich dieses Gesetzes erschienenen Werke, es sei denn, daß das Werk oder eine Ubersetzung des Werkes früher als dreißig Tage vor dem Erscheinen im Geltungsbereich dieses Gesetzes außerhalb dieses Gebietes erschienen ist. Mit der gleichen Einschränkung genießen ausländische Staatsangehörige den Schutz auch für solche Werke, die im Geltungsbereich dieses Gesetzes nur in Ubersetzung erschienen sind.
(2) Den im Geltungsbereich Idieses Gesetzes erschienenen Werken im Sinne des Absatzes 1 werden die Werke der bildenden Künste gleichgestellt, die mit einem Grundstück im Geltungsbereich dieses Gesetzes fest verbunden sind.

(3) Der Schutz nach Absatz 1 kann durch Rechtsverondnung des Bundesministers der Justiz für ausländische Staatsangehörige beschränkt werden, die keinem Mitgliedstaat der Berner Ubereinkunft zum Schutze von Werken der Literatur und der Kunst angehören und zur Zeit des Erscheinens des Werkes weder im Geltungrsbereich dieses Gesetzes noch in einem anderen Mitgliedstaat ihren Wohnsitz haben, wenn der Staàt, dem sie angehönen, deutschen Staatsangehörigen für ihre Werke keinen genügrenden Schutz gewährt.

(4) Für ihre nicht im Geltungsbereich dieses Gesetzes enschienenen Werke grenießen ausländische Staatsangehörige den urheberrechtlichen Schutz nach Inhalt der Staatsverträge. Bestehen keine Staatsvierträgre, so besteht für solche W.erke urheberrechtlicher Schutz, soweit in dem Staat, dem der Unheber angehört, nach einer Bekanntmachung des Bundesministers der Justiz im Bundesgesetzblatt deutsche Staatsangehörige für ihhre Werke einen entsprechenden ISchutz genießen.

(5) Das Folgerecht ( $\$ 26)$ steht ausländischen Staatsangehörigen nur zu, wenn der Staat, dem sie angehören, nach einer Bekanntmachung des Bundesministers der Justiz im Bundesgesetzblatt deutschen Staatsangehörigien ein entsprechendes Recht gewährt.

\section{$\S 132$}

\section{Staatenlose}

(1) Staatenlose mit gewöhnlichem Aufenthalt im Geltungsbereich dieses Gesetzes genießen für ihre Werke den gleichen urheberrechtlichen Schutz wie deutsche Staatsangehörige.

(2) Staatenlose ohne gewöhnlichen Aufenthalt im Geltungsbereich dieses Gesetzes genießen für ihre Werke den gleichen urheberrechtlichen Schutz wie die Angehörigen des ausländischen Staates, in dem sie ihren gewöhnlichen Aufenthalt thalben.

\section{$\S 133$}

\section{Ausländische Flïchtlinge}

Für Ausländer, die Flüchtlinge im Sinne von Staatsverträgen oder anderen Rechtsvorschriften sind, gelten die Bestimmungen des $\S 132$ entsprechend. Hierdurch wird ein Schutz nach $\S 131$ nicht ausgeschlossen.

\section{Verwandte Schutzrechte}

\section{$\S 134$}

\section{Wissenschaftliche Ausgaben und Lichtbilder}

Für den Schutz wissenschaftlicher Ausgab.en ( 8 80) und den Schutz von Lichtbildern (\$ 82) sind die $\S \S 130$ bis 133 sinngemäß anzuwenden. 


\section{$\S 135$}

\section{Schutz des ausübenden Künstlers}

(1) Den nach den $\S \S 83$ bis 94 grewährten Schutz genießen deutsche Staatsangehörige für alle ihre Darbietungen, gleichviel, wo diese stattfinden. § 130 Abs. 2 ist anzuwenden.

(2) Ausländische Staatsangehörige genießen den Schutz für alle ihre Darbietungen, die im Geltungsbereich dieses Gesetzes stattfinden, soweit nicht in den Absätzen 3 und 4 etwas anderes bestimmt ist.

(3) Werden Darbietungen ausländischer Staatsangehöriger erlaubterweise auf Bild- oder Tonträger aufgenommen und sind diese erschienen, so genieBen die ausländischen Staatsangehörigen hinsichtlich dieser Bild- oder Tonträger den Schutz nach $\S 85$ Satz 2, § 86 Abs. 2 und $\S 87$, wenn die Bildoder Tonträger im Geltungsbereich dieses Gesetzes erschienen sind, es sei denn, daß die Bild- oder Tonträger früher als dreißig Tage vor dem Erscheinen im Geltungsbereich dieses Gesetzes außerhalb dieses Gebietes erschienen sind.

(4) Werden Darbietungen ausländischer Staatsangehöriger erlaubterweise durch Funk igesendet, so genießen die ausländischen Staatsangehörigen den Schutz gegen Aufnahme der Funksendung auf Bildoder Tonträger ( $\$ 85$ Satz 1) und Weitersendung der Funksendung ( $\$ 86$ Abs. 1) sowie den Schutz nach $\S 87$, wenn die Funksendung im Geltungsbereich dieses Gesetzes ausgestrahlt worden ist.

(5) Im übrigen genießen ausländische Staatsangehörige den Schutz nach Inhalt der Staatsverträge. $\S 131$ Abs. 4 Satz 2 sowie die $\S 132$ und 133 gelten entsprechend.

\section{$\S 136$}

\section{Schutz des Herstellers von Tonträgern}

(1) Den nach den $\$ \S 95$ und 96 gewährten Schutz genießen deutsche Staatsangehörige oder Unternehmen mit Sitz im Geltungsbereich dieses Gesetzes für alle ihre Tonträger, gleichviel, ob und wo diese erschienen sind. $\S 130$ Abs. 2 ist anzuwenden.

(2) Ausländische Staatsangehörige oder Unternehmen ohne Sitz ịm Geltungsbereich dieses Gesetzes genießen den Schutz für ihre im Geltungsbereich dieses Gesetzes erschienenen Tonträger, es sei denn, daß der Tonträger früher als dreißig Tage vor dem Enscheinen im Geltungsbereich dieses Gesetzes außerhalb dieses Gebietes ienschienen ist.

(3) Im übrigen genießen ausländische Staatsangehörige oder Unternehmen ohne Sitz im Geltungsbereich dieses Gesetzes den Schutz nach Inhalt der Staatsverträge. § 131 Abs. 4 Satz 2 sowie die $\S 132$ und 133 gelten entsprechend.

\section{$\S 137$}

\section{Schutz des Sendeunternehmens}

(1) Den nach § 97 gewährten Schutz genießen Sendeunternehmen mit Sitz im Geltungsbereich dieses Gesetzes für alle Funksendungen, gleichviel, wo sie diese ausstrahlen.
(2) Sendeunternehmen ohne Sitz im Geltungsbereich dieses Gesetzes genießen den Schutz für alle Funksendungen, die sie im Geltungsbereich dieses Gesetzes ausstrahlen.

(3) Im übrigen genießen Sendeunternehmen ohne Sitz im Geltungsbereich dieses Gesetzes den Schutz nach Inhalt der Staatsverträge. $\S 131$ Abs. 4 Satz 2 gilt entsprechend.

\section{$\S 138$}

\section{Schutz des Filmherstellers}

(1) Den nach den §§ 104 und 105 gewährten Schutz genießen deutsche Staatsangehörige oder Unternehmen mit Sitz im Geltungsbereich dieses Gesetzes für alle ihre Bildträger oder Bild- und Tonträger, gleichviel, ob und wo diese erschienen sind. $\S 1330$ Abs. 2 ist anzuwenden.

(2) Für ausländische Staatsangehörige oder Unternehmen ohne Sitz im Geltungsbereich idieses Gesetzes gelten die Bestimmungen in $\S 136$ Abs. 2 und 3 entsprechend.

\section{ZWEITER ABSCHNITT}

\section{Ubergangsbestimmungen}

\section{$\S 139$}

\section{Werke}

(1) Die Vorschriften dieses Gesetzes sind auch auf die vor seinem Inkrafttreten geschaffenen Werke anzuwenden, es sei denn, daß sie zu diesem Zeitpunkt urheberrechtlich nicht geschützt sind oder $\mathrm{daß}$ in diesem Gesetz sonst etwas anderes bestimmt ist. Dies gilt für verwandte Schutzrechte entsprechend.

(2) Die Dauer des Urheberrechts an einem Werk, das nach Ablauf von fünfzig Jahren nach dem Tode des Urhebers, aber vor dem Inkrafttreten dieses Gesetzes veröffentlicht worden ist, richtet sich nach den bisherigen Vorschriften.

\section{$\S 140$}

\section{Ubersetzungen}

Unberührt bleiben die Rechte des Urhebers einer Ubersetzung, die vor dem 1. Januar 1902 erlaubterweise ohne Zustimmung des Urhebers des übersetzten Werkes erschienen ist.

\section{$\S 141$ \\ Verträge}

(1) Die Vorschriften dieses Gesetzes sind mit Ausnahme der $\S \S 42,43$ und 89 auf Verträge, die vor dem Inkrafttreten dieses Gesetzes abgeschlossen worden sind, nicht anzuwenden. Die $\$ \S 40$ und 41 gelten für solche Verträge mit der Maßgabe, daß die in $\S 40$ Abs. 1 Satz 2 und $\S 41$ Abs. 2 genannten Fristen frühestens mit dem Inkrafttreten dieses Gesetzes beginnen. $\S 36$ gilt mit der Maßgabe, daß 
eine Beteiligung an Nutzungserträgnissen, die vor Inkrafttreten dieses Gesetzes gezogen worden sind, nicht verlangt werden kann; jedoch bleiben weitergehende Ansprüche aus anderen gesetzlichen Vorschriften unberührt.

(2) Vor dem Inkrafttreten dieses Gesetzes getroffene Verfügungen bleiben wirksam.

\section{$\S 142$}

\section{Tonträger}

(1) Bei Werken der Musik, die nach $\S 63$ a Abs. 1 des Gesetzes betreffend das Urheberrecht an Werken der Literatur und der Tonkunst vom 19. Juni 1901 (Reichsgesetzbl. S. 227) in der Fassung des Gesetzes zur Ausführung der revidierten Berner Ubereinkunft zum Schutze von Werken der Literatur und Kunst vom 22. Mai 1910 (Reichsgesetzbl. S. 793) auf Vorrichtungen zur mechanischen Wiedergabe frei übertragen werden durften, ist es auch weiterhin zulässig, sie auf Tonträger zu übertragen und diese zu vervielfältigen und $\mathrm{zu}$ verbreiten.

(2) Absatz 1 ist auf Tonfilme nicht anzuwenden.

$$
\S 143
$$

\section{Urheber}

Wer zur Zeit des Inkrafttretens dieses Gesetzes nach den bisherigen Vorschriften, nicht aber nach diesem Gesetz als Urheber eines Werkes anzusehen ist, gilt, abgesehen von den Fällen des $\S 144$, weiterhin als Urheber. Ist nach den bisherigen Vorschriften eine juristische Person als Urheber eines Werkes anzusehen, so sind für die Berechnung der Dauer des Urheberrechts die bisherigen Vorschriften anzuwenden.

\section{$\S 144$}

\section{Inhaber verwandter Schutzrechte}

Wer zur Zeit des Inkrafttretens dieses Gesetzes nach den bisherigen Vorschriften als Urheber eines Lichtbildes oder der Ubertragung eines Werkes auf Vorrichtungen zur mechanischen Wiedergabe für das Gehör anzusehen ist, ist Inhaber der entsprechenden verwandten Schutzrechte, die dieses Gesetz ihm gewährt.

\section{$\S 145$}

\section{Vervielfăltigung und Verbreitung}

(1) War eine Vervielfältigung, die nach diesem Gesetz unzulässig ist, bisher erlaubt, so darf die vor Inkrafttreten dieses Gesetzes begonnene Herstellung von Vervielfältigungsstüdken vollendet werden.

(2) Die nach Absatz 1 oder bereits vor dem Inkrafttreten dieses Gesetzes hergestellten Vervielfältigungsstücke dürfen verbreitet werden.

(3) Ist für eine Vervielfältigung, die nach den bisherigen Vorschriften frei zulässig war, nach diesem Gesetz eine angemessene Vergütung an den Berechtigten zu zahlen, so dürfen die in Absatz 2 bezeichneten Vervielfältigungsstücke ohne Zahlung einer Vergütung verbreitet werden.

\section{$\S 146$}

\section{Ubertragung von Rechten}

(1) Soweit das Urheberrecht vor Inkrafttreten dieses Gesetzes auf einen anderen übertragen worden ist, stehen dem Erwerber die entsprechenden Nutzungsrechte ( $\$ 31$ ) zu. Jedoch erstreckt sich die Ubertragung im Zweifel nicht auf Befugnisse, die erst durch dieses Gesetz begründet werden.

(2) Absatz 1 gilt für verwandte Schutzrechte entsprechend.

\section{DRITTER ABSCHNITT}

Schlußbestimmungen

\section{$\S 147$}

\section{Urheberrolle}

(1) Die Urheberrolle für die in $\S 69$ Abs. 2 Nr. 2 vorgesehenen Eintragungen wird beim Patentamt geführt. Das Patentamt bewirkt die Eintragungen, ohne die Berechtigung des Antragstellers oder die Richtigkeit der zur Eintragung angemeldeten Tatsachen zu prüfen.

(2) Wird die Eintragung abgelehnt, so steht dem Antragsteller die Beschwerde an das Patentgericht zu. Innerhalb der Beschwerdefrist ist eine Gebühr von sechzig Deutsche Mark zu zahlen; wird sie nicht gezahlt, so gilt die Beschwerde als nicht erhoben. Im übrigen gelten die Vorschriften des Patentgesetzes über das Beschwerdeverfahren vor dem Patentgericht entsprechend.

(3) Die Eintragungen werden im Bundesanzeiger öffentlich bekanntgemacht. Die Kosten für die Bekanntmachung hat der Antragsteller im voraus zu entrichten.

(4) Die Einsicht in die Urheberrolle ist jedem gestattet. Auf Antrag werden Auszüge aus der Rolle erteilt; sie sind auf Verlangen zu beglaubigen.

(5) Der Bundesminister der Justiz wird ermächtigt, Bestimmungen über die Form des Antrags und die Führung der Urheberrolle sowie die Erhebung von Kosten durch Rechtsverordnung zu erlassen.

(6) Eintragungen, die nach $\S 56$ ides Gesetzes betreffend das Urheberrecht an Werken der Literatur und der Tonkunst vom 19. Juni 1901 beim Stadtrat in Leipzig vorgenommen worden sind, bleiben wirksam.

\section{$\S 148$}

\section{Anderung der Strafprozeßordnung}

§ 374 Abs. 1 Nr. 8 der Strafprozeßordnung erhält folgende Fassung:

„8. alle Verletzungen des Patent-, Gebrauchsmuster-, Warenzeichen- und Geschmadksmusterrechtes, soweit sie als Vergehen strafbar sind, sowie die Vergehen nach $\S \S 116$ bis 118 des Urheberrechtsgesetzes." 
$\S 149$

Anderung des Gesetzes

über das am 6. September 1952 unterzeichnete Welturheberrechtsabkommen

In das Gesetz über das am 6. September 1952 unterzeichnete Welturheberrechtsabkommen vom 24. Februar 1955 (Bundesgesetzbl. II S. 101) wird nach Artikel 2 folgender Artikel 2 a eingefügt:

\section{"Artikel 2 a}

Für die Berechnung der Dauer des Schutzes, den ausländische Staatsangehörige für ihre Werke nach dem Abkommen im Geltungsbereich dieses Gesetzes genießen, sind die Bestimmungen in Artikel IV Nr. 4 bis 6 des Abkommens anzuwenden."

$$
\S 150
$$

\section{Aufgehobene Vorschriften}

Mit dem Inkrafttreten dieses Gesetzes werden aufgehoben:

1. die $\S \S 57$ bis 60 des Gesetzes betreffend das Urheberrecht an Schriftwerken, Abbildungen, musikalischen Kompositionen und dramatischen Werken vom 11. Juni 1870 (Bundesgesetzblatt des Norddeutschen Bundes S. 339);

2. die $\S \S 17$ bis 19 des Gesetzes betreffend das Urheberrecht an Werken der bildenden Künste vom 9. Januar 1876 (Reichsgesetzbl. S. 4);

3. das Gesetz betreffend das Urheberrecht an Węrken der Literatur und der Tonkunst vom 19. Juni 1901 in der Fassung des Gesetzes zur Ausführung der revidierten Berner Ubereinkunft zum Schutze von Werken der Literatur und Kunst vom 22. Mai 1910 und des Gesetzes zur Verlängerung der Schutzfristen im Urheberrecht vom 13. Dezember 1934 (Reichsgesetzbl. II S. 1395);

4. die $\S \S 3,13$ und 42 des Gesetzes über das Verlagsrecht vom 19. Juni 1901 (Reichsgesetzbl.
S. 217) in der Fassung des Gesetzes zur Ausführung der revidierten Berner Ubereinkunft zum Schutze von Werken der Literatur und Kunst vom 22. Mai 1910;

5. das Gesetz betreffend das Urheberrecht an Werken der bildenden Künste und der Photographie vom 9. Januar 1907 (Reichsgesetzbl. S. 7) in der Fassung des Gesetzes zur Ausführung der revidierten Berner Ubereinkunft zum Schutze von Werken der Literatur und Kunst vom 22. Mai 1910, des Gesetzes zur Verlängerung der Schutzfristen im Urheberrecht vom 13. Dezember 1934 und des Gesetzes zur Verlängerung der Schutzfristen für das Urheberrecht an Lichtbildern vom 12. Mai 1940 (Reichsgesetzbl. I S. 758), soweit es nicht den Schutz von Bildnissen betrifft;

6. die Artikel I, III und IV des Gesetzes zur Ausführung der revidierten Berner Ubereinkunft zum Schutze von Werken der Literatur und Kunst vom 22. Mai 1910;

7. das Gesetz zur Erleichterung der Filmberichterstattung vom 30. April 1936 (Reichsgesetzbl. I S. 404);

8. § 10 des Gesetzes über die Rechtsstellung heimatloser Ausländer im Bundesgebiet vom

- 25. April 1951 (Bundesgesetzbl. I S. 269).

\section{$\S 151$}

\section{Geltung im Land Berlin}

Dieses Gesetz gilt nach Maßgabe des $\S 13$ Abs. 1 des Dritten Uberleitungsgesetzes vom 4. Januar 1952 (Bundesgesetzbl. I S. 1) auch im Land Berlin. Rechtsverordnungen, die auf Grund dieses Gesetzes erlassen werden, gelten im Land Berlin nach $\S 14$ des Dritten Uberleitungsgesetzes.

\section{$\S 152$}

\section{Inkrafttreten}

Dieses Gesetz tritt am ...... in Kraft. 


\section{Begründung}

\section{A. Einleitung}

\section{Gründe für die Reform und Gang der Reformarbeiten}

Aufgabe des Urheberrechts ist es, den Schöpfer eines Werkes der Literatur, der Musik oder der bildenden Künste (Urheber) gegen eine unbefugte wirtschaftliche Auswertung seiner schöpferischen Leistung und gegen Verletzungen seiner ideellen Interessen am Werk zu schützen.

Das deutsche Urheberrecht beruht zur Zeit auf drei Gesetzen:

1. dem Gesetz betreffend das Urheberrecht an Werken der Literatur und der Tonkunst vom 19. Juni 1901 - LUG - (RGBl S. 227) in der Fassung der Gesetze vom 22. Mai 1910 (RGB1. S. 793) und vom 13. Dezember 1934 (RGBl. II S. 1395),

2. dem Gesetz betreffend das Urheberrecht an Werken der bildenden Künste und der Photographie vom 9. Januar 1907 - KUG - (RGBl. S. 7) in der Fassung der Gesetze vom 22. Mai 1910, vom 13. Dezember 1934 und vom 12. Mai 1940 (RGBl. I S. 758) und

3. dem Gesetz über das Verlagsrecht vom 19. Juni 1901 - VerlG - (RGBl. S. 217) in der Fassung des Gesetzes vom 22. Mai 1910.

Abgesehen von dem Verlagsgesetz, das sich bis heute im wesentlichen bewährt hat, sind die geltenden Urheberrechtsgesetze veraltet. Ihre Reformbedürftigkeit wird allgemein anerkannt. Seit Erlaß der Gesetze haben sich eine Reihe bedeutender neuer Verwertungsmöglichkeiten für die Werke der Urheber ergeben, die vom Gesetzgeber nicht oder nur unvollkommen berüdksichtigt sind. Dies gilt besonders für Film, Rundfunk und Fernsehen sowie für die modernen Vervielfältigungsverfahren der Tonbandaufnahme, der Fotokopie und der Mikrokopie. Die Rechtsprechung hat sich zwar bemüht, durch rechtsschöpferische Auslegung und Analogie den durch die neuen technischen Mittel aufgeworfenen Problemen gerecht zu werden. Hierbei sind der Rechtsprechung jedoch Schranken gesetzt. Es ist zudem bedenklich, wenn der geltende Rechtszustand sich immer weiter vom Wortlaut der Gesetze entfernt.

Eine Notwendigkeit, die geltenden Gesetze zu ändern, ergibt sich auch aus der internationalen Entwicklung auf dem Gebiet des Urheberrechts. Da ein Geisteswerk nach Verbreitung über die nationalen Grenzen hinweg strebt, sind schon früh internationale Verträge abgeschlossen worden, um die Urheber auch außerhalb der Grenzen ihres Heimatstaates zu schützen. Die wichtigste dieser Verein- barungen ist die Berner Ubereinkunft zum Schutze von Werken der Literatur und der Kunst, die seit ihrem Zustandekommen im Jahre 1886 etwa alle 20 Jahre ergänzt und geändert worden ist. Deutschland gehört der am 2. Juni 1928 in Rom revidierten Fassung an. Die letzte Revision der Berner Ubereinkunft hat 1948 ohne deutsche Beteiligung in Brüssel stattgefunden. Hierbei sind neue oder erweiterte Rechte für den Urheber eingeführt worden, die zum Teil durch das geltende deutsche Urheberrecht nicht gewährt werden. Es ist ein verständlicher Wunsch der deutschen Urheber, daß Deutschland als Mitbegründer der Berner Ubereinkunft möglichst bald dieser neuesten Fassung beitritt. Der Entwurf eines Beitrittsgesetzes zur Brüsseler Fassung wird gleichzeitig mit dem Entwurf des Urheberrechtsgesetzes vorgelegt. Für den Beitritt ist es erforderlich, die deutschen Gesetze entsprechend $\mathrm{zu}$ ändern.

Weiterhin ist auf eine Entwicklung Rücksicht zu nehmen, die auf einen internationalen Schutz der ausübenden Künstler, der Schallplattenhersteller und der Sendeunternehmen abzielt. Im Rahmen des Europarats ist am 22. Juni 1960 ein Abkommen über den Schutz von Fernsehsendungen abgeschlossen worden, das den Sendeunternehmen ein ausschließliches Recht zur Weitersendung, Festhaltung und öffentlichen Wiedergabe ihrer Fernsehsendungen gewährt. Nach langen Vorarbeiten ist ferner in Rom am 26. Oktober 1961 ein umfassendes internationales Abkommen zum Schutz der ausübenden Künstler, der Hersteller von Tonträgern und der Sendeunternehmen unterzeichnet worden, das ausschließliche Rechte für alle drei Personengruppen vorsieht. Diese Schutzrechte sind in den geltenden deutschen Urheberrechtsgesetzen entweder in anderer Form oder überhaupt nicht geregelt. Eine Ratifizierung der genannten Abkommen durch die Bundesrepublik, die bei der Ausarbeitung der Abkommen mitgewirkt und beide Abkommen unterzeichnet hat, ist daher nur möglich, wenn die deutschen Gesetze auch insoweit entsprechend geändert werden. Der Entwurf eines Zustimmungsgesetzes zu dem Europäischen Abkommen zum Schutz von Fernsehsendungen wird gleichzeitig mit dem Entwurf des Urheberrechtsgesetzes vorgelegt; für das umfassende Abkommen über den Schutz der ausübenden Künstler, der Hersteller von Tonträgern und der Sendeunternehmen soll der Entwurf eines Zustimmungsgesetzes vorgelegt werden, sobald in Zusammenarbeit mit Osterreich und der Schweiz der offizielle deutsche Text des Abkommens fertiggestellt ist.

Die Reformbestrebungen reichen in Deutschland 30 Jahre zurück. Seit 1932 sind mehrere Entwürfe, teils vom Reichsjustizministerium und der "Aka- 
demie für Deutsches Recht “, teils von privater Seite, ausgearbeitet und veröffentlicht worden. Der zweite Weltkrieg brachte diese Arbeiten zum Erliegen. Nach dem Kriege nahm das Bundesjustizministerium die Reformarbeiten wieder auf und veröffentlichte im Frühjahr 1954 - zusammen mit Referentenentwürfen eines Gesetzes über Verwertungsgesellschaften auf dem Gebiet des Urheberrechts sowie eines Gesetzes über den Beitritt zur Brüsseler Fassung der Berner Ubereinkunft - den "Referentenentwurf eines Urheberrechtsgesetzes". Nach zum Teil wesentlicher Uberarbeitung der Referentenentwürfe des Urheberrechtsgesetzes und des Verwertungsgesellschaftengesetzes stellte das Bundesjustizministerium im Sommer 1959 "Ministerialentwürfe" dieser Gesetze nochmals öffentlich zur Diskussion. Der vorliegende Entwurf des Urheberrechtsgesetzes beruht, ebenso wie der gleichzeitig vorgelegte Entwurf des Verwertungsgesellschaftengesetzes, auf diesen Vorarbeiten.

Die für eine Neufassung der Urheberrechtsgesetze bestehenden Gründe gelten nicht für das Verlagsgesetz. Jedoch sind einige änderungsbedürftige Bestimmungen des Verlagsgesetzes neugestaltet in den vorliegenden Entwurf übernommen (vgl. $\$ \S 38$, 39). Im uibrigen ist beabsichtigt, das neue Urheberrechtsgesetz durch ein umfassendes Urhebervertragsgesetz zu ergänzen, das für alle Vertragstypen auf dem Gebiet des Urheberrechts Vorschriften enthalten soll.

\section{Grundzüge des Entwurfs}

\section{Allgemeines}

Das Urheberrecht, das im Ersten Teil des Entwurfs geregelt ist, umfaßt eine Summe einzelner Befugnisse, die teils dem Schutz der Vermögensinteressen des Urhebers dienen (Verwertungsrechte), teils dem Schutz der geistigen und persönlichen Beziehungen des Urhebers zu seinem Werk (Urheberpersönlichkeitsrecht oder droit moral).

a) Die Verwertungsrechte des Urhebers an seinem Werk sind in der Regel als ausschließliche Rechte zur Nutzung des Werkes ausgestaltet, die es dem Urheber ermöglichen, jedem anderen, der nicht zuvor seine Erlaubnis zur Nutzung eingeholt und die hierfür geforderte Vergütung gezahlt hat, die Werknutzung zu verbieten. Wer ohne Erlaubnis des Urhebers das Werk auf eine dem Urheber vorbehaltene Art verwertet, verletzt das ausschließliche Recht des Urhebers und macht sich, wenn er schuldhaft handelt, schadenersatzpflichtig und bei vorsätzlichem Handeln auch strafibar.

Dieses der Ausgestaltung des Eigentumsrechts an körperlichen Sachen entsprechende System ıder Gewährung ausschließlicher Verwertungsrechte ist für das gesamte Rechtsgebiet der sog. Immaterialgüterrechte, $\mathrm{zu}$ denen neben dem Urheberrecht z. B. idas Patentrecht, das Warenzeichenrecht und das Geschmacksmusterrecht gehören, typisch und wird auch von allen ausländischen Rechtsondnungen angewandt, die einen Schutz von Geistesgütern kennen. Während je- doch bei den meisten anderen Immaterialgiuterrechten wie beim Sacheigentum der Gedanke im Vondergrund steht, das ausschließliche Recht als solches auszuüben, d. h. die Nutzung des Schutzobjekts (der Erfindung, des Warenzeichens oder des Geschmacksmusters) einer einzelnen Person oder wenigen Personen ausschließlich vorzubehalten, ist der Urheber meist gerade an einer möglichst weiten Verbreitung seines Werkes, an der Nutzung durch möglichst viele Personen interessiert. Sinn des Urheberrechts ist es daher nicht so sehr, andere von der Nutzung des Werkes auszuschließen; es soll vielmehr in erster Linie dem Urheber die rechtliche Grundlage dafür geben, Art und Umfang der Nutzung seines Werkes zu überwachen und diese von der Zahlung einer Vergütung abhängig zu machen. Dementsprechend ist es ein Grundsatz des Urheberrechts, die ausschließlichen Befugnisse des Urhebers so umfassend zu gestalten, daß möglichst jede Art der Nutzung seines Werkes seiner Kontrolle unterliegt.

Hieraus erklärt es sich, daß auch bei einer mehrfachen Nutzung eines Werkes jeder einzelne Nutzungsvorgang der erneuten Zustimmung des Urhebers bedarf. Hat beispielsweise der Urheber einem Verleger gestattet, sein Werk zu drucken und die Druckexemplare in den Handel zu bringen, so ist darin nicht die Erlaubnis eingeschlossen, die Exemplare zu öffentlichen Vorträgen oder Aufführungen des Werkes oder zur Sendung des Werkes im Rundfunk zu benutzen. Wer also aus einem Buch öffentlich vorlesen oder ein Musikstück im Rundfunk senden will, bedarf hierzu einer besonderen Erlaubnis des Urhebers, auch wenn er das Buch oder die Noten rechtmäßig gegen Zahlung des Kaufpreises erworben hat. Ebenso darf eine Schallplatte, für Ideren Herstellung der Urheber von der Schallplattenfirma ordnungsmäßig eine Lizenzgebühr erhalten hat, nicht ohne erneute Erlaubnis des Urhebers zu einer öffentlichen Wiedergabe des Werkes, z. B. in einem Tanzlokal, benutzt werden. Ferner ist die öffentliche Wiedergabe von Rundfunkmusik in einer Gaststätte nur mit Erlaubnis der Urheber der gesendeten Werke zulässig, auch wenn diese dem Rundfunkunternehmen die Sendeerlaubnis erteilt haben. Nur durch eine solche Erfassung jedes einzelnen Verwertungsaktes wird es möglich, dem Urheber ein dem Wert seiner schöpferischen Leistung angemessenes Entgelt zu sichern.

Die Verwertungsrechte des Urhebers beziehen sich allerdings nur auf die Nutzung des Werkes durch aktiven Gebrauch des Werkes, sei es zur Herstellung von Vervielfältigungsstücken, sei es zur Vermittlung des geistigen Gehalts des Werkes an andere Personen durch Inverkehrbringen der Vervielfältigungsstücke oder durch unkörperliche Wiedergabe des Werkes wie Vortrag, Aufführung, Vorführung oder Sendung im Rundfunk. Der rezeptive Genuß des Werkes durch Lesen, Hören oder Anschauen ist dem Recht des Urhebers nicht unterworfen; hierzu bedarf es niemals seiner Erlaubnis. Darüber hinaus unter- 
liegen die auf den aktiven Gebrauch des Werkes bezogenen Verwertungsrechte in verschiedener Hinsicht Beschränkungen im Interesse der Allgemeinheit, insbesondere ist die unkörperliche Wiedergabe des Werkes dem Urheber nur insoweit vorbehalten, als sie öffentlich geschieht; nur der öffentliche Vortrag, die öffentliche Aufführung oder Vorführung des Werkes bedarf der Erlaubnis des Urhebers, die Wiedergabe eines Werkes im Familien- oder Freundeskreise ist frei.

b) Die persönlichkeitsrechtlichen Befurgnisse des Urhebers, z. B. das Recht, Entstellungen seines Werkes zu verbieten, sind ebenfalls wie die Verwertungsrechte als absolute gegen jeden Dritten wirkende Befugnisse lausgestaltet. Sie weisen die Besonderheit auf, daß sie auch gregenübier denjenigen Personen geltend gemacht werden können, denen der Urheber die Nutzung seines Werkes gestattet hat: Der Herausgeber einer Zeitung beispielsweise darf einen vom Urheber zum Abdruck in der Zeitung eingesandten Artikel, auch wenn Änderungen und Kürzungen des Artikels aus redaktionellen Gründen gestattet sein sollten, niemals in einer Weise ändern, Idaß berechtigte geistige nder persönliche Interessen des Urhebers verletzt werden.

\section{Systematik des Entwurfs}

Im Gegensatz zum geltenden Recht, das das Urheberrecht an Werken der Literatur und der Tonkunst sowie an Werken der bildenden Künste und der Photographie in zwei Sondergesetzen regelt, faßt der Entwurf idas gesamte Rechtsgebiet des Urheberrechts zusammen. Dies erscheint zweckmäßig, weil alle leitenden Rechtsgedanken in gleicher Weise für die Werke der Literatur, der Tonkunst und der bildenden Künste anwendbar sind, die Besonderheiten aber, die für das eine oder andere Gebiet des geistigen und künstlerischen Schaffens bestehen, in dem gemeinschaftlichen Rahmen klarer hervortreten.

Als weitere Abweichung von der Systematik des geltenden Rechts ist hervorzuheben, daß der Entwurf den Urheberrechtsschutz allein der schöpferischen Leistung vorbehält, wie sie der Komponist, der Schriftsteller oder der bildende Künstler erbringt. Der bisher ebenfalls urheberrechtlich gestaltete Schutz der vortragenden oder aufführenden Künstler, die nicht selbst schöpferisch tätig werden, sondern die Schöpfungen der Urhelber wiedergeben, wird mit anderen neugeschaffenen sog. Leistungsschutzrechten unter der zusammenfassenden Bezeichnung "verwandte Schutzrechte" in einem besonderen Teil geregelt.

\section{Erweiterung der ausschlieblichen Rechte des Ur- hebers}

Die geltenden Urheberrechtsgesetze zählen die Verwertungsbefugnisse des Urhebers abschließend auf, mit der Folge, daß andere als die genannten grundsätzlich dem Urheber nicht zustehen. Die persönlichkeitsrechtlichen Befugnisse sind nur unvollkommen geregelt. Beides hat im Laufe der Zeit zu Schwierigkeiten geführt, da durch die technische Entwicklung neue, vom Gesetz noch nicht berücksichtigte Verwertungsmöglichikeiten entstanden sind (z. B. die Verwertung des Wierkes durch Rundfunksendung), die nur durch die Rechtsprechung in ergänzender Auslegung der Gesetze dem Urheber vorbehalten werden konnten. Um diese Schwierigkeiten für die Zukunft zu vermeiden, gestaltet der Entwurf das Urheberrecht als ein umfassendes absolutes Recht, das dem Urheber alle vorhandenen und künftig etwa neu entstehenden Verwertungsmöglichkeiten seines Werkes vorbehält und ihn zugleich allgemein in seinen ideellen Interessen am Werk schützt.

Im einzelnen engeben sich aus diesem umfassenden Recht des Urhebers folgende im Entwurf besonders erwähnten neue Befugnisse, die in den geltenden Urheberrechtsgesetzen nicht ausdrücklich geregelt, zum Teil jedoch durch die Rechtsprechung bereits anerkannt sind:

a) das Recht auf Anerkennung der Urheberschaft (§ 13);

b) das Recht, Entstellungen oder andere Beeinträchtigungen des Werkes $\mathrm{zu}$ verbieten, die geeignet sind, die berechtigten geistigen oder persönlichen Interessen des Urhebers an seinem Werk zu gefährden (§ 14);

c) das Ausstellungsrecht an unveröffentlichten Werken der bildenden Künste ( $\S 15,18)$;

d) das Recht, ein erschienenes literarisches Werk öffentlich vorzutragen ( $\S 15,19$ Abs. 1) - zur Zeit steht dem Urheber das Vortragsrecht nur solange $\mathrm{zu}$, als das Werk noch nicht erschienen ist (vgl. § 11 Abs. 3 LUG);

e) das Senderecht, das die Rundfunk-, Fernseh- und Drahtfunksendung des Werkes umfaßt $(\$ \S 15,20)$;

f) das Recht der öffentlichen Wiedergabe des Werkes mittels Bild- oder Tonträger wie z. B. Schallplatten ( $\S 15,21)$;

g) das Recht der öffentlichen Wiedergabe von Funksendungen des Werkes $(\S \S 15,22)$;

h) das Recht auf Zugang zu Werkstücken ( $\$ 25)$;

i) das sog. Folgerecht ( $\$ 26)$;

k) der Vergütungsanspruch für die Vermietung von Vervielfältigungsstücken ( $\$ 27$ ).

Während mit den zu a) bis c), e) bis h) genannten Rechten im wesentlichen nur das geschriebene Recht der von der Rechtsprechung bereits vorgezeichneten Rechtsentwicklung angepaßt werden soll, handelt es sich bei der Erweiterung des Vortragsrechts, beim Folgerecht und dem Vergütungsanspruch für die Vermietung von Vervielfältigungsstücken um echte neue Befugnisse des Urhebers.

Die Erweiterung des Vortragsrechts auf erschienene Sprachwerke soll eine seit langem als unbillig empfundene Benachteiligung der Schriftsteller gegenüber den Komponisten beseitigen, denen das Aufführungsrecht schon nach geltendem Recht ohne Rücksicht auf das Erscheinen ihrer Werke zusteht. Die Erweiterung entspricht Artikel 11ter der Brüsseler Fassung der Berner Übereinkunft.

Das Folgerecht (droit de suite) gewährt dem Urheber eines Werkes der bildenden Künste, z. B. eines Gemäldes oder einer Plastik einen Anspruch auf 
Beteiligung an dem Erlös, den der Erwerber des Originals des Werkes bei einer späteren Weiterveräußerung erzielt. Eine solche Beteiligung rechtfertigt sich dadurch, daß der Verkaufserlös häufig wegen der zwischenzeitlichen Wertsteigerung des Werkes das an den Urheber gezahlte Entgelt um ein Vielfaches übersteigt und dieser Gewinn in aller Regel auf eine erhöhte Anerkennung der schöpferischen Leistung des Künstlers zurückzuführen ist. Der Beteiligungsanspruch soll 1 vom Hundert des Veräußerungserlöses betragen und bei allen Veräußerungen im geschäftlichen Verkehr geltend gemacht werden können.

Durch den Vergütungsanspruch für die Vermietung von Vervielfältigungsstücken sollen die Urheber insbesondere an den Einnahmen beteiligt werden, die die sog. Leihbüchereien durch das Vermieten von Büchern erzielen. Im geltenden Recht ist dieser Anspruch ausdrücklich ausgeschlossen (vgl. § 11 Abs. 1 LUG). Diese Regelung erscheint mit dem heute allgemein anerkannten Leitgedanken des Urheberrechts, den Urheber tunlichst an dem wirtschaftlichen Nutzen zu beteiligen, der aus seinem Werk gezogen wird, unvereinbar. Der Vergütungsanspruch soll entsprechend diesem Leitgedanken auf die Fälle beschränkt sein, in denen die Vermietung Erwerbszwecken des Vermieters dient. Offentliche Bibliotheken werden daher von der Regelung nicht betroffen.

\section{Unveräußerlichkeit des Urheberrechts}

Nach dem geltenden Recht kann das Urheberrecht als Ganzes und in seinen Teilen (z. B. das Vervielfältigungsrecht, das Aufführungsrecht) abgetreten werden. Nur die aus dem Urheberpersönlichkeitsrecht erwachsenden Befugnisse, wie z. B. das Recht, Entstellungen des Werkes zu verbieten, sind unübertragbar. Der Entwurf sieht - wie das österreichische Recht - von einer derartigen unterschiedlichen Regelung der Ubertragbarkeit der einzelnen urheberrechtlichen Befugnisse ab. Das Urheberrecht soll zukünftig weder im ganzen noch teilweise abtretbar sein. Vielmehr soll der Urheber einem anderen nur das Recht einräumen können, das Werk in bestimmter Weise zu nutzen. Das Urheberrecht selbst verbleibt dabei; belastet mit dem Nutzungsrecht, dem Urheber. Hierdurch wird sichergestellt, daß der Urheber auch dann, wenn er die wirtschaftliche Auswertung seines Werkes einem anderen überläßt, stets eine gewisse Kontrolle über das weitere Schicksal seines Werkes behält.

So soll grundsätzlich eine Weiterübertragung des Nutzungsrechts nur mit Zustimmung des Urhebers möglich sein (§ 34). Dem Urheber soll ein unverzichtbarer gesetzlicher Anspruch auf angemessene Beteiligung an dem von dem Nutzungsberechtigten gezogenen Gewinn zustehen, wenn dieser in einem auffälligen Mißverhältnis zu der für die Einräumung des Nutzungsrechts gezahlten Vergütung steht (§ 36). Der Nutzungsberechtigte soll ferner das Werk nicht eigenmächtig ändern dürfen ( $\left.\begin{array}{l}\S \\ (39\end{array}\right)$. Schließlich soll der Urheber unter gewissen Voraussetzungen das Nutzungsrecht zurückrufen können, wenn es von dem Berechtigten nicht ausgeübt wird (§ 41) oder wenn dem Urheber die Verwertung des Werkes wegen gewandelter Uberzeugung nicht mehr zugemutet werden kann ( $\S 42)$. Erlischt das Nutzungsrecht durch Verzicht oder Zeitablauf, so fallen die entsprechenden Befugnisse automatisch an den Urheber zurück.

\section{Abgrenzung des Urheberrechts gegenüber den Interessen der Allgemeinheit}

Wie jedes absolute Recht, ist auch das Urheberrecht ein sozialgebundenes Recht, das gewissen Schranken im Interesse der Gemeinschaft unterliegt. Die sachgemäße Abgrenzung der Rechte des Urhebers gegenüber den berechtigten Interessen der Allgemeinheit ( $z$. B. an dem ungehinderten Zugang $\mathrm{zu}$ den Kulturgütern, an der Freiheit des geistigen Schaffens und an der freien Berichterstattung über Tagesereignisse) ist ein Kernproblem der Urheberrechtsreform und steht im Vordergrund der Diskussion. Die Schranken des Urheberrechts, die die geltenden Gesetze insbesondere zugunsten der Vervielfältigung zum persönlichen Gebrauch und zugunsten öffentlicher Musikaufführungen vorsehen (§ 15 Abs. 2, §§ $22 \mathrm{a}, 27 \mathrm{LUG}, \S 18 \mathrm{KUG}$ ), gehen sehr weit und entsprechen zum Teil nicht mehr den heutigen Anschauungen. Auf der anderen Seite ergeben sich aus der im Entwurf vorgesehenen Erweiterung der ausschließlichen Befugnisse des Urhebers und aus den vielfachen. neuen Wiedergabemöglichkeiten, die für Geisteswerke in letzter Zeit durch die moderne Technik entwickelt worden sind, zahlreiche neue Berührungspunkte und Überschneidungen mit schutzwürdigen Belangen der Allgemeinheit, die neue Abgrenzungen erforderlich machen. Im ganzen gesehen verfolgt der Entwurf auch bei der Abgrenzung des Urheberrechts gegenüber den Interessen der Allgemeinheit das Ziel einer Verbesserung der Rechtsstellung des Urhebers. Dies geschieht nicht nur in der Weise, daß einzelne Schranken ganz beseitigt werden. Es wird auch in zahlreichen Fällen, in denen das ausschließliche Recht des Urhebers mit Rücksicht auf überwiegende Interessen der Allgemeinheit seine Grenze finden muß, dem Urheber ein Vergütungsanspruch für die Nutzung seines Werkes gewährt; denn oft widerstreitet den Allgemeininteressen nur der Verbotscharakter der urheberrechtlichen Befugnisse, nicht dagegen das wirtschaftliche Interesse des Urhebers, aus der Verwertung seines Werkes angemessenen Nutzen zu ziehen. Im einzelnen ist zu den zur Abgrenzung des Urheberrechts vorgeschlagenen Bestimmungen des Entwurfs folgendes zu bemerken:

\section{a) Erleichterung des Schulunterrichts}

Der Entwurf behält die im geltenden Recht vorgesehene Regelung bei, daß kleinere Werke, z. B. Gedichte, oder Teile von Werken ohne Einwilligung des Urhebers in Sammlungen für den Kirchen-, Schul- oder Unterrichtsgebrauch aufgenommen werden dürfen, jedoch soll in diesen Fällen der Urheber nunmehr einen Vergütungsanspruch erhalten ( $\S 46)$. Einer weiteren Förderung des Schulunterrichts dient die neue Vorschrift, nach der Schulfunksendungen für die Zwecke des Unterrichts vorübergehend auf Bild- oder Tonträger übertragen werden dürfen ( $(47)$. Hierdurch soll den Schulen 
ermöglicht werden, die Sendungen unabhängig von der jeweiligen Sendezeit in den Unterricht einzufügen.

\section{b) Erleichterung der Berichterstattung}

Die Bestimmungen des geltenden Rechts, die der Erleichterung der Presse- und Filmberichterstattung dienen, behält der Entwurf im wesentlichen bei. So soll es weiterhin zulässig bleiben, unter gewissen Voraussetzungen öffentlich gehaltene Reden zu vervielfältigen ( $\$ 48$ ) sowie Zeitungsartikel über politische, wirtschaftliche oder religiöse Tagesfragen, die nicht mit einem Vorbehalt der Rechte versehen sind, in anderen Zeitungen abzudrucken ( $\$ 49$ ). Ebenso bleibt es entsprechend dem Gesetz über die Erleichterung der Filmberichterstattung vom 30. April 1936 (RGBl. I S. 404) gestattet, Werke, die im Verlaufe eirier Filmberichterstattung (Wochenschau) wahrnehmbar werden, in den Filmbericht zu übernehmen. Entsprechendes soll nach dem Entwurf für die der Filmberichterstattung gleichzustellende Funk- und Bildberichterstattung gelten ( $(50)$.

\section{c) Freiheit des geistigen Schaffens}

Wie im geltenden Recht soll die freie Benutzung eines geschützten Werkes zu einer selbständigen Schöpfung nicht an die Genehmigung des Urhebers gebunden sein ( $\$ 24$ ). Auch an der im geltenden Recht vorgesehenen Zitierfreiheit wird im wesentlichen festgehalten ( $\$$ 51). Ebenso bleibt die Vertonung von Gedichten weiterhin frei zulässig, doch soll abweichend vom geltenden Recht dem Urheber des vertonten Werkes ein Vergütungsanspruch gegen den zustehen, der sein Werk in Verbindung mit dem Werk der Musik verwertet (§ 52). Dagegen soll es nicht mehr ohne Erlaubnis des Urhebers zulässig sein, Gedichte in Gesangbücher aufzunehmen oder einzelne Aufsätze, Gedichte oder kleinere Teile eines Schriftwerkes in sog. Anthologien zusammenzustellen und in dieser Form zu verwerten (vgl. $\S 19 \mathrm{Nr} .3$ und 4 LUG).

\section{d) Offentliche Wiedergabe (\$ 53)}

Die im geltenden Recht vorgesehenen Beschränkungen des Musikaufführungsrechts insbesondere bei Volksfesten, Wohltätigkeits- und Vereinsveranstaltungen (vigl. § 27 LUG) entsprechen nicht mehr der heutigen Auffassung von einer richtigen Abgrenzung ides Urheberrechts gegenüber den Interessen der Allgemeinheit. Es wir.d mit Recht hervorgehoben, daß Volksfeste heute meist kommerziellen Charakter tragen und daß der Urheber zur Wohltätigkeit nicht gezwungen werden dürfe. Vor allem aber wird es als ungerecht empfunden, daß allein der Urheber bei solchen Veranstaltungen seine Leistung unentgeltlich zur Verfügung stellen soll, während von den sonst Beteiligten, insbesondere den ausübenden Musikern, niemand eine unentgeltliche Mitwirkung erwartet. Der Entwurf trägt diesen Einwänden Rechnung und beschränkt die Aufführungsfreiheit auf die Fälle, in denen die Veranstaltung keinem Erwerbszweck 'dient, für die Aufführung des Werkes den ausüibenden Künstlern keine besondere Vergütung gezahlt wird und die Teilnehmer ohne Entgelt zugelassen werden. Darüber hinaus sollen
Musikaufführungen allgemein nur noch bei kirchlichen Veranstaltungen ohne Erlaubnis des Urhebers zulässig sein, wobei insoweit aber ein Anspruch des Urhebers auf angemessene Vergütung vorgesehen ist. Diese Regelung entspricht einer Anregung der Kirchen. Die im geltenden Recht nur für Musikaufführungen vorgesehene Ausnahmebestimmung soll nach dem Entwurf grundsätzlich für alle Arten der öffentlichen Wiedergabe eines Werkes gelten, insbesondere auch für Vorträge von Sprachwerken und für Vorführungen von Werken der bildenden Künste. Ausgenommen bleiben jedoch Bü.hnenaufführungen, Vorführungen von Filmwerken und Funksendungen von Werken; sie sollen stets nur mit Erlaubnis des Urhebers zulässig sein.

Der Entwunf übernimmit ferner nicht die Bestimmung des § 22 a LUG, nach der Schallplatten, auf die Werke der Musik mit Erlaubnis des Urhebers aufgenommen 'wonden sind, ohne seine weitere Erlaubnis zu öffentlichen Aufführungen benutzt werden dürfen. Die Anwendbarkeit dieser Bestimmung ist ohnehin bereits durch die Rechtsprechung weitgehend eingeschränkt.

\section{e) Vervielfältigung zum persönlichen Gebrauch} (\$ 54)

Im Bewußtsein der Allgemeinheit am stärksten verwurzelt ist'wohl der Gedanke, 'daß der private Bereich von Ansprüchen des Urhebers freibleiben müsse. Der Ausgestaltung des Urheberrechts wird dieser Gedanke auch künftig weitgehend zugrunde liegen. So bleibt namentlich die Ausschließlichkeitsbefugnis des Unhebers zur unkörperlichen Wiedergabe seines Werkes, wie Vortrag, Aufführung und dergl., ausnahmslos auf die öffentliche Wiedergabe beschränkt (vgl. § 15 A.bs. 2). Es erscheint jedoch nicht gerechtfertigt, diesen Grundsatz auch für das Vervielfältigungsrecht uneingeschränkt aufrechtzuerhalten. Die geltenden Urheberrechtsgesetze geben ihrem Wortlaut nach die Vervielfältigung zum persönlichen Gebrauch ausnahmslos frei ( $\$ 15$ Abs. 2 LUG, § $18 \mathrm{KUG}$ ). Der Bundesgerichtshof hat jedoch in einschränkender Auslegung Idieser Bestimmungen die Vervielfältigung Idurch Tonbandgeräte im privaten Bereich für unzulässig erklärt (vgl. Entscheidung vom 18. Mai 1955, BGHZ 17 S. 266, Anlage 3 [A IV]). Maßgebend war dabei die Erwägung, daß die privat hergestellten Tonbänder den im Handel enhältlichen Schallplatten völlig gleichwertig seien, ihre Freigabe somit zu einem Rückgang der Schallplattenproduktion und Idamit zu einer Schädigung der Urheber führen könnte, die in der Regel am Umsatz der Schallplatten beteiligt sind. Die Entscheidung des Bundesgerichtshofs ist stark kritisiert worden. Es wird an den Gesetzgeber appelliert, ihr nicht zu folgen und den Grundsatz der Urheberrechtsfreiheit des privaten Bereichs uneingeschränkt wiederherzustellen. Mit ldem Tonbandverfahren ist jedoch eine Entwicklung eingeleitet worden, die eine Überprüfung dieses Grundsatzes notwendig macht. Niemand vermag heute vorauszusagen, wieweit das privat bespielte Tonband die Industrieschallplatte tatsächlich verdrängen wird. Die Tendenz ist aber unverkennbar, daß sich hier ein bisher ausschließlich dem gewerblichen Bereich und damit dem Urheberrecht 
unterworfenes Vervielfältigungsverfahren zunehmend in den privaten Bereich verlagert. Eine ähnliche Entwicklung könnte sich in Zukunft auch für die Vervielfältigung literarischer Werke durch Verbesserung der bisherigen Vervielfältigungsverfahren anbahnen. Ein Festhalten an der Vervielfältigungsfreiheit zum persönlichen Gebrauch könnte somit allmählich zu einer teilweisen Aushöhlung des Urheberrechts führen. Der Entwurf schränkt daher in Anlehnung an die Rechtsprechung des Bundesgerichtshofs die Vervielfältigungsfreiheit im privaten Bereich hinsichtlich der Tonbandaufnahmen ein, sieht allerdings - insoweit abweichend von dieser Rechtsprechung - kein Verbotsrecht des Urhebers vor, sondern lediglich einen gesetzlichen Anspruch auf angemessene Vergütung. Andere Vervielfältigungen als solche mittels Tonbandgeräten, z. B. das Abschreiben von Noten, das Fotokopieren von Schriftstücken und dergl., sollen im privaten Bereich weiterhin frei zulässig sein, jedenfalls solange, als auf diesen Gebieten ein dem Tonbandverfahren gleichwertiges Vervielfältigungsverfahren noch nicht entwickelt ist.

\section{f) Vervielfältigung zum sonstigen eigenen Ge- brauch (\$ 55)}

Abgesehen von den Fällen des persönlichen $\mathrm{Ge}$ brauchs sieht der Entwurf vor, daß auch außerhalb des rein privaten Bereichs zum sog. sonstigen eigenen Gebrauch, d. h. zum beruflichen oder gewerblichen Gebrauch beispielsweise durch Wirtschaftsunternehmen, Behörden oder wissenschaftliche Institute, in gewissem Umfang Vervielfältigungsstücke ohne Erlaubnis des Urhebers hergestellt werden dürfen. Solche Vervielfältigungen zum sonstigen eigenen Gebrauch sollen unter bestimmten Voraussetzungen $\mathrm{zu}$ wissenschaftlichen Zwecken, zur Archivierung und zur Unterrichtung über Tagesereignisse zulässig sein, darüber hinaus allgemein ohne besondere Zweckbestimmung, wenn es sich um kleine Teile eines erschienenen Werkes, um einzelne Aufsätze aus Zeitungen oder Zeitschriften oder um vergriffene Werke handelt. Hierbei geht der Entwurf zum Teil über das geltende Recht hinaus und berücksichtigt die aus dem modernen Wirtschaftsleben nicht mehr fortzudenkende Praxis, zu gewerblichen oder beruflichen Zwecken Fotokopien oder Mikrokopien von einschlägiger Fachliteratur herzustellen. Die gesetzliche Anerkennung dieser Ubung soll andererseits nicht zu einer finanziellen Schädigung des Urhebers führen. Es ist idaher vorgesehen, daß den Urhebern für die Vervielfältigung eine angemessene Vergütung zu zahlen ist, sorweit die Vervielfältigung gewerblichen Zwecken dient. Behörden, öffentliche Bibliotheken und wissenschaftliche Institute, die keinen Ertwerbszweck verfolgen, sind danach von der Vergü̈tungspflicht befreit, ebenso die Angehörigen freier Berufe, wie Wissenschaftler, Arzte und Anwälte, die zwar eine Erwerbstätigkeit, nicht aber eine gewerbliche Tätigkeit ausüben. Die Regelung entspricht den vom Bundesgerichtshof in seiner Entscheidung vom 24. Juni 1955 (BGHZ 18 S. 44, Anlage 4, [IV, V]) entwickelten Grundsätzen. Der Bundesgerichtshof erklärt in dieser Entscheidung für das gel- tende Recht zwar die Vervielfältigung zum gewerblichen Gebrauch ohne Genehmigung des Unhebers schlechthin für unzulässig, betont jedoch in der Begründung, daß der wirtschaftliche Sinn der Entscheidung nicht darin liege, die Anfertigung von Fotokopien zu gewerblichen Zwecken grundsätzlich zu unterbinden, sondern vielmehr darin, derartige Vervielfältigungen von der Zahlung einer angemessenen Vergütung an den Urheber bzw. den Verleger abhängig zu machen. Auf dieser Grundlage haben der Bundesverband der deutschen Industrie und die im Börsenverein ides deutschen Buchhandels zusammengeschlossenen Verleger bereits ein Rahmenabkommen getroffen, nach welchem die Industrieunternehmen die Erlaubnis zur Herstellung von Fotokopien gegen Zahlung einer nach bestimmten Richtlinien berechnaten Pauschalvergütung erhalten können.

\section{g) Gesetzliche Nutzungsrechte}

In Anlehnung an das geltende Recht ( $\$ 22$ LUG) ist für den Fall, daß der Urheber eines Werkes der Musik einem Schallplattenhersteller die Aufnahme seines Werkes gestattet, vorgesehen, daß kraft Gesetzes jeder andere ebenfalls berechtigt sein soll, das Werk gegen Zahlung einer angemessenen Vergütung auf Schallplatten zu übertragen (§ 64). Durch dieses sog. gesetzliche Nutzungsrecht soll der Bildung von Monopolen an der Schallplattenaufnahme einzelner Werke vorgebeugt werden. Es liegt ebenso im Interesse der Komponisten wie der Allgemeinheit, daß für solche Aufnahmen der Wettbewerb mehrerer Hersteller offengehalten und dadurch das Streben nach möglichster Vervollkommnung der Aufnahme wachgehalten wird. Im Verhältnis zum geltenden Recht sind die Anwendungsfälle des gesetzlichen Nutzungsrechts allerdings wesentlich eingeschränkt.

Neu ist das in $\S 65$ geregelte gesetzliche Nutzungsrecht zugunsten der Sendeunternehmen. Dieses Recht soll nicht so sehr die Bildung einer Monopolstellung verhüten als vielmehr den vom Rundfunk wahrgenommenen kulturellen Aufgaben Rechnung tragen. Auch hier ist dem Urheber bei Inanspruchnahme des gesetzlichen Nutzungsrechts eine angemesse Vergütung zu zahlen.

\section{h) Sonstige Schranken des Urheberrechts}

Schranken des Urheberrechts sind weiterhin in gewissen Fällen zugunsten der Rechtspflege und der öffentlichen Sicherheit vorgesehen (§ 45). Das Recht des Urhebers, sein Werk auf Bild- oder Tonträger zu übertragen, ist zugunsten der Sendeunternehmen und bestimmter Geschäftsbetriebe in zwei Fällen eingeschränkt, in denen die Aufnahme lediglich technischen Zwecken dient und keine selbständige Nutzung des Werkes darstellt (vgl. §§ 56, 57). Ganz allgemein soll idie Vervielfältigung, Verbreitung und öffentliche Wiedergabe eines Werkes zulässig sein, wenn das Werk nur als unwesentliches Beiwerk neben dem eigentlichen Gegenstand der Vervielfältigung, Verbreitung oder öffentlichen Wiedergabe erscheint, wie etwa ein Gemälde als nebensächlicher Hintergrund einer Filmszene (§ 58). Ferner ist vorgesehen, $\operatorname{da} \hat{B}$ Werke der bildenden Künste unter gewissen Voraussetzungen ohne Ge- 
nehmigung des Urhebers in Ausstellungs- oder Vorsteigerungskataloge aufgenommen ( $\$ 59)$ und, wenn sie bleibend an öffentlichen Wegen, Straßen oder Plätzen aufgestellt sind, frei abgebildet werden dürfen ( $(60)$. Ist ein Bildnis auf Bestellung angefertigt, so sollen der Besteller und ider Dargestellte berechtigt sein, das Bildnis durch Lichtbild $\mathrm{zu}$ vervielfältigen (\$ 61).

\section{i) Schutzfrist}

Zu den Schranken, denen das Urheberrecht im Interesse der Allgemeinheit unterliegt, gehört auch die Befristung des Urheberrechtsschutzes, die wie im geltenden Recht und in Ubereinstimmung mit Artikel 7 Abs. 1 der Brüsseler Fassung der Berner Übereinkunft auf die Dauer von 50 Jahren nach dem Tode des Urhebers bemessen ist ( $\$ \S, 67 \mathrm{ff}$.). Diese Schutzfrist ist unter Hinweis auf die unbegrenzte Dauer des Sacheigentums wiederholt als ungerechtfertigte Beschränkung des Urheberrechts angegriffen worden. Der Fortfall der Schutzfrist würde jedoch dem Wesen des Urheberrechts widersprechen, weil Werke der Literatur, Wissenschaft und Kunst anders als körperliche Gegenstände ihrer Natur nach Mitteilungsgut sind und nach einer die geistigen und wirtschaftlichen Interessen des Urhebers und seiner Erben angemessen berücksichtigenden Frist der Allgemeinheit frei zugänglich sein müssen. Die Befristung des Urheberrechtsschutzes entspricht demgemäß der Auffassung fast aller Kulturstaaten. Der Fortfall der Schutzfrist würde zudem zu erheblichen praktischen Schwierigkeiten führen, da schon nach wenigen Generationen die verfügungsberechtigten Erben des Urhebers nicht mehr ermittelt werden könnten. Nach dem Entwurf kommt die Aufgabe der Befristung des Urheberrechtsschutzes auch deshalb nicht in Betracht, weil die Einführung der sog. Urhebernachfolgevergütung vorgeschlagen wird, die ein Erlöschen des individuellen Urheberrechts voraussetzt.

\section{Urhebernachfolgevergütung}

Unter der Urhebernachfolgevergütung (domaine public payant) ist eine Vergütung zu verstehen, die für die Verwertung aller urheberrechtlich nicht geschützten Werke zu zahlen ist - sei es, daß die Werke niemals geschützt waren, sei es, daß die Schutzfrist abgelaufen ist - und zur Unterstützung und Förderung der lebenden Urheber verwandt werden soll.

Der Gedanke, durch Belastung der Verwertung gemeinfreier Werke mit einer Vergütungspflicht Mittel für eine Förderung des zeitgenössischen Kulturschaffens aufzubringen, ist alt und wird in den meisten Kulturstaaten erörtert. Auch die Brüsseler Konferenz zur Revision der Berner Ubereinkunft und die Genfer Konferenz, die zur Errichtung des Welturheberrechtsabkommens führte, - an der ersten Konferenz haben 35, an der zweiten 50 Staaten teilgenommen - haben sich mit der Urhebernachfolgevergütung befaßt und den Wunsch zum Ausdruck gebracht, daß in allen Staaten die Möglichkeit der Verwirklichung dieser Einrichtung erwogen werde. In mehreren Staaten, darunter Italien und Frankreich, hat die Urhebernachfolgevergütung bereits in gewissem Umfang gesetzliche Anerkennung gefunden. In Deutschland ist ihre Einführung bisher hauptsächlich unter Hinweis auf die mit der Durchführung verbundenen praktischen Schwierigkeiten abgelehnt worden. Im Verlaufe der Vorarbeiten $\mathrm{zu}$ dem vorliegenden Entwurf haben sich jedoch Möglichkeiten einer praktischen Verwirklichung abgezeichnet, die es gerechtfertigt erscheinen lassen, die Einführung der Urhebernachfolgevergütung im Rahmen des neuen Urheberrechtsgesetzes vorzuschlagen.

Mit der Urhebernachfolgevergütung kann keine umfassende Altersversorgung der Urheber erreicht werden. Die hierfür erforderlichen Beträge wären viel $\mathrm{zu}$ hoch, als daß sie allein durch die Urhebernachfolgevergütung aufgebracht werden könnten. Sinn dieser Einrichtung soll es vielmehr sein, Hilfsmaßnahmen nach Art der 1953 auf Veranlassung des damaligen Bundespräsidenten, Professor Heuss, gegründeten Deutschen Künstlerhilfe zu ermöglichen und auf eine sichere finanzielle Grundlage zu stellen.

$\mathrm{Zu}$ der vorgesehenen Regelung ist im einzelnen folgendes zu bemerken: Die Urhebernachfolgevergütung soll grundsätzlich ein Zehntel der üblicherweise für geschützte Werke zu zahlenden Urhebervergütung betragen ( $\S 76$ ). Bereits bei dieser geringen Höhe, die zu keiner wesentlichen Verteuerung der Preise für freie Werke führen wird, ist nach vorläufigen Schätzungen mit einem Aufkommen von etwa $2^{1 / 2}$ bis 3 Millionen DM zu rechnen, $d . h$. dem Vierfachen des Betrages, der zur Zeit der Deutschen Künstlerhilfe für ihre Hilfsmaßnahmen zur Verfügung stcht. Die Einnahmen aus der Urhebernachfolgevergütung sollen für Ehrensolde an verdiente Urheber, für die Hinterbliebenenversorgung und für Förderungsbeihilfen an begabte Urheber verwandt werden ( $\$ 78$ Abs. 1). Die Unkosten für das Einziehungs- und Verteilungsverfahren sollen 5 vom Hundert der Einnahmen nicht übersteigen dürfen ( $\$ 78$ Abs. 2). Der Entwurf geht hierbei davon aus, daß der Urheberfonds zur Vermeidung von Unkosten weitgehend mit den zahlungspflichtigen Verwertern freier Werke Pauschalvereinbarungen über die Abgeltung der Urhebernachfolgevergütung trifft und, soweit Verwertungsgesellschaften bestehen, diesen die Einziehung der Vergütung überträgt (vgl. § 76 Abs. 3, § 77); auch die Verteilung der Urhebernachfolgevergütung braucht keine wesentlichen Kosten zu verursachen, da sie über bereits bestehende Einrichtungen, beispielsweise die Deutsche Künstlerhilfe, durchgeführt werden könnte. Als Rechtsträger für die Einziehung und Verteilung der Vergütung ist ein Urheberfonds vorgesehen, der als Stiftung des bürgerlichen Rechts errichtet werden soll; in einem Organ der Stiftung sollen alle Länder vertreten sein ( $\$ 79)$.

\section{Verwandte Schutzrechte}

Unter den im Zweiten Teil des Entwurfs behandelten verwandten Schutzrechten versteht der Entwurf Rechte, die nicht wie das Urheberrecht die schöpferische Leistung schützen, sondern Leistungen anderer Art, die der schöpferischen Leistung des Urhebers ähnlich sind oder in Zusammenhang mit den 
Werken der Urheber erbracht werden. Einzelne dieser verwandten Schutzrechte sind - wenn auch zum Teil unvollkommen - bereits im geltenden Recht berücksichtigt, wie der Lichtbildschutz und der Schutz der ausübenden Künstler. Neu ist der für wissenschaftliche Ausgaben und Ausgaben nachgelassener Werke vorgesehene Schutz sowie der Schutz der Tonträgerhersteller und der Sendeunternehmen.

\section{a) Schutz der wissenschaftlichen Ausgaben (\$ 80)}

Abweichend vom geltenden Recht sieht der Entwurf für bestimmte wissenschaftliche Ausgaben urheberrechtlich nicht geschützter Werke und Texte (z. B. alter Handschriften, Inschriften und dergl.) einen besonderen Schutz vor, dessen Dauer auf zehn Jahre bemessen ist. Der Entwurf schließt damit eine schon seit langem als unbefriedigend empfundene Lücke der geltenden Gesetze.

\section{b) Schutz der Ausgaben nachgelassener Werke} $(\$ 81)$

Nach geltendem Recht erlischt der Urheberrechtsschutz für Werke, die nach Ablauf der normalen Schutzfrist von fünfzig Jahren nach dem Tode des Urhebers veröffentlicht werden, erst zehn Jahre nach der Veröffentlichung. Diese Regelung, die den Erben des Urhebers ein verlängertes Schutzrecht gewährt, hat sich wegen der oft bestehenden Schwierigkeit, die Erben des Urhebers zu ermitteln, als unzweckmäßig erwiesen. Der Entwurf ersetzt sie durch ein Leistungsschutzrecht zugunsten desjenigen, der ein bisher nicht erschienenes Werk nach Ablauf der Schutzfrist erscheinen läßt. Das Schutzrecht ist auf die Dauer von zehn Jahren nach dem Erscheinen des Werkes beschränkt.

\section{c) Schutz der Lichtbilder (\$ 82)}

Nach geltendem Recht genießen die "Werke der Photographie" Urheberrechtsschutz ebenso wie die Werke der bilidenden Künste. Der weitaus überwiegende Teil der Lichtbilder stellt jedoch keine schöpferische Leistung dar und kommt somit als Schutzobjekt des Urheberrechts nicht in Betracht. Der Entwurf beschränkt daher den Urheberrechtsschutz auf die als Lichtbildwerke bezeichneten schöpferischen Lichtbilder und gewährt den sonstigen Lichtbildern lediglich ein Leistungsschutzrecht, das allerdings in seinem Umfang idem Urheberrechtsschutz an Lichtbildwerken angeglichen ist. Die Schutzfrist soll für Lichtbildwerke und Lichtbilder wie im geltenden Recht einheitlich 25 Jahre betragen.

\section{d) Schutz des ausübenden Künstlers ( $\$ \$ 83$ bis 94)}

Die Darbietung des ausübenden Künstlers, der ein Werk vorträgt oder aufführt, wird im geltenden Recht in der Weise geschützt, daß das Gesetz die durch einen persönlichen Vortrag bewirkte Ubertragung eines Werkes auf „Vorrichtungen für Instrumente, die der mechanischen Wiedergabe für das Gehör dienen", einer Bearbeitung "des Werkes gleichstellt. Diese systematisch verfehlte und zudem unvollkommene Regelung des Schutzes der ausübenden Künstler wird heute allgemein abgelehnt. Nach dem Entwurf soll statt dessen der ausübende Künstler in Übereinstimmung mit dem Internationa- len Abkommen über den Schutz der ausübenden Künstler, der Hersteller von Tonträgern und der Sendeunternehmen vom 26. Oktober 1961 ein Leistungsschutzrecht erhalten, das zwar in der Systematik an das Urheberrecht angelehnt, in der Sache selbst aber abweichend gestaltet ist.

Der Entwurf unterscheidet zwischen der unmittelbaren Verwertung oder sog. Erstvérwertung der Darbietung des ausübenden Künstlers durch Lautsprecherübertragung, Livesendung oder Aufnahme auf Bild- oder Tonträger - z. B. Film, Schallplatte ( $\S 84,85,86$ Abs. 1) und der mittelbaren Verwertung, der sog. Zeitverwertung, durch Benutzung der Film- oder Schallplattenaufnahmen zur Funksendung oder öffentlichen' Wiedergabe ( $\$ 86$ Abs. 2, $\S$ 87). In den Fällen der unmittelbaren Verwertung soll der ausübende Künstler ähnlich wie der Urheber ein ausschließliches Recht erhalten, d. h. er soll insoweit jede Verwertung seiner Darbietung, die ohne seine Einwilligung erfolgt, verbieten können. Dagegen gewährt der Entwurf im Falle mittelbarer Verwertung, d. h. der Verwendung von erlaubterweise hergestellten Bild- oder Tonträgern zur Funksendung und öffentlichen Wiedergabe, nur einen Vergütungsanspruch. Würden die ausübenden Künstler, die durch die zunehmende Verwendung der "mechanischen Musik" ihre Arbeitsplätze bedroht sehen, auch in diesen Fällen ein Verbotsrecht erhalten, so bestände die Gefahr, daß sie dieses Recht zu einer Einschränkung der Musikwiedergaben mittels Tonträger benutzen könnten; dadurch aber würden die Urheber in der Auswertung ihrer Werke beeinträchtigt werden.

Die ausübenden Künstler sollen ferner ein dem Urheberpersönlichkeitsrecht nachgebildetes Recht erhalten, Entstellungen ihrer Darbietung zu verbieten. Die Dauer des Leistungsschutzrechts ist auf 25 Jahre bemessen.

\section{e) Schutz des Tonträgerherstellers (\$\$ 95, 96)}

Die mit der Herstellung von Schallplatten verbundene technisch-organisatorische Leistung genießt nach den geltenden Urhelberrechtsgesetzen keinen selbständigen Schutz. Um einem unbefugten Nachpressen von Schallplatten entgegentreten zu können, behilft sich die Schallplattenindustrie zur Zeit damit, daß sie sich die Rechte der ausübenden Künstler an Schallplatten abtreten läßt. Auf diese Weise wird aber ein wirksamer Schutz der Tonträgerhersteller nicht immer zu erreichen sein. Der Entwurf sieht daher in Ubereinstimmung mit dem Internationalen Abkommen über den Schutz der ausübenden Künster, der Hersteller von Tonträgern und der Sendeunternehmen vom 26. Oktober 1961 ein eigenes Leistungsschutzrecht des Tonträgerherstellers vor.

\section{f) Schutz des Sendeunternehmens (\$97)}

Auch zugunsten der Sendeunternehmen ist in Ubereinstimmung mit dem Internationalen Abkommen über den Schutz der ausübenden Künstler, der Hersteller von Tonträgern und der Sendeunternehmen vom 26. Oktober 1961 und dem Europäischen Abkommen zum Schutz von Fernsehsendungen vom 22. Juni 1960 ein Leistungsschutzrecht vorgesehen. 
Andere als die bezeichneten Leistungsschutzrechte sind im Entwurf nicht vorgesehen. Insbesondere enthält der Entwurf keine Bestimmungen über den Schutz artistischer Leistungen (Kartentricks, Zauberkunststücke und dergl.) und ü.ber den Schutz wissenschaftlicher Erkenntnisse und Methoden. Diese Fragen erscheinen für eine gesetzliche Regelung noch nicht reif; auch im Ausland ist idiese, soweit bekannt, bisher nicht versucht rworden.

Der Entwurf sieht ferner von besonderen Schutzvorschriften für Nachrichten und Titel (Buch- oder Zeitschriftentitel) $a b$, die in einigen ausländischen Urheberrechtsgesetzen enthalten sind. Der Nachrichtenund Titelschutz ist nach deutscher Rechtsauffassung Aufgabe des Wettbewerbsrechts.

Der Entwurf verzichtet schließlich auf eine Neuregelung des Bildnisschutzes ( $\S \S 22,23 \mathrm{KUG})$ und anderer reiner Persönlichkeitsrechte (z. B. Schutz von Briefen). Nachdem der Bundesgerichtshof für das geltende Recht ein allgemeines Persönlichkeitsrecht aus Artikel 1 und 2 des Grundgesetzes abgeleitet hat, erscheint eine Neuregelung einzelner besonderer Persönlichkeitsrechte wenig sinnvoll. In Betracht kommt nur eine Gesamtkodifikation des zivilrechtlichen Persönlichkeitsschutzes, die jedoch wegen ihrer grundsätzlichen Bedeutung für die gesamte Zivilrechtsordnung nicht in ein Sondergesetz rwie das Urheberrechtsgesetz gehört, sonldern in das Bürgerliche Gesetzbuch einbezogen werden müßte, wie es bereits in dem von der Bundesregierung vorgelegten Entwurf eines Gesetzes zur Neuregelung des zivilrechtlichen Persönlichkeits- und Ehrenschutzes (Drucksache des Deutschen Bundestages der 3. Wahlperiode 1237) vorgeschlagen worden war. Solange allerdings eine Neuregelung des Bildnisschutzes im Rahmen einer solchen Gesamtkodifikation des Persönlichkeitsrechts nicht in Kraft getreten ist, wäre es verfehlt, die geltenden Bestimmungen des KUG ü.ber den Billdnisschutz ersatzlos $\mathrm{zu}$ streichen. In $\S 150 \mathrm{Nr}$. 5 ist daher vorgesehen, $\mathrm{da} B$ diese Bestimmungen auch nach Aufhebung des KUG im übrigen ihre Geltung behalten sollen.

\section{Besondere Bestimmungen für Filme}

Der Dritte Teil des Entwurfs enthält besondere Bestimmungen für Filmwerke, die größtenteils auch auf solche Filme für entsprechend anwendbar erklärt werden, deren Bildfolge nicht schöpferisch gestaltet ist und somit keinen Werkcharakter hat (Laufbilder).

Das geltende Recht regelt das Urheberrecht an Filmwerken nur unvollkommen. Es gelten im wesentlichen die allgemeinen Grundsätze. Danach sind Urheber des Filmwerkes alle Personen, die einen schöpferischen Beitrag bei seiner Herstellung geleistet haben. Wer zu diesem Personenkreis gehört, ist streitig. Die Unsicherheit hat jedoch in der Praxis kaum zu Schwierigkeiten geführt, weil sich der Filmhersteller jeweils summarisch alle von den bei der Herstellung des Films Mitwirkenden erworbenen Rechte übertragen läßt. Es fehlt daher nicht an Stimmen, die auch für das künftige Urheberrechtsgesetz besondere Bestimmungen für Filmwerke für entbehrlich halten.
Es ist aber zu berücksichtigen, daß durch die Neugestaltung des Urheberrechts, insbesondere durch die Verstärkung des persönlichkeitsrechtlichen Schutzes des Urhebers, Probleme aufgeworfen werden, die nicht ohne weiteres durch Anwendung der allgemeinen Bestimmungen zu lösen sind. Filmwerke unterscheiden sich von anderen Werken durch die Vielzahl der Mitwirkenden und die hohen Herstellungskosten. Für den Filmproduzenten ist das Kostenrisiko nur tragbar, wenn die ungehinderte Auswertung des Filmwerkes sichergestellt ist. Da$\mathrm{zu}$ ist ein möglichst lückenloser Erwerb aller am Film bestehenden Verwertungsrechte, eine weitgehende Verfügungsfreiheit über diese Rechte und eine gewisse Einschränkung der persönlichkeitsrechtlichen Ansprüche der Mitwirkenden unerläßlich.

Um diesen Erfordernissen Rechnung zu tragen, war im Referentenentwurf von 1954 vorgeschlagen worden, kraft gesetzlicher Fiktion dem Filmhersteller unmittelbar das Urheberrecht am Filmwerk zu gewähren, vorbehaltlich der Urheberrechte an den zur Herstellung des Filmwerkes benutzten Werken wie Roman, Drehbuch und Filmmusik. Diese zweifellos praktische Lösung ist jedoch auf nahezu einhellige Ablehnung gestoßen. Es wird gefordert, daß auch für Filmwerke an dem Grundsatz festgehalten werden müsse, daß Urheberrechte originär allein in der Person des Werkschöpfers entstehen können.

Der vorliegende Entwurf beläßt es daher in Ubereinstimmung mit dem geltenden Recht für die Urheberschaft am Filmwerk bei den allgemeinen Grundsätzen. Wie bisher muß sich somit der Filmhersteller für die Auswertung des Filmwerkes von allen als Urheber in Betracht kommenden Mitwirkenden die ihnen möglicherweise erwachsenden Urheberrechte vertraglich einräumen lassen. Um diesen Rechtserwerb zu erleichtern, ist jedoch zugunsten des Filmherstellers eine Auslegungsregel vorgesehen, nach der im Zweifel jeder, der sich zur Mitwirkung bei der Herstellung eines Filmes verpflichtet, bereits mit dieser Verpflichtung sämtliche ihm etwa aus seiner Mitwirkung erwachsenden Nutzungsrechte am Filmwerk auf den Filmhersteller überträgt (§ 99). Eine ähnliche, allerdings etwas enger umgrenzte Auslegungsregel soll den Erwerb der erforderlichen Nutzungsrechte an den zur Herstellung des Filmwerkes benutzten Werken erleichtern $(\S 98)$. Die Nutzungsrechte sollen zur Erleichterung der Filmauswertung abweichend von der sonst geltenden Regelung ohne Zustimmung des Urhebers übertragbar sein ( $\$ 100)$.

Diese Bestimmungen greifen jedoch nicht durch, soweit es sich um das droit moral der beteiligten Urheber handelt, da die aus diesem Recht fließenden Befugnisse - z. B. das Recht, Entstellungen des Filmwerkes zu verbieten - ihrer Natur nach unübertragbar sind. Um den Filmhersteller auch insoweit vor unbilligen Behinderungen in der Auswertung des Filmwerkes zu schützen, schränkt $\S 103$ für den Bereich des Filmurheberrechts das droit moral in gewissem Umfang ein und verpflichtet $\mathrm{zu}-$ gleich alle Beteiligten, bei der Ausübung dieses Rechts aufeinander und auf den Filmhersteller angemessene Rücksicht zu nehmen. 
In Anerkennung der organisatorischen und wirtschaftlichen Leistung, die mit der Produktion eines Filmes verbunden ist, soll ferner dem Filmhersteller ähnlich wie dem Tonträgerhersteller ein eigenes Leistungsschutzrecht gewährt werden (§ 104).

\section{Sonstige Bestimmungen}

Der Vierte Teil des Entwurfs enthält gemeinsame Bestimmungen für Urheberrecht und verwandte Schutzrechte. Er regelt insbesondere die zivil- und strafrechtlichen Rechtsfolgen von Verletzungen der geschützten Rechte und bringt Bestimmungen über die Zwangsvollstrëckung.

Bei den Rechtsverletzungen unterscheidet der Entwurf klarer als die geltenden Urheberrechtsgesetze zwischen den zivilrechtlichen und strafrechtlichen Vorschriften. An Stelle der in § 40 LUG vorgesehenen Bestimmung, nach der im Strafverfahren auf eine an den Verletzten zu zahlende Buße erkannt werden kann, sieht der Entwurf in bestimmten Fällen einen zivilrechtlichen Anspruch auf Ersatz auch des immateriellen Schadens vor ( $\$ 107$ Abs. 2). Der Anspruch auf Vernichtung und ähnliche Maßnahmen wird ebenfalls rein zivilrechtlich gestaltet; im Strafverfahren kann nicht mehr selbständig auf Vernichtung erkannt werden, doch bleibt es dem Verletzten vorbehalten, seinen zivilrechtlichen Vernichtungsanspruch im Rahmen des Strafverfahrens gegebenenfalls im sog. Adhäsionsverfahren nach den $\S \S 403 \mathrm{ff}$. der Strafprozeßordnung $\mathrm{zu}$ verfolgen (\$ 120).

Die Strafbarkeit wird für einige weniger bedeutende Rechtsverletzungen, z. B. das Unterlassen der Quellenangabe, beseitigt, dafür im übrigen insofern verschärft, als abweichend vom geltenden Recht bei Verletzung des Urheberrechts oder der verwandten Schutzrechte statt auf Geldstrafe auch auf Gefängnisstrafe bis $\mathrm{zu}$ einem Jahr erkannt werden kann ( $\S 116$ bis 118).

Als Neuerung gegenüber dem geltenden Recht ist weiterhin die Ermächtignung der Landesregierungen hervorzuheben, die Rechtsstreitigkeiten auf dem Gebiet des Urheberrechts für mehrere Gerichtsbezinke einzelnen Land- und Amtsgerichten zuzuweisen, sofern dies der Rechtspflege idienlich ist ( $\S 115$ ). Die Bestimmungen des geltenden Rechts ( $\$ 49$ LUG, $\S 46$ KUG), nach denen die Länder die Möglichkeit haben, Sachverständigenkammern einzurichten, die zur Erstattung von Gutachten über Urheberrechtsfragen für Gerichte und Staatsanwaltschaften verpflichtet sind, übernimmt der Entwurf nicht. Von der Ermächtigung haben die Länder mit Ausnahme lediglich Berlins seit langem keinen Gebrauch gemacht; ein praktisches Bedürfnis dafür scheint nicht mehr $\mathrm{qu}$ bestehen.

Der Fünfte Teil des Entwurfs regelt den Anwendungsbereich des Gesetzes und renthält Uibergangsund Schlußibestimmungen.

\section{Zusammenhang des Entwurfs mit anderen Entwürfen}

Zugleich mit dem Entwurf des Urheberrechtsgesetzes werden folgende eingrangs bereits erwähnte $\mathrm{Ge}$ setzentwürfe vorgelegt:

a) Entwurf eines Gesetzes über Verwertungsgesellschaften auf dem Gebiet des Urheberrechts (Verwertungsgesellschaftengesetz),

b) Entwurf eines Gesetzes über die in Brüssel am 26. Juni 1948 beschlossene Fassung der Berner Ubereinkunft vom 9. September 1886 zum Schutze von Werken der Literatur und der Kunst,

c) Entwurf eines Gesetzes über das Europäische Abkommen vom 22. Juni 1960 zum Schutz von Fernsehsendungen.

Ferner wird der Entwurf eines Gesetzes über das Internationale Abkommen vom 26. Oktober 1961 über den Schutz der ausübenden Künstler, der Hersteller von Tonträgern und der Sendeunternehmen vorgelegt werden, sobald der deutsche Text dieses Abkommens fertiggestellt ist.

Die vier genannten Gesetzentwürfe stehen in engem Zusammenhang mit dem Entwurf des Urheberrechtsgesetzes. Das Verwertungsgesellschaftengesetz regelt die Wahrnehmung der im Urheberrechtsgesetz den Urhebern und Leistungsschutzberechtigten gewährten Rechte und Ansprüche durch sog. Verwertungsgesellschaften, deren Tätigkeit einer Erlaubnispflicht und einer Staatsaufsicht unterworfen werden soll. Mit den drei weiteren Gesetzen soll den bezeichneten internationalen Abkommen auf dem Gebiet des Urheberrechts und der verwandten Schutzrechte zugestimmt werden. Voraussetzung hierfür ist die im Entwurf des Urheberrechtsgesetzes vorgesehene Neugestaltung des deutschen Rechts, die dieses mit den in den Abkommen enthaltenen Regelungen in Einklang bringt.

\section{SchluBbemerkung}

Bund, Länder und Gemeinden werden durch die Ausführung des Urheberrechtsgesetzes nicht mit Kosten belastet. 


\section{B. Die einzelnen Vorschriften}

ERSTER. TEIL.

Urheberrecht

\section{ERSTER ABSCHNITT}

\section{Allgemeines}

\section{$\mathrm{Zu} \S 1$}

Die Bestimmung bringt zum Ausdrudk, daß der Zweck des Gesetzes der Schutz des Urhebers ist. Nicht das Werk, auf das sich der Schutz bezieht, sondern die Person des Urhebers steht im Vordergrund.

Gegenstand des Urheberrechtsschutzes sind nach dem Entwurf die "Werke der Literatur, Wissenschaft und Kunst". Diese Formulierung entspricht der üblichen Umschreibung des Schutzgegenstandes in den internationalen Abkommen auf dem Gebiet des Urheberrechts (vgl. Artikel 2 der Berner Ubereinkunft und Artikel I des Welturheberrechtsabkommens). In den geltenden Urheberrechtsgesetzen sind die Werke der Wissenschaft neben den Werken der Literatur und Kunst nicht als selbständige Schutzobjekte aufgeführt. Ihre Erwähnung empfiehlt sich jedoch, weil manche wissenschaftlichen Werke, z. B. Atlanten, weder als Werke der Literatur noch als Werke der Kunst bezeichnet werden können. Eine sachliche Erweiterung des Kreises der geschützten Werke gegenüber dem geltenden Rechı ist nicht beabsichtigt, insbesondere soll ein Schutz wissenschaftlicher Ideen und Erkenntnisse dadurch nicht begründet werden. Nur die persönliche Formgebung wissenschaftlicher Werke unterliegt dem Urheberrechtsschutz, der Gedankeninhalt bleibt frei.

\section{ZWEITER ABSCHNITT}

\section{Das Werk}

\section{Zu $§ 2$ - Geschützte Werke}

Im geltenden Recht sind die einzelnen geschützten Werkarten abschließend aufgezählt (§ 1 LUG, §§ 1 bis $3 \mathrm{KUG}$ ). Dies hat zu Schwierigkeiten bei dem Aufkommen neuer Werkarten geführt; so bedurfte es z. B. einer Gesetzesnovelle um klarzustellen, daß auch ein Filmwerk Urheberrechtsschutz genießt ( $\$ 15$ a KUG). Der Entwurf unterstellt deshalb allgemein die Werke der Literatur, Wissenschaft und Kunst dem Schutz des Gesetzes und beschränkt sich darauf, die einzelnen Werkarten als Beispiele zu nennen (Absatz 1). Sollten sich im Laufe der Zeit neue Werkarten bilden, sind diese somit ohne weiteres geschützt.

Bei der Aufzählung der geschützten Werkarten folgt der Entwurf im wesentlichen dem geltenden Recht, faßt jedoch die Aufzählung straffer zusammen. Die in den geltenden Gesetzen zum Teil bei den einzelnen Werkarten aufgeführten Beschränkungen werden nicht beibehalten, da eine unterschiedliche Behandlung der Werkarten nicht gerechtfertigt erscheint. So ist es nach Absatz 1 Nr. 1 für den Schutz von Reden, die der Entwurf mit den Schriftwerken unter dem Oberbegriff "Sprachwerke" zusammenfaßt, nicht mehr erforderlich, daß sie dem Zweck der Erbauung, der Belehrung oder der Unterhaltung dienen (vgl. § 1 Abs. 1 Nr. 1 LUG). Ferner ist nach Absatz $1 \mathrm{Nr}$. 3 der Schutz von pantomimischen Werken nicht mehr an die Voraussetzung gebunden, daß der Bühnenvorgang schriftlich oder auf andere Weise festgelegt ist (vgl. § 1 Abs. 2 LUG), und nach Absatz 1 Nr. 4 der Schutz von Bauwerken künftig nicht mehr auf solche beschränkt, die künstlerische Zwecke verfolgen (vgl. § 2 Abs. 1 Satz 2 KUG). Eine wesentliche praktische Bedeutung haben diese Einschränkungen ohnehin nicht gehabt.

Die Erwähnung der Lichtbildwerke in Absatz 1 Nr. 5 entspricht dem Wortlaut nach dem geltenden Recht (vgl. §§ 1 und 3 KUG: "Werke der Photographie"), sachlich besteht jedoch eine Einschränkung. Unter "Werken der Photographie" im Sinne des KUG werden nach herrschender Auffassung alle Erzeugnisse der Photographie verstanden, gleichgültig, ob sie die sonst an den Begriff des Werkes gestellte Anforderung einer "persönlichen geistigen Schöpfung" (vgl. Absatz 2) erfüllen oder nicht, also auch alle Aufnahmen, die nicht Ergebnis schöpferischer Tätigkeit sind, wie die meisten Amateuraufnahmen. Der Entwurf übernimmt diese systemwidrige Ausweitung des Urheberrechtsschutzes auf bloße technische Erzeugnisse nicht; er beschränkt den Urheberrechtsschutz auf die Lichtbildwerke und gewährt den nicht schöpferischen Erzeugnissen der Photographie (Lichtbildern) lediglich einen Leistungsschutz, der in $\$ 82$ geregelt ist. Bei der Ausgestaltung des Lichtbildschutzes war allerdings $\mathrm{zu}$ berücksichtigen, daß die Abgrenzung zwischen Lichtbildwerken und Lichtbildern in der Praxis außerordentliche Schwierigkeiten bereiten würde. Um diese $\mathrm{zu}$ vermeiden, sieht der Entwurf - insoweit wieder in Ubereinstimmung mit dem geltenden Recht - für Lichtbildwerke und Lichtbilder einen nach Umfang und Dauer völlig gleichen Schutz vor (vgl. zu § 82). Der Entwurf übernimmt nicht die im Ministerialentwurf von 1959 vorgeschlagene Regelung, nach der für sämtliche Lichtbilder einheitlich nur ein Leistungsschutzrecht gewährt werden sollte. Es erscheint unangemessen, auf diese Weise einem wenn auch nur kleinen Kreis echter schöpferischer Leistungen den urheberrechtlichen Schutz $\mathrm{zu}$ versagen und damit den Eindruck $\mathrm{zu}$ erwecken, als ob auf dem Gebiet der Photographie schöpferische Leistungen nicht möglich wären.

Die Filmwerke werden in den geltenden Urheberrechtsgesetzen nicht als selbständige Werkgattung genannt. Nach heute herrschender Auffassung har- 
delt es sich jedoch auch bei ihnen um Werke eigener Art, nicht etwa nur um die auf dem Filmstreifen festgehaltene Aufführung des Drehbuchs; die Verschmelzung der bei der Verfilmung benutzten Werke $\mathrm{zu}$ einer Einheit und ihre Umwandlung in das Bildliche stellen einen eigenen schöpferischen Vorgang dar, bei dem das Filmwerk als ein neues Werk entsteht. In Ubereinstimmung mit Artikel 2 Abs. 1 der Brüsseler Fassung der Berner Ubereinkunft und Artikel I des Welturheberrechtsabkommens werden daher die Filmwerke in Absatz $1 \mathrm{Nr} .6$ als geschützte Werkart besonders erwähnt. Die allgemeinen urheberrechtlichen Vorschriften des Ersten Teils sowie die Vorschriften des Zweiten Teils über verwandte Schutzrechte gelten für Filmwerke nur, soweit im Dritten Teil des Entwurfs (Besondere Bestimmungen für Filme) nichts anderes bestimmt ist.

Die Erwähnung der Darstellungen wissenschaftlicher oder technischer Art in Absatz $1 \mathrm{Nr} .7$ entspricht $\S 1$ Abs. 1 Nr. 3 LUG. Der Entwurf ersetzt den dort verwendeten Begriff "Abbildungen" durch das Wort "Darstellungen" um klarzustellen, daß auch wissenschaftliche Schemata, Tabellen und graphische Darstellungen Urheberrechtsschutz genießen können. Voraussetzung für den Urheberrechtsschutz der Darstellungen ist wie bei allen in Absatz 1 aufgeführten Werkarten, daß es sich um persönliche geistige Schöpfungen im Sinne des Absatzes 2 handelt.

In Absatz 2 bringt der Entwurf zum Ausdruck, daß unter "Werken" im Sinne des Gesetzes nur personliche geistige Schöpfungen zu verstehen sind. In den geltenden Urheberrechtsgesetzen ist eine solche Definition nicht enthalten; sie bedeutet jedoch keine Anderung des geltenden Rechts, sondern entspricht dem, was zur Zeit schon in Rechtslehre und Rechtsprechung unter dem Begriff "Werke" verstanden wird. Als "persönliche geistige Schöpfungen" sind Erzeugnisse anzusehen, die durch ihren Inhalt oder durch ihre Form oder durch die Verbindung von Inhalt und Form etwas Neues und Eigentümliches darstellen. Dem Vorschlag, die geschützten Werke als "Schöpfungen eigentümlicher Prägung" zu definieren, folgt der Entwurf nicht. Eine solche Begriffsbestimmung erscheint bedenklich, weil sie das Erfordernis der individuellen Form zu sehr betont und zu dem Schluß verführen könnte, daß im Gegensatz zum geltenden Recht Werke von geringem schöpferischen Wert, die sog. "Kleine Münze", in Zukunft keinen Schutz mehr genießen sollen. Ein solche Än. derung gegenüber dem geltenden Recht ist nicht beabsichtigt.

\section{Zu § 3 - Bearbeitungen}

In Ubereinstimmung mit Artikel 2 Abs. 2 ,der Brüsseler Fassung der Berner Uibereinkunft ist vorgesehen, daß Ubersetzungen und andere Bearbeitungen eines Werkes, die persönliche geistige Schöpfungen des Bearbeiters sind, unbeschadet des Urheberrechts am bearbeiteten Werk wie selbständige Werke geschützt werden. Umarbeitungen, die nicht das Ergebnis persönlicher Gestaltungskraft darstellen, sondern von jedem vorgenommen werden können, der über idie notwendige technische Vorbildung verfügt, wie z. B. Änderungen der Tonart oder Stimmlage bei Werken der Musilk, sind keine geistigen Schöpfungen, die Urheberrechtsschutz verdienen.

Die Regelung des Entwurfs entspricht sachlich dem geltenden Recht ( $\$ 2$ A.bs. 1 Satz 2 LUG, $\S 15$ A.bs. 2 KUIG). Der Entwurf übernimmt jedoch nicht die Bestimmung des $\$ 2$ Abs. 2 LUG, nach lder die durch einen persönlichen Vortrag oder durch Lochen, Stanzen usw. bewirkte Ubertragung eines Werkes der Literatur oder der Tonkunst auf „Vorrichtungen für Instrumente, die der mechanischen Wiedergabe für das Gehör dienen", (Tonträger) einer Bearbeitung gleichgestellt wird. Eine solche Uhertragung ist keine persönliche geistige Schöpfung des vortragenden Künstlers oder des Herstellers der mechanischen Vorrichtung, sondern eine Vervielfältigung des übertragenen Werkes (vgl. im einzelnen zu $\$ 16$ Abs. 2). Ein urheberrechtlicher Schutz ist in diesem Falle nicht gerechtfertigt. Nach dem Entwurf sollen statt dessen dem ausübenden Künstler und dem Tonträgerhersteller Leistungsschutzrechte gewährt werden (vgl. $\S \S 83$ bis 96 ).

Der Entwurf beschränkt sich darauf, das wichtigste Beispiel einer Bearbeitung, ldie Ubersetzung eines Sprachwrerkes, ausdrücklich zu nennen. Daneben kommen andere Fälle in Betracht, wie z. B. die Dramatisierung oder Verfilmung eines Werkes und jede andere schöpferische Neugestaltung.

Das Urheberrecht an Bearbeitungen wird mit Recht als abgeleitetes Urheberrecht bezeichnet, da jede Verwertung einer Bearbeitung zugleich auch eine Verwertung ides Originalwerkes bedeutet und somit der Einwilligung des Urhebers des Originalwerkes bedarf. Diese Einschränkung der Rechte des Bearbeiters ist durch die Worte "unbeschadet des Urheberrechts am bearbeiteten Werk" zum Ausdruck gebracht; sie wird durch die Vorschrift des $\S 23$ dahin näher geregelt, ‘daß die Bearbeitung eines Werkes nur mit Einwilligung des Urhebers des bearbeiteten Werkes veröffentlicht oder verwertet werden darf.

Von der Bearbeitung eines Werkes ist dessen freie Benutzung zu einer selbständigen Neuschöpfung zu unterscheilden, $\mathrm{zu}$ deren Verwertung nach $\S 24$ ebenso wie nach geltendem Recht ( $\S$ /13 LUG, $\S 16$ KUG) die Zustimmung des Urhebers des benutzten Werkes nicht erforderlich ist.

\section{Zu § 4 - Sammelwerke}

Die geltenden Gesetze enthalten keine allgemeinen Vorschriften über Sammlungen, sondern beschäftigen sich in § 4 LUG und § 6 KUG nur mit den "Werken, die aus den getrennten Beiträgen mehrerer bestehen (Sammelwerk)", unid geben bei ihnen das Urheberrecht für das "Werk als Ganzes" dem Herausgeber oder, falls ein solcher nicht genannt ist, dem Verleger. Diese Vorschriften ziehen also nur die Sammelwerke im engeren Sinne, wie Konversationslexika oder Enzyklopädien, in Betracht, die aus planmäßig für einen bestimmten Zweck hergestellten Beiträgen bestehen. Nach dem Entwurf 
sollen nunmehr alle Sammlungen von Werken oder anderen Beiträgen als "Sammelwerke" Urheberrechtsschutz genießen, allerdings entsprechend dem Grundgedanken des $\S 2$ Abs. 2 nur unter der Voraussetzung, daß sie durch Auslese oder Anordnung eine persönliche geistige Schöpfung sind. Neben Lexika und Enzyklopädien können somit auch Anthologien, Kochbücher, Adreßbüicher und dergl. als Sammelwerke geschützt sein, sofern die Auslese oder Anordnung der Beiträge, die selbst keine Werke zu sein brauchen, eine schöpferische Leistung darstellt. Handelt es sich bei den Beiträgen um Werke, so bleibt der an ihnen bestehende Unheberrechtsschutz unberührt, wie durch die Worte "unbeschadet des Urheberrechts an den aufgenommenen Werken" zum Ausdrudk gebracht wird. Die Regelung entspricht der schon im geltenden Recht entwickelten Rechtsprechung und im wesentlichen der Bestimmung in Artikel 2 Abs. 3 der Brüsseler Fassung der Berner Ubereinkunft, die allerdings ohne überzeugenden Grund - auf Sammlungen von Werken beschränkt ist.

Das Urheberrecht an idem Sammelwerk steht seinem geistigen Schöpfer zu (§7). Ist der Urheber des Sammelwerkes nicht gienannt, so wird nach § 10 Abs. 2 vermutet, daß der Herausigeber oder, wenn kein Herausgeber bezeichnet ist, der Verleger ermächtigt ist, die dem Urheber zustehenden Rechte geltend zu machen.

\section{Zu § 5 - Amtliche Werke}

Das geltende Recht ( $\S$ 16, 26 LUG) erklärt den Abdruck, die Verbreitung und den öffentlichen Vortrag von "Gesetzbüchern, Gesetzen, Verordnungen, amtlichen Erlassen und Entscheidungen sowie von anderen zum amtlichen Gebrauch hergestellten amtlichen Schriften" für zulässig. Diese Ausnahmevorschriften werden damit gerechtfertigt, daß das öffentliche Interesse die möglichst weite Verbreitung solcher Werke erfordere, und daß die kraft ihres Amtes zur Schaffung solcher Werke berufenen Verfasser entweder überhaupt kein Interesse an der Verwertung ihrer Leistungen hätten oder ihre Interessen hinter denen der Allgemeinheit zurücktreten müßten.

Der Entwurf übernimmt diese Regelung mit einigen zum Teil wesentlichen Änderungen.

Während das geltende Recht lediglich die Verwertung der amtlichen Werke frei zuläßt, sieht der Entwurf einen völligen Ausschluß des Urheberrechtsschutzes für diese Werke vor, d. h. an ihnen sollen auch keine urheberpersönlichkeitsrechtlichen Befugnisse geltend gemacht werden können. Diese Regelung erscheint gerechtfertigt, weil bei amtlichen Werken eine schutzwürdige persönliche Beziehung zwischen Urheber und Werk in der Regel nicht besteht. Es muß der Behörde, die die Entstehung des Werkes veranlaßt hat, freistehen, über das Werk ohne Rücksicht auf persönlichkeitsrechtliche Befugnisse, insbesondere ohne Namensangabe des Urhebers, zu verfügen. Wird ein amtliches Werk durch Dritte unrichtig wiedergegeben oder entstellt, so mag die Behörde, wenn sie dies für notwendig hält, eine Richtigstellung veröffentlichen oder sonst in geeigneter Weise die Offentlichkeit über die Unrichtigkeit der Wiedergabe aufklären. Eine Klage wegen Verletzung des Urheberpersönlichkeitsrechts erscheint hierfür nicht als das geeignete Mittel.

Absatz 1 zählt diejenigen amtlichen Werke auf, die ohne weitere Voraussetzung vom Urheberrechtsschutz ausgenommen sind. Die Aufzählung folgt im wesentlichen der Regelung in §16 LUG, erwähnt jedoch neben den Entscheidungen zusätzlich die amtlich verfaßten Leitsätze zu Entscheidungen um klarzustellen, daß auch an diesen kein Urheberrechtsschutz besteht. Es liegt im Interesse der Allgemeinheit, daß zugleich mit den Entscheidungen auch die amtlich verfaßten Leitsätze vervielfältigt und der Offentlichkeit mitgeteilt werden dürfen.

Absatz 2 regelt die Voraussetzungen, unter denen andere amtliche Werke der Freistellung vom Urheberrechtsschutz unterliegen. Nach § 16 LUG werden neben den Gesetzen, Verordnungen usw. die sonstigen "zum amtlichen Gebrauch hergestellten amtlichen Schriften " zum Abdruck freigegeben. Darunter sind nach der herrschenden Lehre Schriftwerke und Abbildungen wissenschaftlicher oder technischer Art zu verstehen, die von einer Behörde oder einer zur Ausübung eines öffentlichen Amts bestellten Person auf Grund amtlicher Verpflichtung verfaßt und ausschließlich oder überwiegend zum amtlichen Gebrauch bestimmt sind. Der Entwurf erweitert diese Regelung, indem er nicht nur amtliche "Schriften", sondern alle amtlichen Werke vom Urheberrechtsschutz freistellt, gleichgültig, welcher Werkgattung sie angehören. Zugleich enthält der Entwurf eine Änderung des geltenden Rechts, die dieses zum Teil erheblich einschränkt: Statt der Herstellung des Werkes ${ }_{n}$ zum amtlichen Gebrauch" fordert er als Voraussetzung für die Freistellung vom Urheberrechtsschutz, daß das Werk "im amtlichen Interesse zur allgemeinen Kenntnisnahme veröffentlicht" sein muß. Danach bleibt der Urheberrechtsschutz für Werke, die lediglich zum inneramtlichen Gebrauch hergestellt sind, voll erhalten; insoweit ist ein Bedürfnis für eine allgemeine Nachdruckfreiheit nicht anzuerkennen. Für die besonders bedeutsame Frage des Urheberrechtsschutzes amtlicher Kartenwerke ergibt sich hieraus, daß diese in der Regel Urheberrechtsschutz genießen, weil sie nicht im amtlichen Interesse von der Behörde veröffentlicht werden. Ein amtliches Interesse an der Veröffentlichung eines Kartenwerkes kann nur in Ausnahmefällen angenommen werden, z. B. wenn eine Behörde eine Karte von der Meeresküste veröffentlicht, in der die für Badende gefährlichen Stellen besonders bezeichnet sind.

Es kann vorkommen, daß in den Fällen des Absatzes 2 die Behörde zwar eine möglichst weite Verbreitung des Werkes wünscht, dennoch aber ein Interesse daran hat, den Nachdruck des Werkes zu überwachen, etwa weil ein ungenauer oder entstellter Nachdruck besonders nachteilige Folgen haben würde. Der Entwurf sieht daher vor, daß sich 
die Behörde durch einen Vorbehalt der Rechte den Urheberrechtsschutz erhalten kann. Ferner bestimmt Absatz 2 Satz 2 durch die Verweisung auf die Vorschriften über die Quellenangabe in $\S 63$ Abs. 1 und 2, daß bei jeder Vervielfältigung des Werkes und, soweit dies die Verkehrssitte erfordert, auch bei jeder öffentlichen Wiedergabe des Werkes die herausgebende Behörde zu nennen ist.

\section{Zu $\$ 6$ - Veröffentlichte und erschienene Werke}

Der Entwurf knüpft an die Veröffentlichung eines Werkes in verschiedenen Fällen bestimmte Rechtsfolgen, so z. B. die Freigabe der Benutzung des Werkes als Zitat im Falle des $\S 51$ Nr. 2 oder den Beginn der Schutzfrist bei anonymen und pseudonymen Werken ( $\$ 69$ Abs. 1).

Neben der Veröffentlichung ist auch das Erscheinen eines Werkes in zahlreichen Fällen von rechtserheblicher Bedeutung, beispielsweise für das Entstehen eines gesetzlichen Nutzungsrechts nach $\S 64$, für den Beginn der Schutzfrist bei Lichtbildwerken (§ 71) und für die Anwendbarkeit des Gesetzes auf Werke ausländischer Staatsangehöriger (§ 131).

Das künftige Recht sollte daher keinen Zweifel darüber bestehen lassen, was unter der Veröffentlichung und dem Erscheinen eines Werkes zu verstehen ist. Der Entwurf bringt deshalb im Gegensatz zu den geltenden Urheberrechtsgesetzen eine Begriffsbestimmung für die Veröffentlichung und das Erscheinen; sie folgt der bisherigen Rechtsauffassung.

Ein Werk veröffentlichen heißt, es der Offentlichkeit zugänglich machen, gleichviel auf welche Art das geschieht (Absatz 1). Als der Offentlichkeit zugänglich gemacht ist ein Werk anzusehen, wenn die Allgemeinheit die Möglichkeit erhalten hat, es mit Auge oder Ohr wahrzunehmen. Dafür ist nicht erforderlich, daß der Offentlichkeit ein Vervielfältigungsstück des Werkes (z. B. Buch, Noten oder dergl.) zur Verfügung gestellt wird.

Entsprechend den geltenden Gesetzen ( $\$ 35$ LUG, $\S 30 \mathrm{KUG})$ gilt ein Werk nur dann als veröffentlicht, wenn es 'mit Zustimmung des Berechtigten der Offentlichkeit zugänglich gemacht worden ist, wenn also der Berechtigte entweder vorher in die Veröffentlichung eingewilligt oder sie nachträglich genehmigt hat. Berechtigt zur Veröffentlichung ist in erster Linie der Urheber selbst, ferner derjenige, dem ein die Befugnis zur Veröffentlichung einschlieBendes Nutzungsrecht eingeräumt ist, wie z. B. der Verleger.

Das Erscheinen ist eine qualifizierte Art der Veröffentlichung. Nach Absatz 2 Satz 1 ist ein Werk erschienen, sobald mit Zustimmung des Berechtigten Vervielfältigungssstücke des Werkes in genügender Anzahl nach ihrer Herstellung der Offentlichkeit angeboten oder in Verkehr gebracht worden sind. Hinsichtlich des Erfordernisses der Zustimmung des Berechtigten gilt das gleiche wie bei der Veröffentlichung. Nach dem Entwurf genügt zum Erscheinen, daß Vervielfältigungsstücke des Werkes der Offentlichkeit angeboten werden; sie brauchen also nicht schon in Verkehr gebracht wor- den zu sein. Andererseits soll die bloße Aufforderung, Bestellungen auf noch nicht vorhandene Vervielfältigungsstücke zu machen, zum Begriff des Erscheinens nicht ausreichen; die Vervielfältigungsstücke müssen schon hergestellt sein, und zwar in einer zur Deckung des normalen Bedarfs genügenden Anzahl. Soweit es, wie bei den Bestimmungen über den Anwendungsbereich des Gesetzes ( $\S 131$ sowie $\S \S 134$ bis 137), auf den Ort des Erscheinens ankommt, ist durch die Formulierung "nach ihrer Herstellung der Offentlichkeit angeboten oder in Verkehr gebracht " klargestellt, daß die Herstellung der Vervielfältigungsstücke zwar Voraussetzung, nicht aber Bestandteil des Erscheinungsbegriffs ist. Ein Werk ist danach überall dort erschienen, wo Vervielfältigungsstücke des Werkes in genügender Anzahl angeboten oder in Verkehr gebracht worden sind; der Ort der Herstellung der Vervielfältigungsstücke ist gleichgültig.

Für das Erscheinen eines Werkes ist es unerheblich, ob die Vervielfältigungsstücke durch Veräußerung oder lediglich durch Verleihen oder Vermieten in Verkehr gebracht worden sind. Auch ein Werk der Musik, dessen Notenmaterial vom Verlag nur leihweise für Aufführungen zur Verfügung gestellt worden ist, ist erschienen, ebenso ein Film, der in Verleih gegeben worden ist. Entsprechend genügt ein öffentliches Angebot zur Leihe oder zur Miete; ein Angebot der Vervielfältigungsstücke zum Erwerb ist nicht erforderlich. Dieser weite Erscheinensbegriff entspricht der Regelung in Artikel 4 Abs. 4 Satz 1 der Brüsseler Fassung der Berner Ubereinkunft. Dem Vorschlag, den Begriff einzuengen in der Weise, daß nur ein Angebot zum Erwerb oder ein Inverkehrbringen durch Veräußerung das Erscheinen des Werkes bewirkt, wird deshalb nicht gefolgt.

Absatz 2 Satz 2 enthält eine Sonderregelung für Werke der bildenden Künste. Sie trägt dem Umstand Rechnung, daß diese in der Regel anders als Werke der Literatur und der Musik nicht durch Angebot oder Inverkehrbringen von Vervielfältigungsstücken bleibend der Offentlichkeit zugänglich gemacht werden, sondern dadurch, daß sie an öffentlichen Plätzen, in Museen usw. bleibend ausgestellt werden. Bereits im geltenden Recht wird daher teilweise dieser Tatbestand dem Erscheinen des Werkes gleichgeachtet (vgl. § 19 Abs. 1 Satz 2 KUG). Es erscheint gerechtfertigt, die Gleichstellung als allgemeine Regel in die Definition des Erscheinensbegriffs einzubeziehen.

\section{DRITTER ABSCHNITT}

\section{Der Urheber}

\section{Zu $\$ 7$ - Urheber}

Der Satz "Urheber ist der Schöpfer des Werkes" gibt denselben Gedanken wieder wie $\S 2$ Abs. 1 Satz 1 LUG: „Urheber eines Werkes ist dessen Verfasser", gilt aber nicht nur für Werke der Literatur und der Tonkunst, sondern für sämtliche Werke im Sinne des $\$ 2$ Abs. 1. Da nach dem Entwurf nur personliche geistige Schöpfungen als Werke ge- 
schützt sein sollen, kann das Urheberrecht an solchen Werken nur in der Person ihres Schöpfers entstehen.

Von diesem Grundsatz macht der Entwurf keine Ausnahme. Er sieht davon $a b$, wie in den $\S \S 3,4$, 32 LUG, §§ 5, 6, 25 Abs. 2 KUG ein Urheberrecht juristischer Personen an den von ihnen herausgegebenen Werken anzuerkennen; denn juristische Personen können keine das Urheberrecht an Sammlungen oder sonstigen Werken begründende geistige Tätigkeit entfalten. Auch das Urheberrecht an Filmwerken soll nach dem Entwurf in der Person der geistigen Schöpfer des Filmwerkes entstehen; ein fiktives Urheberrecht des Filmherstellers, wie es in $\S 93$ des Referentenentwurfs von 1954 vorgeschlagen worden war, enhält der Entwurf nicht.

Im Entwurf wird der Grundsatz, daß allein der Schöpfer des Werkes Träger des Urheberrechts sein soll, auch insofern folgerichtig durchgeführt, als in keinem Fall ein gesetzlicher Ubergang einzelner oder aller urheberrechtlicher Befugnisse auf andere Personen vorgesehen ist. Maßgebend ist hierfür die Erwägung, daß in allen Fällen die Möglichkeit einer vertraglichen Einräumung der urheberrechtlichen Befugnisse durch den Urheber ausreicht. Soweit nach der Lebenserfahrung von einer stillschweigenden Einräumung urheberrechtlicher Befugnisse auszugehen ist, trägt der Entwurf dem durch Auslegungsregeln Rechnung (vgl. §§ 98 und 99).

\section{Zu § 8 - Miturheber}

Die geltenden Gesetze ( $\$ 6$ LUG, $\S 8$ KUG) nehmen Miturheberschaft an, wenn cin Werk von mehreren gemeinsam in der Weise hergestellt worden ist, daß ihre Arbeiten sich nicht trennen lassen. Der Entwurf stellt in Absatz 1 demgegenüber in Ubereinstimmung mit einem bereits für das geltende Recht in gleiche Richtung weisenden Urteil des Bundesgerichtshofs vom 3. März 1959 - I ZR 17/ 58 - auf die Unmöglichkeit der gesonderten Verwertung der Beiträge ab. Es kommt nicht auf die tatsächliche Untrennbarkeit der Beiträge an, sondern darauf, ob die einzelnen Beiträge unvollständige Teile des ganzen Werkes sind. Es erscheint möglich, daß ein Beitrag eines Miturhebers äußerlich von dem Beitrag des anderen Miturhebers unterscheidbar und damit auch trennbar ist (z. B. einzelne Szenen eines Bühnenwerkes), daß er aber dennoch unselbständig ist und nicht gesondert verwertet werden kann.

Das Rechtsverhältnis der Miturheber untereinander wird nach geltendem Recht als eine Gemeinschaft nach Bruchteilen im Sinne des Bürgerlichen Gesetzbuchs angesehen ( $\$ 6$ LUG, $\S 8$ KUG). Dies entspricht jedoch nicht ider Natur der Miturheberschaft als einer auf gewolltem Zusammentwirkien beruhenden besonders engen Gemeinschaft. Absatz 2 bestimmt daher, daß mehrere Miturheber in einer Gemeinschaft zur gesamten Hand stehen, ähnlich wie eine Gesellschaft des bürgerlichen Rechts. Die Miturheber können danach das Werk nur gemeinsam veröffentlichen, verwerten oder ändern. Damit nicht ein Miturheber ohne triftigen Grund durch Versagen seiner Einwilligung die Verwertung des
Werkes überhaupt verhindern kann, ist zugleich vorgesehen, daß er seine Einwilligung $\mathrm{zu}$ einer gemeinsam $\mathrm{zu}$ trleffenden Maßnahme nicht wider Treu und Glauben versagen kann (Absatz 2 Satz 2). Zur Erleichterung der Abwehr von Verletzungen des gemeinsamen Unheberrechts bestimmt Absatz 2 Satz 3, daß jeder Miturheber berechtigt ist, Ansprüche aus Verletzungen des gemeinsamen Urheberrechts geltend $\mathrm{zu}$ machen, ohne daß er zuvor die Zustimmung ider anderen Miturheber einzuholen braucht. Handelt es sich um Ansprüche auf Leistung, wie z. B. Schadenersatzansprüche oder Ansprüche auf Uberlassung, so soll er jedoch nur Leistung an alle Miturheber verlangen können.

Um gegebenenfalls auch die spätere Genehmigung einer ohne Einwilligung eines Miturhebers vorgenommenen Veröffentlichung, Verwertung oder Anderung des Werkes zu ermöglichen, ist angeregt worden, den Begriff der Einwilligung durch den allgemeineren der Zustimmung zu ersetzen. Es erscheint jedoch bedenklich, auf diese Weise rückwirkend die Heilung einer bereits vollendeten und bei vorsätzlichem Handeln sogar strafbaren Rechtsverletzung zuzula'ssen. Nur bei Rechtsgleschäften kennt das Gesetz den Zustand einer schwebenden Rechtsunwirksamkeit. Die schwebende Rechtsunwirksamkeit reiner Rechtshandlungen wäre mit dem Erfordernis der Rechtssicherheit unvereinbar. Hat der betroffene Miturheber gegen die ohne sein Einverständnis durchgeführte Maßnahme nichts einzuwenden, so mag er auf seine Ansprüche aus der Rechtsverletzung verzichten.

Absatz 3 regelt die Verteilung der Erträgnisse aus aus der Nutzung des Werkes. Nach geltendem Recht finden, da zwischen den Miturhebern eine Gemeinschaft nach Bruchteilen besteht, die $\S \S 742$ und 743 des Bürgerlichen Gesetzbuchs Anwendung, nach denen im Zweifel anzunehmen ist, daß den Miturhebern gleiche Anteile an den Nutzungserträgnissen zustehen. Diese Regelung erscheint nicht angemessen, da häufig die Beiträge der Miturheber an dem gemeinsamen Werk sehr unterschiedlichen Wert haben. Der Entwurf sieht daher vor, daß die Nutzungserträgnisse den Miturhebern nach dem Verhältnis der Bedeutung ihrer, Anteile an der Schöpfung ides Werkes gebühren, sofern nichts anderes zwischen den Miturhebern vereinbart ist.

Absatz 4 läßt in Ausnahme von dem sonst geltenden Grundsatz, Idaß die Verwertungsrechte ebenso wie das Urheberrecht als Ganzes nicht übertragbar und somit auch nicht verzichtbar sind (vgl. § 29 Satz 2), den Verzicht eines Miturhebers auf seinen Anteil an den Verwertungsrechten zu. Im Falle des Verzichts soll entsprechend der Gestaltung der Miturheberschaft als einer Gesamthandsgemeinschaft der Anteil den anderen Miturhebern zuwachsen. Diese Regelung erscheint geboten, um besonders in den Fällen, in denen eine große Zahl von teilweise nur unbedeutend an der Schöpfung des Werkes beteiligten Miturhebern vorhanden ist, eine Zusammenfassung der Verwertungsrechte in der Hand einiger weniger Mitunheber zur Erleichterung der Auswertung des Werkes zu ermöglichen. Ein Verzicht auf die 
persönlichkeitsrechtlichen Bestandteile des Urheberrechts soll dagegen auch einem Miturheber nicht möglich sein.

Von verschiedenen Seiten ist gefordert worden, neben der vorgesehenen Bestimmung über die Miturheberschaft eine Sonderregelung für das sog. Gruppenwerk zu schaffen, ähnlich wie es in Artikel 9 Abs. 3 ides neuen französischen Urheberrechtsgesetzes vom 11. März 1957 vorgesehen ist. Danach soll bei einem Werk, ldas mehrere unter der Leitung eines Herausgebers geschaffen haben, ohne daß ihre Anteile daran nach Umfang, Bedeutung oder in sonstiger Weise unterscheidbar sind (Gruppenwerk), dem Herausgeber das ausschließliche Recht zur Veröffentlichung und Verwertung des Werkes zustehen, wenn er das Zustandekommen des Werkes durch seine leitende Mitarbeit bewirkt hat. Ein Bedürfnis für eine solche Regelung ist jedoch nicht anzuerkennen. Was das Verhältnis der an der Herstellung des Werkes Beteiligten untereinander betrifft, so reicht die in $\S 8$ vorgesehene Regelung aus, nach der ein einzelner die Verwertung des Werkes nicht durch Versagen seiner Einwilligung wider Treu und Glauben verhindern kann; das "Gruppenwerk", bei dem die Beiträge der einzelnen Mitarbeiter nicht unterscheidbar, also auch nicht gesondert verwertbar sind, ist ein typischer Fall der Miturheberschaft, so daß die Anwendbarkeit des $\S 8$ nicht zweifelhaft sein kann. Aber auch für ıdas Verhältnis der Mitarbeiter zum Herausgeber bedarf es keiner Sonderregelung. Der Herausgeber kann sich die für die Verwertung des Werkes erforderlichen Rechte von allen Mitwirkenden ebenso vertraglich einrăumen lassen, wie er dies bei dem Werk eines einzelnen Urhebers tun müßte. Die vorgeschlagene Regelung, die auf ein originäres Unhelberrecht oder zumindest Verwertungsrecht des Herausgebers abzielt, wünde mit der Zielsetzung des Entwurfs unvereinbar sein, den Grundsatz des § 7, daß Urheber nur der Schöpfer des Werkes sein kann, ausnahmslos durchzuführen.

\section{Zu § 9 - Urheber verbundener Werke}

Von der Miturheberschaft, die durch gemeinsame Schöpfung eines einheitlichen Werkes gekennzeichnet ist, ist der Fall zu unterscheiden, daß zwei oder mehrere an sich selbständige Werke im Einverständnis ihrer Urheber zu gemeinsamer Verwertung miteinander verbunden werden. Eine solche Werkverbindung liegt stets dann vor, wenn Werke verschiedener Art miteinanider verbunden werden, z. B. ein Werk der Musik oder ein Werk der bildenden Künste mit einem Werk der Literatur (Lied, Oper, Illustration eine Romans); doch ist auch eine Verbindung 'von Werken gleicher Gattung möglich, etwa im Falle eines Kommentars zu einem Gesetz, der aus selibständigen Beiträgen verschiedener Mitarbeiter besteht.

Im geltenden Recht ( $\$ 5$ LUG, $\S 7 \mathrm{KUG}$ ) ist für diese Tatbestände vorgesehen, daß für jedes der verbundenen Werke dessen Verfasser auch nach der Verbindung als alleiniger Urheber gilt, d. h. an seinem Werk ungeachtet ider Verbindung ein selbständiges
Urheberrecht behält. Hiervon geht auch der Entwurf aus. Es ist aber zu berücksichtigen, ldaß sich verbundene Werke in der Regel gerade in der Verbindung am besten verwerten lassen. Verweigert der eine Urheber seine Zustimmung zu der gemeinsamen Verwertung, so kann er dadurch iden anderen Urheber in der wirksamen Auswertung seiner schöpferischen Leistung empfindlich beeinträchtigen. Um für diesen Fall einen billigen Interessenausgleich $\mathrm{zu}$ schaffen, sieht $\S 9$ abweichend vom geltenden Recht vor, daß jeder Urheber von dem anderen die Einwilligung zur Veröffentlichung, Verwertung oder Anderung der verbundenen Werke verlangen kann, wenn die Einiwilligung dem anderen nach Treu und Glauben zuzumuten ist.

\section{Zu $\S 10$ - Vermutung der Urheberschaft}

Die Bestimmung des Absatzes 1 über die Vermutung der Urheberschaft entspricht dem geltenden Recht ( $\$ 7$ Abs. 1 LUG, $\S 9$ Abs. 1 KUG), jedoch mit einer wesentlichen Anderung. Das geltende Recht knüpft die Vermutung der Urhebenschaft daran, daß der wahre Name des Urhebers angegeben oder durch kenntliche Zeichen ausgedrückt ist. Der Entwurf legt in Abweichung idavon idem vom Urheber benutzten bekannten Decknamen die gleiche Bedeutung bei, :da 'der Schriftsteller- ader Künstlername (Pseudonym) zumeist der einzige Name ist, unter dem die Offentlichkeit den Urheber kennt.

Die Angabe des Urhebers kann nach dem Entwurf daher in dreifacher Weise vorgenommen werden: entweder durch Anführung des wahren Namens oder des bekannten Decknamens oder, was nur bei Werken der bildenden Künste üblich ist, Idurch Anbringung des bekannten Künstlerzeichens. Einzelheiten über die Stelle des Werkes, an der die Urheberbezeichnung anzubringen ist, schreibt der Entwurf in Abrweichung von $\S 7$ Abs. 1 LUG nicht vor, sondern beschränkt sich darauf, die Vermutung 'der Urheberschaft an die "in der üblichen .Weise" geschehene Angabe zu knüpfen.

Das geltende Recht ( $\S 7$ Abs. 3 LUG) stellt weiterhin bei Werken, die vor oder nach idem Enscheinen öffentlich aufgeführt oder vorgetragen worden sind, die Vermutung auf, daß derjenige der Urheber ist, der bei der Ankündigung der Aufführung oder des Vortrages als Verfasser bezeichnet worden ist. Der Entwurf übernimmt diese Bestimmung nicht; denn bei einem öffentlichen Vortrag oder einer öffentlichen Aufführung läßt sich wie bei jeder unkörperlichen Wiedergabe des Werkes die Möglichkeit nicht ausschließen, daß ein unrichtiger Urheber genannt wird. Der Unheber kann in diesen Fällen nicht in gleichem Maße die Richtigkeit der Namensangabe überwachen, wie es bei der Anbringung der Urheberbezeichnung auf dem Original oder auf Vervielfältigungsstücken des Wenkes möglich ist.

Absatz 2 entspricht der Regelung in $\S 7$ Abs. 2 LUG und $\S 9$ Abs. 2 KUG, nach der bei Werken, die unter einem anderen als dem wahren Namen des Verfassers oder ohne den Namen eines Urhebers erschienen sind, der Herausgeber oder, falls ein solcher 
nicht genannt ist, der Verleger berechtigt ist, die Rechte des Urhebers wahrzunehmen. Im Gegensatz zum geltenden Recht wird jedoch nur vermutet, daß der Herausgeber oder Verleger zur Geltendmachung der dem Urheber zustehenden Rechte ermächtigt ist. Dadurch wind dem Urheber eines anonymen oder pseudonymen Werkes ermöglicht, dem Herausgeber oder Verleger die Befugnis zur Wahrnehmung seiner Rechte zu entziehen, wenn er diese Rechte selbst ausüben will. Um Zweifel darüber auszuschließen, wer sich als "Herausgeber" auf die Vermutung nach Absatz 2 berufen kann, ist klargestellt, daß derjenige als zur Geltendmachung der Rechte des Urhebers ermächtigt angesehen wird, der auf den Vervielfältigungsstücken des Wienkes als Herausgeber bezeichnet ist, gleichgültig, ob der so Bezeichnete die Herausigebertätigkeit selbst ausgeübt oder vielleicht nur seinen Namen zur Verfügung grestellt hat.

Es ist vorgeschlagen worden, die Bestimmung des § 4 LUG über die Urheberschaft ibei Sammelwerken als Albsatz 3 hier einzufügen, um Unklarheiten darüber zu vermeiden, wer bei Sammelwerken das Urheberrecht für das Werk als ganzes geltend machen kann. Eine besondere Vermutung über die Urheberschaft an Sammelwerken enscheint jedoch angesichis der Regelung des $\S 10$ überflüssig; denn diese Vorschrift führt zu dem gleichen Ergebnis wie § 4 LUG: Auf Sammelwerken wird üblicherweise der Unheber des Sammelwerkes, dd. h. derjenige, der die Auslese oder Anordnung der einzelnen Beiträgre vornimmt, als Herausgeber bezeichnet. Hier stellt also die Angabe des Herausgebers die Urheberbezeichnung im Sinne des Absatzes 1 dar. Die Angabe des Herausgebers begründet daher die Vermutung, ıdaß der Herausgeber der Urheber des Sammelwerkes ist. Wird im Einzelfall nachgewiesen, daß er die Auslese und Anordnung der Beiträge nicht selbst vorgenommen hat, so wird, da ein besonderer Urheber für das Sammelwerk nicht angegeben ist, nach $\S 10$ Abs. 2 vermutet, daß er als Herausgreber ermächtigt ist, die Rechte des Urhebens geltend zu machen. Ist der Herausgeber nicht angegeben, so tritt ebenso wie nach § 4 LUG der Verleger an seine Stellie.

\section{VIERTER ABSCHNITT}

\section{Inhalt des Urheberrechts}

\section{Allgemeines}

\section{$\mathrm{Zu} \S 11$}

Die Bestimmung umschreibt allgemein den Inhalt des Urheberrechts und bringt zum Ausdruck, daB das Urheberrecht sowohl dem Schutz der ideellen als auch der materiellen Interessen ides Urhebers dient. Beide Seiten des Urheberrechts - idas Persönlichkeitsrecht und das Vermögensrecht (Verwertungsrechte) - bilden eine untrennbare Einheit und sind vielfältig miteinander verflochten. So ist z. B. die Verwertung eines unveröffentlichten Werkes ohne gleichzeitige Ausüibung des Veröffentlichungsrechts nicht möglich und idie Nutzungsrechte bleiben auch nach ihrer Einräumung an Dritte weiterhin dem beim Urheber verbliebenen Persönlichkeitsrecht unterworfen.

Die einzelnen sich aus dem umfassenden Urheberrecht engebenden persönlichkeitsrechtlichen und vermögensrechtlichen Befugnisse des Urhebers sind in den folgenden Bestimmungen näher geregelt.

\section{Urheberpersönlichkeits recht}

Der Entwurf beginnt mit der Umschreibung der persönlichkeitsrechtlichen Befugnisse, die stets unlösbar mit der Person des Urhebers verbunden bleiben. Die geltenden Urheberrechtsgesetze enthalten keine allgemeinen Bestimmungen über die der Wahrung persönlicher Interessen dienenden Befugnisse des Urhebers. Sie tragen jedoch bereits dem Gedanken 'der Schutzbedürftigkeit dieser Interessen durch einzelne Schutzvorschriften zugunsten des Urhebers Rechnung, so z. B. durch das Verbot, den wesentlichen Inhalt eines Werkes der Literatur ohne $\mathrm{Zu}$ stimmung des Urhebers öffentlich mitzuteilen (§ 11 Abs. 1 Satz 2 LUG), durch die Vorschrifen über die Urheberbezeichnung auf Originalen und Kopien von Werken der bildenden Künste $(\S \S 13,18$ Abs. 3 KUG) und über die Verpflichtung zur Quellenangabe bei einzelnen erlaubten Entlehnungen ( $\$ 18$ Abs. 1 Satz 2, § 25 LUG, § 19 Abs. 2 KUG) sowie durch das Verbot, im Falle der Ubertragung des Urheberrechts oder im Falle erlaubter Entlehnungen Änderungen am Werk vorzunehmen $(\S \S 9,18$ Abs. 1 Satz 1, 24 LUG, $\S 12,21 \mathrm{KUG}$ ). Die herrschende Meinung hat aus diesen Ansatzpunkten schon für das geltende Recht drei allgemeine persönlichkeitsrechtliche Befugnisse des Urhebers abgeleitet: das Veröffentlichungsrecht, 'das Recht auf Anerkennung der Urheberschaft und das Recht, Entstellungen und andere die persönlichen Interessen des Urhebers verletzende Beeinträchtigungen des Werkes zu verbieten. Die beiden letzteren Befugnisse sind auch im internationalen Bereich durch Artikel 6 bis der Brüsseler Fassung der Berner Ubereinkunft als "droit moral" des Urhebers ausdrücklich anerkannt; diese Bestimmung lautet:

"Unabhängig von seinen vermögensrechtlichen Befugnissen und selbst nach deren Abtretung behält der Urheber während seines ganzen Lebens das Recht, die Urheberschaft am Werk für sich in Anspruch zu nehmen und sich jeder Entstellung, Verstümmelung oder sonstigen Änderung dieses Werkes oder jeder anderen Beeinträchtigung des Werkes zu widersetzen, welche seiner Ehre oder seinem Ruf nachteilig sein könnte."

Der Entwurf sieht nunmehr eine ausdrückliche Regelung der drei von Rechtsprechung und Lehre entwickelten persönlichkeitsrechtlichen Befugnisse des Urhebers vor und faßt diese unter der Uberschrift "Urheberpersönlichkeitsrecht" in einem besonderen Unterabschnitt zusammen. Es sind Bedenken dagegen erhoben worden, den Begriff „Urheberpersönlichkeitsrecht" als Bezeichnung für die dem Schutz der ideellen Interessen dienenden Befugnisse des Urhebers zu verwenden, aus der Erwägung heraus, daß diese im Gegensatz zu anderen Persönlichkeits- 
rechten nicht unmittelbar die Person des Urhebers selbst, sondern lediglich seine Beziehungen zu einem außerpersönlichen Gut, dem Werk, schützen. Es kann jedoch keinem Zweifel unterliegen, daß die dem Schutz der ideellen Interessen dienenden Befugnisse des Urhebers, wenn das Urheberrechtsgesetz sie nicht gewähren würde, von der Rechtsprechung aus dem heute anerkannten allgemeinen Persönlichkeitsrecht abgeleitet werden würden. Das Urheberpersönlichkeitsrecht ist auch insofern echtes Persönlichkeitsrecht, als es grundsätzlich stets untrennbar mit der Person des Urhebers verbunden bleibt. Es ist im Verhältnis zum allgemeinen Persönlichkeitsrecht in ähnlicher Weise als ein "besonderes" Persönlichkeitsrecht anzusehen wie etwa das Namensrecht nach $\S 12$ des Bürgerlichen Gesetzbuchs oder das Recht am eigenen Bild nach $\S 22$ KUG.

Die Zugehörigkeit des Urheberpersönlichkeitsrechts zum allgemeinen Persönlichkeitsrecht ändert allerdings nichts an der Notwendigkeit seiner Regelung im Urheberrechtsgesetz, da es zusammen mit den Verwertungsrechten des Urhebers eine untrennbare Einheit bildet. Für den Fall, daß das allgemeine Persönlichkeitsrecht - wie es in dem von der Bundesregierung in der 3. Wahlperiode vorgelegten Entwurf eines Gesetzes zur Neuordnung des zivilrechtlichen Persönlichkeits- und Fhrenschutzes (Drucksache des Deutschen Bundestages ler 3. Wahlperiode 1237) in Aussicht genommen wo den war umfassend gesetzlich geregelt werd en sollte, würde daher das Urheberpersönlichkeil srecht von einer solchen Regelung auszunehmen sein. Die erwähnte Gesetzesvorlage sah dementsprechend eine Bestimmung vor, nach der das Gesetz auf Tatbestände, die in den Urheberrechtsgesetzen geregelt sind, nicht anzuwenden ist, es sei denn, daß sich eine Verletzung des allgemeinen Persönlichkeitsrechts aus besonderen, in den Urheberrechtsgesetzen nicht berücksichtigten Umständen ergibt (Artikel 2 Nr. 1).

Entsprechend der Natur des Urheberrechts als untrennbarer Einheit vermögensrechtlicher und persönlichkeitsrechtlicher Bestandteile, stehen auch die Verwertungsrechte des Urhebers im Banne der persönlichen Beziehung zwischen Urheber und Werk und bleiben dies, auch wenn der Urheber durch Einräumung von Nutzungsrechten über sie verfügt hat. Diese ständige Beziehung zur Person des Urhebers findet in zahlreichen weiteren Bestimmungen des Entwurfs ihren Ausdruck: in erster Linie in der Vorschrift des $\S 29$, nach der das Urheberrecht einschließlich der Verwertungsrechte als Ganzes grundsätzlich unübertragbar ist, ferner $z$. B. in den Bestimmungen über die Zustimmungsbedürftigkeit einer Weiterübertragung von Nutzungsrechten (§ 34), über das Rückrufsrecht wegen gewandelter Uberzeugung ( $\S$ 42) und über die Einschränkung der Zwangsvollstreckung in das Urheberrecht (§§ $123 \mathrm{ff}$.).

\section{Zu $§ 12$ - Veröffentlichungsrecht}

Wie schon hervorgehoben, gewähren die geltenden Urheberrechtsgesetze dem Urheber nicht ausdrücklich das Recht, Zeitpunkt und Art der Ver- öffentlichung seines Werkes zu bestimmen. Dieses Recht ergibt sich lediglich für die Werke der Literatur und Tonkunst mittelbar aus der Bestimmung in $\S 11$ Abs. 1 Satz 2 LUG, nach welcher der Urheber, solange nicht der wesentliche Inhalt des Werkes öffentlich mitgeteilt ist, ausschließlich zu einer solchen Mitteilung befugt ist. Damit wird dem Urheber auch die Veröffentlichung des ganzen Werkes und die Art dieser Veröffentlichung vorbehalten. Da es sich hierbei um eines der wichtigsten Rechte des Urhebers handelt, sieht Absatz 1 seine ausdrückliche Anerkennung im Gesetz vor, und zwar für alle Werke.

Das Veröffentlichungsrecht ist besonders eng mit den Verwertungsrechten verbunden. Ein Werk kann nur veröffentlicht, d. h. der Allgemeinheit zugänglich gemacht werden, indem es verbreitet, öffentlich ausgestellt oder öffentlich wiedergegeben, also zugleich verwertet wird. Die Veröffentlichung des Werkes schließt somit stets eine Verwertung des Werkes ein.

Das Veröffentlichungsrecht nach Absatz 1 ist auf das Werk als Ganzes in der ihm vom Urheber gegebenen Gestalt bezogen. Absatz 2 erweitert dieses Recht in der Weise, daß dem Urheber auch die erste öffentliche Mitteilung oder Beschreibung des Inhalts des Werkes vorbehalten ist. Diese Regelung entspricht dem geltenden Recht ( $\$ 11$ Abs. 1 Satz 2 LUG).

\section{Zu § 13 - Anerkennung der Urheberschaft}

Satz 1 gewährt dem Urheber in Ubereinstimmung mit Artikel 6 bis der Brüsseler Fassung der Berner Ubereinkunft das Recht auf Anerkennung seiner Urheberschaft am Werk, das ihm ermöglicht, gegen jeden Klage zu erheben, der seine Urheberschaft bestreitet oder sich selbst die Urheberschaft anmaßt. In den geltenden Urheberrechtsgesetzen ist ein solches Recht nicht vorgesehen.

Satz 2 gibt demgegenüber im wesentlichen den $\mathrm{Zu}$ stand des geltenden Rechts wieder (vgl. § $13 \mathrm{KUG).}$ Danach kann der Urheber bestimmen, ob auf dem Original oder den Vervielfältigungsstücken des Werkes zum Ausdruck gebracht werden soll, wer es geschaffen hat und ob dies durch Anführung des wahren Namens, eines Decknamens oder eines Künstlerzeichens geschehen soll. Für den Fall des unzulässigen Anbringens der Urheberbezeichnung sind in $\S 117$ Strafbestimmungen vorgesehen.

Ein allgemeines Recht des Urhebers, die Angabe seines Namens bei jeder Nutzung seines Werkes zu verlangen, sieht der Entwurf nicht vor. Der Urheber bedarf eines solchen Rechtes nicht, da er bei der Einräumung von Nutzungsrechten vertraglich vereinbaren kann, ob und in welcher Form bei der Werknutzung sein Name genannt werden soll. Dem Urheber steht es somit frei, auf die Namensangabe wirksam zu verzichten; tut er dies, so bleibt ihm als unveräußerliches Persönlichkeitsrecht nach Satz 1 lediglich vorbehalten, einem Bestreiten seiner Urheberschaft oder einer fremden Urheberschaftsanmaßung entgegenzutreten. Etwas anderes gilt allerdings in den Fällen, in denen eine Nutzung 
des Werkes nach dem Entwurf ohne Zustimmung des Urhebers zulässig ist, der Urheber also nicht in der Lage ist, die Angabe seines Namens bei der Nutzung vertraglich zu vereinbaren. Für diese Fälle sieht der Entwurf eine besondere Verpflichtung zur Quellenangabe vor (vgl. § 5 Abs. 2 Satz 2, $\S \S 63$ und 66).

\section{Zu § 14 - Entstellung des Werkes}

Die geltenden Urheberechtsgesetze gewähren dem Urheber nicht ausdrücklich das Recht, Entstellungen seines Werkes zu verbieten, doch wird dieses Recht in Anlehnung an Artikel 6 bis der Brüsseler Fassung der Berner Ubereinkunft von der herrschenden Meinung bereits für das geltende Recht als bestehend anerkannt. Der Entwurf sieht nunmehr ein solches Recht als Teil des Urheberpersönlichkeitsrechts ausdrücklich vor. Das Recht ist wie alle persönlichkeitsrechtlichen Befugnisse unveräußerlich, d. h. der Urheber kann während der ganzen Dauer seines Urheberrechts Entstellungen seines Werkes verbieten, selbst wenn er die Verwertung seines Werkes durch Dritte beschränkt oder unbeschränkt gestattet hat.

Der Entwurf folgt in der Formulierung im wesentlichen Artikel 6 bis der Brüsseler Fassung der Berner Ubereinkunft, jedoch mit einer Änderung: er stellt darauf $a b$, daß die Entstellung oder andere Beeinträchtigung des Werkes geeignet sein muß, die berechtigten geistigen oder persönlichen Interessen des Urhebers am Werk zu gefährden, nicht, wie es in Artikel 6 bls heißt, seine Ehre oder seinen Ruf. Hierdurch soll klarer zum Ausdruck gebracht werden, daß nicht an den allgemeinen Persönlichkeitsschutz gedacht ist, sondern an den Schutz des geistigen und persönlichen Bandes, das zwischen dem Urheber und seinem Werk besteht.

Wenn auch das Recht nach $\S 14$ als Teil des Urheberpersönlichkeitsrechts von dem allgemeinen Persönlichkeitsrecht $\mathrm{zu}$ scheiden ist, so steht es diesem doch in seiner generalklauselartigen Weite und Unbestimmtheit wesensmäßig nahe. Im Gegensatz $\mathrm{zu}$ den klar umgrenzten Rechten aus den $\$ \S 12$ und 13 ist es daher erforderlich, den Umfang des Rechts wie den des allgemeinen Persönlichkeitsrechts durch das Erfordernis einer Interessenabwägung $\mathrm{zu}$ begrenzen. Der Entwurf bringt dies dadurch zum Ausdruck, daß nur eine Gefährdung der berechtigten geistigen und persönlichen Interessen des Urhebers am Werk beachtlich sein soll.

Dẹr Anregung, Bearbeitungen eines Werkes nach dem Tode des Urhebers nur zuzulassen, wenn der Urheber sie durch letztwillige Verfügung gestattet hat, folgt der Entwurf nicht. Dadurch würden die Erben des Urhebers in ihrer Verfügung über das Werk zu stark beschränkt werden.

Es ist auch davon abgesehen worden, dem Urheber eines Werkes der bildenden Künste das Recht zu geben, Instandsetzungsarbeiten an seinem Werk selbst vorzunehmen. Soweit bei der Instandsetzung das Werk entstellt wird, kann der Urheber sich nach $\S 14$ wehren. Ihm darüber hinaus nur auf die
Gefahr hin, daß sein Persönlichkeitsrecht verletzt werden könnte, besondere Ansprüche zu geben, erscheint nicht erforderlich und könnte in der Praxis zu Schwierigkeiten führen.

Es erscheint weiterhin nicht angebracht, in das Gesetz ein Vernichtungsverbot für Werke der bildenden Künste aufzunehmen, soweit an ihrer Erhaltung ein öffentliches Interesse besteht. Die Erhaltung kulturell wertvoller Kunstwerke ist nicht Aufgabe des privatrechtlichen Urheberrechts, sondern des zum Gebiet des öffentlichen Rechts gehörenden Denkmalschutzes.

\section{Verwertungsrechte}

\section{$\mathrm{Zu} \S 15$ - Allgemeines}

Entstanden aus den zum Schutz gegen Nachdruck gewährten Privilegien der Urheber und Verleger hatte das Urheberrecht ursprünglich nur die Aufgabe, die druckschriftliche Verwertung des Werkes zu sichern. Im Laufe der Zeit ist das Verwertungsrecht des Urhebers in immer weiterem Umfang anerkannt worden. Die geltenden deutschen Urheberrechtsgesetze gehen bereits davon aus, dem Urheber grundsätzlich alle Verwertungsmöglichkeiten einzuräumen vorbehaltlich gewisser Einschränkungen, die im Interesse der Allgemeinheit geboten sind. Sie zählen aber die einzelnen Befugnisse des Urhebers nach den bei Erlaß der Gesetze gegebenen Verwertungsmöglichkeiten abschließend auf, so daß sich das Verwertungsrecht des Urhebers darin erschöpfen soll. Diese Regelung hat sich nicht bewährt, weil bei der fortschreitenden Entwicklung der Technik neue Verwertungsarten gefunden worden sind, die gerechterweise ebenfalls dem Urheber vorbehalten sein müssen. So erwähnen die geltenden Urheberrechtsgesetze beispielsweise noch nicht das Senderecht. Zwar ist es heute unstreitig, daß dem Urheber auch dieses besonders wichtige Verwertungsrecht zusteht. Die Rechtsprechung hatte jedoch Schwierigkeiten, hierfür eine mit dem System der geltenden Gesetze vereinbare Begründung $\mathrm{zu}$ finden. Um diese Schwierigkeiten für die Zukunft $\mathrm{zu}$ vermeiden, verzichtet 'der Entwurf auf eine erschöpfende Aufzählung der Verwertungsrechte und gibt dem Urheber statt dessen ganz allgemein das Recht, sein Werk zu verwerten, wobei die einzelnen zur Zeit bekannten, im Geschäftsverkehr entwickelten Verwertungsformen, wie die Vervielfältigung, die Funksendung usw. nur als Beispiele angeführt werden. Dadurch wird klargestellt, daß auch etwaige künftige Verwertungsformen, die heute noch nicht bekannt sind, dem Urheber vorbehalten sein sollen.

Bei der Zuerkennung eines solchen allgemeinen Verwertungsrechts war allerdings zu berücksichtigen, daß neben den im Sechsten Abschnitt des Ersten Teils des Entwurfs aufgeführten besonderen Schranken des Urheberrechts einige Verwertungsrechte nach herrschender Auffassung bereits ihrem Wesen nach gewissen Einschränkungen unterliegen. So gehört es zum Wesen des Verbreitungsrechts, daß es grundsätzlich nur die Erstverbreitung eines Werkexemplars umfaßt, also nur das Recht, ein 
Buch, eine Schallplatte oder dergl. erstmals in Verkehr zu bringen; der Weiterverkauf ist frei zulässig. Ferner gilt für die unkörperliche Wiedergabe des Werkes durch Vortrag, Aufführung usw. der allgemeine Grundsatz, daß dem Urheber nur die öffentliche Wiedergabe vorbehalten ist. Soweit der Entwurf die einzelnen im Geschäftsverkehr entwikkelten Verwertungsrechte als Bestandteile des allgemeinen Verwertungsrechts ausdrücklich nennt, gibt er daher in den $\S \S 16$ bis 22 zugleich abschlieBende Begriffsbestimmungen dieser Rechte. Die Abgrenzungen, die sich aus diesen Begriffsbestimmungen ergeben, können nicht unter Berufung auf das allgemeine Verwertungsrecht überschritten werden. Ist also beispielsweise das Ausstellungsrecht in $\S 18$ als das Recht definiert, das Original oder Vervielfältigungsstücke eines unveröffentlichten Werkes der bildenden Künste oder eines unveröffentlichten Lichtbildwerkes öffentlich zur Schau zu stellen, so soll nicht darüber hinaus ein entsprechendes Recht für Werke der Literatur oder der Musik aus $\S 15$ abgeleitet werden können, ebensowenig das Recht, ein bereits veröffentlichtes Werk der bilidenden Künste oder Lichtbildwerk öffentlich zur Schau zu stellen.

Die Definitionen der einzelnen Verwertungsrechte in den $\S \S 16$ bis 22 verfolgen zugleich einen weiteren Zweck. Viele Bestimmungen des Entwurfs, die Verwertungsrechte des Urhebers betreffen, insbesondere die Vorschriften über die Schranken des Urheberrechts und gewisse Auslegungsregeln für die Einräumung von Nutzungsrechten beziehen sich nicht auf das allgemeine Verwertungsrecht, sondern haben lediglich einzelne Verwertungsbefugnisse des Urhebers zum Gegenstand. Zweifel über den Wirkungsbereich dieser Vorschriften können nur ausgeschlossen werden, wenn die einzelnen Verwertungsrechte durch erschöpfende Begriffsbestimmungen klar voneinander abgegrenzt werden.

Absatz 1 gewährt dem Urheber allgemein das Recht zur Verwertung seines Werkes in körperlicher Form. Darunter sind alle Verwertungsformen zu verstehen, die unmittelbar das Original oder Vervielfältigungsstücke des Werkes (Werkstücke) zum Gegenstand haben. Neben den herkömmlichen, in den geltenden Urheberrechtsgesetzen bereits vorgesehenen Rechten zur Verwertung des Werkes in körperlicher Form, dem Vervielfältigungs- und dem Verbreitungsrecht, führt der Entwurf weiterhin das Ausstellungsrecht an, das der Urheber nach geltendem Recht nicht besitzt. Der Umfang dieser neuen Befugnis ist in $\S 18$ näher umschrieben.

Im Ministerialentwurf von 1959 war vorgeschlagen worden, auch das Verfilmungsrecht als selbständiges Verwertungsrecht des Urhebers mit anzuführen. Die Verfilmung eines Werkes ist jedoch entweder, wenn das Werk unverändert in den Film übernommen wird, eine Vervielfältigung des Werkes und fällt somit bereits unter Absatz 1 Nr. 1 oder sie ist eine besondere Form der Bearbeitung des Werkes, die in $\S 23$ des Entwurfs geregelt ist. Die besondere Erwähnung eines Verfilmungsrechts erscheint daher überflüssig und mit der Systematik des Gesetzes nicht vereinbar. Die Besonderheit, daß - abwei- chend von dem nach $\S 23$ Abs. 1 für Bearbeitungen sonst geltenden Grundsatz, daß nur die Veröffentlichung und Verwertung der Bearbeitung der Einwilligung des Originalurhebers bedarf - bei einer Bearbeitung des Werkes durch Verfilmung bereits die Herstellung der Bearbeitung nur mit Einwilligung des Urhebers des verfilmten Werkes zulässig ist, ergibt sich aus $\S 23$ Abs. 2.

Absatz 2 gewährt dem Urheber das Recht der Verwertung seines Werkes in unkörperlicher Form, die als "Wiedergabe" bezeichnet wird, mit der bereits erwähnten allgemeinen Einschränkung, daß nur die öffentliche Wiedergabe des Werkes ihm vorbehalten ist. Der Begriff "öffentliche Wiedergabe" als Sammelbezeichnung für alle dem Urheber vorbehaltenen unkörperlichen Verwertungsarten wird in zahlreichen Bestimmungen des Entwurfs zur Vereinfachung der Gesetzessprache verwendet (vgl. z. B. $\S 37$ Abs. 3, $\S 53,73,81,106$ und 116).

In den Nummern 1 bis 4 zählt der Entwurf die zur Zeit bekannten Sonderformen des Rechts der öffentlichen Wiejdergabe auf. Unter dem Vortrags-, Aufführungs- und Vorführungsrecht (Absatz 2 Nr. 1) versteht der Entwurf, wie sich aus $\S 19$ ergibt, nur das Recht zur ursprünglichen Wiedergabe des Werkes durch persönliche Darbietung oder - bei der Vorführung - mittels der ursprünglichen, unmittelbar zur Wiedergabe mit technischen Mitteln bestimmten Vervielfältigungsstücke wie Diapositive oder Filmstreifen. Neben dieses Recht der ursprünglichen Wiedergabe treten in den Nummern 2 bis 4 die in den geltenden Urheberrechtsgesetzen im wesentlichen noch nicht berücksichtigten, durch die technische Entwicklung begründeten neuen Wiedergaberechte: das Senderecht, das Recht der Wiedergabe durch Bild- oder Tonträger und das Recht der Wiedergabe von Funksendungen. Bei den letztgenannten beiden Rechten handelt es sich um sog. Zweitverwertungsrechte, d. h. um Rechte an Verwertungsarten, denen jeweils eine dem Urheber vorbehaltene Werkverwertung bereits voraufgegangen ist: bei der Wiedergabe durch Bild- oder Tonträger die Aufnahme des Werkes auf den Bild- oder Tonträger, bei der Wiedergabe von Funksendungen die Funksendung des Werkes.

Im Ministerialentwurf von 1959 war vorgeschlagen worden, die in der deutschen Rechtssprache neuen Begriffe der Wiedergabe durch Bild- oder Tonträger und der Wiedergabe von Funksendungen zu vermeiden und neben dem Senderecht lediglich ein allgemeines Vortrags-, Aufführungs und Vorführungsrecht $\mathrm{zu}$ gewähren, das auch die Zweitverwertungen mitumfaßt. Eine solche Regelung erscheint jedoch unzweckmäßig. Es widerspricht dem allgemeinen Sprachgebrauch, der Aufführung einer Sinfonie im Konzertsaal ihre Wiedergabe durch Plattenspieler oder Rundfunkgerät gleichzustellen. Auch der Urheber, der über sein Wiedergaberecht verfügt, unterscheidet hierbei regelmäßig zwischen der unmittelbaren und der sekundären Wiedergabe: Für eine öffentliche Aufführung im Konzertsaal ist ein höheres Entgelt zu zahlen als für eine bloße Schallplatten- oder Rundfunkwiedergabe; ferner läßt der Urheber das Bühnenauffüh- 
rungsrecht an musikdramatischen Werken in der Regel durch seinen Verleger wahrnehmen, während er die Zweitverwertungsrechte der Schallplattenoder Rundfunkwiedergabe von Aufführungen solcher Werke seiner Verwertungsgesellschaft, der GEMA, zur Wahrnehmung überträgt. Vor allem aber erscheint es verfehlt, den stets gleichen Vorgang der Bild- oder Tonträgerwiedergabe und der Rundfunkwiedergabe terminologisch aufzuspalten in Vorträge, Aufführungen oder Vorführungen, je nachdem, ob sich die Wiedergabe auf Sprachwerke, auf Bühnenwerke oder Werke der Musik oder auf Filmwerke bezieht. Dementsprechend gewährt auch die Brüsseler Fassung der Berner Ubereinkunft die Zweitverwertungsrechte der Wiedergabe von Funksendungen und der Wiedergabe mittels Bild- oder Tonträger als selbständige einheitliche Rechte neben dem Vortrags-, Aufführungs- und Vorführungsrecht (vgl. Artikel $11^{\text {bis }}$ Abs. 1 Nr. 3 und Artikel 13 Abs. 1 Nr. 2 neben Artikel 11 Abs. 1, $11^{\text {ter }}$ und 14 Abs. 1 Nr. 2).

Absatz 3 enthält eine allgemeine Definition des Begriffs der Offentlichkeit der Wiedergabe eines Werkes, die für alle besonderen Wiedergabearten in gleicher Weise maßgebend ist. Die Begriffsbestimmung folgt im wesentlichen den bereits für das geltende Recht von der Rechtsprechung entwickelten Grundsätzen (vgl. zuletzt Entscheidung des Bundesgerichtshofs vom 8. Januar 1960 - I ZR 128/58 mit weiteren Hinweisen, Anlage 6 [I]). Dem Vorschlag, die Bestimmung des Offentlichkeitsbegriffs wie bisher ganz der Rechtsprechung zu überlassen, um dieser die Möglichkeit zu geben, ihn den jeweiligen Gegebenheiten besser anzupassen, folgt der Entwurf nicht. Der Begriff der Offentlichkeit einer Werkwiedergabe hat für die Allgemeinheit besonders große Bedeutung, weil er in zahlreichen Fällen, vor allem bei Musikwiedergaben, die beim Tanzunterricht, bei Betriebsfeiern und bei Vereinsveranstaltungen stattfinden, für die Beurteilung der Frage entscheidend ist, ob die Wiedergabe des Werkes der Erlaubnis des Urhebers bedarf oder erlaubnisfrei und damit vergütungsfrei zulässig ist. Es ist daher wichtig, die Voraussetzungen, unter denen eine Veranstaltung als öffentlich anzusehen ist, jedenfalls in den Grundzügen bereits im Gesetzestext klar zum Ausdruck zu bringen, um so mehr, als sich der Offentlichkeitsbegriff des Urheberrechts wesentlich von dem im sonstigen Recht, z. B. im Strafrecht, verwendeten Offentlichkeitsbegriff unterscheidet.

\section{Zu § 16 - Vervielfältigungsrecht}

Die Begriffsbestimmung des Vervielfältigungsrechts in Absatz 1 entspricht dem geltenden Recht ( $\$ 15$ Abs. 1 LUG, § 17 KUG). Das Vervielfältigungisrecht umfaßt nach dieser Definition die Herstellung jeder Art und Zahl von Vervielfältigungsstücken des Werkes, d. h. von körperlichen Festlegungen, die geeignet sind, das Werk den menschlichen Sinnen auf irgendeine Weise unmittelbar oder mittelbar wahrnehmbar zu machen (Bücher, Noten, Schallplatten und dergl.). Ohne daß es einer besonderen Hervorhebung im Gesetzestext ibedarf, unterliegen danach dem Vervielfältigungsrecht auch das Nachbilden eines Kunstwerkes, das Nachbauen eines Werkes der Baukunst und das Ausführen von Plänen und Entwürfen zu solchen Werken ( $\$ 15$ A.bs. 1 Satz 2 KUG).

Absatz 2 stellt klar, daß die Herstellung von Schallplatten und Tonband- oder Filmaufnahmen eines Werkes ebenso .wie Uberspielungen eines Werkes von einem Toniband auf ein anderes Tonband Vervielfältigungen und nicht Bearbeitungen des Werkes sind. Hierin liegt, wie bereits zu $\S 3$ ausgeführt, eine Anderung des geltenden Rechts, das in $\S 2$ A.bs. 2 LUG die Ubertragung eines Werkes auf "Vorrichtungen für Instrumente, die der mechanischen Wiedergabe für das Gehör dienen", einer Bearbeitung des Werkes gleichstellt. Durch diese Regelung sollte besonders im Interesse der Schallplattenindustrie in einfacher Weise der für solche Vorrichtungen als notwendig erkannte Schutz gewährleistet werden. Die Anwendung urheberrechtlicher Vorschriften auf den Schutz des ausübenden Künstlers oder des Herstellers der mechanischen Vorrichtung (durch Lochen, Stanzen usw.) widerspricht jedoch dem Grundsatz, daß der Urheberrechtsschutz nur einer schöpferischen Tätigkeit zukommen kann; denn die Übertragung eines vorhandenen Werkes auf eine mechanische Vorrichtung ist keine schöpferische Leistung, mag sie künstlerisch und technisch noch so vollendet sein. Der Entwurf folgt deshalb nicht der Konstruktion des geltenıden Rechts und trägt den Interessen der ausübbenden Künstler und der Hersteller von Tonträgern sachgemäßer idurch Zubilligung besonderer Leistungsschutzrechte Rechnung (vgl. $\S \S 83$ bis 96$)$.

Absatz 2 enthält zugleich eine allgemeine Definition der Begriffe "Bildträger" und "Tonträger", auf die an späterer Stelle mehrfach zurückgegriffen wird (vigl. z. B. $\S \S 21,54,64,85,95$ und 104). Abweichend vom geltenden Recht ( $\$ 2$ Abs. 2 , 12 Abs. 2 Nr. 5 LUG) spricht der Entwurf nicht von "Vorrichtungen für Instrumente, die der mechanischen Wiedergabe für das Gehör idienen", sondern legt das Hauptgewicht auf die Eigenschaft der Vorrichtung, Bildoder Tonfolgen wiederholt wiedergeben zu können, gleichviel, ab dies mit Mitteln der Mechanik im im engeren Sinne oder mit Hilfe etwa elektromagnetischer Vorgänge geschieht.

\section{Zu § 17 - Verbreitungsrecht}

Nach geltendem Recht ( $\$ 11$ Abs. 1 Satz 1 LUG, $\S 15$ Abs. 1 Satz 1 KUG) hat der Urheber die ausischließliche Befugnis, "das Werk gewerbsmäßig zu verbreiten". Unter "Verbreiten" ist dabei nach der Entstehungsgeschichte der genannten Vorschriften unid nach herrschender Meinung nur die Verbreitung des Werkes in körperlicher Form, d.h. die Verbreitung des Originals oder der Vervielfältigungsstücke des Werkes zu verstehen. Die seinerzeit vom Reichsgericht vertretene Auffassung, daß auch idie Rundfunksendung Verbreitung im Sinne des Gesetzes sei, wird heute allgemein abgelehnt. In Utbereinstimmung hiermit definiert der Entwurf das Verbreitungsrecht in Absatz 1 als das Recht, das Original oder Vervielfältigungsstücke des Werkes der 
Offentlichkeit anzubieten oder in Verkehr uu bringen. Für die Rundfunksendung des Werkes ist ein besonderes Verwertungsrecht vorgesehen, vgl. $\S 20$ (Senderecht).

Abweichend vom geltenden Recht soll das Verbreitungsrecht jedoch nicht auf die gewerbsmäßige Verbreitung beschränkt sein; zu einer solchen Beschränkung besteht hier ebensowenig Anlaß wie bei den sonstigen Verwertungsrechten. Desgleichen übernimmt der Entwurf nicht die in $\S 1: 1$ Abs. 1 Satz 1 LUG und $\S 15$ Abs. 1 Satz 1 KUG vorgesehene Einschränkung, daß sich das Recht 'des Urhebers "nicht auf das Verleihen" erstreckt. Das Verbreitungsrecht soll vielmehr jede Art des Inverkehrbringens von Werkstücken umfassen, auch das Inverkehrbringen durch Leihe oder Miete. Danach bedarf z. B. der sog. Verleih von Notenmaterial oder von Filmkopien ebenso der Einwilligung des Urhebers wie der Verkauf von Büchern.

Sinn des Verbreitungsrechts ist es jedoch nicht, dem Urhelber eine bleibende ausschließliche Befugnis zum Hanidel mit rechtsmäßig in Verkehr gebrachten Vervielifältigungsstücken seines Werkes zu gewähren. In Uibereinstsimmung mit der herrschenden Rechtsauffassung soll daher nach Absatz 2 die Weiterverbreitung von Werkstücken, die mit Zustimmung des zur Verbreitung im Geltungsbereich dieses Gesetzes Berechtigten im Wege der Veräußerung in Verkehr gebracht worden sind; ohne Erlaubnis des Urhebers zulässig sein. Das Verbreitungsrecht erlischt nach dieser Regelung nur, wenn die Werkstücke durch Veräußerung rechtmäßig in Verkehr gebracht worden sind; an einem lediglich verliehenen oder vermieteten Werkexemplar bleibt das Verbreitungsrecht voll bestehen. Dies erscheint gerechtfertigt, weil hier der Urheber zu erkennen gegeben hat, daß er die Kontrolle über den Verbleib der Werkstücke behalten will.

In zwei Fällen sieht der Entwurf eine Berechtigung des Urhebers an Werkstïcken auch noch nach Erlöschen des Verbreitungsrechts vor : in $\S 26$ (Folgerecht) einen Beteiligungsanspruch des Urhebens an dem aus der Weiterveräußerung des Originals eines Werkes der bildenden Künste erzielten Erlös und in $\S 27$ (Vermietung von Vervielfältigungsstücken) einen Vergütungsanspruch des Urhebers für eine Vermietung von Vervielfältigungsstücken, die Erwerbszwedken dient.

\section{Zu $§ 18$ - Ausstellungsrecht}

$\S 18$ bestimmt den Begriff des Ausstellungsrechts, das sich sowohl auf Originale als auch auf Vervielfältigungsstücke von unveröffentlichten Werken der bildenden Künste und Lichtbildwerken bezieht.

Es ist vorgeschlagen worden, dem Urheber auch das Recht zur Ausstellung seines bereits veröffentlichten Wierkes vorzubehalten. Der Entwurf folgt dieser Anregung nicht. Wenn stets die Zustimmung des Urhebers zur Ausstellung auch veröffentlichter Werke in Schaufenstern oder Ausstellungsräumen eingeholt werden müßte, würde der Kunsthandel erheblich behindert werden, was auch nicht im Interesse der Urheber liegen wünde. Außerdem dürften mit der Ausstellung von Werken ider bildenden
Künste oder Lichtbildwerken kaum nennenswerte Einnahmen zu erzielen sein, so daß den Urhebern ein wesentlicher wirtschaftlicher Vorteil aus der Erweiterung des Ausstellungsrecht nicht enwachsen würde.

\section{Zu $\S 19$ - Vortrags-, Aufführungs- und Vorfüh- rungsrecht}

Wie schon zu $\S 15$ hervorgehoben, beschränkt der Entwurf - abweichend von der bisher gebräuchlichen deutschen Rechtssprache, jedoch übereinstimmend mit dem allgemeinen Sprachgebrauch und der internationalen Terminologie der Brüsseler Fassung der Berner Ubereinkunft - den Begriff ides Vortrags-, Aufführungs- und Vorführungsrechts auf die unmittelbare Werkwiedergabe, während für die mittelbaren Wiedergalben, d. h. die Wiedergabe eines Vortrags oder einer Auffüihrung mittels Bildoder Tonträger und die Wiedergabe von Funksendungen, besondere, sog. Zweitverwertungsrechte vorgesehen sind (vgl. §§ 21 und 22).

Absatz 1 umschreibt dementsprechend das Vortragsrecht als das Recht, ein Sprachwerk durch persönliche Darbietung öffentlich zu Gehör zu bringen. Die Beschränkung des Vortragsrechts auf die akustische Wiedergabe von Sprachwerken und die $\mathrm{Zu}$ ordnung der akustischen Wiedergabe von Werken der Musik zum Aufführungsrecht (vgl. Absatz 2) entspricht der Terminologie des geltenden Rechts (\$11 Abs. 3 LUG). Der Entwurf hält jedoch an der in $\S 11 \mathrm{Abs}$. 3 LUG vorgesehenen sachlichen Einschränkung des Vortragsrechts, nach der dieses Recht nur besteht, solange das Werk nicht erschienen ist, nicht fest. $\mathrm{Zu}$ einer solchen Benachteiligung der Schriftsteller gegenüber den Komponisten denen das Aufführungsrecht an ihren Werken bereits nach geltendem Recht ( $\$ 11$ Abs. 2 LUG) ohne Rücksicht auf das Erscheinen ihrer Werke zusteht, besteht kein ausreichender Grund. Auch die Brüsseler Fassung der Berner Ubereinkunft (Artikel 11 ${ }^{\text {ter) }}$ gewährt den Urhebern von Werken der Literatur ohne Einschränkung das ausschließliche Recht, den öffentlichen Vortrag ihrer Werke zu erlauben.

Im Hinblick darauf, daß der Entwurf den Umfang des Vortragsrechts an Sprachwerken und des Aufführungsrechts an Werken der Musik nicht mehr verschieden bemißt, ist der Vorschlag gemacht worden, künftig auch die rein lakustische Wiedengabe von Werken der Musik als Vortrag zu definieren und den Begriff der Aufführung auf die bühnenmäßige Wiedergabe von Sprachwerken und Werken der Musik zu beschränken. Es ist zuzugeben, daß eine solche neue Begriffsbildung die Systematik des Gesetzes vereinfachen wünde und teilweise auch dem allgemeinen Sprachgebrauch näherkäme (man spricht vom "Vortrag" eines Musikkstückes idurch den Pianisten oder Sänger, allerdings aber wiederum von der "Aufführung" einer Sinfonie). Dias seit 1901 geltende LUG hat jedoch mit seiner Begriffsbestimmung des Auffühnungsrechts die Rechtsspnache so nachhaltig geprägt, idaß ein Abgehen von dieser Terminologie Verwirrung auslösen könnte.

Der Entwurf hält daher in Absatz 2 an der herkömmlichen Definition des Aufführungsrechts fest und bezeichnet als Auffühnung sowohl die akusti- 
sche Wiedergabe von Werken der Musik als auch die bühnenmäßige Darstellung von Werken aller Art wie dramatischen, dramatisch-musikalischen oder pantomimischen Werken. Entsprechend dem Vortragsrecht ist auch idas Aufführungsrecht allgemein auf die unmittelbare Werkwiedergabe durch persönliche Darbietung beschränkt. Wird also z. B. eine Oper durch Fernsehfunk gesendet, so unterliegt die öffentliche Wiedergabe dieser Sendung durch ein Fernsehgerät nicht dem Aufführungsrecht des Urhebers, sondern seinem Recht der Wiedergabe von Funksendungen nach $\S 22$.

Absatz 3 bringt zum Ausdruck, daß das Vortragsund Aufführungsrecht auch idas Recht zur Bildschirm- oder Lautsprecherübertragung ides Vortnags oder der Aufführung in einzelne Räume außerhalb der Veranstaltung erfaßt. Ebenso wie der Vortrag oder die Aufführung selbst soll auch eine solche Ubertragung, sofern sie öffentlich geschieht, nur mit Erlaubnis des Urhebers zulässig sein; es soll also beispielsweise die in einem Konzertsaal aufgeführte Musik nicht ohne Zustimmung des Urhebens in andere, mit dem Konzertsaal nicht in Verbindung stehende Räume, auf Straßen oder auf Plätze übertragen werden dürfen. Obwohl es sich hier, ähnlich wie bei der Wiedergabe einer Funksendung, an sich auch um eine Art Zweitverwertung der Leistung des Urhebers handelt, sieht der Entwurf davon $a b$, dem Urheber insoweit neben dem Vortrags- und Aufführungsrecht ein besonderes Verwertungsrecht zu geben. Das Recht der Bildschirm- und Lautsprecherübertragung ist kaum selbständig verwertbar, es ergänzt lediglich das Vortrags- und Aufführungsrecht in der Weise, daß der Urheber, wenn er die Erlaubnis zu einem öffentlichen Vortrag oder einer öffentlichen Aufführung seines Werkes erteilt, hierbei zugleich bestimmen kann, ob und inwieweit der Vortrag oder die Aufführung auch außerhalb der Veranstaltung durch Bildschirm oder Lautsprecher öffentlich übertragen werden darf, und daß er unerlaubte Ubertragungen nicht nur als Vertragsverletzungen seinem Vertragspartner, sondern als Verletzungen seines Urheberrechts jedem Dritten verbieten kann. Zur Frage, in welchem Umfang die vertragliche Einräumung eines Nutzungsrechts zur öffentlichen Wiedergabe eines Werkes die Erlaubnis zur Bildschirm- oder Lautsprecherübertragung der Wiedergabe einschließt, ist in $\S 37$ Abs. 3 eine Auslegungsregel vorgesehen.

Die Begriffsbestimmung des Vorführungsrechts in Absatz 4 Satz 1 entspricht im wesentlichen dem geltenden Recht. Nach $\S 15$ Abs. 1 Satz 1 KUG hat der Urheber eines Werkes der bildenden Künste oder eines Lichtbildwerkes das ausschließliche Recht, das Werk "gewerbsmäßig mittels mechanischer oder optischer Einrichtungen vorzuführen". Der Entwurf ersetzt die Worte "mechanische oder optische Einrichtungen" durch "technische Einrichtungen", da neue technische Vorführungsmittel erfunden wonden sind (Ampexverfahren), die nicht als mechanische oder optische Einrichtungen angesehen werden könnten. Ferner behält der Entwurf dem Urheber nicht mehr die "gewerbsmäßige", sondern die "öffentliche" Vorführung mittels technischer Einrichtungen vor. Dadurch soll ein sachlich nicht gerechtfertigter
Unterschied zwischen dem Vortragss- und Aufführungsrecht bei Werken der Literatur und Musik und dem Vorführungsrecht bei Werken der bildenden Künste beseitigt werden. Bei Filmwerken ıgewährt bereits das geltende Recht ( $\$ 15$ a Satz 2 KUG) dem Urheber die ausschließliche Befugnis, das Werk öffentlich vorzuführen.

Der Entwurf hält an der Terminologie fest, auch bei Filmwerken - gleichgültig, ob es sich um Stummfilme oder Tonfilme handelt - von "Vorführung" zu sprechen, weil der Schwerpunkt hier stets in der Wiedergabe der Bildfolge liegt. Auch an Tonfilmen besteht somit lediglich ein Vorführungsrecht, nicht auch ein Vortrags- oder Aufführungsrecht; die zur Herstellung ides Filmwerkes benutzten litenarischen Vorlagen und die Filmmusik bleiben hier entsprechend der im Entwurf vertretenen Auffassung, daß Filmwerke einheitliche Werke eigener Art sind, unberücksichtigt. Der Entwurf bezeichnet als „Vorführung" ferner die Wiedergabe von Danstellungen wissenschaftlicher oder technischer Art, die wegen ihrer Verwandtschaft mit den Wierken ider bildenden Künste und den Lichtbildwerken nicht anders als diese behandelt werden können.

Das Vorführungsrecht gehört nach dem System des Entwurfs wie das Vortrags- und Aufführungsrecht zu den Rechten der unmittelbaren Werkwiedergabe. Die Unmittelbarkeit der Werk'wiedergabe ist jedoch bei ihm nicht durch die persönliche Darbietung ides Werkes gekennzeichnet - Werke der bildenden Künste oder Lichtbildwerke können nicht persönlich dargeboten werden wie Wenke der Literatur und Musik -, sondern durch die unmittelbare Verwendung der Vervielfältigungsstücke des Werkes zur Wiedergabe. Dem Vorführungsrecht unterfällt idaher auch die 'Wiedergabe eines Filmwerkes, obwohl sie stets mittels Bildträger vorgenommen wird; insoweit gibt es beim Vorführungsrecht keine Zweitwiedergabe. In $\S 21$ ist dies durch die Beschränkung des Rechtes der Wiedergabe durch Bild- oder Tonträger auf Vorträge und Aufführungen des Werkes zum Ausdruck gebracht. Die Wiedergabe von Funksendungen des Filmwerkes ( $\S 22$ ) läBt sich dagegen als Form der Zweitverwertung von der Vorfüihrung des Filmwerkes unterscheiden. Absatz 4 Satz 2 bestimmt daher, daß das Vorführungsrecht diese Verwertungsart nicht umfaßt.

\section{Zu $§ 20$ - Senderecht}

Die geltenden Urheberrechtsgresetze enthalten noch keine Bestimmungen über die Funksendung des Werkes, doch ist bereits durch die Rechtsprechung dem Urheber das ausschließliche Recht auch zu idieser neuen Art der Wiedergabe seiner Wienke zugesprochen worden. Auch idie Brüsseler Fassung der Berner Ubereinkunft (Artikel 11bis Abss. 1) gewährt den Urhebern von Werken der Literatur und ider Kunst das Senderecht, das dort umschrieben wird als "das ausschließliche Recht, zu erlauben:

1. die Rundfunksendung ihner Werke oder die öffentliche Mitteilung der Werke durch irgend ein anderes Mittel, idas zur drahtlosen Verbreitung von Zeichen, Tönen oder Bildern dient; 
2. jede öffentliche Mitteilung des durch Rundfunk gesendeten Werkes mit oder ohne Draht, wenn diese Mitteilung von einem anderen als dem ursprünglichen Sendeunternehmen vorgenommen wird."

Der Entwurf faßt den Begriff des Senderechts wesentlich straffer zusammen und bestimmt es als das Recht, das Werk durch Funk wie Ton- und Fernsehrundfunk, Drahtfunk oder ähnliche technische Einrichtungen der Offentlichkeit zugänglich zu machen. Unter "Funk" ist dabei jede Ubertragung von Zeichen, Tönen oder Bildern durch elektromagnetische Wellen zu verstehen, die von einer Sendestelle ausgesiandt werden und an anderen Orten von einer belielbigen Zahl von Empfangsanlagen aufgefangen und wieder in Zeichen, Töne oder Bilder zurückverwandelt werden können. Abweichend von Artikel $11^{\text {bis }}$ Abs. 1 der Brüsseler Fassung der Berner Uibereinkunft stellt der Entwurf den so.g. Drahtfunk allgemein der drahtlosen Rundfunksendung gleich, gleichgültig, ob es sich um Erstsendungen oder um Weitersendungen eines bereits gesendeten Werkes handelt, die nach dem Entwurf beide unterschiedslos dem Senderecht unterliegen. Unter "Drahtfunk" ist der Vorgang zu verstehen, daß das Werk von reiner Sendestelle aus einer Mehrzahl von Empfangsanlagen über Drahtleitungen, wie z. B. das Telefonnetz, zugeleitet wird. Das Werk wind hier der Allgemeinheit in ähnlicher Weise zugänglich gemacht wie beim Rundfunk.

Es sind Bedenken dagegen erholben wonden, dem Urheber ein ausschließliches Recht zur Sendung seines Werkes durch Drahtfunk auch für den Fall zu gewähren, daß der Drahtfunk lediglich das Programm des örtlichen Rundfunksenders übernimmt und nur Personen zugänglich macht, die zugleich Rundfunkteilnehmer sind, also lediglich ıder technischen Verbesserung ' des Rundfunkempfangs dient und keinen neuen Hörerkreis eröffnet. Der Anregung, für diesen Fall das Senderecht des Urhebers einzuschränken, folgt der Entwurf nicht. Eine solche Einschränkung des Senderechts wäre mit Artikel $11^{\text {bis }}$ Absatz 1 Nr. 2 der Brüsseler Fassung der Berner Uibereinkunft nicht vereinbar. Zwar bindet die Berner Ubereinkunft iden deutschen Gesetzgeiber nur hinsichtlich der verbandsangehörigen ausländischen Urheber. Es erscheint jedoch nicht gerechtfertigt, die deutschen Urheber hier schlechter zu stellen, deren Rechtsschutz auch in allen anderen Fällen den Bestimmungen der Berner Uibereinkunft angeglichen ist.

Als Sonderform des Rechts der öffentlichen Wiedergabe ist auch das Senderecht auf die Befugnis beschränkt, das Werk durch Funk der Offentlichkeit zugänglich zu machen. Ist die Sendung eines Werkes nur zum Empfang einer einzelnen Penson oder eines im Sinne von $\S 15$ Abs. 3 begrenzten Personenkreises bestimmt, unterliegt sie somit nicht dem Senderecht.

\section{Zu $\S 21$ - Recht der Wiedergabe durch Bild- oder Tonträger}

Die geltenden Urheberrechtsgesetze gewähren dem Urheber kein besonderes Recht der Wiedergabe seines Werkes mittels Bild- oder Tonträger. Nach herrschender Rechtsauffassung wird jedoch die Bild- oder Tonträgerwiedergabe vom Vortrags- und Aufführungsrecht mitumfaßt, d. h. die Wiedergabe eines Sprachwerkes, eines Bühnenwerkes oder eines Werkes der Musik mittels Film oder Schallplatte wird als ein besonderer Vortrag bzw. eine besondere Aufführung angesehen. Der Entwurf hält, wie schon zu $\S 15$ näher ausgeführt, an dieser dem allgemeinen Sprachgebrauch und der internationalen urheberrechtlichen Terminologie widersprechenden Erstreckung des Vortrags- und Aufführungsrechts auf wesensverschiedene Tatbestände nicht fest, sondern verselbständigt das Recht der Wiedergabe des Werkes mittels Bild- oder Tonträger, dessen Umfang in $\S 21$ umschrieben wird.

Nach geltendem Recht ( $\$ 22$ a LUG) war die öffentliche Aufführung mit Hilfe von rechtmäßig hergestellten Tonträgern frei zulässig. Dadurch sollte im Interesse der Schallplattenindustrie der Absatz von Schallplatten gefördert werden. Diese Regelung hat mit der technischen Verfeinerung der Tonträger und der Wiedergabegeräte in steigendem Maße zu einer unbilligen Benachteiligung der Urheber geführt. Heute kann die mechanische Musik die lebende Musik bereits in vielen Fällen vollkommen ersetzen und wird häufig von den Musikveranstaltern sogar bevorzugt. Mit Rücksicht auf diese Entwicklung hat der Bundesgerichtshof in einer Entscheidung vom 6. November 1953 (BGHZ 11, S. 135, vgl. Anlage 2 [VI]) die Anwendung des $\S 22$ a LUG schon für das geltende Recht zum größten Teil verneint und das ausschließliche Recht des Urhebers zur öffentlichen Aufführung seines Werkes auch mittels Tonträger insoweit anerkannt, als die Aufführung durch einen Plattenspieler mit Lautsprecher (elektro-akustische Wiedergabe) stattfindet. Nach Artikel 13 Abs. 1 Nr. 2 der Brüsseler Fassung der Berner Ubereinkunft genießen die Urheber von Werken der Musik ohne jede Einschränkung das ausschließliche Recht, die öffentliche Aufführung ihrer Werke mittels Vorrichtungen zur mechanischen Wiedergabe zu erlauben. Der Entwurf gibt daher die Regelung des $\$ 22$ a LUG auf und gewährt in Satz 1 dem Urheber allgemein das ausschließliche Recht, Vorträge oder Aufführungen seines Werkes mittels Bild- oder Tonträger öffentlich wahrnehmbar zu machen.

Satz 2 erklärt die Bestimmung in $\S 19$ Abs. 3 für entsprechend anwendbar, d. h. das Recht der Bildund Tonträgerwiedergabe soll ebenso wie das Vortrags- und Aufführungsrecht die Befugnis umfassen, die Wiedergabe außerhalb der Veranstaltung, bei der sie stattfindet, durch Bildschirm, Lautsprecher oder ähnliche technische Einrichtungen öffentlich wahrnehmbar zu machen.

\section{Zu $\S 22$ - Recht der Wiedergabe von Funksen- dungen}

Nach geltendem Recht war die Frage, ob dem Urheber auch die ausschließliche Befugnis zur öffentlichen Wahrnehmbarmachung von Funksendungen seines Werkes vorbehalten sein soll, umstritten. Das Reichsgericht (RGZ 136 S. 377) hatte entschieden, die Zustimmung des Urhebers sei nicht erfor- 
derlich, wenn die Sendung seines Werkes durch Lautsprecher öffentlich wiedergegeben werde. Diese Entscheidung entspricht jedoch nicht mehr der heute herrschenden Rechtsauffassung (vgl. Entscheidung des Bundesgerichtshofs vom 31. Mai 1960, BGHZ 33 S. 38, Anlage 10 [II 1]). Auch nach Artikel 11 bis Abs. 1 Nr. 3 der Brüsseler Fassung der Berner Ubereinkunft hat der Urheber das ausschließliche Recht, die öffentliche Mitteilung des durch Rundfunk gesendeten Werkes durch Lautsprecher oder irgendeine andere ähnliche Vorrichtung zur Ubertragung von Zeichen, Tönen oder Bildern zu erlauben.

Der Entwurf gewährt daher in Satz 1 dem Urheber ein entsprechendes Recht, das als Zweitverwertungsrecht ebenso wie das Recht der Bild- und Tonträgerwiedergabe vom Vortrags-, Aufführungs- und Vorführungsrecht zu unterscheiden ist. Satz 2 entspricht der Regelung in $\S 21$ Satz 2.

\section{Zu $\S 23$ - Bearbeitungen und Umgestaltungen}

Bereits aus der Regelung in $\S 3$, nach der Bearbeitungen eines Werkes urheberrechtlichen Schutz nur "unbeschadet des Urheberrechts am bearbeiteten Werk" genießen können, ergibt sich, daß Bearbeitungen nicht frei verwertet werden dürfen, sondern hierzu die Einwilligung des Originalurhebers erforderlich ist. Absatz 1 hebt dies in Ubereinstimmung mit dem geltenden Recht (§ 12 LUG, $\S 15$ Abs. 2 KUG) nochmals ausdrücklich hervor, wobei allerdings auf eine Aufzählung der einzelnen Bearbeitungsarten wie Ubersetzung, Dramatisierung usw., wie sie in $\S 12$ Abs. 2 LUG vorgesehen ist, verzichtet wird.

Bearbeitungen im eigentlichen Sinne verfolgen stets den Zweck, das Originalwerk bestimmten Verhältnissen anzupassen, es z. B. in eine andere Sprache oder in eine andere Kunstform zu übertragen oder es für andere Ausdrucksmittel einzurichten. Der Bearbeiter will hierbei die Identität des Originalwerkes unberührt lassen; er will nur dessen Verwertungsmöglichkeiten erweitern. Es gibt jedoch Umarbeitungen eines Werkes, die keine Bearbeitung im eigentlichen Sinne darstellen. Dies ist der Fall, wenn der Verfasser der Umarbeitung nicht das Originalwerk zur Geltung bringen, sondern das Ergebnis seiner Arbeit als eigenes Werk ausgeben will (Plagiat) oder bei dem Versuch, das fremde Werk zu einer neuen selbständigen Schöpfung frei zu benutzen, scheitert, weil er sich von seinem Vorbild nicht genügend frei machen kann. Es besteht keine Veranlassung, solche Umgestaltungen anders zu behandeln als die echten Bearbeitungen. Der Entwurf stellt sie daher den Bearbeitungen gleich, d. h. auch ihre Veröffentlichung und Verwertung soll nur mit Einwilligung des Urhebers des umgestalteten Werkes zulässig sein.

Nach der Regelung in Absatz 1 bedürfen nur die Veröffentlichung und die Verwertung des bearbeiteten oder umgestalteten Werkes der Einwilligung des Originalurhebers, nicht dagegen die Herstellung der Bearbeitung oder Umgestaltung selbst. Es ist vorgeschlagen worden, auch diese bereits grundsätzlich an die Einwilligung des Originalurhebers $\mathrm{zu}$ binden und nur diejenigen Bearbeitungen frei zuzulassen, die zum persönlichen Gebrauch oder in der Absicht hergestellt werden, die zur Verwertung der Bearbeitung erforderliche Einwilligung einzuholen. Die Zulässigkeit der Bearbeitung von derartigen subjektiven Voraussetzungen abhängig zu machen, die vielfach schwer festzustellen sind, erscheint jedoch nicht bedenkenfrei. Im übrigen würde sich die vorgeschlagene Regelung praktisch nur wenig von der des Entwurfs unterscheiden, weil sie gleichfalls darauf abzielt, nur die Verwertung von Bearbeitungen ohne Einwilligung des Urhebers zu unterbinden. Es erscheint daher richtiger, nur auf die Verwertung abzustellen. Die Brüsseler Fassung der Berner Utbereinkunft sieht zwar in den Artikeln 8 und 12 vor, daß der Urheber das ausschließliche Recht genießt, Ubersetzungen und sonstige Bearbeitungen seines Werkes zu erlauben. Nach verbreiteter Auffassung sind aber auch diese Bestimmungen dahin auszulegen, daß damit lediglich die Verwertung der Ubersetzung oder sonstigen Bearbeitung erfaßt werden soll.

In einem Fall erscheint allerdings eine abweichende Regelung geboten, nämlich bei der Verfilmung eines Werkes. Diese spielt sich in der Regel anders als sonstige Bearbeitungen oder Umgestaltungen eines Werkes nicht im privaten Bereich $a b$ und wird meist bereits in der Absicht der gewerblichen Verwertung vorgenommen. Es wäre auch im Hinblick auf die hohen Herstellungskosten eines Films wirtschaftlich unvernünftig, mit seiner Herstellung zu beginnen, ohne sich zuvor die Einwilligung der Urheber der zur Herstellung benutzten Werke zu sichern. Der Entwurf bestimmt daher in Absatz 2, daß bei einer Bearbeitung oder Umgestaltung eines Werkes durch Verfilmung bereits die Herstellung der Bearbeitung oder Umgestaltung der Einwilligung des Originalurhebers bedarf.

\section{Zu § 24 - Freie Benutzung}

In Ubereinstimmung mit dem geltenden Recht ( $\$ 13$ LUG, § $16 \mathrm{KUG)}$ sieht der Entwurf vor, daß abweichend von der Regelung in $\S 23$ ein in Anlehnung an ein anderes Werk geschaffenes Werk dann ohne Zustimmung des Urhebers des benutzten Werkes veröffentlicht oder verwertet werden darf, wenn es sich von der Vorlage so weit gelöst hat, daß es als eine völlig selbständige Neuschöpfung anzusehen ist (freie Benutzung).

Dieser Grundsatz soll ohne Einschränkung auch für Werke der Musik gelten. Der Entwurf übernimmt nicht die Sonderbestimmung des geltenden Rechts, nach der bei einem Werk der Tonkunst jede Benutzung unzulässig ist, durch welche eine Melodie erkennbar dem Werk entnommen und einer neuen Arbeit zugrunde gelegt wird ( $\S 13$ Abs. 2 LUG). Dieser starre Schutz der Melodie zieht dem musikalischen Schaffen ungerechtfertigt enge Grenzen. Auf dem Gebiet der ernsten Musik werden oft wertvolle selbständige Schöpfungen unter Benutzung fremder Themen geschaffen, wie z. B. Variationen oder Fantasien, deren Verwertung nicht von der Einwilligung des Urhebers der als Anregung benutzten Melodie abhängig sein darf. Die Befürch- 
tung, der Fortfall des Melodienschutzes werde zu einer Ausbeutung von Melodien für Schlager führen, erscheint unbegründet. Bei Werken der leichten Musik steht regelmäßig die Melodie so sehr im Vordergrund, daß im Falle ihrer Entnahme aus einem fremden Werk kaum jemals von einer selbständigen Neuschöpfung gesprochen werden kann, $\S 24$ also ohnehin nicht anwendbar ist.

\section{Sonstige Rechtedes Urhebers}

Der Entwurf faßt in diesem Unterabschnitt drei Rechte des Urhebers zusammen, die weder den rein persönlichkeits-rechtlichen Befugnissen zuzurechnen sind, noch Teile des ausschließlichen Verwertungsrechts nach $\S 15$ darstellen.

\section{Zu § 25 - Zugang zu Werkstücken}

In den geltenden Urheberrechtsgesetzen ist keine Bestimmung vorgesehen, die dem Urheber ermöglicht, sich Zugang zu einem Werkstück zu verschaffen, das sich im Besitz eines anderen befindet, wenn er selbst weder das Original noch ein Vervielfältigungsstück seines Werkes mehr besitzt und aus diesem Grunde an der Verwertung seines Werkes tatsächlich gehindert ist. Der Bundesgerichtshof hat jedoch ein entsprechendes Recht des Urhebers aus dem Persönlichkeitsrecht abgeleitet (Entscheidung vom 26. Oktober 1951 - I ZR 93/51 一, Anlage 1).

Der Entwurf sieht nunmehr eine gesetzliche Regelung des Rechts des Urhebers auf Zugang zu Werkstücken vor, durch die die Interessen des Urhebers und die des Besitzers des Werkstücks angemessen gegeneinander abgegrenzt werden sollen. Danach ist der Besitzer des Originals oder Vervielfältigungsstückes nur verpflichtet, dem Urheber Zugang zu diesem zu gewähren, soweit dies zur Herstellung von Vervielfältigungsstücken oder Bearbeitungen des Werkes erforderlich ist und nicht eigene berechtigte Interessen des Besitzers entgegenstehen (Absatz 1). Der Besitzer kann somit beispielsweise den Zugang verweigern, wenn die Vervielfältigung oder Bearbeitung des Werkes seine berechtigten Interessen verletzen würde, etwa weil es sich um eine nur für ihn persönlich angefertigten Arbeit handelt (Familienbildnis oder dgl.). Ebenso kann der Besitzer verlangen, daß der Urheber bei der Ausübung des Zugangsrechts die erforderliche Rücksicht walten läßt. Absatz 2 stellt klar, daß der Besitzer das Werkstück an den Urheber nicht herauszugeben braucht.

$\S 25$ verpflichtet den Besitzer eines Originals nicht, es aus Rücksicht auf den Urheber aufzubewahren oder vor Beschädigung oder Vernichtung zu schützen. Der Urheber eines Gemäldes z. B. braucht zwar nach $\S 14$ nicht zu dulden, daß dessen Besitzer es durch Ubermalung entstellt; er kann aber nicht verlangen, daß dieser dem Gemälde eine besonders pflegliche Behandlung zuteil werden läßt. Hierzu könnte der Besitzer nur im öffentlichen Interesse - etwa nach den Grundsätzen des Denkmalschutzes - angehalten werden.

\section{Zu § 26 - Folgerecht}

Im geltenden Recht ist eine Beteiligung der bildenden Künstler an den aus der Weiterveräußerung ihrer Originalwerke erzielten Verkaufserlösen, wie sie der Entwurf vorschlägt, nicht enthalten. Sinn dieser neuen urheberrechtlichen Befugnis ist es, eine sich aus dem bisherigen Urheberrechtssystem ergebende Benachteiligung der bildenden Künstler auszugleichen. Während Schriftstellern und Komponisten eine steigende Wertschätzung ihrer Werke regelmäBig in Gestalt höherer Verlagshonorare und Aufführungstantiemen zugute kommt, hat der bildende Künstler bisher kaum eine Möglichkeit, an Wertsteigerungen seines Werkes teilzunehmen. Der Wert eines Werkes der bildenden Künste liegt in erster Linie im Original, an dem dem Urheber, wenn er es veräußert hat, nach geltendem Recht keine urheberrechtlichen Befugnisse mehr zustehen.

Der Wunsch, idiese ungerecht erscheinende Lücke zu schließen durch einen gesetzlichen Anspruch des bildenden Künstlers gegen den Werkeigentümer auf Beteiligung an dem Gewinn, den dieser im Falle der Wertsteigerung des Werkes bei einer Weiterveräußerung erzielt, ist ein altes Anliegen der Urhelber. In einigen ausländischen Staaten, insbesondere in Frankreich, Belgien und Italien, ist er bereits durch gesetzliche Einführung des sog. Folgerechts (droit de suite) verwirklicht worden. Auch die Brüsseler Fassung der Berner Ubereinkunft enthält in Artikel 14 bis eine Bestimmung über das Folgerecht, zu deren Ubernahme die Verbandsländer allerdings nicht verpflichtet sind.

In Deutschland ist die Einführung ides Folgerechts seit Beginn der Arbeiten an der Urheberrechtsreform umstritten. Der Entwurf ides Reichsjustizministeriums von 1932 enthielt erstmals eine Bestimmung über das Folgerecht ( $\$ 18$, Urheberanteil); die späteren Entwiürfe vor 1945 ließen diese Bestimmung jedoch wegen der vielfach gegen sie geäußerten Bedenken wieder fallen. Auch ider Referentenentwurf von 1954 verzichtete auf eine Regelung des Folgerechts im Hinblick auf die mit seiner Durchführung verbundenen praktischen Schwierigkeiten, die sich insbesondere daraus ergeben können, daß der Urheber von der Weiterveräußerung seines Werkes nur schwer Kenntnis erlangen kann und ihm im Falle eines mehrfachen Besitzwechsels die Höhe des bei der Weiterveräußerung erzielten Gewinns unbekannt ist. Erst der Ministerialentwurf von 1959 schlug in $\S 41$ wieder die Einführung des Folgerechts vor und versuchte, dem neuen Recht eine in der Praxis durchsetzbare Ausgestaltung zu geben: Dem Urheber sollte ein Beteiligungsanspruch nur bei Weiterveräußerungen seines Werkes im Wege öffentlicher Versteigerungen zustehen; ferner sollte der Beteiligungsanspruch grundsätzlich als fester Anteil von 3 vom Hunidert des Verkaufspreises gewährt werden ohne Rücksicht auf den vom Veräußerer beim Verkauf gegenüber dem von ihm gezahlten Erwerbspreis erzielten Mehrerlös, mit der Maßgabe, daß der Veräußerer lediglich einredeweise die Zahlung des Urheberanteils sollte verweigern 
oder mindern können, wenn er nachweist, daß er keinen oder nur einen geringfügigen Mehrerlös erzielt hat.

Die Erörterung der im Ministerialentwurf vorgeschlagenen Regelung hat gezeigt, daß der Grundgedanke des Folgerechts, den bildenden Künstler an der durch Weiterveräußerung realisierten Wertsteigerung seiner Originalwerke $\mathrm{zu}$ beteiligen, heute weitgehend als berechtigt anerkannt und dementsprechend üiberwiegend die Einführung des Folgerechts im neuen Urheberrechtsgesetz befürwortet wird. Allerdings haben sich gegenüber der im Ministerialentwurf vorgeschlagenen Ausgestaltung des Folgerechts wesentliche neue Gesichtspunkte ergeben.

Die Beschränkung des Folgerechts auf Verkäufe in öffentlichen Versteigerungen beruhte auf ider Erwägung, idaß idas Folgerecht nur in dieser engen Begrenzung von den Urhebern oder einer von ihnen zu gründenden Verwertungs.gresellschaft ohne fremde Hilfe, insbesondere ohne Mitwinkung und notfalls auch gegen den Widerstand Ider Kunsthändler durchsetzbar sein wünde. Inzwischen haben jedoch die Vertreter des Kunsthandels sich aus Verständnis für die Wünsche der Urheber bereit erklärt, diese bei der Durchsetzung des Folgerechts zu unterstützen. Sie haben selbst vorgeschlagen, das neue Recht auf alle Veräußerungen im geschäftlichen Verkehr zu erstrecken, um eine für das Gefüge des Kunsthandels möglicherweise nachteilige einseitige Belastung der öffentlichen Versteigerungen zu vermeiden. Ist die Mitwirkung des Kunsthandels bei der Einziehung der Urheberbeteiligung gewährleistet, so bestehen gegen eine solche Erweiterung des Folgerechts keine Bedenken; sie ist vielmehr als eine wesentliche Verbesserung, die dem neuen Recht eine größere Breitenwirkung verschafft, nur zu begrüßen. Der Kunsthandel hat jedoch darauf hingewiesen, daß er eine Einziehungshilfe nur dann leisten könne, wenn der Urheberanteil als reine Beteiligung am Verkaufserlös gestaltet, d.h. dem Veräußerer kein Minderungsrecht für den Fall eingeräumt iwind, daß er keinen Mehrerlös erzielt hat. Nur auf diese Weise sei es möglich, den Urheberanteil automatisch vom Verkaufserlös zugunsten der Urheber einzubehalten. Die Einführung einer Mehrerlösklausel - gleich welcher Art - kompliziere das Venfahren und habe zur Folge, daß der Kunsthändler im Falle einer Berufung des Veräußerers auf die Mehrerlösklausel dem Urheber dessen Namen nennen müsse, um ldem Urheber die - notfalls gerichtliche - Nachprüfung der Anwendbarkeit der Mehrerlösklausel zu ermöglichen; die Preisgabe des Namens des Auftraggebers sei aber mit den Grundsätzen des Kunsthandels, besonders des Versteigerergewerbes, unvereinbar und wünde zu einem erheblichen Umsatzrückgang führen, da gerade die Veräußerer von Kunstgegenständen vielfach größten Wert auf Anonymität legten.

Der Entwurf trägt diesen praktischen Gesichtspunkten Rechnung und sieht in Absatz 1 nunmehr vor, daß der Urheberanteil bei jeder Weiterveräußerung des Originals eines Werkes der bildenden Künste im geschäftlichen Verkehr, also bei allen nicht rein privaten Verkäufen, zu entrichten ist, und zwar ohne Rücksicht ldarauf, ob ein Mehrerlös erzielt worden ist oder nicht. Um zu verhindern, daß diese wesentliche Erweiterung des Folgerechts zu einer unbillig hohen Belastung des Kunsthandels und der Veräußerer von Kunstwerken führt, ist ferner vorgesehen, daß der Urheberanteil nicht 3, sondern nur 1 vom Hundert des Veräußerungserlöses betragen soll. Bleibt der Veräußerungserlös unter 500 DM, soll der Urheberanteil ganz entfallen.

Nach ider Regelung des Entwurfs ist der Urheberanteil auch dann zu zahlen, wenn der Veräußerer keinen Mehrerlös erzielt hat und das Werk des Urhebers vielleicht sogar in seinem Wert gesunken ist. Diese Rechtsfolge widerspricht an sich dem Grundgedanken des Folgerechts als einer Beteiligung des bildenden Künstlers an der Wertsteigerung seines Originalwerkes. Es erscheint jedoch richtiger, diesen Widerspruch in Kauf $\mathrm{zu}$ nehmen, als auf idie Einführung des Folgerechts wegen der sonst zu großen Schwierigkeiten der praktischen Durchführung ganz zu verzichten. Die Fälle der Wertminderung von Kunstwerken sind im Vergleich zu iden Fällen bedeutender Wertsteigerungen selten. Auch in Frankreich und Belgien, den ersten Staaten, die das Folgerecht gesetzlich anerkannten, wird der Urheberanteil als reine Beteiligung am Verkaufserlös gewährt. Das italienische Urheberrechtsgesetz stellt ddemgegenüber auf den Mehrerlös ab, aber gerade dieses Beispiel zeigt die Problematik einer solchen Regelung: Während in Frankreich und Belgien iden Urhebern aus dem Folgerecht beträchtliche Einkiünte zufließen - 1959 beispielsweise waren es in Frankreich rund $200000 \mathrm{DM}$, in Belgien rund $20000 \mathrm{DM}$-, hat das Folgerecht in Italien bisher keine Einnahmen gebracht.

Absatz 2 sieht zum Schutz des Urhebers vor, daß im voraus weder auf iden. Anspruch aus dem Folgerecht verzichtet noch üiber ihn verfügt wenden kann und daB die Anwartschaft auf den Anspruch nicht der Zwangsvollstreckung unterliegt.

Absatz 3 nimmt die Werke der Baukunst und der angewandten Kunst vom Folgerecht aus. Die Preise dieser Werke richten sich vielfach nach anderen als künstlerischen Gesichtspunkten; Preissteigerungen beruhen bei ihnen in der Regel nicht auf einer Höherbewertung der schöpferischen Leistung des Urhebers.

\section{Zu $§ 27$ - Vermietung von Vervielfältigungsstücken}

Nach $\S 17$ Abs. 2 erlischt das Verbreitungsrecht des Urhebers an 'dem Original oder an Vervielfältigungsstücken seines Werkes, wenn sie mit $\mathrm{Zu}$ stimmung des Berechtigten im Wege der Veräußerung in Verkehr gebracht worden sind. Danach unterliegt weder die Weiterveräußerung noch die Vermietung solcher Werkexemplare dem ausschließlichen Recht des Urhebers; beides ist ohne seine Zustimmung zulässig, selbst wenn damit ein Erwerbszweck verfolgt wird. Im geltenden Recht ist 
dies für das "Verleihen" ausdrücklich ausgesprochen (§ 11 Abs. 1 Satz 1 LUG, $\S 15$ Abs. 1 Satz 1 KUG), wobei - wie sich aus der Gesetzesbegründung ergibt - in erster Linie an das Vermieten von Vervielfältigungsstücken durch die sog. Leihbüchereien gedacht war. Die Regelung sollte klarstellen, daß der Urheber nicht verlangen kann, an den Einnahmen beteiligt zu werden, die die Leihbüchereien aus dem Vermieten seines Werkes ziehen, was schon damals gefordert worden war. Man wollte nicht in eingelebte Verhältnisse eingreifen; vor allem aber sollte mit Rücksicht auf das allgemeine Interesse an einer Hebung der Volksbildung den ärmeren Bevölkerungsschichten die Benutzung der Leihbüchereien nicht durch eine Verteuerung der Ausleihgebühr erschwert werden.

Die Frage, ob für die Zukunft an dieser Regelung festgehalten oder dem Urheber ein ausschließliches Vermietungsrecht, oder zumindest ein Vergütungsanspruch für die Vermietung von Vervielfältigungsstücken seines Werkes zugebilligt werden soll, ist lebhaft umstritten. Bei den Erörterungen der vom Bundesjustizministerium veröffentlichten Vorentwürfe zum neuen Urheberrechtsgesetz, von denen der Referentenentwurf von 1954 die Beibehaltung des geltenden Rechtszustandes, der Ministerialentwurf von 1959 die Einführung eines Vergütungsanspruchs vorsah, hat sich jedoch gezeigt, daß nach überwiegender Rechtsüberzeugung heute eine angemessene Beteiligung des Urhebers an den Einnahmen der Leihbüchereien und Lesezirkel für billig gehalten wird, entsprechend dem von der höchstrichterlichen Rechtsprechung zur Auslegung der Urheberrechtsgesetze entwickelten Grundsatz, daß der Urheber tunlichst angemessen an den wirtschaftlichen Früchten zu beteiligen ist, die aus seinem Werk gezogen werden. Die bisher gegen einen solchen Vergütungsanspruch erhobenen Bedenken erscheinen nicht mehr ausreichend begründet. Zwar wird nach Einführung der Urheberbeteiligung mi einem gewissen Ansteigen der Ausleihgebühren zu rechnen sein, da die betroffenen Leihbüchereien und Lesezirkel den Betrag auf die Ausleihgebühren aufschlagen werden. Diese Verteuerung dürfte jedoch gering sein und in Kauf genommen werden können. Es ist auch zu berücksichtigen, daß die volksbildenden Aufgaben des Buch- und Zeitschriftenverleihs heute in erster Linie durch die erheblich ausgebauten öffentlichen Bibliotheken (Volksbüchereien) wahrgenommen werden. Die gewerblichen Leihbüchereien führen vorwiegend Unterhaltungsliteratur, bei der der Gedanke der Volksbildung nicht so sehr im Vordergrund steht.

Der Entwurf sieht dementsprechend in Abweichung vom geltenden Recht vor, daß dem Urheber eine angemessene Vergütung zu gewähren ist, wenn Vervielfältigungsstücke seines Werkes nach Erlöschen des Verbreitungsrechts vermietet werden und die Vermietung Erwerbszwecken des Vermieters dient (Absatz 1). Die Vorschrift bezieht sich auf alle Arten von Vervielfältigungsstücken; vergüturgspflichtig ist also nicht nur die Vermietung von Büchern und Zeitschriften, sondern auch die Vermietung von Schallplatten und Noten. Von einer Er- streckung der Vergütungspflicht auf die Vermietung von Originalen, z. B. einer Handschrift oder eines Gemäldes, sieht der Entwurf $a b$, da eine solche Vermietung kaum vorkommen dürfte.

In Absatz 2 wird klargestellt, daß für die Vermietung von solchen Vervielfältigungsstücken, die mit Zustimmung des Urhebers zum Zwecke der Vermietung hergestellt sind, keine Vergütung zu zahlen ist. Gedacht ist hierbei insbesondere an Bücher, die vom. Urheber nur für Leihbüchereien geschrieben werden und im Buchhandel sonst nicht erhältlich sind, ferner an Filmkopien, die regelmäßig ebenfalls nicht zum Verkauf, sondern nur zum Verleih an die Lichtspielhäuser hergestellt werden. Der Urheber kann in diesen Fällen bereits bei der Einräumung des Nutzungsrechts zur Vervielfältigung und Verbreitung an den Verleger oder Filmproduzenten eine Vergütung vereinbaren, die das Vermieten als den bestimmungsmäßigen Gebrauch der Vervielfältigungsstücke berücksichtigt. Ferner ist die Vergütungspflicht für das Vermieten von Werken der Baukunst und der angewandten Kunst ausgeschlossen, die in erster Linie ihres Gebrauchszweckes wegen, nicht wegen der in ihnen verkörperten schöpferischen Leistung des Urhebers vermietet werden.

Aus der Beschränkung der Vergütungspflicht auf das Vermieten zu Erwerbszwecken des Vermieters folgt, daß die öffentlichen Bibliotheken von der Vergütungspflicht nicht betroffen werden. Im Hinblick auf den nichtgewerblichen Charakter und die besonderen volksbildenden Auigaben dieser Institute ist ihre Einbeziehung in die Regelung des Entwurfs von den Autoren selbst nicht gefordert worden. Allerdings haben diese den Wunsch geäußert, daß für die Ausleihe in öffentlichen Bibliotheken eine ähnliche Regelung vorgesehen werden möge, wie sie seit mehreren Jahren in Dänemark, Norwegen und Schweden besteht. In diesen Staaten wird auf Grund besonderer gesetzlicher Vorschriften jährlich ein bestimmter Betrag aus Haushaltsmitteln einem Schriftstellerfonds zugewiesen, der zu Zahlungen an die Schriftsteller für die Ausleihe ihrer Werke in staatlich unterstützten Bibliotheken verwandt wird und teilweise auch der Wahrung allgemeiner sozialer und kultureller Belange der Schriftsteller dient. $\mathrm{Ob}$ eine solche Regelung auf deutsche Verhältnisse übertragbar ist, kann hier dahinstehen. Sie würde, wie in den skandinavischen Staaten, jedenfalls nicht im Rahmen des Urheberrechtsgesetzes, sondern nur im Wege einer Sondergesetzgebung erfolgen können.

Hinsichtlich der Frage der Berechnung und Einziehung der Vergütung sind gesetzliche Bestimmungen nicht vorgesehen. Bei der Vielzahl der Verpflichteten - es gibt im Bundesgebiet allein etwa 28000 Leihbüchereien - werden die Urheber die Wahrnehmung ihrer Rechte einer Verwertungsgesellschaft übertragen müssen. Dieser kann es überlassen bleiben, mit den Organisationen des Leihbuchhandels und der Lesezirkel die zweckmäßigsten Bedingungen für die Berechnung und Einziehung der Vergütung zu vereinbaren. 


\section{FUNFTER ABSCHNITT}

\section{Rechtsverkehr im Urheberrecht}

Nach den geltenden Urheberrechtsgesetzen ( $\begin{aligned} & \S \\ & 8\end{aligned}$ LUG, § $10 \mathrm{KUG)}$ ist das Urheberrecht übertragbar; jedoch verbleiben dem Urheber, wenn nichts anderes vereinbart ist, auch im Falle der Ubertragung des Urheberrechts bestimmte Rechte, nämlich das Recht, Anderungen am Werk, an dessen Titel und an der Bezeichnung des Urhebers zu untersagen (§ 9 LUG, § 12 KUG). Es sind dies aus dem droit moral fließende Rechte des Urhebers, die nach herrschender Auffassung zumindest in ihrem Kern nicht abgetreten werden können. Ein Restbestandteil des Urheberrechts bleibt also stets beim Urheber zurück. Wegen der engen Verbundenheit des Urheberpersönlichkeitsrechts mit den Verwertungsrechten haben sich bei der Abgrenzung der dem Urheber verbleibenden Befugnisse von den übertragbaren Bestandteilen des Urheberrechts Schwierigkeiten ergeben. Der Entwurf schlägt deshalb eine vom geltenden Recht abweichende Regelung vor: Das Urheberrecht soll grundsätzlich weder als Ganzes noch in seinen Teilen (z. B. Verwertungsrechte) übertragbar sein, der Urheber soll vielmehr einem anderen die Verwertung seines Werkes nur dadurch überlassen können, daß er ihm ein vom Urheberrecht abgeleitetes Nutzungsrecht einräumt, ähnlich wie die auf dem Gebiet des Patentrechts übliche Lizenz. Diese Konstruktion ermöglicht es, dem bereits für das geltende Recht entwickelten Gedanken, daß die vermögensrechtlichen Befugnisse auch nach ihrer Abtretung bis $\mathrm{zu}$ einem gewissen Grade im Banne des Urhebers verbleiben, zwanglos Rechnung zu tragen. Hervorzuheben sind insoweit besonders die Bestimmungen über das Erfordernis der Zustimmung des Urhebers zur Weiterübertragung von Nutzungsrechten ( $\S 34$ ) und über die Rückrufsrechte wegen Nichtausübung und wegen gewandelter Uberzeugung ( $\$ \S 41$ und 42). Aus der vorgesehenen Regelung ergibt sich ferner, ohne daß es hierzu einer ausdrücklichen gesetzlichen Bestimmung bedarf, der von der herrschenden Meinung anerkannte Grundsatz des Heimfalls des Urheberrechts, d. h. der Grundsatz, daß ein vom Urheber eingeräumtes Nutzungsrecht, wenn der Erwerber auf dieses verzichtet, automatisch an den Urheber zurückfällt und nicht etwa mit der Wirkung erlischt, daß nunmehr jedermann das Werk in der betreffenden Weise frei nutzen kann.

Der Fünfte Abschnitt gliedert sich in zwei Unterabschnitte, von denen der erste die grundsätzlich nur im Wege der Vererbung mögliche Rechtsnachfolge in das Urheberrecht als Ganzes, der zweite die Einräumung und Weiterübertragung von Nutzungsrechten regelt.

\section{Rechtsnachfolge in das Urheberrecht}

\section{Zu § 28 - Vererbung des Urheberrechts}

In Ubereinstimmung mit dem geltenden Recht ( $\$ 8$ Abs. 1 LUG, \& 10 Abs. 1 KUG) sieht Absatz 1 vor, daß das Urheberrecht vererblich ist, d. h. mit dem
Tode des Urhebers als Ganzes auf den Erben übergeht. Für den Zeitraum von fünfzig Jahren, in welchem der Urheberrechtsschutz auch nach dem Tode des Urhebers besteht (vgl. § 67), sollen die Erben oder Erbeserben des Urhebers grundsätzlich die gleiche Rechtsstellung haben wie der Urheber selbst. Sie können sowohl die Nutzungen aus dem Werk ziehen wie auch die aus dem Urheberpersönlichkeitsrecht fließenden Befugnisse ausüben.

In dem Bestreben, die als willkürlich empfundene starre Schutzfrist von fünfzig Jahren nach dem Tode des Urhebers durch eine den Bedürfnissen des Einzelfalles mehr angepaßte Regelung zu ersetzen, ist angeregt worden, die Vererbung des Urheberrechts in mehreren Erbgängen nur auf den Ehegatten und die nächsten Angehörigen des Urhebers zuzulassen, im übrigen aber auf den ersten Erbfall zu beschränken. Die Geltungsdauer des Urheberrechts soll sich dann nach der Lebenszeit dieser Angehörigen oder der Person richten, die der Urheber zum Erben bestimmt hat. Eine solche Regelung würde jedoch für die Praxis eine zu große Unsicherheit mit sich bringen; denn im Einzelfall wäre schwer festzustellen, ob noch einer der erbberechtigten Rechtsnachfolger des Urhebers lebt. Die Anregung ist daher nicht berücksichtigt.

Für den Fall, daß der Nachlaß des Urhebers an den Staat als gesetzlichen Erben fällt, erlischt nach dem geltenden Recht das Urheberrecht, soweit es dem Erblasser zusteht ( $\$ 8$ Abs. 2 LUG, $\S 10$ Abs. 2 KUG). Der Entwurf übernimmt diese Regelung nicht, weil das dieser Vorschrift zugrunde liegende Mißtrauen, der Staat sei nicht in der Lage, vom Urheberrecht in geeigneter Weise Gebrauch zu machen, nicht gerechtfertigt erscheint und durch die geltende Regelung der Nachlaßmasse ohne zwingenden Grund zum Nachteil der Nachlaßgläubiger unter Umständen erhebliche Werte entzogen werden.

Absatz 2 soll es dem Urheber ermöglichen, für den Fall, daß ihm seine Erben zur Wahrung seines geistigen Nachlasses nicht geeignet erscheinen, die Ausübung des Urheberrechts einer besser geeigneten Persönlichkeit anzuvertrauen, ohne jedoch zugleich seinen Erben die wirtschaftlichen Früchte aus der Nutzung seiner Werke zu entziehen. Hierbei ist die Anwendung des $\S 2210$ des Bürgerlichen Gesetzbuchs ausgeschlossen worden, weil sonst die Ausübung des Urheberrechts durch den Testamentsvollstrecker in gewissen Fällen auf eine Höchstdauer von dreißig Jahren begrenzt wäre.

\section{Zu § 29 - Ubertragung des Urheberrechts}

Der Urheber soll in seiner Entscheidung darüber, wer nach seinem Tode das Urheberrecht erwirbt, nicht beschränkt werden und das Urheberrecht auch einem Vermächtnisnehmer zuwenden können. Um die Erfüllung eines solchen Vermächtnisses oder einer entsprechenden Auflage zu ermöglichen, sieht der Entwurf insoweit eine Ausnahme von dem Grundsatz der Unübertragbarkeit des Urheberrechts vor, ebenso für den Fall der Erbauseinandersetzung unter Miterben. Uber den Grundsatz der Unübertragbarkeit des Urheberrechts vgl. im übrigen die Vorbemerkung zu diesem Abschnitt. 


\section{Zu $\S 30$ - Rechtsnachfolger des Urhebers}

Die Bestimmung stellt klar, daß dem Rechtsnachfolger des Urhebers die dem Urheber nach diesem Gesetz gewährten Rechte zustehen, soweit nichts anderes bestimmt ist. Diese Einschränkung ist erforderlich, weil der Entwurf Bestimmungen kennt, die nur für den Urheber selbst gelten (vgl. §§ 42, 123 und 124).

\section{Nutzungsrechte}

In diesem Unterabschnitt wird geregelt, in welcher Weise und in welchem Umfang Nutzungsrechte vom Urheber eingeräumt und vom Erwerber weiterübertragen werden können. Ein Teil der Bestimmungen gehört dem Urhebervertragsrecht an. Da der Entwurf keine umfassende Regelung des Urhebervertragsrechts vorsieht, vielmehr geplant ist, diese einem besonderen, im Anschluß an das Urheberrechtsgesetz auszuarbeitenden Urhebervertragsgesetz vorzubehalten, ist der Vorschlag gemacht worden, die vertragsrechtlichen Bestimmungen ganz zu streichen, um dem späteren Gesetz nicht vorzugreifen. Es handelt sich jedoch entweder um Vorschriften, die in den geltenden Urheberrechtsgesetzen bereits enthalten sind und nicht gut - wenn auch nur vorübergehend - ersatzlos gestrichen werden können, oder um besonders vordringliche, seit langem im Rahmen der Urheberrechtsreform geforderte Schutzbestimmungen zugunsten des Urhebers, deren Zurückstellung bis zu dem in Aussicht genommenen Urhebervertragsgesetz nicht zumutbar erscheint. Die Bestimmungen können ohne Schwierigkeit später aus dem Urheberrechtsgesetz herausgelöst und in das Urhebervertragsgesetz übernommen werden.

\section{Zu § 31 - Einräumung von Nutzungsrechten}

Wie in der Vorbemenkung zu diesem Abschnitt bereits ausgeführt, kann der Urheber die Verwertung seines Werkes einem anderen dadurch überlassen, daß er ihm Nutzungsrechte einräumt. $\S 31$ enthält die Begriffsbestimmung des Nutzungsrechts, das als einfaches oder ausschließliches Recht eingeräumt werden kann (Absätze 1 bis 3). Absatz 4 beschränkt die Möglichkeit der Einräumung von Nutzungssrechten auf die zur Zeit der Einräumung bekannten Nutzungsarten und erklärt zugleich die Uibernahme einer Verpflichtung zur Einräumung von Nutzungsrechten für unbekannte Nutzungsarten für unwirksam. Diese Bestimmung dient dem Schutz des Urhebers; ihm soll, wenn neue Nutzungsarten entwickelt werden, stets die Entscheidung darüber vorbehalten bleiben, ob und gegen welches Entgelt er mit der Nutzung seines Werkes auch auf die neu erfundene Art einverstanden ist.

Den Vorschlag, für urheberrechtliche Verträge die Schriftform vorzusehen, übernimmt der Entwurf nur für Verträge über künftige Werke, bei ıdenen sich der Urheber für eine lange Zeit bindet (vgl. § 40 Abs. 1 Satz 1). Im übrigen besteht kein Anlaß, von dem allgemeinen Grundsatz der Formfreiheit abzu- weichen. Die Schriftform für alle Verträge vorzuschreiben, würde den Rechtsverkehr zu stark belasten und könnte sich auch nachteilig für den Urheber selbst auswirken, weil er dann z. B. aus einer mündlichen Zusage reines Verlegers oder Filmherstellers keine Ansprüche herleiten könnte.

\section{Zu § 32 - Beschränkung von Nutzungsrechten}

In Anlehnung an das geltende Recht, nach dem auch eine beschränkte Ubertragung des Urheberrechts zulässig ist ( $\$ 8 \mathrm{Abs}$. $3 \mathrm{LUG}, \S 10 \mathrm{Abs}$. $3 \mathrm{KUG}$ ), sieht der Entwurf vor, daß das Nutzungsrecht räumlich, zeitlich oder inhaltlich ibeschränkt eingeräumt werden kann. Danach kann der Urheber z. B. einem Verleger das Vervielfältigungs- und Verbreitungsrecht nur für ein ibestimmtes Land und nur für eine bestimmte Zeit einräumen mit der Wirkung, daß der Verleger Vervielfältigungsstücke des Werkes außerhalb des vereinbarten Gebietes nicht verbreiten darf und das Recht nach Ablauf der vereinbarten Frist erlischt. Der Urheber kann ferner eine inhaltliche Beschränkung des Vervielfältigungs- und Verbreitungsrechts in der Weise vorsehen, daß Vervielfältigungsstücke nur in bestimmter Zahl hergestellt und nur unter Einhaltung eines bestimmten Absatzweges, z. B. im Rahmen einer Buchgemeinschaft, verbreitet werden dürfen. Die Beschränkung muß sich in solchen Fällen jedoch stets auf den Inhalt des eingeräumten Rechts beziehen, $d . h$. beim Vervielfältigungsrecht auf Art und Umfang der Vervielfältigung, beim Verbreitungsrecht auf die Art der Verbreitung. Nicht möglich ist es, das Vervielfältigungs- oder Verbreitungsrecht dahingehend einzuschränken, daß rechtmäßig hergestellte und verbreitete Vervielfältigungsstücke nur in bestimmter Weise, beispielsweise nur zum privaten Gebrauch, benutzt werden dürfen; denn weder das Viervielfältigungsrecht noch das Verbreitungisrecht schließt die Befugnis ein, die Verwendung rechtmäßig hergestellter und verbreiteter Vervielfältigungsstücke zu überwachen.

\section{Zu § 33 - Weiterwirkung einfacher Nutzungsrechte}

Die Bestimmung bringt eine Ausnahme von dem Grundsatz, daß ein einfaches Nutzungsrecht nur schuldrechtliche Wirkung hat. Der Erwenber eines ausschließlichen Nutzungsrechts hätte an sich die Möglichkeit, dem Inhaber eines vorher vom Urheber eingeräumten einfachen Nutzungsrechts die weitere Nutzung des Werkes zu verbieten. Dies könnte jedoch zu unbilligen Ergebnissen führen, z. B. wenn der Inhaber des einfachen Nutzungsrechts auf die weitere Nutzung des Werkes angewiesen ist, um seine zur Vorbereitung der Werknutzung bereits aufgewandten Kosten zu decken. Das einfache Nutzungsrecht soll deshalb gegenüber dem Erwerber des ausschließlichen Nutzungsrechts seine Wirkung behalten. Diese Regelung ist jedoch, wie der Entwurf ausdrücklich klarstellt, nicht zwingend. Der Urheber kann mit dem Inhaber des einfachen Nutzungsrechts vereinbaren, $\mathrm{da}$ isein Recht im Falle der Einräumung eines ausschließlichen Nutzungsrechts abweichend von dem gesetzlichen Grundsatz erlöschen soll. 


\section{Zu §34 - Uberiragung von Nutzungsrechten}

Das geltende Recht enthält außer einer Sonderbestimmung im Verlagsgesetz ( $\$ 28$ ) keine Regelung der Frage, ob und inwieweit die Weiterübertragung von Nutzungsrechten ohne Zustimmung des Urhebers möglich ist. Die herrschende Meinung leitet jedoch aus dem dem Urheber auch im Falle einer Ubertragung seiner vermögensrechtlichen Befugnisse verbleibenden persönlichkeitsrechtlichen Kern des Urhebcrrechts den Grundsatz $a b$, daß die Weiterübertragung der Nutzungsrechte in ider Regel der Zustimmung des Urbeibers 'bedarf. Es erscheint nicht gerechtfertigt, daß das Nutzungsrecht ohne Wissen des Urhebers in die Hand von Personen gelangt, die sein Vertrauen nicht besitzen und von denen er befürchten muß, daß sie von dem Nutzungsrecht einen seinen Absichten zuwiderlaufenden Gebrauch machen werden.

Der Entwurf spricht diesen Grundsatz nunmehr in Absatz 1 Satz 1 ausdrücklich aus. Der Urheber soll den Vorbehalt seiner Zustimmung jedoch nicht dazu mißbrauchen dürfen, eine seine Interessen in keiner Weise beeinträchtigende Ubertragung des Nutzungsiechts willkürlich zu verhindern. Absatz 1 Satz 2 bestimmt daher, daß der Urheber seine $\mathrm{Zu}$ stimmung zur Ubertragung des Nutzungsrechts nicht wider Treu und Glauben verweigern darf.

Absatz 2 soll die Ubertragung von Nutzungsrechten an Sammelwerken erleichtern: Zur Ubertragung der Nutzungsrechte auch an den in das Sammelwerk aufgenommenen Werken soll die Zustimmung des Urhebers des Sammelwerkes genügen.

Absuls 3 biingl in Anlelinung an $\$ 28$ Abs. 1 des Verlagsgesetzes eine Ausnahme von dem Zustimmungserfordernis für den Fall der globalen Ubertragung von Nutzungsrechten im Rahmen der Veräußerung eines Unternehmens, z. B. eines Verlages oder Theaterunternehmens. Hier wäre es für den Unternehmer unzumutbar, vor der Veräußerung sämtliche Urheber fragen zu müssen, mit denen er Nutzungsverträge abgeschlossen hat. Die Interessen der Urheber werden insoweit angemessen durch die in Absatz 5 vorgesehene Haftung des Erwerbers gewahrt.

Absalz 4 erklärt die Bestimmungen in den $\mathrm{Ab}$ sätzen 1 bis 3 für abdingbar. Danach kann der Urheber abweichend von der Regelung in Absatz 1 die Ubertragung des Nutzungsrechts von vornherein allgemein gestatten, sie andererseits aber auch ganz ausschließen mit der Wirkung, daß er seine Zustimmung zur Ubertragung dann ohne Einschränkung versagen kann. Ferner können die Urheber der in ein Sammelwerk aufgenommenen Beiträge sich in Abweichung von Absatz 2 vorbehalten, daß die Weiterübertragung der Nutzungsrechte an ihren Beiträgen stets ihrer Zustimmung bedarf, auch wenn Jer Urheber des Sammelwerkes selbst seine Zustimmung bereits erteilt hat. Entsprechend kann der Urheber auch die Anwendbarkeit des Absatzes 3 vertraglich ausschließen.

Absatz 5 sieht für den Fall, daß die Ubertragung des Nutzungsrechts nach Vertrag oder kraft Gesetzes ohne Zustimmung des Urhebers zulässig ist, in
Anlehnung an $\S 28$ Abs. 2 des Verlagsgesetzes eine gesetzliche Haftung des Erwerbers des Nutzungsrechts für die Verpflichtungen des Veräußerers vor. Die Regelung erscheint notwendig, weil zwischen dem Urheber und dem Erwerber des Nutzungsrechts keine vertraglichen Beziehungen bestehen und der Urheber deshalb seine Interessen gegenüber dem Erwerber vertraglich nicht sichern kann. Soweit das Nutzungsrecht nur mit Zustimmung des Urhebers übertragbar ist, bedarf es keiner gesetzlichen Regelung, da in diesem Fall der Urheber seine Zustimmung davon abhängig machen kann, daß der Erwerber die Verpflichtungen des Veräußerers übernimmt.

\section{Zu § 35 - Einräumung einfacher Nutzungsrechte}

Die Bestimmung sieht vor, daß ebenso wie die Übertragung des ausschließlichen Nutzungsrechts auch die Einräumung eines einfachen Nutzungsrechts durch den Inhaber eines ausschließlichen Nutzungsrechts nur mit Zustimmung des Urhebers möglich ist. Auch in diesen Fällen muß der Urheber vor einer Werknutzung durch unberufene oder ungeeignete Personen, auf deren Auswahl er keinen Einfluß hat, geschützt werden.

Die vorgesehene Regelung paßt jedoch nicht für die Fälle, in denen das ausschließliche Nutzungsrecht nur zur Wahrnehmung der Belange des Urhebers eingeräumt ist, wie insbesondere bei den Verwertungsgesellschaften undBührenvertrieben ${ }_{11}$ deren Aufgabe es gerade ist, das ausschließliche Recht durch Vergabe von einfachen Nutzungsrechten auszuwerten. Der Entwurf sieht daher insoweit eine Ausnahme vor (Absatz 1 Satz 2).

\section{Zu $§ 36$ - Beteiligung des Urhebers}

Diese in den geltenden Urheberrechtsgesetzen nicht enthaltene Bestimmung soll dem Urheber in besonderen Ausnahmefällen bei einer unerwartet erfolgreichen Verwertung seiner Werke eine angemessene Beteiligung sichern.

Es kommt vor, daß junge noch unbekannte Urheber ihre Werke aus wirtschaftlicher Not und rechtlicher Unerfahrenheit anderen gegen eine geringe Vergütung zur Verwertung überlassen, die dann große Gewinne aus den Werken zichen. Es ist darauf hingewiesen worden, daß es dem Rechtscmpfinden widerspreche, den Urheber von einer Beteiligung an diesem Gewinn auszuschließen. Entsprechend einer im neuen französischen Urheberrechtsgesetz von 1957 vorgesehenen Bestimmung (Artikel 35) müsse daher eine laufende Beteiligung des Urhebers an den Gewinnen zwingend vorgeschrieben werden. Gegen eine allgemeine Regelung dieser Art, die eine Einschränkung der Vertragsfreiheit des Urhebers bedeuten würde, bestehen jedoch Bedenken. Häufig hat der Urheber ein Interesse daran, die Verwertung des Werkes gegen eine einmalige Vergütung zu gestatten, deren Höhe dem später durch die Verwertung erzielten Gewinn durchaus entsprechen kann. Der Vorschlag erscheint aber berechtigt für Fälle, in denen der Verwerter 
aus dem Wert einen unerwartet hohen Gewinn gezogen hat, der in auffälligem Mißverhältnis zu dem an den Urheber gezahlten Entgelt steht. Der Entwurf sieht daher in Absatz 1 insoweit einen gesetzlichen Beteiligungsanspruch des Urhebers vor.

Da der Verwerter eines Werkes mit dem erzielten Gewinn oft die weniger erfolgreiche Auswertung anderer Werke desselben Urhebers ausgleicht, bestimmt der Entwurf, daß für die Prüfung der Frage, ob ein auffälliges Mißverhältnis zwischen den Nutzungserträgnissen und dem an den Urheber gezahlten Entgelt besteht, die gesamten Beziehungen zwischen dem Urheber und dem Nutzungsberechtigten zu berücksichtigen sind. Von Verlegerseite ist gefordert worden, darüber hinaus die Beziehungen ides Nutzungsberechtigten auch zu anderen Urhebern zu berücksichtigen. Einem Verleger müsse es möglich bleiben, mit den unerwartet hohen Erträgnissen aus der Verwertung eines einzelnen Bestsellers nicht nur einen etwaigen Verlust aus der Herausgabe von weiteren Werken desselben Autors auszugleichen, sondern auch das Risiko der Förderung anderer noch unbekannter Autoren zu decken. Dieser Forderung ist entgegenzuhalten, daß die Regelung des Entwurfs den sicher notwendigen Gewinn- und Verlustausgleich zwischen Werken verschiedener Autoren keineswegs unmöglich macht, da dem Urheber des erfolgreichen Werkes nur eine angemessene Beteiligung an dem Gewinn zu gewähren ist, dem Verleger also der Hauptanteil an dem Gewinn nach wie vor verbleibt.

Die Befürchtung, daß die neue Bestimmung eine erhebliche Rechtsunsicherheit zur Folge haben und dem Nutzungsberechtigten den Boden für eine vernünftige Kalkulation entziehen werde, erscheint nicht begründet. Die Voraussetzungen des Nachforderungsanspruchs des Urhebers sind so streng gefaßt - sie entsprechen dem objektiven Tatbestand des Wuchers in $\S 138$ Abs. 2 des Bürgerlichen Gesetzbuchs -, daß der Anspruch nur in seltenen Ausnahmefällen gegeben sein wird, in Fällen, in denen in der Regel der Vertragspartner des Urhebers ohnehin bei verständiger Würdigung der Sachlage freiwillig eine Nachzahlung leisten würde.

Absatz 2 sieht im Interesse des Nutzungsberechtigten und im Hinblick auf anderenfalls zu befürchtende Beweisschwierigkeiten eine kurze Verjährungsfrist für den Beteiligungsanspruch des Urhebers vor.

Absatz 3 bestimmt zum Schutze des Urhebers, daß im voraus weder auf den Anspruch verzichtet noch über ihn verfügt werden kann und die Anwartschaft auf den Anspruch nicht der Zwangsvollstrekkung unterliegt.

\section{Zu § 37 - Verträge über die Einräumung von Nutzungsrechten}

Die Bestimmung enthält Auslegungsregeln für Verträge über die Einräumung von Nutzungsrechten.

Absatz 1 entspricht dem geltenden Recht (§ 14 LUG, $\S 2$ Abs. 2 Verlagsgesetz), jedoch zählt der Entwurf die möglichen Bearbeitungsformen, wie Uberset- zung, Dramatisierung usw. nicht im einzelnen auf. Die Auslegungsregel sieht vor, daß dem Urheber im Falle der Einräumung eines Nutzungsrechts im Zweifel das Recht der Einwilligung zur Veröffentlichung oder Verwertung einer Bearbeitung des Werkes nach $\S 23$ des Entwurfs verbleibt. Danach darf beispielsweise ein Verleger, dem der Urheber das Nutzungsrecht zur Vervielfältigung und Verbreitung an einem Roman eingeräumt hat, im Zweifel nur die Originalfassung des Romans vervielfältigen und verbreiten, nicht dagegen eine Ubersetzung, eine Dramatisierung oder eine Verfilmung. Auch sein Verbotsrecht erstreckt sich im Zweifel nicht auf solche Bearbeitungen des Werkes, d. h. er kann die Vervielfältigung und Verbreitung der Bearbeitungen weder dem Urheber noch einem Dritten verbieten.

In $\S 14$ LUG und $\S 2$ Abs. 2 VerlG ist unter Nr. 4 als eine der dem Urheber im Zweifel verbleibenden Bearbeitungsbefugnisse das Recht angeführt, das Werk "zum Zwecke der mechanischen Wiedergabe für das Gehör" zu benutzen, d. h., es auf Tonträger zu übertragen. Da der Entwurf die Ubertragung eines Werkes auf Tonträger nicht mehr als Bearbeitung, sondern als Vervielfältigung des Werkes ansieht (vgl. § 16 Abs. 2), sieht insoweit Absatz 2 eine besondere Auslegungsregel vor. Wie Absatz 1 hat auch diese Bestimmung eine doppelte Bedeutung: Der Erwerber des Nutzungsrechts zur Vervielfältigung darf im Zweifel weder selbst das Werk auf Tonträger übertragen noch dem Urheber oder einem Dritten eine solche Ubertragung verbieten.

Absatz 3 befaßt sich mit dem in $\S 19$ Abs. 3 des Entwurfs als Teil des Vortrags- und Aufführungsrechts besonders hervorgehobenen Recht des Urhebers, Vorträge und Aufführungen außerhalb der Veranstaltung, bei der sie stattfinden, durch Bildschirm, Lautsprecher oder ähnliche technische Einrichtungen öffentlich wahrnehmbar zu machen, und bestimmt allgemein, daß der Erwerber eines Nutzungsrechts zur öffentlichen Wiedergabe des Werkes im Zweifel nicht zu solchen Bildschirm- oder Lautsprecherübertragungen der Wiedergabe berechtigt sein soll. Abweichend von der Formulierung in $\S 19$ Abs. 3 heißt es statt „außerhalb der Veranstaltung, bei der sie stattfinden“, „außerhalb der Veranstaltung, für die sie bestimmt ist", weil einer Auslegungsregel nicht auf objektive Merkmale, sondern auf den subjektiven Willen der Vertragsparteien abzustellen ist.

Im Gegensatz $\mathrm{zu}$ den Auslegungsregeln in den Absätzen 1 und 2 beschränkt sich Absatz 3 auf die positive Seite des Nutzungsrechts: Der Erwerber des Nutzungsrechts soll lediglich im Zweifel selbst eine Bildschirm- oder Lautsprecherübertragung nicht vornehmen dürfen; sein Recht, eine solche Ubertragung Dritten oder auch dem Urheber selbst zu verbieten, bleibt unberührt; denn der Urheber hat seinerseits kein schutzwürdiges Interesse daran, gegen iden Willen des Nutzungsberechtigten eine Bildschirm- oder Lautsprecherübertragung anderen zu gestatten oder selbst vorzunehmen. 


\section{Zu § 38 - Beiträge zu Sammlungen}

Nach den geltenden Gesetzen ( $\S 11$ Abs. 1 KUG, $\S 42$ Abs. 1 Verlagsgesetz) erlangt der Herausgeber oder Verleger einer periodisch erscheinenden Sammlung (Zeitung, Zeitschrift, Kalender, Almanach oder dergl.) hinsichtlich eines angenommenen Beitrages nur das nichtausschließliche Recht, den Beitrag in der Sammlung zu vervielfältigen und zu verbreiten, wenn nicht aus den Umständen zu entnehmen ist, daß er ein ausschließliches Recht erhalten soll.Diese Bestimmung hat oft $\mathrm{zu}$ Zweifeln Anlaß gegeben; denn die Umstände des Falles lassen häufig keine klaren Schlüsse auf den Umfang der Rechtsübertragung zu. Die Praxis hat gezeigt, daß die Herausgeber oder Verleger in der Regel ausschließliche Rechte an den Beiträgen erwerben wollen und daß dies auch gerechtfertigt erscheint. Der Entwurf sieht daher nunmehr in Absatz 1 vor, daß der Herausgeber oder Verleger einer periodisch erscheinenden Sammlung, wenn nichts anderes vereinbart ist, ein ausschließliches Nutzungsrecht erwirbt. Wie im geltenden Recht ( $\$ 11$ Abs. 2 KUG, $\S 42$ Abs. 2 VerlG), ist zugleich vorgesehen, daß der Urheber den Beitrag nach Ablauf eines Jahres anderweit vervielfältigen und verbreiten darf, doch soll abweichend vom geltenden Recht diese Frist nicht mit dem Ablauf des Kalenderjahres beginnen, in welchem der Beitrag erschienen ist, sondern unmittelbar mit dem Erscheinen des Beitrags. Durch die neue Berechnung der Sperrfrist soll vermieden werden, daß diese, je nachdem, ob der Beitrag zu Anfang oder Ende eines Jahres erscheint, zwischen einem und zwei Jahren schwanken kann. Eine solche Schwankung erscheint unzwedkmäßig und nicht gerechtfertigt.

Absatz 2 bestimmt in Ubereinstimmung mit $\S 11$ Abs. 3 KUG und § 3 VerlG, daß der Urheber auch einen Beitrag zu einer nicht periodisch erscheinenden Sammlung nach Jahresfrist anderweit verwerten darf, wenn ihm für dessen Überlassung kein Anspruch auf Vergütung zusteht.

Absatz 3 folgt der Regelung in $\S 42$ Abs. 2 Satz 2 VerlG und bestimmt, daß der Verfasser über einen Beitrag, den er einer Zeitung geliefert hat, alsbald nach dem Enscheinen anderweit verfüggen darf, wenn nichts anderes vereinbart ist.

Durch $\S 38$ des Entwurfs werden idie $\S \S 3$ und 42 des Verlagsgesetzes gegenstandslos. $\S 150 \mathrm{Nr}$. 4 sieht daher ihre Aufhebung vor.

\section{Zu § 39 - Anderungen des Werkes}

Die Bestimmung entspricht im wesentlichen dem igeltenden Recht (vgl. § 9 LUG, § 12 KUG).

Nach Absatz 1 ist dem Inhaber sowohl eines einfachen wie eines ausschließlichen Nutzungsrechts verboten, eigenmächtig Änderungen am Werk, dessen Titel oder Urheberbezeichnung vorzunehmen. Der Nutzungsberechtigte darf danach z. B. nicht das Werk kürzen oder unter einem anderen Titel herausbringen oder bei einem anonym erscheinenden Werk den Namen des Urhebers angeben. Arbweichende Vereinbarungen sind zulässig; idem Urheber verbleibt jedoch stets das unveräußerliche Recht aus $\S 14$, Entstellungen des Werkes zu verbieten, die geeignet sind, seine berechtigten geistigen oder persönlichen Interessen am Werk zu gefähnden.

Absatz 2 schränkt das Verbot des Absatzes 1 für Anderungen "ein, zu denen der Urheber seine Einwilligung nach Treu und Glauben nicht versagen kann. Gedacht ist hierbei besonders an Anderungen, die idurch Art oder Zweck der erlaubten Nutzung des Werkes geboten sind, z. B. Druckfehlerberichtigungen, Uibertragung eines Bildes in eine andere Größe und dergl. Abweichend vom geltenden Recht gilt die Einschränkung jedoch nicht für Anderungen der Unheberbezeichnung. Insoweit soll stets die Einwilligung des Urhebers zu Anderungen erforderlich sein. § 13 ides Verlagsgesetzes, der insoweit mit der neuen Regelung nicht übereinstimmt, wind in $\S 150$ Nr. 4 aufgehoben.

\section{Zu § 40 - Verträge über künftige Werke}

Verträge über künftige Wierke sind nach ıden allgemeinen Grundsätzen des bürgerlichen Rechts zulässig. Sie begegnen keinen Bedenken, sofern sie sich auf ein bestimmtes vom Unheber zu schaffendes Werk beziehen, weil sich der Urheber in diesem Fall über ıden Umfang seiner Verpflichtungen stets klar sein wird. Verpflichtet sich jedoch der Urheber zur Einräumung von Nutzungsrechten an allen seinen künftigen Werken oder an einer bestimmten Gattung dieser Werke (z. B. an allen Romanen), so liegt darin eine ungewöhnlich starke, in ihren wirtschaftlichen Folgen kaum abzusehende Bindung, die nicht unüberlegt eingegangen wenden darf und eine Uberprüfung des Vertragsverhältnisses nach einer gewissen Zeit erforderlich macht.

Dementsprechend ist in Absatz 1 Satz 1, um den Urheber auf die Bedeutung des Vertrages hinzuweisen, aber auch im Interesse der Beweiserleichterung, für solche Verträge die Schriftform vorgesehen. Ferner gewährt Absatz 1 Satz 2 beiden Vertragsteilen ein gesetzliches Kündigungsrecht nach Ablauf von fünf Jahren seit Vertragsabschluß. Die Kündigungsfrist soll höchstens sechs Monate betragen (Absatz 1 Satz 3), so daß der Vertrag spätestens zum Ende der zweiten Hälfte des sechsten Vertragsjahres aufgehoben werden kann.

Nach Absatz 2 Satz 1 kann von keiner Seite auf das Kündigungsrecht im voraus verzichtet werden. Absatz 2 Satz 2 stellt klar, daß andere vertragliche oder gesetzliche Kündigungsrechte unberührt bleiben. Nicht ausgeschlossen wird selbstverständlich auch die Anwendbarkeit des $\S 138$ des Büngerlichen Gesetzbuchs, nach welchem Verträge über künftige Werke wegen Verstoßes gegen die guten Sitten nichtig sein können, z. B. wenn dem Urheber bei einem sog. Optionsvertrag eine einseitige Bindung auferlegt wird und er hierfür keine angemessene Gegenleistung erhält (vgl. Entscheiidung des Bundesgerichtshofs vom 14. Dezember 1956, BGHZ 22 S. 347).

Absatz 3 regelt die Rechtsfolge der Kündigung für den Fall, daß in Erfüllung des Vertrages bereits Nutzungsrechte eingeräumt worden sind. Nach die- 
ser Bestimmung wird die getroffene Verfügung des Urhebers hinsichtlich der Werke unwirksam, die zum Zeitpunkt der Beendigung des Vertrages noch nicht abgeliefert sind. Die Frage einer etwaigen Rückzahlung der an den Urheber bereits gezahlten Vergütungen und Vorschüsse bestimmt sich nach den Vorschriften des bürgerlichen Rechts.

\section{Zu § 41 - Rückrufsrecht wegen Nichtausübung}

Der Urheber hat ein schutzwürdiges Interesse daran, daß sein Werk in der Offentlichkeit bekannt wird. Das Bekanntwerden des Werkes kann aber dadurch verhindert werden, daß der Inhaber eines ausschließlichen Nutzungsrechts sein Recht nicht ausübt; denn neben dem Inhaber des ausschließlichen Nutzungsrechts darf kein anderer, auch nicht der Urheber selbst, das Werk verwerten. Für den Fall, daß ein Verleger das Werk nicht vertragsgemäß vervielfältigt und verbreitet, gibt das Verlagsgesetz ( $\$ 32$ in Verbindung mit $\S 30$ ) dem Urheber ein Rücktrittsrecht, doch hilft diese Bestimmung dem Urheber nicht, wenn der Verleger keine Verpflichtung zur Vervielfältigung und Verbreitung übernommen oder das Verlagsrecht auf einen Dritten übertragen hat. Um auch in diesen Fällen dem Urheber zu ermöglichen, sich gegen die Nichtausübung eines eingeräumten Nutzungsrechts zu wehren, gewährt der Entwurf über die Bestimmungen des Verlagsgesetzes hinaus dem Urheber allgemein ein sog. Rückrufsrecht wegen Nichtausübung. Dic aus Verlegerkreisen geäußerte Ansicht, daß die Interessen des Urhebers durch die $\S \S 323$ bis 326 des Bürgerlichen Gesetzbuchs und die Grundsätze über die außerordentliche Kündigung bei langfristigen Verträgen genügend berücksichtigt seien, trifft nicht zu. Die besonders gelagerten Verhältnisse zwischen dem Urheber und dem Verwerter seiner Werke erfordern eine Sonderregelung, zumal die $\S \S 323$ bis 326 BGB dann keine Handhabe bieten, wenn der Verwerter nicht Vertragspartner des Urhebers ist.

Absatz 1 Satz 1 bestimmt als Voraussetzung des Rückrufsrechts, daß durch die Nichtausübung oder die unzureichende Ausübung des Nutzungsrechts berechtigte Interessen des Urhebers erheblich verletzt werden. In dieser Abgrenzung liegt die erforderliche Sicherung gegen einen Mißbrauch des Rückrufsrechts. Nach Absatz 1 Satz 2 soll die Geltendmachung des Rückrufsrechts nicht zulässig sein, wenn die Nichtausübung oder die unzureichende Ausübung des Nutzungsrechts überwiegend auf Umständen beruht, deren Behebung dem Urheber zuzumuten ist. Es ist hier besonders an den Fall gedacht, daß ein Werk wegen veränderter Umstände nicht herausgebracht werden kann, es dem Urheber aber leicht ist, das Werk den veränderten Umständen anzupassen.

In Absatz 2 wird die Frist, nach deren Ablauf das Rückrufsrecht frühestens geltend gemacht werden kann, auf zwei Jahre bemessen. Aus Urheberkreisen ist angeregt worden, die Frist auf ein Jahr zu verkürzen, weil aktuelle Manuskripte nach zwei Jahren bereits wertlos geworden sein könnten. In derartigen Fällen bleibt es jedoch dem Urheber un- benommen, die Verwertung innerhalb einer kürzeren Frist zu vereinbaren, so daß er bei Nichterfüllung vom Vertrag zurücktreten kann. Im Regelfall wird die Frist von zwei Jahren zur Wahrung berechtigter Belange des Nutzungsberechtigten erforderlich und für den Schutz des Urhebers ausreichend sein.

Es ist vorgesehen, daß die Frist bei einer Ubertragung des Nutzungsrechts von neuem zu laufen beginnt. Hierdurch werden die Interessen des Urhebers nicht gefährdet, da ihm nach § 34 Abs. 1 die Zustimmung zu der Weiterübertragung vorbehalten ist. $\mathrm{Muß}$ er befürchten, daß die als Erwerber des Rechts in Aussicht genommene Person keine Gewähr für die zureichende Ausübung des Nutzungsrechts bietet, so kann er seine Zustimmung verweigern. Der Urheber hat es also in der Hand zu verhindern, 'daß sein Rückrufsrecht durch fortgesetzte Ubertragung des Nutzungsrechts vereitelt wird. Bei der Gesamtveräußerung eines Unternehmens nach $\S 34$ Abs. 3, bei der die Zustimmung nicht erforderlich ist, ist ein Mißbrauch nicht zu befürchten.

In der Regel soll der Urheber nicht sofort mit dem Ablauf der Frist des Absatzes 2 den Rückruf erklären können, vielmehr ist er nach Absatz 3 Satz 1 verpflichtet, dem Inhaber des Nutzungsrechts unter Ankündigung des Rückrufs eine angemessene Nachfrist zur zureichenden Ausübung des Nutzungsrechts zu gewähren. Nach Absatz 3 Satz 2 ist in bestimmten Fällen die Nachfrist entbehrlich.

Die Bestimmungen in Absatz 4 sollen verhindern, daß das Rückrufsrecht vertraglich abbedungen oder seine Ausübung für eine ungebührlich lange Zeit ausgeschlossen wird.

Der Rückruf bewirkt das Erlöschen des Nutzungsrechts (Absatz 5) und verpflichtet den Urheber nach Absatz 6 zur Entschädigung. Gegen die Entschädigungspflicht ist eingewandt worden, sie entwerte das Rückrufsrecht. Ein Rückrufsrecht ohne Entschädigungspflicht würde indessen die schutzwürdigen Interessen des Nutzungsberechtigten, der im Vertrauen auf sein Nutzungsrecht bereits Aufwendungen gemacht oder für den Erwerb des Rechts ein Entgelt gezahlt hat, nicht genügend berücksichtigen. Im übrigen ist der Urheber gegen unberechtigte Entschädigungsansprüche ausreichend geschützt, da die Entschädigung nur $\mathrm{zu}$ leisten ist, wenn und soweit sie der Billigkeit entspricht, also nur, wenn die Zahlung dem Urheber bei Abwägung der Interessen der Beteiligten zugemutet werden kann.

Der Anregung, die Geltendmachung des Rückrufsrechts davon abhängig zu machen, daß die Entschädigung im voraus gezahlt oder Sicherheit für sie geleistet wird, ist der Entwurf nicht. gefolgt. Eine solche Regelung würde die vermögenden Urheber bevorzugen. Aber auch unabhängig von der Frage, ob der Urheber zur Zahlung imstande ist oder nicht, würde das Erfordernis der vorherigen Zahlung oder Sicherheitsleistung die Geltendmachung des Rückrufsrechts in unbilliger Weise erschweren.

Absatz 7 sieht vor, daß neben dem Rückrufsrecht wegen Nichtausübung Rechte und Ansprüche ider Beteiligten nach anderen gesetzlichen Vorschriften 
unberührt bleiben, z. B. das erwähnte Rücktrittsrecht nach dem Verlagsgesetz und die Rechte aus den $\$ \S 323$ bis 326 BGB.

\section{Zu $§ 42$ - Rückrufsrecht wegen gewandelter Uber- zeugung}

In der Regel wird ein Urheber, der einem anderen ein Nutzungsrecht an seinem Werk eingeräumt hat, ein Interesse daran haben, daß das Werk auch verwertet, z. B. vervielfältigt und verbreitet wird. Es kann aber auch vorkommen, daß der Urheber die Verwertung seines Werkes verbieten will, nämlich wenn er selbst aus triftigen Gründen von seinem Werk abgerückt ist und dessen Veröffentlichung und Verwertung nicht mehr verantworten will. Man kann beispielsweise einem Urheber, dessen Werk durch neuere Erkenntnisse der Wissenschaft gänzlich überholt ist, nicht zumuten, daß er die weitere Verbreitung dieses Werkes zuläßt. Nach geltendem Recht ( $\$ 35$ VerlG) kann der Verfasser bis zum Beginn der Vervielfältigung von dem Verlagsvertrag zurücktreten, wenn sich Umstände ergeben, die beim Abschluß des Vertrages nicht vorauszusehen waren und ihn bei Kenntnis der Sachlage und verständiger Würdigung des Falles von der Veröffentlichung des Werkes zurückgehalten haben würden. Dieses Rücktrittsrecht reicht jedoch wegen seiner Beschränkung auf die Zeit bis zum Beginn der Vervielfältigung nicht aus. Es bezieht sich im übrigen auch nur auf Verlagsverträge über Werke der Literatur und der Tonkunst. Der Entwurf sieht daher in Absatz 1 allgemein ein Rückrufsrecht des Urhebers für den Fall vor, daß das Werk seiner Uberzeugung nicht mehr entspricht und ihm deshalb die Verwertung des Werkes nicht mehr zugemutet werden kann.

Das Rückrufsrecht wegen gewandelter Uberzeugung dient in besonderem Maße den persönlichen Interessen des Urhebers. Es soll daher grundsätzlich nur diesem selbst, nicht seinem Rechtsnachfolger zustehen. Eine Ausnahme soll nach Absatz 2 lediglich dann gelten, wenn der Rechtsnachfolger nachweist, $\mathrm{daß}$ die in Absatz 1 genannten Voraussetzungen für den Rückruf in der Person des Urhebers vor dessen Tode erfüllt waren und der Urheber entweder den Rückruf nicht erklären konnte, etwa weil ihm die Person oder der Aufenthaltsort des Nutzungsberechtigten nicht bekannt war, oder er den Rückruf letztwillig verfügt hat.

Absatz 3 bestimmt zum Schutz des Urhebers, daß auf das Rückrufsrecht im voraus nicht verzichtet und seine Ausübung - auch befristet - nicht ausgeschlossen werden kann.

Absatz 4 verpflichtet den Urheber, den Inhaber des Nutzungsrechts stets angemessen zu entschädigen. Die Entschädigung muß mindestens die Aufwendungen decken, die der Nutzungsberechtigte für die durch den Rückruf unterbundene weitere Ausübung des Nutzungsrechts bereits gemacht hat. Erst wenn der Urheber die Aufwendungen ersetzt oder Sicherheit für sie geleistet hat, soll der Rückruf wirksam werden. Diese allgemeine, über die entsprechende Regelung beim Rückrufsrecht wegen Nichtausübung hinausgehende Entschädigungspflicht erscheint geboten, da das Rückrufsrecht wegen gewandelter Uberzeugung ausschließlich auf Gründen beruht, die in der Person des Urhebers liegen. Damit der Inhaber des Nutzungsrechts das Wirksamwerden des Rückrufs nicht dadurch beliebig hinauszögern kann, daß er den Urheber über die Höhe der Aufwendungen im unklaren läßt, soll der Rückruf bereits einen Monat nach seiner Erklärung wirksam werden, wenn der Inhaber des Nutzungsrechts dem Urheber nicht innerhalb dieser Frist die Aufwendungen mitteilt.

Der Urheber soll das Rückrufsrecht wegen gewandelter Uberzeugung nicht dazu mißbrauchen können, ein bestehendes Vertragsverhältnis zu lösen, nur um später einen Vertrag zu günstigeren Bedingungen abzuschließen. Absatz 5 verpflichtet deshalb den Urheber, das Werk dem früheren Nutzungsberechtigten zu angemessenen Bedingungen anzubieten, falls er es wieder verwerten will.

Absatz 6 erklärt die Bestimmungen in $\S 41$ Abs. 5 und 7 für entsprechend anwendbar. Danach erlischt das Nutzungsrecht mit Wirksamwerden des Rückrufs; Rechte und Ansprüche nach anderen gesetzlichen Vorschriften bleiben neben dem Rückrufsrecht unberührt.

\section{Zu $\S 43$ - Urheber in Arbeits- oder Dienstverhält- nissen}

Entsprechend dem allgemeinen Grundsatz des $\S 7$, daß Urheber eines Werkes dessen Schöpfer ist, entsteht auch an einem Werk, das in Erfüllung arbeitsvertraglicher oder dienstlicher Pflichten geschaffen ist, das Urheberrecht in der Person des Arbeitnehmers oder Beamten. Will der Arbeitgeber oder Dienstherr das Werk verwerten, so muß er sich hierfür die erforderlichen Nutzungsrechte vertraglich einräumen lassen. Der Entwurf unterscheidet insoweit nicht zwischen dem angestellten und dem freischaffenden Urheber.

Diese Regelung entspricht im wesentlichen dem geltenden Recht. Auch für dieses wird von der herrschenden Meinung angenommen, daß bei Werken, die im Rahmen eines Anstellungsverhältnisses geschaffen werden, grundsätzlich das Urheberrecht vom Arbeitnehmer oder Beamten erworben wird und kraft - gegebenenfalls stillschweigender vertraglicher Vereinbarung auf den Arbeitgeber oder Dienstherrn übergehen kann. Die geltenden Urheberrechtsgesetze sprechen lediglich in dem Sonderfall, daß eine juristische Person des öffentlichen Rechts als Herausgeber ein Werk veröffentlicht, dessen Verfasser nicht angegeben ist, dieser unmittelbar das Urheberrecht am Werk zu ( $\begin{aligned} & \S \\ & 3\end{aligned}$ LUG, $§ 5$ KUG).

Es ist gefordert worden, diese Sonderbestimmung beizubehalten und allgemein auf Werke auszudehnen, die von Beamten in Erfüllung ihrer Dienstpflichten geschaffen werden. Auch für Werke der angewandten Kunst und für Lichtbildwerke, die von Arbeitnehmern für ein Unternehmen geschaffen 
werden, wird ein unmittelbarer Erwerb des Urheberrechts oder zumindest der Verwertungsrechte durch den Arbeitgeber angestrebt. Derartige Regelungen wären jedoch mit $\S 7$ des Entwurfs unvereinbar. Sie erscheinen auch nicht erforderlich, da sich bisher - soweit ersichtlich - aus der Notwendigkeit des Rechtserwerbs durch den Arbeitgeber oder Dienstherrn in den genannten Fällen keine Schwierigkeiten ergeben haben. In der Regel wird bereits aus dem Wesen des Arbeits- oder Dienstverhältnisses eine stillschweigende Ubertragung der Rechte an den in seiner Erfüllung geschaffenen Werken abgeleitet werden können. Auch hinsichtlich der Ausübung der persönlichkeitsrechtlichen Befugnisse können die erforderlichen Einschränkungen aus der Eigenart des Arbeits- oder Dienstverhältnisses abgeleitet werden. So muß beispielsweise ein Beamter auf Grund seiner dienstrechtlichen Verpflichtungen dulden, daß sein Werk durch weisungsberechtigte Vorgesetzte geändert oder daß es ohne Angabe seines Namens veröffentlicht wird.

Es ist allerdings zu berücksichtigen, d $\gtrsim ß$ der Entwurf abweichend vom geltenden Recht gewisse vertragsrechtliche Schutzvorschriften zugunsten des Urhebers vorsieht, die zum Teil unabdingbar sind, wie das Verbot der Einräumung noch nicht bekannter Nutzungsrechte ( $\S 31$ Abs. 4), der Beteiligungsanspruch des Urhebers bei unerwartet hohen Gewinnen ( $\S 36$ ) und die Rückrufsrechte wegen Nichtausübung und wegen gewandelter Überzeugung ( $\S \S 41$ und 42). Diese Bestimmungen sind in erster Linie zum Schutze des freischaffenden Urhebers gedacht, der kein festes Gehalt bezieht, sondern auf die Erträgnisse aus der Verwertung seiner Werke angewiesen ist. Der wirtschaftlich gesicherte Arbeitnehmer oder Beamte, der kein Risiko für sein Schaffen trägt, bedarf der Schutzbestimmungen in der Regel nicht, wobei jedoch die Sachlage je nach Art des Arbeits- oder Dienstverhältnisses verschieden sein kann. Der Entwurf sieht daher in $\S 43$ eine Bestimmung vor, nach der die Vorschriften des Unterabschnitts "Nutzungsrechte" auf Urheber in Arbeits- oder Dienstverhältnissen Anwendung finden sollen, soweit sich aus dem Inhalt oder dem Wesen des Arbeits- oder Dienstverhältnisses nichts anderes ergibt.

Durch diese Regelung wird ermöglicht, daß namentlich im Falle öffentlich-rechtlicher Dienstverhältnisse wie im geltenden Recht ein unbeschränkter Erwerb der Nutzungsrechte durch den Dienstherrn als stillschweigend vereinbart aus dem Dienstverhältnis abgeleitet werden kann. Für einen Beamten wird wegen seiner besonderen Stellung, insbesondere mit Rücksicht auf die Alimentationspflicht des Dienstherrn, regelmäßig die Unanwendbarkeit der erwähnten zwingenden Schutzvorschriften anzunehmen sein, d. h. er kann die auf den Dienstherrn übergegangenen Nutzungsrechte an den in Erfüllung seiner Dienstpflichten geschaffenen Werke nicht zurückrufen und keine Beteiligung an etwaigen unerwartet hohen Nutzungserträgnissen nach $\S 36$ verlangen. Ahnliches wird für viele Arbeitsverhältnisse gelten, doch kommt es hier stets auf die besonderen Umstände des Einzelfalles an.

\section{Zu § 44 - Veräußerung des Originals des Werkes}

Als Recht am Werk, also an einem immateriellen Gut, ist das Urheberrecht zu unterscheiden von dem Eigentum an den das Werk verkörpernden Festlegungsstücken wie dem Manuskript, dem Buchexemplar oder dem Gemälde. Veräußert der Urheber ein solches Werkexemplar, so will er damit in der Regel nicht über sein Urheberrecht verfügen. Absatz 1 sieht daher in Ubereinstimmung mit $\S 10$ Abs. 4 KUG vor, daß die Ubertragung des Eigentums an dem Original des Werkes im Zweifel die Einräumung eines Nutzungsrechts nicht enthält.

In Ausnahme von diesem Grundsatz soll jedoch nach Absatz 2 der Eigentümer des Originals eines Werkes der bildenden Künste im Zweifel berechtigt sein, es öffentlich auszustellen, auch wenn das Werk noch nicht veröffentlicht ist. Diese Bestimmung entspricht der Interessenlage. Veräußert ein Maler oder Bildhauer das Original seines Werkes an einen Dritten und entläßt er es damit endgültig aus seiner persönlichen Sphäre, so ist nach der Lebenserfahrung davon auszugehen, daß er mit der Ausstellung auch des noch nicht veröffentlichten Werkes einverstanden ist, wenn er nichts anderes vereinbart. Die Regelung gilt nicht nur für den Ersterwerber 'des Originals, d. h. den Vertragspartner des Urhebers, sondern auch für jeden späteren Eigentümer. Eine etwaige Vereinbarung über den Ausschluß des Ausstellungsrechts hat somit dingliche Wirkung; sie soll deshalb im Interesse der Rechtssicherheit und der Beweiserleichterung nur ausdrücklich getroffen werden können.

\section{SECHSTER ABSCHNITT}

\section{Schranken des Urheberrechts}

In der Einleitung (S. 30) ist bereits dargelegt, daß das Urheberrecht nicht unbeschränkt ist, sondern gegenüber den berechtigten Interessen dier Allgemeinheit an idem ungehinderten Zugang zu den Kulturgütern sach.gemäß abgegrenzt werden muß. Wie der Bundesgerichtshof in seiner Entscheidung vom 6. Dezember 1955 (BGHZ 19 S. 227, vgl. Anlage 5 [I]) ausgeführt hat, findet nach den Rechtsgiedanken, die dem Urheberrecht immanent sind, die ausschließliche Herrschaftsmacht des Werksschöpfers über sein Geistesgut an überwiegenden Bedürfnissen der Allgemeinheit ihre Grenze. Es handelt sich hierbei um Schranken, die sich aus der sozialen Natur des Urheberrechts ergeben. Solche Schranken des Urheberrechts sind auch in den ausländischen Urheberrechtsgesetzen und in der Berner Ubereinkunft zum Schutze von Werken der Literatur und der Kunst vorgesehen (vgl. Artikel 9 Abs. 2 und 3, Artikel 10, 10 bis, 11 bis Abs. 2 rund 3, Artikel 13 Abs. 2), einem Aibkommen, das im übrigen den Unhebern auf internationalem Gebiet einen weitgehenden Schutz ihrer Rechte gewährleistet. Diese Abgrenzung des Urheberrechts gegenüber den Interessen der Allgemeinheit hat unterschiedliche Gründe. Sie dient z. B. den Zwedken der Rechtspflege, ider Erleichterung ides Schulunterrichts, der Erleichterung der Unterrich- 
tung der Offentlichkeit und der Freiheit des geistigen Schaffens. Als ein allgemeiner Grundsatz kann igelten, daß der Urheber insbesondere dort im Interesse der Allgemeinheit freien Zugang zu seinen Werken gewȧhren muß, wo dies unmittelbar der Förderung der geistigen und kulturellen Werte dient, die ihrerseits Grundlage für sein Werkschaffen sind. Nicht gerechtfertigt erscheinen dagegen solche Einschränkungen, wenn sie nur dazu dienen sollen, der Allgemeinheit die Erfüllung von Aufgaben zu erleichtern, die keine engere Beziehung zum Werkschaffen des Urhebers haben, wie etwa Sozialfürsorge, Jugendpflege und Wohltätigkeit.

Eine wichtige Grenze für die Einschränkung des Urheberrechts bildet vor allem der von der Rechtsprechung bereits zur Auslegung des geltenden Rechts entwickelte Gedanke, daß der Urheber tunlichst an idem wirtschaftlichen Nutzen zu beteiligen ist, der aus seinem Werk gezogen wind. Aus idiesem Grundsatz folgt nicht nur, daß das Urheberrecht keinen Einschränkungen unterliegen ıdarf, ıdie lediglich dem wirtschaftlichen Interesse einzelner Werknutzer dienen. Es muß auch vermieden werden, daß eine an sich im Allgemeininteresse gebotene Einschränkung mittelbar zu einer nicht gerechtfertigten Förderung derartiger wirtschaftlicher Einzelinteressen führt. In solchen Konfliktslagen erscheint es angebracht, lediglich den Verbotscharakter der betreffenden urheberrechtlichen Befugnis einzugrenzen, dem Urheber jedoch einen Anspruch auf angemessene Vergütung für die Benutzung seines Werkes zu belassen.

Gegenüber einer solchen Abrgrenzung des Urheberrechts ist insbesondere aus Kreisen der Urheber eingewandt worden, das Urheberrecht müsse als sogenanntes geistiges Eigentum idem Sacheigentum gleichgestellt werden und dem Unheber eine unbeschränkte Herrschaft über sein Werk gewähren. Hierbei wird jedoch verkannt, daß zwischen dem Sacheigentum und dem Urheberrecht grundsätzliche Unterschiede bestehen. Sinn des Sacheigentums ist es, dem Eigentümer die alleinige Herrschaft über die ihm gehörende Sache zu geben, damit er andere von der Benutzung ausschließen kann. U.rhebergut ist dagegen seinem Wesen nach Mitteilungsgut. Ein Geisteswerk soll gerade - jedenfalls von dem Augenblick an, in dem der Urheber es veröffentlicht hat - in seinem Gedanken- oder Gefühlsinhalt möglichst vielen anderen Menschen zugänglich ıgemacht werden. Im Gegensatz zum Sacheigentum ist das Urheberrecht also letztlich nicht dazu bestimmt, andere von der Benutzung des Werkes auszuschließen. Es soll vielmehr in erster Linie idem Urheber die rechtliche Grundlage dafür geben, Art und Umfang der Benutzung seines Wierkes zu überwachen und aus dessen Verwertung Einnahmen zu erzielen. Die Folgerung, die aus der Gleichstellung des "geistigen Eigentums" mit dem Sacheigentum gezogen wind, daß nämlich jede sachliche Beschränkung des Urheberrechts - auch im Interesse ider Allgemeinheit - mit der Rechtsnatur ides Urheberrechts nicht vereinbar sei, ist hiernach nicht berechtigt. Diese Folgerung ist darüber hinaus auch deswegen unrichtig, weil schon das Sacheigentum dem Eigentümer keine uneingeschränkte Herrschaft über die Sache gibt, sondern sein Inhalt und seine Schranken nach Artikel 14 des Grundigesetzes durch das Gesetz festgelegt werden.

\section{Zn $\S 45$ - Recintspflege und öffentliche Sicherheit}

In Verfahren vor Gerichten ader Behörden werden häufig zu Beweiszwecken oder aus andenen Gründen Vervielfältigungsstücke von urheberrechtlich geschützten Werken benötigt, die dem Gericht, der Behöndre und den beteiligten Parteien zugänglich gemacht werden müssen. Es 'sei hierfür insbesondere auf das Patenterteilungrsverfahren verwiesen, bei dem im großen Maße einzelne Stellen aus wissenschaftlichen Werken und Aufsätzen herangezogen werden müissen, um die Frage der Neuheit einer Erfindung zu klären. Die Herstellung solcher Vervielfältigungen soll der Urheber nicht verbieten oder von der Zahhlung einer Vengutung abhängig machen dürfen. Dias Werk wird in diesen Fällen nicht um seiner selbst willen, sondern als Beweisoder sonstiges Hilfsmittel für die zu treffende Entscheidung benutzt. Nach Absatz 1 soll daher die Viervielfältigung in den genannten Fällen frei zulässig sein. Eine entsprechende Bestimmung fehlt im geltenden Recht. Dennoch sind auch bisher Vervielfältigungsstücke geschützter Werke zur Verwendung in Verfahren der Gerichte und Behörden ohne Zustimmung der Urheber hergestellt worden, ohne daß diese dagegen vorgegangen sind. Um klare Verhältnisse zu schaffen, empfiehlt es sich, solche die Urheber nicht beeinträchtigende Vervielfältigungen auch gesetzlich $\mathrm{zu}$ erlauben.

Der Anregung, die Vervielfältigung nur ıdann zuzulassen, wenn das Gericht ader die Behönde sie angeordnet hat, folgt der Entwurf nicht. In Eilfällen würde hierdurch das Verfahren unnötig verzögert werden. Für das Arrestverfahren umd idas Verfahren auf Erlaß einer einstweiligen Venfügung liegt dies auf der Hand. A.ber auch bei sonstigen Verfahren sollten Verzögerungen im Interesse der Rechtspflege möglichst vermieden werden.

Auch der Wunsch, die unveröffentlichten Werke von der Vervielfältigungserlaubnis des $\S 45$ auszunehmen, ist nicht berücksichtigt worden. Die für eine solche Regelung angeführten persönlichkeitsrechtlichen Gründie müssen gegenübber den Interessen ider Rechtspflege zurücktreten, zumal die Vervielfältigungisstücke nur in dem gerichtlichen ader behördlichen Verfiahren selbst benutzt und nicht in Vierkehr gebracht werden dürfen.

Ebensowenig erscheint es geboten, dem Urheber für die Vervielfältigung seines Werkes für Zwrecke der Rechtspflege eine Vergüitung zuzubilligen, weil es sich - wie oben dargelegt — nicht um die Vervielfältigung des Werkes um seiner selbst willen handelt.

Häufig wird sich auch die Notwendigkeit ergeben, in einem gerichtlichen oder einem sonstigen Verfahren Werke zu verbreiten, öffentlich auszustellen, öffentlich vorzulesen, vorzuführen oder sonst öffentlich wiederzugeben. Auch dies muß ohne Zustimmung des Urhebers zulässig sein, weil die 
Rechtspflege durch das Verwertungsrecht des Urhebers nicht beeinträchtigt werden darf. Absatz 3 sieht daher eine entsprechende Vorschrift vor.

Absatz 2 in Verbindung mit Absatz 3 gibt im Interesse der Rechtspflege und der öffentlichen Sicherheit die Bildnisse für den Gebrauch der Behörden im gleichen Umfange frei, wie dies im geltenden Recht ( $\$ 24 \mathrm{KUG}$ ) vorgesehen ist, mit der Maßgabe, daß auch die Funksendung zugelassen ist. Nach dieser Bestimmung soll es z. B. zulässig sein, daß die Staatsanwaltschaft das Bild eines gesuchten Verbrechers ohne Zustimmung des Malers vervielfältigt und verbreitet.

\section{Zu §46 - Sammlungen für Kirchen-, Schul- oder Unterrichtsgebrauch}

Nach geltendem Recht ist es zulässig, kleinere Werke der Literatur oder der Musik sowie einzelne Werke der bildenden Künste oder der Photographie nach ihrem Erscheinen ohne Zustimmung des Urhebers in eine Sammlung aufzunehmen, die Werke einer größeren Zahl von Schriftstellern vereinigt und ihrer Beschaffenheit nach für den Kirchen-, Schul- oder Unterrichtsgebrauch bestimmt ist ( $\S 19$ Nr. 4, § 21 Nr. 3 LUG, § 19 KUG).

Der Entwurf erhält diese Bestimmungen im wesentlichen aufrecht, faßt sie jedoch straffer zusammen (Absatz 1). Nach wie vor ist ein öffentliches Interesse daran anzuerkennen, daß solche für die sittliche und geistige Heranbildung der Jugend unentbehrlichen Hilfsmittel ohne weiteres zur Verfügung stehen. Ihre Herausgabe darf daher nicht von der Zustimmung der Urheber oder Verleger abhängig sein.

Um Mißbräuchen dieser Vorschrift vorzubeugen, ist wie im geltenden Recht vorgeschrieben, daß die Sammlung nach ihrer Beschaffenheit nur für den Kirchen-, Schul- oder Unterrichtsgebrauch bestimmt sein muß. Darüber hinaus verlangt der Entwurf, daß diese Zweckbestimmung im Eingang der Sammlung deutlich anzugeben ist.

Die Ausnahme des Absatzes 1, wie angeregt, auf Vervielfältigungen für den Gebrauch in allgemeinbildenden Schulen zu beschränken, erscheint nicht gerechtfertigt. Die vorgesehene Regelung entspricht dem geltenden Recht und hat bisher nicht zu Mißständen geführt. Ebensowenig übernimmt der Entwurf den Vorschlag, § 46 entsprechend dem geltenden Recht dahin einzuschränken, daß Werke der bildenden Künste oder Lichtbildwerke ausschließlich zur Erläuterung des Inhalts in die Sammlung aufgenommen werden dürfen. Es besteht kein Anlaß, Werke der bildenden Künste oder Lichtbildwerke hier anders zu behandeln als Werke der Literatur und Musik. Auch ein Werk der bildenden Künste oder ein Lichtbildwerk muß ohne Zusammenhang mit dem sonstigen Inhalt lediglich aus aus pädagogischen Gründen in ein Schulbuch aufgenommen werden dürfen.

Andererseits ist aber auch von einer mehrfach angeregten Erweiterung der Ausnahmebestimmung, z. B. auf Sammlungen, die für Jugendpflege oder
Erwachsenenbildung bestimmt sind, Abstand genommen worden. Im Rahmen der Jugendpflege wird man in den meisten Fällen mit den Sammlungen für den Schulgebrauch auskommen. Die Erweiterung auf Sammlungen zu Zwecken der Erwachsenenbildung würde die meisten Sammlungen vom Recht des Urhebers freistellen und damit eine $\mathrm{zu}$ große, durch die Interessen der Allgemeinheit nicht gerechtfertigte Erweiterung der Bestimmung bedeuten.

Einer näheren Abgrenzung des Begriffs der Sammlung bedarf es nicht. Mißverständnisse etwa dahin daß auch Schulbuchreihen als Sammlungen aufgefaßt werden, sind nicht zu befürchten, weil nach der jetzigen Fassung des Entwurfs nur die Vervielfältigung von Werken geringen Umfangs und von Werkteilen zulässig ist, deren Abdruck als selbständiger Band kaum in Betracht kommen dürfte.

In Absatz 2 hat der Entwurf die Regelung des Absatzes 1 stärker eingeschränkt als das geltende Recht. Die Vervielfältigung von Werken der Musik ist nur dann gestattet, wenn die Sammlung für den Musikunterricht an allgemeinbildenden Schulen bestimmt ist. Damit bleibt das Verbotsrecht des Urhebers nicht nur wie im geltenden Recht gegenüber den für Musikschulen bestimmten Sammlungen erhalten, sondern auch gegenüber Sammlungen, die für den Musikunterricht an sonstigen Schulen und für den privaten Musikunterricht bestimmt sind. Diese Abgrenzung erscheint zum Schutze der Urheber geboten. Noten werden wegen des Rückgangs der Hausmusik im wesentlichen nur noch zu Unterrichtszwecken verkauft. Eine weiterreichende Ausnahme zugunsten des Unterrichtsgebrauchs würde daher zur Folge haben, daß bei Werken, die hauptsächlich Unterrichtszwecken dienen, die Herausgabe von Noten überhaupt unterbleibt, weil sie sich nicht mehr wirtschaftlich lohnend gestalten ließe. Soweit es sich um Sammlungen handelt, die für den Musikunterricht in allgemeinbildenden Schulen bestimmt sind, überwiegt der pädagogische Gesichtspunkt, daß den Schülern eine Sammlung zur Verfügung stehen muß, in der alle für ihre Fortbildung in Betracht kommenden Werke enthalten sind; hier muß das Verbotsrecht des Urhebers zurücktreten. Für den privaten und sonstigen Musikunterricht tritt dagegen das Bedürfnis, den Unterrichtsstoff in einer einzigen Sammlung vereinigt in Händen zu haben, zurück; es ist dem Schüler zuzumuten, einzelne Werke gesondert zu erwerben, wenn der Urheber die Aufnahme seines Werkes in eine Sammlung nicht gestattet hat.

Absatz 3 gewährt dem Urheber ein Verbietungsrecht für den Fall, daß ihm wegen gewandelter Uberzeugung die Vervielfältigung seines Werkes für den Kirchen-, Schul- oder Unterrichtsgebrauch nicht zugemutet werden kann. Hier muß das Interesse der Allgemeinheit an solchen Sammlungen gegenüber den persönlichkeitsrechtlichen Interessen des Urhebers zurückstehen. Satz 1 regelt im einzelnen die Voraussetzungen des Verbietungsrechts. Danach kann der Urheber trotz gewandelter Uberzeugung die Vervielfältigung seines Werkes nicht verbieten, solange er ein etwa bestehendes vertragliches Nutzungsrecht nicht zurückgerufen hat. 
Satz 2 erklärt für den Fall, daß mit der Vervielfältigung erlaubterweise schon vor Ausübung des Verbietungsrechts begonnen worden ist, die Ubergangsregelung in $\S 145 \mathrm{Abs}$. 1 und 2 für entsprechend anwendbar, um eine unbillige Schädigung des Verlegers zu verhindern. Dieser darf also die bereits begonnene Vervielfältigung vollenden und die hergestellten Vervielfältigungsstücke verbreiten.

Im Gegensatz zum geltenden Recht sieht der Entwurf in Absatz 4 vor, daß in den Fällen des Absatzes 1 eine angemessene Vergütung an den Urheber zu gewähren ist. Hierdurch bleiben die berechtigten wirtschaftlichen Interessen der Urheber gewahrt. $\S 46$ will nur die Herstellung von Sammlungen für den Kirchen-, Schul- oder Unterrichtsgebrauch unabhängig von der Zustimmung der einzelnen Urheber ermöglichen, deren Werke in die Sammlung aufgenommen werden; mit der Vorschrift wird aber nicht bezweckt, daß derartige Sammlungen auf Kosten der Urheber möglichst billig hergestellt werden können. Im übrigen ist nicht zu erwarten, daß die Zubilligung des Vergütungsanspruches zu einer wesentlichen Verteuerung dieser Sammlungen führen wird.

\section{Zu § 47 - Schulfunksendungen}

Die Sendeunternehmen sind schon seit längerer Zeit dazu übergegangen, regelmäßig Schulfunksendungen zu veranstalten. Diese haben sich zur Ergänzung des Unterrichts in Schulen als nützlich erwiesen. Eine unbeschränkte Verwendung solcher Sendungen im Schulunterricht wird jedoch dadurch behindert, daß die Sendungen, die $\mathrm{zu}$ bestimmten Tageszeiten gesendet werden müssen, nicht immer in den Stundenplan der Schule passen. Es besteht daher das Bedürfnis, Schulfunksendungen in den Schulen auf Tonträger aufzunehmen, um sie dem Lehrplan entsprechend später wiederzugeben. Da die Aufnahme auf Tonträger eine Vervielfältigung darstellt, wäre sie nur mit Zustimmung der Urheber zulässig, deren Werke im Schulfunk gesendet worden sind. Es besteht jedoch ein gerechtfertigtes pädagogisches Interesse daran, die Verwendung der Schulfunksendungen für den Unterricht zu erleichtern. Mit der zunehmenden Entwicklung des Fernsehens wird sich auch das Bedürfnis für die Aufnahme von Bildträgern für den Schulgebrauch ergeben. Nach Absatz 1 soll daher die Aufnahme von Schulfunksendungen auf Bild- und Tonträger zulässig sein.

Eine Vergütung für die Urheber ist in $\S 47$ nicht vorgesehen, weil es sich hierbei nicht um eine zusätzliche Verwertung des Werkes, an der der Urheber zu beteiligen wäre, handelt, sondern der Lehrer nur in die Lage versetzt werden soll, eine Schulfunksendung $\mathrm{zu}$ dem ihm richtig erscheinenden Zeitpunkt in den Lehrplan einzufügen.

Die nach Absatz 2 gestattete weitere Verwertung der Bild- oder Tonträger ist dem Zweck der Bestimmung entsprechend auf die Verwendung im Unterricht beschränkt. Die Verpflichtung zur Unbrauchbarmachung der Bild- und Tonträger ist deshalb gerechtfertigt, weil diese nicht dauerndes Unterrichts- material darstellen, sondern nur dazu dienen sollen, den Empfang der Schulfunksendungen für die Schüler auf einen späteren Zeitpunkt zu verschieben. Bei der vorgesehenen Frist ist auf die Notwendigkeit Rücksicht genommen, das Lehrmaterial jeweils für den Jahrgang der Schüler benutzen zu können, für den die Sendung bestimmt ist.

Der Anregung, die Aufnahme der Sendungen nicht nur für Schulen, sondern auch für Anstalten zur Lehrerbildung und für Hochschulen zu gestatten, ist nicht entsprochen worden. Diesen Instituten, für die die Schulfunksendungen nicht unmittelbar bestimmt sind, kann zugemutet werden, die Erlaubnis der Urheber zur Aufnahme der Sendungen einzuholen. Sie sind im übrigen weniger an kurzlebigen Aufnahmen, sondern an Dauerbändern interessiert, für die ohnehin die Erlaubnis der Urheber notwendig ist.

\section{Zu $\$ 48$ - Offentliche Reden}

$\S 48$ gibt im wesentlichen $\S 17$ LUG wieder, verwendet jedoch nicht die Worte "Vorträge und Reden", sondern spricht nur von "Reden". Eine sachliche Anderung bedeutet dies nicht, weil jeder Vortrag zugleich auch eine Rede im Sinne des § 2 Abs. $1 \mathrm{Nr} .1$ ist.

Absatz 1 Nr. 1 bringt jedoch gegenüber dem geltenden Recht einige Änderungen. Einmal besteht keine Veranlassung, öffentliche Reden für den Abdruck in sämtlichen Zeitschriften freizugeben. Denn solche Reden werden vom Recht des Urhebers nur freigestellt, um die schnelle Unterrichtung der Allgemeinheit zu erleichtern. Diesem Zweck dienen aber nur die Zeitungen und solche. Zeitschriften und Informationsblätter (Nachrichtendienste, Korrespondenzen und dergl.), die im wesentlichen den Tagesinteressen Rechnung tragen. Absatz $1 \mathrm{Nr}$. 1 hat außerdem gegenüber dem geltenden Recht eine weitere Einschränkung erfahren: Nach dem Entwurf sollen nur diejenigen Reden vervielfältigt werden dürfen, die sich mit Tagesfragen befassen. Bei Reden über nicht tagesgebundene Themen, z. B. literarischer oder wissenschaftlicher Art, besteht, selbst wenn sie anläBlich eines Tagesereignisses gehalten werden, nicht ein so großes Interesse der Offentlichkeit an schneller Unterrichtung, daß es gerechtfertigt wäre, auch ihren Nachdruck ohne Zustimmung des Urhebers zu gestatten.

Andererseits erscheint § 17 LUG insofern zu eng, als danach nur Reden freigegeben sind, die Bestandteile einer öffentlichen Verhandlung sind. Das bedeutet, daß stets eine Aussprache im Anschluß an die Rede vorgesehen sein muß. Eine derartige Einschränkung erscheint jedoch nicht gerechtfertigt; denn die Offentlichkeit hat ein gleichgroßes Interesse an der Unterrichtung über Reden, die bei sonstigen öffentlichen Versammlungen gehalten werden, bei denen eine Aussprache nicht vorgesehen ist ( $z$. B. Reden von Abgeordneten und inund ausländischen Staatsmännern). Da die Abdrucksfreiheit künftig nur noch für Zeitungen und zeitungsähnliche Zeitschriften oder Informationsblätter gewährt werden soll, erscheint es bedenkenfrei, die 
Ausnahmevorschrift auf solche Reden auszudehnen. Den bei öffentlichen Versammlungen gehaltenen Reden sind die durch Rundfunk gesendeten Reden gleichgestellt worden. Auch hier besteht für diejenigen, die die Rede selbst nicht hören konnten, ein allgemeines Interesse daran, sich über den Wortlaut der Rede in der Presse zu unterrichten.

Absatz 1 Nr. 2 entspricht sachlich dem geltenden Recht ( $\$ 17 \mathrm{Nr}$. 2 LUG). Jedoch soll die Vervielfältigungserlaubnis nur für Reden bei öffentlichen Verhandlungen vor den dort bezeichneten Organen gelten; denn nur mit dem Interesse der Allgemeinheit an der Unterrichtung über öffentliche Verhandlungen läßt sich die Ausnahmevorschrift rechtfertigen.

Absatz 2 entspricht dem geltenden Recht. Er ist jedoch auf die Fälle des Absatzes 1 Nr. 2 beschränkt worden, weil der Abdruck von Sammlungen in Zeitungen oder zeitungsähnlichen Zeitschriften (Absatz 1 Nr.1) ohnehin nicht in Betracht kommen dürfte. Der Anregung, die Vervielfältigung der in Absatz 1 Nr. 2 bezeichneten Werke in Sammlungen dem Urheber stets vorzubehalten, entspricht der Entwurf nicht. Nur bei Sammlungen, die überwiegend Reden desselben Urhebers enthalten, überwiegt dessen Interesse an der Verwertung seiner Werke gegenüber dem berechtigten Informationsinteresse der Allgemeinheit.

Die in Absatz $1 \mathrm{Nr} .1$ und 2 bezeichneten Reden dürfen auch verbreitet und öffentlich wiedergegeben werden. Dies entspricht dem geltenden Recht ( $\$ 26$ LUG).

\section{Zu $\$ 49$ - Zeitungsartikel}

Absatz 1 bringt dem Inhalt nach nur eine geringe Abweichung von dem bisherigen Rechtszustand ( $\$ 18$ LUG). Die Vorschrift lehnt sich an Artikel 9 der Brüsseler Fassung der Berner Ubereinkunft an. Nach Artikel 9 ist der Inhalt von Zeitungen und Zeitschriften grundsätzlich voll geschützt. Nur Artikel über wirtschaftliche, politische oder religiöse Tagesfragen können durch die Presse abgedruckt werden, wenn ihr Abdruck nicht ausdrücklich vorbehalten ist. Für die Meinungsbildung der Offentlichkeit über die bezeichneten Tagesfragen ist es von erheblicher Bedeutung, daß andere Blätter bereits erschienene Artikel, soweit sie solche Tagesfragen betreffen, aufgreifen können, um die darin vertretene Stellungnahme zu erörtern, sie zu unterstützen oder zu bekämpfen. Eine solche Weiterverbreitung der genannten Artikel liegt auch regelmäßig im Interesse der Zeitung selbst. Wünscht sie gleichwohl den Abdruck nicht, so kann sie ihn durch einen Vorbehalt untersagen.

In einem Punkt bringt der Entwurf eine Erweiterung gegenüber dem geltenden Recht, indem neben den Zeitungen auch Informationsblätter, die im wesentlichen den Tagesinteressen Rechnung tragen, in die Regelung einbezogen werden. Solche Informationsblätter dienen gleichfalls der schnellen Unterrichtung der Offentlichkeit und müssen den Zeitungen gleichgestellt werden. Den Vorschlag, entsprechend Artikel 9 der Berner Ubereinkunft außer den Zei- tungen auch die Zeitschriften in die Ausnahmebestimmung einzubeziehen, übernimmt der Entwurf nicht, weil Zeitschriften auch zu politischen, wirtschaftlichen oder religiösen Tagesfragen oft Artikel enthalten, die bleibende Bedeutung haben und deshalb unabhängig von einem Vorbehalt gegen Nachdruck geschützt werden sollten.

Nach Absatz 1 ist auch die Verbreitung und die öffentliche Wiedergabe, d. h. der öffentliche Vortrag und die Funksendung der dort bezeichneten Artikel zugelassen. Dies entspricht $\$ 26$ LUG. Dort ist allerdings die Zulässigkeit der Funksendung nicht erwähnt. Nach der im Schrifttum herrschenden Ansicht ist jedoch schon nach geltendem Recht die Funksendung solcher Artikel zulässig; denn der Rundfunk dient ebenso wie die Presse dazu, die Allgemeinheit über Tagesfragen zu unterrichten.

Absatz 2, der die vermischten Nachrichten tatsächlichen Inhalts und Tagesneuigkeiten betrifft, entspricht sachlich dem § 18 Abs. 3 LUG und dem Artikel 9 Abs. 3 der Berner Ubereinkunft. In der Regel werden Nachrichten tatsächlichen Inhalts und Tagesneuigkeiten, die durch Presse oder Funk veröffentlicht worden sind, überhaupt keine Werke im Sinne des $\S 2$ darstellen, weil sie keine persönlichen geistigen Schöpfungen sind. Sie unterliegen dann dem Urheberrecht nicht. Es ist aber möglich, daß die Wiedergabe einer Tagesneuigkeit in einer individuellen Form geschieht und deshalb als Werk anzusehen ist. Auch in diesem Falle besteht ein Interesse der Allgemeinheit an einer unbeschränkten Vervielfältigung. Anderenfalls müßte bei jeder einzelnen Nachricht nachgeprüft werden, ob sie infolge ihrer besonderen Form ausnahmsweise Werkcharakter hat; gerade das soll jedoch im Hinblick auf die Notwendigkeit einer schnellen Nachrichtenverbreitung vermieden werden. Absatz 2 gibt daher die Vervielfältigung, Verbreitung und öffentliche Wiedergabe von vermischten Nachrichten tatsächlichen Inhalts und von Tagesneuigkeiten frei, die durch Presse oder Funk veröffentlicht worden sind. Es handelt sich hierbei nur um eine Freigabe vom urheberrechtlichen Schutz. Ein sich aus anderen gesetzlichen Vorschriften - z. B. nach dem Gesetz gegen den unlauteren Wettbewerb - ergebender Schutz soll unberührt bleiben, wie ausdrücklich klargestellt ist.

\section{Zu $\$ 50$ - Bild- und Tonberichterstattung}

In den Programmen der Lichtspieltheater ist die filmische Berichterstattung über Tagesereignisse (Wochenschauen) ein regelmäßiger Bestandteil geworden. Auch durch Rundfunk und Fernsehen wird täglich über Tagesereignisse berichtet. Bei derartigen Wiedergaben von Tagesereignissen ist es oft unvermeidlich, daß einzelne Stellen geschützter Werke oder ganze Werke geringen Umfangs, die bei dem Ereignis vorgetragen oder aufgeführt werden, den Besuchern der Lichtspieltheater oder den Rundfunkhörern wahrnehmbar gemacht werden. Es erscheint nicht gerechtfertigt, die Unterrichtung der Allgemeinheit über Tagesereignisse in dieser besonders anschaulichen Form dadurch zu erschweren, daß sie 
an die Zustimmung des Urhebers der geschützten Werke gebunden wird. Bereits nach geltendem Recht ist es daher durch das Gesetz zur Erleichterung der Filmberichterstattung vom 30. April 1936 (RGBl. I S. 404) gestattet, bei der Filmaufnahme solcher Berichte auch urheberrechtlich geschützte Werke, die im Verlauf der festgehaltenen Vorgänge für Auge und $\mathrm{Ohr}$ wahrnehmbar werden, mitzuverfilmen. Eine ähnliche Bestimmung enthält auch Artikel 10 bis der Brüsseler Fassung der Berner Ubereinkunft. Artikel 10 bis weicht insofern von dem Gesetz zur Erleichterung der Filmberichterstattung $a b$, als er sich nur auf kurze Bruchstücke von Werken bezieht. Es kann jedoch vorkommen, daß bei der Veranstaltung, die Gegenstand des Berichts ist, ein ganzes Werk geringen Umfangs vorgetragen oder aufgeführt wird, z. B. ein kleines Gedicht oder ein kurzes Lied. Die Aufnahme eines solchen ganzen Werkes in den Bericht von der Zustimmung des Urhebers abhängig zu machen, besteht ebensowenig ein Grund wie für Bruchstücke größerer Werke. Es kann nicht der Sinn der Berner Ubereinkunft sein, auch in solchen Fällen nur die Aufnahme von Tejlen der Werke zu gestatten. Es bedeutet hiernach zwar einen Verstoß gegen den Wortlaut des Artikels 10 bis, nicht aber gegen den Sinn der Berner Ubereinkunft, wenn ein Verbandsstaat dementsprechend die Aufnahme ganzer Werke in den Bericht zuläßt, zugleich aber den Umfang der zugelassenen Benutzung der Werke zur Verhütung von Mißbräuchen in anderer Weise begrenzt. Im Entwurf ist daher die Aufnahme und Wiedergabe ganzer Werke zu Zwecken der Berichterstattung zugelassen, zur Verhinderung von Mißbräuchen aber bestimmt, daß die Werke nur in einem durch den Zweck der Berichterstattung gebotenen Umfange vervielfältigt, verbreitet und öffentlich wiedergegeben werden dürfen.

Artikel 10 bis der Berner Ubereinkunft bringt andererseits gegenüber dem Gesetz zur Erleichterung der Filmberichterstattung eine Erweiterung. Er bezieht sich nicht nur auf Filmberichte, sondern auch auf Funk- und Bildberichte über Tagesereignisse. Diese Erweiterung erscheint gerechtfertigt und wird vom Entwurf übernommen. Die Bildberichterstattung ist jedoch nicht allgemein freigegeben, sondern nur für Zeitungen und Zeitschriften, die im wesentlichen den Tagesinteressen Rechnung tragen, weil die Bestimmung des $\S 50$ nur dem Bedürfnis der Offentlichkeit nach Unterrichtung über Tagesereignisse entsprechen soll.

Den Vorschlag, die Urheber an den Einnahmen aus den Funk-, Film- oder Bildberichten zu beteiligen, hat der Entwurf nicht übernommen. Das Werk bildet nicht den eigentlichen Gegenstand der Berichterstattung. Die Einnahmen beruhen daher in der Regel nicht auf der Wiedergabe des Werkes.

\section{Zu $§ 51$ - Zitate}

In $\S \S 19,21,23$ LUG und $\S 19$ KUG ist geregelt, in welchen Fällen einzelne Werke oder einzelne Stellen eines Werkes ohne Zustimmung des Urhebers in einem selbständigen Werk eines anderen Urhebers zitiert werden dürfen. Der Entwurf behält diese Bestimmungen im wesentlichen bei, faßt sie aber straffer zusammen.

$\S 51 \mathrm{Nr} .1$ regelt das sog. "große Zitat" zu wissenschaftlichen Zwecken. Im Gegensatz zum geltenden Recht ( $\$ 19$ Nr. 2 und $\S 21$ Nr. 2 LUG) dürfen nicht nur einzelne Aufsätze von geringem Umfang, einzelne Gedichte oder kleinere Kompositionen zitiert werden, sondern einzelne Werke schlechthin, wie es in $\S 19$ Abs. $1 \mathrm{KUG}$ vorgesehen ist; jedoch darf dies nur zur Erläuterung des Inhalts in einem durch den Zweck gebotenen Umfang geschehen. Die Regelung im $\S 51 \mathrm{Nr} .1$ ist elastischer als die des geltenden Rechts und gestattet das große Zitat nur in den tatsächlichen gerechtfertigten Fällen.

In $\S 51$ Nr. 2 ist das sog. "kleine Zitat" geregelt, das literarischen Zwecken dient. Die Vorschrift entspricht im wesentlichen $\S 19 \mathrm{Nr} .1$ und $\S 21 \mathrm{Nr} .1$ LUG. Dabei ist jedoch der im geltenden Recht verwendete Ausdruck „kleinere Teile“ wegen seiner Unbestimmtheit fortgelassen worden; eine sachliche Anderung ist damit nicht beabsichtigt. Die neue Regelung bringt insofern eine Erweiterung, als das Zitat musikalischer Werke bereits nach der Veröffentlichung des Werkes zulässig sein soll, während es nach geltendem Recht erst nach dem Erscheinen des Musikwerkes erlaubt ist ( $\$ 21 \mathrm{Nr}, 1$ LUG).

In $\S 51 \mathrm{Nr} .3$ ist das Musikzitat, das nach herrschender Ansicht schon nach dem geltenden Recht zulässig ist, unter bestimmten Voraussetzungen weiter zugelassen. Die hiergegen geäußerten Bedenken erscheinen nicht stichhaltig. Da das Musikzitat nur in einem durch den Zweck gebotenen Umfang in ein selbständiges Werk der Musik aufgenommen werden darf, sind Mißbräuche nicht zu befürchten.

Die Bestimmung in $\S 51 \mathrm{Nr}$. 4 steht im Zusammenhang mit der Neuerung des Entwurfs, daß in Zukunft - im Gegensatz zur Regelung in § 13 Abs. 2 LUG - ein Werk der Tonkunst nach den allgemeinen Grundsätzen zur Schaffung eines selbständigen neuen Werkes frei verwendet werden darf, selbst wenn dabei dem benutzten Werk erkennbar eine Melodie entnommen wird ( $(24)$. Für den Fall, daß in freier Benutzung eines fremden Themas ein Variationenwerk geschaffen wird, bedarf diese Regelung einer Ergänzung. Es muß zulässig sein, einem solchen Variationenwerk das benutzte Thema unverändert voranzustellen, wie es allgemein üblich und zum Verständnis des Variationenwerks in der Regel erforderlich ist. Die gegen die Zulassung einer solchen Benutzung des fremden Werkes erhobenen Einwände richten sich im wesentlichen nicht gegen die Zitierbefugnis, sondern dagegen, daß es unter bestimmten Voraussetzungen gestattet sein soll, ein Werk für die Schaffung eines Variationenwerkes zu benutzen und dieses ohne Einwilligung des Urhebers des benutzten Werkes zu verwerten. Inwieweit dies zulässig ist, ergibt sich aber nicht aus $\S 51 \mathrm{Nr}$. 4, sondern aus den $\S \S 23$ und 24 des Entwurfs.

\section{Zu $§ 52$ - Vertonungsfreiheit}

Das geltende Recht ( $\$ 20$ LUG) gibt Dichtungen und Gedichte in gewissem Umfange für die Vertonung frei. Danach ist jeder Komponist berechtigt, kleine 
Teile einer Dichtung oder Gedichte von geringem Umfang nach ihrem Erscheinen zu vertonen und in Verbindung mit dem dazu geschaffenen Tonwerk $\mathrm{zu}$ vervielfältigen. Zweck der Vorschrift ist, dem musikalischen Schaffen Spielraum zu gewähren und es dadurch zu fördern. Gegen diese Regelung sind Bedenken erhoben worden. Es ist geltend gemacht worden, daß jeder Urheber grundsätzlich die volle Verfügung über sein Werk haben und auch die künstlerische Verantwortung dafür tragen müsse. Es müsse daher der Entscheidung des Dichters überlassen bleiben, ob er eine Vertonung seines Werkes erlaube. Es gebe Fälle, in denen er eine Vertonung ablehne, weil er darin eine Beeinträchtigung seines dichterischen Werkes erblicke.

Diese Bedenken erscheinen nicht schwerwiegend genug, um die bisher gegebene Vertonungsfreiheit zu beseitigen. Sie stellen einseitig auf den Grundsatz der Verfügungsfreiheit des Dichters über sein Werk $\mathrm{ab}$ und berücksichtigen nicht genügend die besonderen Belange des musikalischen Schaffens. Der Liederkomponist ist weitgehend auf vorhandene Texte angewiesen und wird zum Teil erst durch sie zu seiner Komposition angeregt. Ihn auf die Zustimmung des Textdichters zu verweisen, der möglicherweise eine andere Kunstrichtung vertritt oder aus vielleicht nicht einmal anerkennenswerten Gründen eine Vertonung seines Werkes nicht wünscht, hieße, die Schaffensmöglichkeit der Komponisten in erheblichem Maße einengen und würde zur Folge haben, daß der Allgemeinheit wertvolle Liederkompositionen vorenthalten würden. Zudem hat die Vertonungsfreiheit, von Einzelfällen abgesehen, in der Vergangenheit zu keinen Unzuträglichkeiten geführt.

Der Entwurf erhält daher die Vertonungsfreiheit aufrecht (Absatz 1). Er sieht jedoch eine Beteiligung des Textdichters an den Erträgnissen aus der Verwertung des vertonten Werkes vor, weil es nicht gerechtfertigt erscheint, das Recht des Dichters zugunsten des Komponisten wie im geltenden Recht entschädigungslos einzuschränken. In Absatz 4 ist daher ein Anspruch des Urhebers auf angemessene Vergütung gegen jeden vorgesehen, der sein Werk in Verbindung mit dem Werk der Musik vervielfältigt, verbreitet oder öffentlich wiedergibt.

Nach § 20 Abs. 3 LUG ist die Vervielfältigung des vertonten Gedichts durch Ubertragung auf Tonträger ohne Genehmigung des Urhebers des Gedichts nicht zulässig. Diese Vorschrift stammt aus dem Jahre 1910; sie ist heute nicht mehr gerechtfertigt. Inzwischen ist die Qualität der Tonträger so verbessert worden, daß diese ein hervorragendes Mittel zur Wiedergabe von Werken darstellen. Der Entwurf hat deshalb die Ausnahmevorschrift des $\S 20$ Abs. 3 LUG nicht übernommen.

Absatz 2 nimmt ebenso wie $\S 20$ Abs. 2 LUG Sprachwerke, die ihrer Gattung nach zur Vertonung bestimmt sind, von der Vertonungsfreiheit aus. Es ist hier an die Texte von Oratorien, Opern, Operetten, Singspielen und Schlagern gedacht. Das gleiche soll für Werke gelten, die ausschließlich als Text zu einem Werk der Musik erschienen sind.
Absatz 3 entspricht dem geltenden Recht ( $\$ 20$ Abs. 1 Satz 2 LUG).

\section{Zu §53 - Offentliche Wiedergabe}

Nach § 27 LUG ist es in einigen Fällen gestattet, ein erschienenes Werk der Tonkunst ohne Zustimmung des Urhebers öffentlich aufzuführen. Diese Einschränkung des Aufführungsrechts wind damit gerechtfertigt, daß in dien bezeichneten Fällen idie Interessen ider Allgemeinheit an ider freien Aufführung der Werke die Interessen des Urhebers überwiegen.

Aus Kreisen der Urhelber ist die Fonderung erhoben worden, die Vorschrift ides § 27 LUG ensatzlos zu streichen. Sie berufen sich zur Begründung dieser Forderung darauf, daß eine iderartige Vorschrift weder mit der Brüsseler Fassung der Berner Übereinkunft noch mit dem W'esen des Unheberrechts vereinbar sei. Dies kann indessen nicht anenkannt werden.

Was die Brüsseler Fassung der Berner Ubereinkunft anbelangt, so stellt diese zwar in Artikel 11 den uneingeschränkten Grundsatz auf, Idaß die Urheber musikalischer Werke das ausschließliche Recht genießen, die öffentliche Aufführung ihrer Werke zu erlauben. Nach dem bloßen Wortlaut dieses Artikels wären irgendwelche Einschränkungen des Aufführungsrechts des Urhebens idurch die Gesetzgebung der Verbandsländer nicht zulässig. In dieser Unbedingtheit ist jedoch ider Artikel 11 nicht auszulegen. Bei der Brüsseler Revisionskonferenz wuride vielmehr zum Ausdruck grebnacht, daß ıdie innere Gesetzgebung der Verbandsstaaten gewisse kleine Ausnahmen zulassen könne, insbesondere für kirchliche Feierlichkeiten, für Militärveranstaltungen und zu Zwecken des Unterrichts. Im einzelnen sind idie möglichen Ausnahmen nicht festgelegrt. Es ist daher den Verbandsstaaten überlassen, die einzelnen Ausnahmen ihren nationalen Auffassungen und Gegebenheiten entsprechend zu bestimmen. Die Staaten, die derartige Ausnahmen in ihren Urheberrechtsgesetzen vorsehen, befinden sich also nicht im Widerspruch mit der Brüisseler Fassung ider Berner Ubereinkunft. Tatsächlich finden sich solche Ausnahmen in der Urheberrechts.gesetzgebung ider meisten Verbandsstaaten.

Wie schon in der Vorbemerkung $\mathrm{zu}$ diesem $\mathrm{Ab}$ schnitt dargelegt, sind Einschränkungen des Rechts des Urhebers im Allgemeininteresse mit dem Wesen des Urheberrechts vereinbar. Es ist kein Grund ersichtlich, das Aufführungsrecht des Unhelbers diesem allgemeinen Rechtsgrundsatz nicht zu unterwerfen und die Interessen der Allgemeinheit diesem Recht gegenübler zurücktreten zu lassen.

Der Entwurf sieht daher im Einklang mit idem geltenden Recht auch weiterhin Ausnahmen von dem Aufführungsrecht des Urhebers vor. Eine unveränderte Ubernahme des § 27 LUG wind indessen nicht vorgeschlagen. Es erscheint einerseits angebracht, die in dieser Vorschrift zugelassenen Ausnahmen wesentlich einzuschränken, andenerseits ıürfte zur 
sachgemäßen Wahrung ider Interessen der Allgemeinheit eine gewisse Erweiterung notwendig sein. Im reinzelnen ist hierzu folgrendes zu bemerken:

Die in $\S 27$ Abs. 1 Satz 2 Nr. 1 bis 3 LUG enthaltenen Ausnahmen zugunsten der Veranstaltungen bei Volksfesten sowie zugunsten der Wohltätigkeits- und Vereinsveranstaltungen sind gestrichen.

Die Ausnahme für Veranstaltungen bei Volksfesten ist in jüngster Zeit Gegenstand mehrerer Entscheidungen des Bundesgerichtshofs gewesen (vigl. Entscheidungen vom 6. Dezember 1955, BGHZ 19 S. 227, Anlage $5[\mathrm{I}]$, und BGHZ 19 S. 235). Der Bundesgerichtshof hat in diesen Entscheidungen unter Berufung auf die Entstehungsgeschichte der Ausnahme nur solchen Festen den Charakter eines Volksfestes zuerkannt, "die von allen Bevölkerungsschichten ohne Ansehung ider Person, ides Standes oder Vermögens aufgrund einer längeren Tradition gefeiert werden, und zwar so, daß dem Sinngehalt ides Festes entsprechend idas Volk als Trägrer der Veranstaltung erscheint". Als solche Feste werden im allgemeinen Karnevals-, Kirmes- und Schützenfeste anzusehen sein. Nicht alle Musikveranstaltungen anläßlich von Volksfesten fallen jedoch nach der Rechtsprechung unter die Befreiungsvorschrift. Vielmehr müssen die einzelnen Veranstaltungen selbst nach der Art ihrer Durchführung idie oben wiedergegebenen Merkmale eines Volksfestes aufwieisen. Daran fehlt es, wenn durch die Erhebung eines Eintrittsgeldes - im entschiedenen Falle in Höhe von $1 \mathrm{DM}$ - die allgemeine Zugänglichkeit zu ıder Veranstaltung ausgeschlossen wird. Aber auch wenn kein Eintrittsgeld erhoben wind, ist eine Veranstaltung nicht als Bestandteil eines Volksfestes anzusehen, wenn sie vornehmlich gewerblichen, auf Gewinn gerichteten Interessen des Veranstalters dient, der das Volksfest nur benutzt, um seinen Absatz zu steigern. Nach dieser vom Bundesgerichtshof vorgenommenen Auslegung der Begriffe "Volksfest" und "Veranstaltung bei Volksfesten", die, soweit ersichtlich, überwiegend Zustimmung gefunden hat, entfällt die Vergütungsfreiheit für eine große Zahl von Veranstaltern, die sich bisher auf die Ausnahmevorschrift des geltenden Rechts berufen kkonnten. Für idie verbleibende, vergleichsweise geringe Zahl von Veranstaltungen, die nach ider Rechtsprechung als Veranstaltungen ibei Volksfesten anzusehen sind, dürfte eine gesetzliche Sonderregelung nicht gerechtfertigt sein, zumal die Durchführung von Volksfesten mehr und mehr einen kommerziellen Chanakter annimmt.

Gegen die Ausnahme zugunsten von Wohltätigkeitsveranstaltungen ist mit Recht eingewandt worden, Idaß Idas Gesetz den Urheber nicht zur Wohltätigkeit zwingen könne, sondern diese seinem eigenen, freien Entschluß überlassen müsse. Es kann davon ausgegangen werden, daß die Urheber in solchen Fällen den Veranstaltern ientgegenkommen werden. Im übrigen kann den Belangen der Vieranstalter durch die Vorschrift des $\S 13$ Albs. 3 ides Entwurfs eines Verwertungsgesellschaftengesetzes Rechnung getragen werden, die idie Verwertungsgesellschaften, die die Rechte ider Urheber insoweit wahrnehmen, anhält, bei ihrer Tarifgestaltung auf religiöse, kultu- relle und soziale Belange der Veranstalter einschließlich der Belange der Jugendpflege angemessene Rücksicht zu nehmen.

Die Ausnahme für Vereinsveranstaltungen ist gleichfalls nicht in den Entwurf übernommen worden. Der Begriff der Offentlichkeit wird zwar im Unheberrecht weiter ausgelegt als in anderen Rechtsgebieten, beispielsweise dem Strafrecht. Aber auch nach dem weitergefaßten Begriff des Urheberrechts wind eine Veranstaltung jedenfalls dann nicht als öffentlich angesehen, wenn der Kreis der Teilnehmer bestimmt abgegrenzt ist und sie durch gegenseitige Beziehungen oder durch Beziehungen zum Veranstalter persönlich untereinander verbunden sind ( $\$ 15$ Abıs. 3). Danach wird für Vieranstaltungen kleinerer Vereine, zu denen nur die Mitglieder und die zu ihrem Hausstand gehörigen Personen zugelassen werden, das Merkmal Ider Offentlichkeit in ider Regel zu verneinen sein, so daß für Aufführungen bei solchen Veranstaltungen schon aus diesem Grunde die Zustimmung des Urhebers nicht erforderlich ist. Für solche Vereine ist daher eine Ausnahmevorschrift unnötig. Bei Vereinen dagegen, die über eine große Zahl von beitragenden und unterstützenden Mitgliedern verfügen, enscheint eine Ausnahmevorschrift sachlich nicht gerechtfertigt.

Der Entwurf sieht daher nur noch zwei Ausnahmen vor:

1. Absatz 1 Nr. 1 übernimmt mit einigen Anderungen die bereits im geltenden Recht $(\S 27$ Abs. 1 Satz 1 LUG) enthaltene Bestimmung zugunsten von Veranstaltungen, die keinem gewerblichen Zweck dienen und bei denen die Teilnehmer ohne Entgelt zugelassen werden. Die Bestimmung soll jedoch zugunsten der Urheber eingeschränkt werden. Wenn auch die Veranstalter keinen gewerblichen $Z$ weck verfolgen und aus dem Werk keine Einnahmen erzielen, so werden doch im Falle der Aufführung eines Werkes in der Regel die mitwirkenden Künstler von dem Veranstalter für ihre Tätigkeit entlohnt. Wenn dies aber der Fall ist, so erscheint es nicht gerechtfertigt, den Schöpfer des Werkes leer ausgehen zu lassen. Demgemäß soll nach dem Entwurf die Zustimmung des Urhebers für derartige Veranstaltungen nur dann nicht erforderlich sein, wenn für die Mitwirkung der ausübenden Künstler keine besondere Vergütung gezahlt wird.

In Abweichung vom geltenden Recht spricht der Entwurf nicht vom gewerblichen Zweck schlechthin, sondern vom Erwerbszwedk des Veranstalters. Dies stellt einerseits eine Einschränkung, andererseits eine Erweiterung gegenüber dem geltenden Recht dar. Der Urheber wird insofern günstiger gestellt, als damit die Aufführungsfreiheit nicht Veranstaltern zukommt, die das Werk zwar nicht im Rahmen eines Gewerbebetriebes, aber zur unmittelbaren oder mittelbaren Förderung ihres eigenen Erwerbs auffüh ren. Andererseits kommt es nach der Fassung des Entwurfs darauf an, daß der Veranstalter selbst einen Erwerbszweck verfolgt. Auf Grund des geltenden Rechts ist durch die Rechtspre- 
chung die Anwendung des $\S 27$ Abs. 1 Satz 1 LUG auch in den Fällen ausgeschlossen worden, in denen die Veranstaltung dem gewerblichen Zweck eines Dritten dient (vgl. Entscheidung des Bundesgerichtshofs vom 6. Dezember 1955, BGHZ 19 S. 227, Anlage 5 [I]). So ist u. a. entschieden worden, daß eine Veranstaltung einem gewerblichen Zweck im Sinne des § 27 Abs. 1 Satz 1 LUG diene, wenn ein Verein die öffentliche Aufführung in einem von ihm gemieteten Saal eines Gasthauses veranstaltet und der Gastwirt die Lieferung der Speisen und Getränke übernommen hat. Zur Begründung wurde ausgeführt, daß die Aufführung Gäste anziehe und damit den Absatz an Speisen und Getränken steigere. Damit diene sie einem gewerblichen Zweck, nämlich dem des Gastwirts. Es erscheint in diesen Fällen indes nicht gerechtfertigt, die Verpflichtung zur Zahlung von Gebühren an den Urheber dem Verein aufzuerlegen, der keine gewerblichen Zwecke verfolgt. Dagegen dürfte es billig sein, dem Dritten, dessen Erwerbszweck die Veranstaltung dient, die Verpflichtung aufzuerlegen, dem Urheber eine angemessene Vergütung zu gewähren, wie es in Absatz $1 \mathrm{Nr} .1$ Satz 2 nunmehr vorgesehen ist. Dem Urheber darüber hinaus einen Vergütungsanspruch auch dann zu gewähren, wenn weder der Veranstalter noch ein Dritter gewerblichen Gewinn aus der Veranstaltung zieht, würde der natürlichen Auffassung über die sachgemäße Abgrenzung des Umfanges des Urheberrechtsschutzes nicht entsprechen. Eine Wandergruppe muß ein Lied öffentlich singen dürfen, ohne sich einer Vergütungspflicht auszusetzen. Ebenso müssen öffentliche Schüleraufführungen und ähnliche Veranstaltungen, bei denen kein Eintrittsgeld gefordert und kein Erwerbszweck verfolgt wird, unbeschränkt zulässig bleiben.

2. Absatz 1 Nr. 2 sieht eine in dieser Form im geltenden Recht nicht enthaltene Ausnahme zugunsten kirchlicher Feierlichkeiten vor. In der Regel werden kirchliche Feierlichkeiten ohnehin unter die Regelung des Absatzes 1 Nr. 1 fallen, weil der Zutritt zu diesen Veranstaltungen frei ist und die mitwirkenden Künstler kein besonderes Entgelt erhalten. Der Entwurf stellt jedoch nicht nur solche Feierlichkeiten, sondern alle Veranstaltungen der Kirchen oder sonstigen Religionsgesellschaften vom Verbotsrecht des Urhebers frei. Diese Erweiterung der Ausnahmebestimmung erscheint vertretbar, weil in allen Fällen des Absatzes 1 Nr. 2 dem Urheber ein Vergütungsanspruch gewährt werden soll, und zwar selbst dann, wenn an sich zugleich die Voraussetzungen für eine vergütungsfreie Werknutzung nach Absatz 1 Nr. 1 gegeben wären. Der umfassende Vergütungsanspruch entspricht einer Anregung der Kirchen und beruht auf der Erwägung, daß für Werke der Kirchenmusik eine Verwertung außerhalb kirchlicher Veranstaltungen kaum in Betracht kommt, die Urheber dieser Werke ohne den Vergütungsanspruch also keine ausreichenden Einnahmen aus ihren Werken erhalten würden.
Während § 27 LUG sich nur auf die öffentliche Aufführung eines Werkes bezieht, ist $\S 53$ des Entwurfs auf alle Fälle der öffentlichen Wiedergabe (§ 15 Abs. 2) mit Ausnahme der in Absatz 2 genannten Fälle erstreckt worden. Das bedeutet jedoch keine Anderung des geltenden Rechts. Ein Vortragsrecht besteht für erschiene Werke im geltenden Recht nicht. Die Wiedergabe musikalischer Werke durch Tonträger und die Wiedergabe von Funksendungen solcher Werke fallen zur Zeit unter den Begriff "Aufführung " und das Recht zur Vorführung eines Werkes der bildenden Künste oder eines Werkes der Photographie ist nach $\S 15$ KUG auf Fälle der gewerbsmäßigen Verwertung beschränkt, die ohnehin nicht unter $\S 53$ fallen.

Absatz 2 entspricht dem geltenden Recht (\$ 27 Abs. 2 LUG), nach dem die bühnenmäßige Aufführung von Werken von der Aufführungsfreiheit ausgenommen ist. Die Ausnahme beruht auf dem Gedanken, daß die bühnenmäßige Aufführung eines Werkes einen so großen Aufwand erfordert, daß es den Veranstaltern zugemutet werden kann, auch die Vergütung für die Urheber zu zahlen. Das gleiche gilt auch für die Funksendung und die Vorführung eines Filmwerkes; der Entwurf stellt daher diese Verwertungsarten der Bühnenaufführung gleich.

\section{Zu § 54 - Vervielfältigung zum persönlichen Gebrauch}

Das geltende Recht läßt die Vervielfältigung von Werken ohne Erlaubnis des Urhebers für persönliche Zwecke zu, grenzt also insoweit das ausschließliche Vervielfältigungsrecht des Urhebers ein. So ist gemäß § 15 Abs. 2 LUG eine Vervielfältigung zum persönlichen Gebrauch zulässig, wenn sie nicht den Zweck hat, aus dem Werke eine Einnahme zu erzielen. Ahnlich ist in $\S 18$ Abs. 1 KUG bestimmt, daß eine Vervielfältigung zum eigenen Gebrauch zulässig ist, wenn sie unentgeltlich bewirkt wird. Trotz der verschiedenen Ausdrucksweise verstehen beide Gesetze unter persönlichem und eigenem Gebrauch im wesentlichen dasselbe, nämlich die Vervielfältigungsfreiheit für den Gebrauch ıder Person, die die Vervielfältigung herstellt oder herstellen läßt, und der mit ihr durch ein persönliches Band verknüpften Personen. Nach herrschender Ansicht wird auf Grund dieser Vorschriften bis $\mathrm{zu}$ einem gewissen Grad auch die Vervielfältigung zum beruflichen Gebrauch als zulässig angesehen, jedoch wird hierbei § 18 Abs. 1 KUG enger ausgelegt als $\S 15$ Abs. 2 LUG. Im einzelnen ist die Auslegung dieser Begriffe streitig.

Hinsichtlich der Art und Weise der zugelassenen Vervielfältigung zum persönlichen Gebrauch enthalten die geltenden Gesetze keine einengenden Bestimmungen etwa dergestalt, daß die Vervielfältigung nur mit der Hand oder mit ider Schreibmaschine vorgenommen werden dürfte. In den Begründungen zum LUG und zum KUG ist vielmehr ausdrücklich erwähnt, daß auch mechanische Vervielfältigungsverfahren zulässig seien.

Der Gesetzgeber konnte allerdings seinerzeit davon ausgehen, daß durch idiese Begrenzung des Vervielfältigungsrechts des Urhebers für diesen keine fühl- 
bare Einbuße bei der Verwertung seiner Werke entstehen werde; denn zu Anfang dieses Jahrhunderts war noch das Abschreiben mit der Hand oder mit der Schreibmaschine das gebräuchliche Vervielfältigungsverfahren. Mechanische Verfahren, mit denen einzelne Vervielfältigungsstücke eines Werkes, die den im Handel befindlichen Exemplaren gleichwertig gewesen wären, auf billige Weise hergestellt werden konnten, waren noch nicht bekannt. Zwar gab es schon Apparate, durch die man Musikaufführungen auf Wachsrollen aufnehmen konnte. Die Qualität dieser Tonträger war aber so gering, daB sie mit den von der Industrie hergestellten Schallplatten keinen Vergleich aushielten. In den letzten Jahren haben nun neue Erfindungen einschneidende Änderungen auf dem Gebiet der Vervielfältigungsverfahren gebracht und damit Probleme aufgeworfen, die für das Urheberrecht von weittragender Bedeutung sind. Diese Erfindungen sind das Magnettongerät, die Mikrokopie und die verbesserte Fotokopie.

Durch das Magnettongerät ist es möglich, auf billige und bequeme Weise ein Werk auf Tonträger aufzunehmen. Diese Tonträger stehen in ihrer Qualität den von der Industrie vertriebenen Schallplatten kaum nach. Durch die verbesserten Verfahren der Fotokopie kann jedermann nunmehr in kurzer Zeit Fotokopien eines literarischen Werkes oder eines Werkes der Tonkunst herstellen. Im Hinblick auf diese gegenüber früher geänderte Lage ist von Seiten der Urheber die Forderung erhoben worden, die Vervielfältigung zum persönlichen Gebrauch mit diesen neuen technischen Mitteln nicht zuzulassen. Zur Begründung ist geltend gemacht worden, daß der Absatz der Werke leiden werde, wenn man gestatte, daß sich jedermann mit Hilfe dieser Apparate hochwertige Vervielfältigungsstücke frei herstellen dürfe. Darüber hinaus bestehe auch die Gefahr, daß die auf diese Weise hergestellten Vervielfältigungsstücke mißbräuchlich verwertet würden. Eine mit der Hand oder mit der Schreibmaschine hergestellte Abschrift eines Werkes sei im Handel kaum abzusetzen, eine gute Fotokopie oder ein Tonband dagegen sei leicht an Dritte zu verkaufen.

Für das geltende Recht sind diese Fragen zum Teil bereits vom Bundesgerichtshof entschieden worden. Während der Bundesgerichtshof die Frage, ob Fotokopien zum persönlichen Gebrauch ohne Einwilligung des Urhebers zulässig sind, offengelassen hat (vgl. Entscheidung vom 24. Juni 1955, BGHZ 18 S. 44, Anlage 4 [III 6]) hat er die Herstellung von Vervielfältigungen zum persönlichen Gebrauch mittels Magnettongeräts schon nach geltendem Recht für unzulässig erklärt (vgl. Entscheidung vom 18. Mai 1955, BGHZ 17 S. 266, Anlage 3 [A IV]). Diese Entscheidung beruht im wesentlichen auf der Erwägung, daß durch die Zulassung der privaten Tonaufnahme der Absatz von Schallplatten zum Nachteil der Urheber beeinträchtigt werden könnte.

Abweichend von dieser für das geltende Recht ergangenen Entscheidung läßt der Entwurf die private Vervielfältigung zum persönlichen Gebrauch ohne Rücksicht auf die Art des Vervielfältigungsverfahrens grundsätzlich zu (Absatz 1), sieht jedoch für die Aufnahme auf Bild- oder Tonträger einen Vergütungsanspruch vor (Absatz 3). Hierfür waren folgende Erwägungen maßgebend:

Ein Verbot der privaten Vervielfältigung kann in der Praxis nicht durchgesetzt werden. Eine wirksame Uberprüfung könnte nur dann durchgeführt werden, wenn den Kontrolleuren der privaten Verwertungsgesellschaften gestattet werden würde, die Wohnung jedes einzelnen Staatsbürgers daraufhin zu überprüfen, ob er ein Magnettongerät besitzt, mit diesem urheberrechtlich geschützte Werke aufnimmt und hierfür eine Genehmigung des Urhebers bzw. der Verwertungsgesellschaft nachweisen kann. Eine solche Kontrolle würde jedoch dem in $\mathrm{Ar}$ tikel 13 des Grundgesetzes ausgesprochenen Grundsatz der Unverletzlichkeit der Wohnung widersprechen. Ubertretungen eines solchen Verbots könnten daher nur durch Zufall oder durch Denunziation bekannt werden. Es erscheint aber rechtspolitisch bedenklich, unter diesen Umständen ein gesetzliches Verbot auszusprechen. Dem kann nicht entgegengehalten werden, daß zur Zeit auch zum privaten Rundfunkempfang eine Genehmigung nötig ist. Hier liegen die Verhältnisse anders. Die Post, die den Rundfunkempfang überwacht, ist eine öffentliche Behörde.'Der Genehmigungszwang für den Rundfunkempfang beruht auf dem Fernmeldehoheitsrecht des Staates, während das Vervielfältigungsrecht des Urhebers ein privates Recht ist, das nicht in gleicher Weise geschützt werden kann. Soweit jedoch die Vervielfältigung nicht im privaten Bereich vorgenommen wird, treffen diese Erwägungen nicht zu. Die Aufnahme öffentlicher Vorträge, Aufführungen oder Vorführungen eines Werkes auf Bild oder Tonträger soll daher nach Absatz 5 stets nur mit Einwilligung des Urhebers zulässig sein.

Die Urheber haben selbst zu erkennen gegeben, daß sie gegenüber privaten Vervielfältigungen durch Magnettongeräte ein Verbotsrecht nicht ausüben, sondern die Vervielfältigung gegen Zahlung einer Vergütung gestatten würden. Sie sind daher nur daran interessiert, eine angemessene Vergütung zu erlangen. Hierzu benötigen sie jedoch nicht ein Verbotsrecht, vielmehr genügt es, wenn das Gesetz ihnen einen Anspruch auf angemessene Vergütung gewährt. Ein solcher Anspruch erscheint in den Fällen gerechtfertigt, in denen durch die private Vervielfältigung eine Beeinträchtigung der Einnahmen der Urheber zu befürchten ist. Wer z. B. ein durch Rundfunk gesendetes Musikstück auf Tonband aufnimmt oder eine Schallplatte auf Tonband überspielt, erspart sich dadurch den Kauf einer Schallplatte, an deren Verkaufserlös der Urheber beteiligt wäre. Es mag sein, daß zur Zeit eine nennenswerte Beeinträchtigung des Schallplattenumsatzes durch die private Tonaufnahme noch nicht eingetreten ist; dennoch ist die Gefahr einer solchen Beeinträchtigung nicht zu leugnen. Bis heute sind etwa 1 Million Magnettongeräte in der Bundesrepublik verkauft worden und der Absatz dieser Geräte steigt ständig. Die Gefahr, daß sich der Musikfreund durch private Aufnahmen aus dem Rundfunk mehr und mehr selbst mit mechanischer Musik versorgt und damit den Absatz der Schallplatten beeinträchtigt, ist nicht von der Hand zu weisen. Die 
weitere Ausbreitung der Tonbandvervielfältigung muß als Anfang einer Entwicklung angesehen werden, in deren Verlauf voraussichtlich in immer stärkerem Maße bisher ausschließlich dem Gewerbe vorbehaltene Vervielfältigungsverfahren in die Privatsphäre verlegt werden. Hält man an dem Grundsatz der Vervielfältigungsfreiheit in der Privatsphäre uneingeschränkt fest, so kann dies allmählich zu einer teilweisen Aushöhlung des Urheberrechts führen, die besonders fühlbar wird, wenn in ferner Zukunft das Fotokopierverfahren in einer Weise fortentwickelt wird, daß die Vervielfältigung ganzer Bücher ähnlich einfach und gut möglich ist wie heute die Herstellung von Tonbändern. Es ist hier eine Grundsatzentscheidung durch den Gesetzgeber zu treffen: Entscheidet man sich für die uneingeschränkte Vervielfältigungsfreiheit in der Privatsphäre, so ist dieser Schritt später kaum rückgängig zu machen, da sich dann die Allgemeinheit an diesen Zustand gewöhnt hat. Führt man dagegen jetzt die Vergütungspflicht ein, so ist zu erwarten, daß sich allmählich auf breiterer Basis das Rechtsbewußtsein bildet, daß dem Urheber für die Nutzung seines Werkes auch im privaten Bereich ein angemessenes Entgelt gebührt.

Der Entwurf sieht aus diesen Gründen in Absatz 3 vor, daß für die Aufnahme der Vorführung oder Funksendung eines Werkes auf Bild- oder Tonträger und die Ubertragung eines Werkes von einem Bild- oder Tonträger auf einen anderen dem Urheber eine angemessene Vergütung zu gewähren ist. Die Vergütung ist von demjenigen zu entrichten, der die Vervielfältigung vornimmt oder in Auftrag gibt. Der Anregung, die Verpflichtung zur Zahlung der Vergütung den Herstellern von Magnettongeräten aufzuerlegen, ist nicht entsprochen worden, weil die Hersteller keine urheberrechtlich relevante Verwertungshandlung vornehmen, sondern nur eine Sache verkaufen, die im übrigen nicht nur zur Vervielfältigung geschützter Werke, sondern auch zur Aufnahme von Diktaten, Verhandlungen usw. benutzt werden kann.

Die Zubilligung eines entsprechenden Vergütungsanspruchs für die private Vervielfältigung durch Fotokopie oder Mikrokopie erscheint nicht gerechtfertigt, weil durch diese Vervielfältigungsverfahren im privaten Bereich der Absatz gedruckter Werke jedenfalls zur Zeit nicht beeinträchtigt wird. Für den Privatmann ist es immer noch vorteilhafter, sich eine Zeitschrift zu halten oder Bücher zu kaufen, als sich von dem Inhalt dieser Druckwerke Fotokopien oder Mikrokopien herzustellen. Erst wenn für den Privatmann erschwingliche Geräte erfunden werden sollten, die es ermöglichen, ganze Bücher in ähnlicher Qualität wie gedruckte Werke und billiger als diese herzustellen, wäre eine Beeinträchtigung der Einnahmen der Urheber zu erwarten. In diesem Falle müßte eine Ausdehnung der Vergütungspflicht in Erwägung gezogen werden.

Absatz 2 gestattet, daß sich der zur Vervielfältigung Befugte das zum persönlichen Gebrauch bestimmte Vervielfältigungsstück auch durch einen Dritten anfertigen lassen darf; für die Ubertragung von Werken auf Bild- oder Tonträger und die Vervielfälti- gung von Werken der bildenden Künste gilt dies jedoch nur, wenn es unentgeltlich geschieht. Dies entspricht, soweit es Werke der bildenden Künste betrifft, $\$ 18$ Abs. 1 KUG.

Um eine mißbräuchliche Verwendung der nach $\S 54$ hergestellten Vervielfältigungsstüdke zu verhindern, sieht der Entwurf in Absatz 4 vor, daß die Vervielfältigungsstücke weder verbreitet noch zur öffentlichen Wiedergabe benutzt werden dürfen.

Absatz 5 enthält weitere Einschränkungen der durch Absatz 1 gewährten Vervielfältigungsfreiheit. Neben dem oben bereits erwähnten Verbot der Aufnahme öffentlicher Vorträge, Aufführungen oder Vorführungen eines Werkes auf Bild- oder Tonträger sind die Ausführung von Plänen und Entwürfen zu Werken der bildenden Künste und der Nachbau eines Werkes der Baukunst nicht zugelassen. Soweit es sich um den Nachbau eines Werkes der Baukunst 'handelt, findet sich eine entsprechende Regelung bereits im geltenden Recht ( $\S 18$ Abs. 1 KUG).

\section{Zu §55 - Vervielfältigung zum sonstigen eigenen Gebrauch}

Durch $\S 55$ wird vorgeschlagen, auch außerhalb der privaten Sphäre die Vervielfältigung in gewissem Umfange zum sonstigen eigenen Gebrauch ohne Zustimmung des Urhebers zuzulassen. Der Begriff "eigener Gebrauch" deckt sich nicht mit dem gleichen Begriff in $\S 15 \mathrm{KUG}$, der - wie bereits zu $\S 54$ dargelegt - dasselbe bedeutet wie persönlicher Gebrauch. Er soll vielmehr alle Fälle erfassen, in denen jemand Vervielfältigungsstücke zur eigenen Verwendung und nicht zur Weitergabe an Dritte herstellt oder herstellen läßt. Persönlicher Gebrauch ist danach ein Sonderfall des eigenen Gebrauchs. Daraus folgt, daß eine Vervielfältigung zum persönlichen Gebrauch nicht nur unter $\S 54$, sondern auch unter $\S 55$ fällt. Die Vervielfältigung nach $\S 55 \mathrm{kann}$ - im Gegensatz zur Vervielfältigung zum persönlichen Gebrauch - auch von einer juristischen Person für eigene Zwecke, z. B. von einer Firma für ihre Angestellten und von Behörden zum inneramtlichen Gebrauch, hergestellt werden.

Mit der Zulassung der Vervielfältigung zum sonstigen eigenen Gebrauch geht der Entwurf zum Teil über das geltende Recht hinaus. Nach diesem sind Vervielfältigungen außerhalb der privaten Sphäre nur in geringem Umfange zulässig. Es ist jedoch festzustellen, daß Wirtschaft und Wissenschaft mit dem Fortschreiten der Vervielfältigungstechnik in zunehmendem Maße dazu übergegangen sind, über diesen Umfang hinaus Vervielfältigungsstücke von Schriftwerken auch für den beruflichen und gewerblichen Gebrauch ohne Zustimmung des Berechtigten herzustellen. Der Entwurf nimmt den Standpunkt ein, daß es notwendig ist, diese Ubung $\mathrm{zu}$ einem Teil gesetzlich anzuerkennen, um Hemmungen im Wirtschaftsleben und im Austausch wissenschaftlicher Erkenntnisse zu vermeiden. Damit soll nicht einem offenkundigen Rechtsmißbrauch nachgegeben werden. Vielmehr soll das Gesetz mit einer durch die Entwicklung entstandenen Verkehrsauffassung in Einklang gebracht werden. Ein Auseinanderfallen 
beider als Folge technischen und wirtschaftlichen Fortschritts kann hier wie auch sonst gerade auf dem Gebiet des Urheberrechts letztlich der Rechtsordnung nicht zum Vorteil gereichen.

Die Vervielfältigung zum sonstigen eigenen Gebrauch kann jedoch nicht so weitgehend zugelassen werden wie die Vervielfältigung zum persönlichen Gebrauch, da anderenfalls schwerwiegende Nachteile für die Urheber zu erwarten wären. Der Entwurf beschränkt daher die Vervielfältigungsfreiheit auf einzelne, eng umgrenzte Tatbestände:

1. $\$ 55$ Abs. 1 Nr. 1 läßt die Vervielfältigung zum eigenen wissenschaftlichen Gebrauch zu. Wissenschaftler und wissenschaftliche Institute sollen in ihrer Tätigkeit nicht dadurch behindert sein, daß sie vor der Herstellung von Abschriften aus geschützten Werken jedesmal die Erlaubnis der Urheber einholen müssen. Es kann den Urhebern zugemutet werden, im Interesse der Wissenschaft und Forschung insoweit auf ihr Verbotsrecht zu verzichten. Zur Verhütung von Mißbräuchen ist bestimmt, daß die Vervielfältigung nur zugelassen ist, wenn und soweit sie zu dem wissenschaftlichen $\mathrm{Zweck}$ geboten ist.

2. $\$ 55$ Abs. 1 Nr. 2 erlaubt die Herstellung von Vervielfältigungsstücken zur Aufnahme in ein eigenes Archiv. Hierbei ist an Fälle gedacht, in denen z. B. eine Bibliothek ihre Bestände auf Mikrofilm aufnimmt, um entweder Raum zu sparen oder um die Filme an einem vor Katastrophen sicheren Ort unterzubringen. In beiden Fällen liegt keine zusätzliche Verwertung des Werkes vor, so daß der Urheber hiervon nicht betroffen wird. Um zu verhindern, daß diese Vorschrift von Bibliotheken dazu benutzt wird, ihre Bestände durch Vervielfältigung entliehener Exemplare zu erweitern, ist ausdrücklich vorgesehen, daß die Vervielfältigung nux in einem durch den Zweck gebotenen Umfange zulässig ist und nur dann, wenn als Vorlage ein eigenes Werkstück benutzt wird.

3. $\S 55$ Abs. 1 Nr. 3 gestattet die Vervielfältigung eines durch Funk gesendeten Werkes zur eigenen Unterrichtung über Tagesfragen. Diese Bestimmung ist ein Gegenstück zu $\S 48$ Abs. 1 Nr. 1, der die Vervielfältigung von Rundfunkreden in Zeitschriften oder zeitungsähnlichen Blättern erlaubt. Sie geht insofern weiter, als nicht nur Rundfunkreden, sondern sämtliche durch Funk gesendeten Werke aufgenommen werden dürfen, soweit es zur eigenen Unterrichtung über Tagesfragen erforderlich ist. Hiernach dürfen z. B. Unternehmen und Behörden aktuelle Sendungen in einigen Exemplaren aufnehmen und diese ihren Angehörigen zur Unterrichtung zuleiten.

4. Ohne Rücksicht auf eine besondere Zweckbestimmung läßt Absatz 1 Nr. 4 Buchstabe a die Vervielfältigung von kleinen Teilen eines erschienenen Werkes oder von Aufsätzen $\mathbf{z u}$, die in Zeitungen oder Zeitschriften erschienen sind.

Ein Bedürfnis zur Vervielfältigung von kleinen Teilen eines Werkes wird in der Regel nur bei Schriftwerken gegeben sein. Es tritt außerhalb der privaten Sphäre besonders bei der Anfertigung wissenschaftlicher und technischer Arbeiten zu beruflichen Zwecken auf. In solchen Fällen erscheint es wirtschaftlich untunlich, den Betreffenden zu zwingen, das ganze Werk zu kaufen, andererseits aber auch nicht gerechtfertigt, ihm diese Vervielfältigung nur zu gestatten, wenn er zuvor die Zustimmung des Urhebers eingeholt hat. Ein nennenswerter Nachteil dürfte für die Urheber durch die Zulassung der Vervielfältigung von kleinen Teilen eines Werkes nicht entstehen.

Schwieriger liegt die Frage hinsichtlich der Vervielfältigung ganzer Aufsätze, die in Zeitungen und Zeitschriften erschienen sind. Hier ist die Praxis dazu übergegangen, derartige Aufsätze, insbesondere wenn sie aktuelle Fragen behandeln, in nicht unerheblichem Umfange $\mathrm{zu}$ vervielfältigen. Größere Betriebe bewerkstelligen auf diese Weise eine in die Breite gehende innerbetriebliche Unterrichtung. Zwischen Bibliotheken des In- und Auslandes besteht ein reger Austausch von fotokopierten und mikrokopierten Zeitschriftenaufsätzen. Das praktische Bedürfnis für eine solche Handhabung dürfte kaum in Abrede gestellt werden können. Die Besonderheit gegenüber der oben behandelten Ausnahme für kleine Teile von Werken liegt darin, daß hier zwar ganze Werke vervielfältigt werden, diese Werke für sich allein jedoch nicht bezogen werden können, sondern nur durch Erwerb der ganzen Zeitschrift, von der sie in der Regel nur ein kleiner Teil sind, beschafft werden können. Die Besorgung der ganzen Zeitschrift stößt aber auf zweierlei Schwierigkeiten. Einmal erscheint es unter den heute bestehenden technischen Möglichkeiten unwirtschaftlich, fünf oder sechs Exemplare einer Zeitschrift zu kaufen, nur um einen darin enthaltenen, wenige Seiten umfassenden Aufsatz mehrfach zu erhalten. Zum anderen ist die betreffende Nummer der Zeitschrift häufig nicht mehr und jedenfalls nicht in kurzer Zeit erhältlich, insbesondere wenn es sich um ausländische Zeitschriften handelt.

Gegen die Freigabe der Vervielfältigung von Werkteilen und Aufsätzen ist geltend gemacht worden, sie widerspreche dem anerkannten Grundsatz, daß der Urheber tunlichst wirtschaftlich zu beteiligen sei, wenn sein Werk gewerblich genutzt werde. Von diesem Grundsatz ist auch der Bundesgerichtshof in der erwähnten Entscheidung vom 24. Juni 1955 (BGHZ 18 S. 44, Anlage 4) ausgegangen, in der er die Vervielfältigung zum gewerblichen Gebrauch ohne $\mathrm{Zu}$ stimmung des Urhebers für unzulässig erklärt, aber in der Begründung betont hat, daß der wirtschaftliche Sinn der Entscheidung nicht darin liege, die Anfertigung von Fotokopien zu gewerblichen Zwecken grundsätzlich zu unterbinden, sondern vielmehr darin, derartige Vervielfältigungen von der Zahlung einer angemessenen Vergütung an den Urheber abhängig zu machen. Diesem Grundsatz entsprechend hat der Börsenverein des Deutschen Buchhandels im Jahre 1958 mit dem Bundesverband der Deut- 
schen Industrie ein "Rahmenabkommen über die Herstellung von fotomechanischen Vervielfältigungen (Fotokopien, Mikrokopien) in gewerblichen Unternehmen zum innerbetrieblichen $\mathrm{Ge}-$ brauch" abgeschlossen, durch das den Unternehmen die Herstellung von Vervielfältigungen, insbesondere das Fotokopieren von Zeitungsund Zeitschriftenaufsätzen, gegen Zahlung einer Pauschalvergütung gestattet wird. Der Entwurf trägt dieser für das geltende Recht getroffenen Regelung in der Weise Rechnung, daß er zwar die Herstellung von Vervielfältigungen in dem beschriebenen Umfang zuläßt, dem Urheber jedoch einen Anspruch auf angemessene Vergütung gewährt, wenn die Vervielfältigung gewerblichen Zwecken dient (vgl. Absatz 2).

5. Die Vervielfältigung ganzer Werke oder Teile davon wird ebenfalls ohne Rücksicht auf eine besondere Zweckbestimmung zugelassen, wenn es sich um ein vergriffenes Werk handelt und der Berechtigte nicht auffindbar ist (Absatz 1 Nr. 4 Buchstabe b). Mit dieser Bestimmung soll insbesondere dem Bedürfnis von Bibliotheken und wissenschaftlichen Instituten zur Vervollständigung ihrer Bestände an wissenschaftlichen Werken und zur Herstellung von weitenen Leseexemplaren Rechnung getragen werden. Die Beschränkung der Vervielfältigungsfreiheit für vergriffene Werke auf die Fälle, in denen der Berechtigte nicht auffindbar ist und deshalb seine Einwilligung nicht eingeholt werden kann, beruht auf der Erwägung, daß grundsätzlich dem Urheber oder seinem Verleger die Entscheidungsfreiheit verbleiben muß, wann und in welcher Höhe eine Neuauflage des Werkes veranstaltet werden soll. Wartet jedoch der Berechtigte mit der Neuauflage länger als drei Jahre, so erscheint es zumutbar, daß er seine Einwilligung zur Vervielfältigung erteilen muß, falls er keine besonderen Weigerungsgründe vorbringen kann. Dies ist in Absatz 1 Nr. 4 Buchstabe b Satz 2 vorgesehen.

Der Anregung, eine Ausnahmebestimmung für Blindenhörbüchereien zu schaffen, ist der Entwurf nicht gefolgt. Die Blindenhörbüchereien sind Einrichtungen, die Werke der Literatur auf Tonbänder aufnehmen und diese an Blinde ausleihen. Da es sich hierbei um eine Vervielfältigung und Verbreitung von Werken handelt, ist hierzu zwar die Zustimmung der Urheber erforderlich. Man kann aber wohl erwarten, daß sich die Urheber und Verleger jederzeit freiwillig bereit finden werden, diese Tätigkeit der Blindenhörbüchereien unentgeltlich zu gestatten, so daß sich eine gesetzliche Regelung erübrigen dürfte. In der Tat ist im April 1961 eine entsprechende Vereinbarung zwischen den Verlegern und der Schallplattenindustrie einerseits und der Arbeitsgemeinschaft der deutschen Blindenhörbüchereien andererseits zustande gekommen.

Wer nach Absatz 1 berechtigt ist, ohne Zustimmung des Urhebers eine Vervielfältigung vorzunehmen, darf sich die Vervielfältigungsstücke auch durch einen Dritten herstellen lassen, gleichgültig, ob die Vervielfältigung entgeltlich oder unentgelich vorge- nommen wird. Würde man nur die Vervielfältigung durch den, der das Vervielfältigungsstück benötigt, selbst zulassen, so würde das auf eine Benachteiligung derjenigen Firmen und Personen hinauslaufen, die sich die Anschaffung eines Vervielfältigungsgerätes nicht leisten können. Der Entwurf läßt für die in Absatz 1 genannten Vervielfältigungsarten die Vervielfältigung durch jeden Dritten zu. Damit werden also auch die gewerblichen Fotokopier-Unternehmen berechtigt, auf Bestellung diese Vervielfältigungen vorzunehmen.

Entsprechend dem bereits erwähnten Grundsatz, daß der Urheber tunlichst angemessen zu beteiligen ist, wenn sein Werk gewerblich genutzt wird, sieht Absatz 2 vor, daß dem Urheber in allen Fällen der Vervielfältigung zum sonstigen eigenen Gebrauch eine angemessene Viergütung zu gewähren ist, wenn die Vervielfältigung gewerblichen Zwecken des zur Vervielfältigung Befugten dient. Damit werden die Angehörigen der freien Berufe, wie Wissenschaftler und Anwälte, die zwar eine Erwerbstätigkeit; aber keine gewerbliche Tätigkeit ausüben, von der Vergütungspflicht freigestellt. Nach geltendem Recht ist es zweifelhaft, inwieweit die Angehörigen dieser Berufe Vervielfältigungen gemäß § 15 Abs. 2 LUG frei herstellen dürfen. Der Bundesgerichtshof hat diese Frage in der Entscheidung vom 24. Juni 1955 (BGHZ 18 S. 44, Anlage 4 [IV]) offen gelassen. Würde man die Angehörigen der freien Berufe der Vergütungspflicht unterwerfen, indem man die Vergütung nicht nur für die Vervielfältigung zu gewerblichen Zwecken, sondern darüber hinaus zu Erwerbszwecken vorsähe, würde dies in der Praxis zu Schwierigkeiten führen, weil bei diesem Personenkreis oft schwer zu unterscheiden ist, ob die Vervielfältigung zur persönlichen Unterrichtung oder zu beruflichen Zwecken hergestellt wird. Für Anwälte würde es auch zu Uberschneidungen zwischen $\S 45$ und $\S 55$ kommen, weil der größte Teil der von Anwälten benötigten Vervielfältigungen zur Verwendung in Verfahren vor einem Gericht oder einer Behörde hergestellt wird und damit nach $\S 45$ frei zulässig wäre.

In Absatz 3 sind durch Verweisung auf $\S 54$ Abs. 4 und 5 die für die Vervielfältigung zum persönlichen Gebrauch bestimmten Einschränkungen der Vervielfältigungsfreiheit auch auf die Vervielfältigung zum sonstigen eigenen Gebrauch erstreckt worden. Insbesondere ist es also nicht zulässig, die nach $\S 55$ erlaubterweise hergestellten Vervielfältigungsstücke $\mathrm{zu}$ verbreiten oder $\mathrm{zu}$ öffentlichen Wiediergaben zu benutzen.

\section{Zu $§ 56$ - Vervielfältigung durch Sendeunterneh- men}

Die Bestimmung, die im greltenden Recht nicht enthalten ist, soll den Erfordernissen des modernen Sendebetriebs Rechnung tragen. Die technische Entwicklung der Schallplatten und Tonbänder hat dazu geführt, daß die Sendeunternehmen mehr und mehr dazu übergegangen sind, Vorträge und Aufführungen von Künstlern nicht unmittelbar zu senden (sog. Live-Sendungen), sondern die Vorträge und Aufführungen zunächst auf Tonträgern festzuhalten und 
die Sendung erst mittels dieser Vorrichtungen vorzunehmen. Nur auf diese Weise kann der moderne Sendebetrieb durchgeführt werden, der sich über fast 24 Stunden erstreckt und mehrere Sender desselben Sendeunternehmens umfaßt, die auf verschiedenen Wellen $\mathrm{zu}$ verschiedenen Zeiten dasselbe Programm bieten. Auch eine vorausplanende Programmgestaltung ist nur unter Benutzung von Bandaufnahmen möglich, da die Mitwirkenden meistens zu den im Programm festgesetzten Sendezeiten nicht zur Verfügung stehen.

Die Sendung eines Werkes und seine Aufnahme auf Bild- oder Tonträger stellen begrifflich zwei gesonderte Verwertungsarten dar. Beide Handlungen bedürfen daher normalerweise der Genehmigung des Urhebers. Nun liegt die Besonderheit der von den Sendeunternehmen zu Sendezwecken hergestellten Ton- oder Bildträger darin, daß sie nicht zu einer gesonderten Verwertung des Werkes bestimmt sind, wie die im Handel erhältlichen Industrieschallplatten, sondern nur in technischer Hinsicht die Sendung erleichtern sollen, also nur ein Hilfsmittel für die Sendung bilden. Es erscheint bei dieser Sachlage nicht gerechtfertigt, diese Aufnahmen dem Verbotsrecht des Urhebers zu unterwerfen.

Aus diesen Gründen ist auch dem Artikel 11 bis Abs. 3 Satz 1 der Brüsseler Fassung der Berner Ubereinkunft, der festlegt, daß die Erlaubnis des Urhebers zur Sendung eines Werkes grundsätzlich nicht die Erlaubnis zur Aufnahme des gesendeten Werkes auf Bild- oder Tonträger einschließt, ein Satz 2 hinzugefügt worden, nach dem es den Ver. bandsländern vorbehalten bleibt, für die von einem Sendeunternehmen mit seinen eigenen Mitteln und für seine eigenen Sendungen hergestellten Bildoder Tontıäger eine besondere Regelung zu treffen, soweit es sich um sog. ephemere, also nicht für die Dauer bestimmte Aufnahmen handelt.

Im Einklang mit dieser Bestimmung der Brüsseler Fassung der Berner Ubereinkunft sieht der Entwurf in Absatz 1 vor, daß Sendeunternehmen derartige Bild- oder Tonträger ohne Genehmigung des Urhebers herstellen und zur Funksendung über jeden ihrer Sender oder Richtstrahler je einmal benutzen dürfen. Die Bild- oder Tonträger sollen spätestens einen Monat nach der ersten Funksendung unbrauchbar gemacht werden, sofern sie nicht wegen ihres außergewöhnlichen dokumentarischen Werts in ein amtliches Archiv aufgenommen werden (Absatz 2). Die Zulassung der Aufnahme in öffentliche Archive, zu denen auch Archive der öffentlich-rechtlichen Rundfunkanstalten $\mathrm{zu}$ rechnen sind, steht im Einklang mit Artikel 11 bis Abs. 3 Satz 3 der Brüsseler Fassung der Berner Ubereinkunft. Das Sendeunternehmen hat jedoch nicht das Recht, die im amtlichen Archiv aufbewahrten Bildund Tonträger ohne Zustimmung des Urhebers zu weiteren Sendungen zu benutzen. Die Bestimmung, daß der Urheber von der Aufnahme in das Archiv unverzüglich zu benachrichtigen ist (Absatz 2 Satz 2), soll ihm die Prüfung ermöglichen, ob die gesetzlichen Voraussetzungen für die Aufnahme in das Archiv gegeben sind.
\$ 56 läßt die nach $\$ 32$ des Gesetzes über die Errichtung von Rundfunkanstalten des Bundesrechts vom 29. November 1960 (BGBl. I S. 862) vorgesehene Verpflichtung der Rundfunkanstalten unberührt, alle Wortsendungen zur Beweissicherung wortgetreu aufzuzeichnen und eine gewisse Zeit aufzubewahren. Die Rundfunkanstalten sind auf Grund dieser öffentlich-rechtlichen Sonderregelung zu solchen Aufzeichnungen ohne Einwilligung der Urheber berechtigt.

\section{Zu §57 - Vervielfältigung durch Geschäftsbetriebe}

Für Geschäftsbetriebe, die Vorrichtungen zur Herstellung von Bild- oder Tonträgern vertreiben (insbesondere Magnettongeräte), besteht die Notwendigkeit, dem Kunden die Wirkungsweise Idieser Geräte zu zeigen. Dies wind in der Regel ıdurch Uiberspielen einer Schallplatte oder durch Aufnahme einer Rundfunksendung geschehen. Darin liegt aber eine Vervielfältigung, idie der Zuistimmung ides Urhebens bedürfte, sorweit es sich um geschützte Werke handelt. Es erscheint indessen nicht gerechtfertigt, diese Vervielfältigung von ider Zustimmung des Urhebers abhängig zu machen; ıdenn ıdie Vervielfältigung dient nicht dazu, das Werk als solches zu nutzen. Der Entwurf läßt daher diese Vervielfältigung frei, bestimmt aber, um Mißbräuchen vorzubeugen, daß die Bild- oder Tonträger unverzüglich wieder unbrauchbar zu machen sind, also z. B. die Aufnahme auf ein Magnetband wieder zu löschen ist.

Dem Urheber für die nach $\S 57$,erlaubte Vervielfältigung seines Werkes einen Vergütungsanspruch zuzubilligen, wie angeregt wonden ist, erscheint nicht gerechtfertigt. In den Geschäftsbetrieben wird idas Wenk nicht um seiner selbist willen benutzt, sondern nur, um dem Kaufinteressenten die technische Wirkungsweise ides Aufnahmegerätes zu zeigen.

\section{Zu $§ 58$ - Unwesentliches Beiwerk}

Die für dien Urhelber in diesem Gesetz vorgesehenen Befugnisse sollen ihm nur ermöglichen, die Verwertung seines Werkes zu erlauben oder zu verbieten, wenn idas Wierk den eigentlichen Gegenstand der Verwertungshandlung idarstellt. Es kommt jedoch vor, daß Werke mehr ader weniger zufällig als unwesentliches Beiwerk bei der Vervielfältigung und Wiedergabe anderer Werke erscheinen. Beispielsweise werden bei der Herstellung von Spielfilmen oft Szenen von Innenräumen aufgenommen, die mit urheberrechtlich geschützten Gemälden ausgestattet sind. Da ddiese Gemälde zugleich mit dem Film vervielfältigt und wiedergegeben werden, wäre hierzu die Zustimmung ihrer Urhelber erforderlich. Dies erscheint jedoch nicht gerechtfertigt, soweit diese Werke nur unwesentliches Beiwerk im Film idarstellen und für idie Filmhandlung überhaupt keine Rolle spielen. In solchen Fällen soll nach § 58 idie Zustimmung der Urheber zur Verwertung nicht erforderlich sein. Eine ähnliche Regelung findet sich im neuen englischen Urheberrechtsgesetz (Copyright Act 1956, Artikel 9 Abs. 6). Sie ist allendings auf die Verwertung von Werken der bilddenden Künste im Film und 
im Fernsehen beschränkt. Es dürfte jedoch zu einer solchen Einschränkung kein ausreichender Grund bestehen. Die gleichen Grundsätze müsssen auch 'bei der Verwertung anderer Werkarten gelten, z. B. wenn ein Werk der Musik zufällig bei der Aufnahme eines Reiseberichts für das Fernsehen ertönt und mit dem Bericht zugleich gesendet wird.

\section{Zu $\$ 59$ - Katalogbilder}

Diese Bestimmung enthält eine dem geltenden Recht unbekannte Regelung, durch die die Herausgabe illustrierter Ausstellungs- und Versteigerungskataloge erleichtert werden soll. Das Beidürfnis nach solchen Verzeichnissen ist für alle Beteiligten, namentlich für ddie Veranstalter und das Publikum, offensichtlich gegeben. Aruch für den Urheber sind die Kataloge von Nutzen, da sie das Bekanntwerden und iden Absatz seiner Werke föridern.

\section{Zu § 60 - Werke an öffentlichen Plätzen}

$\S 60$ gibt iden Inhalt ides $\S 20$ KUG wieder, nach idem bleibend an öffentlichen Wegen, Straßen oder Plätzen befindliche Werke für ıdie Viervielfältigung, Verbreitung und Vorführung freigegeben sind. Der Entwurf erweitert jedoch diese Befugnisse um die Funksendung.

Dem Urheber, wie vorgeschlagen worden ist, einen Vergütungsanspruch für den Fall zu gewähren, idaß aus der zugelassenen Verwertung ein Gewinn gezogen wind, dürfte kein Anlaß bestehen. Die Regelung des $\S 60$ beruht auf der Erwägung, daß die Aufstellung eines Kunstwerkes an öffentlichen Orten zum Ausdrudk bringt, daß ıdamit das Werk der Allgemeinheit gewidmet wind. Aus dieser Zweckbestimmung rechtfertigt sich eine Beschränkung des Urheberrechts in ider Weise, Idaß jedermann das Werk abbilden und die Abbildungen verwerten darf.

Die Beschränkung, wie weiter angeregt, auf die in öffentlichen Museen dauernd ausgestellten Kunstwerke auszudehnen, erscheint nicht angemessen. Diese Kunstwerke wenden nicht in dem gleichen Maße der Allgemeinheit gewidmet wie idie Werke, die an öffentlichen Plätzen aufgestellt sind. Auch wäre im Einzelfall schwer festzustellen, ob ein solches Kunstwerk bleibend ausigestellt ist.

\section{Zu § 61 - Bildnisse}

Absatz 1 entspricht im wesentlichen dem $\S 18$ Abs. 2 KUG. Danach ist dem Besteller eines Bildnisses und seinem Rechtsnachfolger die Vervielfältigung des Bildnisses idurch Lichtbild freigegeben, und zwar nicht nur zum eigenen Gebrauch, sondern auch zu Geschenkzwecken; er kann idie Vervielfältigung auch durch einen Dritten entgeltlich oder unentgeltlich herstellen lassen. Der Entwurf weicht jedoch insoweit vom geltenden Recht $a b$, als er nur die Vervielfältigung durch Lichtbild zuläßt, während gemäß § 18 Abs. 2 KUG nach dem Tolde ides Urhebers die Vervielfältigung auch auf andere Wieise erfolgen idarf. Diese verschiedene Behandlung 'der Rechte ides Urhelbers vor und nach seinem Tode erscheint nicht gerechtfertigt. Aus der Begründung zum KUG ergibt sich, Idaß dem Urheber die Vervielfältigung des Bildnisses auf anderem Wege als durch Lichtbild bei seinen Lebzeiten wegen seiner pensönlichen Beziehung zu seinem Werk vorbehalten worden ist. Da das droit monal aber nach dem Torde des Urhebers bis zum Erlöschen des Urheberrechtsschutzes fortbesteht, wäre es nicht folgerichtig das Urheberrecht nach dem Tode des Urhebers insoweit zu beschränken. Handelt es sich jedoch bei dem Bildnis um ein Lichtbildwrerk, so soll idie Viervielfältigrung auch auf andere Weise als durch Lichtbild zulässig sein; bei Lichtbildwerken ist in der Regel die persönliche Beziehung des Urhebers $\mathrm{zu}$ seinem Werk nicht so eng wie bei Wenken ider bildenden Künste.

Die gleiche Rücksichtnahme wie der Besteller des Bildes verdienen der Abgebildete selbst und nach seinem Tode seine Angehörigen. Dies sieht. $A b$ satz 2 vor

In Absatz 3 ist bestimmt, wer als Angehöriger im Sinne des Absatzes 2 anzusehen ist. Es sind dies die Kinder und der Ehegatte, und, wenn weder ein Ehegatte noch Kinder vorhanden sind, die Eltern. Dies entspricht der Regelung in $\S 22$ Satz 4 KUG, in dem der Kreis der Angehörigen, die nach dem Tode des Abgebildeten das Recht am eigenen Bilde wahrnehmen können, in gleicher Weise bestimmt ist.

\section{Zu § 62 - Anderungsverbot}

Diese Bestimmung entspricht im wesentlichen den Vonschriften des geltenden Rechts ( $\S 24$ LUG und $\S 21 \mathrm{KUG})$, nach denen in Fällen der freien Werknutzung Anderungen des benutzten Werkes nur in bestimmtem Umfange zulässig sind. Außerdem bringt § 62 Abs. 1 Satz 2 durch die Bezugnahme auf $\S 39$ zum Ausdruck, daß Anderungen des Werkes und seines Titels zulässig sind, zu denen der Urheber seine Einwilligung nach Treu und Glauben nicht versagen kann. Daß der Urheber Entstellungen und solche Beeinträchtigungen seines Werkes stets verbieten kann, die seine berechtigten geistigen oder persönlichen Interessen am Werk gefährden können, folgt unmittelbar aus $\S 14$.

Die gegen die Zulassung von Ubersetzungen ( $A b$ satz 2) geltend gemachten Bedenken erscheinen nicht begründet. Die Regelung entspricht dem geltenden Recht und ist notwendig, weil sonst z. B. fremdsprachliche Zitate oder Werke, die in Sammlungen für den Kirchen-, Schul- oder Unterrichtsgebrauch aufgenommen werden sollen, nur in der Ursprache vervielfältigt werden dürften.

\section{Zu \$ 63 - Quellenangabe}

Die Bestimmung regelt in Anlehnung an $\S 25$ LUG und $\S 19 \mathrm{Abs}$. $2 \mathrm{KUG}$, inwieweit in Fällen der freien Werknutzung die Quelle anzugeben ist.

In Absatz 1 sind die Fälle der Vervielfältigungsfreiheit aufgeführt, in denen die Verpflichtung zur Quellenangabe unter allen Umständen besteht. Sie betreffen vor allem Tatbestände, in denen Werke oder Teile von Werken in einem fremden Werk 
oder in Verbindung mit diesem oder für die Zwecke eines anderen Werkes vervielfältigt werden dürfen. Hier ist für den Urheber die Kennzeichnung seiner geistigen Schöpfung zur Abhebung von dem fremden Werk besonders wichtig. Die Verpflichtung zur Quellenangabe soll nach Absatz 1 Satz 2 nur bestehen, wenn die Quelle auf dem benutzten Werk genannt ist. Diese Einschränkung besteht für Werke der bildenden Künste schon nach geltendem Recht ( $\$ 19$ Abs. 2 KUG). Sie erscheint aber auch für sonstige Werke gerechtfertigt.

Absatz 2 regelt die Fälle der freien Werkwiedergabe. Hier soll die Quellenangabe nur erforderlich sein, wenn und soweit es die Verkehrssitte erfordert.

Absatz 3 trägt dem selbständigen Interesse der Zeitungsunternehmen an der Quellenangabe Rechnung.

\section{SIEBENTER ABSCHNITT}

\section{Gesetzliche Nutzungsrechte}

\section{Zu § 64 - Herstellung von Tonträgern}

Die durch § 22 LUG im Jahre 1910 eingeführte Zwangslizenz zur Herstellung von Tonträgern ist im Entwurf grundsätzlich aufrechterhalten worden. Nach wie vor ist ein Bedürfnis dafür anzuerkennen, daß die Werke der Tonkunst allen Herstellern von Tonträgern für die Ubertragung auf solche Vorrichtungen gegen angemessene Gebühr zur Verfügung stehen. Damit wird Monopolbildungen zugunsten einzelner Firmen vorgebeugt. Es liegt ebenso im Interesse der Komponisten wie der Allgemeinheit, daß für die Aufnahme auf Tonträger der Wettbewerb mehrerer Fersteller offengehalten und dadurch das Streben nach Vervollkommnung der Tonträger wachgehalten wird. Der Entwurf hält daher grundsätzlich an der Bestimmung des § 22 LUG fest, sieht aber keine Zwangslizenz vor, sondern eine gesetzliche Lizenz (Absatz 1 Satz 1). Bei einer Zwangslizenz muß derjenige, der ein Werk auf Tonträger übertragen will, zunächst die Erlaubnis hierzu vom Urheber einholen, und dieser darf sie bei Vorliegen der Voraussetzungen der Zwangslizenz nicht verweigern. Verweigert er die Erlaubnis dennoch, so muß der Hersteller auf ihre Erteilung klagen. Dieses Verfahren ist umständlich und kostet den Hersteller unter Umständen so viel Zeit, daß sich dann die Aufnahme des Werkes auf Tonträger nicht mehr lohnt, weil das Publikumsinteresse an dem betreffenden Werk geschwunden ist. Insbesondere bei Schlagermusik kann dies leicht so liegen. Der Entwurf schlägt daher die gesetzliche Lizenz vor, wie sie auch im englischen Recht vorgesehen ist. Danach erhält der Hersteller bei Vorliegen der vorgeschriebenen Voraussetzungen kraft Gesetzes das Recht, das Werk auf Tonträger zu übertragen und diese $\mathrm{zu}$ vervielfältigen und $\mathrm{zu}$ verbreiten, wenn er dem Urheber seine Absicht, dieses Recht auszuüben, durch eingeschriebenen Brief mitgeteilt hat und seit Absendung des Briefes zwei Wochen verstrichen sind (vgl. Absatz 3).
Voraussetzung für die gesetzliche Lizenz ist, daß der Urheber eines Werkes der Musik einem Hersteller von Tonträgern gestattet hat, das Werk zu gewerblichen Zwecken auf Tonträger zu übertragen und diese $\mathrm{zu}$ vervielfältigen und $\mathrm{zu}$ verbreiten. Das gesetzliche Nutzungsrecht soll hiernach abweichend vom geltenden Recht nicht entstehen, wenn der Urheber die Erlaubnis zur Herstellung von Tonträgern nicht einem Tonträgerhersteller erteilt, sondern einem Dritten, etwa seinem Verleger, ein entsprechendes Recht eingeräumt hat, weil in diesem Fall noch kein Hersteller eine Monopolstellung erlangt hat.

Die Lizenz erscheint auch nicht gerechtfertigt, wenn der Urheber seine Rechte an eine Verwertungsgesellschaft übertragen hat. Insoweit bedarf es keines gesetzlichen Nutzungsrechts, weil die Verwertungsgesellchaften nach $\S 11$ des Entwurfs eines Verwertungsgesellschaftengesetzes dem Abschlußzwang unterliegen sollen, jeder Tonträgerhersteller also diese Rechte gegen Zahlung einer angemessenen Vergütung erwerben kann. Der Entwurf schließt daher in Absatz 1 die Geltendmachung der gesetzlichen Lizenz für diesen Fall aus.

Absatz 1 Satz 2 stellt klar, daß das gesetzliche Nutzungsrecht des Tonträgerherstellers nicht die Befugnis umfaßt, das Werk auf Tonträger aufzunehmen, die mit Bildträgern zur gleichzeitigen Wiedergabe verbunden sind (Tonfilme). Satz 3 erklärt die Bestimmungen in $\S 46$ Abs. 3 über das Widerspruchsrecht bei gewandelter Uberzeugung für entsprechend anwendbar. Der Urheber soll die Ausübung des gesetzlichen Nutzungsrechts verhindern können, wenn sich seine Uberzeugung gewandelt hat und ihm deshalb die weitere Verbreitung des Werkes nicht mehr zugemutet werden kann.

Die Absätze 2 und 4 entsprechen dem geltenden Recht ( $\$ 22$ Abs. 1 Satz 2 und 3 LUG) mit der Maßgabe, daß die Bestimmung in $\S 22$ Abs. 1 Satz 3 LUG, nach der im Falle der Gegenseitigkeit auf Grund einer entsprechenden Bekanntmachung die Ausfuhr von Tonträgern auch nach Staaten zugelassen werden kann, in denen das Werk einen Schutz gegen die Ubertragung auf Tonträger genießt, in den Entwurf nicht übernommen ist. Eine solche Bestimmung würde Artikel 13 der Brüsseler Fassung der Berner Ubereinkunft widersprechen. Nach dieser Vorschrift genießen die Urheber von musikalischen Werken das ausschließliche Recht, die Aufnahme ihrer Werke auf Tonträger zu erlauben. Dieses Recht kann zwar von der inneren Gesetzgebung des Verbandslandes nach Artikel 13 Abs. 2 eingeschränkt werden, jedoch ist ausdrücklich bestimmt, daß sich die Wirkung dieser Maßnahme auf das Gebiet des betreffenden Verbandslandes beschränkt.

Entsprechend dem geltenden Recht ( $\S 22$ Abs. 1 Satz 1 LUG) ist dem Urheber für die Vervielfältigung und Verbreitung des Werkes auf Grund der gesetzlichen Lizenz eine angemessene Vergütung zu gewähren (Absatz 5 Satz 1). Satz 2, wonach der Vergütungsanspruch bei Einräumung eines ausschließlichen Nutzungsrechts dem Nutzungsberech- 
tigten zustehen soll, beruht auf der Erwägung, daß der Inhaber des ausschließlichen Nutzungsrechts hier in vermögensrechtlicher Hinsicht an die Stelle des Urhebers tritt; das gesetzliche Nutzungsrecht beschränkt unmittelbar das vertraglich eingeräumte ausschließliche Nutzungsrecht.

Für vertonte Sprachwerke ist in Absatz 6 in Ubereinstimmung mit dem geltenden Recht ( $\$ 22$ Abs. 2 LUG) vorgeschrieben, daß auch gegen den Verfasser des Textes die gesetzliche Lizenz durchgreift, sofern er einmal einem Hersteller von Tonträgern gestattet hat, den Text in Verbindung mit dem Werk der Musik auf Tonträger zu übertragen. Es ist angeregt worden, das gesetzliche Nutzungsrecht auch für die in $\S 52$ bezeichneten Sprachwerke vorzusehen. Diese Werke dürfen jedoch bereits auf Grund des $\S 52$ ohne Einwilligung des Urhebers in jeder Weise, also auch durch Ubertragung auf Tonträger vervielfältigt werden.'Die vorgeschlagene Regelung erübrigt sich daher.

Absatz 7 stellt klar, daß die Einräumung eines Nutzungsrechts zur Verwendung des Werkes in einem Tonfilm das gesetzliche Nutzungsrecht nicht entstehen läßt.

\section{Zu $\S 65$ - Funksendung}

Der Rundfunk hat sich im Laufe der Zeit zu einem der wichtigsten Mittel entwickelt, um Werke der Literatur und Kunst den breiten Volksschichten nahezubringen. Weite Kreise der Bevölkerung werden mit den Werken der Dichter und Komponisten fast nur durch den Empfang von Rundfunksendungen bekannt. Dieser erfüllt somit eine wichtige kulturelle Aufgabe. Es liegt im Interesse der Allgemeinheit, daß ihm die Erfüllung dieser Aufgabe möglichst erleichtert wird. In der Regel werden die Urheber selbst das größte Interesse daran haben, daß ihre Werke durch Rundfunk gesendet werden; denn abgesehen von den damit verbundenen wirtschaftlichen Vorteilen kann der Urheber durch die Sendung seines Werkes in weiten Kreisen bekannt werden. Soweit der Urheber sein Senderecht selbst wahrnimmt, dürfte daher der Rundfunk unschwer die erforderliche Sendeerlaubnis erlangen können. Hat der Urheber jedoch einem Dritten ein ausschließliches Nutzungsrecht zur Funksendung eingeräumt, so ist er selbst an der weiteren Verwertung seines Senderechts gehindert. Die Sendeunternehmen müssen dann die Sendeerlaubnis von dem Erwerber des ausschließlichen Rechts einholen, der sie möglicherweise nicht erteilt. Der Entwurf sieht für diesen Fall ein gesetzliches Nutzungsrecht zur Funksendung vor. Eine solche gesetzliche Lizenz ist in der Brüsseler Fassung der Berner Ubereinkunft für die innere Gesetzgebung der Verbandsländer zugelassen (Artikel 11 bis Abs. 2). Es ist dort nur vorgeschrieben, daß die gesetzliche Lizenz in keinem Falle das droit moral oder den Anspruch des Urhebers auf eine angemessene Vergütung beeinträchtigen darf. Von der Möglichkeit einer solchen gesetzlichen Lizenz haben bereits mehrere Staaten Gebrauch gemacht, wie Bulgarien, Italien, Japan, Jugoslawien, Monaco, Polen und die Tschechoslowakei.
Absatz 1 bestimmt, daß das gesetzliche Nutzungsrecht nur an Sprachwerken und Werken der Musik besteht. Damit scheidet der Entwurf alle anderen Arten von Werken von der Regelung des $\S 65$ aus diese Werke sind nicht in gleichem Maße für die Durchführung des Sendebetriebs notwendig wie Sprachwerke und Werke der Musik. Der Zusatz "für die Dauer dieses Nutzungsrechts" stellt klar, daß das gesetzliche Nutzungsrecht entfällt, wenn das vertraglich eingeräumte Senderecht durch Zeitablauf oder Rückruf erloschen ist. Nur während Bestehens eines vertraglichen ausschließlichen Nutzungsrechts zur Funksendung ist ein schutzwürdiges Bedürfnis für das gesetzliche Nutzungsrecht anzuerkennen.

Nach Absatz 2 ist für die Sendung eine angemessene Vergütung zu entrichten. Die Verfügung soll jedoch nicht dem Urheber, sondern entsprechend §64Abs. 6 dem Inhaber des ausschließlichen Nutzungsrechts gewährt werden.

Absatz 3 sieht vor, daß ein gesetzliches Nutzungsrecht nicht in Anspruch genommen werden kann, wenn der Urheber ein ausschließliches Nutzungsrecht lediglich zur Sendung des Werkes im Rahmen eines Tonfilmes eingeräumt hat. Dies entspricht § 64 Abs. 7.

\section{Zu $\$ 66$ - Anderungsverbot; Quellenangabe}

Soweit auf Grund eines gesetzlichen Nutzungsrechts die Benutzung eines Werkes zulässig ist, dürfen aus denselben Gründen wie bei freien Werknutzungen Anderungen an dem Werk nicht vorgenommen werden; ebenso ist die Quelle deutlich anzugeben. Dies bestimmt $\S 66$ durch Verweisung auf $\S 62$ Abs. 1 und 2 und $\S 63$ Abs. 1 und 2.

\section{ACHTER ABSCHNITT}

\section{Dauer des Urheberrechts}

\section{Zu § 67 - Allgemeines}

Nach Absatz 1 soll das Urheberrecht entsprechend dem geltenden Recht (§ 29 LUG, § 25 Abs. 1 KUG in der Fassung des Gesetzes zur Verlängerung der Schutzfristen im Urheberrecht vom 13. Dezember 1934 - RGBl. II S. $1395 \rightarrow 50$ Jahre nach dem Tode des Urhebers erlöschen. Diese Schutzdauer entspricht der Regelung in fast allen ausländischen Urheberrechtsgesetzen und der in Artikel 7 Abs. 1 'der Brüsseler Fassung der Berner Ubereinkunft vorgesehenen Mindestschutzdauer. Nur wenige Staaten kennen eine Schutzfrist von mehr als 50 Jahren, z. B. Brasilien (60 Jahre), Spanien und Kolumbien (80 Jahre); in Portugal ist das Urheberrecht unbefristet.

Besonders aus Urheberkreisen ist gegen die Befristung des Urheberrechtschutzes eingewandt worden, ebenso wie das Sacheigentum keiner zeitlichen Beschränkung unterworfen sei, müsse auch das Urheberrecht ewige Dauer haben. Wie bereits in der 
Vorbemerkung zum Sechsten Abschnitt ausgeführt, wird jedoch bei der Gleichstellung des Urheberrechts mit dem Sacheigentum das Wesen des Urheberrechts verkannt. Inhalt und Grenzen des Urheberrechts richten sich nach eigenen Maßstäben. Es liegt im Wesen der geistigen Schöpfungen auf dem Gebiete der Literatur und Kunst, daß sie als Mitteilungsgut nach Ablauf einer gewissen Zeit gemeinfrei werden. Der Urheber und seine Erben haben in der Zeit zwischen der Schöpfung des Werkes und dem Ablauf von 50 Jahren nach dem Tode des Urhebers - von Ausnahmefällen abgesehen - hinreichend Gelegenheit, das Werk zu verwerten und dadurch den verdienten Lohn für die geistige Schöpfung zu erhalten. Nur wenige Werke werden nach Ablauf dieser Frist noch zu verwerten sein. Das sind gerade die Meisterwerke der Literatur und Kunst, die in den Kulturbestand eines Volkes eingehen und deren Verbreitung und Wiedergabe im allgemeinen Interesse dann jedermann freistehen muß. Das folgerichtig durchgeführte ewige Urheberrecht würde zudem zu erheblichen praktischen Schwierigkeiten führen, weil schon nach wenigen Erbgängen infolge der oft unübersehbaren Erbverhältnisse und der zunehmenden Rechtszersplitterung die für den Rechtsverkehr erforderliche sichere Feststellung der Rechtsinhaber nicht mehr oder nur unter großen Schwierigkeiten möglich sein würde. Eine Aufhebung der zeitlichen Begrenzung des Urheberrechts würde zudem der vorgeschlagenen und von den Urhebern selbst geforderten Urhebernachfolgevergütung den Boden entziehen. Die Einführung einer Vergütungspflicht für die Verwertung gemeinfreier Werke zugunsten der Gesamtheit der lebenden Urheber setzt gerade das Erlöschen des individuellen Urheberrechts voraus.

Der Entwurf folgt auch nicht dem Vorschlag, die Schutzfrist um einen beschränkten Zeitraum zu verlängern, etwa auf 80 Jahre nach dem Tode des Urhebers. Es kann dahingestellt bleiben, ob die dafür angeführten Gründe, insbesondere die Erhöhung der durchschnittlichen Lebenserwartung der nächsten Angehörigen des Urhebers, eine derartige Verlängerung der Schutzfrist im gegenwärtigen Zeitpunkt rechtfertigen. Die Verlängerung der Schutzfrist über 50 Jahre hinaus soll auf der nächsten Konferenz zur Revision der Berner Ubereinkunft, die 1965 in Stockholm abgehalten werden soll, erörtert werden. Es empfiehlt sich, jedenfalls das Ergebnis dieser internationalen Konferenz vor einer Änderung des deutschen Rechts abzuwarten.

Im geltenden Recht ( $\S 29$ Satz 1 LUG) ist vorgesehen, daß das Urheberrecht erst erlischt, wenn außer einer Frist von 50 Jahren seit dem Tode des Urhebers auch 10 Jahre seit der ersten Veröffentlichung des Werkes abgelaufen sind. Hierdurch soll für die Herausgabe nachgelassener Werke unabhängig von der normalen Schutzfrist ein besonderer Schutz gewährt werden, um dem Rechtsnachfolger des Urhebers den Ausgleich der durch die Herausgabe entstandenen Kosten zu ermöglichen. Das Bedürfnis für einen solchen Schutz ist anzuerkennen, doch erscheint die Regelung des geltenden Rechts unzweckmäßig, weil sie zu einer Verewigung des Urheberrechts an nichtveröffentlichten Werken und damit schon nach wenigen Erbgängen zu Schwierigkeiten für den Nachweis der Rechtsinhaberschaft führt. Zwar stellt, um diesen Schwierigkeiten zu begegnen, § 29 Satz 2 LUG die Vermutung auf, daß das Urheberrecht dem Eigentümer des "Werkes", d. h. des Originals des Werkes (Originalhandschrift, Originalgemälde), zustehe. Diese Vermutung wird jedoch häufig der wahren Rechtslage nicht entsprechen und der Gegenbeweis schwer zu führen sein.

Der Entwurf sieht daher eine abweichende Regelung vor, die zwei Fälle unterscheidet:

1. Veröffentlicht der Rechtsnachfolger des Urhebers das Werk noch kurz vor Ablauf der 50jährigen Schutzfrist, so soll der Schutz nicht auf die kurze Zeit bis zum Ablauf der 50 Jahre beschränkt, sondern wie im geltenden Recht noch für volle 10 Jahre nach der Veröffentlichung gewährt werden, damit der Rechtsnachfolger die durch die Herausgabe entstandenen Kosten durch die alleinige Verwertung des Werkes während 10 Jahren ausgleichen kann. Dies ist in $\S 67$ Abs. 2 bestimmt.

2. Wird das Werk jedoch erst nach Ablauf der Frist von $50 \mathrm{Jahren}$ nach dem Tode des Urhebers erstmals veröffentlicht, so soll das Schutzrecht nicht mehr dem Rechtsnachfolger des Urhebers zustehen, vielmehr soll derjenige, der das Werk zuerst im Geltungsbereich dieses Gesetzes erscheinen läßt, nach $\S 81$ für 10 Jahre ein besonderes Leistungsschutzrecht erhalten. Insoweit wird auf die Begründung zu $\S 81$ Bezug genommen.

Für beide Fälle ist angeregt worden, die vorgesehene 10jährige Schutzfrist für Werke der Musik auf 25 Jahre zu erhöhen, weil beispielsweise eine Sinfonie sich in der Regel nicht in 10 Jahren durchsetze und daher nicht genügend ausgewertet werden könne. Eine solche Sonderregelung für Werke der Musik, die auch das geltende Recht nicht kennt, erscheint jedoch nicht ausreichend gerechtfertigt.

Mit Ablauf der Schutzfrist erlöschen sowohl die Verwertungsrechte wie auch die persönlichkeitsrechtlichen Befugnisse des Urhebers. Es ist angeregt worden, jedenfalls das Urheberpersönlichkeitsrecht unbefristet fortbestehen zu lassen, da auch gemeinfreie Werke gegen Entstellungen, insbesondere entstellende Bearbeitungen, geschützt sein müßten. In einigen ausländischen Urheberrechtsgesetzen, z. B. im italienischen Gesetz von 1941 und im französischen Gesetz von 1957, ist ein ewiges droit moral vorgesehen. Zur Geltendmachung des droit moral ist nach Artikel 23 des italienischen Gesetzes neben den Verwandten des Urhebers, wenn öffentliche Interessen es erfordern, auch der Minister für Volkskultur berechtigt. Im französischen Urheberrechtsgesetz sind neben den Verwandten des Urhebers keine besonderen Organe zur Geltendmachung des droit moral vorgesehen; jedoch wird in dem Gesetz über die Bildung eines Literaturfonds von 1946 in der Fassung des Gesetzes vom 25. Februar 1956 bestimmt, daß es zu den Aufgaben des Fonds gehört, den Werken der Literatur nach dem Tode ihrer Urheber und selbst nach Ablauf der Schutz- 
frist Achtung zu sichern. Eine ähnliche Regelung findet sich im neuen schwedischen Urheberrechtsgesetz von 1960. Nach Artikel 51 dieses Gesetzes können die Gerichte öffentliche Benutzungen eines Werkes, durch die kulturelle Interessen verletzt werden, auf Antrag einer vom König zu bestimmenden Stelle bei Strafe untersagen. Diese Befugnis besteht nach dem Tode des Urhebers unabhängig vom Ablauf der Schutzfrist.

Wie die unterschiedlichen ausländischen Regelungen zeigen, liegt die Schwierigkeit eines Schutzes gemeinfreier Werke gegen Entstellung darin, eine geeignete Stelle zur Wahrnehmung dieses Schutzes zu finden. Die entfernten Erben des Urhebers dürften hierfür kaum geeignet sein, da sie oft keine genügend enge Beziehung mehr zu dem Werk des Urhebers haben. Die Betrauung eines staatlichen Organs oder einer anderen Organisation mit dieser Aufgabe würde dem Einwand einer Kulturlenkung ausgesetzt sein. Es handelt sich nämlich in Wahrheit bei freien Werken nicht mehr um eine Wahrung des Urheberpersönlichkeitsrechts, d. h. der geistigen und persönlichen Beziehungen des Urhebers zu seinem Werk, sondern um den Schutz allgemeiner kultureller Belange. Unabhängig davon, ob man eine geeignete Stelle zur Wahrung dieser Belange finden könnte, müßte darüber hinaus die Entscheidung im einzelnen Fall stets den Gerichten vorbehalten bleiben. Es dürfte aber eine Uberforderung der Gerichte bedeuten, sie mit kulturkritischen und kulturwertenden Fragen zu befassen. Es erscheint daher richtiger, den Schutz freier Werke gegen Entstellungen wie bisher dem kritischen Urteil der Allgemeinheit zu überlassen.

\section{Zu $\$ 68$ - Miturheber}

Die Bestimmung über die Berechnung der Schutzfrist für den Fall der Miturheberschaft entspricht dem geltenden Recht ( $\$ 30$ LUG, § $27 \mathrm{KUG}$ ) und Artikel 7 bis der Brüsseler Fassung der Berner Ubereinkunft.

\section{Zu $\$ 69$ - Anonyme und pseudonyme Werke}

Nach geltendem Recht ( $\$ 31$ Abs. 1 LUG) erlischt das Urheberrecht für Werke der Literatur und der Tonkunst, deren Urheber nicht oder nur unter einem Decknamen angegeben sind (anonyme und pseudonyme Werke) 50 Jahre nach der ersten Veröffentlichung. Absatz 1 übernimmt diese Regelung, doch soll sie in Ubereinstimmung mit Artikel 7 Abs. 4 Satz 2 der Brüsseler Fassung der Berner Ubereinkunft für pseudonyme Werke nur dann gelten, wenn unbekannt ist, wer sich hinter dem gewählten Decknamen verbirgt.

Absatz 2 folgt im wesentlichen der Regelung in \$ 31 Abs. 2 LUG, allerdings soll nach Absatz 2 Nr. 1 die normale Schutzfrist dem Urheber nicht nur zugute kommen, wenn sein Name innerhalb der Frist von 50 Jahren seit der Veröffentlichung des Werkes nach $\S 10$ Abs. 1 angegeben wird, sondern auch dann, wenn der Urheber auf andere Weise als Schöpfer des Werkes bekanntgeworden ist. Diese
Anderung berücksichtigt die Bestimmung des Artikels 7 Abs. 4 Satz 3 der Brüsseler Fassung der Berner Ubereinkunft.

Absatz 3 stellt klar, daß zur Anmeldung des wahren Namens zur Eintragung in die Urheberrolle (§ 147) der Urheber oder, nach seinem Tode, sein Rechtsnachfolger berechtigt ist. Für den Fall, daß der Urheber die Ausübung des Urheberrechts einem Testamentsvollstrecker übertragen hat ( $\$ 28$ Abs. 2), soll dieser zur Anmeldung berechtigt sein.

Absatz 4 nimmt entsprechend dem geltenden Recht die Werke der bildenden Künste von der vorgesehenen Sonderregelung der Schutzfrist für anonyme und pseudonyme Werke aus.

\section{Zu $\$ 70$ - Lieferungswerke}

Die Bestimmung stellt in Ubereinstimmung mit dem geltenden Recht ( $\$ 33$ LUG, $\S 28 \mathrm{KUG}$ ) klar, daß bei Lieferungswerken, soweit sich die Schutzfrist nach der Veröffentlichung bemißt, der Zeitpunkt der Veröffentlichung der letzten Lieferung maßgebend ist. Voraussetzung hierfür ist, daß es sich bei den Lieferungen um inhaltlich nicht abgeschlossene Teile handelt. Erscheint ein Werk in mehreren selbständigen, in sich abgeschlossenen Bänden, so verbleibt es bei der allgemeinen Berechnung der Schutzfrist, $d$. $h$. für jeden Band bemißt sich die Schutzfrist selbständig nach dem Zeitpunkt seiner Veröffentlichung.

\section{Zu $§ 71$ - Lichtbildwerke .}

Abweichend von der allgemeinen Regelung der Schutzfrist in $\S 67$ soll die Schutzfrist für Lichtbildwerke nur 25 Jahre nach dem Erscheinen des Werkes betragen. Diese Bestimmung entspricht dem geltenden Recht ( $\$ 26$ Satz 1 KUG) und steht in Einklang mit Artikel 7 Abs. 3 der Brüsseler Fassung der Berner Ubereinkunft, der es der nationalen Gesetzgebung freistellt, die Schutzfrist für Werke der Photographie abweichend von dem sonst geltenden Grundsatz der 50jährigen Schutzfrist festzusetzen.

Es ist vorgeschlagen worden, die Sonderregelung der Schutzfrist für Lichtbildwerke aufzuheben und diesen einen ebenso langen Schutz zu gewähren wie anderen Werken. Dies würde indessen zur Folge haben, daß Lichtbildwerke länger geschützt wären als photographische Erzeugnisse ohne Werkcharakter (Lichtbilder). Denn eine Angleichung der Dauer auch des für diese in $\S 82$ vorgesehenen Leistungsschutzes an die allgemeine urheberrechtliche Schutzfrist erscheint ausgeschlossen. Eine Schutzfrist von 50 Jahren nach dem Tode des Lichtbildners würde den Rahmen der sonst für Leistungsschutzrechte vorgesehenen Schutzfristen von höchstens 25 Jahren sprengen und ist auch von keiner Seite gefordert worden. Eine unterschiedliche Regelung der Schutzfrist von Lichtbildwerken und Lichtbildern würde jedoch mit dem vom Entwurf bei der Ausgestaltung des Lichtbildschutzes verfolgten Ziel in Widerspruch stehen, zur Vermeidung der außerordentlichen praktischen Schwierigkeiten der Abgrenzung zwischen Lichtbildwerken und Lichtbil- 
dern, die in jedem einzelnen Fall auftreten würden, den Schutz für beide Arten photographischer Erzeugnisse unterschiedslos auszugestalten (vgl. Begründung zu $\S 2$ Abs. 1 Nr. 5). Es erscheint daher richtiger, an der im geltenden Recht vorgesehenen einheitlichen Schutzfrist von 25 Jahren für Lichtbildwerke und Lichtbilder festzuhalten, zumal diese Regelung, soweit ersichtlich, bisher zu keinen Unzuträglichkeiten geführt hat.

Für die Berechnung der Schutzfrist ist entsprechend § 26 Satz 2 KUG vorgesehen, daß das Schutzrecht nach einer bestimmten Frist unabhängig vom Erscheinen des Lichtbildwerkes erlischt. Jedoch ist diese Frist abweichend vom geltenden Recht nicht vom Tode des Urhebers, sondern von der Herstellung des geltenden Rechts erscheint unzweckmäBig, weil sich häufig, insbesondere bei Lichtbildwerken, die in gewerblichen Unternehmen hergestellt sind, der Urheber schwer ermitteln lassen wird.

\section{Zu § 72 - Berechnung der Fristen}

Die Bestimmung übernimmt für die Berechnung der urheberrechtlichen Schutzfristen die im geltenden Recht (§ 34 LUG, § 29 KUG) und Artikel 7 Abs. 6 der Brüsseler Fassung der Berner Ubereinkunft vorgesehene Regelung.

\section{NEUNTER ABSCHNITT}

\section{Urhebernachfolgevergütung}

Es ist eine viel kritisierte Tatsache, daß Urheber kulturell wertvoller Werke zu ihren Lebzeiten aus ihren Werken keinen ausreichenden Nutzen ziehen können, während nach Ablauf der Schutzfrist, wenn sich die Werke durchgesetzt haben, Dritte diese Werke mit erheblichem Gewinn verwerten. Durch eine Verlängerung der Schutzfrist kann dieser Unbilligkeit nicht begegnet werden. Mit der im Entwurf vorgeschlagenen Einführung einer Urhebernachfolgevergütung soll versucht werden, sie für die lebenden Urheber wenigstens zu mildern.

Unter der Urhebernachfolgevergütung ist eine Vergütung zu verstehen, die für die Verwertung von urheberrechtlich nicht oder nicht mehr geschützten Werken zu entrichten ist und zur Unterstützung und Förderung der zeitgenössischen Urheber verwandt werden soll. Die Einrichtung der Urhebernachfolgevergütung beruht auf dem Gedanken, daß den Urhebern von Werken bleibender Bedeutung gleichsam im Vorgriff auf ihre für spätere Zeit der Allgemeinheit zugute kommenden Leistungen ein Ausgleich aus der Verwertung bereits frei gewordener Werke verstorbener Urheber gewährt werden sollte.

Die Bestrebungen, eine Urhebernachfolgevergütung einzuführen, sind alt und nicht auf Deutschland beschränkt. Der Gedanke stammt aus Frankreich und wird unter der Bezeichnung "domaine public payant" in fast allen Kulturstaaten erörtert. Sowohl die Brüsseler Konferenz zur Revision der Berner Ubereinkunft von 1948 wie auch die Genfer Urheberrechtskonferenz von 1952, die zur Unterzeichnung des Welturheberrechtsabkommens führte, haben sich mit dem Problem der Urhebernachfolgevergütung befaßt und übereinstimmend folgende Entschließung gefaßt:

"Die Konferenz erkennt die Bedeutung an, welche die Errichtung und Gründung von Wohlfahrtsund Unterstützungskassen aus Mitteln einer abgabepflichtigen Nutzung gemeinfreier Werke im Interesse der Verbesserung der Lebensbedingungen und der Arbeitsmittel für zeitgenössische Autoren literarischer und künstlerischer Werke haben kann,

dankt für die Initiative, die in verschiedenen Staaten schon von öffentlicher oder privater Seite ergriffen worden ist,

und drückt den Wunsch aus, daß in allen Staaten, in denen sich die Institutionen zur Anwendung einer solchen Maßnahme bereit erklären, die Möglichkeit der Verwirklichung des "domaine public payant" gemäß den Gegebenheiten des jeweiligen Staates erwogen wird."

In verschiedenen Staaten bestehen bereits gesetzliche Regelung des "domaine public payant", z. B. in Argentinien, Chile, Frankreich, Italien, Jugoslawien, Mexiko, Spanièn, der Tschechoslowakei, Ungarn, Uruguay und Venezuela. Die Ausgestaltung der Urhebernachfolgevergütung ist je nach den nationalen Gegebenheiten allerdings sehr unterschiedlich. Zum Teil sind nur bestimmte Formen der Verwertung freigewordener Werke vergütungspflichtig (z. B. in Italien nur die Aufführung, die Sendung und die verlagsmäßige Verwertung) oder es ist nur für die Verwertung bestimmter Werkarten eine Vergütung zu zahlen (z. B. in Frankreich nur für die Verwertung literarischer Werke). Weitere Unterschiede bestehen hinsichtlich der Berechnung und der Höhe der Vergütung sowie hinsichtlich des für ihre Einziehung vorgesehenen Verfahrens. In der Regel fließen die Einnahmen aus der Urhebernachfolgevergütung selbständigen Kultur- oder Urheberfonds $\mathrm{zu}$, deren Aufgabe - nicht immer ausschließlich, jedoch meist überwiegend - die Unterstützung und Förderung verdienter Urheber ist. Teilweise sind die Verwertungsgesellschaften der Urheber mit der Einziehung und Verwendung der Urhebernachfolgevergütung unter staatlicher Aufsicht beauftragt (z. B. in Mexiko). In Italien und Spanien erhält der Staat die Einnahmen, der dafür seinerseits gewisse $\mathrm{Zu}$ schüsse an Hilfsorganisationen der Urheber zahlt; diese Zuschüsse sind in Italien erheblich niedriger als die Einkünfte aus der Urhebernachfolgevergütung. Soweit selbständige Kultur- oder Urheberfonds bestehen, werden diese vielfach neben den Einkünften aus der Verwertung gemeinfreier Werke zusätzlich aus weiteren Quellen gespeist, z. B. aus Beiträgen der Urheber selbst (Chile, Frankreich, Tschechoslowakei), aus Staatszuschüssen (Argentinien, Frankreich, Tschechoslowakei) oder aus einer Kulturabgabe für die Verwertung geschützter und ungeschützter Werke (Argentinien). In einigen 
Staaten, die keine Urhebernachfolgevergütung kennen, bestehen Kulturfonds, die ausschließlich Einkünfte aus solchen anderen Quellen beziehen, z. B. in Bulgarien. In der sowjetisch besetzten Zone Deutschlands wurde 1949 ein Kulturfonds errichtet, dem ursprünglich neben einer Kulturabgabe auch Einkünfte aus der Verwertung gemeinfreier Werke zuflossen, der jedoch seit 1960 allein durch eine Kulturabgabe finanziert wird, d. h. durch Aufschläge auf die Rundfunkgebühren, die Kaufpreise für Schallplatten und die Eintrittspreise für bestimmte Veranstaltungen, ohne Rücksicht darauf, ob es sich um freie oder geschützte Werke handelt.

In Deutschland wurde die Einführung einer Urhebernachfolgevergütung bereits bei den Beratungen zum LUG erörtert, damals jedoch abgelehnt, insbesondere unter Hinweis auf die praktischen Schwierigkeiten der Einziehung und Verteilung und die Gefahr, daß die dadurch verursachten Kosten die Einnahmen übersteigen könnten. Auch in den vor 1945 ausgearbeiteten Entwürfen zur Urheberrechtsreform waren keine Bestimmungen über eine Urhebernachfolgevergütung vorgesehen. Nach Wiederaufnahme der Reformarbeiten nach dem zweiten Weltkrieg wurde die Einführung der Urhebernachfolgevergütung wiederum lebhaft erörtert. Die gesamte Urheberschaft trat nachhaltig für sie ein. Auch der damalige Bundespräsident, Professor Heuss, befürwortete in einem offenen Brief an Walter von Molo vom 15. April 1952 (Bulletin der Bundesregierung 1952 S. 507) den Gedanken, "die "frei" gewordenen Dichter oder Schriftsteller in gewissem Umfange zu Mitwirkenden bei der Sicherung der Lebensarbeit und der Lebenswürde ihrer Nachfolger zu machen". Nachdem der Referentenentwurf von 1954 noch eine abwartende Stellung bezogen und von Bestimmungen über die Urhebernachfolgevergütung wegen noch nicht ausreichender Klärung der Frage abgesehen hatte, enthielt der Ministerialentwurf von 1959 in den $\S \S 69$ bis 74 formulierte Vorschläge für die Einführung der Urhebernachfolgevergütung.

Die Erörterung dieser Vorschläge hat gezeigt, daß die stets befürchteten Schwierigkeiten der praktischen Durchführung überwindbar erscheinen und insbesondere die Kosten des Einziehungs- und Verteilungsverfahrens auf einen geringen Bruchteil der zu erwartenden Einnahmen beschränkt werden können. Der vorliegende Entwurf hält daher an dem Vorschlag der Einführung der Urhebernachfolgevergütung fest.

Das Ziel der Urhebernachfolgevergütung, eine Hilfe für die Urheber zu ermöglichen, die sich um das deutsche Kulturschaffen verdient gemacht haben und wirtschaftliche Not leiden, wird allgemein als berechtigt anerkannt. Es ist das Anliegen, das zur Zeit bereits die 1953 auf Veranlassung des damaligen Bundespräsidenten gegründete "Deutsche Künstlerhilfe", allerdings mit unzureichenden Mitteln, verfolgt. Der Künstlerhilfe, die neben Urhebern auch notleidende ausübende Künstler betreut, stehen zur Zeit rund 750000 DM zur Verfügung, von denen etwa 600 Personen laufende $\mathrm{Zu}-$ wendungen von $100,-\mathrm{DM}$ monatlich erhalten; aus dem verbleibenden Restbetrag werden einmalige Zuwendungen in Sonderfällen gezahlt. Da die unterstützten Künstler nach strengen künstlerischen Anforderungen ausgewählt und nur Fälle einer wirklichen Notlage berücksichtigt werden, ist es offensichtlich, daß die Deutsche Künstlerhilfe - jedenfalls in ihrer jetzigen Form - den verdienten Urhebern keine wirksame Hilfe bieten kann.

Es werden indessen Bedenken dagegen erhoben, die als notwendig erkannte Verstärkung der Hilfe für verdiente Urheber durch die vorgesehene Urhebernachfolgevergütung, d. h. durch eine Belastung der Verwertung freier Werke mit einer Vergütungspflicht, zu erreichen. Es wird eingewandt, die Urheberhilfe sei eine Aufgabe des ganzen Volkes und dürfe nicht auf die kleine Gruppe der Verwerter freier Werke abgewälzt werden. Die Einführung der Urhebernachfolgevergütung werde zu einer Verteuerung gerade der wertvollen Kulturgüter führen, und die Ausgestaltung der Urhebernachfolgevergütung als einer Nachwirkung des Urheberrechts nach Ablauf der Schutzfrist sei auch rechtsdogmatisch bedenklich, weil das Urheberrecht nur individuelle Rechte der Urheber oder ihrer Erben begründen könne. Richtiger sei es, die notwendigen Mittel zur Unterstützung der Urheber aus allgemeinen Steuergeldern oder durch Einführung einer Kulturabgabe zu beschaffen, h. h. durch Erhebung eines Aufschlags auf die Eintrittspreise für kulturelle Veranstaltungen, auf die Rundfunkgebühren und die Kaufpreise von Büchern und Schallplatten, ohne Rücksicht darauf, ob es sich um freie oder noch geschützte Werke handelt. Teilweise wird auch vorgeschlagen, den Urhebern lediglich bei dem Aufbau einer eigenen berufsständischen Altersversorgung durch staatliche Zuschüsse zu helfen.

Gegen eine Finanzierung der Urheberhilfe aus allgemeinen Steuergeldern, die etwa durch Erhöhung der bisher nur geringen öffentlichen Zuschüsse zur Deutschen Künstlerhilfe erreicht werden könnte, spricht die Unsicherheit einer solchen Maßnahme, die darin besteht, daß die notwendigen Mittel von Jahr zu Jahr sowohl dem Grunde wie der Höhe nach von den zuständigen Stellen neu bewilligt werden müßten.

Dieser Nachteil würde bei Einführung einer zweckgebundenen Kulturabgabe vermieden werden können. Die Einführung einer Kulturabgabe wäre jedoch Sache der Länder. Es ist ungewiß, ob und wann eine Regelung auf Länderebene verwirklicht werden kann. Da eine ausreichende Urheberhilfe jedoch ein dringliches Anliegen der Gegenwart ist, muß die Möglichkeit einer Finanzierung der Urheberhilfe über eine Kulturabgabe zur Zeit außer Betracht bleiben.

Auch der weitere Alternativvorschlag zur Urhebernachfolgevergütung, der Aufbau einer berufsständischen Altersversicherung der Urheber mit staatlicher Unterstützung, erscheint nicht durchführbar. Die freischaffenden Urheber bilden in ihrer Gesamtheit keinen organisierten oder organisierbaren Berufsstand. Es steht nicht zu erwarten, daß es zu einem Zusammenschluß der Urheber in einer kollektiven Versicherungseinrichtung kommt, selbst 
wenn ihnen hierfür ein Zuschuß aus öffentlichen Mitteln in Aussicht gestellt werden würde. Hinzu kommt, daß sich eine solche Altersversicherung in ihrem Kern stets auf freiwillige regelmäßige Beitragszahlungen der Urheber stützen müßte, die meisten selbständigen Urheber aber wegen der geringen Höhe und der Unbeständigkeit ihres Einkommens $\mathrm{zu}$ solchen Beitragszahlungen nicht in der Lage sein dürften. Aus diesem Grunde muß auch die Einführung einer Pflichtversicherung etwa durch Einbeziehung der Urheber in die Sozialversicherung außer Betracht bleiben. Einen gewissen Ansatzpunkt für eine eigenständige Altersversicherung der Urheber bieten die Verwertungsgesellschaften der Urheber. Die GEMA, die Verwertungsgesellschaft der Komponisten, Textdichter und Musikverleger, hat eine Sozialkasse geschaffen, aus der ihren Mitgliedern eine angemessene Versorgung im Alter (200, - bis 500,- DM monatlich) und Unterstützung bei Krankheit und anderen Notfällen gewährt wird. In $\S 8$ des Entwurfs eines Verwertungsgesellschaftengesetzes ist eine Bestimmung vorgesehen, die allgemein den Verwertungsgesellschaften die Schaffung derartiger Versorgungseinrichtungen nahegelegt. Es erscheint jedoch fraglich, ob sich für alle Bereiche des geistigen Schaffens Verwertungsgesellschaften bilden werden und ob, wenn dies der Fall sein sollte, diese Verwertungsgesellschaften sämtlich so hohe Einkünfte erzielen werden, daß der Aufbau von Versorgungseinrichtungen möglich wird.

Wie die vorstehenden Ausführungen zeigen, sind die anderen vorgeschlagenen Möglichkeiten zur Finanzierung einer Urheberhilfe entweder überhaupt nicht oder zur Zeit nicht erfolgversprechend. Somit bleibt, wenn man dem Anliegen der Urheberschaft Rechnung tragen will, nur die Einführung einer Urhebernachfolgevergütung in der vom Entwurf vorgeschlagenen Form, die wegen ihres Sachzusammenhangs mit dem Urheberrecht im Rahmen der Urheberrechtsreform als Teil des Urheberrechtsgesetzes geregelt werden kann und damit Aussicht auf eine baldige Verwirklichung bietet.

Die gegen die Urhebernachfolgevergütung als solche erhobenen Bedenken rechtspolitischer und rechtsdogmatischer Art erscheinen nicht durchschlagend. Der Einwand, die Urheberhilfe sei eine Aufgabe des ganzen Volkes und dürfe nicht auf den kleinen Kreis der Verwerter gemeinfreier Werke abgewälzt werden, übersieht, daß die Urhebernachfolgevergütung nicht immer und ausschließlich zu einer Belastung der Verwerter, d. h. der Verleger, der Schallplattenhersteller, der Bühnenunternehmen usw., führt, sondern auch von der Allgemeinheit in Gestalt höherer Preise für den Erwerb oder den Genuß freier Werke zu tragen sein wird.

Die Befürchtung, daß durch ein solches Ansteigen der Preise der Zugang der Allgemeinheit gerade zu den bedeutenden Kulturgütern erschwert werde, erscheint übertrieben. Bei einer Vergütung in Höhe von nur $1 / 10$ der sonst üblichen Urhebertantieme, d. h. bei Büchern und Schallplatten 1 vom Hundert des Ladenpreises (vgl. § 76), dürfte sich die etwaige Preiserhöhung in zumutbaren Grenzen halten. Dem Einwand der Verteuerung der Kulturgüter ist zu- dem entgegenzuhalten, daß dem kulturellen Interesse der Allgemeinheit durch die mit der Urhebernachfolgevergütung ermöglichte Förderung des zeitgenössischen Kulturschaffens im Ergebnis weit mehr gedient sein dürfte, als durch die unbeschränkte Freigabe der Verwertung gemeinfreier Werke.

Auch die rechtsdogmatischen Bedenken, die gegen eine Regelung der Urhebernachfolgevergütung im Rahmen des Urheberrechtsgesetzes geltend gemacht werden, treffen nicht zu. Es ist zwar richtig, daß die Urhebernachfolgevergütung kein Urheberrecht im Sinne des individuellen subjektiven Rechts des einzelnen Urhebers an seinem Werk beinhaltet. Sie knüpft jedoch zeitlich an das Erlöschen des individuellen Urheberrechts an und stellt gewissermaßen eine Nachwirkung des Urheberrechts nach Ablauf der Schutzfrist dar. Hieraus ergibt sich die sachliche Zugehörigkeit der Urhebernachfolgevergütung zum Urheberrecht im objektiven Sinne, d. h. zum Rechtsgebiet des Urheberrechts, dessen Gesamtregelung Aufgabe des Urheberrechtsgesetzes ist. Demzufolge ist die Einführung der Urhebernachfolgevergütung in Deutschland stets im Zusammenhang mit der Urheberrechtsreform erörtert worden, so schon bei den Beratungen zum LUG (vgl. Reichtagsdrucksachen 10. Legislaturperiode, II. Session 1900-1902, zweiter Anlageband, Aktenstück Nr. 214 S. 1312 ff.). Soweit im Ausland bereits eine Urhebernachfolgevergütung eingeführt ist, wird sie ebenfalls überwiegend in den Urheberrechtsgesetzen geregelt. Sondergesetze sind nur dort erlassen, wo die errichteten Kulturoder Urheberfonds neben der Urhebernachfolgevergütung noch andere Einkünfte erhalten, insbesondere Einkünfte aus einer auch die geschützten Werke erfassenden Kulturabgabe, die allerdings im steuerlichen Bereich liegt und in einem Urheberrechtsgesetz nicht geregelt werden kann. Da auch der Begriff "Urheberrecht" in Artikel $73 \mathrm{Nr}$. 9 des Grundgesetzes, durch den dem Bund die ausschließliche Gesetzgebungskompetenz für dieses Gebiet zugewiesen wird, in dieser Sicht auszulegen ist, ist die Zuständigkeit des Bundes für die Regelung der Urhebernachfolgevergütung gegeben.

Was die finanziellen Ergebnisse der Urhebernachfolgevergütung anlangt, so ist nach vorläufigen Schätzungen $\mathrm{zu}$ erwarten, daß die Einnahmen für den Urheberfonds bei Zugrundelegung eines Satzes von $1 / 10$ der üblichen Urhebervergütung für den Anfang insgesamt etwa $2^{1 / 2}$ bis 3 Millionen DM jährlich betragen werden; eine spätere Erhöhung der Einnahmen nach Erfassung aller vergütungspflichtigen Verwertungsvorgänge erscheint nicht ausgeschlossen. Die Summe stellt etwa das Vierfache des Betrages dar, der zur Zeit der Deutschen Künstlerhilfe für ihre Aufgaben zur Verfügung steht. Sie kann nahezu unvermindert für die vorgesehenen Zwecke verwandt werden, da sowohl für die Einziehung der Vergütung bestehende Institutionen (Verwertungsgesellschaften) als auch für die Auswahl der begünstigten Personen vorhandene Gremien (Ausschüsse bei den Kultusministerien der Länder) herangezogen werden können. Der Entwurf begrenzt demzufolge den zur Deckung der für den 
Urheberfonds unvermeidbar entstehenden Unkosten erforderlichen Betrag auf höchstens 5 vom Hundert der Einnahmen (vgl. § 78 Abs. 2).

$\mathrm{Zu}$ der Ausgestaltung der Urhebernachfolgevergütung im einzelnen ist folgendes zu bemerken:

\section{Zu § 73 - Allgemeines}

Absatz 1 enthält den Grundsatz, daß jeder, der ein urheberrechtlich nicht geschütztes Werk öffentlich wiedergibt, also insbesondere öffentlich vorträgt, aufführt, vorführt oder durch Funk sendet, oder der Vervielfältigungsstücke eines solchen Werkes gewerbsmäßig verbreitet, eine Vergütung an den Urheberfonds ( $\$ 79)$ zu zahlen hat. Hierbei soll es nicht darauf ankommen, ob es sich um ein gemeinfreies Werk - sei es das Werk eines klassischen Dichters, das niemals urheberrechtlich geschützt gewesen ist, sei es ein erst gemeinfrei gewordenes Werk - handelt oder um das Werk eines ausländischen Urhebers, das zwar in seinem Heimatstaat geschützt wird, mangels eines internationalen Abkommens zwischen seinem Heimatstaat und der Bundesrepublik jedoch nicht den Schutz des Urheberrechtsgesetzes in Anspruch nehmen kann. Andere Verwertungsarten als die genannten sollen nicht erfaßt werden. Insbesondere soll keine gesonderte Vergütung für die Vervielfältigung gezahlt werden; sie bereitet nur die Verbreitung vor, aus der erst der Gewinn gezogen wird. Ferner soll die Verbreitung von Originalen nicht vergütungspflichtig sein, weil insoweit auch bei Bestehen des Urheberrechtsschutzes regelmäßig keine besondere Vergütung an den Urheber gezahlt wird. Der Entwurf erfaßt auch die Verfilmung nicht; es erscheint ausreichend die Urhebernachfolgevergütung hier bei der Vorführung des Films erheben.

Selbstverständlich soll in den Fällen, in denen während des Laufs der Schutzfrist die Benutzung eines Werkes ohne Rücksicht auf das noch bestehende Urheberrecht vergütungsfrei zulässig ist, auch keine Urhebernachfolgevergütung zu zahlen sein. Infolgedessen bestimmt Absatz 2, daß die Urhebernachfolgevergütung insoweit nicht entrichtet $\mathrm{zu}$ werden braucht, als auch ein urheberrechtlich geschütztes Werk nach den Bestimmungen des Sechsten Abschnitts frei benutzt werden darf.

\section{Zu $§ 74$ - Verbreitung von Vervielfältigungs- stiicken}

Absatz 1 sieht vor, daß nur für die im Wege der Veräußerung in Verkehr gebrachten Vervielfältigungsstücke die Vergütung $\mathrm{zu}$ entrichten ist und daß sie für jedes Vervielfältigungsstück nur einmal gezahlt zu werden braucht. Damit ist die Geltendmachung des Vergütungsanspruchs sowohl dann ausgeschlossen, wenn das Vervielfältigungsstück nur vermietet wird, wie es z. B. mit dem Aufführungsmaterial für Bühnenwerke geschieht, als auch dann, wenn ein Vervielfälttigungsstück unter Entrichtung der Urhebernachfolgevergütung erworben worden ist und anschließend weiterverbreitet wird.
Absatz 2 stellt eine Ubergangsregelung für die Vervielfältigungsstücke dar, die vor Bekanntmachung der Errichtung des Urheberfonds ( $\$ 79$ Abs. 2) hergestellt sind. Da bei der Kostenberechnung für diese Vervielfältigungsstücke die Urhebernachfolgevergütung noch nicht berücksichtigt $\mathrm{zu}$ werden brauchte, erscheint es angemessen, die gewerbsmäßige Verbreitung hier vergütungsfrei zu lassen.

\section{Zu $§ 75$ - Ausnahmen}

Absatz 1 sieht in bestimmten Ausnahmefällen eine Freistellung von der Urhebernachfolgevergütung vor. Nach Nummer 1 soll für die Verwertung bestimmter Werke, deren erleichterte Verbreitung besonders im allgemeinen Interesse liegt, keine Urhebernachfolgevergütung zu zahlen sein. Nummer 2 stellt klar, daß für die Verwertung geschützter Ausgaben freier Werke ( $\$ 80$ und 81) keine Urhebernachfolgevergütung $\mathrm{zu}$ entrichten ist. Nummer 3 nimmt Ausgaben von Werken, deren Ladenpreis weniger als 2,50 DM beträgt, von der Urhebernachfolgevergütung aus, deren Betrag in diesem Fall verschwindend gering sein würde. Unter die Ausnahme fallen Kleinbuchreihen (z. B. Taschenbücher), Notenhefte und ähnliche billige Ausgaben.

Absatz 2 stellt darüber hinaus dem Urheberfonds frei, in besonderen Ausnahmefällen auf die Urhebernachfolgevergütung $\mathrm{zu}$ verzichten. Hierbei ist z. B. an den Fall gedacht, daß die Gesamtausgabe der Werke eines klassischen Dichters nur mit beträchtlichen Subventionen veranstaltet werden kann, die bei Geltendmachung des Anspruchs auf die Urhebernachfolgevergütung noch erhöht werden müßten.

\section{Zu §76 - Höhe der Urhebernachfolgevergütung}

Die Urhebernachfolgevergütung soll die Verbreitung gemeinfreier Werke nicht unbillig erschweren. Es erscheint angemessen, sie grundsätzlich auf $1 / 10$ derjenigen Vergütung festzusetzen, die während der Schutzfrist an den Urheber oder seine Rechtsnachfolger gezahlt wird (Absatz 1 Satz 1).

Absatz 1 Satz 2 enthält eine Sonderregelung für die gewerbsmäßige Verbreitung von Vervielfältigungsstücken. In diesem Fall soll die Vergütung 1 vom Hundert des Ladenpreises betragen. Diese Regelung beruht auf der Erwägung, daß während des Bestehens des Urheberrechts an den Berechtigten durchschnittlich 10 vom Hundert des Ladenpreises abgeführt werden. Um die Abrechnung nicht durch Pfennigbeträge zu erschweren, sieht der Entwurf eine Abrundung vor; danach beträgt z. B. die Urhebernachfolgevergütung für die Verbreitung von Vervielfältigungsstücken bei einem Ladenpreis von $12,50 \mathrm{DM} 15 \mathrm{Pf}$, bei einem Ladenpreis von $12,40 \mathrm{DM}$ $10 \mathrm{Pf}$.

Absatz 2 bestimmt die Höhe der Vergütung in den Fällen, in denen ein gemeinfreies Werk bearbeitet worden ist und die noch geschützte Bearbeitung mit Einwilligung des Bearbeiters verwertet werden soll. Da hier zugleich das der Bearbeitung zugrunde liegende Werk verwertet wird, muß die Urhebernachfolgevergütung grundsätzlich gezahlt werden. Mit 
Rücksicht auf die an den Bearbeiter zu entrichtende Urhebervergütung soll sie jedoch nur die Hälfte der in Absatz 1 vorgesehenen Sätze betragen.

Absatz 3 verpflichtet den Urheberfonds zum Abschluß von Pauschalverträgen über die Höhe der Urhebernachfolgevergütung, wenn die Einzelabrechnung unverhältnismäßig hohe Kosten verursachen würde. Dies wird insbesondere im Buch- und Musikverlag weitgehend der Fall sein. Durch die pauschale Bemessung der Urhebernachfolgevergütung soll eine unbillige finanzielle und arbeitsmäßige Belastung der Verwerter freier Werke verhindert werden.

\section{Zu § 77 - Einziehung der Urhebernachfolgever- giitung}

Die Bestimmung verfolgt ebenso wie $\S 76$ Abs. 3 das Ziel, die mit der Einziehung der Urhebernachfolgevergütung verbundenen Unkosten möglichst niedrig zu halten.

Gläubiger der Urhebernachfolgevergütung ist nach $\S 73$ der Urheberfonds. Diesem obliegt ihre Geltendmachung und Einziehung, insbesondere sind von ihm die in $\S 76$ Abs. 3 vorgesehenen Pauschalvereinbarungen über die Höhe der $\mathrm{zu}$ entrichtenden Beträge mit den Verwertern zu treffen. Soweit in einzelnen Verwertungsbereichen dem Urheberfonds nur wenige Verwerter gegenüberstehen, wie etwa auf dem Gebiet der Funksendung, der Schallplattenproduktion und der verlagsmäßigen Verwertung freier Werke, sind mit der Einziehung der Urhebernachfolgevergütung keine wesentlichen Unkosten verbunden. Anders liegt es bei Vorträgen, Aufführungen und Vorführungen freier Werke, die durch eine Vielzahl einzelner Verwerter vorgenommen werden. Bei der geringen Höhe der Urhebernachfolgevergütung würde sich hier der Aufbau eines selbständigen Uberwachungssystems zur Erfassung aller Verwertungsfälle nicht lohnen. Der Entwurf ermächtigt daher in Satz 1 den Urheberfonds, die Einziehung der Urhebernachfolgevergütung insoweit den Verwertungsgesellschaften zu überlassen, die jeweils die entsprechenden Nutzungsrechte oder Vergütungsansprüche an urheberrechtlich geschützten Werken wahrnehmen und hierzu bereits die notwendigen Uberwachungs- und Inkassosysteme errichtet haben. Die Mitwirkung der Verwertungsgesellschaften soll sich dabei auf die bloße Einziehung beschränken; die Pauschalsätze für die Höhe der Urhebernachfolgevergütung soll auch in diesen Fällen - gegebenenfalls auf Grund von Gesamtverträgen mit den betreffenden Verwerterorganisationen - durch den Urheberfonds festgesetzt werden.

Durch die Einziehung der Urhebernachfolgevergütung werden den Verwertungsgesellschaften in der Regel keine zusätzlichen Kosten entstehen, da die. Urhebernachfolgevergütung als Aufschlag auf die für die Verwertung geschützter Werke ohnehin zu zahlende Urhebertantieme berechnet werden kann. Dennoch könnten an sich die Verwertungsgesellschaften zu Recht als Entschädigung für die Einziehungshilfe eine angemessene Beteiligung des Urheberfonds an den allgemeinen Unkosten des
Kontroll- und Inkassosystems verlangen. Andererseits ist $\mathrm{zu}$ berücksichtigen, $\mathrm{da} \beta$ ein dringendes Interesse daran besteht, die Einnahmen aus der Urhebernachfolgevergütung möglichst ungeschmälert dem vorgesehenen Zweck der Unterstützung und Förderung der Urheber zuzuführen, und daß die Verwertungsgesellschaften als Interessenvertretungen der Urheber selbst hierauf bedacht sein sollten. Dieser besonderen Lage versucht die in Satz 2 vorgesehene Regelung dadurch gerecht $\mathrm{zu}$ werden, daß den Verwertungsgesellschaften grundsätzlich kein Unkostenersatz geleistet, dafür jedoch ein Zuschuß zu den von ihnen geschaffenen Versorgungseinrichtungen zur Verbesserung der Versorgung verdienter Urheber gewährt werden soll.

\section{Zu $\$ 78$ - Verwendung der Urhebernachfolgever- guitung}

Absatz 1 regelt die Verwendung der Einnahmen aus der Urhebernachfolgevergütung. Die vorgesehene Zweckbestimmung entspricht der in der Vorbemerkung zu diesem Abschnitt dargelegten Zielsetzung der Urhebernachfolgevergütung.

Auf die Zuwendungen aus der Urhebernachfolgevergütung soll, ebenso wie es heute bereits bei den Zuwendungen aus der Deutschen Künstlerhilfe der Fall ist, kein Rechtsanspruch für den einzelnen Urheber oder dessen Hinterbliebene bestehen. Demzufolge werden die Zuwendungen nicht auf Unterstützungen und sonstige Sozialleistungen anzurechnen sein. Die Gewährung von Steuerfreiheit für diese Zuwendungen bleibt der Steuergesetzgebung vorbehalten.

Dem Vorschlag, eine Bindung hinsichtlich der Verteilung der Urhebernachfolgevergütung in der Weise zu schaffen, daß die Einnahmen jeweils den Urhebern derjenigen Kunstgattung zufließen sollen, aus der sie stammen, folgt der Entwurf nicht. Eine solche Bestimmung hätte zur Folge, daß der wreitaus größte Teil der Urhebernachfolgevergütung den Komponisten zugute käme, die bildenden Künstler dagegen fast leer ausgingen. Gerade bei den bildenden Künstlern aber ist nach den Erfahrungen der Deutschen Künstlerhilfe die Not am größten. Man würde also durch eine spartenmäßige Verteilung der Urhebernachfolgevergütung das mit dieser Einrichtung verfolgte Ziel nur unvollkomemn erreichen.

Die Einführung der Urhebernachfolgevergütung erscheint nur vertretbar, venn die Einnahmen daraus ohne wesentlichen Unkostenabzug zur Ausschüttung gelangen können. Absatz 2 schreibt daher zwingend vor, daß der Urheberfonds zur Deckung von Unkosten höchstens 5 vom Hundert der Einnahmen einbehalten darf. Bei den nach vorläufiger Schätzung zu erwartenden Einnahmen in Höhe von $2 \frac{1}{2}$ bis 3 Millionen DM entspricht dies einem Betrag von etwa 125000 DM. Gieht man davon aus, daß der Urheberfonds sich für die Einziehung der Urhebernachfolgevergütung gemäß $\S 77$ weitgehend der kosténlosen Hilfe der Verwertungsgesellschaften bedient und die Verteilung der Urhebernachfolgevergütung bestehenden Einrichtungen, beispielsweise der Deutschen Künstlerhilfe, überlassen kann, so dürfte diese Summe zur Unkostendeckung ausreichen. 


\section{Zu § 79 - Errichtung des Urheberfonds}

Wie sich aus den $\$ \S 73$ bis 78 ergibt, soll der Anspruch auf die Urhebernachfolgevergütung einem Fonds zustehen, dem Urheberfonds, dem es obliegt, den Anspruch geltend zu machen, einzuziehen und die Einnahmen zu verteilen. $\$ 79$ regelt die Errichtung dieses Urheberfonds, für den die Rechtsform einer Stiftung des bürgerlichen Rechts vorgesehen ist, die der privatrechtlichen Gestaltung der Urhebernachfolgevergütung am besten entspricht (Absatz 1 Satz 1).

Der Entwurf geht davon aus, daß der Urheberfonds unter Beteiligung aller Länder errichtet wird, und bestimmt daher, daß in einem Organ der Stiftung alle Länder vertreten sein müssen (Absatz 1 Satz 2). Diese Beteiligung aller Länder erscheint geboten, da die Urhebernachfolgevergütung im ganzen Bundesgebiet geltend gemacht und an Begünstigte verteilt werden soll, gleichviel, an welchem Ort sie beheimatet sind. Durch die Beteiligung der Länder können zugleich die Erfahrungen der Ausschüsse nutzbar gemacht werden, die bei den Kultusministerien der Länder zur Auswahl der für eine Unterstützung durch die Deutsche Künstlerhilfe in Betracht kommenden Personen bestehen.

Eine Verpflichtung der Länder, den Urheberfonds zu errichten oder sich an der Errichtung zu beteiligen, wird durch § 79 nicht begründet. Gleichwohl wird davon ausgegangen werden können, daß die Länder von der durch den Entwurf gebotenen Möglichkeit der Unterstützung verdienter Urheber und Förderung begabter Urheber Gebrauch machen werden.

Nach Absatz 2 Satz 1 ist die Errichtung des Urheberfonds durch den Bundesminister der Justiz im Bundesanzeiger bekanntzumachen, sobald das vorgesehene Organ der Stifung, in dem die Länder vertreten sein müssen, gebildet ist, d. $h$. sobald sichergestellt ist, daß sich alle Länder an der Stiftung beteiligen. Um klare Rechtsverhältnisse zu schaffen, soll erst vom Zeitpunkt dieser Bekanntmachung an die Verpflichtung zur Zahlung der Urhebernachfolgevergütung bestehen (Absatz 2 Satz 2).

\section{ZWEITER TEIL}

\section{Verwandte Schutzrechte}

Im Zweiten Teil des Entwurfs sind eine Reihe von Rechten zusammengefaßt, durch die Leistungen geschützt werden sollen, die zwar nicht als schöpferisch anzusehen, wohl aber der schöpferischen Leistung des Urhebers ähnlich sind oder im Zusammenhang mit den Werken der Urheber erbracht werden. Zur ersten Gruppe gehören die für wissenschaftliche Ausgaben und Ausgaben nachgelassener Werke gewährten Schutzrechte ( $\S \S 80$ und 81 ) sowie die Rechte an Lichtbildern ( $(82)$, zur zweiten Gruppe die Rechte der ausübenden Künstler ( $\$ \S 83$ bis 94), der Tonträgerhersteller ( $\$ \S 95$ und 96 ) und der Sendeunternehmen ( $\$ 97$ ) sowie das später zu behandelnde, im Dritten Teil des Entwurfs innerhalb der besonderen Bestimmungen für Filme vorgese- hene Leistungsschutzrecht des Filmherstellers (§ 104).

Wähnend gegen den Schutz der wissenschaftlichen Ausgaben, der Ausgaben nachgelassener Werke und der Lichtbilder keine grundsätzlichen Bedenken erhoben werden, sind die Schutzrechte der ausübenden Künstler, der Hersteller von Tonträgern und der Sendeunternehmen umstritten. Die Urheber befürchten, daß durch die Gewährung dieser Rechte ihr eigener Schutz beeinträchtigt wierden könnte. Sie haben daher die Streichung dieser Rechte gefordert und die Auffassung vertreten, daß auf dem Gebiet kultureller Leistungen Ausschließlichkeitsrechte mit ihren weitreichenden Vierbotswirkungen nur dem Urheber zustehen dürften und der Schutz der ausübenden Künstler, der Tonträgerhersteller und der Sendeunternehmen arbeits- bzw. wettbewerbsrechtlich ausgestaltet werden sollte.

Das Arbeitsrecht reicht jedoch für einen wirksamen Schutz nicht aus, da es stets nur Rechte gegen den Vertragspartner des ausübendien Künstlers begründen kann, nicht gregenüber Dritten, die seine Leistung unbefugt verwerten. Das Wettbewerbsrecht bietet ebenfalls keinen hinreichenden Schutz, weil die besonderen Voraussetzungen der Bestimmungen des Gesetzes gegen den unlauteren Wettbewerb nicht immer vorliegen und oft schwer beweisbar sind. Soweit es sich um den Schutz der ausübenden Künstler handelt, ist ferner zu berücksichtigren, daß das geltende Recht diesen bereits Schutzrechte an ihren Darbietungen gewährt ( $\$ 2$ Abs. 2 LUG), die der Bundesgerichtshof in vier Entscheidungen vom 31. Mai 1960 (BGHZ 33 S. 1, 20, 38 und 48, Anlagen 7 bis 10 ) ausdrücklich in Charakter und Umfang als dem Urheberrecht gleichwertig, d. h. als umfassende ausschließliche Rechte anerkannt hat. Wie sich aus der Begründung der Urteile ergibt, ist der Bundesgerichtshof dabei keineswegs nur widerstrebend einer veralteten Gesetzeskonstruktion gefolgt nach $\S 2$ Abs. 2 LUG gilt die auf Tonträger aufgenommene Darbietung eines ausübenden Künstlers als urheberrechtlich geschützte Bearbeitung des Werkes -, sondern grundsätzlich von der inneren Berechtigung und Notwendigkeit dieser Rechte ausgegangen. Die bestehenden Schutzrechte können nicht ersatzlos gestrichen werden. Es kommt hinzu, daß die Gewährung ausschließlicher Schutzrechte für ausübende Künstler, Hersteller von Tonträgern und Sendeunternehmen im Zuge der internationalen Entwicklung liegt. Das in Rom am 26. Oktober 1961 unterzeichnete Internationale Abkommen über den Schutz der ausübenden Künstler, der Hersteller von Tonträgern und der Sendeunternehmen sieht ausschließliche Rechte für alle drei Personengruppen vor. Auch das Europäische Abkommen zum Schutz von Fernsehsendungen vom 22. Juni 1960 begründet ausschließliche Rechte der Sendeunternehmen an ihren Fernsehsendungen. Die Ratifizierung dieser Abkommen durch die Bundesrepublik setzt die Gewährung entsprechender Rechte durch die innerdeutsche Gesetzgebung voraus.

Es ist weiterhin gefordert worden, daß die gesetzliche Regelung der Leistungsschutzrechte, wenn sie unumgänglich erscheine, jedenfalls nicht mit dem Urheberrecht zusammen im gleichen Gesetz erfolgen 
möge. Anderenfalls bestehe die Gefahr, daß wiederum, wie es der Bundesgerichtshof zur Bestimmung des Umfangs der Rechte der ausübenden Künstler nach § 2 Abs. 2 LUG getan habe, in sachlich nicht gerechtfertigter Weise urheberrechtliche Grundsätze zur Auslegung der leistungsschutzrechtlichen Bestimmungen herangezogen werden könnten. Es trifft $\mathrm{zu}$, daß rechtsdogmatisch eine klare Trennungslinie zu ziehen ist zwischen dem Schutz der schöpferischen Leistung des Urhebers und dem Schutz der das greschaffene Werk wiedergebenden Leistung des ausübenden Künstlers sowie der mehr technisch-wirtschaftlichen Leistung der Tonträgerhersteller und Sendeunternehmen. Inhalt und Umfang der Leistungsschutzrechte sind jeweils unter Berücksichtigung der besonderen Bedürfnisse der zu schützenden Personengruppen selbständig zu bestimmen und können nicht einfach aus einer entsprechenden Anwendung urheberrechtlicher Grundsätze gewonnen werden. Diesem Erfordernis kann jedoch auch bei einer Regelung der Leistungsschutzrechte im Urheberrechtsgesetz Rechnung getragen werden, wenn, wie es der Entwurf vorsieht, eine systematisch eindeutige Abgrenzung zum Urheberrecht erfolgt. Die Einbeziehung der Leistungsschutzrechte in das Urheberrechtsgesetz erscheint wegen des engen Sachzusammenhangs geboten, weil diese Rechte vorwiegend gerade durch die Darbietung und Verwertung urheberrechtlich geschützter Werke begründet werden. Auch im Ausland sind die leistungsschutzrechtlichen Bestimmungen, soweit vorhanden, fast ausnahmslos in die Urheberrechtsgesetze eingefügt worden.

\section{ERSTER ABSCHNITT}

\section{Schutz bestimmter Ausgaben}

\section{Zu $\S 80$ - Wissenschaftliche Ausgaben}

Nach geltendem Recht genießen wissenschaftliche Ausgaben urheberrechtlich nicht geschützter Werke und Texte, z. B. alter noch nicht gedruckter Handschriften, Inschriften und dergl., nur Schutz, soweit sie persönliche geistige Schöpfungen sind, der Verfasser also Lücken des Textes durch eigene Schöpfungen ausfüllt oder den Text durch Anmerkungen erläutert. Es besteht jedoch ein anzuerkennendes Bedürfnis, auch die Herausgabe des Textes als solche zu schützen, die zwar keine schöpferische Leistung darstellt, aber häufig bedeutende wissenschaftliche Arbeit und die Aufwendung hoher Kosten erfordert. In Erfüllung einer bereits seit den Beratungen zum LUG erhobenen Forderung schlägt der Entwurf daher vor, den Verfassern solcher Ausgaben unabhängig von einem etwa bestehenden Urheberrechtsschutz ein besonderes Leistungsschutzrecht zu gewähren, das in seinem Umfang, abgesehen von der Schutzdauer, dem Urheberrecht voll entsprechen soll.

Absatz 1 bestimmt als Voraussetzung für dieses Leistungsschutzrecht, daß die Ausgabe das Ergebnis wissenschaftlich sichtender Tätigkeit darstellt und sich wesentlich von den bisher bekannten Aus- gaben der Werke oder Texte unterscheidet. Durch das erste Erfordernis soll hervorgehoben werden, daß das bloße Auffinden eines alten Schriftstückes das Schutzrecht nicht begründet, vielmehr nur die wissenschaftlich fundierte Herstellung eines bisher unbekannten Originaltextes. Das zweite Erfordernis dient der Rechtssicherheit: Stellt beispielsweise ein Musikwissenschaftler durch textkritische Untersuchung fest, daß die bisher unbekannte Originalfassung eines alten Musikstückes mit einer bekannten Ausgabe dieses Werkes vollständig oder doch im wesentlichen übereinstimmt, so würde ein dem Musikwissenschaftler für seine Entdeckung gewährtes Schutzrecht an der Originalfassung in der Praxis nicht durchsetzbar sein, da bei öffentlichen Wiedergaben des Werkes kaum jemals mit Sicherheit festgestellt werden könnte, ob die Originalfassung oder die freie Ausgabe des Werkes benutzt worden ist. Es ist vorgeschlagen worden, im Hinblick auf diese vorwiegend bei öffentlichen Wiedergaben auftretenden Schwierigkeiten der praktischen Durchsetzung das Schutzrecht des $\S 80$ auf das Vervielfältigungs- und Verbreitungsrecht zu beschränken. Dadurch würde es jedoch für wissenschaftliche Ausgaben von Werken der Musik wertlos, weil bei diesen Werken, anders als bei Werken der Literatur, dem Vervielfältigungs- und Verbreitungsrecht neben dem Recht der öffentlichen Wiedergabe nur eine untergeordnete Bedeutung zukommt.

Absatz 2 stellt klar, daß das Schutzrecht dem Verfasser der Ausgabe zusteht, also dem Musik- oder Literaturwissenschaftler selbst, nicht dem Verlag oder Institut, für das er tätig wird.

Absatz 3 sieht eine Schutzdauer von zehn Jahren vor. Es erscheint geboten, die Frist kürzer als die sonst für Leistungsschutzrechte in der Regel geltende Schutzfrist (25 Jahre) zu bemessen, da anderenfalls die wissenschaftliche Arbeit durch das neue Recht zu stark behindert werden könnte. Nach zehn Jahren muß die geschützte Ausgabe als Grundlage für neue wissenschaftliche Ausgaben ohne Einschränkung benutzt werden können. Die Anknüpfung der Schutzfrist an das Erscheinen, hilfsweise die Herstellung der Ausgabe, entspricht der in $\S 71$ für Lichtbildwerke vorgesehenen Regelung.

\section{Zu § 81 - Ausgaben nachgelassener Werke}

Die Bestimmung sieht eine Schutzfrist für die Erstausgabe nachgelassener Werke (editio princeps) vor. Das Recht unterscheidet sich von dem Recht an wissenschaftlichen Ausgaben nach $\S 80$ dadurch, daß es keine wissenschaftliche Leistung voraussetzt, sondern allein an die Tatsache geknüpft wird, daß jemand ein bisher unbekanntes oder nur durch mündliche Uberlieferung bekanntes Werk nach Ablauf der urheberrechtlichen Schutzfrist der Offentlichkeit durch Vervielfältigung und Verbreitung zugänglich macht. Das Sammeln alter Märchen, Volkslieder oder Volkstänze, das Auffinden alter Schriften oder Kompositionen und die Herausgabe solcher Werke erfordern, auch wenn eine wissenschaftlichtextkritische Bearbeitung entbehrlich ist, oft einen erheblichen Arbeits- und Kostenaufwand, der es 
gerechtfertigt erscheinen läßt, dem Herausgeber für eine gewisse Zeit das ausschließliche Recht zur Verwertung der Ausgabe zu gewähren.

Das geltende Recht trägt dem Schutzbedürfnis für Ausgaben nachgelassener Werke durch eine besondere Verlängerung der Schutzfrist Rechnung. Wird ein Werk nicht innerhalb der normalen Schutzfrist von 50 Jahren nach dem Tode des Urhebers veröffentlicht, so erlischt der Urheberrechtsschutz nach $\S 29$ Satz 1 LUG nicht, sondern dauert fort bis 10 Jahre nach der späteren Veröffentlichung des Werkes. Wie schon zu $\S 67$ erwähnt, erscheint diese Regelung unzweckmäßig, weil sie zu einer Verewigung des Urheberrechts an unveröffentlichten Werken führt und nicht dem Herausgeber des Werkes, der die schutzwürdige Leistung erbringt, Schutz gewährt, sondern dem Erben des Urhebers, der möglicherweise nichts zu dem Auffinden des alten Werkes beigetragen hat und sich zudem meist schwer ermitteln läßt. Nach dem Entwurf (Absatz 1 Satz 1) soll daher nicht der Rechtsnachfolger des Urhebers, sondern der Herausgeber des Werkes das Schutzrecht erhalten. Zugleich ist vorgesehen, das Schutzrecht nicht für die Veröffentlichung des nachgelassenen Werkes, sondern für die Herausgabe, d. h. das "Erscheinenlassen" des Werkes zu gewähren, denn erst dadurch, daß Vervielfältigungsstücke des Werkes hergestellt und der Offentlichkeit angeboten werden, wird der Allgemeinheit der bleibende Besitz des Werkes vermittelt.

Entsprechend der neuen Ausgestaltung des Rechts fordert der Entwurf abweichend vom geltenden Recht als Schutzvoraussetzung lediglich, daß das Werk bisher nicht erschienen ist; eine vorherige Veröffentlichung des Werkes auf andere Weise als durch Vervielfältigung und Verbreitung, also insbesondere durch öffentliche Wiedergaben wie öffentlichen Vortrag oder öffentliche Aufführung, soll unschädlich sein. Diese Änderung dient in erster Linie der Rechtssicherheit. Da die öffentliche Wiedergabe eines Werkes keine Spuren hinterläßt, kann bei alten Werken kaum jemals mit Sicherheit festgestellt werden, ob sie bereits früher einmal öffentlich wiedergegeben und damit veröffentlicht worden sind das Erscheinen eines Werkes ist dagegen in der Regel leicht nachweisbar. Darüber hinaus hat die neue Regelung aber auch die erwünschte Folge, daß künftig auch die Aufzeichnung und Erstausgabe volkstümlicher Werke, wie Märchen, Volkslieder oder Volkstänze, die sich im Volk durch öffentliche Wiedergaben erhalten haben, Schutz genießt.

Da das Schutzrecht des $\S 81$ nicht für eine der schöpferischen Leistung des Urhebers verwandte wissenschaftliche Tätigkeit gewährt wird, sondern lediglich die faktische Herausgabe des Werkes belohnen soll, erscheint es im Gegensatz zu $\S 80$ nicht angemessen, es in seinem Umfang dem Urheberrecht völlig anzugleichen. Der Entwurf beschränkt das Schutzrecht daher auf die ausschließliche Befugnis, das Werk zu vervielfältigen und zu verbreiten und die Vervielfältigungsstücke zur öffentlichen Wiedergabe des Werkes zu benutzen. Dem Herausgeber stehen danach keine persönlichkeitsrechtlichen Befugnisse am Werk zu und auch das Verwertungs- recht nur mit einer Einschränkung: Offentliche Wiedergaben, zu denen keine Vervielfältigungsstücke benutzt werden, sollen nicht der Zustimmung des Herausgebers bedürfen. Volkslieder oder Volkstänze dürfen also z. B. dort, wo sie sich durch Uberlieferung ohne schriftliche Fixierung erhalten haben, auch nach ihrer Aufzeichnung und Herausgabe ohne Rücksicht auf das Recht aus $\S 81$ weiter frei aufgeführt werden. Absatz 1 Satz 3 verweist für den Umfang des Schutzrechts im übrigen auf die betreffenden Bestimmungen des Ersten Teils des Entwurfs und erklärt insbesondere die dort vorgesehenen Schranken des Urheberrechts für sinngemäß anwendbar.

Wie bereits erwähnt, sollen nur Ausgaben solcher Werke geschützt sein, für die kein Urheberrechtsschutz besteht, gleichgültig, ob der Schutz abgelaufen ist oder im Geltungsbereich dieses Gesetzes niemals bestanden hat. Dabei soll jedoch, wie Absatz 1 Satz 2 ausdrücklich klarstellt, stets Voraussetzung sein, daß der Urheber des herausgegebenen Werkes länger als 50 Jahre tot ist. Für die Herausgabe des Werkes eines zeitgenössischen ausländischen Urhebers, das mangels gegenseitiger internationaler Abkommen in Deutschland nicht geschützt ist, ist der Schutz aus $\$ 81$ nicht gerechtfertigt.

Absatz 2 sieht für das Schutzrecht uneingeschränkte Ubertragbarkeit vor, da es ein reines Verwertungsrecht ohne persönlichkeitsrechtlichen Einschlag ist.

Nach Absatz 3 soll das Schutzrecht in Ubereinstimmung mit der entsprechenden Regelung des geltenden Rechts und der für das Recht an wissenschaftlichen Ausgaben ( $(80)$ vorgesehenen Frist nach 10 Jahren erlöschen.

\section{ZWEITER ABSCHNITT}

\section{Schutz der Lichtbilder}

\section{$\mathrm{Zu} \S 82$}

Wie bereits $z u \S 2$ Abs. 1 Nr. 5 ausgeführt, unterscheidet ider Entwurf aus Griunden ider Systematik zwischen Lichtbildwenken, d. h. solchen Lichtbildern, die Ergebnis einer schöpferischen Tätigkeit sind und demzufolge idie Voraussetzungen des urheberrechtlichen Werkbegrliffs ( $\$ 2$ Abs. 2) erfüllen, und sonstigen Erzeugnissen ider Photographie, den einfachen Lichtbildern. Die Lichtbildwerke sind, wie alle Wierke der Literatur, Wissenschaft und Kunst, unmittelbar auf Grund der Vorschriften des Ersten Teils des Entwunfs geschützt, mit der einzigen Besonderheit, daß für sie entsprechend dem geltenden Recht eine verkürzte Schutzfrist von 25 Jahren nach Erscheinen bzw. nach der Herstellung vorgesehen ist (§ 71). Nach $\S 82$ soll idieser Schutz in vollem Umfange auch für Lichtbildwerke gelten.

Im Hinblick darauf, daß es sich bei dem Schutz der Lichtbilder nicht um den Schutz einer schöpferischen Leistung, sondern einer rein technischen Leistung handelt, die nicht einmal besondere Fähigkeiten voraussetzt, ist die Gleichstellung mit dem Urheberrechtsschutz an sich ungewöhnlich und mit der Aus- 
gestaltung der anderen Leistungsschutzrechte nicht voll vereinbar. Sie ist jedoch idurch das geltende Recht, das ebenfalls allen Lichtbilidiern vollen urheberrechtlichen Schutz gewährt, auch soweit sie nicht das Engeibnis schöpferischer Tätigkeit sind, vorgezeichnet und aus praktischen Gnünden unvermeidbar. Würde man den Schutz für Lichtbildwerke und Lichtbilder untenschiedlich igestalten, so wünden sich für die dann erfonderliche Abrgrenzung zwischen Lichbildwerken und Lichtbildern, wie von allen Sachverständigen bestätigt wind, unüberwimdliche Schwierigkeiten ergeben. Der Entwurf hält daher im Ergebnis an der Regelung ides geltenden Rechts fest, zumal sie ibisher - soweit iensichtlich - zu keinen Mißständen geführt hat und eine gewisse Angleichung des Lichtbildschutzes an die übrigen Leistungsschutzrechte durch die für Lichtbilidwerke und Lichtbilder gleichenmaßen geltende kurze Schutzfrist von 25 Jahren erreicht wind.

\section{DRITTER ABSCHNITT \\ Schutz des ausübenden Künstlers}

Das geltende Recht negelt iden Schutz des ausübenden Künstlers in $\S 2$ Abs. 2 in Verbindung mit $\S 2$ Abs. 1 und $\S 11$ LUG. Danach wind die Ubertragung eines Werkes der Literatur oder Tonkunst auf „Vorrichtungen für Instrumente, die der mechanischen Wiedergabe für das Gehör dienen“, d. h. Schallplatten, Tonbänder und idengleichen, als Bearbeitung angesehen, wenn sie durch persönlichen Vortrag bewirkt wird. Als Bearbeiter gilt ider "Vortragenıde", worunter auch der Aufführende, also jeder ausübende Künıstler zu verstehen ist. Diese Regelung widenspricht, wie bereits zu $\S \S 3$ und 16 hervorgehoben, idem beherrschenden Grundsatz des Urheberrechts, daß nur die schöpferische, nicht aber idie lediglich nachschaffende Leistung urheberrechtlichen Schutz genießen kann. Die Aufnahme Ider Darbietung eines ausübenden Künstlens auf Tonträger stellt keine Bearbeitung, sondern eine Vervielfältigung des Werkes dar. Die Regelung des geltenden Rechts erscheint somit für den Schutz ides ausülbenden Künstlers ungeeignet, zumal sie auch infolge ihrer verfehlten systematischen Einordnung zu zahlreichen Zweiffelsfragen über iden Kreis ider Berechtigten und über die Reichweite des Schutzes geführt hat. Der Entwurf übernimmt diaher nicht idie in $\S 2$ Abs. 2 LUG vorgesehene Regelung, sondern gewährt dem ausübeniden Künstler ein besonderes Leistungsschutzrecht.

Es ist die Auffassung vertreten worden, dieses Schutzrecht sei übenflüssig, da sich ider ausübende Künstler bereits durch eine entsprechende Ausgestaltung seines Arbeitsvertrages ausreichend gegen eine unberechtigte Ausnutzung seiner Leistung schützen könne. Dabei wind jedoch venkannt, ıdaß der ausülbende Künstler auf Grund des Arbeitsvertrages immer nur Ansprüche gegen seinen Vertragspartner, nicht gegen einen Dritten geltend machen kann, der unbefugt seine Darbietung verwertet, indem er z. B. ein Konzert, bei dem der Künstler mitwirkt, aufnimmt und Viervielfältigungen dieser Aufnahme verbreitet. Um sich gegen idenartige Verletzungen schützen zu können, bedarf der Künstler eines besonderen Leistungsschutzrechts, das als absolutes Recht gegen jeden wirkt. Insoweit genügt zur Wahrung der Interessen des ausübenden Künstlers auch nicht das von ider Rechtsprechung anerkannte alilgemeine Persönlichlkeitsrecht. Zwar wind sich Ider ausübende Künstler auf Grund idieses Rechts im allgemeinen einer ungenehmigten Aufnahme seiner Danbietung auf Tonträger widersetzen können; jedoch schützt ihn das Pensönlichkeitsrecht nicht gegen eine Verwertung seiner Darbietung, wenn dadurch nur seine Vermögensinteressen berührt wernden, wie es z. B. bei der Vervielfältigung eines von ihm bespieltien Tonträgers older bei uder Verwendung eines solchen Tonträgers zu einer öffentlichen Wiedergabe in der Regel Ider Fall sein wind. Das allgemeine Persönlichkeitsrecht ist auch ideshalb für die mit der Gewährung eines Leistungsschutzrechts verfolgten Ziele unzureichend, weil es seiner Natur nach nicht ïbertragibar ist und ideshalb idem ausübenden Künstler nicht idie Möglichkeit verschaffen kann, idurch Abtretung seiner Rechte seine Darbietung wirtschaftlich zu nutzen.

Auch im Hinblick auf die internationale Entwicklung empfiehlt es sich, dem ausübenden Künstler ein besonderes Schutzrecht an seiner Leistung $\mathrm{zu}$ gewähren. Das Internationale Abkommen über den Schutz der ausübenden Künstler, der Hersteller von Tonträgern und der Sendeunternehmen, das in Rom am 26. Oktober 1961 von 18 Staaten, darunter auch der Bundesrepublik, unterzeichnet worden ist, sieht im Grundsatz ein absolutes Leistungsschutzrecht der ausübenden Künstler an ihren Darbietungen vor. Die Bundesrepublik hat bei den langjährigen vorbereitenden Verhandlungen stets den Abschluß eines solchen Abkommens befürwortet. Eine baldige Ratifizierung des Abkommens durch die Bundesrepublik wäre daher zu begrüßen; sie setzt voraus, daß das neue Urheberrechtsgesetz entsprechende Schutzrechte gewährt. Im übrigen ist $\mathrm{zu}$ berücksichtigen, daß den ausübenden Künstlern bereits nach geltendem deutschen Recht absolute Schutzrechte zustehen, mögen diese auch systematisch anders gestaltet sein als das im Entwurf vorgesehene Leistungsschutzrecht. Den ausübenden Künstlern diese Befugnisse ersatzlos $\mathrm{zu}$ nehmen, dürfte nicht zu rechtfertigen sein.

Abweichend vom geltenden Recht ( $\$ 2$ Abs. 2 LUG), das nach der ihm vom Bundesgerichtshof in vier Grundsatzentscheidungen vom 31. Mai 1960 (BGHZ 33 S. 1, 20, 38 und 48, Anlagen 7 bis 10) gegebenen Auslegung dem ausübenden Künstler ein umfassendes ausschließliches Recht an allen Arten der Nutzung seiner Leistung gewährt, unterscheidet der Entwurf hinsichtlich des Umfangs des Leistungsschutzrechts zwischen der unmittelbaren Verwertung der Darbietung des ausübenden Künstlers durch Lautsprecherübertragung, Aufnahme auf Bildoder Tonträger oder Funksendung und der mittelbaren Verwertung durch Benutzung der Bild- oder Tonträger oder der Funksendung zu öffentlichen Wiedergaben der Darbietung. Nur in den Fällen der unmittelbaren Verwertung soll der ausübende Künstler ähnlich wie der Urheber ein ausschließliches Recht erhalten, d. h. nur insoweit soll er jede unerlaubte Verwertung seiner Darbietung verbieten 
können. Dagegen sieht der Entwurf für den Fall der öffentlichen Wiedergabe der auf Bild- oder Tonträger fixierten oder durch Funk gesendeten Darbietung lediglich einen Vergütungsanspruch vor. Diese Regelung erscheint notwendig, um eine Beeinträchtigung der Interessen der Urheber zu verhindern. Die Urheber erhalten aus der öffentlichen Wiedergabe ihrer Werke mittels Bild- oder Tonträger und der öffentlichen Wiedergabe von Funksendungen ihrer Werke oft beträchtliche Einnahmen. Sie sind daher an einer weitgehenden Verwendung der Bild- oder Tonträger interessiert. Anders liegt es bei den ausübenden Künstlern. Diese fühlen sich durch die zunehmende Verwendung "mechanischer Musik" in ihrer Existenz bedroht und haben zu erkennen gegeben, daß sie ihre Verbotsrechte benutzen könnten, um die Verwendung der mechanischen Musik einzuschränken. Dađurch würden aber die Urheber in der Auswertung ihrer Werke empfindlich behindert. Im übrigen erscheint es bedenklich, die Entscheidung über das äußerst schwierige und vielschichtige Problem der ${ }_{\text {Mecha- }}$ nisierung" der Kunst in die Hände der ausübenden Künstler, also einer Interessentengruppe selbst zu legen.

Dagegen dürfte die weitere aus Urheberkreisen ausgesprochene Befürchtung, daß schon die Gewährung eines Vergütungsanspruchs an die ausübenden Künstler die Rechte der Urheber beeinträchtigen könnte, nicht begründet sein. Bei Vorträgen oder Aufführungen eines Werkes durch persönliche Darbietung muß der Veranstalter schon jetzt neben der Vergütung an die Urheber auch ein Entgelt an die ausübenden Künstler zahlen. Es dürfte für den Veranstalter kein Anlaß bestehen, die an die Urheber zu zahlende Vergütung bei öffentlichen Wiedergaben ihrer Werke mittels Bild- oder Tonträger deshalb geringer zu bemessen, weil in Zukunft auch die auf diesen Bild- oder Tonträgern aufgenommenen Künstler ein Entgelt erhalten, das im übrigen niedriger sein wird als bei ihrer persönlichen Mitwirkung.

Ebenso wie hinsichtlich des Umfangs der Rechte des ausübenden Künstlers (teilweise Abschwächung zu einem Vergütungsanspruch) sieht der Entwurf auch hinsichtlich der Schutzfrist eine Einschränkung der dem ausübenden Künstler formal nach geltendem Recht zustehenden Befugnisse vor. Während sich nach § 2 Abs. 2 LUG aus der für das "fiktive Bearbeiterurheberrecht" des ausübenden Künstlers vorgesehenen entsprechenden Anwendung urheberrechtlicher Grundsätze eine Schutzfrist von $50 \mathrm{Jah}$ ren nach dem Tode des ausübenden Künstlers ergibt, soll die Schutzfrist nach dem Entwurf (§ 92) wie bei den sonstigen Leistungsschutzrechten nur 25 Jahre betragen.

Die Einschränkungen der Befugnisse des ausübenden Künstlers gegenüber dem geltenden Recht sind eine Folge der neuen richtigeren systematischen Einfügung des Rechts des ausübenden Künstlers in die Gruppe der Leistungsschutzrechte, die es ermöglicht, Umfang und Dauer des Rechts unabhängig von der Ausgestaltung des Urheberrechts nach eigenen, der besonderen Interessenlage entsprechenden
Grundsätzen zu entwickeln. Ein unbilliger oder gar unzulässiger, dem Gesetzgeber verfassungsrechtlich verwehrter Eingriff in "wohlerworbene Rechte" kann darin nicht gesehen werden.

\section{Zu $\$ 83$ - Ausübender Künstler}

Nach der in dieser Vorschrift enthaltenen Begriffsbestimmung versteht der Entwurf unter einem "ausübenden Künstler" nur denjenigen, der ein Werk im Sinne des $\S 2$ vorträgt oder aufführt oder bei dem Vortrag oder der Aufführung eines solchen Werkes künstlerisch mitwirkt, also den Musiker, Sänger, Schauspieler, Tänzer und jeden anderen Werkinterpreten. Nicht vorausgesetzt wird, daß das Werk Urheberrechtsschutz genießt; der ausübende Künstler soll auch dann geschützt sein, wenn das Urheberrecht an dem vorgetragenen Werk infolge Ablaufs der Schutzfrist schon erloschen ist oder wenn es sich um das Werk eines Ausländers handelt, das im Inland nicht geschützt ist. Von einer Erweiterung des Schutzes auf Darbietungen, die nicht Vorträge oder Aufführungen eines Werkes darstellen, wie in der Regel Zirkus- und Varietévorführungen, sieht der Entwurf ab. Wenn auch ein Schutzbedürfnis für solche Darbietungen in gewissem Umfang nicht schlechthin zu verneinen sein dürfte, so fehlt es doch für eine gesetzliche Regelung zur Zeit an der notwendigen Klärung und Abgrenzung dieses Problems.

Die Fassung des Entwurfs stellt klar, daß nicht nur die unmittelbar das Werk Vortragenden oder Aufführenden, wie die Sänger, Musiker, Schauspieler oder Tänzer, als ausübende Künstler im Sinne des Gesetzes anzusehen sind, sondern auch die sonst bei dem Vortrag oder der Aufführung künstlerisch Mitwirkenden, also insbesondere der Dirigent und der Regisseur. Da Voraussetzung für den Schutz stets eine künstlerische Mitwirkung ist, wird das technische Personal nicht erfaßt.

Handelt es sich um Ensembledarbietungen eines Werkes wie Chor-, Orchester- und Bühnenaufführungen, so sollen alle Mitwirkenden gleichermaßen als ausübende Künstler geschützt sein, also nicht lediglich der Dirigent, der Regisseur und die Solisten, sondern auch jedes einzelne Orchester- oder Chormitglied. Dies entspricht der bereits für das geltende Recht zu § $2 \mathrm{Abs}$. 2 LUG vom Bundesgerichtshof vertretenen Auffassung (vgl. Entscheidung vom 31. Mai 1960, BGHZ 33 S. 48, Anlage 10 [IV]). Der Entwurf sieht jedoch in den $\$ \S 90$ und 93 Abs. 2 gewisse Einschränkungen für die Geltendmachung der Rechte der Ensemblemitglieder vor.

\section{Zu § 84 - Bildschirm- und Lautsprecherübertragung}

Die Bestimmung soll es dem ausübenden Künstler ermöglichen, eine heimliche Erweiterung des Teilnehmerkreises von Veranstaltungen durch Bildschirm- und Lautsprecherübertragungen seiner Darbietung in Räume außerhalb der Veranstaltung zu verbieten oder nur gegen Zahlung einer zusätzlichen Vergütung zu gestatten. Die Regelung entspricht der für den Urheber in $\S 19$ Abs. 3 vorgesehenen Bestimmung. 
Der Anregung, dem ausübenden Künstler ein Verbietungsrecht auch für Lautsprecherübertragungen zuzubilligen, die in dem Veranstaltungsraum selbst durchgeführt werden, kommt der Entwurf nicht nach. In diesen Fällen dient die Einschaltung des Lautsprechers lediglich der Verbesserung der Akustik, nicht einer Erweiterung des Hörerkreises.

\section{Zu $\S 85$ - Vervielfältigung}

Abrweichend von $\S 2$ Abs. 2 LUG, der dem ausübenden Künstler nur Rechte an der von ihm bespielten mechanischen Vorrichtung, nicht aber das ausschließliche Recht zur Aufnahme iseines Vortrags auf solche Vorrichtungen gewährt, soll nach Satz 1 bereits die Aufnahme ider Danbietung des ausübenden Künstlers nur mit seiner Einwilligung zulässig sein. Der Bundesgerichtshof hat dieses Recht in seiner Entscheildung vom 31. Mai 1960 (BGHZ 33 S. 20, Anlage 8 [II]) bereits für das geltende Recht aus dem allgemeinen Persönlichkeitsrecht des Künstlers und den allgemeinen bürgerlich-rechtlichen Grundsätzen des Verbots sittenwidriger Vermögensschädigung und unlauteren Wettbewerbs abgeleitet. Wie die Aufnahme auf Bild- oder Tonträger vorgenommen wird, ob unmittelbar oder mittelbar unter Empfang einer Rundfunksendung der Darbietung, macht für den Schutz des ausübenden Künstlers nach Satz 1 keinen Unterschied.

Darüber hinaus gewährt Satz 2 dem ausübenden Künstler das Recht zur Vervielfältigung der Bilidoder Tonträger, auf die seine Darbietung aufgenommen ist. Gegen das Vervielfältigungsrecht ist eingewandt worden, der ausübende Künstler könne mit demjenigen, dem er die Aufnahme seiner Darbietung auf Bild- oder Tonträger gestatte, also z. B. dem Schallplattenhersteller oder dem Rundfunkunternehmen, vertragliche Vereinbarungen über die Zulässigkeit und die Bedingungen der Hersiellung von Vervielfältigungsstücken seiner Darbietung treffen. Indessen ist zu berücksichtigen, daß die mit Einwilligung des ausübenden Künstlers hergestellten Bild- oder Tonaufnahmen in unberufene Hände gelangen und von Personen vervielfältigt werden können, mit denen der ausübende Künstler nicht in Vertragsbeziehungen steht. Für diese Fälle muß der ausübende Künstler ein gegen jedermann durchsetzbares Verbietungsrecht haben. Dieses Recht reicht aber zur Wahrung seiner Belange auch aus; eines besonderen Verbreitungsrechts bedarf es darüber hinaus nicht.

Es ist der Vorschlag gemacht worden, eine Ausnahmebestimmung einzufügen, nach der Vervielfältigungen ohne Einwilligung des ausübenden Künstlers zulässig sein sollen, wenn und soweit der ausübende Künstler die Aufnahme seiner Darbietung auf Bild- oder Tonträger gerade zum Zweck der Vervielfältigung der Bild- oder Tonträger gestattet hat, wie es insbesondere bei dem für einen Schallplattenhersteller oder ein Rundfunkunternehmen tätigen Künstler regelmäßig der Fall ist. Für eine solche Ausnahme ist jedoch ein ernstliches Bedürfnis nicht anzuerkennen, da sich in derartigen Fällen der Vertragspartner des ausübenden Künstlers das Vervielfältigungsrecht zu- gleich mit Idem Aufnahmerecht vertraglich einräumen lassen kann. Durch $\S 88$ ist sichergestellt, daß der ausübende Künstler die Möglichkeit, Idie Vervielfältigung $\mathrm{zu}$ gestatten, selbst dann stets behält, wenn er seine Rechte einem Dritten, z. B. einer Verwertungsgesellschaft, im voraus übertragen hat. Soweit der ausübende Künstler in einem Arbeitsoder Dienstverhältnis tätig ist, bestimmt sich nach der in $\S 89$ vorgesehenen Regelung der Umfang des Vervielfältigungsrechts des Arbeitgebers oder Dienstherrn nach dem Wesen des Betriebs- oder Dienstverhältnisses, wenn keine besonderen Vereinbarungen über die Einräumung des Vervielfältigungsrechts getroffen worden sind. Eine Einschränkung des Vervielfältigungsrechts erscheint um so weniger geboten, als dieses Recht seit Einfügung des $\S 2$ Abs. 2 in das LUG im Jahre 1910 uneingeschränkt und unstreitig bestanden hat und sich bisher aus ider Notwendigkeit der vertraglichen Einräumung dieses Rechts für Schallplattenindustrie und Rundfunk offenbar keine wesentlichen Schwie. rigkeit ergeben haben.

\section{Zu $§ 86$ - Funksendung}

Der in Absatz 1 enthaltene Grundsatz, daß Darbietungen des ausübenden Künstlers nur mit seiner Einwilligung durch Funk gesendet werden dürfen, entspricht dem geltenden Recht. Zwar ergibt sich aus § 2 Abs. 2 LUG ein Senderecht des ausübenden Künstlers nur hinsichtlich seiner auf Tonträger aufgenommenen Darbietungen (vgl. Entscheidung des Reichsgerichts vom 14. November 1936, RGZ 153 S. 1); die herrschende Meinung leitet jedoch darüber hinaus aus dem allgemeinen Persönlichkeitsrecht des ausübenden Künstlers seine Befugnis $a b_{r}$ auch die unmittelbare Sendung (Live-Sendung) seiner Darbietung zu verbieten. Es entspricht der natürlichen Rechtsauffassung, dem ausübenden Künstler die Entscheidung darüber vorzubehalten, ob seine Darbietung nur einem überschaubaren, durch persönliche Anwesenheit mit ihm verbundenen Teilnehmerkreis oder einer unbegrenzten Offentlichkeit zugänglich sein soll.

Absatz 2 schränkt das ausschließliche Senderecht des ausübenden Künstlers aus den bereits in der Vorbemerkung zu diesem Abschnitt dargelegten Gründen für den Fall ein, daß ein erschienener Bildoder Tonträger, auf den die Darbietung des Künstlers aufgenommen ist (z. B. eine im Handel erhältliche Schallplatte) zur Funksendung benutzt wird. Der ausübende Künstler hat hier kein schutzwürdiges Interesse daran, die Funksendung zu verbieten, weil in diesem Fall seine Darbietung durch die Funksendung keiner wesentlich größeren oder andersartigen Offentlichkeit zugänglich gemacht wird, als es schon durch Vervielfältigung und Verbreitung des Bild- oder Tonträgers geschehen ist. Die Zuerkennung eines Verbotsrechts hinsichtlich der Benutzung von Industrieschallplatten zu Sendezwecken würde andererseits zu einer Gefährdung der Interessen der Urheber führen können.

Allerdings erscheint es nicht gerechtfertigt, die Benutzung der Bild- oder Tonträger zu Sendezwecken kostenlos zu gestatten. Der ausübende Künstler soll 
daher insoweit einen Anspruch auf angemessene Vergütung erhalten, an der er, soweit es sich um Tonträger handelt, nach $\S 96$ den Hersteller des Tonträgers angemessen zu beteiligen hat.

Die Ausnahmevorschrift des Absatzes 2 ist auf die Verwendung erschienener, d. h. mit Zustimmung des ausübenden Künstlers der Offentlichkeit angebotener oder in Verkehr gebrachter Bild- oder Tonträger (vgl. § 6 Abs. 2) beschränkt. Soweit andere Bild- oder Tonträger, insbesondere die von den Sendeunternehmen selbst hergestellten, lediglich zur Erleichterung des Sendebetriebs bestimmten Bild- oder Tonträger benutzt werden, soll das Einwilligungsrecht des ausübenden Künstlers nach $\mathrm{Ab}$ satz 1 unberührt bleiben. Es erscheint nicht gerechtfertigt, dem ausübenden Künstler auch hinsichtlich dieser nicht zur Verbreitung bestimmten Festlegungen seiner Darbietung die weitere Kontrolle über ihre Verwendung zu entziehen. Er muß beispielsweise die Benutzung solcher Bild- oder Tonträger durch andere Sendeunternehmen oder ihre Weiterverwendung nach seiner Entlassung aus dem Dienst des Sendeunternehmens verhindern können. Der Schutz dieser Interessen kann auf vertraglicher Grundlage allein nicht wirksam gesichert werden, weil durch Vertrag keine Verbotsrechte gegenüber Dritten begründet werden können. Andererseits ist es dem Sendeunternehmen zuzumuten, sich zugleich mit der ohnehin erforderlichen Einwilligung des ausübenden Künstlers zur Aufnahme seiner Darbietung auf Bild- oder Tonträger auch das Recht der Benutzung der Bild- und Tonträger zur Funksendung in dem erforderlichen Umfang einräumen zu lassen. Für festangestellte ausübende Künstler in Arbeits- oder Dienstverhältnissen bestimmt sich der Umfang der Nutzungsbefugnis, wenn keine besonderen Vereinbarungen getroffen sind, nach der in $\S 89$ vorgesehenen Regelung nach dem Wesen des Arbeits- oder Dienstverhältnisses.

Der Entwurf unterscheidet nicht zwischen der Erstsendung und der sog. Anschluß- oder Weitersendung, d. h. der Ubernahme und gleichzeitigen Ausstrahlung einer Funksendung durch ein anderes Sendeunternehmen. Beide Sendearten werden in Ubereinstimmung mit der Begriffsbestimmung des Senderechts des Urhebers ( $\S 20)$ von dem Begriff "Funksendung" erfaßt. Für Weitersendungen gelten somit die gleichen Grundsätze, wie für die Erstsendung der Darbietung. Handelt es sich bei der Erstsendung um eine Live-Sendung, so unterliegt auch die Weitersendung dem ausschließlichen Recht des ausübenden Künstlers nach Absatz 1, d. h. die Weitersendung soll entsprechend dem auch der Regelung in '\$ 84 zugrundeliegenden Gedanken, daß dem ausübenden Künstler die Bestimmung über den unmittelbaren Wirkungsbereich seiner Darbietung stets in vollem Umfang vorzubehalten ist, nur mit seiner Einwilligung zulässig sein. Handelt es sich bei der Erstsendung jedoch um eine nach Absatz 2 ohne Einwilligung des ausübenden Künstlers zulässige Sendung mittels erschienener Bild- oder Tonträger, so soll auch die Weitersendung nicht der Einwilligung des ausübenden Künstlers bedürfen, allerdings wie die Erstsendung vergütungspflichtig sein. Dies kommt in der Formulierung des Absat- zes 2 dadurch zum Ausdruck, daß nicht auf die bei der Weitersendung nur mittelbare - Benutzung der Bild- oder Tonträger zur Funksendung, sondern auf die Sendung (Erst- oder Weitersendung) der auf ihnen aufgenommenen Darbietung abgestellt wird.

\section{Zu § 87 - Offentliche Wiedergabe}

Für das geltende Recht hat der Bundesgerichtshof in zwei Entscheidungen vom 31. Mai 1960 (BGHZ 33 S. 1 und 38, Anlagen 7 [C I] und 9 [II]) aus dem "fiktiven Bearbeiterurheberrecht" nach § 2 Abs. 2 LUG das Recht des ausübenden Künstlers abgeleitet, auch die öffentliche Wiedergabe seiner Darbietung mittels Tonträger und die öffentliche Hörbarmachung von Funksendungen seiner Darbietung zu verbieten. Danach ist die öffentliche Wiedergabe von Schallplatten und Rundfunkmusik, beispielsweise in Gaststätten, nur mit Einwilligung des ausübenden Künstlers zulässig.

Der Entwurf sieht, hiervon abweichend, aus den gleichen Gründen wie bei der Funksendung mittels Bild- oder Tonträger ( $\$ 86$ Abs. 2) für diese weiteren Fälle der Zweitverwertung der Darbietung des ausübenden Künstlers lediglich einen Vergütungsanspruch vor. Die ausübenden Künstler sollen zwar ein angemessenes Entgelt auch für die mittelbare Verwertung ihrer Leistung erhalten, diese jedoch nicht verbieten können, weil die Gefahr besteht, daß sie ein solches Verbotsrecht dazu benutzen könnten, die Verwendung "mechanischer Musik" zum Nachteil der Urheber einzuschränken oder ganz zu untersagen. Für die ausübenden Künstler bedeutet diese Regelung keine wesentliche Schlechterstellung gegenüber dem geltenden Recht, denn der Bundesgerichtshof hat in der Begründung zu der ersten der beiden erwähnten Entscheidungen vom 31. Mai 1960 (Anlage 7 [C I 3 b]) bereits angedeutet, daß sich die ausübenden Künstler dem Vorwurf eines Rechtsmißbrauchs aussetzen könnten, falls sie die nach geltendem Recht erforderliche Einwilligung in die Benutzung der von ihnen bespielten Tonträger selbst dann versagen würden, wenn ihnen ein angemessenes Entgelt angeboten wird. Das Ziel auch der Entscheidungen des Bundesgerichtshofs ist es also letztlich nur sicherzustellen, daß die ausübenden Künstler eine angemessene Vergütung für die Ausnutzung ihrer Leistung erhalten.

Handelt es sich um die öffentliche Wiedergabe von Darbietungen mittels Tonträger, so hat der ausübende Künstler den Hersteller des Tonträgers wie im Falle des $\S 86$ Abs. 2 an der ihm zustehenden Vergütung angemessen zu beteiligen ( $\$ 96)$.

Zur praktischen Verwirklichung der Vergütungsansprüche aus $\S 87$ haben sich die ausübenden Künstler bereits zu Verwertungsgesellschaften zusammengeschlossen, an denen zum Teil auch die Schallplattenindustrie beteiligt ist. Eine gemeinsame Wahrnehmung der Vergütungsansprüche mit den entsprechenden Rechten der Urheber wird angestrebt. Voraussichtlich wird die GEMA für alle Beteiligten das Inkasso übernehmen, so daß der einzelne Musikveranstalter oder sonstige Verwerter durch 
eine einzige Zahlung sämtliche an einer Schallplatten- oder Rundfunkwiedergabe bestehenden Rechte und Ansprüche abgelten kann.

\section{Zu $\$ 88$ - Abtretung}

Die Bestimmung stellt zunächst klar, daß die dem ausübenden Künstler nach den $\S \S 84$ bis 87 zustehenden Einwilligungsrechte und Vergütungsansprüche an Dritte, d.h. insbesondere auch an Verwertungsgesellschaften, abgetreten werden können. Für die Vergütungsansprüche, die reine Vermögensrechte sind, soll dieser Grundsatz uneingeschränkt gelten. Eine besondere Lage besteht jedoch hinsichtlich der Einwilligungsrechte wegen ihres persönlichkeitsrechtlichen Einschlags. Die Vollabtretung würde hier zu einer bedenklichen Einschränkung der Verfügungsmacht des ausübenden Künstlers übrer seine Arbeitskraft führen. Hat beispielsweise der ausübende Künstler sein Recht nach $\S 85$ Satz 1, die Aufnahme seiner Darbietung auf Bild- oder Tonträger zu gestatten, oder sein Einwilligungsrecht zu Funksendungen seiner Darbietung nach $\S 86$ Abs. 1 für alle seine Darbietungen im voraus auf eine Verwertungsgesellschaft übertragen, so könnte er bei unbeschränkter Wirksamkeit einer solchen Abtretung niemals mehr ohne Zustimmung der Verwertungsgesellschaft für eine Schallplattenfirma oder ein Sendeunternehmen tätig werden. Diese Bindung erscheint unzumutbar. Der Entwurf sieht daher im Interesse des ausübenden Künstlers, aber auch im Interesse seiner Vertragspartner vor, daß der ausübende Künstler stets, auch wenn er seine Einwilligungsrechte nach den $\$ \S 84,85$ und 86 Abs. 1 voll abgetreten hat, die Befugnis behält, Einwilligungen auch selbst zu erteilen. Der Anregung, einen völligen Ausschluß der Abtretbarkeit der Einwilligungsrechte vorzusehen, folgt der Entwurf nicht. Dem ausübenden Künstler soll die Möglichkeit, sich zur Wahrnehmung seiner Rechte einer Verwertungsgesellschaft zu ibedienen, nicht grundsätzlich genommen werden.

Die Regelung des Entwurfs schränkt lediglich die dingliche Wirkung einer Abtretung der Einwilligungsrechte ein. Die Wirksamkeit schuldrechtlicher sog. Exklusivverträge, durch die sich der ausübende Künstler verpflichtet, nur für bestimmte Schallplattenfirmen oder Rundfunkunternehmen tätig zu werden, bleibt unbenührt.

\section{Zu $\S 89$ - Ausübende Künstler in Arbeits- oder Dienstverhältnissen}

Auch der ausübende Künstler, der seine Darbietung in Erfüllung seiner Verpflichtungen aus einem Arbeits- oder Dienstverhältnis erbringt, erwirbt nach der Regelung des Entwurfs die sich aus den $\$ \S 84$ bis 87 ergebenden Rechte. Der Entwurf unterscheidet ebenso wie bei den Urhebern (vgl. § 43) auch bei den ausübenden Künstlern insoweit nicht zwischen Freischaffenden und Arbeitnehmern. Es ist jedoch $\mathrm{zu}$ berücksichtigen, daß die Anstellungsverträge der ausübenden Künstler in Arbeits- oder Dienstverhältnissen, z. B. die Verträge der bei Schallplattenfirmen, Rundfunkanstalten oder Konzert- und Theaterunternehmen fest angestellten
Künstler, häufig keine ausdrücklichen Vereinbarungen darüber enthalten, in welchem Umfange der Arbeitgeber oder Dienstherr die Darbietung benutzen und gegebenenfalls anderen ihre Benutzung gestatten darf; denn die langfristigen, zuweilen unkündbar auf Lebenszeit laufenden Verträge sind meist zu einer Zeit abgeschlossen worden, als der Umfang der Rechte der ausübenden Künstler noch umstritten und ihre künftige gesetzliche Ausgestaltung nicht abzusehen war. Es liegt auf der Hand, daß sich in diesen Fällen aus dem Wesen des Arbeitsoder Dienstverhältnisses auch ohne besondere Viereinbarung die Befugnis des Arbeitgebers oder Dienstherrn ergeben muß, die Darbietung des ausübenden Künstlers entsprechend dem unmittelbaren Vertragszweck zu vierwenden: Eine Rundfunkanstalt muß beispielsweise zur Sendung der Darbietungen seiner angestellten Musiker befugt sein, eine Schallplattenfirma zur Aufnahme der Darbietung auf Tonträger und zur Vervielfältigung der Tonträger. In Sonderfällen kann sich danüber hinaus, wie der Bundesgerichtshof in seiner Entscheidung vom 31. Mai 1960 (BGHZ 33 S. 20, Anlage 8 [V]) ausgesprochen hat, aus dem Wesen des Arbeits- oder Dienstverhältnisses die Verpflichtung des ausübenden Künstlers ergeben, gegen Zahlung einer angemessenen Vergütung auch eine über den unmittelbaren Vertragszweck hinausgehende Verwertung seiner Darbietung zu dulden. In der erwähnten Entscheidung, die allgemeine Zustimmung gefunden hat, handelte es sich um die Duldung der Aufnahme und der Rundfunksendung einer Opernaufführung durch die bei einer Städtischen Oper fest angestellten Musiker. Mit der in $\S 89$ vorgesehenen Bestimmung soll dieser Gedanke, daß sich bei fest angestellten ausübenden Künstlern der Umfang der Nutzungsbefugnisse des Arbeitgebers oder Dienstherrn nach dem Wesen des Arbeits- oder Dienstverhältnisses zu bestimmen hat, wenn Vereinbarungen darüber fehlen, gesetzlich festgelegt werden.

Es bedarf keiner besonderen Erwähnung im Gesetz, daß sich aus dem Wesen des Arbeits- oder Dienstvierhältnisses nur ein Vierfügungisrecht ides Arbeitgebers oder Dienstherrn über die Leistung des ausübenden Künstlers engeben kJann. Dritten gegenüber, denen der Arbeitgeber ader Dienstherr die Benutzung ider Darbietung nichit gelstattet hat oder nicht gestatten durfte, bleiben idie Rechte auch des angestellten ausübenden Künstlers vollen Umfiangs bestehen. Denn nach ider Regelung ides Entwurfs, idie lediglich eine Auslegungisregel für den Utbergang der Rechte auf iden Arbeitgeber oder Dienstherrn idarstellt, wind, wie eingangs schon hervorgehoben, das Entstehen ider Rechte in der Person ides ausiubeniden Künstlers nicht iberührt.

Dem Vonschlag, idie Rechte ider bei einem Unternehmien fest angestellten ausübenden Künstler von vornherein uneingeschränkt dem Inhaber des Unternehmens zuzusprechen, fol.gt der Entwurf nicht. Eine solche Regelung wünde eine unbillige Benachteiligung der ausübenden Künstler in Arbeits- oder Dienstverhältnissen bedeuten und erscheint auch zur Wahrung der Interessen ider Arbeitgeber oder Dienstherren nicht notwendig, selbst für den Fall, daß Idie ausübenden Künstler ihre Rechte im voraus 
einer Verwertungsgesellschaft übertragen haben. Denn für diesen Fiall ergibt sich aus $\S 88$, daß idem ausübenden Künstler istets idie Befugnis verbleibt, die zur vertragssmäßigen Nutzung ihrer Leistung durch iden Arbeitgeber oder Dienstherrn erforderlichen Einwilligungen selbst zu erteilen.

\section{Zu § 90-Chor-, Orchester- und Bühnenaufführungen}

Die Bestimmung enthält eine Sonderregelung für Ensembledarbietungen. Wirkt bei einer Darbietung eine große Zahl ausübender Künstler mit, wie es bei Chor-, Orchester- und Bühnenaufführungen ıder Fall ist, so muß sich der einzelne im Interesse der Gesamtheit gewisse Beschränkungen seines Leistungsschutzrechtes gefallen lassen. Es wäre unangemessen, wenn ein einzelner ausübender Künstler z. B. die A.ufnahme oder die Funksendung eines Konzertes verbieten und auf diese Weise seine Kollegen um eine vielleicht erwünschte zusätzliche Einnahme aus ihrer Leistung bringen könnte. Auch idie Rechtssicherheit und idie Erleichterung des Rechtsverkehrs erfordern in idiesen Fällen eine einheitliche Wiahrnehmung der Leistungsischutzrechte aller Mitwirkenden durch wenige Repräsentanten des Ensembles.

Absatz 1 sieht daher vor, daß in den Fällen der $\S \S 84,85$ und 86 Abs. 1, also zur Bilddschirm- oder Lautsprecherübertragung, Vervielfältigung older Funksendung einer Ensembledarbietung, neben der Einwilligung ider Solisten, des Dirigenten und ides Regisseurs, ideren selbständige Rechte unberührt bleiben, die Einwilligung bestimmter Vertreter der mitwirkenden Künstlergruppen, wie Chor, Orchester, Ballett oder Bühnenensemble, genügen soll. Haben diese ihr Einverständnis zur Uibertragung, Viervielfältigung ader Funksendung erteilt, so ist ein etwaiger Wilderspruch einzelner Ensemblemitglieder unbeachtlich. Als Vertreter der Künstlergruppen sind nach dem Entwurf in erster Linie die gewählten Vorstände anzusehen. Besteht ausnahmsweise kein Vorstand, etwa weil sich die Beteiligten nicht auf gemeinsame Vertreter einigen konnten, so soll an dessen Stelle der Leiter ider Gruppe treten, z. B. der Chordirektor, der Dirigent oder der Ballettmeister. Will also beispielsweise ein Rundfunkunternehmen eine Opernaufführung im Fernsehen übertragen, so beidarf es nach $\S 90$ hierfür nelben der Einwilligung der Solisten, des Dirigenten und des Regisseurs nur ider Einwilliligung des Chor- und Orchestervonstandes sowie der Vertreter ides Bühnenensembles und gegebenenfalls des Balletts.

Absatz 2 enthält eine entsprechende Zusammenfassung der sonstigen Rechte der bei Ensembledarbietungen mitwirkenden ausübenden Künstler, d. h. der Vergütungsansprüche und der etwaigen, sich au,s der Verletzung von Einwilligungsrechten engebenden Unterlassungs-, Vernichtungs- ader Schadenensatzansprüche (vgl. §§ 107, 108). Zur Geltendmachung idieser Ansprüche soll für die Gesamtheit der betreffenden Künstlergruppen wiederum deren Vorstand bzw. Leiter allein rermächtigt sein. Um eine Wahrnehmung der Ansprüche durch eine Verwertungsgesellschaft zu ermöglichen, ist vorgesehen, daß Idie Ermächtigung auf eine Verwertungsgesell- schaft übertragen werden kann. Die Ansprüche ider Solisten, des Dirigenten und des Regisseurs werden von dieser Regelung nicht berührt. Sie sollen eibenso wie diie Einwilligungsrechte nach Absatz 1 selbständig neben den zusammengefaßten Gruppenrechten geltend gemacht wenden können.

\section{Zu § 91 - Schutz des Veranstalters}

Bei Darbietungen, die von einem Unternehmen (Bühnenunternehmen, Konzertunternehmen oder dengl.) veranstaltet wenden, sind die wirtschaftlichen Interessen des Inhabers des Unternehmens zu berücksichtigen. Dieser muß dargegen geschützt werden, daß ıdie von ihm mit Mühe und Kosten idurchgeführten Darbietungen von anderen ohne seine Erlaubnis durch Bildschirm- oder Lautsprecherübertragung in Räume außerhalb der Veranstaltung, durch Aufnahme auf Bild- oder Tonträger und ideren Viervielfältigung oder durch Funksendung ausgenutzt werden.

In der Regel wind der Unternehmer eine solche Ausnutzung bereits auf Grund seines Hausrechts verhindern können. Es ist aber möglich, daß rdie Handlungen ohne sein Wissen vorgenommen werden. $\S 91$ sieht daher vor, daß es bei Darbietungen, die von einem Unternehmen veranstaltet werden, in den Fällen der $\S \S 84,85$ und 86 Abs. 1 neben der Einwilligung des ausübenden Künstlens auch der Einwilligung des Inhabers ides Unternehmens bedarf.

\section{Zu § 92 - Dauer der Rechte}

Der Bestimmung einer Schutzfrist für die Rechte des ausübenden Künstlers und des Veranstalters (§ 91) bedarf er nur für den Fall, daß die Darbietung auf Bild- oder Tonträger aufgenommen und dadurch einer wiederholten Verwertung zugänglich gemacht wird. Die Schutzfrist soll nach dem Entwurf in diesem Falle in Ubereinstimmung mit der für den Lichtbildschutz und die Rechte der Tonträgerhersteller und Sendeunternehmen vorgesehenen Regelung 25 Jahre betragen, und zwar grundsätzlich 25 Jahre nach dem Erscheinen des Bild- oder Tonträgers, hilfsweise 25 Jahre nach der Darbietung, wenn der Bild- oder Tonträger innerhalb dieser Frist nicht erschienen ist. Diese Schutzdauer dürfte ausreichen, um dem ausübenden Künstler eine angemessene wirtschaftliche Auswertung seiner Darbietung zu sichern.

Für den Schutz des ausübenden Künstlers gegen Entstellung seiner Darbietung ist die Schutzfríst in $\S 93$ Abs. 3 besonders geregelt.

\section{Zu § 93 - Schutz gegen Entstellung}

Ebenso wie dem Urheber in Bezug auf sein Werk ein "droit moral" zusteht, soll auch dem ausübenden Künstler ein solches Recht für seine künstlerische Leistung eingeräumt werden. In Anlehnung an die Vorschrift des $\S 14$, die dem Urheber einen Schutz gegen Entstellung seines Werkes gibt, bestimmt Absatz 1, daß der ausübende Künstler das Recht hat, eine Entstellung oder eine andere Beeinträchtigung seiner Leistung $\mathrm{zu}$ verbieten, die ge- 
eignet ist, sein Ansehen oder seinen Ruf als ausübender Künstler zu gefährden. Ein weitergehender Schutz der ideellen Interessen des ausübenden Künstlers erscheint nicht erforderlich. Insbesondere ist kein Recht auf Namensnennung vorgesehen; denn der ausübende Künstler wird regelmäßig in der Lage sein, sich das Recht auf Namensnennung vertraglich auszubedingen.

Das vorgesehene Schutzrecht ist ein Ausschnitt aus dem allgemeinen Persönlichkeitsrecht des ausübenden Künstlers. Ebenso wie beim Urheberrecht (vgl. Vorbemerkung zu $\$ \S 12$ bis 14) besteht jedoch auch beim Leistungsschutzrecht des ausübenden Künstlers eine so enge Beziehung zwischen dem droit moral und den vermögensrechtlichen Befugnissen, daß es trotz Anerkennung des allgemeinen Persönlichkeitsrechts durch die Rechtsprechung des Bundesgerichtshofs und selbst für den Fall einer umfassenden gesetzlichen Regelung des Persönlichkeitsschutzes richtiger erscheint, das droit moral des ausübenden Künstlers im Urheberrechtsgesetz gesondert zu regeln. Hierdurch wird zugleich ermöglicht, den Besonderheiten Rechnung zu tragen, die sich z. B. bei Ensembleaufführungen aus der Konkurrenz der Rechte einer Vielzahl von Mitwirkenden ergeben. Der Entwurf sieht in Absatz 2 für diese Fälle vor, daß die einzelnen ausübenden Künstler bei der Ausübung ihrer Rechte aus $\S 93$ angemessene Rücksicht aufeinander zu nehmen haben. Dadurch soll auf eine gerechte Interessenabwägung hingewirkt werden, falls einer der Mitwirkenden die Verwertung der Aufführung wegen Entstellung seiner Leistung. untersagen will, andere dagegen an dieser Verwertung gerade interessiert sind, um aus ihr zusätzliche Einnahmen zu erzielen.

$\mathrm{Da}$ es sich um einen Schutz ideeller Intenessen des Künstlens handelt, ist es nicht gerechtfertigt, die Dauer dieses Schutzes auf 25 Jahre zu beschränken; der ausübende Künstler muß vielmehr während seines ganzen Lebens gegen die Entstellung seiner Leistung geschützt sein. Absatz 3 Satz 1 bestimmt daher, daß der Schutz gegen Entstellungen grundsätzlich erst mit dem Tode des ausübenden Künstlers erlischt. Die Schutzfrist soll jedoch nach Absatz 3 Satz 2 stets mindestens 25 Jahre betragen, auch wenn der ausübende Künstler früher verstirbt. Damit berücksichtigt der Entwurf in angemessenem Umfang das Interesse der nahen Angehörigen, Entstellungen der Darbietung des Künstlers, falls diese auf Bild- oder Tonträger aufgenommen ist, auch nach dessen Tode verhindern zu können.

\section{Zu § 94 - Beschränkung der Rechte}

Die Bestimmung erklärt die Vorschriften über die Schranken des Urheberrechts im Sechsten Abschnitt des Ersten Teils ides Entwurfs ( $\$ \S 45$ bis 63) für sinngemäß anwendibar. Die ausübenden Künstler sollen in ihren Rechten nicht besser grestellt sein als die Urheber, sondern den gleichen Einschränkungen im Interesse der Allgemeinheit unterliegen wie diese.

Der Anregung, hinsichtlich der Rechte der ausübenden Künstler entsprechend den Vorschriften der
$\S \S 64$ bis 66 gesetzliche Nutzungsrechte zugunsten der Tonträgerhersteller und der Sendeunternehmen vorzusehen, folgt der Entwurf nicht. Eine derartige Regelung läge weder im Interesse ider Allgemeinheit noch im Interesse ider Tonträgrerhersteller und Sendeunternehmen und würde Idem mit den gesetzlichen Nutzungsrechten an den Werken der Urheber verfolgten Ziel widersprechen. Sinn dieser Nutzungsrechte ist es, der Allgemeinheit urheberrechtlich geschützte Werke in möglichst vielfältiger Form, insbesondere in zahlreichen miteinander wetteifernden Interpretationen verschiedener ausübender Künstler, nahezubringen. Würlde man auch die Darbietung des ausübenden Künstlers dem gesetzlichen Nutzungsrecht unterwerfen, so würde dies den Wettbewerb in der künstlerischen Qualität der Werkinterpretation gerade unterbinden.

\section{VIERTER ABSCHNITT}

\section{Schutz des Herstellers von Tonträgern}

Der Schutz des Hierstellers von Tonträgern beruht zur Zeit auf zwei Grundlagen: Der Hersteller von Tonträgern läßt sich in ider Regel von den ausübenden Künstlern, deren Darbietungen er auf Tonträger aufnimmt, ihre Rechte aus § 2 Albs. 2 LUG abtreten. Dadurch erwirbt er das ausschließliche Recht, den Tonträger zu vervielfältigen und.gewerbsmäßig zu verbreiten. Außerdem genießt der Tonträgerhersteller den Schutz, iden $\S 1$ des Gesetzes gegen den unlauteren Wettbewerb (UWG) gegen die sittenwidrige Ausbeutung einer Leistung durch Mitbewerber bietet.

Der bestehende Schutz sichert die wirtschaftlichen Interessen des Herstellers von Tonträgern nicht in ausreichendem Maße. Die ausübenden Künstler haben sich weitgehend zu Verwertungsgesellschaften zusammengeschlossen, die ihre Rechte an Tonträgern wahrnehmen sollen. Dadurch kann idem Tonträgerhersteller der Erwerb dieser Rechte erschwert werden. Außendem wirken bei der Herstellung eines Tonträgers nicht immer ausübende Künstler mit, z. B. ıdann nicht, wwenn Tierstimmen oder andere Naturgeräusche, die keine Werke sind, auf Tonträger übertragen werden. In ıdiesen Fällen kann sich der Tonträgerhersteller gegen eine unerlaubte Nachbildung oder Verwendung der Tonträger durch keine von den ausübenden Künstlern abgeleiteten Rechte schützen. Auch der Schutz auf Grund des Gesetzes gegen den unlauteren Wettbewerb wind wegen der besonderen rein wettbewerblichen Voraussetzungen in § 1 UWG nicht immer durchgreifen, zumal insoweit häufig Beweisschwierigkeiten bestehen wrerden.

Der Entwurf sieht daher ein eigenes Leistungsschutzrecht des Herstellers von Tonträgern vor. Zwar erbringt dieser keine künstlerische Leistung wie der ausübende Künstler. Der Schutz erscheint jedoch mit Rücksicht auf die hochwertige technische Leistung und die großen wirtschaftlichen Aufwendungen, die die Herstellung eines zum Vertrieb geeigneten Tonträgers erfordert, gerechtfertigt. 
Auch das Internationale Abkommen über den Schutz der ausübenden Künstler, der Hersteller von Tonträgern und der Sendeunternehmen vom 26 . Oktober 1961 sieht ein eigenes Schutzrecht des Tonträgerherstellers vor. Der Leistungsschutz des Tonträgerherstellers beschränkt sich, anders als der Schutz des ausübenden Künstlers, nach dem Entwurf nicht auf die Aufnahme von Darbietungen eines Werkes auf Tonträger. Da es sich hier um den Schutz einer technischen, nicht einer künstlerischen Leistung handelt, kann es auf den Werkcharakter des aufgenommenen Objekts nicht entscheidend ankommen.

Es ist angeregt worden, das Leistungsschutzrecht nur denjenigen zu geben, die gewerbsmäßig Tonträger herstellen. Die Leistung des nichtgewerblichen Herstellers ist jedoch nicht grundsätzlich geringer zu bewerten als die des gewerblichen. Eine unterschiedliche Behandlung wäre daher nicht gerechtfertigt.

\section{Zu $§ 95$ - Vervielfältigungs- und Verbreitungsrecht}

Absatz 1 Satz 1 umschreibt den Umfang des Schutzrechts des Tonträgerherstellers, das nach dem Entwurf auf das ausschließliche Recht, den Tonträger zu vervielfältigen und $\mathrm{zu}$ verbreiten, beschränkt sein soll. Hinsichtlich der Benutzung des Tonträgers zur Funksendung und öffentlichen Wahrnehmbarmachung ist ein eigenes Recht des Tonträgerherstellers nicht vorgesehen, doch soll er insoweit einen Anspruch auf angemessene Beteiligung an der dem ausübenden Künstler nach $\S 86$ Abs. 2 und $\S 87$ zustehenden Vergütung erhalten (vgl. § 96).

Absatz 1 Satz 2 stellt klar, daß im Falle einer gewerblichen Herstellung des Tonträgers der Inhaber des Unternehmens als Tonträgerhersteller anzusehen ist. Im Hinblick darauf, daß es bei der Herstellung eines Tonträgers weniger auf die persönliche Leistung als auf die Bereitstellung der erforderlichen technischen und wirtschaftlichen Mittel ankommt, erscheint es geboten, hier von dem sonst geltenden Grundsatz, daß Inhaber des Schutzrechts wird, wer die geschützte Leistung persönlich erbringt, abzuweichen.

Das Schutzrecht des Tonträgerherstellers soll für das technische Können und die wirtschaftlichen Aufwendungen gewährt werden, die für die erstmalige Aufnahme einer Werkdarbietung oder einer sonstigen Tonfolge auf einen Tonträger erforderlich sind, nicht für die Herstellung eines Tonträgers durch Kopieren einer bereits vorhandenen Aufnahme. Da der vom Entwurf in Ubereinstimmung mit dem Sprachgebrauch verwendete Begriff der Herstellung eines Tonträgers auch die Herstellung der Kopie umfaßt, stellt Absatz 1 Satz 3 klar, daß das Schutzrecht des $\S 95$ nicht durch bloße Vervielfältigung eines vorhandenen Tonträgers erworben werden kann, also z. B. nicht durch Uberspielung einer Schallplatte auf Tonband oder durch Mitschneiden einer durch Rundfunk gesendeten Tonaufnahme.

Die Schutzfrist soll nach Absatz 225 Jahre betragen. Die Berechnung der Schutzfrist, die für erschienene Tonträger auf den Zeitpunkt des Erschei- nens, für nichterschienene auf den Zeitpunkt der Herstellung abstellt, entspricht der für den Lichtbildschutz und den Schutz des ausübenden Künstlers vorgesehenen Regelung.

In Absatz 3 werden, wie bei allen verwandten Schutzrechten, die Bestimmungen über die Schranken des Urheberrechts für sinngemäß anwendbar erklärt.

Absatz 4 stellt klar, daß das Schutzrecht nach § 95 einen sich aus anderen gesetzlichen Vorschriften etwa ergebenden Schutz des Tonträgerherstellers nicht ausschließt. Gedacht ist hierbei insbesondere an den Schutz nach § 1 UWG. Die Aufrechterhaltung dieses Schutzes erscheint insbesondere aus zwei Gründen erforderlich:

Es ist möglich, daß ein Tonträger eines ausländischen Herstellers nach den Bestimmungen über den Geltungsbereich des Urheberrechtsgesetzes in der Bundesrepublik keinen Schutz genießt. Gehört in diesem Fall der Hersteller einem Lande des Pariser Verbandes zum Schutze des gewerblichen Eigentums an, so besteht nach Artikel 10 bis der Pariser Verbandsübereinkunft für jedes Verbandsland die Verpflichtung, ihm einen wirksamen Schutz gegen unlauteren Wettbewerb zu sichern. Wenn $\mathrm{z}$. B. der Tonträger dieses Herstellers in der Bundesrepublik von einem anderen Hersteller unerlaubterweise vervielfältigt wird, könnte das nach § 1 UWG unzulässig sein. Dieser Schutz darf den ausländischen Staatsangehörigen nicht entzogen werden.

Ferner ist zu berücksichtigen, daß der dem Tonträgerhersteller nach geltendem Recht aus § 1 UWG zustehende Schutz unbefristet ist. Würde $\S 95$ als lex specialis die Anwendung dieser Bestimmung ausschließen, so könnte sich in Zukunft der Tonträgerhersteller auch nach Ablauf seines Leistungsschutzrechtes nicht mehr auf $\S 1$ UWG berufen: denn nach herrschender Ansicht ist in den Fällen, in denen ein Sonderschutz gewährt wird, nach Erlöschen dieses Sonderschutzrechtes für einen Schutz aus § 1 UWG kein Raum mehr. Eine Schlechterstellung des Tonträgerherstellers gegenüber dem geltenden Recht ist aber insoweit nicht beabsichtigt.

\section{Zu §96 - Anspruch auf Beteiligung}

Aus den gleichen Gründen, aus denen der Entwurf dem ausübenden Künstler keine ausschließlichen Rechte an der Zweitverwertung seiner Darbietung durch Funksendung oder öffentliche Wiedergabe mittels Bild- oder Tonträger zubilligt (vgl. zu $\$ 86$ Abs. 2 und $\S 87$, kommt auch ein ausschließliches Recht des Tonträgerherstellers an der Benutzung seines Tonträgers zu öffentlichen Wiedergaben nicht in Betracht. Es erscheint jedoch gerechtfertigt, dem Tonträgerhersteller eine angemessene Vergütung für diese zusätzliche Auswertung seiner Leistung zuzubilligen. Dies könnte in der Weise geschehen, daß dem Tonträgerhersteller ein eigener Vergütungsanspruch neben dem des ausübenden Künstlers gewährt würde. Eine solche Mehrheit von Ansprüchen, die zu einer zusätzlichen Belastung der Sendegesellschaften und der Veranstalter öffentlicher Wiedergaben mittels Tonträger führen würde, 
erscheint jedoch nicht wünschenswert. Es soll daher im Falle der Verwendung eines Tonträgers zur Funksendung oder öffentlichen Wiedergabe dem ausübenden Künstler und dem Hersteller des Tonträgers nur eine einzige angemessene Vergütung $\mathrm{zu}$ zahlen sein. Bei der Abwägung, wem der Anspruch zuerkannt werden soll, ist dem ausübenden Künstler für seine künstlerische Leistung der Vorzug vor dem Hersteller des Tonträgers zu geben, der nur eine - wenn auch hochqualifizierte - technische Leistung erbringt. Der Entwurf gewährt daher im Außenverhältnis allein dem ausübenden Künstler den Vergütungsanspruch, sieht jedoch in $\$ 96$ einen Anspruch des Tonträgerherstellers auf eine angemessene interne Beteiligung an der Vergütung vor. In der Praxis hat der Streit, wer den Vergütungsanspruch und wer den Beteiligungsanspruch erhalten soll, weitgehend an Bedeutung verloren, nachdem sich ausübende Künstler und Tonträgerhersteller in der Gesellschaft zur Verwertung von Leistungsschutzrechten (GVL) zu einer gemeinsamen Verwertung ihrer Rechte zusammengeschlossen haben.

Entsprechend der Regelung in $\S 86$ Abs. 2 ist der Beteiligungsanspruch des Tonträgerherstellers auf erschienene, d. h. der Offentlichkeit angebotene oder in Verkehr gebrachte Tonträger beschränkt.

Für die Höhe der Beteiligung des Tonträgerherstellers an der Vergütung des ausübenden Künstlers legt der Entwurf keinen bestimmten Anteilssatz fest. Er beschränkt sich darauf, auszusprechen, daß die Beteiligung angemessen sein muß. Uber die Angemessenheit haben im Streitfall die Gerichte zu entscheiden. Der Anregung, die Entscheidung der in $\S 14$ des Entwurfs eines Verwertungsgesellschaftengesetzes vorgesehenen Schiedsstelle zu übertragen, folgt der Entwurf nicht. Die Schiedsstelle soll oei Streitigkeiten zwischen Verwertungsgesellschaften und Verwertern, nicht aber bei Auseinandersetzungen der einzelnen Berechtigten untereinander zur Entscheidung berufen sein.

\section{FUNFTER ABSCHNITT}

\section{Schutz des Sendeunternehmens}

\section{Zu $§ 97$}

In Übereinstimmung mit dem Europäischen Abkommen zum Schutz von Fernsehsendungen vom 22. Juni 1960 und dem Internationalen Abkommen über den Schutz der ausübenden Künstler, der Hersteller von Tonträgern und der Sendeunternehmen vom 26. Oktober 1961 sieht der Entwurf auch für die Sendeunternehmen einen selbständigen Schutz gegen die unbefugte Ausnutzung ihrer Sendungen vor. Ebenso wie die Aufnahme einer Aufführung auf einen Tonträger erfordert auch die Veranstaltung einer Sendung einen kostspieligen technischen und wirtschaftlichen Aufwand. Diese Leistung der Sendegesellschaft soll sich ein Dritter nicht mühelos zunutze machen können, indem er die Sendung zur Weitersendung übernimmt, auf Bild- oder Ton- träger überträgt oder öffentlich wiedergibt. Es erscheint allerdings wie bei den sonstigen Leistungsschutzrechten nicht gerechtfertigt, den Sendeunternehmen in gleich umfassender Weise ausschlieBliche Rechte an ihren Sendungen zu gewähren, wie den Urhebern an ihren Werken. Vielmehr ist auch hier der Schutz auf das unbedingt Erforderliche zu beschränken. Im einzelnen ergibt sich der Schutzumfang aus Absatz 1.

Nach Absatz 1 Nr. 1 soll dem Sendeunternehmen ohne Einschränkung lediglich das Recht der Weitersendung seiner Funksendung zustehen.

Absatz 1 Nr. 2 gewährt ferner ein ausschließliches Vervielfältigungsrecht, beschränkt dieses aber auf Vervielfältigungen $\mathrm{zu}$ Erwerbszwecken. Soweit nicht unmittelbar in den Tätigkeitsbereich des Unternehmens eingegriffen wird wie im Falle der Weitersendung, hat das Sendeunternehmen ein schutzwürdiges Interesse nur daran, eine Erwerbszwecken dienende Ausnutzung seiner Leistung zu verhindern bzw. von seiner Erlaubnis abhängig zu machen. Das Vervielfältigungsrecht soll sich auf jede Art der Vervielfältigung der Funksendung beziehen, d. h. sowohl auf die Ubertragung der Sendung auf Bild- oder Tonträger und deren Vervielfältigung wie auch auf die photographische Aufnahme einzelner Bilder einer Fernsehsendung. Dies letztere ausdrücklich klarzustellen, erscheint erforderlich, da neuerdings Fälle bekanntgeworden sind, in denen von aktuellen Fernsehsendungen Lichtbilder zur gewerblichen Verwertung in Zeitungen und dergl. hergestellt wurden. Dem Sendeunternehmen soll auch diese neue Art der Verwertung seiner Leistung vorbehaiten sein.

Im übrigen soll dem Sendeunternehmen nach $A b$ satz 1 Nr. 3 lediglich ein eng umgrenztes Recht zur öffentlichen Wiedergabe seiner Fernsehsendungen zustehen. Aus der Formulierung folgt, daß sich das Recht nur auf Wiedergaben der Fernsehsendungen in sog. Fernsehstuben oder in Lichtspieltheatern bezieht, in denen von den Zuschauern ein besonderes Eintrittsgeld erhoben wird. Fernsehwiedergaben in Gaststätten, die ohne Eintrittsgeld zugänglich sind, sollen dem Recht aus $\S 97$ nicht unterworfen sein und somit keiner Erlaubnis durch das Sendeunternehmen bedürfen.

Die Absätze 2 und 3 entsprechen den für die Leistungsschutzrechte der ausübenden Künstler und der Hersteller von Tonträgern vorgesehenen Regelungen (vgl. \$§ 92, 94 und 95 Abs. 2 und 3).

\section{DRITTER TEIL}

\section{Besondere Bestimmungen für Filme}

Der Dritte Teil des Entwurfs sieht in seinem Ersten Abschnitt gewisse Sonderbestimmungen für Filmwerke vor. Diese Bestimmungen werden im Zweiten Abschnitt größtenteils auf Laufbilder für entsprechend anwendbar erklärt, d. $h_{\text {q }}$ auf' solche Filme, 
deren Bildfolgen, wie etwa im Falle eines reinen Dokumentarfilms oder einer sog. Fernsehaufzeichnung, keine schöpferische Leistung darstellen.

Unter Filmen versteht der Entwurf die Bildfolgen, nicht die Filmstreifen oder Magnetbänder (Bildträger oder Bild- und Tonträger), auf denen die Bildfolgen aufgezeichnet sind. Die Vorschriften des Dritten Teils gelten somit grundsätzlich nicht nur für fixierte Filme, sondern ebenso für Fernsehfilme, die ohne vorherige Aufzeichnung live gesendet werden. Lediglich das Leistungsschutzrecht des Filmherstellers ist an die Voraussetzung der Aufnahme des Filmes (Filmwerkes oder Laufbildes) auf Bildträger oder Bild- und Tonträger gebunden (vgl. §§ 104 und 105).

\section{ERSTER ABSCHNITT}

\section{Filmwerke}

Das geltende Recht enthält keine ins einzelne gehende besondere Regelung für Filmwerke. Durch die Novelle von 1910 wurde lediglich einerseits klargestellt, daß die Verfilmung eines Sprachwerkes eine Bearbeitung ist und daher der Zustimmung des Verfassers dieses Werkes bedarf ( $\$ 12$ Abs. 2 Nr. 6 LUG), andererseits ein besonderes Urheberrecht am Filmwerk anerkannt ( $\$ 15$ a KUG). Die bestehende Regelung ist unvollkommen. Sie ist durch Rechtsprechung und Schrifttum in Anwendung allgemeiner Grundsätze des Urheberrechts ergänzt worden, doch können diese allgemeinen Grundsätze den Besonderheiten des Filmwerkes nicht ausreichend Rechnung tragen. Ein Filmwerk unterscheidet sich von anderen Werkarten vor allem durch den großen Kreis der an seiner Herstellung beteiligten Personen. In der Regel erbringen viele dieser Personen schöpferische Beiträge und erwerben dadurch Urheberrechte am Filmwerk. Als solche Urheber des Filmwerkes kommen neben dem Regisseur namentlich der Kameramann und der Cutter in Betracht, der die einzelnen aufgenommenen Szenen des Films schneidet und zusammenfügt, sowie möglicherweise auch einzelne Filmdarsteller, sofern sie ausnahmsweise schöpferisch zur Gestaltung des Filmwerkes beitragen. Neben den Urhebern des Filmwerkes treten als weitere Berechtigte am Filmwerk noch hinzu die Urheber der zu seiner Herstellung benutzten Werke, wie z. B. der Autor eines dem Filmwerk als Vorlage dienenden Romans, sowie die leistungsschutzberechtigten ausübenden Künstler.

Durch diese Vielzahl der Personen, die Rechte am Filmwerk geltend machen könnten, wird die einheitliche Auswertung des Filmwerkes erschwert. Andererseits erfordern die Interessen des Filmherstellers gerade eine möglichst ungehinderte Verwertbarkeit, da Filmwerke in der Regel unter groBem Kostenaufwand zum Zwedk der gewerblichen Verwertung hergestellt werden. Das Kostenrisiko ist für den Filmhersteller nur tragbar, wenn er sicher ist, daß die Verwertung nicht durch Verbotsrechte der Mitwirkenden beeinträchtigt werden kann.

Der Entwurf sieht daher besondere Bestimmungen für Filmwerke vor, durch die dem Filmhersteller der
Erwerb der Rechte am Filmwerk und die Verfügung über diese Rechte erleichtert werden soll. Dabei unterscheidet der Entwurf zwischen den Rechten der Urheber der zur Herstellung des Filmwerkes benutzten selbständigen Werke, wie Roman, Drehbuch und Filmmusik ( $\$ 98$ ), dem Urheberrecht am Filmwerk selbst, das die bei den Dreharbeiten erbrachten schöpferischen Beiträge des Regisseurs, Kameramannes, Cutters usw. umfaßt ( $\S 99$ ), und den Leistungsschutzrechten der Lichtbildner und ausübenden Künster (§§ 101, 102).

\section{Zu $\$ 98$ - Recht zur Verfilmung}

Der Filmhersteller, der von einem Urheber das Recht erwirbt, sein Werk zu verfilmen, will nicht nur das Werk - unverändert oder bearbeitet zur Herstellung eines Filmwerkes benutzen, sondern auch das unter Benutzung des Werkes hergestellte Filmwerk anschließend verwerten können. Er muß daher das Recht haben, das Filmwerk zu vervielfältigen, die Filmkopien zu verbreiten und das Filmwerk entsprechend seiner Zweckbestimmung öffentlich vorzuführen oder durch Funk zu senden. Außerdem benötigt der Filmhersteller für die Verwertung im Ausland, die bei der internationalen Verbreitung von Filmwerken die Regel ist, auch das Recht, das Filmwerk in fremde Sprachen zu übersetzen oder es sonst den ausländischen Verhältnissen anzupassen.

Der Filmhersteller läßt sich diese zur Aüswertung des Filmwerkes erforderlichen Rechte heute regelmäßig vom Urheber vertraglich einräumen. In Anerkennung dieser auch den Urhebern bekannten Praxis sieht der Entwurf zur Vereinfachung des Rechtsverkehrs und zur Vermeidung von Streitigkeiten über den Inhalt derartiger Verträge in $A b$ satz 1 eine entsprechende Auslegungsvorschrift für den Abschluß von Verfilmungsverträgen vor. Danach erwirbt der Filmhersteller durch einen solchen Vertrag im Zweifel neben dem eigentlichen Verfilmungsrecht (Nummer 1) stets das ausschließliche Recht, das Filmwerk zu vervielfältigen und zu verbreiten (Nummer 2), ferner - je nach der Zweckbestimmung des Filmwerkes - das ausschließliche Vorführungsrecht oder das ausschließliche Senderecht (Nummern 3 und 4). Das ausschließliche Recht zur Verwertung von Ubersetzungen und anderen Bearbeitungen oder Umgestaltungen des Filmwerkes (Nummer 5) soll der Filmhersteller im Zweifel allerdings nur unter Beschränkung auf filmische Bearbeitungen erwerben, d.h. der Filmhersteller soll das Filmwerk beispielsweise nicht in einer Bühnenfassung verwerten dürfen. Das Recht, Bearbeitungen oder Umgestaltungen des Filmwerkes herzustellen, ist neben dem Recht zur Verwertung der Bearbeitungen oder Umgestaltungen nicht besonders erwähnt, weil die Herstellung von Bearbeitungen oder Umgestaltungen des Filmwerkes nach $\S 23$ der Einwilligung des Urhebers nicht bedarf.

Von der Auslegungsregel des Absatzes 1 wird das Recht der öffentlichen Wiedergabe von Funksendungen des Filmwerkes (z. B. Fernsehwiedergaben in Gaststätten) nicht erfaßt, da der Filmhersteller dieses Recht zur bestimmungsmäßigen Auswertung 
des Filmwerkes nicht benötigt. Dieses Recht verbleibt somit im Zweifel dem Urheber, der es einer Verwertungsgesellschaft zur Wahrnehmung übertragen kann.

Im Hinblick darauf, daß die Filmkomponisten auch ihre Vorführungsrechte und Senderechte regelmäßig nicht auf den Filmhersteller übertragen, sondern durch ihre Verwertungsgesellschaft, die GEMA, gesondert wahrnehmen lassen, ist angeregt worden, für Werke der Musik die Anwendung der Auslegungsregeln in Absatz 1 Nr. 3 und 4 auszuschließen. Diesem Wunsch hat der Entwurf nicht entsprochen. Abgesehen davon, daß eine derartige Sonderregelung zugunsten einer einzelnen Gruppe von Urhebern nur schwer zu rechtfertigen sein dürfte, erscheint sie auch nicht erforderlich. Die Fälle, in denen die Filmkomponisten ihre Rechte einer Verwertungsgesellschaft übertragen haben, werden von der Regelung ohnehin nicht erfaßt, weil hier die Rechtslage nicht zweifelhaft ist. Soweit aber die Filmkomponisten ihre Rechte ausnahmsweise noch selbst innehaben, sind die Auslegungsvorschriften auch für Werke der Musik angebracht.

Der Urheber räumt üblicherweise das Verfilmungsrecht an seinem Werk nur für ein bestimmtes Filmwerk ein; eine Wiederverfilmung soll der Filmhersteller nicht vornehmen dürfen. Absatz 2 Satz 1 bestimmt daher, daß die nach Absatz 1 dem Filmhersteller zustehenden Befugnisse im Zweifel nicht zu einer Wiederverfilmung des Werkes berechtigen. Diese lediglich die positive Seite des Nutzungsrechts des Filmherstellers betreffende Auslegungsregel ändert nichts daran, daß dieser auf Grund des ihm nach Absatz $1 \mathrm{Nr}$. 1 zustehenden ausschließlichen Verfilmungsrechts jedem anderen einschließlich des Urhebers verbieten kann, das Werk anderweit filmisch zu verwerten. Die Möglichkeit, eine Zweitverfilmung des Werkes durch andere zu verhindern, muß dem Filmhersteller grundsätzlich verbleiben, da durch diese, auch wenn sie sich in der Ausführung wesentlich von der Erstverfilmung unterscheidet, die Auswertung des ersten Filmwerkes empfindlich beeinträchtigt werden kann. Allerdings erscheint ein zeitlich unbeschränkter Schutz vor einer Zweitverfilmung nicht erforderlich, da die Auswertung eines Filmes in der Regel innerhalb verhältnismäßig kurzer Zeit abgeschlossen ist. In der Praxis wird es daher mehr und mehr üblich, das ausschließliche Verfilmungsrecht des Filmherstellers zeitlich zu begrenzen und dem Urheber die erneute filmische Verwertung seines Werkes zu gestatten, wenn hierdurch eine Konkurrenz für das ursprüngliche Filmwerk nicht mehr zu befürchten ist. Dieser Entwicklung trägt der Entwurf durch die Auslegungsregel in Absatz 2 Satz 2 Rechnung, nach der der Urheber im Zweifel nach Ablauf von zehn Jahren nach Herstellung des Filmwerkes zur anderweitigen filmischen Verwertung seines Werkes berechtigt sein soll. Die Befugnis des Filmherstellers, das von ihm hergestellte Filmwerk weiter zu verwerten, sofern dies ausnahmsweise nach zehn Jahren noch möglich sein sollte, wird dadurch nicht berührt. Aus der Anknüpfung der Frist an den Zeitpunkt der Herstellung des Filmwerkes ergibt sich für den Ur- heber keine Unbilligkeit. Er hat zwar auf diesen Zeitpunkt keinen Einfluß, da der Filmhersteller eine Verpflichtung zur Ausübung des Verfilmungsrechts in der Regel nicht übernimmt. Verzögert jedoch der Filmhersteller über Gebühr die Herstellung des Filmwerkes, so kann der Urheber das Nutzungsrecht nach Maßgabe des $\S 41$ wegen Nichtausübung zurückrufen. Der in $\S 100$ vorgesehene Ausschluß des Rückrufsrechts bezieht sich nicht auf das Verfilmungsrecht, sondern lediglich auf die Rechte zur Auswertung des fertiggestellten Filmwerkes (vgl. Begründung zu $\S 100$ ).

Absatz 3 stellt klar, daß für den Fall der Einräumung eines Verfilmungsrechts an einer nach $\S 80$ oder $\S 81$ geschützten Ausgabe eines freien Werkes die Bestimmungen der Absätze 1 und 2 entsprechend anzuwenden sind.

\section{Zu §99 - Rechte am. Filmwerk}

Die Bestimmung behandelt die am Filmwerk selibst bestehenden Urheberrechte. Die Frage, wer Urheber eines Filmwerkes ist, gehört zu den umstrittensten Fragen des Filmrechts. Das geltende Recht läßt die Frage offen. Im Schrifttum wind das Urhebernecht ganz oder zum Teil idem Filmihersteller, idem Drehbuchverfasser, dem Regisseur, den führenden Darstellern oder sonistigen an ider Gestaltung ides Filmwerkes maßgeblich beteiligten Personen zugesprochen.

Der Entwurf unterscheidet, wie schon in ider Einleitung zu diesem Abschnitt erwähnt, zwischen dem Urheberrecht an den zur Herstellung des Filmwerkes benutzten Werken, 'dem Urheberrecht am Filmwerk selbst und den Leistungsschutzrechten der Lichtbildner und der ausübenden Künstler, die bei der Herstellung des Filmwerkes mitgewirkt haben. Unter den zur Herstellung des Filmwerkes ibenutzten Werken (vgl. Absatz 3 und $\S 98$ ) versteht ider Entwurf sowohl die Werke, idie vor der Herstellung des Filmwerkes als selbiständige Werke vorhanden waren und als Vorlage für die Herstellung dienten (wie Roman, Bühnenstück older Schlager), als auch diejenigen Werke, die zwar bereits unmittelbar mit der Zweckbestimmung für das Filmwerk geschaffen wunden, aber dennoch von idiesem untenscheidbar und gesondert verwertibar sind (wie Drehbuch und Filmmusik). Die Urheber idieser Wienke scheiden als Urheber des Filmwenkes aus, weil daas Filmwerk etwas anderes und mehr ist, als nur idie Darstellung der für idas Filmwenk benutzten Werke. Desgleichen scheiden die ausübendien Künstler als Urheber des Filmwerkes aus, denen nach der Regrelung des Entwurfis kein Urheberrecht, sondern nur ein Leistungs. schutzrecht zusteht.

Damit ist der Personenkreis, der als Urheber ides Filmwenkes in Betracht kommt, gegenüber idem geltenden Recht schon näher eingegrenzt. Für ıdas Urheberrecht am Filmwerk kommen nur die Pensonen in Frage, die bei der Henstellung des eigentlichen Filmwerkes, also bei den Dreharbeiten, tätig geworden sind. Geht man von dem Grundsiatz des $\$ 7$ aus, daß Unheber eines Werkes dessen Schöpfer ist, so sind von diesen Personen alle diejenigen als Urheber des Filmwerkes anzusehen, dieren Beitrag 
eine persönliche geistige Schöpfung darstellt. Dies können je mach Lage des Einzelfalles sein: der Regissseur, ider Kameramann, ider Cutter und andere Mitwirkende, möglicherweise auch der Filmhensteller selbst, wenn er die Gestaltung des Filmwerkes schöpferisch mitbestimmt.

Es ist offensichtlich, daß bei dieser Betrachtungsweise idie Feststellung der Urheber des Filmwerkes auf erhelbliche Schwierigkeiten stoßen, in manchen Fällen sogar unmöglich sein kann. Die schöpferischen Beiträge der Filmurheber finden in ider Regiel ihre Festlegung nur auf idem Filmstreifen selbst. Dieser läßt jedoch nicht erkennen, von wem sie herrühren, und häufig werden die einzelnen Mitwirkenden selbst nicht wissen, was sie an schöpferischen Leistungen beigetragen haben. Um diese Schwierigkeiten zu vermeiden, idie bei Anwendung des $\S 7$ auf Filmwerke entstehen, und um zugleich dem Interesse des Filmherstellens an einer möglichst ungehinderten Auswertung ides Filmes entgegenzukommen, war daher in $\S 93$ des Referentenentwurfs von 1954 vorgeschlagen worden, dem Filmhensteller kraft gresetzlicher Fiktion originär idas alleinige Urheberrecht am Filmwerk zuzuerkennen. Die Erörterung dieses Vonschlags hat jedoch gezeigt, daß gegen eine solche Regelung grundsätzliche Bedenken bestehen, die durch die unzweifelhaften praktischen Vorteile nicht aufgewogen werden können: Würde in einem Fall ıder Grundsatz ides $\S 7$, daß das Urheberrecht der Schöpfer des Werkes erwirbt, aus praktischen Erwägungen durchbrochen, so wünde damit ein Präzedienzfall geschaffien, dessen Auswirkungen nicht abzusehen wären. Das Filmwerk ist nicht das einzige Wierk, das durch eine Vielzahl schwer bestimmbarer Urheber giekennzeichnet ist. Eine ähnliche Lage kann bei Hönspielen, Schulbüchern und anderen Gruppenwerken bestehen. Der Ministerialentwurf von 1959 ließ daher den Vorschlag, das Urheberrecht am Filmwerk idem Hersteller zuzuerkennen, fallen und verzichtete auf jede Sonderregelung der Urhelbenschaft am Filmwerk. Er sah insbesondere auch davon ab, zugunisten bestimmter Personen wie etwa des Regisseurs Vermutungen thinsichtlich der Urhebenschaft am Filmwerk aufzustellen, aus 'der Erwägung heraus, daB es angesichts der Vielfältigkeit ides filmischen Schaffens an Regeltatbeständen fehle, die eine solche Vermutung rechtfiertigen könnten. Diese Lösung, die es im wesentlichen bei dem geltenden Rechtszustand beläßt, hat überwiegend Zustimmung gefunden, vor allem deshallb, weil bisher die Fnage ider Filmurhebenschaft trotz der bestehenden Rechtsunsicherheit in der Praxis zu keinen Streitfällen Anlaß gegeben hat; ider Filmhersteller läßt sich nämlich stets vorsonglich die Rechte aller als Filmurheber in Betracht kommenden Personen im voraus vertraglich übertragen. Der vorliegende Entwurf folgt aus diesen Gründen der Regelung des Ministerialentwurfs und beläßt es für Filmwerke bei idem allgemeinen Grundsatz ides $\S 7$, nach welchem jeweils die Personen Urheber des Filmwerkes sind, die bei seiner Henstellung einen schöpferischen Beitrag geleistet haben.

Auch in Zukunft wird sich der Filmhersteller somit die Nutzungsrechte am Filmwerk von allen als Film- urheber in Betracht kommenden Personen vertraglich einräumen lassen müssen. Um es ihm jedoch $\mathrm{zu}$ erleichtern, die für die Auswertung des Filmwerkes erforderlichen Rechte lückenlos zu erwerben, sieht der Entwurf in Anlehnung an die Regelung des $\S 98$ in $\S 99$ Absatz 1 eine Auslegungsregel vor, nach der der Filmhersteller im Zweifel diese Rechte von allen bei der Herstellung des Filmes vertraglich Mitwirkenden eingeräumt erhält. Anders als in $\S 98$ erstreckt sich diese Auslegungsvorschrift auf alle bekannten Arten der Nutzung des Filmwerkes, da bei den unmittelbar im Filmwerk aufgehenden schöpferischen Beiträgen eine solche umfassende Rechtseinräumung die Regel bilden dürfte. Nicht erfaßt wird jedoch das Recht zu einer selbständigen Verwertung des Beitrags außerhalb des Filmwerkes. Der Filmhersteller darf also z. B. im Zweifel nicht einen schöpferischen Einfall des Regisseurs für einen anderen Film verwenden.

Die Auslegungsregel des Absatzes 1 sichert den Filmhersteller nicht für den Fall, daß der bei der Herstellung des Filmwerkes Mitwirkende seine Rechte bereits im voraus auf einen Dritten, beispielsweise einer Verwertungsgesellschaft, übertragen hat. Es ist deshalb gefordert worden, anstelle der Auslegungsregel den Ubergang der Rechte auf den Filmhersteller kraft Gesetzes zwingend vorzuschreiben. Ein solcher gesetzlicher Rechtsübergang würde sich jedoch im Ergebnis kaum von einem fiktiven originären Urheberrecht des Filmherstellers unterscheiden und begegnet daher den gleichen Bedenken wie dieses. Ein Bedürfnis, den Filmhersteller vor der Rechtsunsicherheit zu schützen, die sich aus der Möglichkeit unkontrollierbarer Vorausabtretungen ergibt, ist jedoch anzuerkennen. Der Entwurf sieht daher in Absatz 2 eine der Regelung in $\S 88$ entsprechende Bestimmung vor, nach der der Filmurheber auch im Falle einer Vorausabtretung gegenüber dem Filmhersteller die Verfügungsmacht über seine Rechte behält. Wie im Falle des $\S 88$ dient diese Bestimmung zugleich der Wahrung der persönlichen Handlungsfreiheit der Filmschaffenden, die anderenfalls bei einer Vorausabtretung ihrer Rechte an eine Verwertungsgesellschaft nicht mehr ohne deren Zustimmung für einen Filmhersteller tätig werden könnten.

Absatz 3 stellt klar, daß die Urheberrechte an den zur Herstellung des Filmwerkes benutzten Werken von der Regelung des $\S 99$ nicht berührt werden, selbst wenn, wie es z. B. beim Drehbuchautor oder Filmkomponisten der Fall sein kann, der Urheber des benutzten Werkes zugleich auch unmittelbar bei den Dreharbeiten mitwirkt.

\section{Zu $\S 100$ - Einschränkung der Rechte}

Die Bestimmung soll dem Filmhersteller im Hinblick auf die hohen Herstellungskosten die Verfügung über die Rechte am Filmwerk erleichtern. Satz 1 schließt zu diesem Zweck die Anwendbarkeit der Bestimmungen des Ersten Teils des Entwurfs über das Erfordernis der Zustimmung des Urhebers zur Weiterübertragung von Nutzungsrechten und zur Einräumung einfacher Nutzungsrechte sowie über die Rückrufsrechte wegen Nichtausübung und 
wegen gewandelter Uberzeugung für alle am Filmwerk bestehenden Nutzungsrechte aus, gleichgültig, ob diese von den Urhebern des Filmwerkes ( $\S 99$ ) oder von den Urhebern der zur Herstellung des Filmwerkes benutzten Werke ( $\S 98$ ) eingeräumt worden sind. Unberührt bleibt die Anwendbarkeit der genannten Bestimmungen lediglich auf das Verfilmungsrecht nach $\S 98$ Abs. 1 Nr. 1. Solange der Film nicht hergestellt, das Verfilmungsrecht also nicht ausgeübt ist, bedarf der Filmhersteller keines besonderen Schutzes, da er noch keine wesentlichen Aufwendungen gemacht hat.

Satz 2 schließt für den Fall, daß der Film unerwartet hohe Einnahmen erbringt, für die Urheber des Filmwerkes etwaige Beteiligungsansprüche nach $\S 36$ aus. Wegen der meist bestehenden Unklarheit, welche Personen zu den Filmurhebern zu rechnen sind, würde die Anwendbarkeit des $\S 36 \mathrm{zu}$ einer nicht tragbaren Rechtsunsicherheit führen. Der Forderung der Filmwirtschaft, $\$ 36$ auch für Urheber der zur Herstellung des Filmwerkes benutzten Werke auszuschließen, folgt der Entwurf nicht. Hier besteht keine Ungewißheit über den Personenkreis der Urheber und es ist kein Grund ersichtlich, der sonst den Ausschluß des $\S 36$ rechtfertigen könnte. Hat der Filmhersteller z. B. für ein geringes Entgelt das Verfilmungsrecht an einem Roman eines noch unbekannten Autors erworben, und wird der nach dem Roman gedrehte Film ein Welterfolg, der Millionenbeträge einspielt, so würde es dem Rechtsempfinden widersprechen, den Romanautor an dem unerwarteten Erfolg nicht mitzubeteiligen. Selbstverständlich gilt auch für die Anwendung des § 36 im filmischen Bereich, daß der Beteiligungsanspruch nur seltene krasse Mißverhältnisse zwischen Leistung und Gegenleistung ausgleichen soll. Eine unzumutbare Belastung wird der Filmwirtschaft aus der Anwendung des $\S 36$ somit nicht erwachsen.

\section{Zu § 101 - Rechte an Lichtbildern}

Ein Film setzt sich technisch aus zahlreichen einzelnen in kurzer Zeitfolge nacheinander aufgenommenen Lichtbildern zusammen. An diesen Lichtbildern entstehen nach $\S 82$ jeweils selbständige Leistungsschutzrechte in der Person des Lichtbildners, d.h. beim Film in der Person des Kameramannes. Zur Auswertung des Filmwerkes benötigt der Filmhersteller auch diese Rechte. $\mathrm{Da}$ es sich lediglich um Leistungsschutzrechte handelt, die zudem für den Kameramann gewissermaßen als Zufallsprodukte seiner auf die Herstellung des Films gerichteten Tätigkeit keine selbständige Bedeutung haben, sieht der Entwurf den unmittelbaren Ubergang dieser Rechte auf den Filmhersteller vor, allerdings nur, soweit es sich um die filmische Verwertung der Lichtbilder handelt. Das Recht zu einer selbständigen Verwertung der einzelnen Filmbilder, etwa als Illustrationen zu dem Roman, nach dem der Film gedreht wurde, soll dem Kameramann verbleiben, soweit nichts anderes vereinbart ist.

\section{Zu $\S 102$ - Ausübende Künstler}

Die Bestimmung schränkt die Rechte der ausübenden Künstler ein, die bei der Herstellung eines
Filmwerkes mitwirken oder deren Darbietungen z. B. durch Einblenden vorhandener Schallplatten oder Filmaufnahmen erlaubterweise zur Herstellung des Filmwerkes benutzt werden. Das Filmwerk soll ohne Einwilligung der ausübenden Künstler auf Bildträger oder Bild- und Tonträger aufgenommen ( $\$ 85$ Satz 1), vervielfältigt ( $\$ 85$ Satz 2 ) und live gesendet oder weitergesendet werden dürfen $(\S 86$ Abs. 1). Für die Verwertung des Filmstreifens zur Funksendung und für die öffentliche Wiedergabe der Funksendung sollen die ausübenden Künstler Vergütungsansprüche nach $\S 86$ Abs. 2 und $\S 87$ nicht geltend machen können. Darüber hinaus sollen den ausübenden Künstlern auch hinsichtlich der öffentlichen Vorführung eines Filmwerkes keine Rechte zustehen. Dies braucht allerdings in $\S 102$ nicht besonders erwähnt zu werden, da es sich bereits aus der Ausgestaltung des Leistungsschutzrechts des ausübenden Künstlers im Zweiten Teil des Entwurfs ergibt: Für Vorführungen seiner Darbietung wird dem ausübenden Künstler nach den $\S \S 83$ bis 94 allgemein weder ein Einwilligungsrecht noch ein Vergütungsanspruch gewährt.

Die vorgesehenen Beschränkungen ider Rechte ıder bei der Herstellung eines Filmwerkes beteiligten ausübenden Künstler enscheinen im Hinblick darauf gerechtfertigt, daß die ausübenden Künstler für ihre Mitwirkung in der Regel eine angemessene Verguiutung erhalten, durch idie bereits nach heutiger Praxis alle ihre etwaigen Rechte am Filmwerk abgregolten wenden. Hinzu kommt, daß die in ider Gesamtschöpfung des Filmwerkes laufgegangenen Leistungen der mitwirkenden ausübenden Künstler in der Regel nicht wiederholbar sind, durch die Verwertung des Filmwerkes den ausübenden Künstlern somit für ihr persönliches Auftreten auf der Bühne oder im Konzertsaal keine Konkurrenz entsteht, die sie in ihrem weiteren Schaffen beeinträchtigen könnte. Der Entwurf sieht allendings abweichend von ider geltenden Vertragspraxis nicht einen Ubergang der Rechte auf den Filmhersteller vor, sondern bestimmt, daß die Rechte überhaupt nicht entstehen sollen. Diese Regelung dient der Vereinfachung der Rechtslage und bedeutet keinen Nachteil für den Filmhensteller, da dieser zur Wahrung seiner eigenen Rechtsstellung neben iden von den Urhebern erworbenen Nutzungsrechten am Filmwerk und dem ihm nach $\S 104$ gewährten Leistungsschutzrecht die Rechte der ausüibenden Künstler als abgeleitete Rechte nicht benötigt.

Da die Einschränkungen der Rechte der ausübenden Künstler - wie alle besonderen Bestimmungen für Filmwerke - ihren Grund darin haben, daß der Filmhersteller im Hinblick auf die hohen Herstellungskosten in der Auswertung des Filmwerkes so wenig wie möglich beschränkt sein soll, enscheinen sie nur gerechtfertigt, soweit idie Auswertung ides Filmwerkes selbst in Fnage steht. Für iden Fall, idaß die Darbietung eines ausübenden Künstlers aus dem Filmwerk herausgelöst und beispielsweise durch Aufnahme auf Schallplatten odier durch Sendung im Hörfunk gesondert verwertet wird, sollen seine Rechte voll erhalten bleiben. Dies wind durch die einschränkenden Worte "in Ansehung des Filmwerkes" klangestellt. 


\section{Zu § 103 - Schutz gegen Entstellung}

Wie alle Urheber und Inhaber verwandter Schutzrechte genießen auch idie bei der Herstellung eines Filmwerkes beteiligten Urheber und Schutzrechtsinhaber Schutz gegen eine Entstellung ihrer schöpferischen oder künstlerischen Leistung nach den allgemeinen Vorschriften der $\S \S 14$ und 93. Wegen ider großen Zahl dieser Personen erscheint es jedoch geboten, die Ausübuung ider Rechte aus den $\S \S 14$ und 93 gewissen Beschränkungen zu unterwerfien. Gerade bei Filmwerken wird sich häufig idie Notwendigkeit nachträglicher Anderungen ergeben, etwa auf Grund ıder freiwilligen Selbistkontrolle ider deutschen Filmwirtschaft oder zur Anpassung des Filmwerkes ıan ausländische Verhältnisse. Der Filmhersteller muß hier einen gewissen ISpielnawm erhalten, um dem Filmwerk eine möglichst weite Verbreitung $\mathrm{zu}$ sichern, ohne idie eine Einsplelung ider zu seiner Herstellung aufgewandten Kosten oft nicht möglich sein wird.

Der Entwurf schränkt idaher iden Schutz gegen Entstellungen in zweifacher Hinsicht ein. Die bei der Henstellung ides Filmwerkes beteiligten Urheber und Schutzrechtsinhaber sollen in Ansehung ides Filmwerkes Rechte aus iden $\$ \S 14$ und 93 nur im Falle einer gröblichen Entstellung oder anderen Beeinträchtigung ihrer Werke oder Leistungen igeltend machen können, und sie sollen verpflichtet isein, bei ider Ausübung ider Rechte laufeinander und auf iden Filmhensteller angemessene Rücksicht zu nehmen. Die letztgenannte Einschränkung entspricht der in $\S 93$ Abs. 2 für Ensembledarbietungen lausübender Künstler vorgesehenen Regelung.

\section{Zu § 104 - Schutz des Filmherstellers}

Nach dem Entwurf wind dem Filmhersteller ein eigenes Urheberrecht am Filmwerk nur noch in Ausnahmefällen zustehen, da er meist an der Herstellung des Filmwerkes nicht schöpferisch beteiligt sein wind. Es ist aber zu berücksichtigen, daß die Herstellung eines Filmes regelmäßig eine erhebliche orgianisatorische und wirtischaftliche Leistung idarstellt, die nicht geringer zu bewerten ist, als etwa idie Leistung eines Tonträgerhenstellers oder eines Sendeunternehmens. Der Hersteller eines Tonfilmes hat zwar bereits nach $\S 95$ als Tonträgerhersteller ein. Schutzrecht an dem Tonstreifen des Filmes. Außerdem steht ihm auf Grund des § 101 der Lichtbildschutz an den einzelnen Filmbildern zu. Diese Rechte reichen jedoch für einen wirksamen Schutz seiner im Filmstreifen verkörperten Gesamtleistung nicht aus und es erscheint auch systematisch richtiger, der Einheit des Filmwerkes entsprechend ein einheitliches Leistungsschutzrecht zu gewähren.

Das Leistungsschutzrecht bezieht sich nach Absatz 1 entsprechend dem Recht des Tonträgerherstellers lediglich auf dem Filmstreifen, d.h. den Bildträger oder Bild- und Tonträger, auf den das Filmwerk aufgenommen worden ist, nicht auf das Filmwerk als solches. An einem live gesendeten Fernsehfilmwerk erwirbt das Sendeunternehmen somit kein Recht als Filmhersteller nach $\S 104$, sondern lediglich das Leistungsschutzrecht für Funksendungen nach $\S 97$.
Das Recht des Filmherstellers soll nach Absatz 1 Satz 1 das ausschließliche Recht zur Vervielfältigung und Verbreitung des Filmstreifens sowie das ausschließliche Recht umfassen, den Filmstreifen zu öffentlichen Vorführungen und zur Funksendung zu benutzen (Verwertungisrecht). Darüber hinaus sieht Absatz 1 Satz 2 einen dem Urheberpersönlichkeitsrecht nachgebildeten Schutz gegren Entstellungen und Kürzungen des Filmstreifens vor, der es dem Filmhersteller ermöglichen soll, gegen solche Entstellungen oder Kürzungen selbständig vorzugehen.

Absatz 2 stellt klar, daß das Recht des Filmherstellers insgesamt, einschließlich der Befugnis nach Absatz 1 Satz 2, übertragbar ist.

Absatz 3 bemißt die Schutzfrist entsprechend der Regelung bei den sonstigen Leistungsschutzrechten. Absatz 4 erklärt wie bei allen Leistungsschutzrechten die Vorschriften des Ersten Teils des Entwurfs über die Schranken des Urheberrechts für sinngemäß anwendbar.

\section{ZWEITER ABSCHNITT \\ Laufbilder}

\section{Zu $§ 105$}

Abgesehen von $\S 99$, der die Rechte der Filmurheber betrifft, haben die für Filmwerke geltenden Vorschriften des Ersten Abschnitts ihre Grundlage nicht speziell in der Werkeigenschaft eines Filmes, sondern in den durch die Vielzahl der Mitwirkenden und die hohen Herstellungskosten bedingten Besonderheiten des filmischen Schaffens, die gleichermaBen für die Herstellung eines Filmes ohne schöpferische Gestaltung der Bildfolge, z. B. eines reinen Dokumentarfilmes, der Fernsehübertragung einer Opernaufführung mit feststehender Kamera oder dergl., gelten. Der Entwurf erklärt daher die Bestim. mungen des Ersten Abschnitts auf solche nichtschöpferischen Bildfolgen oder Bild- und Tonfolgen, die als Laufbilder bezeichnet werden, für entsprechend anwendbar, d. h. die Auslegungsvorschrift für Verfilmungsverträge ( $\S 98$ ), die Erleichterungen hinsichtlich der Verfügungsmöglichkeiten über Nutzungsrechte am Filmwerk ( $\$ 100)$, die Bestimmung über den Erwerb der Rechte an Lichtbildern (§ 101), die Einschränkungen des droit moral ( $\$ 103)$ und das Leistungsschutzrecht des Filmherstellers ( $\$ 104)$ sollen auch für Laufbilder gelten. Diese Regelung dient zugleich der Rechtssicherheit, denn bei der Herstellung eines Filmes wird nicht immer klar vorauszusehen sein, ob der Film Werkqualität erreichen oder mangels schöpferischer Gestaltung der Bildfolge lediglich ein Laufbild bleiben wird.

In einem Fall sieht der Entwurf jedoch eine Ausnahme von der Gleichstellung der Laufbilder mit den Filmwerken vor: Die Bestimmung des $\S 102$ über die Einschränkung der Rechte der ausübenden Künstler soll auf Laufbilder keine Anwendung finden. Die Ausnahme hat folgende Gründe:

Anders als bei einem Filmwerk, bei dem alle Beiträge zu einer schöpferischen Einheit verschmolzen werden und die Leistung des ausübenden Künstlers I gegenüber dieser Gesamtleistung zurücktritt, steht 
bei Laufbildern häufig die Darbietung des ausübenden Künstlers im Vordergrund. Ein typischer Fall eines Laufbildes ist die einfache filmische Aufzeichnung oder Live-Sendung einer Werkdarbietung ausübender Künstler, etwa einer Opernaufführung, der Aufführung eines Bühnenstückes oder auch derSolodarbietung einzelner Sänger, Tänzer oder Musiker. Hier wird durch die "Verfilmung" der Darbietung des ausübenden Künstlers nichts Eigenständiges geschaffen; die Aufzeichnung oder Funksendung dient vielmehr lediglich dazu, den Kreis der unmittelbaren Teilnehmer an der Darbietung des ausübenden Künstlers durch technische Mittel zu erweitern. Im Gegensatz zum Filmwerk kann somit die Verwertung des Laufbildes den Künstler in seinem Schaffen unmittelbar beeinträchtigen, da sie seine persönliche Darbietung ersetzt und entbehrlich macht. Es besteht insoweit kein Unterschied zwischen der als Laufbild fixierten oder im Fernsehen gesendeten und der auf Tonträger aufgenommenen oder im Hörfunk gesendeten Darbietung des ausübenden Künstlers. Den an der Herstellung eines Laufbildes beteiligten ausübenden Künstlern müssen daher die Rechte aus den $\S \S 83$ bis 87 ohne Einschränkung verbleiben.

\section{VIERTER TEII}

\section{Gemeinsame Bestimmungen für Urheberrecht und verwandte Schutzrechte}

Der Vierte Teil des Entwurfs umfaßt Bestimmungen, die sowohl für das Urheberrecht wie für die verwandten Schutzrechte anwendbar sind. Der Erste Abschnitt regelt das Verbot der Benutzung rechtswidriger Vervielfältigungen und Sendungen. Der Zweite Abschnitt enthält zivilrechtliche und strafrechtliche Vorschriften für den. Fall der Verletzung eines nach diesem Gesetz geschützten Rechts. Der Dritte Abschnitt regelt die Zwangsvollstreckung in ein durch dieses Gesetz gewährtes Recht.

\section{ERSTER ABSCHNITT}

\section{Verwertungsverbot}

\section{Zu § 106}

Die Bestimmung, die in den geltenden Urheberrechtsgesetzen nicht enthalten ist, stellt in Absatz 1 klar, daß derjenige, der auf Grund einer Erlaubnis des Urhebers oder auf Grund der Bestimmungen in $\S \S 45$ bis 66 berechtigt ist, ein Werk zu verbreiten oder öffentlich wiederzugeben, hierzu keine rechtswidrig hergestellten Vervielfältigungsstücke benutzen darf. Die Verwertung solcher Vervielfältigungsstücke, die nach $\S 108$ Abs. 1 dem Vernichtungsanspruch des Urhebers unterliegen, soll der Urheber stets und ausnahmslos verbieten können. Ebenso soll auch der ausübende Künstler die Verwertung eines Tonträgers untersagen können, der unter Verstoß gegen $\S 85$ ohne seine Einwilligung hergestellt ist.

Entsprechendes gilt nach Absatz 2 für rechtswidrig veranstaltete Funksendungen.

\section{ZWEITER ABSCHNITT}

\section{Rechtsverletzungen}

1. Bürgerlich-rechtliche

Vorschriften; Rechtsweg

\section{Zu § 107 - Anspruch auf Unterlassung und Schaden- ersatz}

$\S 107$ regelt die Rechtsfolgen der widerrechtlichen Verletzung des Urheberrechts oder eines anderen nach diesem Gesetz geschützten Rechts, worunter hier in gleicher Weise wie in $\S 823$ des Bürgerlichen Gesetzbuchs nur absolute Rechte, nicht schuldrechtliche Ansprüche, wie z. B. Vergütungsansprüche, zu verstehen sind. $\S 107$ gibt im wesentlichen den geltenden Rechtszustand wieder ( $\S \S 36,37$ LUG, $\S 31$ KUG, § 1004 BGB)

Die in Absatz 1 Satz 1 neben dem Schadenersatzanspruch erwähnten Ansprüche auf Beseitigung und Unterlassung werden in den geltenden Urheberrechtsgesetzen nicht ausdrücklich geregelt, jedoch von der Rechtsprechung seit langem in entsprechender Anwendung des $\S 1004$ BGB gewäh̆rt. Es ist angeregt worden, auch die vorbeugende Unterlassungsklage im Gesetz ausdrücklich zu erwähnen. Die Zulassung einer solchen Klage dürfte jedoch wie bisher der Rechtsprechung überlassen bleiben können, die diese Klagemöglichkeit auch bei allen anderen Unterlassungsansprüchen ohne besondere gesetzliche Regelung gewährt. Ebensowenig erscheint eine Bestimmung über den Anspruch auf Auskunftserteilung erforderlich; die Verpflichtung zur Auskunft ergibt sich nach der Rechtsprechung bereits aus allgemeinen Grundsätzen des bürgerlichen Rechts.

Art und Umfang des Schadenersatzanspruchs richten sich nach den allgemeinen Bestimmungen des bürgerlichen Rechts ( $\$ \S 249 \mathrm{ff}$. BGB). Im übrigen sind die Bestimmungen über unerlaubte Handlungen ( $\S 823$ ff. BGB) ergänzend heranzuziehen.

Absatz 1 Satz 2 sieht vor, daß der Verletzte an Stelle von Schadenersatz von dem Verletzer die Herausgabe des Gewinns verlangen kann, den dieser durch die Verletzung des Rechts erzielt hat. Ein solcher Anspruch ist in den geltenden Urheberrechtsgesetzen nicht ausdrücklich vorgesehen, aber von der Rechtsprechung anerkannt.

Absatz 2 Satz 1 bringt im Hinblick auf den persönlichkeitsrechtlichen Einschlag der Rechte der Urheber, der Verfasser wissenschaftlicher Ausgaben $(\S 80)$, der Lichtbildner $(\S 82)$ und der ausübenden Künstler ( $(83)$ eine Erweiterung des geltenden Rechts. Danach können die genannten Personen, wenn ihnen Schadenersatzansprüche wegen einer Verletzung ihrer Rechte zustehen, auch wegen des Schadens, der nicht Vermögensschaden ist, eine billige Entschädigung in Geld verlangen. Diese Rechtsfolge ist in den geltenden Urheberrechtsgesetzen nicht vorgesehen; nach § 40 LUG und $\S 35$ KUG kann der Ersatz eines immateriellen Schadens nur im Strafverfahren in Form einer Buße verlangt werden. Durch die Rechtsprechung ist jedoch bereits über die durch die geltenden Gesetze gezogenen 
Schranken hinaus (vgl. $\S \S 253,847$ BGB) bei Verletzungen von Persönlichkeitsrechten eine Geldentschädigung für den immateriellen Schaden zugebilligt worden (vgl. Entscheidungen des Bundesgerichtshofs BGHZ 26 S. 349 und 30 S. 7).

Absatz 2 Satz 2 entspricht $\S 847$ Abs. 1 Satz 2 BGB, jedoch soll der Anspruch abweichend von der dort vorgesehenen Regelung wegen der Vererblichkeit des ihm zugrunde liegenden Urheberpersönlichkeitsrechts auf die Erben übergehen können.

Absatz 3 stellt klar, daß der Verletzte neben den erwähnten Rechtsbehelfen auch Ansprüche aus anderen gesetzlichen Vorschriften (insbesondere Ansprüche aus ungerechtfertigter Bereicherung nach $\S \S 812$ ff. BGB) geltend machen kann.

\section{Zu § 108 - Anspruch auf Vernichtung und ähn- liche Maßnahmen}

$\S 108$ regelt den Vernichtungsanspruch und die weiteren Maßnahmen, die im Falle einer Verletzung des Urheberrechts eine Fortdauer oder Ausweitung der Beeinträchtigung verhüten sollen. Die Regelung entspricht im wesentlichen dem geltenden Recht ( $\S 42$ LUG, § 37 KUG), sieht jedoch einigre Abweichungen vor.

Nach Absatz 1 sollen insbesondere Originale nicht mehr dem Vernichtungsanspruch unterliegen, ebensowenig Vervielfältigungsstücke von Werken der bildenden Künste, die lediglich unrechtmäßig zu einer öffentlichen Vorführung benutżt worden sind. Andererseits wird der Vernichtungsanspruch erweitert auf Vervielfältigungsstücke, die lediglich zur rechtswidrigen Verbreitung bestimmt sind.

Absatz 2 stellt bei den zur Vervielfältigung bestimmten Vorrichtungen wie Platten, Formen usw. an Stelle der Vernichtung die Unbrauchbarmachung in den Vordergrund, da diese im allgremeinen dem Urheber ausreichenden Schutz bietet.

Absatz 3 bestimmt abweichend vom geltenden Recht (§ 42 Abs. 4 Satz 2 LUG, § 37 Abs. 4 Satz 2 KUG), daß in den Fällen, in denen mildere Maßnahmen als Vernichtung oder Unbrauchbarmachung zur Beseitigung der Beeinträchtigung ausreichen, dies nicht erst im Vollstreckungsverfahren zu berücksichtigen ist, sondern der Verletzte von vornherein nur die Durchführung der milderen Maßnahmen verlangen kann.

Absatz 4 entspricht sachlich der in $\S 42$ Abs. 2, Abs. 4 Satz 1 LUG und $\S 37$ Abs. 2, Abs. 4 Satz 1 KUG enthaltenen Regelung.

Für die Anwendung des $\S 108$ ist es nicht erforderlich, daß der Verletzer schuldhaft gehandelt hat, ein rechtswidriges Handeln genügt. Ferner braucht die rechtswidrige Herstellung der Vervielfältigungsstücke oder Vervielfältigungsvorrichtungen nicht bereits vollendet zu sein. Dies ergibt sich eindeutig aus der Fassung des Entwurfs, so daß eine dahin gehende besondere Bestimmung wie im geltenden Recht (§ 42 Abs. 3 LUG, $\S 37$ Abs. 3 KUG) entbehrlich erscheint.

Von der Ubernahme der verwickelten und praktisch kaum zur Anwendung gelangten Bestimmungen des
KUG, die sich auf nur teilweise rechtswidrige Sammelwerke oder sonstige aus mehreren verbundenen Werken bestehende Sammlungen beziehen $(\$ \S 39$, $45 \mathrm{KUG}$ ), ist im Entwurf abgesehen. Die Interessen der Beteiligten sind in derartigen Fällen regelmäßig so gelagert, daß sich eine Einigung unschwer herbeiführen lassen wird. Ist dies aber nicht der Fall, so werden sich zumeist an dem fehlerhaft hergestellten Werk ohne wesentliche Schädigung seines Wertes Anderungen vornehmen lassen, die den Interessen des Verletzten Rechnung tragen.

Die Vorschriften des $\S 108$ gelten auch bei der Verletzung verwandter Schutzrechte.

Der Anregung, den Inhalt des Vernichtungsanspruchs und seine Vollstreckung im einzelnen zu regeln, ist der Entwurf nicht nachgekommen. Auch das geltende Recht enthält hierüber keine Regelung, ohne daß sich daraus Schwierigkeiten ergeben haben.

\section{Zu $\$ 109$ - Anspruch auf Uberlassung}

Absatz 1 entspricht den Vorschriften in $\S 43$ LUG und § $38 \mathrm{KUG}$. Den Uberlassungsanspruch - wie angeregt - für den Fall auszuschließen, daß dem Verletzer hinsichtlich der Vervielfältigungsstücke oder Vorrichtungen Bearbeiter- oder Leistungsschutzrechte zustehen, erscheint nicht exforderlich. Durch die Uberlassung als solche wird nicht in die Rechte des Verletzers eingegriffen. Dies würde nur durch eine etwaige spätere Verwertung der Vervielfältigungsstücke durch den Verletzten geschehen, sofern sie ohne die erforderliche Einwilligung des Verletzers vorgenommen wird. Diesem bleibt es unbenommen, sich in einem solchen Falle gegen die Verletzung seines Rechts $\mathrm{zu}$ wehren.

Absatz 2 stellt klar, daß auch dem Uberlassungsanspruch nur die Vervielfältigungsstücke und Vorrichtungen unterliegen, die sich im Eigentum der an der Rechtsverletzung Beteiligten oder ihrer Erben befinden.

\section{Zu § 110 - Haftung des Inhabers eines Unter- nehmens}

$\S 110$ lehnt sich an die Vorschriften in $\S 13 \mathrm{Abs} .3$ und $\S 16$ Abs. 4 des Gesetzes gegen den unlauteren Wettbewerb an, nach denen der Inhaber eines Unternehmens für Rechtsverletzungen seiner Arbeitnehmer oder Beauftragten einzustehen hat, auch wenn er selbst an der Rechtsverletzung nicht beteiligt ist. Eine Verpflichtung zum Schadenersatz wird für den Inhaber des Unternehmens durch die Bestimmung jedoch nicht begründet; insoweit bietet § 831 BGB dem Urheber bereits ausreichend Sicherheit. Die Regelung erscheint notwendig, um dem Urheber bei Verletzungen seiner Rechte innerhalb eines Unternehmens die Durchsetzung seiner Ansprüche auf Unterlassung, Vernichtung und ähnliche Maßnahmen zu erleichtern.

\section{Zu § 111 - Ausnahmen}

Nach Absatz 1 Satz 1 sollen unter bestimmten Voraussetzungen die Ansprüche auf Unterlassung, Vernichtung, Unbrauchbarmachung und Uberlassung 
ausnahmsweise durch Entschädigung des Verletzten in Geld abgewendet werden können, wenn den Verpflichteten kein Verschulden an der Rechtsverletzung trifft. Dies ist der Fall, wenn die Rechtsverletzung selbst unverschuldet war oder der Inhaber eines Unternehmens nach $\S 110$ für eine schuldhafte Rechtsverletzung eines Arbeitnehmers oder Beauftragten ohne eigenes Verschulden einzustehen hat. Als Voraussetzung für die Möglichkeit der Geldentschädigung ist vorgesehen, daß dem Verpflichteten durch die Erfüllung der Ansprüche ein unverhältnismäßig großer Schaden entstehen würde und dem Verletzten die Abfindung in Geld zugemutet werden kann. Als Entschädigung soll der Betrag zu zahlen sein, der im Falle einer vertraglichen Einräumung des Rechts als Vergütung angemessen gewesen wäre (Absatz 1 Satz 2). Bei der vorgesehenen Regelung ist besonders an den Fall gedacht, daß sich ein Filmhersteller versehentlich ein zur Auswertung des Filmwerkes erforderliches Nutzungsrecht nicht hat einräumen lassen. Bei der großen Zahl der Personen, die Rechte am Filmwerk geltend machen können, und der oft bestehenden Unsicherheit über den Kreis dieser Personen kann dies in der Praxis vorkommen, ohne daß den Filmhersteller ein Verschulden trifft. Stellt sich das Versäumnis erst heraus, nachdem das Filmwerk unter großem Kostenaufwand fertiggestellt ist, so würde der betreffende Rechtsinhaber ohne die vorgeschlagene Sonderregelung die Auswertung des Filmwerkes untersagen und die Vernichtung des Filmstreifens verlangen können. Mit Rücksicht auf den im Filmwerk verkörperten hohen wirtschaftlichen Wert würde eine solche Rechtsfolge häufig $\mathrm{zu}$ der Bedeutung der unverschuldeten Rechtsverletzung ganz außer Verhältnis stehen. Die Rechtsprechung hat schon nach geltendem Recht in solchen Fällen den Grundsatz des $\S 251$ Abs. 2 BGB entsprechend angewandt, wonach der Schadenersatzpflichtige den Gläubiger in Geld entschädigen kann, wenn die Herstellung des früheren Zustands nur mit unverhältnismäßig hohen Aufwendungen möglich ist (vgl. KG Ufita Bd. 11 S. 287 [289]).

Für die Anwendbarkeit des $\$ 111$ soll es ausreichen, daß den Verpflichteten selbst kein Verschulden trifft. Das Verschulden seiner Angestellten und Beauftragten braucht er sich nicht entgegenhalten zu lassen, doch kann ein eigenes Verschulden darin liegen, daß er bei der Auswahl oder Beaufsichtigung seiner Angestellten oder Beauftragten nicht die erforderliche Sorgfalt hat walten lassen. Der Anregung, die Haftung über diese Regelung hinaus auch bei eigenem Verschulden auszuschließen, sofern es sich nur um leichte Fahrlässigkeit handelt, ist der Entwurf nicht gefolgt. Dies würde eine nicht mehr zu rechtfertigende Beschränkung der Ansprüche aus den $\S \S 107$ bis 109 bedeuten.

Die in Absatz 1 Satz 1 und 2 vorgeschlagene Regelung erscheint nicht ausreichend für die Fälle, in denen die unverschuldete Verletzungshandlung nicht zugleich die letzte Verwertung darstellt. Wenn z. B. ein Filmhersteller unverschuldet ein Recht nicht erworben hat und dies nach Herstellung des Filmwerkes bekannt wird, so wäre er trotz dieser Rege- lung an der Auswertung des Filmwerkes gehindert, weil die Auswertung eine weitere, nunmehr schuldhafte Urheberrechtsverletzung darstellen würde. Absatz 1 Satz 3 bestimmt daher, daß die Einwilligung des Verletzten mit der Zahlung der Entschädigung als erteilt gilt, soweit sie für die Verwertung im üblichen Umfang erforderlich ist. Durch diese Fiktion wird insoweit die weitere Verwertung rechtmäßig.

Absatz 2 schränkt in bestimmten weiteren Fällen die Ansprüche auf Vernichtung, Unbrauchbarmachung und Uberlasisung rein. Dies gilt insibesondere nach Nummer 1 für Bauwerke, die auch nach geltendem Recht ( $\$ 37$ Albis. 5 KUG) nicht idem Anspruch auf Vernichtung unterliegen. In Nummer 2 wind, ebenfalls in Uibereinstimmung mit idem geltenden Recht ( $\$ 42$ Aibs. 1 Satz 2 LUG, $\S 37$ Abs. 1 Satz $3 \mathrm{KUG}$ ), vorgeschrieben, ıdaß bei nur teilweiser Widernechtlichkeit die Maßnahmen nach $\S \S 108$ und 109 auf die widerrechtlichen Teile beschränkt bleiben sollen. Dies ist geboten, um ibestehende Werte nach Möglichkeit zu erhalten. Dem bestehenden Rechtszustand entspricht es ferner, die vorbeugeniden Maßnahmen der Vernichtung und Utberlassung beim bloßen Fehlen der vorgeschriebenen Quellenangabe ( $\$ 5$ Abs. 2 Satz 2, $\S \S 63,66)$ nicht Platz greifen zu lassen; doch kann in diesem Falle die nachträgliche Quellenangabe verlangt werden, soweit sie durchführbar ist (Nummer 3).

\section{Zu § 112 - Verjährung}

Nach geltendem Recht ( $\S 50,51$ LUG, $\S \S 47,48$ KUG) beginnt die dreijährige Verjährungsfrist für Scha'denersatzansprüche aus Urheberrechtsverletzungen abweichend von $\S 852$ BGB nicht mit dem Zeitpunkt, in dem der Verletzte von dem Schaden und der Person ides Ersatzpflichtigen Kenntnis erlangt, sondern mit dem Zeitpunkt der Verletzungshiandlung. Dadurch sollen die an der Verwertung urheberrechtlich geschützter Werke beteiligten Wirtschaftskreise vor einer übermäßig späten Geltendmachung von Schadenersatzansprüchen ibewahrt wenden. Diese Regelung bedeutet jedoch eine nicht ausreichend gerechtfertigte Benachteiligung ider Urheber und wind 'deshalb vom Entwurf nicht übernommen. Statt dessen ist nunmehr für die Verjährung auch ider Schadenersatzansprüche aus Urheberrechtsverletzungen eine dem § 852 BGB entsprechende Regelung vorgesehen. (Absatz 1). Absatz 2 entspricht $\S 52$ LUG und $\S 50$ KUG.

\section{Zu $§ 113$ - Bekanntmachung des Urteils}

In Anlehnung an die Vorschriften in $\$ 23$ Abs. 4 und 5 des Gesetzes gegen den unlauteren Wettbewerb bestimmt Absatz 1, daß bei Klagen auf Grund dieses Gesetzes unter gewissen Voraussetzungen der obsiegenden Partei im Urteil idie Befugnis zugesprochen werden kann, idas Urteil auf Kosten der unterliegendien Partei öffentlich bekanntzumachen. Die Urheber bedürfen der Anerkennung in ter Offientlichkeit. Sie haben ein schutzwürdiges Interesse daran, der Offentlichkeit anzuzeigen, ıdaß ihre Schöpfungen von anderen entstellt oder zu Unrecht 
ausgenutzt wurden oder daß ein gegen sie erhobener V.orwurf des Plagiats unibegründet ist. Auch im Falle der Verletzung eines Leistungssschutzrechts kann ein berechtigtes Interesse an der Bekanntmachung des Urteils bestehen.

In der Abweichung von $\S 23$ Abs. 4 UWG soll im Intenesse der unterliegenden Partei das Urteil enst nach Rechtskraft bekanntgemacht werden dürfen; allendings ist mit Rücksicht auf besondens gielagerte Fälle ‘dem Gericht die Möglichkeit gegeben, der obsiegenden Partei eine vorherige Bekanntmachung des Urteils zu gestatten.

In Absatz 2 ist die Frist zur Bekanntmachung auf sechs Monate festgelegt.

Absatz 3 soll die Bekanntmachung des Urteils auch einer armen Partei ermöglichen, die nicht in ider Lage ist, die Bekanntmachungskosten zunächst selbst auszulegen.

\section{Zu § 114 - Rechtsweg}

Für Rechtsstreitigkeiten auf dem Gelbiet des Urheberrechts und der verwandten Schutzrechte ist in dè̀ großen Mehrzahl aller Fälle der ondentliche Rechtsweg gegeben. Es kann jedoch vorkommen, daß Fragen dies Urheberrechts oder ider verwandten Schutzrechte in einem Arbeits- oder Dienstverhältnis istreitig werden, wenn ider Urhelber oder Schutzrechtsinhaber in Erfüllung arbeitsvertraglicher oder dienstlicher Pflichten Werke geschaffen oder Leistungen erbracht hat und Unklarheit darüber besteht, inwieweit ider Arbeitgeber oder Dienstherr zur Nutzung der Werke oder Leistungen berechtigt ist. In einem solchen Fall wären die Gerichte der Arbeitsgerichtsbarkeit oder - bei öffentlich-rechtlichen Dienstverhältnissen — der Verwaltungsgerichtsbarkeit für die Entscheidung zuständig. Aus der Ausgestaltung des Urheberrechts und der verwandten Schutzrechte als absoluter, gegen jedermann wirkender Rechte kann sich dann ergeben, daß ein Streit darüber, ob und inwieweit der Arbeitgeber oder Dienstherr an dem Wenk oder ider Leistung seines Arbeitnehmers oder Beamten Rechte erworben hat, nicht nur zwischen den Parteien des Arbeitsoder Dienstverhältnisses, sondern auch im Verhältnis des Arbeitnehmers oder Beamten zu einem Dritten Bedeutung gewinnt. Hat beispielsweise ein Bühnenunternehmen ohne besondere Einwilligung der bei ihm fest angestellten ausübenden Künstler die Rundfunkübertragung einer Bühnenaufführung gestattet (vgl. Entscheidung ides Bundesgerichtshofis vom 31. Mai 1960; BGHZ 33 S. 20, Anlage 9), so können die ausübenden Künstler mit der Behauptung, daß das Bühnenunternehmen nach idem Anstellungsvertra.g nicht berechtigt gewesen sei, in dieser Form über ihre Leistung zu verfügen, sowohl ihren Arbeitgeber als auch das betreffende Rundfunkunternehmen wegen Verletzung ihres Leistungsschutzrechts in Anspruch nehmen. Uiber denselben Sachverhalt hätten dann im ersten Fall die Arbeitsgerichte, im zweiten Fall die ordentlichen Gerichte zu entscheiden.

Würde man es für diese Fälle bei der allgemeinen Zuständigkeitsregelung belassen, so würden sich darais folgende Nachteile ergreben: Einmal muß damit gerechnet werden, daß dire Zuständigkeit von drei Gerichtszweigen für das Gebiet des Urheberrechts $\mathrm{zu}$ abweichenden höchstrichterlichen Entscheidungen führen würde. Zum anderen ergibt sich aus dem oben angeführten Beispiel, daß idem Urheber oder Schutzrechtsinhaber sowohl die Möglichkeit eröffnet wird, im einzelnen Streitfall zwischen der Zuständigkeit zweier venschiedener Gerichtszweige $\mathrm{zu}$ wählen als auch denselben Sachverhalt gleichzeiti.g durch zwei verschiedene Gerichte entscheilden zu lassen, je nachidem, welche Persion .er verklagt. Schließlich wüinde, wenn man idie Zuständigkeit der Gerichte der Arbeits- und Verwaltungsgerichtsbarkeit beibehält, die in $\S 115$ vorgesehene Konzentration der Rechtspnechung in Urheberrechtsstreitsachen bei wenigen ondentlichen Gerichten weitgehend gregenstandislos werden.

Um idiese Nachteile zu vermeiden, wird vorgeschlagen, für alle Rechtsistreitigkeiten, durch die ein Anspruch aus einem der in diesem Gesetz geregelten Rechtsverhältnisse geltend gemacht wind, (Urheberrechtsstreitsachen) ausischließlich iden Rechtsweg zu den ordentlichen Gerichten vorzusehen (Satz 1). Jedioch ssoll die Zuständigkeit der Gerichte ider Arbeits- und Verwaltungsgerichtsbarkeit für solche Urheberrechtsstreitsachen unberührt ibleiben, die ausschließlich Ansprüche auf Leistung einer vereinbarten Vergütung zum Gegenstand haben (Satz 2). In solchen Fällen sind keine Rechtsfragen zu entscheiden, die Inhalt oder Umfang urheberrechtlicher Befugnisse betreffen.

Die im Entwurf vorgesehene Regelung entspricht $\S 39$ des Gesetzes über Arbeitnehmererfindungen.

\section{Zu § 115 - Gerichte für Urheberrechtsstreitsachen}

Ahnlich wie im Patentrecht (vgl. \& 51 des Patentgesetzes) und im Warenzeichenrecht (vgl. § 32 des Warenzeichengesetzes) hat sich auch im Urheberrecht das Bedürfnis gezeigt, idie Rechtsprechung zusammenzufassen. Das Urheberrecht ist ein Gebiet, mit dem nicht jeder Richter in ausreichendem Maße vertraut sein kann. Eine einwandfreie Rechtsprechung auf diesem Gebiet setzt Erfahrungen voraus, die das erkennende Gericht nur gewinnen kann, wenn es ständig mit Rechtsstreitigkkeiten dieser Art befaßt ist. In Anlehnung an $\S 32$ des Warenzeichengesetzes sieht daher Absatz 1 für die Landesregierungen die Ermächtigung vor, durch Rechtsverordnung die zur Zuständigkeit der Landgerichte gehörenden Urheberrechtsstreitsachen für die Bezirke mehrerer Landgerichte einem von ihnen zuzuweisen, wenn dies der Rechtspflege dienlich ist.

Damit auch die mit Urheberrechtsstreitsachen befaßten Amtsgerichte besondere Erfahrungen auf dem Gebiet des Urheberrechts gewinnen können, sieht Absatz 2 eine Ermächtigung der Landesregierungen vor, auch die in die Zuständigkeit der Amtsgerichte fallenden Unheberrechtsstreitsachen zusammenzufassen. Die Regelung erlaubt es den Landesregierungen, die amtsgerichtlichien Urheberrechtsstreitsachen entweder für iden gesamten Bereich Ides Landgerichts für Urheberrechtsstreitsachen (Absatz 1) oder nur 
jeweils für einzelne Landgerichtsbezirke zu konzentrieren. Die neue Bestimmung kommt den Vorschlägen entgregen, eine ausschließliche Zuständigkeit der Landgrerichte für alle Urheberrechtsstreitsachen $\mathrm{zu}$ begründen oder in Urheberrechtsstreitsachen ohne Rücksicht auf den Streitwert stets die Berufung zuzulassen.

Absatz 3 gestattet es den Landesregierungen, die vorbezeichneten Ermächtigungen auf die Landesjustizverwaltungen $\mathrm{zu}$ übertragen.

Die Absätze 4 und 5 sind den Bestimmungen in $\S 32$ Abs. 3 und 4 des Warenzeichengesetzes nachgebilldet.

Der Anregung, eine Bestimmung entsprechend $\S 53$ des Patentgesetzes einzufügen, nach der das Gericht anordnen kann, daß die Prozeßkosten für eine Partei, deren wirtschaftliche Lage durch die Belastung mit den vollen Kosten gefährdet wünde, nach einem Teil des wirklichen Streitwerts zu bemessen sind, wird im Entwurf nicht entsprochen. Für Urheberrechtsstreitsachen erscheint eine solche Regelung nicht notwendig. In ider Regel haben die Urheberrechtsstreitsachen keinen so ungewöhnlich hohen Streitwert wie die Patentprozesse. Bedürftige Urheber und Leistungsschutzberechtigte können das Armenrecht in Anspruch nehmen. In Patentstreitsachen, die in ider Regel von Firmen betrieben werden, werden dagegen die Voraussetzungen für die Gewälhrung des Armenrechts vielfach nicht vorliegen; auch können geschäftliche Rücksichten idie klagende Firma von der Inanspruchnahme des Armenrechts abhalten.

Der Entwurf sieht auch davon ab, die Zuständigkeit der Spezialgerichte, wie vorgeschlagen 'worden ist, auf verlagsrechtliche Prozesse und Prozesse über den Titel eines Werkes sowie auf Streitigkeiten über die Verletzung des Namensrechts durch literarische Werke und durch Filme auszudehnen. Für verlagsrechtliche Prozesse erübrigt sich eine entsprechende Bestimmung, da hierbei auch immer zugleich Ansprüche aus einem der im Urheberrechtsgesetz geregelten Rechtsverhältnisse geltend gemacht ,werden dürften, für idie $\S 115$ ohnehin anwendbar ist. Für Titelprozesse ist die Anwendung des $\S 115$ nur dann gerechtfertigt, wenn Urheberrechtsschutz für den Titel in Anspruch genommen wird; für diesen Fall gilt $\S 115$ bereits nach der Regelung des Entwurfs. Wird aber die Klage auf das Wettbewerbsrecht gestützt, so ist es nicht gerechtfertigt, die besondere Zuständigkeit nach § 24 des Gesetzes gegen den unlauteren Wettbewerb zu beseitigen. Die Zuständigkeit auf Prozesse über Namensrechtsverletzungen im Zusammenhang mit literarischen Werken und Filmen auszudehnen, erscheint unzweckmäßig, weil kein Zusammenhang mit dem Urheberrecht besteht und sich diese Ansprüche im übrigen schwer abgrenzen ließen.

\section{Strafrechtliche Vorschriften}

Die Strafbestimmungen des Entwurfs lehnen sich im wesentlichen an die entsprechenden Bestimmungen im geltenden Recht an ( $\$ \S 38$ bis 48,50 bis 53 LUG;
$\S \S 32$ bis 45,47 bis $50 \mathrm{KUG})$. Während jedoch bisher nur reine Geldstrafe vorgesehen war, soll in $\mathrm{Zu}$ kunft auch auf eine Gefängnisstrafe erkannt werden können.

Der Entwunf übernimmt einige weniger bedeutende oder zu unbestimmte Straftatbestände ides geltenden Rechts nicht. So ist insbesondere von der Strafvorschrift in § 44 LUG und § 40 KUG für die Fälle unterlassener Quellenangabe '(vgl. § 63) abgesehen worden. Schon bisher ist für solche Unterlassungen nur eine geringfügige Geldstrafe (bis zu $150 \mathrm{DM}$ ) vorgesehen. Die bürgerlich-rechtlichen Ansprüche reichen hier zum Schutze des Urhebers aus. Die Belastung des Gesetzes mit nicht unbedingt erforderlichen Strafvorschriften sollte vermieden werlen. Hinzu kommt, daß der Entwurf jetzt die Bezeichnung der Quelle nicht nur für bestimmte Fälle der Vervielfältigung vorschreibt, sondern auch für alle gesetzlich zugelassenen öffentlichen Wiedergaben fremder Werke die Angabe der Quelle verlangt, wenn und soweit die Verkehrssitte es erfordert. Insoweit fehlt es aber an ider für eine Strafvorschrift erforderlichen Bestimmtheit des Straftatbestandes.

Auch für das Urheberpersönlichkeitsrecht im allgemeinen erscheint ein strafrechtlicher Schutz entbehrlich. Die dabei für den Verkehr in Betracht kommenden Ermessensfragen eignen sich zum größten Teil nicht für eine strafrechtliche Regelung. Nur die in $\S 117$ geregelten zwei Tatbestände, die die unzulässige Bezeichnung von Originalen und Vervielfältigungsstücken von Werken der bildenden Künste zum Gegenstand haben und über den Schutz des Urhebers hinaus auch Interessen der Allgemeinheit wahren sollen, sind scharf genug umrissen, um den Gegenstand besonderer Strafvorschriften $\mathrm{zu}$ bilden. Im übrigen erscheinen die dem Urheber gewährten bürgerlich-rechtlichen Ansprüche, die seine ideellen Interessen mitberücksichtigen, zur Wahrung seiner persönlichen Interessen am Werk ausreichend. Aus diesem Grund ist auch die Strafvorschrift in $\S 38$ Abs. 2 LUG und $\S 32$ Abs. 2 KUG nicht in den Entwurf übernommen, nach der mit Geldstrafe bestraft wird, wer an dem Werk, an dessen Titel oder an der Bezeichnung des Urhebers unerlaubte Anderungen vorgenommen hat. Dasselbe gilt für die Bestimmung in $\S 39$ LUG, nach der mit Geldstrafe bestraft wird, wer den wesentlichen Inhalt eines Werkes, bevor er vom Berechtigten öffentlich mitgeteilt ist, vorsätzlich ohne dessen Einwilligung öffentlich mitteilt. Auch dies ist eine aus dem droit moral des Urhebers erwachsende Bestimmung, die entbehrlich erscheint, weil der bürgerlich-rechtliche Schutz ausreicht.

Der Entwurf bringt insoweit eine Erweiterung des geltenden Rechts, als er auch für zahlreiche verwandte Schutzrechte Strafvorschriften vorsieht (§ 118).

Schließlich sind die Bestimmungen des geltenden Rechts über die Buße ( $\$ 40 \mathrm{LUG}, \S 35 \mathrm{KUG})$ in den Entwurf nicht übernommen, an deren Stelle der in $\S 107$ Abs. 2 gewährte bürgerlich-rechtliche Anspruch auf Ersatz auch des immateriellen Schadens getreten ist. Ferner sieht der Entwurf für die Geltend- 
machung des Anspruchs auf Vernichtung und sonstige Maßnahmen im Strafverfahren eine vom geltenden Recht abweichende Regelung vor (vgl. § 120).

\section{Zu $\$ 116$ - Unerlaubte Verwertung urheberrecht- lich geschützter Werke}

$\S 116$ gewährt wie das geltende Recht (§ 38 LUG, $\S 32$ KUG) strafrechtlichen Schutz gegen Eingriffe in das Verwertungsrecht des Urhebers und in ausschließliche Nutzungsrechte, die dieser Dritten eingeräumt hat. Die im geltenden Recht für die Verletzung von Verwertungsrechten allein angedrohte Geldstrafe erscheint jedoch für schwerwiegende Fälle wie gewerbs- oder gewohnheitsmäßige oder im Rückfall begangene Verletzungen nicht ausreichend. Der Entwurf bestimmt daher, daß nicht nur auf Geldstrafe, sondern auch auf Gefängnis bis zu $1 \mathrm{Jahr}$ erkannt werden kann.

Der Entwurf stellt klar, daß auch die vorsätzliche Vervielfältigung, Verbreitung und öffentliche Wiedergabe eines Werkes in bearbeiteter oder umgestalteter Form ohne die nach $\S 23$ Abs. 1 erforderliche Einwilligung des Urhebers des bearbeiteten oder umgestalteten Werkes strafbar ist. Nicht erfaßt wird von der Strafbestimmung die in $\S 23$ Abs. 2 behandelte Herstellung einer Bearbeitung oder Umgestaltung durch Verfilmung. Das in den $\S \S 15$, $18 \mathrm{neu}$ aufgeführte Ausstellungsrecht ist ebenfalls in die Strafbestimmung nicht einbezogen worden. Das Ausstellungsrecht, wie es der Entwurf vorsieht, ist in der Hauptsache persönlichkeitsrechtlicher Natur. Aus den in der Vorbemerkung zu diesem Unterabschnitt dargelegten Gründen erscheint eine Strafandrohung wegen Verletzungen des Urheberpersönlichkeitsrechts nur in den Fällen des $\S 117$ angezeigt.

Es ist angeregt worden, die Strafbarkeit der unberechtigten Verwertung von Teilen eines Werkes ausdrücklich hervorzuheben. Werkteile genießen jedoch, sofern sie persönliche geistige Schöpfungen sind, ohnehin vollen Werkschutz. Trifft hingegen diese Voraussetzung nicht $\mathrm{zu}_{\text {, ist ein besonderes }}$ Schutzbedürfnis nicht anzuerkennen.

\section{Zu § 117 - Unzulässiges Anbringen der Urheber- bezeichnung}

Die Bestimmung wiederholt im wesentlichen den Inhalt der $\S \S 34,33$ Abs. 1 Nr. 1 KUG, stellt aber nicht wie das geltende Recht nur das Anbringen der Urheberbezeichnung auf dem Original oder den Vervielfältigungsstücken und Bearbeitungen des Werkes unter Strafe, sondern auch das Verbreiten der unzulässig bezeichneten Werkstücke. Dies erscheint geboten, weil durch das Verbreiten in das Urheberpersönlichkeitsrecht und in die Interessen der Allgemeinheit in ebenso empfindlicher Weise eingegriffen wird wie durch das Anbringen der Urheberbezeichnung.

\section{Zu § 118 - Unerlaubte Eingriffe in verwandte Schutzrechte}

§ 118 enthält strafrechtliche Vorschriften für den Fall der unerlaubten Verwertung varwandter Schutzrechte, die der Regelung in \$116 entsprechen.

\section{Zu $§ 119$ - Strafantrag}

Im wesentlichen übereinstimmend mit dem geltenden Recht (§ 45 LUG, § 41 KUG) sieht § 119 vor, daß die Strafverfolgung nach diesem Gesetz von einem Antrag des Verletzten abhängt.

Die Vorschriften des geltenden Rechts über eine besondere Verjährungsfrist für die Strafverfolgung ( $\S 50,51,53 \mathrm{LUG}$; $\S 47$ bis $49 \mathrm{KUG}$ ) sind nicht aufrechterhalten worden. Die Abweichungen von den allgemeinen Verjährungsvorschriften des $\S 67$ des Strafgesetzbuchs sind durch kein praktisches Bedürfnis gerechtfertigt.

\section{Zu § 120 - Anspruch auf Vernichtung und ähnliche Maßnahmen}

Im geltenden Recht ist vorgesehen, daß auf Antrag des Verletzten auf die Maßnahmen der Vernichtung, Unbrauchbarmachung und Uberlassung auch im Strafverfahren erkannt werden kann, und zwar als echte strafrechtliche Unrechtsfolgen (§ 46 LUG und $\S 42 \mathrm{KUG})$. Dem bürgerlich-rechtlichen Anspruch auf Vernichtung, Unbrauchbarmachung und Uberlassung sind auf diese Weise entsprechende Strafmaßnahmen zur Seite gestellt, die jedoch im Gegensatz zu anderen vergleichbaren Nebenstrafen, wie etwa der Einziehung nach $\S 40$ des Strafgesetzbuchs, wegen ihrer Bindung an den Antrag des Verletzten nicht selbständig im öffentlichen Interesse durchgesetzt werden können. Diese Verquickung von zivil- und strafrechtlichen Grundsätzen entspricht der Sache nach dem in den $\S \S 403 \mathrm{ff}$. der Strafprozeßordnung geregelten sog. Adhäsionsverfahren, ohne daß jedoch die Bestimmungen über dieses Verfahren anwendbar sind, die eine eingehende Regelung der bei der Verfolgung von bürgerlich-rechtlichen Ansprüchen im Strafverfahren notwendig auftretenden Konkurrenzprobleme enthalten. So bleibt die Frage, welchen Einfluß etwa der Verzicht auf den bürgerlich-rechtlichen Vernichtungsanspruch, die Rechtshängigkeit dieses Anspruchs oder die rechtskräftige Entscheidung über den Anspruch auf die Durchführung des strafrechtlichen Vernichtungsverfahrens haben soll, ungeklärt. Daß für das geltende Recht aus diesen Unklarheiten Schwierigkeiten nicht entstanden oder jedenfalls nicht bekannt geworden sind, ist wohl allein darauf zurückzuführen, daß der strafrechtliche Vernichtungsanspruch praktische Bedeutung niemals erlangt hat. Um aber für die Zukunft eine klare Rechtslage zu schaffen, verzichtet der Entwurf auf diesen unvollkommenen, vom Standpunkt des Strafrechts aus ungewöhnlichen und überflüssigen Strafanspruch und verweist in Satz 1 den Verletzten für die Geltendmachung der Vernichtung und der sonstigen Maßnahmen im Strafprozeß auf das in den $\S \S 403$ ff. StPO geregelte Adhäsionsverfahren, mit welchem dem Verletzten wegen der klaren Abgrenzung zum Zivilverfahren im Ergebnis weit besser gedient sein dürfte.

Die Bestimmung in $\S 403$ Abs. 1 StPO, nach der im Verfahren vor dem Amtsgericht das Adhäsionsverfahren nur zulässig ist, soweit der Anspruch zur sachlichen Zuständigkeit des Amtsgerichts gehört, würde allerdings den Anwendungsbereich der neuen 
Regelung $\mathrm{zu}$ weitgehend einschränken, weil die urheberrechtlichen Ansprüche auf Vernichtung, Unbrauchbarmachung oder Uberlassung oft die Zuständigkeitsgrenze der Amtsgerichte überschreiten werden. Insoweit sieht der Entwurf daher eine Sonderregelung vor.

Die Regelung des strafrechtlichen Vernichtungsanspruchs im geltenden Recht verdrängt als Spezialvorschrift $\S 40 \mathrm{StGB}$, der für Gegenstände, die durch eine vorsätzliche Straftat hervorgebracht oder zu ihrer Begehung benutzt oder bestimmt sind, allgemein ohne Antrag des Verletzten die Einziehung vorsieht. Nach der Neufassung des Satzes 1 wäre ein Rückgriff auf diese Bestimmung möglich. Die Anwendung würde jedoch den vom Entwurf im Ergebnis beibehaltenen Grundsatz durchbrechen, daß die Entscheidung über das Schicksal der rechtswidrig hergestellten Vervielfältigungsstücke und Vorrichtungen allein dem Verletzten vorbehalten bleiben soll. Satz 2 schließt deshalb die Anwendbarkeit des $\S 40$ StGB ausdrücklich aus.

Eines besonderen Hinweises darauf, daß $\S 120$ auch auf den Erben des Verletzten Anwendung findet, bedarf es nicht, weil sich dies bereits aus $\S 30$ ergibt.

Die Neufassung des $\S 120$ hat zur Folge, daß auf die dort vorgesehenen Maßnahmen nicht mehr im selbständigen Verfahren erkannt werden kann, wie es im geltenden Recht ( $\$ 47$ Abs. 2 LUG, $\S 43$ Abs. 2 KUG) vorgesehen war. Die Bestimmungen der Strafprozeßordnung über das selbständige Verfahren sind auf das Adhäsionsverfahren nicht anwendbar. Läßt sich im Falle einer Urheberrechtsverletzung ein Strafverfahren nicht durchführen, etwa weil der Täter schuldlos handelte, so kann der Verletzte die Vernichtung, Unbrauchbarmachung oder Uberlassung der Vervielfältigungsstücke oder Vorrichtungen nunmehr allein im Zivilrechtswege betreiben.

\section{Zu $\$ 121$ - Bekanntmachung des Urteils}

Die Bestimmung sieht aus den gleichen Gründen wie im bürgerlich-rechtlichen Verfahren (vgl. zu $\S$ 113) auch für das Strafverfahren die Möglichkeit vor, eine öffentliche Bekanntmachung des Urteils anzuordnen.

Absatz 1 Satz 1 ist, soweit sich nicht aus der Natur des Strafverfahrens Besonderheiten ergeben, der entsprechenden Bestimmung in $\S 113$ Abs. 1 angepaßt. Ein besonderer Hinweis darauf, daß die Verurteilung erst nach Rechtskraft bekanntgemacht werden darf, war nicht erforderlich, da dies für das Strafverfahren bereits aus dem Fehlen einer vorläufigen Vollstreckbarkeit folgt. Satz 2 soll dem Verletzten den zur Durchführung der Bekanntmachung notwendigen Erwerb einer Urteilsausfertigung erleichtern; die Bestimmung entspricht $\S 200$ Abs. 3 StGB. Satz 3 entspricht $\S 113$ Abs. 2 Satz 2.

Absatz 2 folgt der Regelung in $\S 23$ Abs. 3 des Gesetzes gegen den unlauteren Wettbewerb.

Absatz 3 entspricht $\S 113$ Abs. 2 Satz 1.

\section{DRITTER ABSCHNITT \\ Zwangsvollstreckung}

\section{Allgemeines}

\section{$\mathrm{Zu} \S 122$}

Die geltenden Urheberrechtsgesetze ( $\$ 10$ LUG, $\S 14 \mathrm{KUG}$ ) lassen die Zwangsvollstreckung in das Recht des Urhebers und, soweit es sich um Werke der Literatur oder der Musik handelt, in das Original seines Werkes (Originalhandschrift) gegen den Urheber selbst nur mit dessen Einwilligung $\mathrm{zu}_{\text {; }}$ gegen den Erben des Urhebers kann die Zwangsvollstreckung durchgeführt werden, wenn der Erbe einwilligt oder wenn das Werk bereits erschienen ist. Der Entwurf enthält entsprechende Schutzbestimmungen zugunsten des Urhebers und seiner Rechtsnachfolger für die Zwangsvollstreckung wegen Geldforderungen ( $\$ \S 123$ bis 129). Im übrigen soll sich nach $\S 122$ die Zulässigkeit der Zwangsvollstreckung nach den allgemeinen Bestimmungen, d. h. nach den Vorschriften der Zivilprozeßordnung, richten. Danach kann das Urheberrecht als solches nicht Gegenstand der Zwangsvollstreckung sein, weil es nicht übertragbar ist (vgl. $\S 857$ Abs. 3 ZPO). Auch die aus dem droit moral erwachsenden einzelnen Rechte des Urhebers sind der Zwangsvollstreckung entzogen, weil sie als höchstpersönliche Rechte nicht abgetreten werden können.

Ferner ergibt sich aus der Anwendbarkeit der allgemeinen Bestimmungen, daß die Zwangsvollstrekkung in Nutzungsrechte, die der Urheber Dritten eingeräumt hat, grundsätzlich zulässig ist. Die Nutzungsrechte können unbeschränkt gepfändet werden. Ihre Verwertung ist allerdings dadurch beschränkt, daß ihre Ubertragung auf den pfändenden Gläubiger oder Dritte nach $\S 34$ an die Zustimmung des Urhebers gebunden ist, soweit die Anwendbarkeit dieser Bestimmung nicht ausgeschlossen ist (vgl. § 100). Ohne Einschränkung unterliegen der Zwangsvollstreckung Originale, die der Urheber oder sein Rechtsnachfolger an Dritte veräußert hat.

Da sich die Sondervorschriften der $\S \S 123$ bis 129 nur auf Zwangsvollstreckungen wegen Geldforderungen beziehen, ist auch die Zwangsvollstredkung gegen den Urheber selbst und seine Rechtsnachfolger nach den allgemeinen Vorschriften unbeschränkt zulässig, soweit ein rechtskräftig festgestellter Anspruch auf Einräumung eines Nutzungsrechts oder auf Herausgabe eines Originals vollstreckt werden soll.

Von der Zwangsvollstreckung in Nutzungsrechte ist die Zwangsvollstreckung $\mathrm{zu}$ unterscheiden, die in Geldforderungen vorgenommen wird, die dem Urheber aus der Verwertung seines Werkes entstanden sind. Die Zwangsvollstreckung in die bezeichneten Forderungsrechte, beispielsweise in den Anspruch auf Zahlung der Vergütung für die Einräumung eines Nutzungsrechts, soll wie nach geltendem Recht keiner Beschränkung unterliegen. Das gleiche gilt für die Zwangsvollstreckung in Vervielfältigungsstücke von Werken aller Art. 
2. Zwangsvollstreckung wegen Geldforderungen gegen den $\mathrm{Urheb}$ e r

\section{Zu $§ 123$ - Urheberrecht}

Entsprechend dem geltenden Recht ( $\$ 10$ Satz 1 LUG, § 14 Abs. 1 KUG) ist gegen den Urheber die Zwangsvollstreckung wegen Geldforderungen in das Urheberrecht nur mit seiner Einwilligung zulässig. Gegenüber dem bisherigen Rechtszustand enthält § 123 Satz 1 die weitere Einschränkung, daß die Zwangsvollstreckung nur insoweit zulässig ist, als der Urheber Nutzungsrechte einräumen kann. Im Hinblick auf $\S 31$ Abs. 4 ist die Vollstreckung daher auf die zur Zeit bekannten Nutzungsarten begrenzt.

Die Bestimmung in Satz 2, daß die Einwilligung des Urhebers zur Zwangsvollstreckung nicht durch den gesetzlichen Vertreter erteilt werden kann, entspricht $\S 10$ Satz 1 LUG und $\S 14$ Abs. 1 KUG.

\section{Zu § 124 - Originale von Werken}

Ebenfalls in Anlehnung an $\S 10$ Satz 1 LUG bestimmt Absatz 1, daß die Zwangsvollstreckung wegen Geldforderungen gegen den Urheber auch in die ihm gehörenden Originale seiner Werke nur mit seiner Einwilligung zulässig ist und daß die Einwilligung nicht durch den gesetzlichen Vertreter erteilt werden kann. Der Entwurf enthält insoweit eine Erweiterung des geltenden Rechts, als Absatz 1 nicht nur die Originale von Werken der Literatur und Tonkunst betrifft, sondern auch die Originale sonstiger Werke, sofern es sich nicht um Bauwerke oder bereits veröffentlichte Werke handelt (vgl. Absatz 2 Satz 1 Nr. 2 und 3). Die Einschränkung der Zwangsvollstreckung in Originale nicht veröffentlichter Werke der bildenden Künste - mit Ausnahme der Werke der Baukunst - soll zugunsten des Urhebers verhindern, daß Werke, die noch nicht vollendet sind oder die er nicht veröffentlichen will, dem $\mathrm{Zu}$ griff der Gläubiger preisgegeben und öffentlich versteigert werden. Hat jedoch der Urheber das Original veräußert oder das Werk veröffentlicht, so entfällt dieses Schutzbedürfnis, weil sich der Urheber dadurch zu seinem Werk bekannt hat.

Eine geringe Abweichung vom geltenden Recht bringt Absatz 2 Satz $1 \mathrm{Nr}$. 1, der allgemein die Zwangsvollstreckung in das Original auch gegen den Willen des Urhebers für zulässig erklärt, soweit sie zur Durchführung der Zwangsvollstreckung in ein Nutzungsrecht am Werk notwendig ist. Hat z. B. der betreibende Gläubiger die Zwangsvollstreckung mit Einwilligung des Urhebers in das Nutzungsrecht zur Vervielfältigung des Werkes erwirkt, so muß er auch die Benutzung der dem Urheber gehörigen Handschrift erzwingen können, soweit dies notwendig ist, um das Werk zu vervielfältigen.

In Absatz 2 Satz 2 ist klargestellt, daß in den Fällen der Zwangsvollstreckung nach Absatz 2 Satz 1 Nr. 2 und 3 das Original des Werkes ohne Zustimmung des Urhebers verbreitet werden darf. Die gepfändeten Originale dürfen also veräußert werden.
3. Z wangs vollstreckung wegen

Geldforderungen gegen den

Rechtsnachfolger des Urhebers

\section{Zu $\$ 125$ - Urheberrecht}

$\S 125$ beschränkt gegen den Rechtsnachfolger des Urhebers ( $(30)$ die Zwangsvollstreckung wegen Geldforderungen in das Urheberrecht in entsprechender Weise wie die Zwangsvollstreckung gegen den Urheber selbst, jedoch mit dem Unterschied, daß es seiner Einwilligung zur Zwangsvollstreckung nicht bedarf, wenn das Werk erschienen ist. Dies entspricht dem geltenden Recht $(\S 10$ Satz 2 LUG, $\S 14$ Abs. 2 KUG).

Es ist angeregt worden, die Zwangsvollstreckung gegen den Rechtsnachfolger des Urhebers darüber hinaus nur dann von seiner Einwilligung abhängig zu machen, wenn sie seine berechtigten Interessen verletzen würde. Der Entwurf folgt dieser Anregung nicht, weil die berechtigten Interessen des Rechtsnachfolgers keinen geeigneten Maßstab für die Beschränkung der Zwangsvollstreckung abgeben. Diese Beschränkung rechtfertigt sich vielmehr allein aus dem vom Rechtsnachfolger wahrgenommenen persönlichkeitsrechtlichen Interesse des Urhebers, unfertige oder sonst nicht für die Offentlichkeit bestimmte Werke dieser nicht zugänglich zu machen. $\mathrm{Ob}$ jedoch ein Werk nach Auffassung des Urhebers zur Veröffentlichung geeignet ist, läßt sich nach dessen Tode kaum jemals eindeutig klären. Es ist daher im Interesse der-Rechtssicherheit geboten, die Zulässigkeit der Zwangsvollstreckung gegen den Rechtsnachfolger des Urhebers allein von leicht feststellbaren Tatsachen wie dem Erscheinen des Werkes abhängig zu machen.

$\S 125$ enthält insofern eine Erweiterung gegenüber dem geltenden Recht, als er den Schutz gegen die Zwangsvollstreckung nicht nur den Erben des Urhebers, sondern auch seinen sonstigen Rechtsnachfolgern im Sinne des $\S 30$ (Vermächtnisnehmer) zubilligt. Diese Erweiterung ist geboten, weil der Entwurf auch sonst zwischen den Eriven und dem Vermächtnisnehmer nicht unterscheidet.

\section{Zu § 126 - Originale von Werken}

Absatz 1 macht die Zwangsvollstreckung wegen Geldforderungen gegen den Rechtsnachfolger des Urheb.ers $(\S 30)$ in die ihm gehörenden Originale von Werken des Urhebers gleichfalls von seiner Einwilligung abhängig. Die Einwilligung soll jedoch nach Absatz 2 abgesehen von den in $\S 124$ Abs. 2 genannten Fällen, dann nicht erforderlich sein, wenn es sich um Originale eines bereits erschienenen Werkes handelt. Dies entspricht für Werke der Literatur und der Musik dem geltenden Recht ( $\$ 10$ Satz 2 LUG). Die Tatsache, daß ein Original auch nach Erscheinen des Werkes für die Erben des Urhebers einen Erinnerungswert haben kann, rechtfertigt keine andere Regelung, da die verschuldeten Erben sich auch von anderen wertvollen Andenken an den Urheber trennen müssen.

Es ist vorgeschlagen worden, die Zwangsvollstrekkung auch in das Original eines noch nicht erschie- 
nenen, aber veröffentlichten Werkes sowie in das Original eines unveröffentlichten Werkes der bildenden Künste ohne Einwilligung des Rechtsnachfolgers zuzulassen, sofern nicht der Rechtsnachfolger ein berechtigtes Interesse an dem Untenbleiben der Zwangsvollstreckung hat. Der Entwurf sieht von einer solchen Erweiterung der Ausnahmen in Absatz 2 ab, weil aus den zu $\S 125$ genannten Gründen das berechtigte Interesse des Rechtsnachfolgers keinen geeigneten Maßstab dafür bietet, ob die Zwangsvollstreckung ohne seine Einwilligung zulässig sein soll.

\section{Zu § 127 - Testamentsvollstrecker}

§ 127 gewährt für den Fall, daß ein Testamentsvollstrecker eingesetzt ist, diesem das Einwilligungsrecht nach den $\S \S 125$ und 126.

4. Zwangsvollstreckung wegen Geldforderungen gegen den

Verfasser wissenschaftlicher Ausgaben und gegen den Lichtbildner

\section{Zu $§ 128$}

Nach § 128 sollen auch der Verfasser von wissenschaftlichen Ausgaben ( $(80)$ und der Lichtbildner (\$ 82) sowie deren Rechtsnachfolger in gleicher Weise wie der Urheber und seine Rechtsnachfolger gegen Zwangsvollstreckungen geschützt sein. Es handelt sich hierbei um Inhaber solcher verwandter Schut:rrechte, für die auch diejenigen Bestimmungen des Ersten Teils zur Anwendung kommen, die aus dem Urheberpersönlichkeitsrecht erwachsen, welches Grundlage auch für die Beschränkung der Zwangsvollstreckung ist.

5. Z wangsvollstreckung wegen Geldforderungen in bestimmte Vorrichtungen

\section{Zu $§ 129$}

Nach geltendem Recht ( $\$ 14$ Abs. 3 KUG) ist die Zwangsvollstreckung in solche Formen, Platten, Steine oder sonstige Vorrichtungen eingeschränkt, die ausschließlich zur Vervielfältigung eines Werkes der bildenden Künste bestimmt sind. Diese Vorrichtungen stellen gleichsam ein Zubehör der Nutzungsrechte dar, zu deren Ausübung sie geschaffen wurden. Der bestimmungsmäßige Gebrauch solcher Vorrichtungen durch Personen, die nicht zur Ausübung der in Betracht kommenden Nutzungsrechte berechtigt sind, würde eine Urheberrechtsverletzung darstellen. Die Verwertung solcher Vorrichtungen zur Befriedigung von Geldforderungen müßte sich daher auf eine Verwertung des Stoffes beschränken, aus dem sie bestehen. Das wäre eine unwirtschaftliche Maßnahme, da der Stoffwert gegenüber der Bedeutung, die den Vorrichtungen wegen der darin verkörperten Arbeit und für die Ausübung urheberrechtlicher Befugnisse zukommt, völlig in den Hintergrund tritt.
Der Entwurf erhält diese Regelung aufrecht, sieht jedoch in Absatz 1 eine Ausnahme für den Fall vor, daß der Gläubiger zur Nutzung des Werkes mittels dieser Vorrichtungen berechtigt ist, etwa aufgrund eines eigenen, vom Urheber vertraglich erworbenen Vervielfältigungs- und Verbreitungsrechts. In diesem Fall werden die Vorrichtungen durch die Zwangsvollstreckung nicht ihrem bestimmungsmäßigen Gebrauch entzogen. Der Entwurf geht hingegen insofern über das geltende Recht hinaus, als er die Regelung nicht auf Vorrichtungen zur Vervielfältigung von Werken der bildenden Künste be schränkt, sondern auch die Vorrichtungen zur Vervielfältigung sonstiger Werke erfaßt, wie beispielsweise den Stehsatz eines literarischen Werkes, die Schallplattenmatrizen eines Werkes der Tonkunst oder das Filmnegativ, weil hier die gleichen Erwägungen maßgebend sind wie für Werke der bildenden Künste.

Der Entwurf erstreckt die vorstehend geschilderte Regelung ferner auf Vorrichtungen, die ausschließlich zur Funksendung eines urheberrechtlich geschützten Werkes (vgl. Absatz 1) oder zur Vorführung eines urheberrechtlich geschützten Filmwerkes (Absatz 2) bestimmt sind.

Absatz 3 bringt entsprechende Einschränkungen der Zwangsvollstreckung für die nach $\S 80$ geschützten wissenschaftlichen Ausgaben, die nach § 81 geschützten Ausgaben nachgelassener Werke, die nach § 82 geschützten Lichtbilder und die nach $\S 85$ Satz 2, §§ 95, 97, 104 und 105 geschützten Bildund Tonträger. Auch in diesen Fällen kann der Vollstreckungsgläubiger, wenn er die entsprechenden Verwertungsrechte nicht besitzt, die Vorrichtungen zur Vervielfältigung, Vorführung oder Funksendung nicht verwenden, ohne die betreffenden Schutzrechte zu verletzen. Sie haben für ihn gleichfalls nur den Stoffwert.

\section{FUNFTER TEII}

Anwendungsbereich Ubergangs- und Schlubbestimmungen

\section{ERSTER ABSCHNITT}

\section{Anwendungsbereich des Gesetzes}

\section{Urheberrecht}

\section{Zu $\$ 130$ - Deutsche Staatsangehörige}

Absatz 1 hält an dem Grundsatz des geltenden Rechts ( $\$ 54$ LUG, §51 Abs. 1 KUG) fest, daß deutsche Staatsangehörige für ihre Werke auch dann Schutz genießen, wenn diese noch nicht oder nur im Ausland erschienen sind (Satz 1). Es kommt hierbei nur auf die Staatsangehörigkeit des ursprünglichen Trägers des Urheberrechts, also des Urhebers selbst, an; ob auch die Rechtsnachfolger des Urhebers ( $\S 30$ ) deutsche Staatsangehörige sind, ist ohne Belang. 
Satz 2 bestimmt, daß es bei Werken von Miturhebern ( $\$$ ) genügt, wenn ein Miturheber deutscher Staatsangehöriger ist, was nach herrschender Meinung auch für das geltende Recht angenommen wird.

Absatz 2 sieht mit Rücksicht auf Artikel 116 Abs. 1 des Grundgèsetzes vor, daß auch solche Urheber Schutz genießen, die zwar nicht deutsche Staatsangehörige, aber Deutsche im Sinne des Grundgesetzes sind.

Der Anregung, den deutschen Staatsangehörigen über die nach diesem Gesetz begründeten Rechte hinaus den sich aus Staatsverträgen für ausländische Urheber in der Bundesrepublik etwa ergebenden weitergehenden Schutz zu gewähren, kommt der Entwurf nicht nach. Rechtstechnik und Systematik internationaler Verträge sind in der Regel andersartig als in der deutschen Gesetzgebung, so daß die unmittelbare Anwendung der Verträge zu Rechtsunsicherheit führen würde.

\section{Zu § 131 - Ausländische Staatsangehörige}

§ 131 stimmt im wesentlichen mit dem geltenden Recht ( 55 LUG, §51 Abs. 2 KUG) überein.

Nach Absatz 1 genießt ein ausländischer Urheber den Schutz für jedes seiner Werke, das er im Original oder in einer Ubersetzung zuerst im Geltungsbereich dieses Gesetzes hat erscheinen lassen. Eine geringe Abweichung gegenüber dem geltenden Recht besteht darin, daß ein früheres Erscheinen des Werkes im Ausland den Schutz nicht ausschließt, wenn es nicht länger als dreißig Tage vor dem Erscheinen im Geltungsbereich dieses Gesetzes zurückliegt. Diese Regelung entspricht Artikel 4 Abs. 3 Satz 2 der Brüsseler Fassung der Berner Ubereinkunft.

Absatz 2 stellt - ebenfalls abweichend vom geltenden Recht-den im Geltungsbereich dieses Gesetzes erschienenen Werken die Werke der bildenden Künste gleich, die mit einem Grundstück im Geltungsbereich dieses Gesetzes fest verbunden sind. Diese Bestimmung entspricht Artikel 4 Abs. 5 Satz 2 der Brüsseler Fassung der Berner Ubereinkunft.

Absatz 3 bringt eine weitere Neuerung gegenüber dem geltenden Recht. Er knüpft an Artikel 6 Abs. 2 der Brüsseler Fassung der Berner Ubereinkunft an. Danach ist die Bundesrepublik berechtigt, gegenüber Angehörigen verbandsfremder Staaten, die Urheber deutscher Staatsangehörigkeit nicht hinreichend schützen, den Schutz einzuschränken, sofern der ausländische Urheber weder im Geltungsbereich dieses Gesetzes noch in einem anderen Verbandsland seinen Wohnsitz hat. Von dieser Befugnis könnte, wenn nichts anderes gesetzlich vorgeschrieben wird, nur im Wege eines Gesetzes Gebrauch gemacht werden. Da es aber häufig darauf ankommen wird, die Vergeltungsmaßnahme schnell durchzuführen, um damit einen Druck auf den betreffenden ausländischen Staat ausüben zu können, ist in Absatz 3 vorgesehen, daß der Bundesminister der Justiz die Vergeltungsmaßnahme im Wege einer Rechtsverordnung einführen kann. Damit ist die
Möglichkeit gegeben, sich dem jeweiligen Rechtszustand möglichst elastisch anzupassen.

Absatz 4 Satz 1 stellt klar, daß die nicht im Geltungsbereich dieses Gesetzes erschienenen Werke von ausländischen Urhebern nur den Schutz genieBen, der sich aus bestehenden Staatsverträgen ergibt. In dieser Hinsicht kommt in erster Linie die Berner Ubereinkunft in Betracht sowie das am 24. Februar 1955 von der Bundesrepublik Deutschland ratifizierte Welturheberrechtsabkommen vom 6. September 1952. Wenn es jedoch nach den gesetzlichen Bestimmungen eines Landes, mit dem kein Staatsvertrag besteht, eines solchen Vertrages zur Erlangung des Urheberrechtsschutzes nicht bedarf, sondern nur der Feststellung der materiellen Gegenseitigkeit, so wird es häufig im deutschen Interesse liegen, möglichst schnell die Gegenseitigkeit zugunsten dieses Landes herzustellen und damit für die deutschen Staatsangehörigen dort Schutz zu erwirken. Mit Rücksicht hierauf ist in Satz 2 vorgeschrieben, daß ausländische Urheber auch dann im Geltungsbereich dieses Gesetzes geschützt sein sollen, wenn in dem Staat, dem sie angehören, nach einer Bekanntmachung des Bundesministers der Justiz im Bundesgesetzblatt deutsche Werke einen entsprechenden Schutz genießen.

Nach Absatz 5 sollen ausländische Staatsangehörige die Ansprüche aus dem Folgerecht (\$26) stets nur unter der Voraussetzung der Gegenseitigkeit geltend machen können, auch wenn es sich um ein zuerst im Bundesgebiet erschienenes Werk handelt. Insoweit wird Absatz 1 eingeschränkt. Diese Regelung entspricht Artikel 14 bis Abs. 2 der Brüsseler Fassung der Berner Ubereinkunft.

\section{Zu $\S 132$ - Staatenlose}

Nach dem Zusatzprotokoll 1 zum Welturheberrechtsabkommen sollen Staaténlose und Flüchtlinge, die ihren gewöhnlichen Aufenthalt in einem vertragschließenden Staat haben, für die Anwendung des Welturheberrechtsabkommens den Angehörigen dieses Staates gleichgestellt werden. § 132 greift diesen Gedanken bezüglich der Staatenlosen auf und sieht die Einfügung einer entsprechenden Rechtsnorm in das deutsche Urheberrechtsgesetz vor, nach der - auch unabhängig von dem Welturheberrechtsabkommen - Staatenlose mit gewöhnlichem Aufenthalt im Geltungsbereich dieses Gesetzes hinsichtlich des urheberrechtlichen Schutzes ihrer Werke den deutschen Staatsangehörigen gleichstehen. Staatenlose ohne gewöhnlichen Aufenthalt im Geltungsbereich dieses Gesetzes sollen den Angehörigen des ausländischen Staates gleichstehen, in dem sie ihren gewöhnlichen Aufenthalt haben.

\section{Zu § 133 - Ausländische Flüchtlinge}

Nach Artikel 14 des Abkommens über idie Rechtsstellung der Flüchtlinge vom 28. Juli 1951 (BGBl. 1953 II S. 560), dem auch die Bundesrepublik angehört, genießt jeder Flüchtling in dem Land, in dem er seinen gewöhnlichen Aufenthualt hat, den Urhe- 
berrechtsschutz, der dort den Staatsangehörigen dieses Landes gewährt wird. Im Gebiet jiedes anderen vertragschließenden Landes genießt er den Schutz, der in diesem Gelbiet den Staatsangehörigen des Landes gewährt wind, in dem er seinen igewöhnlichen Aufenthalt hat. Eine entsprechende Regelung enthält das in der Begründung zu $\S 132$ erwähnte Zusatzprotokoll 1 zum Welturheberrechtsabkommen. Wie in $\S 132$ für idie Staatenlosen soll auch der Urheberrechtsschutz für ausländische Flüchtlinge unabhängig von den internationalen Albkommen im Urheberrechtsgesetz geregelt werden. § 133 Satz 1 erklärt daher die Bestimmungren des $\S 132$ für alle Ausländer, die im Sinne von Staatsverträgen oder anderen Rechtsvonschniften Flüchtlinge sind, für entsprechend anwendbar. Satz 2 stellt klar, daß § 133 den Urheberrechtsschutz für Flüchtlinge nicht $a b-$ schließend regelt, sondern die allgemeinien Vorschriften in $\S 131$ auch für Flüchtlinge gelten. Ein Flüchtling, Ider gemäß $\S 133$ keinen Urheberrechtsschutz grenießt, weil die Staatsangehörigen des Landes, in dem er seinen gewöhnlichen Aufenthalt hat, in der Bundesrepublik keinen urheberrechtlichen Schutz haben, kann z. B. einen solchen Schutz in Anspruch nehmen, wenn er sein Werk zuerst in ider Bundesrepublik hat erscheinen lassen (vgl. § 131 Abs. 1).

\section{Verwandte Schutzrechte}

Bei der Regelung des Anwendungsbereiches dieses Gesetzes hinsichtlich der verwandten Schutzrechte können die für urheberrechtlich geschützte Werke geltenden Bestimmungen ( $\S 130$ bis 133) vielfach entsprechend angewendet wenden. Lediglich für den Schutz von Ausgaben nachgelassener Werke nach $\S 81$ ist keine Beschränkung der Anwendung des Gesetzes vorgesehen. Der Schutz nach $\S 81$ wind dafür gewährt, daß das nachgelassene Werk dem deutschen Publikum zugänglich gemacht wird. Nach dem Zweck dieser Vonschrift kann es keinen Unterschied machen, ab die Veröffentlichung von einem Inländer oder von einem Ausländer vorgenommen worden ist.

\section{Zu $\S 134$ - Wissenschaftliche Ausgaben und Licht- bilder}

$\S 134$ rerklärt die für die Werke geltenden Bestimmungen über den Anwendungsbereich des Gesetzes allgemein für entsprechend anwendbar auf iden Schutz von wissenschaftlichen Ausgaben ( $(80)$ und von Lichtbildern ( $\$ 82$ ), ida diese verwandten Schutzrechte weitgehend dem Urhelberrecht angeglichen sind.

\section{Zu $§ 135$ - Schutz des ausübenden Künstlers}

In Anlehnung an die für Urheber vorgesehene Regelung in $\S 130$ bestimmt Absatz 1 , daß die deutschen ausübenden Künstlier den nach $\S \S 83$ bis 94 gewährten Schutz für alle ihre Darbietungen genieBen, gleichviel, wo diese stattfinden.
Für den Schutz ausländischer Künstler unterscheidet der Entwurf zwischen der unmittelbaren Nutzung der Darbietungen durch Lautsprechenübertragung, Aufnahme auf Bild- oder Tonträger und Funksendung und der mittelbaren Nutzung auf Bild- oder Tonträger aufgenommener oder durch Funk gesendeter Darbietungen. In den ersten Fällen wird der Schutz an die Voraussetzung geknüpft, daß die Darbietungen im Geltungsbereich dieses Gesetzes stattfinden (Absatz 2).

Gegen eine unierlaubte Verwendung von Bild-oder Tonträgern sollen ausländische ausübende Künstler dagegen nur geschützt sein, wenn die Bild- oder Tonträger im Geltungsbereich dieses Gesetzes erschienen sind, es sei denn, daB sie früher als 30 Tage vorher im Ausland erschienen sind (Absatz 3). Diese Regelung entspricht dem Grundgedanken des $\S 131$ Abs. 1, nach dem ausländische Urheber für ihre Werke nur dann Schutz genießen, wenn sie diese zuerst im Geltungsbereich dieses Gesetzes haben erscheinen lassen.

Die durch Funk gesendeten Darbietungen ausländi. scher Künstler sollen gegen weitere Verwertung 'durch Aufnahme auf Bild- o'der Tonträger, Weitersendung oder öffentliche Wiedengabe der Funksendung nur geschützt sein, wenn die Funksendung im Geltungsbereich dieses Gesetzes ausgestrahlt worden ist (Absatz 4).

Im übrigen sollen nach Absatz 5 die ausländischen ausübenden Künstler Schutz nach Inhalt der Staatsverträge genießen.

\section{Zu $\$ 136$ - Schutz des Herstellers von Tonträgern}

Entsprechenid der für ausübende Künstler geltenden Regelung bestimmt $\S 136$, daß deutsche Hersteller von Tonträgern den Schutz nach $\$ \S 95$ und 96 unbeschränkt genießen (Absatz 1), ausländische Tonträgerhersteller jedoch nur, wenn die Tonträger im Geltungsbereich dieses Gesetzes zuerst erschienen sind (Absatz 2). Im übrigen sollen ausländische Tonträgerhersteller den Schutz nach Inhalt der Staatsverträge genießen (Absatz 3).

\section{Zu $\S 137$ - Schutz des Sendeunternehmens}

Für den Schutz der Sendeunternehmen nach $\S 97$ unterscheidet der Entwurf zwischen den Unternehmen, die ihren Sitz im Geltungsbereich dieses Gesetzes haben und den übrigen Unternehmen. Die ersten genießen den Schutz, gleichviel, wo sie ihre Sendungen ausstrahlen (Absatz 1). Die anderen haben den Schutz für die Sendungen, die sie im Geltungsbereich dieses Gesetzes ausstrahlen (Absatz 2); im übrigen werden sie nach Inhalt der Staatsvertrăge geschützt (Absatz 3).

\section{Zu $§ 138$ - Schutz des Filmherstellers}

Für den Schutz 'des Filmherstellers nach §§ 104 und 105 sollen die gleichen Grundsätze gelten wie für den Schutz des Tonträgerherstellers ( $\$ 136$ ). 


\section{ZWEITER ABSCHNITT}

Ubergangsbestimmungen

\section{Zu $§ 139$ - Werke}

Der in Absatz 1 enthaltene Grundsatz, daß die neuen Vorschriften auch für bereits vor Inkrafttreten des Gesetzes geschaffene urheberrechtlich geschützte Werke Anwendung finden sollen, entspricht der Regelung der geltenden Urheberrechtsgesetze (§ 62 Satz 1 LUG, § 53 Abs. 1 Satz 1 KUG). Die Regelung, die nach Satz 2 auch für die verwandten Schutzrechte gilt, ist im Interesse der Rechtsvereinfachung geboten, weil andernfalls jahrzehntelang ziwei Urhebernechtsordnungen nelbeneinander bestehen würden. Soweit sich aus ider vorgeschlagenen Regelung Unbilligkeiten ergeben können, sind in $\S 139$ A.bs. 2 und $\S \S 140$ bis 146 Ubergangsbestimmungen vongesehen.

Absatz 2 trifft eine Sonderregelung für Werke, die nach Ablauf von 50 Jahren nach dem Tode des Urhebers veröffentlicht worden sind. Nach geltendem Recht genießen an einem solchen Werk die Erben des Urhebers noch für zehn Jahre nach der Veröffentlichung vollen Urheberrechtsschutz. Der Entwurf gewährt statt dessen demjenigen, der das Werk erscheinen läßt, ein zehnjähriges ausschließliches Verwertungsrecht am Werk (vgl. § 81). Für den Fall, daß das Werk vor Inkrafttreten dieses Gesetzes veröffentlicht worden ist, erscheint es angemessen, es bei der Regelung des geltenden Rechts, d. h. bei dem zehnjährigen Urheberrechtsschutz zugunsten der Erben des Urhebers zu belassen, da sich die Erben auf diesen Schutz eingestellt haben.

\section{Zu $\$ 140$ - Ubersetzungen}

Nach § 62 Satz 2 LUG können Ubersetzungen, sonstige Bearbeitungen und für den Schulgebrauch bestimmte Sammlungen, die vor Inkrafttreten des LUG am 1. Januar 1902 erlaubterweise ganz oder zum Teil erschienen sind, weiterhin von dem Bearbeiter vervielfältigt, verbreitet oder öffentlich vorgeführt werden. $\S 140$ erhält diese Regelung aufrecht, soweit es sich um Ubersetzungen handelt. In den anderen Fällen erscheint die Leistung des Bearbeiters nicht so schutzwürdig, daß die Verwertung der Bearbeitung oder Sammlung für alle Zukunft ohne Rücksicht auf die Rechte der Urheber der benutzten Werke gestattet bleiben müßte.

\section{Zu § 141 - Vertrăge}

Absatz 1 sieht vor, daß das neue Gesetz grundsätzlich nicht für Verträge gilt, die vor seinem Inkrafttreten geschlossen sind. Dies erscheint gerechtfertigt, weil die Parteien beim Abschluß dieser Verträge noch von dem bisherigen Rechtszustand ausgegangen sind. Von diesem Grundsatz sind jedoch einige Ausnahmen zu machen:

Die Regelung des Rückrufsrechts wegen gewandelter Uberzeugung ( $\$ 42)$ muß auch für die früher geschlossenen Verträge gelten, weil sie sich auf einen Tatbestand bezieht, der von dem Inhalt des zwi- schen dem Urheber und dem Verwerter geschlossenen Vertrages unabhängig ist.

Die $\S \S 43$ und 89 sollen gleichfalls auch für die vor dem Inkrafttreten des Gesetzes geschlossenen Verträge gelten, weil diese Bestimmungen $u$. a. auch dazu dienen sollen, Streitfragen zu klären, die sich aus der Auslegung der früher geschlossenen Verträge im Hinblick auf die durch das Gesetz neu geschaffenen Rechte ergeben könnten.

Die $\S \S 40$ und 41 sind im Interesse der Urheber gleichfalls auf die früheren Verträge anzuwenden; zur Wahrung der wohlerworbenen Rechte der Nutzungsberechtigten ist vorgesehen, daß die in $\S 40$ Abs. 1 Satz 2 und $\S 41$ Abs. 2 genannten Fristen frühestens mit dem Inkraftreten dieses Gesetzes beginnen.

Für die Vorschrift in $\S 36$ über die Beteiligung des Urhebers an unerwartet hohen Gewinnen des Verwerters seines Werkes gilt das gleiche wie für das Rückrufsrecht wegen gewandelter Uberzeugung. Da jedoch der Verwerter in diesen Fällen bis zum Inkrafttreten dieses Gesetzes nicht mit der Beteiligung zu rechnen brauchte, soll er nur verpflichtet sein, den Urheber an den späteren Gewinnen zu beteiligen. Soweit sich Ansprüche auf eine weitergehende Beteiligung aus anderen gesetzlichen Vorschriften ergeben, sollen diese unberührt bleiben.

Absatz 2 stellt klar, daß die vor dem Inkrafttreten dieses Gesetzes getroffenen Verfügungen wirksam bleiben. Zweifel können sich insoweit namentlich bei Verfügungen über Nutzungsrechte an erst künftig bekannt werdenden Nutzungsarten ergeben, die nach der Rechtsprechung bisher zulässig sind, nach $\S 31$ Abs. 4 jedoch in Zukunft ausgeschlossen sein sollen.

\section{Zu $§ 142$ - Tonträger}

Absatz 1 erhält unter Berücksichtigung von Artikel 13 Abs. 3 der Brüsseler Fassung der Berner Ubereinkunft teilweise die Bestimmung in $\S 63$ a Abs. 1 LUG aufrecht, nach der die vor dem 1. Mai 1909 auf Tonträger übertragenen Werke weiterhin frei auf Tonträger übertragen werden dürfen. Im Gegensatz zu $\S 63$ Abs. 1 Satz 2 2. Halbsatz LUG soll es jedoch nach dem Entwurf nicht mehr zulässig sein, die auf diese Weise hergestellten Tonträger auch frei zu öffentlichen Wiedergaben zu benutzen. Nachdem durch Streichung des $\S 22$ a LUG die öffentliche Wiedergabe mit Hilfe von Tonträgern allgemein dem Verbotsrecht des Urhebers unterliegt, würde die Aufrechterhaltung der Wiedergabefreiheit nach $\$ 63$ a LUG die einzelnen Veranstalter dazu zwingen, bei jedem Tonträger nachzuprüfen, ob das Werk bereits vor dem 1. Mai 1909 im Inland erlaubterweise auf Tonträger aufgenommen worden ist. Dies würde eine zu große Unsicherheit für den Rechtsverkehr bedeuten.

Absatz 2 nimmt Tonfilme von der in Absatz 1 vorgesehenen Regelung aus um klarzustellen, daß die dort bezeichneten Werke nicht frei zur Herstellung eines Tonfilmes benutzt werden dürfen. 


\section{Zu $\$ 143$ - Urheber}

Der Entwurf weicht hinsichtlich der Regelung der Frage, wer als Urheber eines Werkes anzusehen ist, in mehreren Punkten vom geltenden Recht ab. So ist das Urheberrecht, das nach geltendem Recht juristischen Personen des öffentlichen Rechts sowie Herausgebern oder Verlegern von Sammelwerken zusteht ( $\S 3,4$ LUG, $\S 5,6$ KUG), in den Entwurf nicht übernommen. Für diese Fälle bestimmt Satz 1, daß derjenige, der nach den bisherigen Vorschriften als Urheber anzusehen ist, auch weiterhin als Urheber gilt. Ausgenommen ist von dieser Regelung nur das bisherige Urheberrecht am Lichtbild und das bisherige Bearbeiter-Urheberrecht des ausübenden Künstlers nach § 2 Abs. 2 LUG (vgl. dazu $\S$ 144).

Soweit bisher juristische Personen als Urheber angesehen wurden, passen für die Berechnung der Schutzfristen die neuen, nur auf die Lebenszeit des Urhebers abgestellten Vorschriften nicht. Es soll deshalb nach Satz 2 insoweit bei der alten Schutzdauer verbleiben.

\section{Zu $\S 144$ - Inhaber verwandter Schutzrechte}

$\S 144$ bestimmt entsprechend dem in $\S 139$ Abs. 1 enthaltenen Grundsatz, daß sich der Lichtbildschutz und der Schutz mechanischer Vorrichtungen nach $\$ 2$ Abs. 2 LUG auch für vor Inkrafttreten des Gesetzes hergestellte Lichtbilder und Vorrichtungen nach den neuen Vorschriften richtet, d.h. an die Stelle des bisherigen Urheberrechtsschutzes treten nunmehr die insoweit vorgesehenen verwandten Schutzrechte. Eine Aufrechterhaltung des Urheberrechtsschutzes wäre mit dem streng durchgeführten Grundsatz des Entwurfs, daß nur die schöpferische Leistung Urheberrechtsschutz genießen kann, unvereinbar.

\section{Zu § 145 - Vervielfältigung und Verbreitung}

Die Absätze 1 und 2 enthalten entsprechend dem geltenden Recht ( $\$ 63$ LUG, $\$ 54$ KUG) eine Ubergangsregelung für den Fall, daß mit einer Vervielfältigung, die mach dem neuen Gesetz unzulässig ist, bisher aber erlaubt war, wie z. B. die Vervielfältigung von Liederbüchern und Anthologien nach $\S 19$ Abs. 1 Nr. 3 und 4 LUG, vor Inkrafttreten des Gesetzes bereits begonnen worden ist. In diesem Falle soll die Vervielfältigung noch nach Inkrafttreten des Gesetzes vollendet werden dürfen und die Verbreitung der rechtmäßig hergestellten Vervielfältigungsstücke frei zulässig sein. Die in $\S 63$ Satz 2 LUG und $\S 54$ Satz 1 KUG vorgesehene weitere Bestimmung, daß vorhandene Vorrichtungen zur Vervielfältigung (wie Formen, Platten, Steine, Druckstöcke, Matrizen) noch 6 Monate bzw. 3 Jahre nach Inkrafttreten des Gesetzes benutzt werden dürfen, behält der Entwurf nicht bei. Angesichts der Bedeutung und des Umfangs des neuen Urheberrechtsgesetzes wird es ohnehin notwendig sein, das Gesetz erst nach einer längeren Frist seit seiner Verkündung in Kraft treten zu lassen. Es ist nicht erforderlich, die Weiterbenutzung der vorhandenen Vorrichtungen zur Vervielfältigung darüber hinaus zuzulassen, soweit es sich nicht um die Vollendung einer bereits begonnenen Vervielfältigung nach $\mathrm{Ab}$ satz 1 handelt.

Als Absatz 3 ist eine Ubergangsbestimmung für die Fälle vorgesehen, in denen die bisher frei zulässige Vervielfältigung auch nach dem neuen Gesetz erlaubt, in Zukunft aber vergütungspflichtig ist. In diesen Fällen soll die begonnene Vervielfältigung ohne Zahlung einer Vergütung vollendet werden dürfen. Eine andere Regelung würde zu dem unangemessenen Ergebnis führen, daß beispielsweise für die Vollendung einer begonnen Vervielfältigung von Sammlungen für den Kirchen-, Schul- oder Unterrichtsgebrauch ( $\$ 46)$ vom Inkrafttreten des Gesetzes an eine Vergütung bezahlt werden müßte, während die begonnene Vervielfältigung einer nach der Regelung des Entwurfs dem Verbotsrecht des Urhebers unterliegenden Anthologie nach Absatz 1 kostenfrei vollendet werden darf.

\section{Zu § 146 - Ubertragung von Rechten}

Nach bisherigem Recht ist es möglich, die aus dem Urheberrecht fließenden Verwertungsrechte, z. B. das Vervielfältigungsrecht oder das Aufführungsrecht, auf einen Dritten zu übertragen. Der Entwurf läßt eine solche Ubertragung nicht mehr $\mathrm{zu}$, sondern sieht nur die Einräumung von Nutzungsrechten vor (\$31). Absatz 1 Satz 1 stellt klar, daß diese neue Regelung entsprechend dem in $\S 139$ enthaltenen Grundsatz auch für vor Inkrafttreten dieses Gesetzes getroffene Verfügungen über das Urheberrecht gelten soll in der Weise, daß nunmehr an die Stelle der erworbenen Verwertungsrechte die entsprechenden Nutzungsrechte treten.

Die Auslegungsregel in Absatz 1 Satz 2 entspricht dem von der Rechtsprechung entwickelten Grundsatz, daß sich Verfügungen über das Urheberrecht im Zweifel nicht auf neue, zur Zeit des Vertragsabschlusses noch nicht bekannte Werknutzungsarten erstrecken. Es bedarf keiner besonderen Erwähnung, daß die Bestimmung nicht auf Rechte anwendbar ist, die, wie das Senderecht, durch das neue Urheberrechtsgesetz nicht begründet, sondern lediglich bestätigt werden. Nach Absatz 2 soll die vorgesehene Regelung für verwandte Schutzrechte entsprechend gelten.

\section{DRITTER ABSCHNITT}

\section{Schlußbestimmungen}

\section{Zu § 147 - Urheberrolle}

$\S 147$ regelt die Einrichtung der in $\S 69$ Abs. 2 Nr. 2 vorgesehenen Urheberrolle. Er lehnt sich an die $\S \S 56$ bis 58 LUG an, enthält jedoch einige Abweichungen vom geltenden Recht.

Nach $\S 56$ Abs. 1 LUG wird die Urheberrolle beim Stadtrat in Leipzig geführt. Der Entwurf sieht statt dessen vor, das Patentamt mit dieser Aufgabe zu betrauen, in dem eine Urheberrechtsabteilung bereits besteht (Absatz 1). Uber Beschwerden gegen die Ablehnung eines Eintragungsantrags soll nach Absatz 2 das Patentgericht entscheiden. 
Die Bestimmungen in den Absätzen 3 und 4 entsprechen dem geltenden Recht ( $\$ 57$ Abs. 1 Satz 2, Abs. 2 LUG in Verbindung mit der Bekanntmachung des Reichskanzlers vom 28. April 1903 [RGBI. S. 211], § 58 Abs. 2 Satz 2 LUG und dem Gesetz über Bekanntmachungen vom 17. Mai 1950 [BGBl. S. 183]).

Absatz 5 entspricht § 57 Abs. 1 Satz 1 LUG.

Absatz 6 enthält eine Ubergangsregelung für die bestehenden Eintragungen in der beim Stadtrat in Leipzig geführten Eintragungsrolle.

\section{Zu § 148 - Finderung der Strafprozebordnung}

Die in dieser Bestimmung vorgesehene Anderung der Strafprozeßordnung bringt keine Abweichung vom geltenden Recht. Nach $\S 374$ Abs. 1 Nr. 8 StPO werden auch bisher alle Urheberrechtsverletzungen im Wege der Privatklage verfolgt. Die Bestimmung soll nur redaktionell vereinfacht und dem neuen Gesetz angepaßt werden.

\section{Zu $\$ 149$ - Anderung des Gesetzes thber das am 6. September 1952 unterzeichnete Welturheberrechtsabkommen}

Nach Artikel IV Nr. 4 des Welturheberrechtsabkommens vom 6. September 1952 (Bundesgesetzbl. 1955 II S. 102), dem auch die Bundesrepublik angehört, ist kein vertragschließender Staat verpflichtet, einen längeren Schutz zu gewähren als den, der für Werke der betreffenden Art in dem vertragschlieBenden Staat festgesetzt ist, in dem das Werk zuerst veröffentlicht wurde; ist das Werk nicht veröffentlicht, so braucht kein längerer Schutz gewährt zu werden als der, der in dem vertragschließenden Staat, dem der Urheber angehört, für Werke der betreffenden Art festgesetzt ist. Die Frage, ob diese Einschränkung des Schutzes für ausländische Werke mit der Ratifikation des Welturheberrechtsabkommens durch die Bundesrepublik in deren Gebiet unmittelbar wirksam geworden ist, oder ob hierzu eine besondere gesetzliche Regelung erforderlich ist, ist streitig. Um klarzustellen, daß die Einschränkung des Schutzes auch für die Bundesrepublik gilt, sieht $\S 149$ eine entsprechende Ergänzung des Gesetzes über das am 6. September 1952 unterzeichnete Welturheberrechtsabkommen vor.

\section{Zu $\S 150$ - Aufgehobene Vorschriften}

Durch § 150 werden die geltenden urheberrechtlichen Vorschriften aufgehoben, die durch das neue Urheberrechtsgesetz ersetzt werden oder sonst gegenstandslos geworden sind (Nummern 1 bis 7). Das Gesetz betreffend das Urheberrecht an Werken der bildenden Künste und der Photographie kann nicht gänzlich außer Kraft gesetzt werden, weil für die darin enthaltenen Vorschriften über den Bildnisschutz (vgl. $\S \S 22$ bis 24, 33 Abs. 1 Nr. 2) keine entsprechende Regelung im neuen Urheberrechtsgesetz vorgesehen ist (vgl. Einleitung S. 35). Die Vorschriften sollen daher bis zu einer Neuregelung des Bildnisschutzes in Kraft bleiben (vgl. Nummer 5).

$\S 10$ das Gesetzes über die Rechtsstellung heimatloser Ausländer im Bundesgebiet vom 25. April 1951 gewährt heimatlosen Ausländern hinsichtlich ihrer Urheberrechte und gewerblichen Schutzrechte die günstigste Behandlung, die Angehörigen fremder Staaten zusteht. $\mathrm{Da}$ alle heimatlosen Ausländer zugleich Flüchtlinge im Sinne des von der Bundesrepublik ratifizierten Abkommens über die Rechtsstellung der Flüchtlinge vom 28. Juli 1951 (Bundesgesetzbl. 1953 II S. 560) sind und damit nach Artikel 14 dieses Abkommens in der Bundesrepublik hinsichtlich des Schutzes dieser Rechte wie Inländer behandelt werden, kann Artikel 10 des Gesetzes über die Rechtsstellung heimatloser Ausländer im Bundesgebiet außer Kraft gesetzt werden (Nummer 8). Dies empfiehlt sich schon deshalb, weil Meistbegünstigungsklauseln auf dem Gebiet des Urheberrechts und des gewerblichen Rechtsschutzes unüblich sind und sich aus ihnen leicht Unklarheiten über den Umfang des gewährten Schutzes ergeben können.

\section{Zu $\$ 151$ - Geltung im Land Berlin}

$\S 151$ enthält die übliche Berlin-Klausel.

\section{Zu $§ 152$ - Inkrafttreten}

Für das Inkrafttreten dieses Gesetzes wird, wie bereits zu § 145 erwähnt, eine verhältnismäßig geräumige Frist vorzusehen sein, um es den beteiligten Kreisen zu ermöglichen, sich auf den neuen Rechtszustand einzustellen. 


\title{
Auszug aus dem Urteil des Bundesgerichtshofs vom 26. Oktober 1951
}

\author{
- I ZR 93/51 -
}

\section{Tatbestand:}

Chefarzt und Direktor des Tuberkulose-Krankenhauses der Beklagten war bis zu seinem am 31. Dezember 1938 erfolgten Tode Professor Dr. Sch., der neue Methoden zur Bekämpfung der Lungen-Tuberkulose auf lungenchirurgischem Gebiet eingeführt hat. Auf Veranlassung von Professor Dr. Sch. wurden insbesondere in Pneumolysefällen und bei Thorakoplastiken sog. Nachuntersuchungen vorgenommen, deren Ergebnisse in einer seit 1937 eingeführten Kartothek auf Karteikartenformularen niedergelegt wurden.

Nach dem Tode von Professor Dr. Sch. wurde im Jahre 1939 der Kläger zum Chefarzt berufen. Er hat die vorgenannte Kartothek bis zu seinem Ende 1945 erfolgten Ausscheiden als Chefarzt weitergeführt und weiterentwickelt. Die Karteikarten enthielten in ihrer letzten Form eine kurze Krankengeschichte der Privat- oder Kassenpatienten, den Befund vor der Operation, die Operation selbst, deren Verlauf, und einen Auszug aus dem Bericht über die Nachuntersuchung des Patienten. Nachdem sie zunächst in der Ambulanz angelegt und geführt worden waren, wurde diese Aufgabe seit 1943 auf den einzelnen Stationen erledigt. Nach der Entlassung der Patienten kamen die Karteikarten zur Eintragung der Nachuntersuchungen in die Ambulanz des Krankenhauses.

Mit der Klage hat der Kläger Herausgabe der Kartothek ... sowie die Feststellung begehrt, daß ihm allein die wissenschaftliche Auswertung der während dieser Zeit festgehaltenen Nachuntersuchungen zustehe. Hilfsweise hat der Kläger beantragt, die Beklagte zu verurteilen, ihm die herausverlangten Karteikarten zur wissenschaftlichen Auswertung im Original oder in Abschrift auf die Dauer von sechs Monaten in seiner Praxis in Heidelberg zur Verfügung zu stellen. Der Kläger ist der Auffas- sung, daß er Eigentümer wie auch Inhaber des Urheberrechts an den Karteikarten sei.

...

Entscheidungsgründe:

Das von dem Kläger in Anspruch genommene Urheberrecht an den strittigen Karteiblättern kann Klaggrundlage weder für seinen auf zeitlich unbegrenzte Herausgabe gerichteten Hauptantrag noch für seinen Hilfsantrag auf vorübergehende Besitzüberlassung bilden.

Das Urheberrecht gewährt dem Werkschöpfer oder seinem Rechtsnachfolger kein Recht auf den Besitz der Werkstücke. Das Besitzrecht kann vielmehr nur aus dem Eigentum hergeleitet werden. Ist der Urheber eines Werkes nicht zugleich Besitzer des von ihm geschaffenen Werkstückes, so berechtigen ihn seine urheberrechtlichen Befugnisse nur, von dem Besitzer zu verlangen, daß dieser ihm das Werkstück zur Ausübung seiner urheberrechtlichen Befugnisse zugänglich macht, etwa um $\mathrm{Ab}$ schriften oder Fotokopien anzufertigen. In den Entwürfen zu einem neuen Urheberrechtsgesetz ist vorgesehen, dieses Recht des Urhebers auf Zugang zu den von ihm geschaffenen Werkstücken ausdrücklich festzulegen (vgl. $\$ 35$ des Hoffmann'schen Entwurfes, $\S 24$ des R.MM-Entwurfes, $\S 23$ AkademieEntwurf). Dieses Recht des Urhebers folgt aber schon nach geltendem Recht aus seinem unveräußerlichen Persönlichkeitsrecht. Die Klage richtet sich aber nicht auf Zugang zu der Kartothek, der dem Kläger von der Beklagten nicht streitig gemacht wird, sondern auf zeitlich unbegrenzte oder begrenzte Besitzüberlassung. Da für das Besitzrecht das Urheberrecht nicht entscheidungserheblich ist, kann unentschieden bleiben, ob die Karteikarten Schriftwerke im Sinne von \$1 LitUG darstellen. 
Anlage 2

\section{Auszug aus dem Urteil des Bundesgerichtshofs vom 6. November 1953}

$$
\text { - I ZR 97/52 - (BGHZ 1.1, S. 135) }
$$

\section{Leitsätze}

1. Die in $\S 22$ a LitUrhG vorgesehene Aufführungsfreiheit für mechanische Musik ist mit Art 13 Abs 1 und 2 der Rom-Fassung der Revidierten Berner Ubereinkunft vereinbar.

2. Die öffentliche Wiedergabe auf Schallplatten festgelegter Tonwerke wird, wenn sie durch einen. Plattenspieler mit Lautsprecher stattfindet, nicht von dem Ausnahmetatbestand des $\$ 22$ a erfabt. Sie bedarf also der Erlaubniserteilung durch den Urheber.

\section{Tatbestand:}

Die Klägerin ist ein rechtsfähiger Verein kraft staatlicher Verleihung, dem auf Grund von Verträgen mit deutschen Textdichtern und Komponisten sowie mit ausländischen Aufführungsrechtsgesellschaften die Wahrnehmung der Urheberrechte an nahezu dem gesamten urheberrechtlich geschützten Musikbestand zusteht, soweit es sich nicht um dessen bühnenmäBige Aufführung handelt. Der Beklagte betreibt unter der Firma "Record Walter Kwiecinski“ ein Handelsgeschäft mit Musikinstrumenten und Schallplatten. Er ließ in der Zeitung "Niedersächsische Hotel- und Gaststättennachrichten" am 23. Mai 1950 ein Inserat folgenden Wortlauts erscheinen:

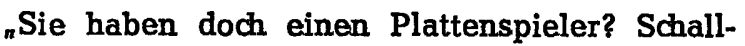
platten aller Art, Spezialität moderne Tanzmusik

\section{GEMA-FREI}

Plattenspieler, Musiktruhen.

Fordern Sie Listen an von "Record" über den Verlag dieser Zeitung."

Die Klägerin ist der Auffassung, daß der Beklagte durch dieses Inserat gegen die $\S \S 1,3$ des Gesetzes gegen den unlauteren Wettbewerb verstoßen und sich zugleich der Anstiftung zu einer Urheberrechtsverletzung schuldig gemacht habe. Sie hat beantragt, dem Beklagten zu untersagen, in öffentlichen Ankündigungen Schallplatten mit moderner Tanzmusik als "GEMA-frei" zur öffentlichen Aufführung mittels Plattenspieler anzubieten.

Der Beklagte hat um Klagabweisung gebeten. Nach seiner Ansicht bedarf die öffentliche Aufführung rechtmäßig hergestellter Schallplatten mit geschützter Musik gemäß § 22 a LitUrhG auch dann keiner Erlaubnis des Urheberberechtigten, wenn die Wiedergabe durch moderne Plattenspieler mittels Lautsprecher erfolge. . . .

\section{Entscheidungsagrüne:}

I. Das von der Klägerin beanstandete Inserat des Beklagten ist von dem Berufungsgericht rechtsirrtumsfrei dahin ausgelegt worden, daß es die Behauptung enthält, Schallplatten mit urheberrechtlich geschützter Tanzmusik dürften ohne Erlaubnis der Klägerin, der Treuhänderin der musikalischen Aufführungsrechte der Komponisten, öffentlich mittels moderner Plattenspielapparate aufgeführt werden. Von dieser Auslegung gehen auch übereinstimmend die Parteien aus, wobei sie im Einklang mit dem gewöhnlichen Sprachgebrauch unter "Plattenspielern" zutreffend Wiedergabegeräte für Schallplatten verstehen, die sich zur Hörbarmachung der Töne eines Lautsprechers bedienen. Die Entscheidung des Rechtsstreites hängt davon $a b$, ob diese in dem Inserat aufgestellte Behauptung des Beklagten zutrifft. Ist dies $\mathrm{zu}$ verneinen, so stellt sie, ohne daß es auf ein Verschulden des Beklagten ankäme, einen objektiv widerrechtlichen Eingriff in die von der Klägerin verwalteten Urheberrechte dar. Da der Beklagte in dem Rechtsstreit den Standpunkt vertreten hat, zu der beanstandeten Behauptung berechtigt zu sein, ist die für ein Unterlassungsbegehren erforderliche Wiederholungsgefahr gegeben.

II. Gemäß § 11 Abs 1 LitUrhG hat der Urheber die ausschließliche Befugnis zur Vervielfältigung und gewerbsmäßigen Verbreitung seines Werkes. Das Urheberrecht an einem Werk der Tonkunst gewährt auch das ausschließliche Recht zur öffentlichen Aufführung des Werkes ( $\$ 11$ Abs 2 LitUrhG). Diese Ausschließlichkeitsrechte des Urhebers erstrecken sich auch auf Vorrichtungen für Instrumente, die der mechanischen Wiedergabe für das Gehör dienen, auf die das urheberrechtlich geschützte Werk übertragen worden ist (§ 12 Abs 2 Ziff 5 LitUrhG). Derartige Vorrichtungen stellt das Gesetz Bearbeitungen des Werkes gleich, wenn sie mittels eines persönlichen Vartrages hergestellt sind oder der technische Ubertragungsvorgang als solcher eine künstlerische Leistung darstellt ( $\S 2$ Abs 2 LitUrhG, vgl hierzu BGHZ 8, 88 ff). Gestattet der Urheber eines Tonkunstwerkes einem anderen, sein Werk zum Zwedk der mechanischen Wiedergabe $\mathrm{zu}$ vervielfältigen, so kann nach Erscheinen des Werkes jeder Dritte, der im Inland eine gewerbliche Hauptniederlassung oder den Wohnsitz hat, die gleiche Erlaubniserteilung gegen

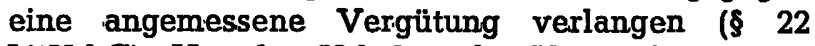
LitUrhG). Hat der Unheber die Vervielfältigungserlaubnis freiwillig oder auf Grund der Zwangslizenz des $\S 22$ LitUrhG erteilt, so sieht $\S 22 \mathrm{a}$ LitUrhG vor, daß die rechtmäßig hergestellten Vervielfältigungsexemplare ohne weitere Erlaubnis des 
Werkschöpfers zur öffentlichen Aufführung benutzt werden dürfen.

...

V. Die Entscheidung des Rechtsstreits hängt somit allein davon $a b$, welche rechtliche Tragweite der in $\S 22$ a LitUrhG vorgesehenen Erlaubnisfreiheit für die öffentliche Aufführung urheberrechtlich geschützter Werke mittels mechanischer Schallvorrichtungen zukommt.

a) Dieser Bestimmung ging in Deutschland folgende Rechtsentwicklung auf dem Gebiet der mechanischen Musik voraus:

Zur Zeit des Inkrafttretens des ersten deutschen Reichsgesetzes betreffend das Urheberrecht an Schriftwerken, Abbildungen, musikalischen .Kompositionen und dramatischen Werken vom 11. Juni 1870 war die mechanische Musik zwar bereits bekannt, aber infolge ihrer technischen Unvollkommenheit für die gewerbliche Auswertung urheberrechtlicher Befugnisse praktisch bedeutungslos. Dieses Gesetz enthielt dementsprechend keine besonderen Bestimmungen über den Schutz von Werken gegen eine mechanische Wiedergabe.

Auf Betreiben der Schweizer Spielwerkindustrie wurde sodann in $\mathrm{Nr} 3$ des Schlußprotokolls zur Berner Ubereinkunft vom 9. September 1886 von den vertragschließenden Ländern, $\mathrm{zu}$ denen Deutschland gehörte, vereinbart: „Es besteht Einverständnis darüber, daß die Fabrikation und der Verkauf von Instrumenten, welche zur mechanischen Wiedergabe von Musikstücken dienen, die aus geschützten Werken entnommen sind, nicht als den Tatbestand der musikalischen Nachbildung darstellend angesehen werden sollen." Das Reichsgericht hat unter der Herrschaft des Urheberrechtsgesetzes von 1870 zugunsten der Urheber in feststehender Rechtsprechung den Standpunkt vertreten, daß sich diese Bestimmung nur auf solche mechanischen Musikinstrumente beziehe, bei denen der Tonträger fest'mit der mechanischen Vorrichtung verbunden sei, die ihn hörbar mache, während a us w e chs el b a re Tonträger von ihr nicht ergriffen würden, sondern wie Vervielfältigungsstücke des Werkes zu behandeln seien, deren Herstellung und Verwertung von der Erlaubnis des Werkschöpfers abhängig sei (RGZ 22, 174; 27, 60; RGSt 32, 41).

Dieser Rechtsprechung wurde durch $\$ 22$ des Gesetzes betreffend das Urheberrecht an Werken der Literatur und Tonkunst vom 19. Juni 1901 die Grundlage entzogen. Diese Gesetzesvorschrift stellte - abgesehen von der sog. Pianola-Klausel mechanische Musikinstrumente mit auswechselbaren Bestandteilen den konstanten Spielwerken gleich und nahm die Ubertragung von Werken der Tonkunst auf derartige mechanische Vorrichtungren von dem Urheberrechtsschutz aus. Soweit gemäß § 22 die mechanische Vervielfältigung erlaubt war, bedurfte nach $\S 26$ auch die öffentliche Aufführung mit Hilfe derartiger Schallvorrichtungen keiner Erlaubnis des Werkschöpfens. Diese Durchbrechung des Urheberschutzes erfolgte zugunsten der damals in Deutschland aufblühenden Industrie für mechanische Musikinstrumente, die geltend machte, daß sie ohne eine solche urheberrechtliche Sonderregelung für mechanische Musik der ausländischen Konkurrenz unterliegen müsse (Stenographische Berichte des Reichstags für 1900/1901, Band I Nr 97 Seite 386 [401], Begründung zum Entwurf der Novelle vom 22. Mai 1910, Verhandlungen des Reichstags XII. Legislaturperiode II. Session Aktenstück Nr 341 Seite 1788 ff). Ausgenommen von dieser Vergünstigung wurden jedoch solche Instrumente, "durch die das Werk hinsichtlich der Stärke und Dauer des Tones und hinsichtlich des Zeitmaßes nach Art eines persönlichen Vortrags wiedergegeben werden kann." Zur Begründung dieser sog. Pianola-Klausel wurde ausgeführt: „Der Komponist solle gegen eine mechanische Wiedergabe geschützt wierden, die mit der von Menschen selbst ausgeführten gleichwertig ist" (Bericht der XI. Kommission des Reichstages, Stenographische Berichte des Reichstages für 1900/ 1901, Band II Aktenstück Nr 214 Seite 1293).

Diese Bestimmung des deutschen Urheberrechts mußte geändert werden, um Deutschland den Beitritt zu der in Berlin revidierten Fassung der Berner Ubereinkunft vom 13. November $1908 \mathrm{zu}$ ermöglichen; denn diese Fassung gewährte den Urhebern verbandseigener Werke der Tonkunst unter Aufhebung der Bestimmung Nr. 3 des Schlußprotokolls - erstmalig die ausschließliche Befugnis zur Ubertragung ihrer Werke auf mechanische Vorrichtungen sowie zur öffentlichen Aufführung mittels dieser Tonträger. Dies führte zu der deutschen Gesetzesnovelle vom 22. Mai 1910, durch die außer dem hier in Betracht kommenden § 22 a die $\S \S 2$ Abs 2, 12 Abs 2 Nr 5, 14 Abs 4, 20 Abs 3, die Neufassung von $\S 22$ und die $\S \S 22$ b bis $c$ und 63 a dem Gesetz von 1901 eingefügt wurden.

b) Das ausschließliche Recht des Urhebers, sein Werk auf Vorrichtungen für mechanische Musikinstrumente zu übertragen und mit ihrer Hilfe zur öffentlichen Aufführung zu bringen, folgt nunmehr aus seinem in $\S 11$ LitUrhG festgelegten ausschließlichen Aufführungs- und Vervielfältigungsrecht. Im wesentlichen um die Änderung gegenüber dem früheren Rechtszustand und die Abhängigkeit des fiktiven Bearbeiterurheberrechtes, das § 2 Abs 2 an der auf einen Tonträger festgelegten Wiedergabe des Werkes vorsieht, von dem Urheberrecht des Werkschöpfers zu verdeutlichen, wurde in $\S 12$ Abs 2 Ziff 5 ausdrücklich klargestellt, daß die Befugnisse, die Inhalt der in $\S 11$ aufgeführten ausschließlichen Werknutzungsrechte des Urhebers sind, auch an mechanischen Vorrichtungen, auf die das Werk übertragen ist, nur mit Erlaubnis des Werkschöpfers ausgeübt werden dürfen. Wenn nun $\S 22$ a bestimmt, daß derartige Tonträger, die auf Grund einer freiwilligen Erlaubnis des Urhebers oder der Zwangslizenz des $\S 22$ hergestellt worden sind, ohne weitere Genehmigung zur öffentlichen Aufführung benutzt werden dürfen, so handelt es sich um eine Aus a hmebestim $\mathrm{mung}$, durch die in die Ausschließlichkeit des Aufführungsrechtes des Werkschöpfers eingegriffen wird.

Es sei bemerkt, daß diese Ausnahmebestimmung, die in ähnlicher Weise nur das Schweizer Urheberrecht kennt (Art 21 des Schweizer Urheberrechts- 
gesetzes von 1922) im Schrifttum des Inlands sowie des Auslands weitgehend auf Widerspruch gestoßen ist (Ostertag Le droit d'Auteur 1928, 1944; 1929,$10 ; 1930,13$ und 36; 1932, 58; 1934, 9; GRUR 1930, 285; Dienstag-Elster [Handbuch] S 179; Ulmer Urheber- und Verlagsrecht S 185). Sie wird als unbillige Einschränkung der Werknutzungsrechte des Urhebers empfunden, dem durch diese Regelung Aufführungstantiemen entgingen, die in der Regel durch die Vergütung für die mechanische Vervielfältigungserlaubnis nicht ausgeglichen würden. Die deutschen Entwürfe für eine Urheberrechtsreform gehen übereinstimmend davon aus, daß die durch $\S 22$ a LitUrhG gewährte Aufführungsfreiheit nicht beizubehalten sei. Der Vorbehalt für die Landesgesetzgebung in Art 13 Abs 2 der Berner Ubereinkunft ist auf der Brüsseler Konferenz dahin eingeschränkt worden, daß das Recht des Komponisten auf eine angemessene Vergütung gewahrt bleiben muß. Es besteht im Schrifttum Einmütigkeit, daß $\S 22$ a mit dieser Brüsseler Fassung der Berner Ubereinkunft, der Deutschland bislang nicht beigetreten ist, nicht $\mathrm{zu}$ vereinbaren ist.

VI. Das Reichsgericht ist in ständiger Rechtsprechung von dem Ausnahmecharakter des $\S 22$ a LitUrhG ausgegangen und hat hieraus gefolgert, daß diese Gesetzesvorschrift wie alle Ausnahmebestimmungen grundsätzlich e $\mathrm{n} \cdot \mathrm{g}$ auszulegen sei (RGZ 153, 1 ff [23]; 140, 239; 128, 102 ff). Dem schließt sich der Senat an. Eine enge Auslegung der durch $\S 22$ a geschaffenen Befugnislücke in der umfassenden Urheberbefugnis des § 11 LitUrhG ist schon nach dem das ganze Urheberrecht beherrschenden Leitgedanken geboten, den Urheber tunlichst an dem wirtschaftlichen Nutzen zu beteiligen, der aus seinem Werk gezogen wird (RGZ 118,$285 ; 122,68 ; 123,312 ; 128,113 ; 130,206 ; 134$, $201 ; 153,22)$.

Auf diesem Grundsatz beruht auch die Rechtsprechung des Reichsgerichts, wonach selbst bei einer uneingeschränkten Ubertragung des Urheberrechtes die Ausnutzung neuer Verwertungsmöglichkeiten, die die Parteien nach dem Stand der Technik im Zeitpunkt der Ubertragung nicht in Rechnung gestellt haben, dem Werkschöpfer vorbehalten bleiben (RGZ 118, 285 [Verfilmung]; RGZ 123, 312 [Rundfunksendung]). Aus dem gleichen Rechtsgedanken hat das Reichsgericht in seiner für die Schallplattenwiedergabe durch den Rundfunk grundlegenden Entscheidung vom 14. November 1936 (RGZ 153, 1 ff) den Umfang der durch § 22 a LitUrhG gewährten Aufführungsfreiheit nach den Verwertungsmöglichkeiten von Schallvorrichtungen beurteilt, wie sie bei Erlaß der Novelle von 1910 gegeben oder doch nach dem damaligen Stand der Technik voraussehbar waren. Das Reichsgericht führt hierzu u.a. aus: "In welchem Umfang die Ausnahme bezweckt wurde, läßt sich bloß nach den technischen Möglichkeiten beurteilen, welche bei Erlaß des Gesetzes von 1910 vorlagen. Diese bestanden damals nur in der regelmäßigen, einfachen, erstmaligen, auf dem Grammophon zum unmittelbaren Hören bestimmten Wiedergabe (Elster Arch. f. UrhR. Band 5 [1932] S 116 ff, GRUR
Band 40 [1935] S 210). Eine beträchtlich weitergehende Wiedergabeart und eine Erstreckung des Ausnahmebereichs auf sie lagen nicht in Zweck und Absicht des Gesetzes." Von dieser grundsätzlichen Auffassung aus hat sich das Reichsgericht die Frage gestellt, ob die Rundfunksendung „in ihren tatsächlichen Wirkungen den Verhältnissen gleichzusetzen sei, die das Gesetz bei Schaffung des $\S 22$ a vor Augen hatte und die daher nach dem Zweck der Vorschrift eine Beschränkung der urheberrechtlichen Befugnis rechtfertigen können." Das Reichsgericht hat diese Frage für die rundfunkmäßige Sendung von Schallplatten verneint und die Zustimmung sowohl des Komponisten sowie des Inhabers des Schutzrechtes an der Schallplatte ( $\$ 2$ Abs 2) für diese neue Verwertungsart des Urheberrechtsgutes als erforderlich erachtet.

Soweit das Reichsgericht dieses Ergebnis unter Anknüpfung an seinen in früheren Entscheidungen für die Rundfunksendung entwickelten erweiterten Verbreitungsbegriff (RGZ 113, 413; 123, 312; 136, 381) auch darauf stützt, daß die Wiedergabe eines Werkes durch den Rundfunk in den außerhalb des Kreises der "öffentlichen Aufführung" liegenden Teilbereich der "Verbreitung" falle, der durch $\S 22$ a nicht freigegeben sei, vermag der Senat dieser Begründung nicht zu folgen. Der Senat geht vielmehr davon aus, daß der Verbreitungsbegriff sich nur auf die Verbreitung körperlicher Werkexemplare beschränkt und auf die unkörperliche Wiedergabe des Werkes nicht zu erstrecken ist. Der Senat folgt dagegen der weiteren, die Entscheidung tragenden Begründung des Reichsgerichts, wonach dem Begriff der "öffentlichen Aufführung " in der Ausnahmevorschrift des $\S 22$ a nur die engre Bedeutung zukommt, die der Gesetzgeber im Jahre 1910 nach dem damaligen Entwicklungsstand der Technik im Auge haben konnte. Die Entscheidung des Rechtsstreits hängt hiernach davon $a b$, ob die Lautsprecherwiedergabe von Schallplatten mittels moderner Plattenspielapparate in ihren Wirkungen den bei Schaffung des $\S 22$ a bekannten Wiedergabemöglichkeiten mechanischer Musik gleichzusetzen ist.

Im Jahre 1910 geschah die Tonaufnahme der Schallplatte in der Weise, daß durch eine mit einer Membran festverbundene Nadel die mechanischen Bewegungen fortlaufend aufgezeichnet wurden, die die Nadel unter dem Impuls der Schallschwingungen ausführte. Die Wiedergabe stellte eine Umkehr dieses mechanischen Aufnahmevorganges dar. Durch die Drehung der Platte wurde eine in ihrer Tonspur entlanggeführte Nadel zu der Wiederholung der mechanischen Schwingungen gezwungen, die zur Bildung der Tonspur geführt hatten. Diese Schwingungen wurden - durch Hebelwirkung vergrößert - auf eine Membran übertragen, die den mechanisch-akustischen Wandler darstellte. Die akustischen Schwingungen wurden durch einen Schalltrichter verstärkt und damit für das menschliche Ohr hörbar gemacht. Die Umformung der auf der Schallplatte festgelegten Töne erfolgte somit durch ein ausschließlich mechanisch-akustisches Verfahren, wobei die Wirksamkeit der in sich geschlosse- 
nen Apparatur von den beschränkten mechanischen Möglichkeiten abhängig war. Die auf diese Weise erzeugten Schallwellen waren nur sehr begrenzt weiterleitungsfähig und nur einer beschränkten Verstärkung zugänglich. Der Tonqualität waren dadurch, daß größere Massen in Schwingungen versetzt werden mußten, enge Grenzen gesetzt. Um die notwendige Lautstärke zu erreichen, mußte der Nadeldruck verhältnismäßig stark sein, was die Lebensdauer der Platte sowie die Klangreinheit der Wiedergabe herabsetzte.

Die Wiedergabe einer Schallplatte durch einen modernen Plattenspieler mit elektro-akustischem Lautsprecher beruht auf einem völlig anderen Prinzip. Bei diesem Verfahren wird als Wandler ein sog. Tonabnehmer benutzt, der die mechanischen Schwingungen nicht in akustische, sondern in elektrische Schwingungen umwandelt. Diese elektrischen Schwingungen werden sodann durch den Lautsprecher in Schallwellen umgeformt. Der Hörer vernimmt somit Schallwellen, die erst durch eine Verwandlung elektrischer Wellen entstehen, die wiederum auf eine Umformung der zunächst erzeugten mechanischen Schwingungen der Nadel zurückgehen. Diese der Rundfunktechnik entnommene Wiedergabeart mit der ihr eigentümlichen beliebig steigerungsfähigen Verstärkung kleinster elektrischer Impulse ermöglicht es, die mechanischen Bewegungen der Nadel auf ein Minimum zu beschränken, was eine erhebliche Klangverbesserung gegenüber dem mechanisch-akustischen Verfahren zur Folge hat. Bei diesem Verfahren können weiterhin die mechanisch schwingenden Massen sehr gering gehalten werden, was sich gleichfalls auf die Tonqualität günstig auswirkt und zugleich die Haltbarkeit der Schallplatte wesentlich erhöht. Gewonnen aber wurde vor allem durch das elektro-akustische Verfahren eine beliebig steigerungsfähige Klangstärke und Reichweite der Schallplattenaufführung. Die in dem Tonabnehmer in elektrische Wellen kleinster Energie verwandelten Schallschwingungen können über beliebig große Verstärker oder ganze Verstärkeranlagen einer unbegrenzten Zahl von Lautsprechern zugeführt werden. Da die elektrischen Wellen auch bei längeren Zuleitungswegen keine Abschwächung erfahren, können diese auch in größerer Entfernung von der übrigen Wiederglabeapparatur aufgestellt weriden, ahne daß die Klangstärke beeinträchtigt würde.

Aus dem elektro-akustischen Ubertragungsweg kann nun zwar nicht gefolgert werden, das $\mathrm{Ab}$ spielen von Schallplatten mittels moderner Plattenspieler erfülle nicht den Tatbestand einer " $\mathrm{m} \mathrm{e}$ chanischen Wiedergabe für das Gehör" im Sinn von $\S 12$ Abs 2 Ziff 5 LitUrhG. Denn unter diesen Begriff fallen alle nur für das Gehör bestimmten Werkwiedergaben, die nicht unmittelbar durch die Leistung eines ausübenden Künstlers bewirkt werden, sondern mit Hilfe von Vorrichtungen erfolgen, auf die das Werk festgelegt ist, mag auch deren Hörbarmachung nicht ausschlieBlich auf rein mechanischen Gesetzen beruhen (RGZ 153, 1 [10]).

Entscheidend ist vielmehr allein, ob die öffentliche Wiedergabe von Schallplatten auf dem elek- tro-akustischen Ubertragungsweg den urheberrechtlichen Tatbestand der öffentlichen Aufführung im Sinn der Ausnahmebestimmung des $\$ 22$ a LitUrhG erfüllt. Dies ist $\mathrm{zu}$ verneinen. Diese Wiedergabeart, deren Prinzip heute auch weitgehend bei der Ton a f $\mathrm{n}$ a h me verwendet wird, war dem Gesetzgeber im Jahre 1910 völlig unbekannt und in seiner umwälzenden Bedeutung für die mechanische Musik nicht voraussehbar. Diese neuartige Wiedergabetechnik ermöglicht ihrer Natur nach eine ganz andersartige und weitergehende wirtschaftliche Ausbeutung von Schallvorrichtungen, als sie der Gesetzgeber bei Festlegung der Aufführungsfreiheit im $\S 22$ a in Betracht ziehen konnte. Theoretisch könnte die Reichweite der Lautsprecherwiedergabe die gleiche sein wie die einer Rundfunksendung. Der Unterschied besteht nur darin, daß die Hörbarmachung der Funksendung von einem Empfangsgerät abhängig ist, das keine Verbindung durch einen festen Leitungskörper mit dem Sendeapparat voraussetzt, während bei der Lautsprecherwiedengabe durch Plattenspieler auf diese Verbindung nicht verzichtet werden kann. Aber auch diese Wiedergabeart ist ihrem Wesen nach geeignet, in einer beliebigen Vielheit voneinander getrennter Räume eine nahezu unbegrenzte Hörerschaft zu erfassen. Weiterhin fällt ins Gewicht, daß die Tonqualität bei dieser Wiedergabetechnik der einer unmittelbaren Aufführung durch ausübende Künstler fast gleichwertig ist. Die Lautsprecherwiedergabe ist deshalb, jedenfalls urheberrechtlich gesehen, nicht nur eine technische Verbesserung, sondern ähnlich wie die Rundfunksendung als ein völlig neues technisches Mittel, mechanische Musik darzubieten, zu werten, wobei vom urheberrechtlichen Blickpunkt weniger die Höhe der erfinderischen Leistung als die durch diese Wiedergabeart erschlossene neue gewerbliche Nutzungsmöglichkeit mechanischer Musik bedeutsamn ist (im Ergebnis ebenso Möhring, GEMAFestschrift 1953 S 54; Kurtze JR 1952, 343). Die Erwägung, die es dem Gesetzgeber um die Jahrhundertwende tragbar erscheinen lieB, den Urheberrechtsschutz nicht auf mechanische Musikinstrumente zu erstrecken, weil "das Spielen mechanischer Musikinstrumente immer nur ein notdürftiger Ersatz für wirkliche Musik bleiben werde und vornehmlich in Kreisen sich verbreiten werde, in welchen musikalische Reproduktionen schon bislang keinen Eingang gefunden haben", trifft auf die elektro-akustische Wiedergabe mechanischer Musik jedenfalls nicht mehr zu. Die Qualität und Reichweite dieser Wiedergabeart hat dazu geführt, daß sie bei öffentlichen Veranstaltungen bereits weitgehend die Originalmusik verdrängt hat. Nicht nur bei öffentlichen Tanzvergnügungen und Sportdarbietungen, auch auf Ausstellungen, in Kurorten, Theatern und Lichtspielhäusern ist die Schallplattenübertragung mittels Lautsprecher vielfach an die Stelle unmittelbarer Musikdarbietungen getreten.

Es kann nicht in der Absicht der Novelle von 1910 gelegen haben, den Ausnahmebereich des $\S 22$ a auf diese gegenüber dem damaligen Stand der Technik völlig neuartige Wiedergabeart $\mathrm{zu}$ erstrecken, die den Musikveranstaltern weiterge- 
hende gewerbliche Auswertungsmöglichkeiten eröffnet als die damals bekannten mechanischen Musikdarbietungen. Weder erfordert es der Zweck des $\S 22$ a, durch eine den Abnehmern mechanischer Musikinstrumente eingeräumte urheberrechtliche Vorzugsstellung den Gewerbezweig der Hersteller dieser Instrumente zu begünstigen, noch erlaubt es der das gesamte Urheberrecht durchziehende Leitgedanke, den Unheber an den wirtschaftlichen Früchten seines Werkes angemessen zu beteiligen, öffentliche mechanische Musikveranstaltungen durch Lautsprecherwiedergabe der Ausnahmevorschrift des $\S 22$ a zu unterstellen und solche Veranstaltungen damit dem Schutzbereich des Urhebers zu entziehen. Bei der weittragenden Bedeutung, die der gewerblichen Auswertung mechanischer Musik infolge dieser neuen Wiedergabetechnik zukommt, würde es auf eine Aushöhlung und wirtschaftliche Entwertung des dem Urheber durch $\S 11$ Abs 2 LitUrhG vorbehaltenen Aufführungsrechtes hinauslaufen, wenn diese Wiedergabeart in die durch $\S 22$ a gewährte Erlaubnisfreiheit einbezogen würde. Der Urheber verlöre ersatzlos die Aufführungsgebühren, die ihm bei einer öffentlichen Darbietung seines Werkes durch ausübende Künstler zufließen würden. Wenn er auch für die Vergabe der mechanischen Vervielfältigungserlaubnis an den Erlösen aus der Schallplattenherstellung beteiligt wird, so kann hierin schon deshalb keine angemessene Entschädigung für die öffentliche Auswertung seines Werkes in der durch die Lautsprecherwiedergabe ermöglichten Art und Reichweite erblickt werden, weil der Absatz der Schallplatten sich durch diese neuen gewerblichen Verwertungsmöglichkeiten nicht in entsprechendem Maße steigert. Denn die Schallplatten werden durch diese Wiedergabetechnik, die die mechanische Musik zu einer ernsthaften Konkurrenz der lebenden Musik gemacht hat, ungleich weniger abgenutzt, was ihre Lebensdauer entsprechend verlängert.

Die Gesichtspunkte, aus denen das Reichsgericht in seiner Entscheidung vom 11. Juni 1932 (RGZ 136, 377) eine Verletzung des Urheberrechts durch die Lautsprecherübertragung von geschützter, im Rundfunk gesendeter Musik zu gewerblichen Zwecken verneint hat, treffen im Streitfall nicht zu. Abgesehen davon, daß dieses Urteil sich nicht auf die Sendung von Schallplatten bezieht, hat das Reichsgericht diese Entscheidung im wesentlichen darauf abgestellt, daß die Gestattung der Wiedergabe des Werkes durch Rundfunk ihrer Natur nach eine Erlaubnis zur Ubermittlung in unbegrenzte Weite und an eine unbestimmt große Menge von Menschen bedeute. Eine dergestalt einmal freigegebene Offentlichkeit könne durch gewerbsmäßige Lautsprecherdarbietung nicht mehr gesteigert, nicht "noch öffentlicher" gemacht werden. Dort handelte es sich somit um die Abgrenzung des Aufführungsrechtes aus $\S 11$ LitUrhG, wenn die öffentliche Darbietung des Werkes durch den Rundfunk ausdrücklich gestat tet war, während es hier um die Grenzen der ge setzlichen $\mathrm{Z}$ wangser $\mathbf{l}$ a u b is der öfentlichen Aufführung mechanischer Vorrichtungen geht. Es bedarf bei dieser Sachlage keiner Stellungnahme, ob dieser Entscheidung des Reichsgerichts, die im Schrifttum lebhafte Kritik gefunden hat, zu folgen ist.

Abzulehnen ist die Ansicht des Beklagten, bei Herausnahme der Lautsprecherwiedergabe von Schallplatten aus dem Ausnahmebereich des $\S 22$ a müßte zwangsläufig die durch $\S 27$ LitUrhG freigegebene Aufführung erschienener Werke der Tonkunst der Erlaubnispflicht unterstellt werden, wenn sie mittels Lautsprecherübertragung erfolgten. Diese Ansicht verkennt, daß die Erlaubnisfreiheit gewisser nicht gewerbsmäßiger oder unentgeltlicher Aufführungen vom Gesetzgeber i m In ter esse der Allgemeinheit für geboten erachtet wunde. Bei $\S 27$ handelt es sich somit um eine Anerkennung der sozialen Gebundenheit des Urheberrechtes, während $\S 22$ a die Abnehmer und Hersteller mechanischer Musikinstrumente begünstigen will. Die Gründe, die eine Einschränkung des Begriffs der öffentlichen Aufführung in $\S 22$ a rechtfertigen, können deshalb nicht auf $\S 27$ übertragen werden, der von dem umfassenden Aufführungsbegriff des $\S 11$ Abs 2 LitUnhG ausgeht.

Es ist somit im Ergebnis festzustellen, daß die öffentliche Aufführung von Schallplatten mit urheberrechtlich geschützter Musik durch Plattenspieler mit Lautsprecherwiedergabe mit den sich aus $\S 27$ LitUrhG ergebenden Einschränkungen gemäß § 11, $\S 12$ Abs. 2 Nr. 5 LitUrhG nur mit Erlaubnis des Urhebers zulässig ist. 


\section{Auszug aus dem Urteil des Bundesgerichtshofs vom 18. Mai 1955}

$$
\text { - I ZR 8/54 - (BGHZ } 17 \text { S. 266) }
$$

\section{Leitsätze}

1. Die Ubertragung des Vortrags oder der Aufführung eines Werkes der Literatur oder Tonkunst auf ein Magnettonband ist eine Vervielfăltigung im Sinn der \$§ 11, 15 Abs 1 LitUrhG. Dies gilt nicht nur für das Uberspielen eines Tonträgers, insbesondere von Schallplatten (BGHZ 8, 88) auf ein Magnettonband, sondern auch dann, wenn die Magnettonaufnahme die erste Festlegung des Werkes auf einen Tonträger darstellt.

Diese Vervielfältigung steht ausschlieblich dem Urheber zu. Die Vorschrift des $§ 15$ Abs. 2 LitUrhG, wonach eine Vervielfaltigung zum persönlichen Gebrauch ohne Erlaubnis des Urhebers zulässig ist, wenn sie nicht den Zweck hat, aus dem Werk eine Einnahme zu erzielen, ist eine echte Ausnahmebestimmung. Sie ist auf Vervielfältigungen, die durch Magnettonaufnahmen hergestellt werden, nicht anwendbar.

2. Für die Auslegung urheberrechtlicher Gesetzesbestimmungen ist der das Urheberrecht beherrschende Rechtsgedanke bedeutsam, daß die Herrschaft des Urhebers über sein Werk die natürliche Folge seines geistigen Eigentums ist, das durch die Gesetzgebung nur seine Anerkennung und nähere Ausgestaltung gefunden hat. Nach diesem Rechtsgedanken sind neue Nutzungsmöglichkeiten für Urhebergut, die die Entwicklung der Technik erschlieBt, in der Regel in das Ausschlieblichkeitsrecht des Urhebers einzubeziehen. Ein allgemeiner Grundsatz, daB die Ansprüche der Urheber stets vor der privaten Sphäre des Einzelnen Halt zu machen hätten, ist dem Urheberrecht fremd.

3. Dem Urheber gebuhrt im Grundsatz ein Entgelt für jede Nutzung seines Werkes, mag diese auch keinen unmittelbaren wirtschaftlichen Ertrag abwerfen.

\section{Tatbestand:}

Die Klägerin nimmt auf Grund von Verträgen die sie mit der Mehrzahl deutscher Komponisten geschlossen hat, deren Aufführungsrechte wahr. Durch Abkommen mit ausländischen Aufführungsgresellschaften ist sie mit der Wahrnehmung der gleichen Rechte für die angeschlossenen ausländischen Komponisten betraut. Außerdem werden der Klägerin in der Regel von den ihr angeschlossenen Urhebern deren Rechte zur Herstellung von Schallvorrichtungen mit übertragen. Diese sogenannten mechanischen Vervielfältigungsrechte überläßt die Klägerin dem Bureau International de l'Edition Mechanique (BIEM) zur Auswertung. Die Klägerin verwaltet jedoch in Deutschland für das BIEM diese mechanischen Rechte, an denen der Schallplattenindustrie eine Lizenz erteilt worden ist.

Die Beklagite bringt von ihr hergestellte Magnettonbandgeräte in den Handel. Die Geräte werden entweder als tragibareș Koffergerät ( ${ }_{n}$ GrundigReporter"), welches an Rundifunkgeräte und Plattenspieler angeschlossen werden kann, oder in fester Verbindung mit Rundfunkgeräten und Plattenspielern ("Grundig-Tonband-Kombination" und "Grundig Musikschrank") hengestellt. Die Geräte besitzen mehrfache Verwendungsmöglichkeiten:

a) in Verbindung mit einem Rundfunkapparat ist die akustische Aufnahme der Sendung,

b) in Verbindung mit einem Plattenspieler die Aufnahme der Platte auf ein Tonband möglich;

c) ferner kann mit Hilfe eines Mikrophons die Aufnahme von unmittelbaren akustischen Schalldarbietungen vor dem Mikrophon, sei es von Gesprächen, Gesang oder Musik sowie Geräuschen jeder Art erfolgen,

d) schließlich können die Aufnahmen sogleich nach der Aufnahme hörbar gemacht werden.

Für jede gewünschte Verwendungsmöglichkeit besitzen die Geräte besondere Tasten, welche mit der Aufschrift "Radio", "Platte" und "Mikrophon" versehen sind. Wird eine Taste bedient, so geht der beabsichtigte Aufnahmevorgang vollautomatisch vor sich.

....

Die Beklagte weist auf die verschiedenen Verwendungsmöglichkeiten in ihren Werbeprospekten u. a. mit folgenden Worten hin: "So wie der Zeitungsreporter alles aufschreibt, was berichtenswert und interessant ist, halten die Grundig-Reporter klanglich alles das fest, was Thnen gefällt und was Sie als Erinnerung aufbewahren wollen".

"Sie können beispielsweise von ihren Lieblingsmelodien, die im Rundfunk erklingen, Bandaufnahmen anfertigen".

Weiterhin wird in den Prospekten hervorgehoben, daß eine "Anschlußbuchse für Wiedergabe oder Uberspielen von Schallplatten auf Band" vorhanden ist. Wie die Aufnahme von Rundfunksendungen und Schallplatten auf das Tonband vorgenommen wind, wird in den Gebrauchsanweisungen genau geschildert. Es wird darauf hingewiesen, daß die Geräte für Filmamateure zur musikalischen Untermalung von Filmaufnahmen, für Schauspieler und Redner zur Kontrolle und Verbesserung der Stimme, für vielbeschäftigte Geschäftsleute als Diktiergerät und zur wahrheitsgetreuen Aufnahme von wichtigen Telefongesprächen, für Inhaber von 
Ladengeschäften als wertvolle Verkaufshelfer zum ständigen Abspielen von Werbetexten usw. hervorragend geeignet seien. Die Geräte seien gleichermaßen für Presse (Interview und Reportagen), für Unterricht (Vorträge und Vorlesungen) und vor allem für die Unterhaltung des Benutzers geschaffen.

Die Klägerin ist der Ansicht, daß auch private Benutzer der von der Beklagten vertriebenen Magnettongeräte Musikwerke, an denen ihr urheberrechtliche Befugnisse zur Wahrnehmung übertragen sind, nicht ohne ihre - der Klägerin - Erlaubnis auf Tonbänder aufnehmen dürfen. Dies gelte ins-. besondere, wenn es sich um das Uberspielen von Rundfunksendungen oder Schallplattenaufnahmen auf ein Tonband handele. Auf diese Rechtsansicht wies die Klägerin zusammen mit Firmen der deutschen Schallplattenindustrie in einem gemeinschaftlich abgefaßten Rundschreiben die Hersteller von Magnetton- oder sonstigen Aufnahmegeräten, die Groß- und Einzelhändler derartiger Geräte sowie die Tonstudios und Lichtspielhäuser hin. Mit den Firmen AEG und Loewe-Opta-Radio AG, welche ebenfalls Magnettongeräte herstellen und vertreiben, kam es zu einer Vereinbarung, wonach diese Firmen der Klägerin bis zur rechtskräftigen Klärung der Streitfrage eine Lizenzgebühr für jedes von ihnen verkaufte Magnettongerät zahlen. Die Beklagte, die das Rundschreiben im April 1950 erhielt, hat die Zahlung einer Lizenzgebühr abgelehnt. ....

\section{Entscheidungsgründe:}

A. Die Kernfrage des vorliegenden Rechtsstreits geht dahin, ob durch die Festlegung eines Werkes des von der Klägerin verwalteten Musikrepertoires auf Magnettonband in die der Klägerin übertragenen urheberrechtlichen Nutzungsrechte auch dann eingegriffen wird, wenn die Aufnahme des Werkes auf Tonband nur zum persönlichen Gebrauch und ohne die Absicht, eine Einnahme aus dem Werk zu erzielen, vorgenommen wird. Nur wenn diese Frage in Ubereinstimmung mit der Rechtsauffassung der Urteile der Vorinstanzen zu bejahen ist, bedarf es einer Erörterung der weiteren Frage, welche Rechte die Klägerin aus einer Verletzung ihrer Urheberrechte durch solche privaten Magnettonaufnahmen gegen die Beklagte herleiten kann, die diese Tonbandaufnahmen nicht selbst vornimmt, sondern lediglich hierfür geeignete Selbstaufnahmegeräte vertreibt.

I. Wie der Senat bereits in seiner Entscheidung vom 21. November 1952 (BGHZ 8, 88) dargelegt hat, stellt das Uberspielen eines Tonträgers, insbesondere von Schallplatten auf Magnettonbänder eine Vervielfältigung im Sinne von $\S 11$ LitUrhG dar. Unter den Vervielfältigungsbegriff fällt aber auch die Erstaufnahme des Vortrags oder der Aufführung eines Werkes auf Tonträger; denn Vervielfältigung im Sinne des Urheberrechts ist jede körperliche Festlegrung eines Werkes, die geeignet ist, das Werk den menschlichen Sinnen auf irgend eine Art mittelbar oder unmittelbar wahrnehmbar zu machen (RGZ 107, 277 [279]).

...
II. Jede Vervielfältigung eines urheberrechtlich geschützten Werkes ist grundsätzlich ausschließlich dessen Urheber vorbehalten. . . . .

Die Verwendung der von der Beklagten vertriebenen Selbstaufnahmegeräte zur Herstellung von Tonbandaufnahmen urheberrechtlich geschützter Werke für persönliche Gebrauchszwecke wäre hiernach für den Urheber nur dann rechtlich unangreifbar, wenn diese Vervielfältigung durch eine besondere Bestimmung des Urheberrechts gerechtfertigt wäre. Insoweit könnte nur § 15 Abs 2 LitUrhG in Betracht kommen, wonach eine Vervielfältigung zum persönlichen Gebrauch zulässig ist, wenn sie nicht den Zweck hat, aus dem Werk eine Einnahme zu erzielen.

....

IV. Die Entscheidung der Frage, ob Magnettonaufnahmen urheberrechtlich geschützter Werke nicht der Erlaubnis des Urheberberechtigten bedürfen, wenn sie nur für den persönlichen Gebrauch und ohne Einnahmezweck hergestellt werden, hängt somit allein davon $a b$, ob diese besondere Vervielfältigungsart noch in den Anwendungsbereich des $\S 15$ Abs 2 LitUrhG fällt.

a) Es ist dem Berufungsgericht beizupflichten, daß dem reinen Wortlaut nach die Herstellung solcher Magnettonaufnahmen durch $\S 15$ Abs 2 LitUrhG gedeckt ist. . . . .

b) Bei der Abgrenzung des Anwendungsbereichs des § 15 Abs 2 LitUrhG ist jedoch zu beachten, daß weder bei Schaffung des Gesetzes von 1901 noch bei Erlaß der Novelle von 1910 die Möglichkeit bekannt war, im häuslichen Bereich durch einen einfachen, keine technischen Vorkenntnisse erfordernden rein mechanischen Vorgang Aufführungen aller Art auf Magnettonbänder zu übertragen, welche die festgelegte Aufführung in einwandfreier Lautstärke und völlig naturgetreu wiedergeben. Zwar war ein Verfahren, Schallwellen auf einem magnetisierten Draht festzuhalten, bereits um die Jahrhundertwende von dem Dänen Poulsen erfunden worden und dieses Verfahren war auch in Deutschland durch mehrere deutsche Patente (Petersen und Poulsen) in den Jahren 1898 bis 1902 bekannt geworden. Diese Erfindungen gewannen jedoch wegen der ungenügenden Lautstärke der Wiedergabe zunächst keine praktische Bedeutung. Erst Ende der zwanziger Jahre hat dieses Verfahren erstmalig bei größeren Rundfunksendern und bei der Tonfilmherstellung Verwendung gefunden. Für die private Vervielfältigung ist dieses Verfahren auf elektromagnetischer Grundlage erst durch die seit einigen Jahren im Handel befindlichen Selbstaufnahmegeräte bedeutsam geworden (Mediger GRUR 1951, 385).

Es handelt sich somit bei der Vervielfältigung eines Werkes mittels solcher Selbstaufnahmegeräte um einen Sachverhalt, der bei Erlaß des $\S 15$ Abs 2 LitUrhG im Jahre 1901 wie auch bei der Anderung des Gesetzes im Jahre 1910 außerhalb des Vorstellungskreises des Gesetzgebers lag. Für die Frage, ob dieser Vervielfältigungsvorgang, der einen vom Gesetzgeber nicht in Betracht gezogenen neuen Tat- 
bestand darstellt, noch von dem Sinngehalt dieser Gesetzesnorm erfaßt wird, ist nicht entscheidend, ob es sich bei dem Magnettonverfahren - rein technisch gesehen - um ein völlig neuartiges Verfahren oder nur um eine verfeinerte Art der schon 1910 bekannten mechanischen Vervielfältigungsmethoden handelt. Denn im Streitfall geht es nicht um die technischen Gesetze des Vervielfältigungsvorganges, sondern um seine Verlegung in den privaten Bereich durch Selbstaufnahmegeräte der von der Beklagten vertriebenen Art, die dem privaten Benutzer die Herstellung einzelner Vervielfältigungsstücke zum persönlichen Gebrauch ohne wesentlichen Aufwand an Zeit oder Mühe durch eine einfache, rein mechanische Handhabung dieses Gerätes ermöglichen. Der Gesetzgeber konnte bei den ihm 1910 bekannten Arten der mechanischen Festlegung einer Aufführung - insbesondere den Schallplatten - wegen des kostspieligen und mühsamen, besondere Kenntnisse voraussetzenden Vervielfältigungsvorganges nicht damit rechnen, die Herstellung einzelner Stücke solcher Vervielfältigungen für persönliche Gebrauchszwecke könnte ernsthaft in Betracht kommen. Es bleibt somit zu prüfen, ob durch den neuen Sachverhalt, den die Erfindung des Magnettonverfahrens geschaffen hat, ein urheberrechtlich bedeutsamer, vom Gesetzgeber nicht gesehener Interessenkonflikt aufgetreten ist, dessen Lösung nicht aus $\S 15$ Abs 2 LitUrhG entnommen werden kann, weil er nicht mehr unter den Interessenausgleich fällt, den allein der Gesetzgeber mit dieser Rechtsnorm angestrebt hat.

Entgegen der Auffassung der Beklagten muß auch gegenüber einem sprachlich eindeutigen Wortlaut eine Auslegung nach dem Sinn und Zweck des Gesetzes Platz greifen, wenn der zur Entscheidung stehende Interessenkonflikt bei Erlaß des Gesetzes noch nicht ins Auge gefaßt werden konnte, weil er erst durch die Veränderung der tatsächlichen Verhältnisse nach diesem Zeitpunkt in Erscheinung getreten ist (vgl BGHZ 2, 176 [184]). Die Bindung des Richters an Gesetz und $R$ e c h t (Art 20 Abs 2 GrundG) gestattet dem Richter nicht nur, das Recht im Sinne seiner Weiterentwicklung durch Auslegung des gesetzten Rechts fortzubilden, sondern verpflichtet ihn sogar dazu, wenn die Findung einer gerechten Entscheidung dies erfordert (BGHZ 3, 308 [315]). Höher als der Wortlaut des Gesetzes steht sein Sinn und Zweck. Diesen im Einzelfall der Rechtsanwendung nutzbar zu machen und danach unter Berücksichtigung von Treu und Glauben den Streitfall einer billigen und vernünftigen Lösung zuzuführen, ist die Aufgabe des Richters (so RGZ 142, 36 [40 f]).

Es handelt sich hierbei um ein Problem ider Rechtsfindung, das sich der Rechtsprechung gerade auf dem Gebiet des Urheberrechtes durch die rasch fortschreitende Entwicklung der Technik, die eine Anpassung der aus der Jahrhundertwende stammenden Urhebergesetze an die veränderten Verhältnisse erforderlich machte, bereits mehrfach gestellt hat. Vom urheberrechtlichen Blickpunkt aus ist bedeutsam für die Gesetzesauslegung nicht der technische Fortschritt als solcher, der durch die neuen technischen Errungenschaften erzielt worden ist, sondern dessen $\mathrm{A}$ u s wirkungen auf die- jenigen Rechtsverhältnisse, die durch die Urheberrechtsgesetzgebung geregelt werden sollten. Jedem Gesetz liegt eine Interessenabwägung zugrunde, die in bestimmter Weise auf das soziale Leben einwirken will. Sollen neue Tatbestandsgruppen, die bei Erlaß des Gesetzes noch nicht bekannt waren, dem Gesetz eingreordnet werden, so ist zu prüfen, ob eine Gesetzesbestimmung, die ihrem buchstäblichen Sinn nach diesen neuen Sachverhalt erfaßt, auf ihn auch nach dem ihr zugrundeliegenden Rechtsgedanken angewendet werden kann. Auszugehen ist hierbei von dem Interessenkonflikt, den die fragliche Rechtsnorm vorfand, und dem Interessenausgleich, den sie herbeiführen wollte.

Es fragt sich somit im Streitfall, ob nach Sinn und Zweck des § 15 Abs 2 LitUrhG und der für diese Bestimmung maßgebenden Wertentscheidung unter Berücksichtigung der aus dem Gesamtsystem des Urheberrechts zu entnehmenden Wertungen es gerechtfertigt und geboten erscheint, durch eine einschränkende Auslegung dieser Gesetzesbestimmung den von dem Gesetzgeber nicht ins Auge gefaßten Tatbestand der Aufnahme eines urheberrechtlich geschützten Werkes auf Magnettonband von der Vervielfältigungsfreiheit zum persönlichen Geibrauch auszunehmen.

c) Der Umstand, daß diese Befugnislücke in dem Vervielfältigungsrecht des Urhebers gesetzestechnisch als eine Ausnahme gefaßt ist, vermag allein noch nicht eine einschränkende Auslegung zu rechtfertigen. Es ist vielmehr zu untersuchen, ob sich diese Gesetzesbestimmung auch sachlichrechtlich als eine echte Ausnahme von den das Urheberrecht beherrschenden Grundgedanken darstellt oder ob es sich um eine im Wesen des Urheberrechtes liegende Begrenzung der Herrschaftsmacht des Werkschöpfers über sein Geistesgut handelt.

1. Eine echte, in der Natur der Sache liegende Grenze des Ausschließlichkeitssrechtes des Urhebers würde vorliegen, wenn die Ansicht der Beklagten zuträfe, daß die Rechte des Urhebers stets vor dem Interesse des Einzelnen an einer Freihaltung seiner privaten Sphäre von urheberrechtlichen Ansprüchen zurücktreten müßten. Ein solcher Grundsatz kann aber in dieser Allgemeinheit dem Urheberrecht nicht entnommen werden. So ist es anerkannten Rechtes, daß das Urheberpersönlichkeitsrecht auch innerhalb der privaten Sphäre zu achten ist. Auch im häuslichen Bereich darf niemand unter Verletzung der persönlichkeitsrechtlichen Interessen des Urhebers dessen Werk verändern oder das Recht des Werkschöpfers auf Anerkennung seiner Urheberschaft schmälern. Zu Unrecht will die Beklagte aus der Regelung, die für die $\mathrm{gew}$ e $\mathrm{rbli}$ c he $\mathrm{n}$ Schutzrechte getroffen worden ist ( $\$ 6 \mathrm{PatG}$; $\$ 5$ GeschmMG) folgern, auch die dem Urheber vorbehaltenen Werknutzungsrechte könnten sich ihrem Wesen nach nicht auf die private Nutzung seines Werkes erstrecken. Dieser Vergleich mit den gewerblichen Schutzrechten verkennt, daß es sich auf dem Gebiet des gewerblichen Rechtsschutzes um andere Rechtsgüter handelt als im Urheberrecht. Schutzobjekt des Urheberrechtes ist ein immaterielles Gut, das seiner wesensgemäßen Zweckbe- 
stimmung nach in der Regel vorwiegend dem geistigen oder ästhetischen Genuß des Einzelnen dient, der seiner Natur nach bei vielen Geisteswerken ausschließlich im rein privaten Bereich stattfindet.

Wenn sich in allen Kulturstaaten mehr und mehr die Erkenntnis gefestigt hat, daß der Urheber eines Geisteswerkes Anspruch nicht nur auf einen Schutz der persönlichen Beziehungen zu seinem Werk, sondern auch auf die gesetzliche Sicherung eines gerechten wirtschaftlichen Lohnes für seine Leistung hat, so ist es letztlich gerade der Werkgenuß des Einzelnen - gleichgültig, ob dieser Werkgenuß in der Offentlichkeit oder im häuslichen Bereich stattfindet -1 der die innere Rechtfertigung für den Anspruch des Urhebers auf eine angemessene Vergütung bildet. In der Befriedigung des Kunstverlangens des Einzelnen liegt die Dankesschuld verankert, die es an den geistig Schaffenden seitens der Allgemeinheit durch einen wirksamen Rechtsschutz seiner persönlichen und wirtschaftlichen Interessen an seiner Schöpfung abzutragen gilt. Die dem früheren Privilegienwesen zugrunde liegende Rechtsvorstellung, dem Urheber stehe ein wirtschaftlicher Nutzen aus seiner Geistesschöpfung nur insoweit $\mathrm{zu}$, als ihm der Gesetzgeber durch eine in seinem Ermessen stehende Verleihung von ausschließlichen Nutzungsrechten einen solchen Ertrag zubillige, ist durch die Lehre vom geistigen Eigentum, das dem Urheber durch die Schöpfung des Werkes zuwächst, in allen Kulturstaaten seit langem überwunden. Für das moderne Urheberrecht wird allseitig anerkannt, daß die Nutzungsrechte des Urhebers nur die Ausstrahlungen seines durch den Schöpfungsakt begründeten geistigen Eigentums sind. Die Herrschaft des Urhebers über sein Werk, auf den sich sein Anspruch auf einen gerechten Lohn für eine Verwertung seiner Leistung durch Dritte gründet, wird ihm hiernach nicht erst durch den Gesetzgeber verliehen, sondern folgt aus der Natur der Sache, nämlich aus seinem geistigen Eigentum, das durch die positive Gesetzgebung nur seine Anerkennung und Ausgestaltung findet. Dieser das Urheberrecht beherrschende Rechtsgedanke ist bei der Auslegung urheberrechtlicher Gesetzesnormen stets im Auge zu behalten (vgl Ulmer aaO S 35-46, S 59 ff). Er kommt sowohl in der Präambel und in Art 1 des Welturheberrechtsabkommens vom 6. September 1952, das von Deutschland mitunterzeichnet wurde (Bl. f. PMZ 1952, 440; HaertelSchneider, Taschenbuch des Urheberrechts 1955 S 246) zum Ausdruck, wie auch in Art 27 Abs II der Allgemeinen Erklärung der Menschenrechte der Vereinten Nationen, in der Fassung vom 10. Dezember 1948, der die deutsche Bundesrepublik beigetreten ist (Bundesanzeiger $1952 \mathrm{Nr} 89 \mathrm{~S} \mathrm{7)}$. Diese Bestimmung lautet: "Jeder hat Anspruch auf Schutz der ideellen und Vermögensinteressen, die sich aus seiner wissenschaftlichen, literarischen oder künstlerischen Urheberschaft ergeben."

Es bedeutet auch durchaus keine grundsätzliche Entscheidung des Gesetzgebers zugunsten der Freihaltung des privaten Bereichs von der Ausübung urheberrechtlicher Befugnisse, wenn er die Nutzungsrechte des Urhebers, soweit die Aufführung, die Vorführung oder der Vortrag seines Werkes in Frage steht, auf die öffentliche Ausübung dieser Befugnisse beschränkt hat. Denn dies erklärt sich allein daraus, daß bei der Eigenart dieser Werknutzung keine wesentliche Einbuße des Urhebers zu befürchten steht, wenn sie bei Vornahme im privaten Bereich von der Vergütungspflicht freigestellt wird. Damit wird aber keineswegs im Grundsatz dem Werkschöpfer jeglicher wirtschaftliche Ertrag aus dem Genuß seines Werkes im häuslichen Bereich abgeschnitten. Denn das Bedürfnis nach einem Werkgenuß in der privaten Sphäre kann in der Regel nur befriedigt werden, indem Vervielfältigungsstücke des Werkes (z. B. Noten, Schallplatten) erworben und mit der Entrichtung des Kaufpreises für das Werkstück gleichzeitig die Vergütungspflicht des gewerblichen Vervielfältigers abgegolten wird. Es trifft somit nicht den Kern des hier zu entscheidenden Problems, wenn geltend gemacht wird, daß nach urheberrechtlichen Grundsätzen der Werkgenuß im privaten Kreis frei von einer Urhebervergütung sei. Der Gesetzgeber konnte nur nach dem damaligen Stand der technischen Entwicklung davon ausgehen, daß es zum wirtschaftlichen Schutze der Leistung des Urhebers ausreicht, wenn der Urheber nicht in ein unmittelbares Verhältnis zu dem privaten Nutzer seiner Leistung gebracht wird, sondern die Vergütungspflicht dem Werkmittler, also dem Verleger, dem Veranstalter der öffentlichen Aufführung oder dem Schallplattenhersteller auferlegt wird, der dann - wirtschaftlich gesehen - durch entsprechende Preiskalkulation die Urhebervergütung von demjenigen einzieht, dem die Leistung des Urhebers entsprechend ihrer wesensgemäßen Zweckbestimmung - durch ihren rein ideellen GenuB zugute kommt. Der Werkgenuß, den die private Aufführung eines Werkes vermittelt, wird in der Regel mit dem Erwerb des grundsätzlich mit einer Urhebergebühr belasteten Vervielfältigungsexemplars abgegolten, so daß die Freistellung der nichtöffentlichen Aufführung von einer Urhebervergütung in Wahrheit nur den Sinn hat, eine doppelte Leistung zu verhindern (vgl Troller: "Anspruch des Urhebers auf Entgelt für den privaten Werkgenuß", Schweizerische Mitteilungen für gewerblichen Rechtsschutz und Urheberrecht 1951, 53 [56]). Gerade weil aber die private Werknutzung im allgemeinen von dem Besitz eines Vervielfältigungsstückes abhängig ist, war es geboten, dem Urheber das $\mathrm{V}$ e r vi e lfältigungsrecht ohne Begrenzung auf die gewerbliche oder öffentliche Sphäre vorzubehalten, wollte man nicht sein Recht auf ein gerechtes Entgelt für den Werkgenuß im häuslichen Bereich ernsthaft gefährden.

Wäre es richtig, daß nach dem Grundgedanken des Urheberrechtes die private Sphäre eine unüberschreitbare Schranke für die Nutzungsrechte des Urhebers und damit praktisch für seinen Vergütungsanspruch bildete, so würde der Urheber aus allen Werken, die vorwiegend für den Werkgenuß im privaten Bereich geschaffen werden, wie dies vor allem für die Werke der Literatur zutrifft, kaum noch wirtschaftliche Früchte aus seiner Arbeit ziehen können, sobald die Technik es dem einzelnen 
ermöglicht, ohne besondere Kosten und Mühen Werkstücke im häuslichen Bereich selbst herzustellen, die einen einwandfreien Werkgenuß vermitteln und den gewerblich hergestellten Vervielfältigungsstücken gleichwertig sind. Schon diese Uberlegung zeigt, daß es mit urheberrechtlichen Grundsätzen unvereinbar ist, anzunehmen, der Schutz der privaten Sphäre verbiete es schlechthin, dem Urheber ein Entgelt für seine Werkschöpfung zufließen zu lassen, wenn die Nutzung des Werkes sich ausschließlich im privaten Raum abspielt. Nach dem Grundgedanken des Urheberrechtes, das vor allem auch die wirtschaftlichen Belange des geistig Schaffenden sichern will, ist bei einem solchen Interessenwiderstreit zwischen der schöpferischen Sphäre des Urhebers und der privaten Sphäre des Werknutzers vielmehr der schöpferischen Sphäre, ohne die eine Werknutzung überhaupt nicht möglich wäre, der Vorzug zu geben, wie dies das Reichsgericht für den Fall des Zusammentreffens persönlichkeitsrechtlicher Interessen des Urhebers mit Belangen des Sacheigentümers eines Kunstwerkes bereits im Jahre 1912 anerkannt hat (RGZ 79, 397).

So ergibt denn auch $\S 15$ Abs 1 LitUrhG mit aller Deutlichkeit, daß grundsätzlich jede Vervielfältigung ohne Einwilligung des Urhebers verboten ist, gleichgültig, ob der Vervielfältigungsvorgang privat, öffentlich oder gewerbsmäßig vor sich geht. $\S 15$ Abs 2 LitUrhG stellt, wie bereits hervorgehoben wurde, nicht auf den Vervielfältigungsvorgang als solchen, sondern allein auf den Gebrauchszweck der Vervielfältigung ab (de Boor, GRUR 1954, 440 [444]). Werden innerhalb der privaten Sphäre Vervielfältigungsstücke zu dem Zweck, sie gewerbsmäßig zu vertreiben, hergestellt, so stellt dies unbestritten eine Urheberverletzung dar. Auch die Kontrolle solcher Vervielfältigungsvorgänge setzt aber in gewissem Umfang ein Eindringen in den privaten Bereich voraus, ohne daß hieraus jemals die Zulässigkeit derartiger Vervielfältigungen gefolgert worden wäre, wie auch die Uberprüfung des Rundfunkempfanges durch sogenannte Schwarzhörer stets unbeanstandet hingenommen worden ist. Es kann demnach nicht, wie die Beklagte geltend macht, der tragende Sinn der Freigabe der Vervielfältigung zum persönlichen Gebrauch gewesen sein, die private Sphäre des Werknutzers vor Ansprüchen des Urhebers abzuschirmen.

2. Aber auch die weitere Voraussetzung, die $\S 15$ Abs 2 LitUrhG für die Vervielfältigungsfreiheit vorsieht - das Fehlen eines Einnahmezwedkes setzt dem Vervielfältigungsrecht des Urhebers nicht etwa eine allen urheberrechtlichen Ausschließlichkeitsrechten wesensgemäße Schranke. Aus der gesetzlichen Regelung, die die Werknutzungsrechte des Urhebers gefunden haben, kann nicht etwa entnommen werden, der Gesetzgeber habe den Urheber grundsätzlich nur an dem geldwerten Gewinn aus seiner Leistung beteiligen, $\mathrm{ihm}$ aber keinen Vergütungsanspruch für die ohne unmittelbaren wirtschaftlichen Nutzen erfolgende Auswertung seiner Leistung zubilligen wollen. Der in Rechtsprechung und Schrifttum anerkannte Leitgedanke des Urheberrechts, daß der Urheber tunlichst angemessen an den wirts chaftlichen Früchten zu beteiligen sei, die aus seinem Werk gezogen werden (BGHZ 11, 135 [143]; BGHZ 13, 115 [118]) stellt nur eine $\mathrm{M}$ ind e s t forderung zum Schutz der materiellen Belange des Urhebers dar und ist auf das im Urheberrecht herrschende System der gewerbsmäßigen Werkvermittlung zugeschnitten. Dieser Leitgedanke berechtigt jedoch nicht $\mathrm{zu}$ dem Gegenschluß, daß dem Urheber für seine Leistung, wenn sie ohne unmittelbaren wirtschaftlichen Nutzen ausgewertet wird, eine Vergütung nicht gebühre (BGHZ 13, $115[120,124,126 \mathrm{ff}])$. Eine solche Auffassung würde auf eine Aushöhlung der Nutzungsrechte des Urhebers hinauslaufen, soweit die Vorgänge, die bisher seinen Vergütungsanspruch auslösten, durch die Entwidklung der Technik völlig in die private Sphäre verlegt werden.

3. Damit ist klargestellt, daß es sich bei der Vervielfältigungsfreiheit nach $\S 15$ Abs 2 LitUrhG um eine e chte Ausnahme von dem Grundgedanken des Gesetzes handelt, nach dem dem Urheber ein wirtschaftlicher Ertrag auch aus dem privaten Werkgenuß - wenn auch in der Regel mittelbar über die Tantiemepflicht des Werkmittlers zufließen soll. Dann aber darf diese Einschränkung des Vervielfältigungsrechtes des Urhebers nicht über ihren eigentlichen Sinn und Zweck hinaus erstreckt werden.

a) Der mit dieser Ausnahmebestimmung verfolgte Zweck kann nur aus der tatsächlichen und rechtlichen Lage, die der Gesetzgeber bei Erlaß dieser Bestimmung vorfand, entnommen werden. Das Literarische Urhebergesetz vom 11. Juni 1870 enthielt keine dem $\S 15$ Abs 2 LitUrhG entsprechende Bestimmung. $\S 4$ dieses Gesetzes lautete: "Jede mechanische Vervielfältigung eines Schriftwerkes, welche ohne Genehmigung des Berechtigten hergestellt wird, heißt Nachdruck und ist verboten." Das Abschreiben war gestattet, sofern es nicht bestimmt war, "den Drudk zu ersetzen." Infolge der damals noch unvollkommenen Entwicklung der mechanischen Musikinstrumente enthielt das Gesetz von 1870 keine besonderen Bestimmungen über den Schutz von Werken gegen ihre Ubertragung auf Schallvorrichtungen. Unter der Herrschaft dieses Gesetzes hat jedoch das Reichsgericht bereits in ständiger Rechtsprechung den Standpunkt vertreten, daß auswechselbare Tonträger wie Nachdrucksstüdke zu behandeln seien, deren Herstellung und Verwertung nur mit Erlaubnis des Urhebers zulässig sei (RGZ 22, 174; 27, 60; RGSt 32, 41). Das Gesetz betreffend das Urheberrecht an Werken der Literatur und Tonkunst vom 19. Juni 1901 wollte die Rechtslage der Urheber im Bezug auf das Vervielfältigungsrecht gegenüber dem nach dem Literarischen Urhebergesetz von 1870 gegebenen Rechtszustand $v$ e $r$ b e s s e r $n$, indem es dem Urheber auch die $\mathrm{nichtm}$ e chanis che Vervielfältigung vorbehielt. Andererseits sollte "die Möglichkeit gewahrt bleiben ", Abschriften für den persönlichen Gebrauch anzufertigen, wobei der Gesetzgeber vor allem an Mitglieder von Gesangoder Theatervereinen gedacht hat, die sich für unentgeltliche Aufführungen Abschriften und Auszüge von Noten und Rollen eines Bühnenwerkes anfertigen wollten. In der amtlichen Begründung des 
zweiten Entwurfs (Regierungsvorlage, Reichstagsverhandlungen, 10. Legislaturperiode II. Session 1900/1901, 1. Anlagenband Nr. 97 der Aktenstücke) heißt es u. a.:

„Die rechtswidrige Vervielfältigung wird vom Entwurfe dem hergebrachten Sprachgebrauche gemäß als Nachdruck bezeichnet. Unter diesen Begriff fällt jedoch, wie sich aus $\S 15$ Abs 1 ergibt, nicht nur die mechanische Vervielfältigung im Sinne des $\S 4$ des Gesetzes vom 11. Juni 1870. Vielmehr soll grundsätzlich jede Vervielfältigung dem Urheber vorbehalten bleiben, so daß es seiner Einwilligung bedarf, selbst wenn es sich um ein einzelnes Exemplar handelt und wenn das Exemplar auf anderem als mechanischem Wege hergestellt werden soll. Eingriffe in die berechtigten Interessen des Urhebers sind durch das geltende Gesetz nicht vollständig ausgeschlossen, namentlich darf, wie die Rechtsprechung annimmt, von den verschiedenen Stimmen einer Opernpartitur je eine Abschrift ohne $\mathrm{Zu}-$ stimmung des Komponisten hergestellt und zur öffentlichen Aufführung des Werkes benutzt werden. Die neue Vorschrift beseitigt diesen Mißstand. Andererseits muß aber die Möglichkeit gewahrt bleiben, Abschriften für den eigenen Privatgebrauch anzufertigen. Der $\S 15$ Abs 2 erklärt deshalb eine Vervielfältigung für statthaft welche nur dem persönlichen Gebrauche dient und auch nicht den Zweck hat, aus dem Werke eine Einnahme zu erzielen; daß die Vervielfältigung auf nichtmechanischem Wege bewirkt wird, ist dabei nicht vorausgesetzt. Hiernach dürfen Mitglieder von Gesang- oder Theatervereinen Abschriften und Abzüge von Noten oder den Rollen eines Bühnenwerkes herstellen, um sie für Aufführungen $\mathrm{zu}$ benutzen, $\mathrm{zu}$ denen die Hörer ohne Entgelt zugelassen werden (§ 27 Abs 1 Satz 1 des Entwurfes). Soll dagegen mittels der Aufführung eine Einnahme erzielt werden, so muß das Nachdrucksverbot Platz greifen, weil sonst die Verwertung des Werkes im Wege des Verlages empfindlich beeinträchtigt würde."

b) Nach dieser Begründung ging es dem Gesetzgeber in Warheit nur darum, das Vervielfältigungsrecht zum persönlichen Gebrauch i m b is h e r igen $\mathrm{Umfange}$ bestehen $\mathrm{zu}$ lassen. Hierbei war sein Anliegen im wesentlichen, im Interesse der Musikpflege und aus sozialen Gründen einem beschränkten Kreis kapitalschwacher Musikausübender die gebührenfreie Vervielfältigung von Noten mittels Abschriften zu ermöglichen (vgl hierzu Verhandlung des Deutschen Reichstages 1900/ 1902, 10. Legislaturperiode, II. Session, 2. Anlageband Aktenstück 214 Seite 1282). Da andererseits auf Betreiben der Industrie für mechanische Musikinstrumente die Ubertragung von erschienenen Werken der Tonkunst auf mechanische Vorrichtungen - abgesehen von der sogenannten Pianolaklausel - allgemein, d. h. ohne Beschränkung auf persönliche Gebrauchszwecke vom Urheberschutz freigestellt wurde $(\S 22 \mathrm{MitUrhG}$ von $1901 ; \mathrm{vgl}$ hierzu BGHZ 11, 135 [141]), bestand für den Gesetzgeber von 1901 schon aus diesem Grunde keine Veranlassung, bei der Abfassung des $\S 15$
Abs 2 diese besondere Vervielfältigungsart $\mathrm{zu}$ berücksichtigen. Aber auch daraus, daß durch die Novelle vom 22. Mai 1910 die Vervielfältigung mittels Tonträger nicht ausdrücklich von der Regelung des $\S 15$ Abs 2 LitUrhG ausgenommen worden ist, obwohl durch diese Novelle $\S 22$ des Gesetzes von 1901 beseitigt und u. a. die Vorschriften der $\S \S 2$ Abs 2, 12 Abs 2 Nr. 5 in das Gesetz eingefügt wurden, kann nicht entnommen werden, der Gesetzgeber habe die Festlegung urheberrechtlich geschützter Werke auf Schallvorrichtungen in den Anwendungsbereich dieser Ausnahmevorschrift einbeziehen wollen. Es ist vielmehr den Vorinstanzen beizupflichten, daß der Gesetzgeber von 1910 nach dem damaligen Stand der Technik ebensowenig wie im Jahre 1901 daran gedacht hat, es werde technisch und auch wirtschaftlich ernsthaft in Betracht kommen, einzelne Tonaufnahmen nur für persönliche Gebrauchszwecke herzustellen. Die Herstellung der damals bekannten Formen mechanischer Vervielfältigung der Aufführung von Sprach- und Tonkunstwerken, insbesondere der Schallplatte, erforderten so erhebliche Geldmittel, und technische Vorkenntnisse, daß die Anfertigung nur einzelner Vervielfältigungsstücke für den persönlichen $\mathrm{Ge}-$ brauch praktisch ausschied. Wenn der Gesetzgeber von 1910 somit die Utbertragung der Aufführung eines Werkes auf Schallvorrichtungen nicht ausdrücklich von der Vervielfältigungsfreiheit für den persönlichen Gebrauch ausnahm, so erklärt sich dies daraus, daß bei den damals bekannten Arten solcher Tonträger angesichts der technischen Schwerfälligkeit und der Kostspieligkeit des Vervielfältigungsverfahrens die Annahme fern lag, diese könnten in einzelnen Exemplaren für den persönlichen Gebrauch hergestellt werden. Der Gesetzgeber konnte vielmehr davon ausgehen, daß bei derf Vervielfältigungsarten, die bei Schaffung des Gesetzes allein für eine nichtgewerbliche Vervielfältigung in Betracht kamen, die Freigabe der privaten Vervielfältigungen keine ins Gewicht fallende Beeinträchtigung der wirtschaftlichen Interessen des Urhebers zur Folge haben würde. Denn die Notenabschriften konnten wegen ihrer schlechten Lesbarkeit nicht ernsthaft mit Druckexemplaren in Wettbewerb treten. Sie eigneten sich in der Regel auch nicht für die Festlegung komplizierterer Kompositionen für mehrere Instrumente. Ihre Anfertigung kam, wegen der Umständlichkeit und Mangelhaftigkeit des Verfahrens, in der Regel nur für solche Personen in Betracht, die sich den Ankauf von Druckexemplaren nicht leisten konnten, also von vornherein wegen ihrer schlechten finanziellen Lage als Käufer von Notenblättern oder Büchern ausfielen.

c) Die von der Beklagten vertretene Auffassung, $\S 15$ Abs 2 LitUrhG müsse auch auf private Magnettonaufnahmen Anwendung finden, kann sich weder auf den dargelegten allgemeinen Sinn noch den besonderen Zweck dieser Ausnahmebestimmung berufen, die Musikausübung durch minderbemittelte Musikliebhaber zu erleichtern. Denn für die private Bandaufnahme mittels eines Magnettongerätes kommt bei den noch beträchtlichen Anschaffungskosten dieser Apparate nur eine Bevöl- 
kerungsschicht in Frage, die des durch $\S 15$ Abs 2 angestrebten sozialen Schutzes nicht bedarf. Die Freistellung der privaten Bandaufnahme von einer Urhebervergütung würde aber auch nicht der Musikpflege durch $\mathrm{Musik}$ a u übende dienen. Während die privaten Vervielfältigungen, die der Gesetzgeber nach dem damaligen Stand der Technik allein in Betracht ziehen konnte, das Werk nur in Sinnbildern, die dem Auge wahrnehmbar sind, festlegten und es zum vollen Werkgenuß noch der Aufführung bedurfte, die besondere Fähigkeiten voraussetzt, wird auf dem Magnettonband nicht nur das Werk, sondern zugleich auch dessen Aufführung festgehalten. Zum Genuß des Werkes genügt die Hörbarmachung der Vervielfältigung, ein Vorgang, der keinerlei musikalisches Verständnis oder Können voraussetzt, sondern auf rein mechanischem Wege ausgelöst wird. Daß Musikliebhaber dieses Verfahren a u c h zu dem Zweck benützen können, um durch Aufnahme und Wiedergabe ihr Spiel oder ihre Stimme zu überprüfen und zu verbessern, kann gegenüber der unbeschränkten Verwendbarkeit des Verfahrens für jedermann um so weniger ins Gewicht fallen, als es sich auch insoweit um eine zusätzliche Nutzung handelt, für die bislang keine Möglichkeit bestand.

Eine Vervielfältigungsfreiheit für private Bandaufnahmen würde somit einen völlig anderen Personenkreis begünstigen, als dies in der Absicht des Gesetzgebers gelegen hat. Sie würde darüber hinaus schon deshalb einen viel einschneidenderen Einbruch in das Vervielfältigungsrecht des Urhebers bedeuten, als es den Vorstellungen des Gesetzgebers entsprach, weil die Vervielfältigung von jedem mühelos vorgenommen werden kann und das Interesse an dem Besitz solcher Vervielfältigungsstücke sich nicht auf den Kreis der Musikausübenden beschränkt.

d) Können hiernach die besonderen Zwecke, die der Gesetzgeber nach den Gesetzesmaterialien mit der Freigabe der Vervielfältigung für den persönlichen Gebrauch verfolgt hat, für die Zulässigkeit privater Magnettonaufnahmen nicht herangezogen werden, so bleibt zu prüfen, ob diese neuartige Vervielfältigungsart nach den maßgebenden Wertentscheidungen, die das Urheberrecht in dem Widerstreit zwischen den Belangen der Urheber und der Allgemeinheit getroffen hat, in die zu Lasten des Urhebers geschaffene Ausnahmevorschrift einzubeziehen ist. Es wurde bereits dargelegt, daß das Interesse des Einzelnen, innerhalb seiner privaten Sphäre nach freiem Belieben mit Urhebergut verfahren zu dürfen, keine grundsätzliche Schranke für den dem Urheber gebührenden Rechtsschutz bildet. Andererseits ist nach dem Schutzgedanken, der das Urheberrecht beherrscht, davon auszugehen, daß die durch die Entwicklung der Technik herbeigeführte Erschließung neuer Nutzungsmöglichkeiten für Urhebergut vor allem den Urhebern zugute kommen soll, deren schöpferischer Tätigkeit dieses Gut $\mathrm{zu}$ danken ist (vgl RGZ 118, 282 [Verfilmung]; RGZ 123, 312 [Rundfunksendung]; BGHZ 11, 135 [143]). Selbst wenn, wie die Beklagte geltend macht, die privaten $\mathrm{Ma}-$ gnettonaufnahmen die Einnahmen der Urheber aus dem Schallplatten- oder Notengeschäft nicht mindern sollten, sondern nur ein neues, zusätzliches Musikbedürfnis befriedigen, würden die Werkschöpfer durch eine Befreiung dieser Vervielfältigungsart von jeglicher Urhebervergütung eine nach urheberrechtlichen Grundsätzen nicht gerechtfertigte wirtschaftliche Einbuße erleiden. Das Reichsgericht hat bereits im Jahre 1891 ausgesprochen, daB neue Arten der mechanischen Vervielfältigung nicht deshalb vom Verbot des Nachdrucks frei sind, weil sie das geistige Produkt einem weiteren Kreis von Menschen zuführen (RGZ 27, 60 [64]). Die Auffassung der Beklagten wäre auch mit dem gesetzgeberischen Ziel der Novelle von 1910 unvereinbar, das dahin geht, dem Werkschöpfer durch Erstreckung seines ausschließlichen Vervielfältigungsrechts auf die Ubertragung seines Werkes auf Tonträger einen wirtschaftlichen Nutzen gerade auch aus dem Werkgenuß im privaten Bereich zu sichern, der an den Besitz solcher Werkstücke anknüpft. Denn praktisch würde es zu einer weitgehenden Entwertung der mechanischen Rechte der Musikschaffenden führen, wenn die Urhebergebühr für die Herstellung solcher Schallträger nur deshalb entfallen sollte, weil sich mit Hilfe komplizierter technischer Apparaturen der nunmehr nur noch rein automatisch zu bewirkende Vervielfälti gungsvorgang a us dem gewerblichen in den privaten sektor verlagert hat. Dies würde einen Rückschritt gegenüber dem Rechtszustand von 1870 bedeuten, unter dessen Herrschaft das Reichsgericht ausgeführt hat: "Die Möglichkeit der Benutzung der Komposition auf anderem als von dem Urheber genehmigten Wege soll erschwert werden dadurch, daß die ohne diese Genehmigung ins Leben gerufene mechanische Vervielfältigung des in dauernden Zeichen fixierten Tonwerks und der Vertrieb der so hergestellten Exemplare verboten ist" (RGZ 27, 60 [66]).

e) In diesem Zusammenhang ist auch zu berücksichtigen, daß die Magnettonaufnahme auf Grund ihrer Vollkommenheit und ihrer unbegrenzten Haltbarkeit, die sie gewerblichen Vervielfältigungen gleichstellt, uneingeschränkt verke h r s fä h i g ist, wodurch sich die Gefahren für den Urheber im Vergleich zu der von dem Gesetzgeber allein ins Auge gefaßten unzulänglichen privaten Vervielfältigungsmöglichkeit durch Handabschriften erheblich steigern. $\mathrm{Da}$ es für die Vervielfältigungsfreiheit nach § 15 Abs 2 LitUrhG nur auf die Zweckbestimmung des Erstgebrauchers ankommt, die aus der Beschaffenheit des Magnettonbandes nicht zu ersehen ist, die einmal zulässigerweise hergestellten Tonträger aber, da dem Urheber nur dăs gewerbsmäßige Verbreiten vorbehalten ist, von dem Hersteller verliehen oder verschenkt werden können, die Tonträger auch uneingeschränkt der Pfändung zugänglich sind, sowie durch Erbgang an Dritte gelangen können, fehlt es für den Urheber an jeder einigermaßen zuverlässigen Kontrollmöglichkeit, daß solche ursprünglich nur für den persönlichen Gebrauch hergestellten Schallträger nicht in den Händen Dritter g e w e r b li ch genutzt werden.

f) Es ist dem Berufungsgericht beizupflichten, daß diese weitgehende Gefährdung der wirtschaftlichen 
Belange der Urheber dem Schutzgedanken des Urheberrechtes widerspricht und daß demgegenüber das Interesse der Betroffenen, ihre private Sphäre von urheberrechtlichen Ansprüchen freizuhalten, zurücktreten muß. Bei dieser Interessenabwägung fällt des weiteren auch folgendes ins Gewicht:

Eine ganz wesentliche Einnahmequelle der Komponisten ist die Vergütung, die ihnen aus dem Absatz von Schallplatten zufließt. Auch die Schallplatten sollen weitgehend dem Werkgenuß im privaten Bereich dienen. Das Magnettonband ist nun seiner Natur nach geeignet, mit den mit einer Urhebergebühr belasteten Schallplatten in ernstlichen Wettbewerb zu treten. Das Magnetband ermöglicht die Fixierung einer technisch hochstehenden Aufführung auf rein mechanischem Wege und deren einwandfreie, durch kein Nadelgeräusch beeinträchtigte Widergabe. Es hat gegenüber der Schallplatte den Vorteil längerer Vortragsdauer und größerer Haltbarkeit. Durch die Möglichkeit, das bespielte Band jederzeit $\mathrm{zu}$ löschen und andere Werke auf das Band zu übertragen, erübrigt sich - anders als beim Ankauf von Schallplatten - bei wechselndem Musikbedarf der Erwerb neuer Bänder.

Sollen Schallplatten auf Band überspielt werden, so bedarf es hierzu nicht eines Ankaufs der Schallplatte. Die Ubertragung auf Band ist vielmehr ohne weiteres durch Aufnahme einer Rundfunksendung von Schallplatten durchführbar, ganz abgesehen von der Möglichkeit, sich mit Hilfe geliehener Schallplatten ein Bandarchiv mit den jeweiligen Lieblingsstücken anzulegen. Für den Besitzer eines Magnettongerätes würde somit der Ankauf einer Schallplatte, wie das Berufungsgericht zutreffend hervorhebt, reizlos und überflüssig. Eine Verringerung der Schallplattenumsätze ginge aber zu Lasten der Lizenzgebühren der Urheber.

g) Für die Rechtslage ist es ohne Bedeutung, wie groß der tatsächliche Schaden der Urheber bei dem gegenwärtigen Stand der Verbreitung der Magnettongeräte ist. Entscheidend ist allein, daß diese neuartige private Vervielfältigungsart von Urhebergut ih rem Wesen nach geeignet ist, dem Urheber erheblche wirtschaftliche Nachteile zuzufügen, wenn sie nicht in sein Ausschließlichkeitsrecht einbezogen wird. Besteht aber auch nur die Möglichkeit schweren Schadens für den Urheber, so hat die Gesetzesauslegung das ihrige zu tun, daß er verhütet werde (so RGZ 113, 413, [423]). Die auf § 286 ZPO gestützte Rüge der Beklagten, das Berufungsgericht habe ihren Beweisangeboten über den tatsächlichen Umfang der Beeinträchtigung der wirtschaftlichen Belange der Urheber durch das Magnettonverfahren nachgehen müssen, ist hiernach unbegründet.

h) Wenn schließlich geltend gemacht wird, die Herstellung von Magnetbandaufnahmen im häuslichen Bereich entziehe sich jeder Kontrollmöglichkeit durch die Urheberberechtigten, so stellt dieser Einwand gegenüber der Aufgabe des Gerichts, dasjenige zu ermitteln, was rechtens ist, eine sachfremde Erwägung dar. Das Bestehen eines Rechtsanspruchs kann nicht vom Grade seiner Durchsetzbarkeit abhängen. Zudem übersieht die Beklagte hierbei, daß die Parteien es in der Hand haben, durch geeignete Vorkehrungen und Absprachen die Abgeltung der Ansprüche der Urheber in einer Weise sicherzustellen, die besondere Kontrollmaßnahmen im privaten Bereich entbehrlich macht.

Die Aufnahme von Werken des von der Klägerin verwalteten Musikrepertoires auf Maǵnettonband stellt nach alledem auch dann eine Verletzung der der Klägerin übertragenen urheberrechtlichen Befugnisse dar, wenn sie nur zum persönlichen Gebrauch und ohne Gewinnabsicht erfolgt denn diese private Festlegung der Aufführung eines Werkes kann nach dem Schutzgedanken des Urheberrechts nicht der Ausnahmevorschrift des § 15 Abs 2 LitUrhG unterstellt werden, die nur eine sehr viel engere, wirtschaftlich nicht ins Gewicht fallende Befugnislücke im Ausschließlichkeitsrecht des Urhebers bezweckte.

B. . . . . 


\section{Auszug aus dem Urteil des Bundesgerichthofs vom 24. Juni 1955}

$$
\text { - I ZR 88/54 - (BGHZ 18, S. 44) }
$$

\section{Leitsätze}

1. Die fotomechanische Vervielfältigung (Fotokopie oder Mikrokopie) eines Schriftwerkes ist ohne Einwilligung des Berechtigten auch unter den Voraussetzungen des $\$ 15$ Abs 2 LitUrhG nicht ohne weiteres zulässig. Ob sie allgemein unzulässig ist oder nur dann, wenn zu dem gleichen Zweck eine Vervielfältigung mittels eines der älteren Vervielfältigungsverfahren, insbesondere hand- oder maschinenschriftlich, - vor allem wegen ihres Umfanges - nicht bewirkt worden wäre, bleibt unentschieden.

2. Eine Vervielfältigung wird nur dann mzum persönlichen Gebrauch" im Sinne des § 15 Abs 2 LitUrhG bewirkt, wenn der Gebrauch zum mindesten überwiegend rein persönlichen Bedürfnissen des Gebrauchenden dienen soll.

3. Der Gebrauch, den die Angestellten eines Erwerbsunternehmens im Interesse dieses Unternehmens von Fotokopien und Mikrokopien machen, die das Unternehmen gerade für einen solchen Gebrauch hergestellt hat, geht uber den Rahmen der privaten Gebrauchszwecke hinaus, die allein durch $\S 15$ Abs 2 LitUrhG von dem Vervielfältigungsverbot freigestellt werden sollten.

\section{T a t bestand :}

Der Kläger nimmt als Spitzenorganisation der Verlags- und Buchhändler-Verbände in der Bundesrepublik wirtschaftliche und sonstige Belange seiner Mitglieder wahr. Eine Reihe von Verlegern hat ihm die Verlagsrechte an literarischen Beiträgen, die in von ihnen verlegten Zeitschriften erschienen sind, uneingeschränkt übertragen, damit er im eigenen Namen gegen Verletzungen dieser Verlagsrechte vorgehen könne. Eine solche Verletzung sieht der Kläger in der fotomechanischen Vervielfältigung (Fotokopie und Mikrokopie) von in den Zeitschriften erscheinenden wissenschaftlichen $\mathrm{Ab}$ handlungen. Insbesondere beanstandet er, daß, wie es in zunehmendem Maße geschehe. Erwerbsunternehmen mit eigenen Fotokopierstellen für ihre Werksangehörigen Fotoduplikate von Abhandlungen aus Zeitschriften anfertigen.

Die Beklagte besitzt eigene Fotokopierstellen in Frankfurt/Main und in Berlin, die in der Hauptsache innerbetriebliche Unterlagen vervielfältigen, gelegentlich aber auch zur Vervielfältigung bedeutsamer Abhandlungen aus wissenschaftlichen Zeitschriften benutzt werden, die die Beklagte in einem oder mehreren Stücken regelmäßig bezieht. Sie bedient sich dabei sowohl des Fotokopier- als auch des Mikrofilmverfahrens (Mikrokopie).
Der Kläger hat geltend gemacht: mit der in dieser Weise - ohne Einwilligung der Verleger - stattgefundenen Vervielfältigung von Abhandlungen aus Zeitschriften verletze die Beklagte schuldhaft die an diesen Abhandlungen bestehenden Urheberund Verlagsrechte. Auf die Bestimmung des $\S 15$ Abs 2 LitUrhG könne sie sich nicht berufen, da diese Vorschrift auf Vervielfältigungen, die auf fotomechanischem Wege angefertigt würden, nicht erstreckt werden könne. Zudem stelle die Beklagte die Vervielfältigungen nicht zum "persönlichen Gebrauch" und auch nicht ohne die Absicht her, "aus dem Werk eine Einnahme zu erzielen". . . . .

Die Beklagte hat ... geltend gemacht: $\S 15$ Abs 2 LitUrhG betreffe Vervielfältigungen jeder Art, gleichviel, durch welches Verfahren sie hergestellt worden seien. Sie habe die beanstandeten Vervielfältigungen zum persönlichen Gebrauch hergestellt. Dieser Gebrauch sei nicht auf die private oder häusliche Sphäre beschränkt. Eine Vervielfältigung zum persönlichen Gebrauch liege auch dann vor, wenn ein Leiter oder ein Angestellter einer juristischen Person Vervielfältigungen für seine betriebliche Arbeit herstellen lasse. Die Grenze des persönlichen Gebrauchs werde nur dann überschritten, wenn die Vervielfältigung für die Offentlichkeit bestimmt sei. Die Vervielfältigungen seien auch nicht $\mathrm{zu}$ dem Zweck hergestellt worden, im Sinne des $\S 15$ Abs 2 LitUrhG "aus dem Werk" eine Einnahme zu erzielen. . . . .

\section{Entscheidungsgründe:}

I. Das Berufungsgericht hat die Klagebefugnis des Klägers mit zutreffender Begründung bejaht. ... .

II. In der Sache selbst ist das Berufungsgericht ohne Rechtsirrtum davon ausgegangen, daß die Herstellung von Fotoduplikaten eines Schriftwerkes, mag sie im Wege der Fotokopie oder der Mikrokopie erfolgen, im Sinne der $\S 11,15$ Abs 1 LitUrhG eine Vervielfältigung des Schriftwerkes ist. . . . .

Nach den $\S \S 1,15$ Abs .1 LitUrhG gehört das Vervielfältigungsrecht $\mathrm{zu}$ den ausschließlich dem Urheber vorbehaltenen Werknutzungsrechten. Eine Vervielfältigung ohne Einwilligung des Berechtigten ist nach $\S 15$ Abs. 1 LitUrhG grundsätzlich unzulässig. Statthaft ist sie ohne Einwilligung des Berechtigten nur, wenn sie unter die Bestimmung des $\S 15$ Abs 2 LitUrhG fällt, wonach eine Vervielfältigung zulässig ist, sofern sie zum persönlichen Gebrauch und ohne die Absicht vorgenommen wird, aus dem Werk eine Einnahme zu erzielen. Unstreitig liegt die Einwilligung der Berechtigten hier der Verleger - zu den mit der Klage bean- 
slandeten folomechanischen Vervielfältigungen der Beklagten nicht vor. Deshalb kommt es, wie das Berufungsgericht mit Recht bemerkt, darauf an, ob die Beklagte sich für ihr Verfahren mit Erfolg auf $\S 15$ Abs. 2 LitUrhG berufen kann.

III. Das Berufungsgericht hat sich zunächst mit der Frage befaßt, ob der Begriff der Vervielfältigung nach § 15 Abs 2 LitUrhG der gleiche sei wie der in Absatz 1 dieser Bestimmung, hinsichtlich dessen das Gesetz ausdrücklich festlegt, daß es gleichgültig sei, durch welches Verfahren die Vervielfältigung bewirkt werde, oder ob er in einem engeren Sinne verstanden werden müsse und demzufolge auf fotomechanische Vervielfältigungen nicht erstreckt werden könne. Die Frage ist in einem Urteil des LG Leipzig vom 7. 12. 1933 und vielfach im Schrifttum in dem zweiten Sinne beantwortet worden (Marwitz, Börsenblatt f. d. Deutschen Buchhandel, 1931, Nr 252; Hillig, daselbst, 1933, $\mathrm{Nr} 80 \mathrm{im}$ Anschluß an das vorbezeichnete Urt. d. LG Leipzig; Ostertag, Ufita IX, 105; Splett GRUR 1949, 157; von Erffa GRUR 1951, 226; Möhring in Gema, Magnettongeräte und Urheberrecht, 1952, S 88; Voigtländer-Elster-Kleine, Anm 2 a Abs $3 \mathrm{zu}$ § 15 LitUrhG; vgl auch Runge, Urheber- und Verlagsrecht, S $154 \mathrm{ff}$ ). Das Berufungsgericht hat sie im Sinne der ersten Alternative entschieden, da für die engere Auslegung des Begriffs der Vervielfältigung in § 15 Abs 2 kein zwingender Grund vorliege, dem Gesetzgeber bei Erlaß des literarischen Urheberrechtsgesetzes im Jahre 1901 zudem mechanische Vervielfältigungsverfahren einfacherer Art wie das Kopieren mittels der Kopierpresse, die Hektografie, die Heliografie sowie das Lichtpausverfahren bekannt gewesen seien und der Mikrofilmgedanke schon im Jahre 1870 bei der Belagerung von Paris eine Rolle gespielt habe. Bei der Bestimmung des § 15 Abs 2 LitUrhG handele es sich zwar um eine Ausnahmevorschrift, die nach dem Willen des Gesetzgebers eng auszulegen sei. Jedoch sei es verfehlt, damit bereits bei dem Begriff der Vervielfältigung $\mathrm{zu}$ beginnen. Es sei geboten und genügend, die einschränkenden Merkmale des persönlichen Gebrauchs und des Fehlens einer Er. werbsabsicht zum Ansatzpunkt zu nehmen.

Diesen Ausführungen kann nicht in vollem Umfange beigetreten werden.

1. Dem reinen Wortlaute nach werden allerdings durch \& 15 Abs 2 LitUrhG auch fotomechanische Vervielfältigungen erfaßt. Der Gesetzgeber hat diese Bestimmung nicht auf handschriftliche Vervielfältigungen beschränken wollen. In der amtlichen Begründung zum 2. Entwunf des Gesetzes (Regierungsvorlage, Reichstagsverhandlungen, 10. Legislaturperiode II. Session 1900/1901 Nr 97 der Drucksachen) wird ausdrücklich bemerkt, es werde nicht vorausgesetzt, daß die Vervielfältigung auf nichtmechanischem Wege bewirkt werde. Dem Gesetzgeber waren, wie das Berufungsgericht mit Recht bemerkt, bei Erlaß des Gesetzes im Jahre 1901 auch verschiedene mechanische Vervielfältigungsverfahren bekannt. Die heutigen Fotokopier- und Mikrofilmverfahren sind aber, mag man sie als absolute technische Neuerungen ader als Verfeinerungen der früheren Verfahren ansehen, in jedem Falle me ch a $\mathrm{n}$ is ch e Vervielfältigungsverfahren. Sie stehen als solche zu der handschriftlichen Vervielfältigung in demselben Gegensatz, in dem die früheren mechanischen Verfahren zu ihr gestanden haben, so daß kein begründeter Anlaß gegeben ist, sie lediglich wegen ihrer technischen Eigenart von dem Vervielfältigungsbegriff des $\S 15$ Abs 2 LitUrhG auszunehmen.

2. Hieraus folgt aber entgegen der Meinung des Berufungsgerichts noch nicht, daß die fotomechanische Vervielfältigung unter den Voraussetzungen des § 15 Abs. 2 LitUrhG, also zum persönlichen Gebrauch und ohne Erwerbsabsicht, zulässig ist. Wie der erkennende Senat in seinem zum Abdruck in der Entscheidungssammlung bestimmten Urteil vom 18. Mai 1955 (Magnettonband) - I ZR 8/54 - ausgeführt hat, stellt sich die Bestimmung des $\S 15$ Abs 2 LitUrhG nicht als Ausdruck einer im Wesen des Urheberrechts liegenden Begrenzung der Herrschaftsmacht des Urhebers, sondern als eine e $c h t e$ Ausnahme von den das Urheberrecht beherrschenden Grundgedanken und somit - übereinstimmend mit der Wortfassung - als eine echte Ausnahme von den Bestimmungen der §§ 11, 15 Abs 1 LitUrhG dar. Die dort verfügte Einschränkung des Vervielfältigungsrechts des Urhebers darf daher nicht über ihren eigentlichen Sinn und Zweck hinaus erstreckt werden, selbst wenn der Wortlaut des Gesetzes dies zuließe. Wie der erkennende Senat ebenfalls in dem vorbezeichneten Urteil unter Hinweis auf die Entscheidungen des Bundesgerichtshofs in BGHZ 2, 176 [184] und des Reichsgerichts in RGZ 142, 40 [41] ausgeführt hat, muß auch gegenüber einem sprachlich eindeutigen Wortlaut eine Auslegung nach dem Sinn und Zweck des Gesetzes Platz greifen, wenn der zur Entscheidung stehende Interessenkonflikt bei Erlaß des Gesetzes noch nicht ins Auge gefaßt werden konnte, weil er erst durch eine nach diesem Zeitpunkt eingetretene Anderung in Erscheinung getreten ist. Diese Voraussetzung ist aber im vorliegenden Falle erfüllt. Durch die heutigen fotomechanischen Vervielfältigungsverfahren ist eine Sachlage entstanden, die der Gesetzgeber ides Jahres 1901, mag er auch mit einer fortschreitenden Entwicklung der damals bekannt gewesenen mechanischen Vervielfältigungsverfahren gerechnet haben, nicht in den Kreis seiner Uberlegungen einbeziehen konnte. Die Herstellung von Kopien mittels der Kopierpresse und ebenso die Hektografie setzten die Anfertigung einer band- oder maschinenschriftlichen Abschrift voraus. Das Verfahren der Heliografie, bei dem Tiefdruckplatten mittels Fotographie und Ätzung hergestellt werden muBten, war umständlich und kostspielig. Das vom Berufungsgenicht weiter genannte Lichtpausverfahren spielte nur für Vervielfältigungen technischer Zeichnungen eine Rolle. Alle diese Verfahren kamen ebenso wie die Hand- oder Maschinenschrift praktisch nicht für die Vervielfältigung ganzer Schriftwerke, zumal größeren Umfanges, sondern in der Regel nur für die Vervielfältigung einzelner Stellen aus Schriftwerken in Betracht. Gegenüber der Hand- und Maschinenschrift erwiesen sie sich im Grunde nur dann als vorteilhaft, wenn mehrere Vervielfältigungsstücke hergestellt werden sollten. Die Mikrofotografie steckte damals noch in den An- 
fängen und hatte keine praktisch in Betracht kommende Bedeutung. Der Druck schied, sofern es sich um die Herstellung eines oder weniger Vervielfältigungsstücke handelte, als zu kostspielig aus. Mit den heutigen fotomechanischen Vervielfältigungsvenfahren ist dagegen ein Weg geöffnet worden, schnell und verhältnismäßig preiswert auch einzelne Vervielfältigungsstücke selbst umfangreicher Schriftwerke in einer Ausführung herzustellen, die, wenn auch das einzelne Vervielfältigungsstück nicht in gleicher Weise verkehrsfähig ist wie das handelsüibliche Druckexemplar, für den persönlichen Gebrauch doch in der Regel einen vollwertigen Ersatz eines solchen Exemplars bietet. Der damit gegebene neue Sachverhalt hat ebenso wie die Sachlage, die durch die Entwicklung der Magnettongeräte geschaffen und in dem Urteil des erkennenden Senats vom 17. Mai 1955 behandelt worden ist, einen neuen urheberrechtlich bedeutsamen Interessenkonflikt hervorgerufen, dessen Lösung auch hier nicht ohne weiteres aus $\S 15$ Abs 2 LitUrhG entnommen weriden kann, weil er sich mit dem dort geregelten Interessenkonflikt nicht deckt und bei wörtlicher Anwendung des $\S 15$ Abs 2 in einer Weise entschieden würde, die dem vom Gesetzgeber erstrebten Interessenausgleich nicht oder jedenfalls in vielen Fällen nicht entspräche.

3. Der mit § 15 Abs 2 LitUrhG verfolgte Zweck ergibt sich, wie der erkennende Senat aaO ausgeführt hat, aus dem Vergleich der durch diese Bestimmung geschaffenen Rechtslage mit dem früheren Rechtszustande. Das literarische Urhebergesetz vom 11. Juni 1870 enthielt keine dem § 15 Abs 2 entsprechende Bestimmung. § 14 dieses Gesetzes lautete: "Jede mechanische Vervielfältigung eines Schriftwerkes, welche ohne Genehmigung des Berechtigten hergestellt wird, heißt Nachdruck und ist verboten." Das Abschreiben war gestattet, sofern es nicht dazu bestimmt war, "den Druck zu ersetzen." Demgegenüber wollte das literarische Urheberrechtsgesetz vom 19. 6. 1901 die Rechtslage der Urheber in Bezug auf das Vervielfältigungsrecht verbessern und behielt deshalb dem Urheber auch die nichtmechanische Vervielfältigung vor. Andererseits sollte, wie die oben erwähnte amtliche Begründung des zweiten Entwurfs ergibt, die Möglichkeit gewahrt bleiben, Abschriften für den eigenen privaten Gebrauch anzufertigen. Dabei dachte der Gesetzgeber, wie ebenfalls aus der amtlichen Begründung hervorgeht, vor .allem an Mitglieder von Gesang- und Theatervereinen, die sich für unentgeltliche Aufführungen Abschriften und Auszüge von Noten und Rollen eines Bühnenwerkes anfertigen wollten. Dem Gesetzgeber des Jahres 1901 ging es, wie der Senat aaO hervorgehoben hat, hiernach darum, das Vervielfältigungsrecht zum persönlichen Gebrauch im bis h e r ige $n$ Um ange bestehen zu lassen. Daß damit nicht nur kapitalschwachen Musik- und Theaterliebhabern, an die der Gesetzgeber im Interesse der Kunstpflege und aus sozialen Gründen in erster Linie gedacht hatte, die Beschaffung ihres Notenund Rollenmaterials erleichtert wurde, sondern auch den Benutzern sonstiger literarischer Werke, insbesondere dem Wissenschaftler, die Möglichkeit gegeben war, Vervielfältigungen für ihren per- sönlichen Gebrauch anzufertigen, lag klar zutage und ist auch in der Rechtslehre allgemein anerkannt worden.

4. Die mit § 15 Abs 2 LitUrhG erfolgte Lösung des Interessenkonflikts zwischen Urheber und Benutzer ging $\mathrm{zu}$ Lasten des Urhebers, dessen nach dem Grundgedanken des Gesetzes insoweit unbeschränkte Herrschaftsmacht sich eine Einschränkung gefallen lassen mußte. Das war aber für den Urheber tragbar. Nach dem damaligen Stand der Tech. nik konnte insbesondere die Vervielfältigung von Noten- und Rollenmaterial, die der Gesetzgeber hatte ermöglichen wollen, keine ins Gewicht fallende Beeinträchtigung seiner wirtschaftlichen Interessen bedeuten (vgl hierzu die Ausführungen des erkennenden Senats aaO). Eine solche Beeinträchtigung war aber mit Rücksicht auf den engen Rahmen, đer jeder privaten Vervielfältigung nach Art und Umfang durch den Stand der Technik gezogen war, auch von den Vervielfältigungen nicht zu befürchten, die den Benutzern von literarischen Schriftwerken für ihren persönlichen Gebrauch durch $\S 15$ Abs 2 LitUrhG gestattet waren. Jedenfalls konnte sie nicht so erheblich sein, daß sie im Interesse der Erleichterung wissenschaftlicher Arbeit, für die Vervielfältigungen im Rahmen des $\S 15$ Abs 2 vor allem in Betracht kamen, dem Urheber und dem Verleger nicht hätte zugemutet werden können.

5. Wollte man den durch die Entwidklung der fotomechanischen Vervielfältigungsverfahren entstandenen Interessenkonflikt durch wörtliche Anwendung des $\S 15$ Abs 2 LitUrhG lösen, so würde das in zahlreichen Fällen eine Beeinträchtigung der Interessen der Urheber bedeuten, die weit über die Beeinträchtigung hinausginge, die der Gesetzgeber bei Erlaß des Gesetzes von 1901 als tragbar und billig empfunden hatte. Das Berufungsgericht schätzt allerdings das Interesse an Reproduktionen von Schriftwerken und Noten gering ein. Es meint, die Bedeutung der Vervielfältigungen werde meist, vor allem in zeitlicher Hinsicht, sehr bedingt sein. Bei Zeitschriften würden wegen der entstehenden Unkosten schon aus wirtschaftlichen Gründen in der Regel allenfalls nur Fotokopien von kleineren Aufsätzen hergestellt werden. Diese Auffassung ist jedoch mit dem vorgetragenen Sachverhalt nicht zu vereinbaren. Auch bei Zugrundelegung der von der Beklagten mitgeteilten Kostenbeträge ist das Fotokopieren von Zeitschriftenaufsätzen gegenüber der Anschaffung des Druckexemplars des betreffenden Zeitschriftenheftes vielfach durchaus lohnend. $\mathrm{Daß}$ an der Anfertigung solcher Fotokopien nur ein geringes Interesse bestehe, widerspricht der Lebenserfahrung. Das Berufungsgericht beachtet überdies nicht die Möglichkeiten, die insbesondere nach den überreichten Prospekten der Firma Lumoprint durch das Mikrofilmverfahren gegeben sind, mittels dessen unschwer und preiswert auch Buchwerke und längere Abhandlungen reproduziert werden können. Daß die unmittelbare Auswertung der Mikrofilme nur mit Hilfe eines allerdings noch recht kostspieligen Lesegerätes möglich ist $t_{r}$ mag deren Verwendungsbereich einschränken, ändert aber nichts an der Tatsache, daß mit dem Mikrofilmverfahren ein Vervielfältigungsmittel gegeben ist, dessen Frei- 
stellung von einer Urhebervergütung mit dem Zweck, den der Gesetzgeber mit $\S 15$ Abs. 2 LitUrhG verfolgt hat, nicht $\mathrm{zu}$ vereinbaren wäre und $\mathrm{zu}$ einer durch diese Vorschrift nicht gewollten Beeinträchtigung der Interessen der Urheber führen müßte. Ebensowenig kann der Meinung der Revision der Beklagten beigetreten werden, daß die Interessen der Urheber durch das Fotokopieren von Zeitschriftenaufsätzen und Teilen aus solchen Aufsätzen, um die es sich im vorliegenden Rechtsstreit handelt, überhaupt nicht berührt würden, weil der Urheber für seinen in der Zeitschrift veröffentlichten Aufsatz ein Pauschalhonorar erhalte, das von der Höhe der Auflage der Zeitschrift unabhängig sei. Diese Meinung widerstreitet der wirtschaftlichen Erfahrung, daß die Höhe der Einnahmen der Verleger sich zwangsläufig und jedenfalls mit der Zeit auch auf die Höhe der den Autoren gezahlten Honorare auswirken muß. Daß der Autor an dem Aufsatz nicht finanziell interessiert sei, sonderm nur ein Interesse daran habe, daß sein Beitrag durch Druck oder Fotokopie möglichst weiten Kreisen zugänglich gemacht wende, trifft entgegen der Ansicht der Revision der Beklagten jedenfalls in dieser Allgemeinheit nicht zu. Soweit aber das ideelle Interesse der Urheber im Vordergrund stehen sollte, wird auch dieses Interesse beeinträchtigt, wenn die fotomechanische Vervielfältigung im Rahmen des $\S 15$ Abs 2 LitUrhG freigegeben und infolge der Nachteile, die hieraus den Verlegern entstehen, die Drucklegung literarischen oder wissenschaftlichen Geistesgutes erschwert wird. $\mathrm{Zu}$ Unrecht vermißt die Revision der Beklagten auch den Nachweis, daß den Verlegern in der Vergangenheit durch das Fotokopieren von Zeitschriftenaufsätzen ein Schaden erwachsen sei. Daß die Verleger hierdurch jedenfalls in gewissem Umfange geschädigt worden sind, liegt so klar zutage, daß dafür kein Beweis erbracht zu werden brauchte. Auf die Höhe des tatsächlich entstandenen und für die Zukunft zu erwartenden Schadens kann es, wie der Senat aaO ausgeführt hat, aber nicht ankommen. Entscheidend ist allein, daß die in Rede stehenden fotomechanischen Vervielfältigungsverfahren i h rem Wesen $n$ a $\mathrm{ch}$ geeignet sind, dem Verleger und damit auch dem Urheber wirtschaftlich beachtliche Nachteile zuzufügen. Besteht auch nur die Möglichkeit einer solchen Schädigung, so muß die Gesetzesauslegung das ihrige tun, um sie zu verhüten (RGZ .136, 413 [423]; v.gl auch BGHZ 11, $135[148 / 50])$.

6. Eine billige, dem Zweck der gesetzlichen Regelung entsprechende Lösung des Interessenkonflikts kann unter diesen Umständen nur durch eine einschränkende Auslegung des § 15 Abs 2 LitUrhG erfolgen. $\mathrm{Ob}$ es allerdings angezeigt ist, diese Bestimmung dahin auszulegen, daß die Herstellung fotomechanischer Vervielfältigungen aus ihrem Anwendungsbereich überhaupt auszunehmen sei, erscheint zweifelhaft. Gewisse Unterschiede in der Sach- und Rechtslage sind im Vengleich zu den im Urteil des Senats vom 18. Mai 1955 behandelten Aufnahmen geschützter Musik durch Magnettongeräte nicht $\mathrm{zu}$ verkennen. Das Berufungsgericht hat hierauf bereits hingewiesen. Es wird sich deshalb die Frage stellen, ob der Gesetzeszweck eine
Auslegung des $\S 15$ Abs 2 LitUrhG erfordert, die die Herstellung fotomechanischer Vervielfältigungen im privaten Bereich ohne Einwilligung des Berechtigten überhaupt unterbinden würde, oder ob es genügen müßte, diese Bestimmung einschränkend dahin auszulegen, daß sie die Verwendung fotomechanischer Vervielfältigungsverfahren nur dann nicht decken könne, wenn diese dazu dienen sollen, Vervielfältigungen herzustellen, die, vor allem wegen ihres Umfanges, mit den älteren Verfahren, insbesondere hand- oder maschinenschriftlich, nicht hergestellt worden wären, vor allem also, wenn mittels der fotomechanischen Verfahren ein Ersatz für das Druckexemplar geschaffen werden soll, das der private Vervielfältiger sich anderenfalls zu beschaffen genötigt gewesen wäre. Diese Frage braucht hier jedoch nicht anschließend entschieden $\mathrm{zu}$ werden, denn im vorliegenden Falle verbietet sich die Anwendung des § 15 Abs 2 LitUrhG und zwar ohne Einschränkung - schon deshalb, weil es sich hier nicht um Vervielfältigungen „zum persönlichen Gebrauch" im Sinne dieser Bestimmung handelt.

IV. Das Berufungsgericht hat allerdings die Frage, ob die mit der Klage beanstandeten Vervielfältigungen der Beklagten "zum persönlichen Gebrauch" im Sinne von $\S 15$ Abs 2 LitUrhG bestimmt seien, mit gewissen Einschränkungen bejaht. Es hat ausgeführt: Eine juristische Person könne als solche keinen persönlichen Gebrauch machen. Wenn im Gesetz von einer Vervielfältigung zum persönlichen Gebrauch die Rede sei, só könne nur der Gebrauch durch natürliche Personen gemeint sein. Bei Vervielfältigungen im Betriebe einer Körperschaft sei deshalb zu fragen, ob und inwieweit die in dem Verband tätigen natürlichen Personen Vervielfältigungsstücke erfondern dünften und ob und inwiew.eit die Körperschaft für diese Vervielfältigungen Hilfskräfte und Einrichtungen zur Verfügung stellen dünfe. Dabei sei zu berücksichtigen, daß nach herrschender Meinung (Ulmer, Urheber- und Verlagsrecht, S 165) im Rahmen des $\S 15$ Abs 2 LitUrhG der Benutzer die Vervielfältigung nicht selbst herzustellen brauche, sondern sich dazu einer bezahlten Hilfskraft bedienen könne, daß eine Mitbenutzung durch Personen statthaft sei, die mit dem Vervielfältiger durch ein persönliches Band verbunden seien und daß schließlich der Gebrauch kein ausschließlich privater zu sein brauche, sondern auch beruflichen Zwecken dienen dürfe. Wesentlich sei, daß der Gebrauch auf einen engen Rahmen beschränkt bleibe und die Persönlichkeit des Benutzers im Vordergrund stehe. Deshalb sei zu verlangen, daß die Herstellung der Vervielfältigung auf dessen eigene Initiative zurückgehe und durch seine eigene Arbeit veranlaßt werde. Daher sei es zulässig, daß der einzelne Ingenieur eines Betriebes der Beklagten die für eine bestimmte Konstruktionsarbeit nötigen Unterlagen oder solche wichtigen Unterlagen fotokopieren lasse, die öfter gebraucht würden und die er für vorkommende Fälle zum Handgebrauch zur Venfügung haben wolle. Unzulässig sei es dagegen, wenn die Zentralverwaltung oder die Zentralbücherei eines Unternehmens für die unterstellten Abteilungen Fotokopien zentral herstelle und verteile, gleichviel, ob dies im vor- 
aus allgemein angeordnet worden sei oder ob es im Einzelfalle geschehe. Das Berufungsgericht hat es demzufolge für zulässig erachtet, daß Sachbearbeiter der Beklagten im Einzelfalle je ein Fotoduplikat von Aufsätzen oder Abhandlungen oder Teilen davon sich durch die Fotokopierstellen der Beklagten haben anfertigen lassen, und hat nur beanstandet, daß die Fotokopierstelle der Beklagten in Frankfurt/Main auf Veranlassung des Direktors der Fabrikenleitung Fotoduplikate von einer Seite eines Zeitschriftenaufsatzes für eine Anzahl ihm unterstellter Betriebe und ferner der Leiter der Informationsabteilung der Beklagten Fotoduplikate nicht nur für sich selbst, sondern auch für die Mitarbeiter seiner Abteilung hat herstellen lassen. In diesen Fällen habe sowohl zwischen dem Direktor der Fabrikenleitung und den ihm unterstellten Betriebsleitern als auch zwischen dem Leiter der Informationsabteilung und dessen Mitarbeitern kein "persönliches Band" bestanden, wie es für eine nach § 15 Abs 2 LitUrhG zulässige Mitbenutzung $\mathrm{zu}$ fordern sei.

Diese Ausführungen halten indessen einer rechtlichen Nachprüfung nicht stand.

Allerdings unterliegt die Auffassung des Berufungsgerichts, daß eine juristische Person von einer Vervielfältigung keinen persönlichen Gebrauch im Sinne des $\S 15$ Abs 2 LitUrhG machen könne, jedenfalls dann keinen rechtlichen Bedenken, wenn es sich bei ihr, wie im vorliegenden Falle bei der Beklagten, um ein Erwerbsunternehmen handelt. Die Anwendung des $\S 15$ Abs 2 LitUrhG würde daher ohne weiteres entfallen, wenn man die Beklagte s e Ibs t im Rechtssinne als "Gebraucher" der Fotoduplikate ansehen wollte. Entgegen der Meinung des Berufungsgerichts kann diese Bestimmung aber auch dann nicht angewendet werden, wenn allein auf den Gebrauch der Fotoduplikate durch die $\mathrm{S}$ a c h b e a r b e it e r der Beklagten abgestellt wird.

Nach dem vorgetragenen Sachverhalt werden die Fotoduplikate von den Fotokopierstellen der Beklagten in der Regel auf Anforderung der Sachbearbeiter, gelegentlich auch auf Weisung leitender Stellen angefertigt und den Sachbearbeitern zur Verfügung gestellt. Das geschieht auf Anordnung oder doch mit Wissen und Willen der Organvertreter der Beklagten, und zwar in der Annahme, daß die Sachbearbeiter die Fotoduplikate für die Erledigung der ihnen im Betriebe der Beklagten obliegenden Aufgaben benötigen oder die Duplikate für die Sachbearbeiter im Hinblick auf deren Aufgabenbereich von Interesse sind. Die Fotoduplikate sollen demnach im Betriebe der Beklagten und für d e r e n gewerblichen Zwecke benutzt werden.

Unter diesen Umständen ist aber der Gebrauch, den die Sachbearbeiter von den Fotoduplikaten machen, wenn sie diese bestimmungsgemäß benutzen, kein persönlicher Gebrauch im Sinne des § 15 Abs 2 LitUrhG. Die Frage, ob ein Gebrauch für gewerbliche Zwecke s t e t $s$ die Anwendung des $\S 15$ Abs 2 LitUrhG ausschließt, kann dabei dahinstehen. Denn jedenfalls setzt ein persönlicher Gebrauch im Sinne dieser Ausnahmebestimmung voraus, daß der Gebrauch zum mindesten überwiegend rein persönli- chen Bedürfnissen des Gebrauchenden dienen soll. Inwieweit dies beispielsweise bei Vervielfältigungen zutrifft, die der Anwalt, der Arzt oder der Hochschullehrer für ihre beruflichen Arbeiten anfertigen oder anfertigen lassen, ist Frage des Einzelfalles und bedarf hier keiner Entscheidung. Denn der Gebrauch, den im vorliegenden Falle die Angestellten eines Erwerbsunternehmens wie des der Beklagten im Interesse dieses Unternehmens von Fotoduplikaten machen, die das Unternehmen gerade für einen solchen Gebrauch hergestellt hat, geht in jedem Falle über den Rahmen der privaten Gebrauchszwecke hinaus, die allein durch $\S 15$ Abs 2 LitUrhG von dem Vervielfältigungsverbot freigestellt werden sollten. Dies gilt ohne Rücksicht darauf, ob die Fotokopienstellen der Beklagten die Fotoduplikate im Einzelfalle auf Anforderung der Sachbearbeiter herstellen oder ob die Herstellung auf Anweisung leitender Stellen für die diesen unterstellten Abteilungen oder im Auftrage eines Abteilungsleiters für seine Mitarbeiter erfolgt. Deshalb ist es nicht gerechtfertigt, daß das Berufungsgericht diesen Fällen eine unterschiedliche Beurteilung hat zuteil werden lassen. Entgegen der Meinung des Landgerichts kann es auch nicht darauf ankommen, ob die Herstellung der Fotoduplikate "laufend" oder nur vereinzelt erfolgt. Die rechtliche Charakterisierung des Gebrauchs, für den die Fotoduplikate bestimmt sind, wird dadurch ensichtlich nicht berthrt.

V. Kann hiernach $\S 15$ Abs 2 LitUrhG im vorliegenden Falle schon deshalb nicht angewendet werden, weil das Merkmal der „Vervielfältigung zum persönlichen Gebrauch" nicht vorliegt, so brauchte auf die Frage, ob auch die weitere Voraussetzung für die Anwendung dieser Bestimmung - daß nämlich die Vervielfältigung nicht den Zweck haben darf, eine Einnahme zu erzielen - nicht erfüllt ist, nicht eingegangen zu werden. Soweit das Berufungsgericht meint, die Bestimmung des $\S, 15 \mathrm{Abs} 2$ LitUrhG müsse, wenn sie keine unmittelbare Anwendung finden könne, jedenfalls entsprechend angewendet werden, kann ihm nicht beigetreten werden. Die entsprechende Anwendung des $\S 15$ Abs 2 LitUrhG verbietet sich im vorliegenden Falle schon deshalb, weil wie die Ausführungen unter

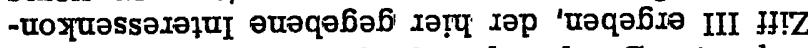
flikt ein anderer ist als der, den der Gesetzgeber mit jener Bestimmung ausgleichen wollte. Entgegen der Meinung des Berufungsgerichts kann dabei nicht allein auf die Beeinträchtigung abgestellt werden, die die Urheber durch die Vervielfältigungstätigkeit der Beklagten erlitten haben. Vielmehr ist hier die Sachlage in Betracht zu ziehen, die sich ergeben würde, wenn Vervielfältigungen, wie sie die Beklagte vorgenommen hat, allgemein vorgenommen würden. Daß alsdann aber eine Schädigung der Urheber zu befürchten wäre, die weit über das $\mathrm{MaB}$ der vom Gesetzgeber mit der Ausnahmebestimmung des $\S 15$ A.bs 2 LitUrhG als tragbar gebilligten Beeinträchtigungen hinausginge, kann nach den Ausführungen unter Ziff III nicht zweifelhaft sein.

Der Senat verkennt bei alledem nicht, daß die innerbetriebliche Arbeit der Beklagten, indem ihr 
die Berufung auf $\S 15$ Abs 2 LitUrhG versagt wird, eine gewisse Erschwerung erleidet, zumal das hieraus folgende Verbot der Herstellung von Fotoduplikaten sich auch auf $\mathrm{T}$ eile von Zeitschriftenaufsätzen erstreckt. Dieser Umstand rechtfertigt es jedoch nicht, zu Lasten der Urheber dem Merkmal des persönlichen Gebrauchs eine dem Sinn und Zweck des Gesetzes nicht entsprechende Auslegung zu geben. Im übrigen ist zu betonen, daß - wirtschaftlich gesehen - der Sinn der Entscheidung, zu der der Senat gelangt ist, nicht darin besteht, in Fällen der vorliegenden Art die Herstellung fotomechanischer Vervielfältigungen grundsätzlich zu unterbinden, sondern daß es in Wahrheit darum geht, die Herstellung fotomechanischer Vervielfältigungen von der Zahlung einer angemessenen Vergütung an die Verleger abhängig zu machen. Die von der Beklagten angeschnittene Frage, ob und inwieweit der Verleger, sofern ihm eine angemessene Vergütung angeboten wird, die Einwilligung in die Vervielfältigung verweigern darf, ohne sich dem Vorwurf des Rechtsmißbrauchs auszusetzen, hängt von den Uimständen des Einzelfalles ab. Der vorgetragene Sachverhalt bietet insoweit zu näheren Erörterungen keinen Anlaß. 


\section{Auszug aus dem Urteil des Bundesgerichtshofs vom 6. Dezember 1955}

$$
\text { - I ZR 39/54 - (BGHZ } 19 \text { S. 227) }
$$

\section{Leitsätze}

Als Volksfeste im Sinne des $\$ 27$ LitUrhG sind nur Feste anzusehen, die von allen Bevölkerungsschichten ohne Ansehung der Person, des Standes oder Vermögens auf Grund einer längeren Tradition gefeiert werden. Die im Rahmen solcher Feste stattfindenden öffentlichen Aufführungen geschutzter Werke der Tonkunst bedürfen nur dann keiner Genehmigung dèr Urheberberechtigten, wenn sie allen Kreisen der Bevölkerung zugänglich sind und nicht überwiegend im eigennützigen Erwerbsinteresse ihres Veranstalters durchgeführt werden.

Tatbestand:

Die Klägerin nimmt auf Grund von Verträgen, die sie mit der Mehrzahl der deutschen und ausländischen Komponisten geschlossen hat, deren Aufführungsrechte in Deutschland wahr. Der Beklagte betreibt in dem 360 Einwohner zählenden rheinischen Dorf Macken, Kreis St. Goar, eine Gastwirtschaft, in der er durch drei Musiker anläßlich der Kirmestage in Macken am 17. und 18 Februar 1952 und des Karneval-Rosenmontags am 25. Feruar 1952 Tanz- und Unterhaltungsmusik aus dem Repertoirc der Klägerin aufführen ließ, ohne hierzu die Erlaubnis der Klägerin eingeholt zu haben. Der Zutritt zu diesen Veranstaltungen war unentgeltlich.

Die Klägerin hat den Beklagten wegen Urheberrechtsverletzung auf Schadensersatz in Anspruch genommen. Die Höhe des Schadensersatzes hat sie unter Zugrundelegung der doppelten Gebühr ihres Tarifs UA - B IV berechnet. Sie hat weiterhin beantragt, dem Beklagten zu untersagen, das der Klägerin geschützte Musikrepertoire an den Karnevalstagen und an den Tagen des Kirmesfestes in Macken ohne deren Genehmigung öffentlich aufzuführen.

Der Beklagte hat Klagabweisung beantragt. Er ist der Ansicht, daß die fraglichen Musikdarbietungen keiner Genehmigung der Klägerin bedürfen, weil es sich um Aufführungen bei Volksfesten handele, die gemäß § 27 Abs 1 S 2 Ziff 1 LitUrhG ohne Einwilligung der Unheberberechtigten statthaft seien.

\section{Entscheidungsgründe:}

I. Die Entscheidung des Rechtsstreits erfordert eine Auslegung des $\S 27$ Abs 1 Satz 2 Ziff 1 des Gesetzes betreffend das Urheberrecht an Werken der Literatur und Tonkunst vom 19. Juni 1901 (RGBl Ir 227). Nach dieser Bestimmung sind öffentliche Aufführungen geschützter Werke der Tonkunst ohne Einwilligung des Urheberberechtigten zulässig, wenn sie "bei Volksfesten" mit Ausnahme von Musikfesten, stattfinden 'und es sich nicht um eine bühnenmäßige Aufführung von Tonwerken handelt (§ 27 Abs 2 LitUrhG). Das Gesetz enthält weder eine Begriffsbestimmung, was unter einem "Volksfest" zu verstehen ist, noch ist allein aus dem Gesetzeswortlaut zu entnehmen, welche Musikdarbietungen, die im zeitlichen und räumlichen Zusammenhang mit einem Volksfest stattfinden, als Aufführungen "bei" einem Volksfest im Sinne dieser Vorschrift anzusehen sind. Für die hiernach gebotene Gesetzesauslegung ist maßgebend, welchen Interessenkonflikt der Gesetzgeber ausgleichen wollte, indem er Musikdarbietungen "bei Volksfesten" von dem den Komponisten gemäß $§ 11$ Abs 2 LitUrhG zugebilligten ausschließlichen Aufführungsrecht ausnahm.

Während in Deutschland bis 1901 dem Urheber das ausschließliche Recht der öffentlichen Aufführung bei erschienenen Werken der Tonkunst nur bei einem entsprechenden Vorbehalt zustand ( $\$ 50$ des Gesetzes vom 11. Juni 1870), gewährt das literarische Urhebergesetz von 1901 dem Urheber das ausschließliche Aufführungsrecht unabhängig von einem entsprechenden Vorbehalt auch nach Erscheinen des Werkes. Dieses Ausschließlichkeitsrecht des Urhebers ist jedoch durch $\S 27$ LitUrhG - abgesehen von den bereits erwähnten Aufführungen bei Volksfesten - zugunsten unentgeltlicher, keinen gewerblichen Zwecken dienender Aufführungen sowie zugunsten von Aufführungen bei Wohltätigkeits- und Vereinsveranstaltungen, eingeschränkt. Das Gesetz von 1.901 erweiterte hiernach einerseits das Aufführungsrecht der Urheber erschienener Werke der Tonkunst, indem es dieses Recht nicht mehr an einen Vorbehalt band, brachte aber andererseits eine Beschränkung dieses Aufführungsrechts, der die Urheberberechtigten, die sich das Aufführungsrecht vorbehalten hatten, nach dem Gesetz von 1870 nicht unterlagen.

In der Begründung des Gesetzentwurfs von 1901 wird zu dieser Beschränkung des Aufführungsrechts durch § 27 LitUrhG ausgeführt:

„Wenn gemäß § 11 des Entwurfs die Grenzen erweitert werden, die bisher der ausschlieBlichen Befugnis des Komponisten zur öffentlichen Aufführung seines Werkes gezogen waren, so erscheint es zur Schonung hengebrachter Gewohnheiten geboten, für einige Ausnahmefälle die Aufführung freizugeben (\$27 Abs 1). Zunächst soll eine Aufführung, bei der die Hörer ohne Entgelt zugelassen werden, keiner Erlaubnis bedürfen, wenn sie keinem gewerblichen Zwecke dient. Dahin gehören die üblichen Veranstaltungen im Bereiche der Kirche, der Schule, des Heeres und der Flotte. Im Gegensatz hierzu dienen die Konzerte in Gastwirtschaften einem gewerblichen 
Zwecke; sie können deshalb, auch wenn sie ohne Entgelt und unter freiem Himmel stattfinden, um so weniger freigegeben werden, als dadurch dem Berechtigten ein empfindlicher Ausfall an Einnahmen lediglich zugunsten der gewerblichen Unternehmer angesonnen würde. Andererseits läßt sich für Volksfeste, mit Ausnahme von Musikfesten, das Aufführungsrecht nicht zur Geltung bringen, da es hier mit erheblichen, zu dem voraussichtlichen Ertrag in keinem Verhältnis stehenden Belästigungen verbunden wäre.

Dem Volksgefühl würde es widersprechen, wenn Aufführungen, deren Ertrag ausschließlich für Wohltätigkeitszwecke bestimm' ist, fortan von der vorherigen Erlaubnis einzelner Urheber abhängig gemacht 'werden sollten, während sie bisher im großen und ganzen keiner Beschränkung unterlagen. Nur muß zur Verhütung von Umgehungen 'daran festgehalten werlen, daß die Mitwirkenden, zu denen auch der Veranstalter gehört, keine Viengütung erhalten ( $\$ 27$ Abs. 1 Nr. 2). Dem Urheber eines Werkes kann man eine Vergütung nicht wohl versagen, wenn diejenigen eine Vergütung beanspruchen, welche bei der Aufführung des Werkes mitwirken.

Endlich will der Entwurf die private Musikpflege durch Vereine dem Einfluß des Aufführungsrechts selbst dann entziehen, 'wenn außer den Mitgliedern noch deren Hausgenossen Zutritt erhalten und dadurch eine gewisse Offfentlichkeit hergestellt wird ( $\$ 27$ Abs. 1 Nr. 3). Mit dem Gemütsleben des deutschen Volkes ist die Pflege der Musik in solchen Vereinen so verwachsen, daß jede Erschwerung ihres Gedeihens bitter empfunden wenden würde. Sollten, wie seitens der Komponisten besorgt wird, bei der einzelnen Aufführung fremde Personen gegen ein Eintrittsgelld zugelassen werden, das der Verein in ider Form eines Mitgliedsbeitrags erhebt, so würde darin eine unstatthafte Um.gehung des Gesetzes zu finden sein."

(vgl. Stenographische Berichte über die Verhandlungen des Reichstags, 10. Legislaturperiode, II. Session 1900/1902, 1. Anlagebandd, Aktenstück Nr. 97 S 402).

Hiernach hat der Gesetzgeber Musikaufführungen bei Volksfesten von einem Genehmigungszwang aus der Erwägung heraus freigestell't, Idaß die Einholung der Erlaubnis "mit erheblichen, zum voraussichtlichen Ertrag in keinem Verhältnis stehenden Belästigungen verbunden wäre“. Nachdem aber seit Schaffung der Klägerin von dieser Aufführungsrechte an nahezu allen unter Urheberschutz stehenden musikalischen Werken der Welt erworben werden können, eine „Belästigung" 'durch Einholung der Genehmigung ider Urheber ider e in ze ln e n Werke, also nicht mehr in Frage steht und zudem die Volksfeste weitgehend zu einer recht einträglichen Erwenbsquelle geworden sind, kann die Aufführungsfreiheit bei Volksfesten auf diese Erwägung nicht mehr gestützt werden. Da andererseits auch schon zur Zeit der Entstehung ides Gesetzes von 1901 Volksfeste größeren Umfanges veranstaltet wurden und die Vorstellung des Gesetzgebers, ¿durch die Freistellung von Aufführungsgebähren werde dem Urheber nur ein geringfü.giger - gegenüber den mit der Erlaubniseinholung verbundenen Belästigungen nicht ins Gewicht fallender - Einnahmeausfall zugemutet, im Gesetz nicht zum Ausıdruck gekommen ist, kann aus diesem Teil der Begründung zu $\$ 27$ LitUrhG für die Auslegung der fraglichen Befreiungsvorschrift nichts Entscheidendes entnommen wenden (so auch OLG München JW 1932,890 [891]).

Bedeutsam ist dagegen für die Auslegung, daß der Gesetzgeber bei dieser Einschränkung des Aufführungsrechtes ides Urhebers zugunsten bestimmter Musikdarbietungen allein einen Ausgleich der

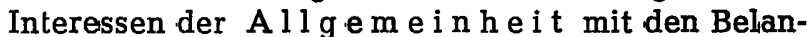
gen der Urheber im Auge hatte. Dies ergibt sich nicht nur einideutig aus den Gesetzesmaterialien, sondern ist auch aus den Wertentscheidungen, die der Gesamtregelung des Urheberrechts zugrundeliegen, zu entnehmen. Denn nach den Rechtsgedanken, die dem Urheberrech't immanent sind, findet die ausschließliche Herrschaftsmacht des Werkschöpfers über sein Geistesgut an überwiegenden Bedürfnissen der Allgemeinheit ihre Grenze (de Boor, Ufita 1944, 345 [361]). Es han'delt sich hierbei um Schranken, die dem Urheberrecht seiner sozialen Natur nach wesensgemäß sind (Ulmer, Urheberund Verlagisrecht $\mathbf{S}$ 5).

Es kann hier dahinstehen, ob die generelle Befreiung von Urhebergebühren für Aufführungen bei Volksfesten angesichts des weitgehend kommerzielilen Charakters, iden solche Festlichkeiten heute in der Regel aufweisen, aus Ider sozialen Bindung ides Urheberrechtes noch zu rechtfertigen ist. Für die Abgrenzung des Anwendungsbereichs dieser Norm genügt es klarzustellen, daß diese Vorschrift allein auf eine Abwägung der Interessen der Allgemeinheit mit den Belangen der Urheber zurückgeht, wobei 'der Gesetzgeber zu dem Ergebnis gelangt ist, daß das Interesse des Urhebers an der Ablführung von Aufführungsgebühren hinter dem Interesse der Allgemeinheit an einer ungehinderten Pflege althergebrachter Volksfesttradition zurückzutreten habe.

Aus diesem besonderen Interessenausgleich'szweck ergibt sich für die Auslegung folgendes:

Als Volksfeste im Sinne dieser Bestimmung sind nur solche Feste anzusehen, die von allen Bevölkerungsschichten ohne Ansehen der Person, des Standes oder Vermögens auf Grund einer längeren Tradition gefeiert werden, und zwar so, daß dem Sinngehalt des Festes entsprechend idas Volk als Träger der Veranstaltung erscheint. Es muß sich somit um Feste handeln, die nicht im wirtschaftlichen Interesse einzelner, sondern im Interesse der Allgemeinheit veranstaltet werden und jedermann zugänglich sind. Diese Begriffsbestimmung eines Volksfestes im Sinne ides § 27 LitUrhG entspricht der in Rechitsprechung und Schrifttum herrscheniden Auffassung (vgl insbesondere ständige Rechtsprechung des Kammergerichts Berlin u. a. in GRUR 1939, 149 und 187; GRUR 1954, 40 [42]; Schulze, Rechtsprechung zum Urheberrecht, KGZ 
6 vom 15. Mai 1953; KGZ 8 vom 29. September 1953; KGZ 10 vom 20. Oktober 1953; OLG München JW 1932, 890; Marwitz-Möhring, Deutsches Urheberrecht an Werken ider Literatur und Tonkunst 1929 S 216; Allfeld, Kommentar zum LitUrhG 1928 S 265 ff; Riezler Deutsches Urheber- und Erfinderrecht 1909 S 287; Goldbaum, Urheber- und Urhebervertragsrecht 2. Aufl 1927 S 198).

Hiernach werden zu den Volksfesten im allgemeinen Karneval-, Kirmes- und Schützenfeste zu rechnen sein. Das bedeutet aber nicht, daß etwa für alle Musikdarbietungen, die in räumlichem und zeitlichem Zusammenhang mit einem solchen Volksfest stattfinden, die Befreiungsvorschrift des $\S 27$ LitUrhG eingreift. Aus dem dargelegten Gesetzeszwed, im Interesse der Allgemeinheit im Brauchtum verwurzelte Feste des Volkes von Urhebergebühren freizustellen, folgt vielmehr, daß unter Aufführungen, die b e i Volksfesten stattfinden, nur solche Musikdarbietungen zu verstehen sind, Idie im Rahmen von Veranstaltungen stattfinden, die nach ider Art ihrer Durchführung die oben idargelegten Merkmale eines Volksfestes aufweisen. Es dürfen also nicht bestimmte Bevölkerungskreise von der Teilnahme an der Veranstaltung ausgeschlossen sein. Als echte Bestandteile eines Volksfestes sind vielmehr nur solche Musikaufführungen anzusehen, die auf eine überlieferte Volksf́esttradition zurückgehen und die allen Bevölkerungsschichten zugänglich sind.

Eine weitere Voraussetzung für rdie Aufführungsfreiheit ist, daß die fraglichen Musikdarbietungen nicht von einem Veranstalter im überwiegenden Interesse eines eigennützigen Gewinnstrebens durchgeführt werden, denn ider Sinngehalt der Befreiungsvorschrift, die von dem Rechtsgedanken der sozialen Gebundenheit dés Urheberrechts ausgeht, deckt nicht eine Freistellung von Urhebergebühren, die in Wahrheit allein den wirtschaftlichen Erwerbsinteressen des Veranstalters der Musikaufführungen zugute kommen würde. Das Interesse der Allgemeinheit an einer ungehinderten Pflege alten Volksfestbrauchtums wird nicht beeinträchtigt, wenn Unternehmern, die im eigenwirtschaftlichen In'teresse anläßlich eines Volksfestes Musik darbieten, zugemutet wird, den Urhebern der aufgeführten Werke ein Entgelt zu entrichten. Da die Aufführungstantiemen im Vergleich zu den sonstigen Unkosten einer solchen Festlichkeit verhältnismäßig geringfügig sind, steht nicht zu befürchten, daß sich etwa gewerbliche Veranstalter, wie Gastwirte, Saalbesitzer, Hoteliers u. a., durch die Notwendigkeit, Urhebergebühren zu entrichten, davon abhalten lassen werden, durch Musikdarbietungen die Bevölkerung zum Besuch ihrer Geschäftsbetriebe anzuregen und damit die allgemeine Festesfreude, die aus AnlaB eines Volksfestes herrscht, ihren geschäftlichen Interessen nutzbar zu machen. Es wäre mit dem speziellen Gesetzeszweck ides $\S 27$ Abs 1 Satz 2 Zifff i1 LitUrhG, der lediglich darauf abzielt, im Interesse 'der Allge me in he it zur Wahrung alten Volksbrauchtums ıdem Ausschließlichkeitsrecht des Urhebers eine Schranke zu setzen, nicht zu vereinbaren, wenn auch solche von gewerblichen Unternehmern zur Erzielung eines wirtschaftlichen Nutzens veranstaltete Musikaufführungen in die Aufführungsfreiheit einbezogen würden. Insoweit steht in Wahrheit kein Ausgleich zwischen den Belangen des Urhebers und denen' der Allgemeinheit in Frage. Bei solcher Sachlage muß vielmehr der allgemeine, das Urheberrecht beherrschende Grundsatz Platz greifen, nach dem der Urheber an dem aus seiner Leistung erzielten wirtschaftlichen Gewinn angemessen $\mathrm{zu}$ beteiligen ist.

Dieser Abgrenzung ides Begriffs der Aufführung bei einem Volksfest im Sinne des § 27 LitUrhG kann nicht entgegengehalten werden, daß idie keinen gewerblichen Zwecken dienende, unentgeltliche öffentliche Aufführung eines Werkes ider Tonkunst bereits durch $\S 27$ Abs $1 \mathrm{~S}$ a t $z_{1} 1$ LitUrhG von einem Genehmigungszwang befreit sei, sich bei dieser Auslegung deshalb eine Sonderbestimmung für Volksfeste erübrigt hätte. Nach herrschender Auffiassung, der sich der erkennende Senat angeschlossen hat, reicht bereits die mittelbare Förderung der gewerblichen Interessen eines Dritten aus, die Anwendung des $\S 27$ Abs 1 Satz 1 auszuschließen (BGHZ 17, 376). Bei der Entwicklung, die selbst echte Volksfeste wie Karneval, Kirmes und Schützenfeste in der Gegenwart genommen haben, sind mit ihnen in der Regel Erwerbsinteressen einzelner eng verknüpft. Dies steht aber auch nach der hier vertretenen Auslegung einer Berufung auf die zugunsten von Volksfesten getroffene Befreiungsvorschrift nicht schlechthin entgegen. Maßgebend ist vielmehr, ob nach idem Charakter der Veranstaltung das Volk als Träger der fraglichen Musikdanbietung anzusehen ist. Dies wird für die Musikaufführungen bei den allgemein zugänglichen Umzü.gen in der Regel zutreffen. Aiber auch wenn die Musikidarbietungen in einer Gastwirtschaft stattfinden und damit mittelbar der Umsatzsteigerung des Inhabers der Gastwirtschaft dienen, kann der Volksfesteinwand durchgreifen, wenn der Veranstalter dieser Aufführungen nicht ider Gastwirt, sondern die die Gastwirtschaft besuchenden Volksfestteilnehmer sind oder die $\mathrm{Mu}$ sikdarbietungen von einem Verein, etwa einem Schützen- oder Karnevalverein, durchgeführt werden, der als traditionsgemäßer Träger des Volksfestbrauchtums anzusehen ist, und die weiteren Voraussetzungen für iden Volksfestcharakter nämlich Zugänglichkeit für alle Bevölkerungsschichten und das Fehlen eines eigennützigen Gewinnstrebens des Veranstalters - erfüllt sind. 


\section{Auszug aus dem Urteil des Bundesgerichtshofs vom 8. Januar 1960}

$$
\text { - I ZR } 128 / 58 \text { - }
$$

Tat bestand:

Der Beklagte veranstaltet als Tanzlehrer in Berlin-Schöneberg Tanzkurse, die in mehrere Tanzzirkel, nämlich Anfänger-, Fortgeschrittene-, Vorturnier- und Ehepaaranfängerzirkel aufgeteilt sind. Jeder Kursus umfaßt 10 Doppelstunden und erstreckt sich üblicherweise über ca. $1 / 4 \mathrm{Jahr}$. An den Kursen nehmen Tanzstundenschüler und -schülerinnen der verschiedensten Lebensalter und Lebensstellungen teil, so Schüler, Studenten, Handlungsgehilfen, Angestellte. Die Kurse finden in einem gemeinsamen Tanzstundenball ihren A.bschluß. $\mathrm{Zu}$ dem Unterricht und dem Ball ist außer den Kursusteilnehmern deren Eltern und sonstigen Erziehungsberechtigten lder Zutritt gestattet, un'd zwar können für den Aibschlußiball von diesen Personen Eintrittskarten zum Preise von $3 \mathrm{DM}$ enworben werden.

Die Klägerin verwaltet die Urheberrechte der meisten in- und ausländischen Komponisten. Der Beklagte hat unstreitig auf den von ihm veranstalteten Abschlußbällen Musik aus dem von der Klägerin verwalteten Repertoire aufführen lassen, ohne eine Einwilligung der Klägerin einzuholen. Die Klägerin ist der Auffassung, daß hierdurch in die von ihr verwalteten Unheberrechte eingegriffen wonden sei, weil es sich bei den fraglichen Abschlußbällen um öffentliche Veranstaltungen gehandelt habe. . . .

\section{Entscheidungsgründe :}

I. Das Berufungsgericht hat im Gegensatz zum Landgericht die Offentlichkeit der Musikudarbietungen bei den ivon, dem Beklagten tdurchgeführten $A b$ schlußibällen bejaht und die Klage gemäß § 11 Abs 2, 37 LitUrhG ffür begründet erachtet. Hierbei geht das Berufungsgericht in Ubereinstimmung mit der Rechitsprechung des Reichsgerichts, der sich ider erkennende Senat angeschlossen hat, Idavon aus, daB die Offentlichkeit im Sinne ides Unheberrechts stets bei der Anwesenheit mehrerer Zuhörer gegeben sei, die nicht infolge wechselseitiger persönlicher Beziehungen uniter sich oder zu dem Veranstalter der Aufführung einen in sich geschlossenen, nach außen bestimmt abgegrenzten Kreis von innerlich iverbundenen Menschen bilden (RG JW 1911, 253; RGSt 21, 254, 256; 22, 241; 40, 462; BGHZ 17, $336=$ GRUR 1955, 549 Betriebsfeier). Zwar sei die Voraussetzung, daß ıdie Besucher der Tanzstunldenabschlußbälle des Beklagten einen in sich geschlossenen, nach außen bestimmt abgegrenzten Personenkreis gebildet haben, gegeben; denn die Beschränkung des Personenkreises auf Teilnehmer der Tanzstundenkurse des Beklagten unid deren Erziehungsberechitigte sei, wie die Beweisaufnahme ergeben habe, durch die Kontrolle 'der Eintrittskarten und ider Teilnehmer an den Abschlußbällen eingehalten worden. Es fehle aber an der weiter enfonderlichen inneren persönlichen Verbundenheit der Ballbesucher. Es sei zwar möglich, daß das persönliche Band unter den Teilnehmern eines Tanzstundenabschlußiballes, die sich erst bei Beginn des Tanzkurses bei einem Tanzlehrer zusammengefunden haben, ohne sich vorher gekannt zu haben, allein durch ihre Beziehungen zu dem Veranstaliter, Idem Tanzlehrer, begründet sein kann (BGH vom 19. Juni 1956 I ZR 104/54 NJW 1956, $1553=$ GRUIR 1956, 515 - Tanzstunde). Ob dies auch Idann zu igelten habe, wenn an einem Kursus über 100 Personen teilgenommen haben, könne dahingestellt bleiben. Denn im Streitfall stände der Annahme einer persönlichen Verbundenheit des Hörerkreises nicht nur die hohe Teilnehmerzahl an den einzelnen Albschlußbällen, sondern noch weitere Umstän'de entgegen. Während bei idem Tatbestand, der der Tanzstundenentscheidung ides Bundesgerichtshofs vom 19. Juni 1956 zugrunde gelegen habe, Teilnehmer :der Tanzkurse ausschließlich Schüler bestimmter Schulklassen gewesen seien, hier also von vornherein von einer gewissen Verbundenheit ausgegangen werden konnte, hätten tdie Kurse ides Beklagten von Personen der verschiedensten Berufsgruppen und Altersklassen besucht werden können. Da aber an den einzelnen Kursen des Beklagten jeweils 46 bis 1.20 Personen unterschiedlicher Lebensstellung und Lebensalter beteiligt gewesen seien, sei die Kursusdauer von nur 10 Doppelstunden zu kurz, um unter den Teilnehmern das Gefühl eines engen persönlichenZusammenschlusses aufkommen zu lassen. Vor allem aber falle ins Gewicht, ıdaß die AbschluBbälle des Beklagten nicht nur von den Mitgliedern eines einzelnen Tanzkurses, sondern von den Teilnehmern an 2 bis 4 verschiedenen Kursen und deren Angehörigen besucht worden seien. Bei solcher Fallgestaltung reichten aber die persönlichen Beziehungen des Einzelnen zum Veranstalter, die sich aus der Teilnahme an einem der von diesem durchgeführten Tanzkurse ergäben, nicht aus, ein inneres persönliches Band der Zusammengehörigkeit unter iden aus verschiedenen Tanzkursen bei den Abschlußibällen zusammengeführten Tanzkursusteilnehmer und deren Erziehungsberechtigten $\mathrm{zu}$ begründen. Hierbei sei auch $\mathrm{zu}$ berücksichtigen, daß die verschiedenartige Zusammensetzung nach Lebensaltern innerhalb der einzelnen Kurse dem .Entstehen eines persönlichen Bandes zwischen Lehrer und Kursusteilnehmern erschwerend gegenüberstehe.

Diese Ausführungen des Berufungsgerichts lassen einen Rechtsirrtum nicht erkennen. Der Angriff der Revision, das Berufungsgericht habe den Begriff der Offentlichkeit verkannt, ist unbegründet. $\mathrm{Ob}$ im Einzelfall eine auf persönliche Verbundenheit beruhende Gemeinschaft des Hörerkreises vorliegt, 
ist im wesentlichen Tatfrage (BGH 17, $376 \ldots$ Betriebsfeier). Entgegen der Auffassung der Revision rechtfertigen aber die einzelnen vom Berufungsgericht hervorgehobenen tatsächlichen Umstände seine rechtliche Würdigung, 'wonach die Musikdarbietungen auf den fraglichen Abschlußbällen des Beklagten als öffentliche Aufführungen im Sinn von $\S 11$ Abs. 2 LitUrhG anzusehen sind. Die Angriffe ider Revision, die im wesentlichen idahin gehen, daB auch eine hohe Teilnehmerzahl an den einzelnen Tanzstundenkursen und eine unterschiedliche Zusammensetzung der Teilnehmer nach Lebensalter und Beruf sowie die Erweiterung des Personenkreises durch Eltern und sonstige Erziehungsberechtigte der Annahme eines persönlichen Bandes aller Teilnehmer zu idem Tanzlehrer als dem Veranstalter der Abschlußbälle nicht entgegenstehen, verkennen, daß dieses Band ider einzelnen Teilnehmer zu dem Tanzlehrer stark genug sein muß, auch unter sämtlichen Besuchern der Abschlußbälle das Gefühl zu erzeugen, einer in 'sich geschlossenen Gemeinschaft anzugehören. Selbst wenn der Revision beizupflichten wäre, Idaß 'das Gemeinschaftserlebnis eines Tanzkurses unabhängig von der Teilnehmerzahl und von Unterschieden im Bildungsgrad, Lebensstellung und Alter, auch rwenn er nur 10 Doppelstunden umfaßt, geeignet sein kann, eine persönliche innere Verbundenheit zwischen den Kursusteilnehmern zu schaffen, so kann dies doch nicht für Aibschlußbälle gelten, Idie Schüler verschiedener Tanzkurse mit teilweise unterschiedlichen Ausbil.dungszielen (Anfänger-, Fortgeschrittene-, Turnierzirkel) erstmalig zusammenführen. Bei derartigen Aibschlußbällen muß eine eigentliche Lehrtätigkeit des Tanzlehrers zwangsläufig schon ideshalb ausscheiden, weil hier Tanzschüler granz verschiedener Ausbildungsstufen in einer individueller Betreuung nicht mehr zugänglichen Zahl $\mathrm{zu}$ einem einmaligen gemeinsamen Tanzvergnügen zusammengeführt werden. Dementsprechend ist auch von dem Beklagten nichts ldafür dargetan worden, daß er etwa in seiner Eigenschaft als Tanzlehrer irgendeinen Einfluß durch belehrende Hinweise auf den Ablauf dieser Tanzveranstaltungen nimmt. Allein schon ideshalb, weil bei den fraglichen Bällen Schüler der verschiedenartigsten Kurse des Beklagten unter Einbeziehung ihrer Angehörigen $\mathrm{zu}$ einem einmaligen gemeinsamen Tanzvergnügen zusammengefaßt werden, können diese Bälle mit dem eigentlichen Tanzunterricht und dem dadurch etwa unter den Teilnehmern an den Einzelkursen erzeugten Gemeinschaftsgefühl nichts mehr zu tun haben. Es entspricht somit durchaus der Lebenserfahrung, wenn idas Berufungsgericht annimmt, daß die persönlichen Beziehungen der einzelnen Kursusteilnehmer untereinander und zu ihrem Tanzlehrer nicht ausreichen, auch ein persöndiches Band unter allen Teilnehmern der Abschlußbälle zu schaffen, bei denen der Tanzlehrer in Wahrheit nicht mehr als Lehrer, sondern allein als Veranstalter eines Tanzvergnügens mit einer Vielzahl von Teilnehmern, die einander zum großen Teil bislang völlig unbekannt waren, auftritt. 


\section{Auszug aus dem Urteil des Bundesgerichtshofs vom 31. Mai 1960

$$
\text { - I ZR 53/58 - (BGHZ 33, S. 1) }
$$

\section{Leitsätze}

Das fiktive Bearbeiterurheberrecht an einer Schallvorrichtung im Sinne von $\S 2$ Abs. 2 LitUrhG umfaBt auch die ausschliebliche Befugnis zur öffentlichen Aufführung. Offentliche Musikdarbietungen in Gaststätten mittels Tonträger (Schallplatten, Tonbänder usw.) bedürfen deshalb der Erlaubnis der Hersteller der Tonträger, wenn die ausübenden Künstler, deren Wiedergabeleistung auf dem Tonträger festgelegt ist, diesen ihr Aufführungsrecht aus $\S 2$ Abs. 2, § 11 LitUrhG übertragen haben.

\section{T a t best and :}

Die Kläggerin zu 2) (GEMA) nimmt auf Grund von Verträgen, die sie mit der Mehrzahl der deutschen Komponisten g'eschlossen hat, deren Aufführungsrechte wahr. Durch Abkommen mit ausländischen Aufführungsgesellschaften ist sie mit der Wahrnehmung ider gleichen Rechte für idie angeschlossenen ausländischen Komponisten betraut. Außerdem werdien ihr in ider Regel von den ihr angeschlossenen Urhebern deren Rechte zur Herstellung von Schallvorrichtungen mitübertragen. Diese sog. mechanischen Vervielfältigungsrechte überläßt die Klägerin zu 2) zur Auswertung der Klägerin zu 1) (BIEM), w'elche ıdie Rechtsform einer société civile nach französischem Recht besitzt. Die Klägerin zu 2) ist ebenso rwie verschiedene ausländische Auffiührungsgesellschaften, die ebenfalls idiese Rechte der Klägerin zu 1) übertragen haben, Gesellschafterin der Klägerin zu 1).

In dem zwischen idem BIEM und den Schallplattenherstellern abgeschlossenen Normalvertrag von 1952 in der vom 1. Januar 1956 gelteniden Fassung, der nach 'dem übereinstimm'enden Parteivortrag gegenwärtig noch gillt, heißt es:

"Das BIEM erteilt dem Fabrikanten gemäß den Bedingungen und Beschränkungen dieses Vertrages das nicht ausschließliche Recht, idie Werke des BIEM-R'epertoires . . . mechanisch aufzunehmen, von diesen Aufnahmen Reproduktionsexemplare anzufertigen, diese Exemplare unter seiner Marke in Verkehr zu bringen und an das Publikum für den Privatgebrauch zu verkaufen."

Die beklagten Schallplattenhersteller haben auf Grund entsprechender Verträge die in idem BIEMVertrag für idie Schallplattenindustrie vorgesehenen Befugnisse erworben und ausgewertet. Sie sind der Auffassung, daß den ausübenden Künstlern, ideren Wiedergabeleistungen auf iden von ihnen hergestellten Schallplatten festgelegt seien, gemäß § 2 Albs. 2 LitUrhG ein Bearbeiterurheberrecht an den Schallplatten zustehe und dieses auf Grund von $\S 2$ Abs. 1 in Verb. mit $\S .11$ Abs. 2 LitUrhG auch die ausschließliche Befugnis umfasse, die Schallplatten öffentlich abzuspielen. Sie behaupten, daß ihnen dieses Auffiührungsrecht von den ausübenden Künstlern abgetreten worden sei....

Die Klägerinnen vertreten den Standpunkt, daß das sog. fiktive Bearbeiterurheberrecht an der Schallplatte kein Aufführungsrecht im Sinne von $\S 11$ Abs. 2 LitUrhG gewähre. . . .

Entscheidungsgründe:

A. . .

B. In der Sache geht das Berufungsgericht davon aus, daß nach der geltenden gesetzlichen Regelung des Urheberrechts der ein Schrift- ader ein Tonwerk wiedergelbende ausübende Künstler nicht Werkschöpfer sei und ihm deshalb an sich ein urheberrechtlicher Schutz nicht zustehe (RGZ 153, 1, $21 \mathbf{f f}_{\text {; }}$ BGHZ 8, 88). Wenn jedoch, so führt idas Berufungsgericht aus, ein Werk der Literatur oder Tonkunst durch persönlichen Vortrag auf Tonträger, wie beispielsweise Schallplatten, übertragen werde, so stehe idie auf diese Weise hergestellte Vorrichtung gemäß $\S 2$ Abs. 2 LitUrhG einer Bearbeitung des Werkes gleich und der Vortragende gelte als Bearbeiter. Dieses "fiktive" Bearbeiterurheberrecht aber habe den gleichen rechtlichen Inhalt und Umfang wie das Urheberrecht eines echten Bearbeiters im Sinne von $\S 2$ A b s. 1 LitUrhG, umschließe somit auch die ausschließliche Befugnis zur öffentlichen Aufführhung des Tonträgers. . . . Da die Beklagten unstreitig an iden 'von ihnen hergestellten Schallplatten von den mitwirkenden Künstlern ıderen urheberrechtliche Befugnisse üb'ertragen erhalten hätten, seien sie auch gegen den Willen der Klägerinnen berechtigt, von den Veranstaltern öffentlicher Schallplattenaufführungen Unterlassung und Schadensersatz zu verlangen. . .

C. I. Der Hauptangriff der Revision 'der Klägerinnen richtet sich gegen den Rechtsstandpunkt des Berufungsgerichts, wonach den ausübenden Künstlern gemäB $\S 2$ Abs. 2 LitUrhG die Befugnis zustehen soll, die öffentliche Aufführung von Werken der Literatur und Tonkunst mittels ISchallvorrichtungen, auf ıde ihr persönlicher Vortrag Idieser Werke festgelegt worden ist, zu verbieten, auch wenn es sich um für :die Kläggerin zu 2) geschüitzte Werke handele und die Klägerin zu 2) die öffentliche Aufführung gestattet habe.

1. Nach Meinung dder Revision der Klägerinnen soll diese Auffassung unyereinbar mit dem Ge s e tz e s w o r t l a u t sein, nach dem ein Bearbeiterurheberrecht nicht etwa an der Wiedengabeleistung als solcher, sondern allein an der Schallvorrichtung, auf der idiese Leistung festgehalten ist, entstehe. Ein körperlicher Gegenstand aber könne nicht "aufgeführt" werden, denn unter Aufführung verstehe das 
Gesetz nur die Mitteilung eines geistigen Werkes. Dies ergebe sich auch aus der Fassung der gleichfalls durch die Novelle von 1910 eingefügten $\S \S 22$ a und $63 \mathrm{a}$, 'die allein von einer "Benutzung" der fraglichen Vorrichtungen zu öffentlichen Auffühmungen, nicht ldagegen von einer öffentlichen Aufführung der Vorrichtungen selbst sprächen. Hiernach müsse ein Aufführungsrecht an der Vorrichtung schon begrifflich ausscheiden.

Diese sprachliche Ausdeutung des $\S 2$ Abs. 2 LitUrhG verkennt, idaß die Bestimmung ihrem eindeutigen Wortlaut nach die Schallvorrichtung ausdrücklich einer Werkbearbeitung $\mathrm{gle}$ i ch stellt, obwohl auf der Hand liegt, daß ein stoffliches Erzeugnis wie eine Schallvorrichtung von einem geistigen Werk, wie einer Werkbearbeitung im Sinn von $\S 2$ Abs. 1 LitUrhG, wesensverschieden ist. Das rechtstechnische Ziel dieser Gleichstellung, die nach herrschender Meinung zu Recht rechtsdogmatisch als eine Fiktion gewertet wird, ist aber gerade, die gleichen Rechtsfolgen, die das Gesetz an die Bearbeitung eines Werkes knüpft, auf die mit Hilfe des persönlichen Vortrags eines ausübenden Künstlers hergestellte Schallvorrichtung zu erstrecken. Hätte der Gesetzgeiber, wie die Klägerinnen gelten'd machen, die auf einer Schallvorrichtung festgelegte Wiedergabeleistung nur gegen unbefugte Vervielfältigung und Verbreitung schützen wollen, so 'wäre dies gesetzestechnisch ohne Schwierigkeit durch eine entsprechende Begrenzung der AusschlieBlichkeitsrechte zu erreichen gewesen. Durch die uneingeschränkte Gleichstellung der Schallvorrichtung mit einer Werkbearbeitung sollte aber gerade sichergestellt werden, daß Inbalt und Umfang ider hiernach an der Schallvorrichtung bestehenden Befugnisse sich völlig mit denen an einer Werkbearbeitung decken. Dies erhellt eindeutig aus der Begründung zum Entwurf ides Gesetzes zur Arusführung ider Revidierten Berner Utbereinkunft vom 13. Navember 1908 (Verhandlungen des Reichstags XII. Legislaturperiode II. Session Bd. 275 Nr. 341 S. 1793), in der es heißt:

"Inhalt und Umfang ider hiernach begründeten urheberrechtlichen Befugnisse sowie die Dauer des Schutzes und idie Folgen einer Verletzung ergeben sich ohne weiteres idaraus, daß der Vortragende in Ansehung der den Vortrag fixierenden Vorrichtung in der gleichen Weise geschützt wird wie der Bearbeiter eines Wenkes in Ansehung seiner Bearbeitung ( $\$ 2$ Satz 2 des Gesetzes vom 19. Juni 1901); daß das Originalwerk als solches geschützt sei, ist für den Schutz der Bearbeitung nicht erfonderlich."

Diese rechtliche Gleichstellung der Schallvorrichtung - und nicht etwa der unfixierten Wiedergabeleistung ides ausülbenden Künstlers - mit einem Geisteswerk bot sich deshalb an, weil idie an sich flüchtige, an Raum und Zeit geknüpfte Darbietung des ausübenden Künstlers nur mit ihrer Festlegung auf einen Tonträger von der unmittelibaren Bindung an seine Person und an den vergänglichen Wiedergabevorgang befreit und erst damit wiederholter Auswertung zugänglich gemacht wwird. Gegenstand dieses Schutzes bildet aber die Schallvorrichtung nicht etwa in ihrer Eigenschaft als stoffliches Erzeugnis, sondern allein als Träger der Wiedergabeleistung des "vortragenden" Künstlers. Dies folgt zwangsläufi.g daraus, daß der Gesetzgeber nur in dem inidividuellen Element, das jeder Wiedergabeleistung anhaftet, die Rechtfertigung für die Zuerkennung eines urheberrechtlich ausgestalteten Schutzes erblickt und dementsprechend nicht den Hersteller des Tonträgers - den Schallplattenfabrikanten -, sondern den ausübenden Künstler einem Werkbearbeiter gleichgestellt und seiner Person die Bearbeitungsurheberrechte zugeordnet hat ( $\begin{aligned} & \$ \\ & 2\end{aligned}$ Abs. 2 S. 3 LitUrhG). Da aber die Wiedrergabeleistung des ausübeniden Künstlers, auch wenn sie auf einem Leistungsträger festgehalten ist, im Sinne des Urheberrechtes "aufgeführt" werden kann, ist aus dem Wortlaut des $\S 2$ Abs. 2 LitUrhG nur zu entnehmen, daß dem ausübenden Künstler mit der Zuerkennung eines Bearbeiterurheberrechts an Ider Schallvorrichtung auch das Recht zugebilligt werden sollte, über die öffentliche Darbietung seiner Leistung mittels dieses Tonträgers $\mathrm{zu}$ bestimmen.

2. Aber auch soweit die Klägerinnen aus der Gesetzes's y tematik folgern wollen, daß das Bearbeiterurheberrecht des ausübenden Künstlers an seiner festgelegten Leistung auf ldas Recht zur Vervielfältigung und Verbreitung des Tonträgers beschränkt sei, kann ihnen nicht ibeigepflichtet werden. Es ist zwar richtig, idaß $\S 22$ a LitUrhG, auf den die Revision in diesem Zusammenhang verweist, für Werke, die auf Schallvorrichtungen festgelegt sind, in gewissem Umfange eine Auffühnungsfreiheit vorsieht. Diese Aufführungsfreiheit galt aber bereits bei Erlaß ider Novelle von 1910, die die fragliche Bestimmung in das Gesetz betr. das Urheberrecht an Wenken der Literatur und Tonkunst einfügte, nicht uneingeschränkt, da sie nur für r e c h.t m ä B i.g hergestellte Schallvorrichtungen in Betracht kam. Die Meinung der Revision, daß der Gesetzgeber, falls er den ausübenden Künstlern durch § 2 .Abs. 2 LitUrhG ein Aufführungsrecht an den von ihnen ibespielten oder besungenen Schallvorrichtungen eingeräumt haben sollte, ihnen idieses Aufführungsrecht gleichzeitig durch $\S 22$ a LitUrhG im vollee $\mathrm{Um}$ f a $\mathrm{ng}$ entzogen habe, ist hiernach nicht zutreffend. Die Gesetzessystematik, die die Rechte ides ausübenden Künstlers an der Schallivorrichtung zunächst vollinhaltlich den Rechten an einer Werkbearbeitung gleichstellt und sodann in $\S 22$ a LitUrhG Ausnahmen vom Aufführungsrecht vorsieht, soweit mechanische Musikaufführungen in Frage stehen, ohne zwischen dem echten Urheberrecht und dem fiktiven Bearbeiterurheberrecht des ausübenden Künstlers zu unterscheiden, spricht hiernach entgegen der Meinung der Klägerinnen gerade dafü̈r, daß auch bei der Fassung des $\S 22$ a LitUrhG von einer Gleichschaltung beider Rechte nach Inhalt und Umfang ausgegangen worden ist (so auch RGZ 153, 1 ff, insbeson'dere 23). Aus ider Gesetzessystematik kann hiernach nur in Ubereinstimmung mit dem Berufungsgericht gefolgert wenden, daß in allen Fällen, in denen der Ausnahmetatbestand des $\S 22$ a LitUrhG $n$ ich $t$ eingreift, idies in gleicher Weise für den Werkschöpfer wie für den ausübenden Künstler zu 
gelten hat, soweit ihm gemäß § 2 Abs. 2 LitUrhG ein fiktives Bearbeiterurheberrecht an seiner auf einem Tonträger festgehaltenen Leistung zusteht.

3. Damit allein freilich ist idie hier strittige Frage, ob öffentliche Schallplattenaufführungen der Erlaubnis der ausülbenden Künstler, ideren Leistungen auf den Schallplatten festgelegt sind, oder ihrer Rechtsnachfolger bedürfen, noch nicht entschieden. Wie der Senat in seinem Urteil vom 6. November 1953 (BGHZ 11, 135 - Schallplatten-Lautsprecher-Ubertragung) Idargelegt hat, handelt es sich bei dem gegenwärtig üblichen Tonaufnahme- und Tonwiedergabeverfahren, das auf dem elektro-akustischen Prinzip beruht, um eine technische Errungenschaft, die außerhalb des Vorstellungskreises des Gesetzgebers von 1910 gelegen hat und die eine ganz andersartige und weitengehende Auswertung von Schallvorrichtungen ermöglicht, als idies der Gesetzgeber bei Erlaß der Novelle von 1910 in Betracht ziehen konnte. Wenn aber ein zur Entscheidung stehender Interessenkonflikt bei Erlaß des Gesetzes noch nicht ins Auge gefaßt werden konnte, weil er erst durch Veränderung der tatsächlichen Verhältnisse nach diesem Zeitpunkt in Erscheinung getreten ist, so muß auch gegenüber einem sprachlich eindeutigen Gesetzeswortlaut eine Auslegung nach dem Sinn und Zweck ides Gesetzes Platz greifen (BGHZ 2, 176, 184; 11, 135; 17, 266, 278). Der enkennende Senat ist in der Entscheidung vom 6 . November 1953 unter Berücksichtigung der dem Urheberrecht zugrunde liegenden Wertentscheidungen zu dem Ergebnis ıgelangt, daß öffentliche Musikdarbietungen, idie sich dder heute üblichen elektro-akustischen Wiedergabetechnik bedienen, ider Erlaubnis der Werksch ö p f e r bedürfen, weil solche $\mathrm{Mu}$ sikaufführungen nicht durch die eng auszulegende Ausnahmevorschrift des $\S 22$ a LitUrhG gedeckt sind. Es bleibt aber zu prüfen, ob nach dem Sinn und Zweck ides $\$ 2$ Albs. 2 LitUrhG die Gleichstellung der Rechte ides ausübenden Künstlers an der Schallvorrichtung mit den Rechten eines Werkbearbeiters auch für diesen vom Gesetzgeber nicht berücksichtigten neuartigen Sachverhalt zu gelten hat oder ob insorweit eine einschränkende Auslegung des $\S 2$ Abs. 2 LitUrhG geboten ist.

a) Das Berufungsgericht hat nicht verkannt, daß durch $\$ 2$ Abs. 2 LitUrhG mittelbar ein Schutz der Enzeugnisse der Industrie für mechanische Musikinstrumente gegen unbefugte Nachbildung angestrebt wurde und daß es gerade diese Industrie war, die ıdarauf drang, ıdie Auffühnungsfreiheit fiür die von ihr hergestellten Schallträger durch die Einfügung von $\$ 22 \mathrm{a}$ in das Gesetz sicherzustellen. Zu Recht aber geht das Berufungsgericht davon aus, daß dieser nur die damaligen Verhältnisse berücksichtigende Anlaß für die durch $\S 22$ a getroffene Regelung allein es nicht rechtfertige, $\S 2$ Abs. 2 LitUrhG entgegen seinem Wortlaut im Wege restriktiver Gesetzesauslegung einzuschränken, falls nicht 'weitere, idem Gesamtsystem ides Urheberrechts oder allgemeinen Rechtsvorschriften mu entnehmende Wertentscheidungen des Gesetzgebers idies igebieten.

b) In diesem Zusammenhang macht die Revision der Klägerinnen geltend, daß durch die Anerken- nung eines Aufführungsrechtes des ausübenden Künstlers an seiner auf einer Schallvorrichtung festgelegten Leistung die Rechte der Werkschöpfer empfindlich beeinträchtigt würden. Würde der ausübende Künstler oder ider Schallplattenhersteller als sein Rechtsnachfolger für ıdie öffentliche Aufführung von Schallplatten older sonstiger Tonträger Lizenzgebühren erheben können, so würde dies einen Rückgang des 'Schallplattenumsatzes und damit der Lizenzeinnahmen lder Werkschöpfer aus einer Verwertung ihres mechanischen Vervielfältigungsrechtes zur Folge haben. Auch würde durch idie Zahlung von Aufführungsgebühren an die Beklagten ein erheblicher Teil der Geldmittel aufgezehrt, die die Musikveranstalter für öffentliche Musikdarbietungen zu zahlen !bereit und in der Lage seien, was sich zwangsläufig auf die Höhe der an die Werkschöpfer zu zahlenden Aufführungstantiemen auswirken müsse. Wenn aber die ausübenden Künstler oder die Tonträgerindustrie, was zu befürchten sei, die Benutzung von Tonträgern zu öffentlichen Aufführungen schlechthin - also auch bei Angebot einer angemessenen Vergütung - untersagten, so entgingen den Werkschöpfern darüber hinaus die ihnen sonst zufallenden Aufführungstantiemen für öffentliche Darbietungen mechanischer Musik. Da erfahrungsgemäß in zahlreichen Fällen mechanische $\mathrm{Mu}$ sik nicht idurch unmittelbare Darbietungen lebender Künstler ersetzt werde, würde auch dies notwendig einen erheblichen Einnahmeausfall der Werkschöpfer zur Folge haben. Das aber laufe auf eine dem Geist des Urheberrechts widersprechende wirtschaftliche Aushöhlung der Nutzungsbefugnisse hinaus, die dem schöpferisch tätigen Menschen an seinem Werk vorbehalten seien.

Diesen Ausführungen der Revision kann nicht beigepflichtet werden. Werke der Literatur und Tonkunst bedürfen zu ihrer lautlichen Wiedergabe stets der Vermittlung durch den ausübenden Künstler. Das Musikwerk kann lder breiten Masse des Publikums überhaupt nur durch klingende Wiedergabe zugänglich gemacht werden und ist vom Werkschöpfer von vornherein für liese Wiedergabeart bestimmt. Es ist nun niemals in Zweifel gezogen worıden, ıdaß der ausübende Künstler weder gezwungen werden kann, sein Können für diese Werkvermittlung zur Verfügung zu stellen, noch daß ihm ein angemessenes Entgelt für seine Leistungen etwa aus dem Gesichtspunkt abzusprechen sei, dies könnte eine Schmälerung der Einnahmen der Werkschöpfer aus ihrem Vervielfältigungs- und Aufführungsrecht zur Folge haben. Ist der Genuß eines Geisteswerkes von der Mittlertätigkeit Dritter abhängig, so ist es nur gerecht, wenn der Werkschöpfer sich mit den jeweiligen Werkmittlern in das wirtschaftliche Entgelt teilen muß, das ider Werknutzer für die Auswertung des Werkes aufzurwenden bereit und in der Lage ist. Soweit Werke der Tonkunst unmittelbar durch lebende Musiker dargeboten werden, ist dies von dem Urheber auch stets als Selbstverständlichkeit hingenommen wonden. Hinsichtlich der Frage des Entgeltes aber kann es, soweit hierdurch die Interessen ider Werkschöpfer berührt werden, keinen grundsätzlichen Unterschied ausmachen, ob der ausübenide Künstler seine Wiedergabeleistung unmit- 
telbar oder unter Zwischenschaltung eines Tonträgers für öffentliche Aufführungen zur Verfügung stellt. In der Regel wird sogar die Vergütung, die für die ausübenden Künstler für öffentliche Darbietungen ihrer Leistung mit Hilfe von Schallträgern in Betracht kommt, von erhelblich geringerer Höhe sein als die Entlohnung, die ihnen für unmittelbare $\mathrm{Mu}-$ sikdarbietungen üblicherweise geboten wird. Es steht deshalb kaum zu befürchten, daß Musikveranstalter, wenn sie auch an tdie ausübenden Künstler Aufführungsgebühren für mechanische Musikaufführungen entrichten müssen, auf diese verzichten und 'damit die zusätzlichen Einnahmequellen, die die Vervollkommnung ider mechanischen Musik den Urhebern erschlossen hat, versiegen werden. Eine Beteiligung der ausübenden Künstler oder der Tonträgerindustrie an diesen Einnahmequellen aber steht dem urheberrechtlichen Schutzgedanken so wenig entgegen, wie beispielsweise die übliche Beteiligung des Notenverlegers an den Urhebergebühren für Aufführungen der von ihm verlegten Musikwerke.

Soweit sich aber die Klägerinnen darauf berufen, die Belastung von Schallvornichtungen mit zusätzlichen Aufführungsgebühren zugunsten der aufführenden Künstler könne einen Rückgang des Schallplattenabsatzes und damit eine Minderung der Einnahmen der Urheber aus ihren Vervielfältigungsrechten zur Folge haben, hat das Berufungsgericht zu Recht darauf hingewiesen, daß dieser etwaige Einnahmeausfall durch die zusätzlichen Aufführungstantiemen ausgeglichen wird, die den Werkschöpfern dadurch anfallen, daß die mit Hilfe der Darbietungen ausübender Künstler hergestellten Schallträger erfahrungsgemäß zu öffentlichen Musikaufführungen auch in Fällen benutzt werden, in denen lebende Musikaufführungen nicht in Betracht kommen. Es läßt nach alledem keinen Rechtsirrtum erkennen, wenn das Berufungsgericht davon ausgeht, daß eine wirtschaftliche Aushöhlung des Urheberrechts der Werkschöpfer durch die Anerkennung eines Aufführungsrechtes der ausübenden Künstler an Schallvorrichtungen im Sinne von $\S 2$ Abs. 2 LitUrhG nicht $\mathrm{zu}$ befürchten sei. Hierbei bedarf es keiner Stellungnahme zu der weiteren Frage, ob etwa die ausübenden Künstler oder ihre Rechtsnachfolger sich dem Vorwurf eines Rechtsmißbrauchs aussetzen würden, falls sie die Einwilligung in die Benutzung der von ihnen bespielten Tonträger zu öffentlichen Aufführungen selbst dann untersagen würden, wenn ihnen ein angemessenes Aufführungsentgelt angeboten wird (vgl. BGHZ 18, 44, 57 - Fotokopie); denn der Parteivortrag bietet für die Annahme, daß ein solcher Sachverhalt in Frage stehe, keine greifbaren Anhaltspunkte.

c) Entgegen der Auffassung der Revision läßt sich eine einschränkende Auslegung des $\S 2$ Abs. 2 LitUrhG auch nicht aus dem Gesichtspunkt rechtfertigen, daß andernfalls die Allgemeinheit in unzumutbarer Weise beeinträchtigt würde. Die Klägerinnen machen insoweit geltend, daß als Träger des fiktiven Bearbeiterurheberrechts anders als bei den Werkschöpfern eine unübersehbare Vielzahl von Personen in Betracht kämen und es deshalb für die Veranstalter öffentlicher Tonträgerdarbietungen eine unverhältnismäßige, vom Gesetzgeber nicht in Betracht gezogene Belästigung darstelle, wenn sie vor Durchführung ihrer Veranstaltung die Einwilligung aller, ihnen in der Regel im einzelnen gar nicht bekannten oder erkennbaren ausübenden Künstler einholen müßten, deren Leistungen auf den fraglichen Tonträgern festgelegt seien. Dieses Argument übersieht, daß das gleiche für das Vervielfältigungsund Verbreitungsrecht gilt, die sich hieraus etwa ergebenden Schwierigkeiten hinsichtlich der Aktivlegitimation den Gesetzgeber aber nicht gehindert haben, die Rechte des ausübenden Künstlers an der Schallvorrichtung den Rechten eines Werkbearbeiters gleichzuondnen. Hierbei ging der Gesetzgeber davon aus, wie die Gesetzesbegründung ausdrücklich hervorhebt, daß in der Praxis diese Rechte regelmäßig vertraglich auf den Hersteller der Schallvorrichtung übertragen werden, wie dies auch im Streitfall nach dem übereinstimmenden Parteivortrag $\mathrm{zu}$ unterstellen ist. Im übrigen lassen sich Schwierigkeiten beim Erwerb des hier strittigen Aufführungsrechtes auch durch dessen Ubertragung auf eine einheitliche Verwertungsgesellschaft beheben, wie die Entwicklung der Klägerin zu 2) zeigt, die das Aufführungsrecht der Werkschöpfer betreut.

d) Schließlich sind auch die Bedenken, die die Revision der Klägerinnen aus den Unterschieden in den Schutzgegenständen, der Schaffensweise und der Interessenlage herleiten will, nicht begründet.

aa) Es trifft zwar zu, daß Schutzobjekt des Urheberrechts ein immaterielles Gut, ein Geisteswerk, ist, während das Bearbeiterurheberrecht des ausübenden Künstlers an ein materielles Gut, die Schallvorrichtung geknüpft ist. Richtig ist auch, daß die Tätigkeiten, die die fraglichen Ausschließlichkeitsrechte auslösen - die schöpferische Arbeit des Werkschaffenden und die Wiedergabeleistung des ausübenden Künstlers - , ihrer Natur nach unterschiedlich sind. Hierbei kann offen bleiben, ob nicht auch einer "nachschaffenden" Wiedergabeleistung eine schöpferische Eigenart anhaften kann, die es rechtfertigt, ihr auch ohne körperhafte Festlegung auf einem Leistungsträger aus allgemeinen urheberrechtlichen Gesichtspunkten einen Schutz zuzuerkennen (vgl. hierzu Urteil des Senats vom 31. Mai 1960 I ZR

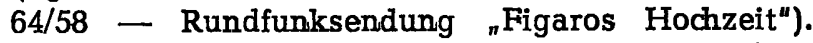
Diese im Schrifttum umstrittene Frage bedarf hier jedoch deshalb keiner Entscheidung, weil die Beklagten nur in Ansehung von Tonträgern Aufführungsrechte in Anspruch nehmen, und zwar ohne Rücksicht darauf, ob die auf den Tonträgern festgehaltenen Leistungen schöpferische Elemente aufweisen. Der Schutz aus $\S 2$ Abs. 2 LitUrhG aber greift unabhängig davon ein, ob die festgelegte Wiedergabeleistung die für den Werkbegriff im urheberrechtlichen Sinn maßgebende Voraussetzung einer eigenschöpferischen Prägung erfüllt (vgl. Urteil des Senats vom 31. Mai 1960 I ZR 7,1/58 Orchester Graunke).

Gerade die Erkenntnis der Verschiedenheit der in Frage stehenden Schutzgegenstände hat dazu geführt, daß die Gleichstellung einer Schallvorrichtung mit einer Werkbearbeitung in $\$ 2$ Abs. 2 LitUrhG in Rechtsprechung und Schrifttum nahezu einhellig als eine "Fiktion" gekennzeichnet wird. Von einer 
Fiktion kann aber nur gesprochen werden, wenn unzweifelhaft $\mathrm{u} \mathrm{ngl}$ l i $\mathrm{c}$ h e Tatbestände nach dem Willen des Gesetzgebers hinsichtlich der Rechtsfolgen gleich behandelt werden soll.

Fraglich kann hiernach nur sein, ob diese vom Gesetzgeber gewollte Gleichstellung verschiedenartiger Tatbestände hinsichtlich der sich an sie knüpfenden Rechtsfolgen bei dem von ihm nicht berücksichtigten neuartigen Tatbestand von mechanischen Musikaufführungen, die nicht unter die Aufführungsfreiheit des $\S 22$ a LitUrhG fallen, zu Ergebnissen führt, die mit Sinn und Zweck des $\S 2$ Abs. 2 LitUrhG oder allgemeinen Rechtsgrundsätzen unvereinbar ist. Dies aber kann nicht anerkannt werden. Wenn auch davon auszugehen ist, daß Anlaß für die fragliche Gesetzesbestimmung das Bestreben bildete, die Industrie mechanischer Musikinstrumente gegen unbefugte Nachbildungen zu schützen, und diese Industrie bei Erlaß dieser Bestimmung nach dem damaligen Stand der Technik für eine Aufführungsfreiheit mechanischer Musikdarbietungen eingetreten ist, so muß doch der Veränderung der Interessenlage Rechnung getragen werden, die für die Tonträgerindustrie dadurch eingetreten ist, daß die Technik neue Möglichkeiten erschlossen hat, Tonträger für öffentliche Musikdarbietungen $\mathrm{zu}$ benutzen, die nach der Rechtsprechung des erkennenden Senats dem Aufführungsrecht der Werkschöpfer unterliegen. Damit aber hat sich, wie der vorliegende Rechtsstreit und auch die Bemühungen der Tonträgerindustrie erweisen, de lege ferenda ein eigenes selbständiges Aufführungsrecht an den von ihnen hergestellten Erzeugnissen zugebilligt zu erhalten, der Standpunkt der Tonträgerindustrie zur Aufführungsfreiheit mechanischer Musikdarbietungen grundlegend geändert. $\mathrm{Ob}$ diese Interessenlage es rechtfertigt, der Tonträgerindustrie im Gegensatz zur gegenwärtigen Gesetzeslage ein originäres, nicht von den ausübenden Künstlern abgeleitetes Aufführungsrecht zu gewähren, steht hier nicht zur Erörterung. Es ist vielmehr nur eine Klarstellung geboten, daß es dem Schutzgedanken des § 2 Abs. 2 LitUrhG, soweit diese Vorschrift mittelbar im Interesse der Schallplattenhersteller ergangen ist, nicht zuwiderläuft, wenn entsprechend dem Gesetzeswortlaut eine Gleichstellung der Rechte an der Schallvorrichtung mit denen an einer Werkbearbeitung im Sinn von $\S 2$ Abs. 1 LitUrhG hinsichtlich des Aufführungsrechtes auch angenommen wird. Hierbei kann dahinstehen, ob die starke $\mathrm{Zu}$ nahme offentlicher Musikdarbietungen mittels Schallträger die Gefahr eines Rückgangs der Nachfrage nach Schallplatten für den privaten Bedarf heraufbeschwört. Denn jedenfalls werden die Schallplatten durch solche öffentlichen Darbietungen in weitergehendem Ausmaß genutzt als durch ein Abspielen im privaten Bereich. Wenn die Schallplattenhersteller für eine solche weitergehende Nutzung ihrer nur für den Privatgebrauch in den Verkehr gebrachten Schallplatten über die Forderung von Aufführungsgebühren ein zusätzliches Entgelt anstreben, so entspricht dies nur dem Grundsatz der Leistungsäquivalenz, das für Güterumsatzgeschäfte in der Regel maßgebend ist.

Aber auch aus dem Umstand, daß nach Satz 3 des $\S 2$ Abs. 2 LitUrhG die Rechte an der Schallvorrich. tung originär in der Penson des ausübenden Künstlers entstehen, dessen persönlicher Vortrag festgehalten wird, ergeben sich gegen den vom Berufungsgericht vertretenen Standpunkt keine durchgreifenden Bedenken. Dies könnte nur dann der Fall sein, wenn ein schutzwürdiges Interesse der ausübenden Künstler an einem Aufführungsrecht an den mit ihrer Zustimmung hergestellten und in den Verkehr gebrachten Tonträgern ernsthaft nicht in Betracht kommen könnte. So aber liegt es nicht.

Wenn die Revision meint, der ausübende Künstler könne sich bereits durch eine entsprechende Ausgestaltung seines Vertrages mit dem Hersteller des Tonträgers gegen eine von ihm nicht gebilligte Verwertung des Tonträgers ausreichend sichern, so verkennt sie, daß ihm der Vertrag immer nur Rechte gegen seinen Vertragspartner, nicht aber gegen Dritte gewährt, die in den Besitz des Tonträgers gelangen. Die Festlegung der Wiedergabeleistung des ausübenden Künstlers auf einen Tonträger gegen seinen Willen wind zu Recht nahezu einhellig als Mißachtung seiner Persönlichkeit mißbilligt. Sie ist, wie der erkennende Senat in seiner Entscheidung vom 31. Mai 1960 I ZR 64/58 (Rundfunksendung "Figaros Hochzeit") näher dargelegt hat, sowohl nach allgemein bürgerlich-rechtlichen wie persönlichkeits- und wettbewerbsrechtlichen Grundsätzen rechtswidrig. Aber auch wenn der ausübende Künstler der Festlegung seiner Leistung zugestimmt und hierfür eine Vergütung empfangen hat, ist damit sein Interesse, über Art und Umfang der Verwertung des Tonträgers auch mit Wirkung gegenüber vertraglich nicht gebundenen Dritten selbst entscheiden zu können, nicht erschöpft. Ein ausübender Künstler, der etwa nur bereit ist, Tonbandaufnahmen seiner Leistung für Rundfunksendungen zu gestatten oder lediglich für den Privatgebrauch bestimmte Schallplatten zu bespielen, kann durch die Verwendung dieser Tonträger für beliebige öffentliche Aufführungen wie beispielsweise als musikalische Untermalung für Kinoreklamen, in Gaststätten, bei Sportvenanstaltungen, auf Jahrmärkten etc. nicht nur in seinen künstlerischen und damit seinen persönlichkeitsrechtlichen Belangen, sondern auch in seiner wettbewerbsrechtlichen Position empfindlich beeinträchtigt werden (vigl. hierzu auch Urteil des Senats vom 31. Mai 1960 I ZR 87/58 - Künstlerlizenz bei öffentlicher Wiedergabe von Rundfunksendungen). Aus diesem Grunde gehen auch die Bestrebungen der ausübenden Künstler seit geraumer Zeit dahin, auf internationaler Basis eine Konvention zu erreichen, die ihnen ein Aufführungsrecht in allen der Konvention angeschlossenen Staaten an den mit ihrer Einwilligung hergestellten Tonträgern gewährleistet, mögen diese auch mit ihrer Einwilligung in den freien Handel gelangt sein. $\mathrm{Ob}$ diese Bestrebungen de lege ferenda berechtigt sind oder ob dem etwa widersprechende Interessen der Werkschöpfer es zweckmäßig erscheinen lassen, die Rechte der ausübenden Künstler für diese Nutzungen ihrer Leistung auf eine angemessene Vergütung zu beschränken, wie dies der deutsche Ministerialentwurf zum Urheberrechtsgesetz vorsieht (vgl. Entwurf $\S 84$ ), ist hier nicht zu erörtern. Für die g eg en wär ti ge Gesetzeslage in der Bundesrepublik, die nach dem ein- 
deutigen Wortlaut des $\S 2$ Abs. 2 LitUrhG dem ausübenden Künstler einen urheberrechtlich ausgestalteten Schutz an seiner fixierten Leistung zubilligt, genügt es festzuhalten, daß auch vom Blickpunkt der Interessenlage des ausübenden Künstlers aus diese geltende Regelung der Einbeziehung des Aufführungsrechtes in diesen Schutz nicht entgegensteht.

bb) Der Senat vermag sich auch nicht der von der Revision weiterhin vertretenen Auffassung anzuschließen, wonach die Anerkennung eines Aufführungsrechtes des ausübenden Künstlers an mit seiner Einwilligung in den Verkehr gebrachten Schallplatten gegen allgemeine Prinzipien unserer Rechtsordnung verstoßen solle, weil ein Gegenstand, der mit Zustimmung des Berechtigten in den freien Handel gebracht worden sei, von dem Erwerber auch nach Belieben verwendet werden könne. Nach einhelliger Meinung darf das Eigentumsrecht an Gegenständen, die ein urheberrechtlich geschütztes Werk verkörpern, nur unbeschadet des Urheberrechts ausgeübt werden (RGZ 79, 397 - FrescoGemälde). Die Sachherrschaft des Eigentümers hat somit dort ihre Grenze, wo sie Urheberrechte verletzt. Eine Schöpfung des urheberrechtlichen Aufführungsrechtes durch das Inverkehrbringen von Festlegungsexemplaren des geschützten Gutes scheidet schon deshalb aus, weil im Urheberrecht nur das Recht zur Verbreitung von Werkstücken, nicht dagegen das Recht zu unkörperlichen Werkwiedergaben wie Aufführung, Vorführung oder Sendung erschöpft werden kann (BGHZ 5, 116 - Parkstraße 13, Ulmer Urheber- und Verlagsrecht 2. Aufl. S. 196). Da aber der Gesetzgeber das Recht des ausübenden Künstlers an der Schallvorrichtung, auf der seine Wiedergabeleistung festgelegt ist, ausdrücklich als Bearbeiterurheberrecht ausgestaltet hat, dem Werkbearbeiter das Aufführungsrecht aber auch verbleibt, wenn Vervielfältigungsstücke seiner Werkbearbeitung in den Verkehr gebracht worden sind, muß das gleiche auch für das Aufführungsrecht des ausübenden Künstlers an seiner festgelegten Wiedergabeleistung gelten. Dem steht nicht entgegen, daß es sich hier in Wahrheit nicht um einen Geistesschöpfungsschutz, sondern um einen Leistungsschutz handelt. Zu Unrecht meinen die Klägerinnen, eine Beschänkung der sich aus dem Eigentum ergebenden Herrschaftsrechte durch Rechte Dritter könne nur beim "echten" Urheberrecht in Betracht kom. men. Vielmehr können auch außerhalb des eigentlichen Werkschöpfungsschutzes an ein und demselben körperlichen Gegenstand von vornherein neben dem Eigentumsrecht mehrere privatrechtlich geschützte Ausschließlichkeitsrechte, die die Befugnisse des Eigentümers beschränken, entstehen, wie beispielsweise das Recht am eigenen Bild ( $\$ \S 22 \mathrm{ff}$ KunstUrhG) erweist, das kein Urheberrecht, sondern ein Persönliçkeitsrecht ist, gleichwohl aber wie ein Urheberrecht wirkt.

cc) Es kann aber auch nicht anerkannt werden, daß die schutzwürdigen wirtschaftlichen Interessen der ausübenden Künstler sowie der Schallplattenhersteller mit dem Verkauf der Schallplatte ihre Erledigung finden. Diese Ansicht der Revision wird der Tatsache nicht gerecht, daß das Urheberrecht bei dem von ihm angestrebten Interessenausgleich zwi- schen den Urhebern und der Allgemeinheit private und öffentliche Aufführungen gerade wegen der andersartigen Interessenlage rechtlich unterschiedlich behandelt und nur die öffentliche Aufführung in das Ausschließlichkeitsrecht des. Urhebers einbezieht. Dieser Unterschied in der. Interessenlage ist aber auch gegeben, soweit die ausübenden Künstler und die Tonträgerhersteller in Frage stehen. Denn durch öffentliche Aufführungen wird das geschützte Gut in der Regel einem sehr viel umfassenderen Hörerkreis zugänglich gemacht als durch in häuslichem Bereich durchgeführte Aufführungen. Hierbei kann, wie bereits hervorgehoben wurde, dahinstehen, ob öffentliche mechanische Musikdarbietungen sich günstig oder ungünstig auf den Absatz von Schallplatten auswirken und ob durch sie die Aussicht des ausübenden Künstlers, zu unmittelbaren Darbietungen herangezogen zu werden, in einer ins Gewicht fallenden Weise geschmälert wird. Entscheidend ist vielmehr, daß die mit ihrer Festlegung geschützte Wiedergabeleistung durch öfentliche Aufführungen in sehr viel weitergehendem Ausmaß ausgenutzt wird als durch ihre Hörbarmachung innerhalb der Privatsphäre und daß die Veranstalter öffentlicher mechanischer Musikdarbietungen hieraus zumeist einen gewerblichen Nutzen ziehen, der bei privaten Aufführungen nicht in Betracht kommt. Auch für das fiktive Bearbeiterurheberrecht des $\S 2$ Abs. 2 LitUrhG gilt aber entgegen der von den Klägerinnen vertretenen Ansicht der allgemeine Leitgedanke, den die Rechtsprechung für den eigentlichen Werkschöpfungsschutz anerkannt hat, daß nämlich der Urheber tunlichst überall da, wo aus seinem Geisteswerk ein wirtschaftlicher Nutzen gezogen wird, daran zu beteiligen ist (so ausdrücklich das Reichsgericht in seiner Entscheidung über Schallplattensendungen im Rundfunk, RGZ 153, 1, 22).

Der weitere Einwand der Klägerinnen, es widerspreche der allgemein gültigen Güterumsatzordnung, wenn die ausübenden Künstler, obwohl sie für ihre Leistung bereits von den Schallplattenherstellern honoriert worden seien, an dem Ertrag aus dem "bestimmungsgemäßen" Gebrauch der im freien Verkehr befindlichen Schallplatten beteiligt sein wollten, verkennt gleichfalls, daß die festgelegte Wiedergabeleistung des ausübenden Künstlers - in ähnlicher Weise wie ein Geisteswerk in der verschiedenartigsten Weise ausgewertet werden kann und daß ein schutzwürdiges Interesse des ausübenden Künstlers nicht von der Hand zu weisen ist, allein darüber zu entscheiden, für welche dieser Nutzungsarten er seine Leistungen freigeben will. Ist er nur bereit, seine Zustimmung zur Herstellung von Tonträgern für den privaten Gebrauch zu erteilen und wird er nur für eine solche, die öffentliche Aufführung nicht einschließende Rechtseinräumung von dem Hersteller des Tonträgers entlohnt, so liegt es eben nicht mehr im Rahmen des "bestimmungsgemäßen" Gebrauches des Tonträgers, wenn er für öffentliche Aufführungen benutzt wird. Für diese von ihm nicht gestattete besondere Nutzungsart seiner Leistung ist bei solcher Fallgestaltung aber dem ausübenden Künstler auch kein Entgelt zugeflossen.

Die Eigenart der Rechtslage im Vergleich zu sonstigen Austauschgeschäften über materielle Güter 
liegt darin begründet, daß das in den Verkehr gebrachte körperliche Gut - die Schallvorrichtung nicht schlechthin als stoffliches Erzeugnis, sondern nur in seiner Eigenschaft als "Träger" der auf ihm festgelegten Wiedergabeleistung des ausübenden Künstlers wie ein Geisteswerk geschützt ist und auch nur durch diese Leistung seinen Verkehrswert erhält. In die Belange des ausübenden Künstlers aber wird durch öffentliche Darbietungen in ganz anderer Weise als durch eine Benutzung des Tonträgers im privaten Bereich eingegriffen. Das unterscheidet die Interessenlage des ausübenden Künstlers grundlegend von derjenigen anderer Personen, die außer ihm an der Herstellung des Tonträgers mitgewirkt haben, wie beispielsweise des Toningenieurs. Hierin liegt die Rechtfertigung dafür, daß das rechtliche Schicksal der festgelegten Wiedergabeleistung durch $\S 2$ Abs. 2 LitUrhG unabhängig davon gestaltet worden ist, welches die jeweiligen Eigentumsverhältnisse an dem stofflichen Träger dieser Leistung sind.

Es kann somit der Ansicht der Revision nicht beigepflichtet werden, daß es mit allgemeinen Rechtsgrundsätzen, insbesondere mit der Eigentumsordnung unvereinbar sei, wenn in Ubereinstimmung mit dem Wortlaut des $\S 2$ Abs. 2 LitUrhG davon ausgegangen wird, daß das fiktive Bearbeiterurheberrecht des ausübenden Künstlers an der auf seinem persönlichen Vortrag beruhenden Schallvorrichtung auch das Aufführungsrecht umfaßt. Ob den dargelegten Interessen der ausübenden Künstler nur durch die Zuerkennung eines Ausschließlichkeitsrechtes in Ansehung öffentlicher Aufführungen oder etwa auch durch die Einräumung bloßer Vergütungsansprüche in ausreichender Weise vom Gesetzgeber Rechnung getragen werden kann, ist eine Frage, die der Urheberrechtsreform vorbehalten bleiben muß. Denn sieht das Gesetz, wie dies in der Bundesrepublik zutrifft, insoweit urheberrechtlich ausgestaltete Ausschließlichkeitsrechte vor, so ist der Richter hieran gebunden, weil es dem Gesetzgeber freisteht, auch durch eine solche Regelung den dargelegten Interessen Schutz zu gewähren.

4. Allein diese Gesetzesauslegung steht auch im Einklang mit der Rechtsprechung des Reichsgerichts, wonach die Rundfunksendung von Schallplatten dem Ausschließlichkeitsrecht des vortragenden Künstlers aus $\S 2$ Abs. 2 LitUrhG untersteht (RGZ 153, $1 \mathrm{ff}$ ). Zu Unrecht wollen die Klägerinnen einen Unterschied zu der hier strittigen Frage des Aufführungsrechtes daraus herleiten, daß das Reichsgericht die Rundfunksendung auch unter den Verbreitungsbegriff eingeordnet hat (RGZ 113, 413, Tor und Tod; 136, 377, 381 - Lautsprecher). Denn das Reichsgericht hat in den angeführten Entscheidungen die Rundfunksendung von Schallplatten a $u \mathbf{c h}$ als öffentliche Aufführung im Sinne des $\S 11$ Abs. 2 LitUrhG gewertet, und zwar unter Hinweis darauf, daß die Ubermittlung von Werken der Tonkunst im Gesetz betr. das Urheberrecht an Werken der Literatur und der Tonkunst stets, auch bei mechanischer Wiedergabe "Aufführung" genannt werde (RGZ 153, 17, 19; vgl. auch RGZ 136, 377). Dieses öffentliche Aufführungsrecht aber hat das Reichsgericht auch dem ausübenden Künstler an der von ihm bespielten Schallplatte zugesprochen, wobei es hervorgehoben hat, daß infolge der ausdrücklichen rechtlichen Gleichstellung des Vortragenden mit einem Bearbeiter trotz aller Unterschiede zwischen seiner Wiedergabeleistung und einer Werkschöpfung die allgemeinen Leitgedanken und Grundsätze der Rechtsanwendung Geltung haben müßten, die für das Urheberrecht an einem Geisteswerk herausgebildet worden seien.

Die Erwägungen, die das Reichsgericht zu dem Ergebnis geführt haben, daß die Rundfunksendung von Schallplatten an die Erlaubnis der ausübenden Künstler, die die Schallplatten besungen oder bespielt haben, gebunden sei, rechtfertigen diese Folgerung aber auch dann, wenn die Rundfunksendung als dem Urheber vorbehaltene Werknutzung eigener Art gewertet wird, die weder unter den Aufführungs- noch unter den Verbreitungsbegriff fällt. Denn auch bei solcher rechtsdogmatischen Einordnung (vgl. Urteil des Senats vom 31. Mai 1960 I ZR 87/58 - Künstlerlizenz bei öffentlicher Wiedergabe von Rundfunksendungen) unterliegt das Senderecht dem Ausschließlichkeitsrecht des vortragenden Künstlers, das das Senderecht mitumfaßt.

Der erkennende Senat hat sich der vorn Reichsgericht in seinem Rundfunk-Schallplatten-Urteil vertretenen Auffassung, wonach der vortragende Künstler gegen die öffentliche Aufführung seiner auf Tonträgern festgelegten Leistung geschützt ist, bereits in seiner Entscheidung vom 21. November 1952 (BGHZ 8, 88, 90, 97 - Schallplatten - gewerbliche Bandübertragung) angeschlossen. In dieser Entscheidung ging es allendings um eine weder vom Werkschöpfer noch vom Inhaber des fiktiven Bearbeiterurheberrechts genehmigte Vervielfältigung von Schallplatten und deren öffentliche Aufführung, so daß der Senat keine Veranlassung hatte, sich näher mit der hier strittigen Frage auseinanderzusetzen, ob $\S 2$ Abs. 2 LitUrhG auch die Befugnis gewährt, die Benutzung rechtmäßig hergestellter und mit Zustimmung des ausübenden Künstlers in den Verkehr gebrachter Schallvorrichtungen zu öffentlichen Aufführungen zu untersagen. Diese Frage aber ist aus den dargelegten Gründen in Ubereinstimmung mit dem Berufungsgericht zu bejahen. 


\section{Auszug aus dem Urteil des Bundesgerichtshofs vom 31. Mai 1960}

$$
\text { - I ZR 64/58 - (BGHZ 33, S. 20) }
$$

\section{Leitsätze}

Die Tonbandaufnahme einer Opernaufführung zu Zwecken der Rundfunksendung bedarf grundsätzlich der Einwilligung jedes einzelnen bei der Aufführung unmittelbar mitwirkenden ausübenden Künstlers. Soweit die Orchesterleistung in Frage steht, ist im Zweifel der Orchestervorstand berechtigt, dieses Zustimmungsrecht für die einzelnen Orchestermitglieder wahrzunehmen. Orchestermitglieder, die bei Theater- oder Orchesterunternehmen der öffentlichen Hand fest angestellt sind, sind, wenn es an einer ausdrücklichen vertraglichen Regelung fehlt, in der Regel auf Grund ihres Dienstvertrages verpflichtet, Tonbandaufnahmen von Auffuhrungen durch Sendeunternehmen und deren Verwertung für Rundfunksendungen gegen Zahlung einer angemessenen Sondervergütung seitens ihres Arbeitgebers zu dulden.

\section{Tatbestand:}

Das beklagte Sendeunternehmen hat eine Aufführung der Oper "Figaros Hochzeit" in der Städtischen Oper Berlin mit Zustimmung der Bühnenleitung und des Gastdirigenten auf Tonband aufgenommen und gesendet sowie anderen Rundfunkanstalten zur Sendung überlassen. Es bezahlte hierfür 6000,- DM an die Städtische Oper, die ihrerseits dem mitwirkenden Orchester einen Anteil von 1500,- DM anbot.

Die klagende Deutsche Orchestervereinigung, ein eingetragener Verein, nimmt auf Grund von Beitritts- und Abtretungserklärungen die Rechte der an dieser Opernaufführung beteiligten Mitglieder des Opernorchesters mit Ausnahme des Dirigenten wahr. Schon vor der Aufführung hatte die Klägerin allen deutschen Sendeanstalten, darunter auch dem Beklagten mitgeteilt, Tonbandaufnahmen für Sendezwecke und Rundfunksendungen dürften nur mit $\mathrm{Zu-}$ stimmung der mitwirkenden Musiker erfolgen. Die Klägerin ist der Auffasung, diese den mitwirkenden Musikern zustehenden Zustimmungsrechte seien nicht etwa auf den Arbeitgeber des Orchesters übergegangen. Aus den Arbeitsverträgen und den Tarifverträgen und Tarifordnungen sowie der Orchestersatzung ergebe sich keine Verpflichtung der Orchestermitglieder zur Duldung von Bandaufahmen und Sendungen durch Rundfunkanstalten, zumal da diese nicht Arbeitgeber des Orchesters seien. Der Orchestervorstand habe nachweislich gegenüber der Stadt Berlin der geplanten Rundfunksendung von "Figaros Hochzeit" widersprochen.

Nach Ansicht des Beklagten entsteht in der Person der Orchestermusiker überhaupt kein Recht der streitigen Art. Etwaige Rechte bezüglich der Orche- sterdarbietungen gebührten allenfalls dem jeweiligen Dirigenten, nicht hingegen den einzelnen Orchestermitgliedern, so daB die von dem Dirigenten und dem Bühnenunternehmer erteilte Einwilligung für den Mitschnitt ausreiche. Bei Gruppenleistungen wie Opernaufführungen könnten zudem nicht einzelne Beteiligte zum Nachteil der übrigen Mitwirkenden, wie z. B. des Chores und der Solisten, eine sachgemäße Verwertung der Leistung unterbinden. Das Klagebegehren sei aber auch deshalb unbegründet, weil die Orchestermitglieder auf Grund ihres Dienstverhältnisses verpflichtet gewesen seien, an allen Aufführungen der Städtischen Oper, insbesondere auch bei Bandaufnahmen, mitzuwirken. Seit 1948 sei es ständige Ubung, daß Aufführungen der Städtischen Oper mittels Tonbandaufnahmen oder als Lifesendungen im Rundfunk übertragen würden, und zwar auf Grund der gleichen Erlaubniserteilungen wie im vorliegenden Falle. Diese Ubung habe sich ohne Widerspruch der Orchestermitglieder entwickelt und sei zum Inhalt des Arbeitsverhältnisses geworden. Der Orchestervorstand habe auch in dem hier streitigen Fall nicht widersprochen.

...

Entscheidungsgründe:

I. . . . .

II. Das Berufungsgericht geht davon aus, daß dem ausübenden Künstler unabhängig davon, ob und gegebenenfalls welcher künstlerische Wert seiner Wiedergabeleistung beizumessen ist, das Recht $\mathrm{zu}-$ steht, darüber zu entscheiden, ob seine unmittelbare Darbietung eines Werkes der Literatur oder Tonkunst auf einem Tonträger festgehalten werden darf. Dem ist im Grundsatz beizupflichten. Bedenklich aber erscheint, wenn das Berufungsgericht dieses Ergebnis aus einem sog. "Leistungsschutzrecht" des ausübenden Künstlers, dessen Notwendigkeit "allgemein anerkannt werde", herleiten will, ohne die rechtlichen Grundlagen dieses Leistungsschutzes nach geltendem Recht näher zu erörterm. Es ist zwar richtig, daß seit Jahren sowohl auf nationaler wie auf internationaler Basis unter der Bezeichnung "Leistungsschutzrecht" Bestrebungen im Gange sind, den ausübenden Künstlern, aber auch den Herstellern von Ton- und Bildträgern sowie den Sendegesellschaften gegen bestimmte ungenehmigte Ausnutzungen ihrer Leistungen durch eine gesetzliche Sonderregelung Schutz zu gewähren. Auch sehen nahezu sämtliche einschlägigen Gesetzentwürfe vor, daß unmittelbare Vorträge oder Aufführungen eines ausübenden Künstlers nicht ohne dessen ausdrückliche oder stillschweigende Zustimmung körperlich festgelegt oder durch Funk gesendet werden dürfen. 
Solange aber eine solche Sonderregelung nicht Gesetz geworden ist, bedarf es der Prüfung, ob und inwieweit die als Leistungsschutzrechte geltend gemachten Ansprüche nach der gegenwärtigen Gesetzeslage begründet sind.

Das Berufungsgericht wertet die strittigen Befugnisse der Orchestermitglieder, über die Herstellung von Tonträgern und deren Verwendung zu Funkzwecken zu entscheiden, als eine Ausstrahlung ihres Persönlichkeitsrechtes. Der Bundesgerichtshof hat auch ohne gesetzliche Sonderregelung die ungenehmigte Tonbandaufnahme eines Gespräches als einen widerrechtlichen Eingriff in das durch Art. 1, Art. 2 GG gewährleistete allgemeine Persönlichkeitsrecht angesehen, das dem Menschen die Freiheit der Selbstbestimmung über seine individuelle Sphäre sichert, soweit dies für die Freiheit der Entfaltung seiner Persönlichkeit unerläBlich ist (BGHZ 27, 284). Auch im Schrifttum wird überwiegend davon ausgegangen, daß jede lautliche Äußerung eines Menschen als Ausdruck seiner Persönlichkeit seiner freien Selbstbestimmung unterliegt und deshalb nicht ohne seine Erlaubnis auf Tonträger aufgenommen oder durch Funk gesendet werden dürfe (vgl. hierzu auch $\S 18$ des Ministerialentwurfes eines Gesetzes zur Neuordnung des zivilrechtlichen Persönlichkeits- und Ehrenschutzes, Begründung S. 23). Das gleiche muß grundsätzlich auch für die Darbietung eines Werkes der Tonkunst durch einen ausübenden Künstler unter Verwendung von Musikinstrumenten gelten, da auch in dieser Wiedergabeleistung, die durch seine höchstpersönlichen Fähigkeiten geprägt ist, die einmalige Individualität des Künstlers zum Ausdruck kommt. Dem kann nicht entgegengehalten werden, die Wiedergabeleistung sage, zumal wenn es sich um die Gemeinschaftsleistung eines Chores oder Orchesters handele, in der Regel weder über die künstlerischen noch über die sonstigen persönlichen Verhältnisse des Mitwirkenden etwas aus. Auch die Stimme oder das äußere Erscheinungsbild eines Menschen lassen in dieser Richtung keine unmittelbaren Rückschlüsse zu. Sie gehören aber der nach seiner Eigenart einmaligen Individualsphäre des Einzelnen an, und hieraus rechtfertigt sich das Selbstbestimmungsrecht über diese Ausstrahlung der Persönlichkeit. In gleicher Weise liegt es aber auch bei den hier in Frage stehenden Wiedergabeleistungen der Mitglieder eines Opernorchesters. Auch wenn der Hörer nicht in der Lage sein sollte, bei solchen, auf eine Gesamtwirkung zielenden Gruppenleistungen die Eigenart und persönliche Färbung jeder Einzelleistung herauszuhören, ändert dies nichts daran, daß jede Einzelleistung unlösbar mit der Individualität des betreffenden Orchestermitgliedes verknüpft ist und daß das Orchester nur unter Einsatz der individuellen Fähigkeiten des Einzelnen zum Erklingen kommt. Hierin liegt auch die innere Rechtfertigung für die in $\S 2 \mathrm{Abs}$. 2 LitUrhG getroffene Regelung, wonach jede Festlegung der klanglichen Wiedergabe eines Werkes der Tonkunst auf einen Tonträger in der Person des vortragenden Künstlers urheberrechtlich ausgestaltete Ansprüche an der Schallvorrichtung entstehen läßt, und zwar unabhängig davon, ob sein Vortrag als „künstlerische" Leistung oder gar als eine "eigentümliche
Schöpfung" zu werten ist (vgl. Urteil des Senats vom 31. Mai 1960 I ZR 71/58 - Orchester Graunke).

Das persönlichkeitsrechtliche Schutzbedürfnis jedes auch nur an einer Gruppenleistung mitwirkenden Künstlers gegen eine ungenehmigte Verwertung der gemeinsamen Darbietung ergibt sich schon daraus, daß die Qualität der Darbietung abhängig sein kann von der Kenntnis ihres Wirkungsbereiches und jeder ausübende Künstler es grundsätzlich in der Hand haben muß zu verhindern, daß flüchtig gemeinte Darbietungen, die er nur einem fest umrissenen Kreis von Hörern oder Zuschauern zugänglich machen wollte, gegen seinen Willen einen umfassenderen, insbesondere dauernden Wirkungsbereich erhalten. Die hier strittige Festlegung seiner Leistung auf Tonband birgt zusätzlich noch besondere Gefahren in sich, weil der ausübende Künstler keinen Einfluß auf die Auswahl des Tonbandherstellers und damit die technische Qualität der Musikaufnahme nehmen kann, wenn die Tonbandaufnahme nicht seiner Erlaubnis bedarf. Auch wäre ihm dann jegliche Kontrolle darüber verwehrt, in welcher Weise seine Wiedergabeleistung mit Hilfe des Tonträgers erneut hörbar gemacht wird. In diesem Zusammenhang ist weiter zu berücksichtigen, daß Tonbandaufnahmen es ermöglichen, Kürzungen oder Zusammenschnitte mit anderen Darbietungen vorzunehmen, ja daß sogar eine völlige Entstellung der Leistung durch willkürliche Veränderung der Tonqualitäten eintreten kann. Schließlich kann der Zeitpunkt der Wiedergabe und der für sie gewählten Umqebung - beispielsweise in Kinos, Warenhäusern, Omnibussen - abträglich für ihre künstlerische Wirkung sein. Es ist hiernach dem Berufunasqericht beizupflichten, daß bereits aus persönlichkeitsrechtlichen Erwäđunqen davon auszucehen ist, daß iedem ausübenden Künstler unabhänđia von dem Ranq seiner künstlerischen Leistunq und ohne Rücksicht darauf, ob seine Leistuna mehr oder weniqer in einer Gruppenleistunq aufcreht, im Grundsatz das Recht zusteht, über Art und Umfang der Verwertuna seiner Leistung selbst zu entscheiden, insbesondere Tonbandaufnahmen zu Sendezwerken sowie die Verwendung unqenehmigter Tonbandaufnahmen für Rundfunksendungen zu untersagen.

Rerhtlichen Bedenken beqernet es dardeqen, wenn das Berufunasqericht dieses Erqebnis anch. soweit es um die erstmaline Festlequna der Wienerqabeloistınn auf einen Tonträđer $\sigma e h t$, aus $\$ 2$ Abs. 2 T.ittJrhG herleiten will. Das Berufunnstericht verkennt zwar nicht. daß diese Vorschrift nicht unmittelhar als Ansnruchstrundlace herandegocen werden kann. weil sie nur die Rechtslare hinsichtlich der bereits herqestellten Schallvorrichtınn betrifft, nicht darenen die Fracre renelt. unter welchen Voraussetzuncen die Erstfixieruna einer Auffiihrunq oder eines Vortrages zulässiq ist $\mathrm{BCH}$ Es meint aber, aleichwohl sei aus dieser Vorschrift zu entnohmen, daß dem ausübenden Künstler auch die Befumis zustehe. sich qeaen die Erstfestlemung seiner T.eistund zur Wehr zu setzen. Dem kann nicht heigenflichtet werden. \& 2 Abs. 2 LittrhG gewährt dem austibenden Künstler an seiner Wiedergabeleistung die Rechte eines Werkbearbeiters nur unter 
der Voraussetzung, daß diese bereits auf einem Tonträger festgehalten ist, weil nur durch eine solche Festlegung seine anderenfalls vergängliche Leistung von der unmittelbaren Bindung an seine Person und den flüchtigen Leistungsvorgang befreit und damit ähnlich einem Geisteswerk wiederholter Nutzung zugänglich wird (vgl. auch Urteil des Senats vom 31. Mai 1960 I ZR 87/58 - Künstlerlizenz bei öffentlicher Wijedergabe von Rundfunksendungen). Würde die lautliche Darbietung eines Werkes der Tonkunst auch ohne ihre Ubertragung auf eine Schallvorrichtung stets einer Werkbearbeitung im urheberrechtlichen Sinn gleichzuachten sein, so hätte es der Sonderregelung in $\$ 2$ Abs. 2 LitUrhG nicht bedurft, weil dann den ausübenden Künstlern bereits auf Grund von Abs. 1 dieser Gesetzesbestimmung, wonach Werkbearbeiter als Urheber anzusehen sind, die ihnen gemäß Abs. 2 ausdrücklich zuerkannten Befugnisse an den von ihnen besungenen oder bespielten Schallvorrichtungen zustehen würden.

Hiermit wird zu der umstrittenen Fraqe, ob nicht auch ausübenden Künstlern an ihrer Wiedergabeleistung als solcher, und zwar unabhängig von ihrer Festlequnq auf einen Tonträger, ein echtes Urheberrecht zustehen $\mathbf{k}$ a $\mathbf{n} \mathbf{n}$ (so vor allem Troller, Jurisprudenz auf dem Holzweg S. 64 ff.), nicht im Grundsatz Stellung genommen. Voraussetzung für das Eingreifen eines Werkschöpfungsschutzes müßte aber jedenfalls sein, daß die Wiederqabeleistung eine eigenpersönliche Formprägung offenbart.

Um dieses Problem aber geht es im Streitfall nicht; denn die fraglichen Mitglieder des Orchesters der Städtischen Oper Berlin nehmen das Recht, Tonbandaufnahmen von Opernaufführungen zu Sendezwecken zu untersagen, ohne Rücksicht darauf in Anspruch, ob ihrem Einzelbeitrag zu der Gruppenleistung eine schöpferische Eigenart zukommt. Insoweit aber handelt es sich nicht um ein urheberrechtliches, sondern um ein persönlichkeits-, wettbewerbs-, werk- und dienstvertraqsrechtliches Problem. Aus der urheberrechtlichen Vorschrift des $\$ 2$ Abs. 2 LitUrhG, die nur die Rechte an der bereits hergestellten Schallvorrichtung betrifft, kann mithin Abschließendes für die Lösung dieser Frage nicht gewonnen werden.

Mit dem Urheberrecht verbindet die Fragestellung zwar u. a. die Tatsache, daß Gegenstand der Wiedergabeleistungen der ausübenden Künstler in der Regel Werke der Literatur und Tonkunst sind und daß das Schutzbedürfnis für die Wiedergabeleistung sich ähnlich wie für Urheberrechtsgut entwickelt hat. Der Ruf nach einem Schutz von Werken der Literatur, Tonkunst und bildenden Kunst wurde auch erst dringlich, nachdem es der Technik, insbesondere durch die Erfindung der Buchdruckerkunst, gelungen war, diese Werke in einer Vielzahl von Exemplaren zu verbreiten, ohne daß der Werkschöpfer die Möglichkeit hatte, diese Auswertung seines Geistesgutes von der Entrichtung eines Entgelts abhängig zu machen, weil solche Werke, erst einmal der Ơffentlichkeit preisgegeben, sich weitgehend einer tatsächlichen Herrschaftsmacht entziehen und damit, falls nicht Ausschließlichkeitsnechte eingrei- fen, der unentgeltlichen Ausbeutung durch Dritte ausgeliefert sind. Bezeichnenderweise ist auch der urheberrechtliche Schutz den Umweg über das sog. Privilegienwesen gegangen, das vorwiegend den Schutz der Verwerter von Urhebergut, nicht aber der Werkschöpfer im Auge hatte, wie auch die einzige Leistungsschutzrechtsbestimmung im geltenden Recht, § 2 Abs. 2 LitUrhG, im Interesse von Verwertern der Darbietungen ausübender Künstler, nämlich der Schallplattenindustrie, erlassen wurde. Erst als auch die Wiedergabeleistung mehr und mehr dem tatsächlichen Machtbereich des ausübenden Künstlers entglitt, weil die Technik immer neue Möglichkeiten erschloß, sie ohne sein Wissen, ja sogar gegen seinen ausdrücklich erklärten Willen über den von ihm gestatteten Rahmen hinaus auszuwerten, hat sich die Frage nach Art und Umfang eines Schutzes seiner Leistung ernsthaft gestellt. Die Entwicklungsgeschichte des Urheberrechtes bietet hiernach zwar Parallelen zu dem äußeren Anlaß für die Schutzbedürftigkeit von Wiedergabeleistungen Ein solcher Schutz muß aber seine innere Rechtfertigung anderen Gesichtspunkten entnehmen, als sie das Urheberrecht, das dem Schutz von schöpferischen Geisteswerken dient, beherrschen.

In diesem Zusammenhang gewinnen die Besonderheiten Bedeutung, die den in Frage stehenden Leistungen anhaften. Aufführung oder Vortrag eines Werkes der Literatur oder Tonkunst sind ohne körperliche Festlegung vergänglich. Sie sind nicht nur an die Zeit ihrer Darbietung, sondern auch an den Raum, in dem sie stattfinden, gebunden, soweit sie nicht mittels technischer Hilfsmittel über diesen Raum, den sie ihrer natürlichen Tonstärke nach zu füllen vermögen, ausgestrahlt werden. Sie haben, soweit eine Festlegung ausscheidet, kein den Schaffensvorgang überdauerndes "Leistungsergebnis" zum Ziel, das ohne weitere Inanspruchnahme des ausübenden Künstlers von Dritten genutzt werden könnte. Aufführung oder Vortrag sind als solche nicht wiederholbar, sondern höchstens durch erneute Leistung nachvollziehbar. Andererseits besteht vielfach selbst bei demjenigen Hörerkreis, der bereits in den Genuß der fraglichen Leistung kam, ein Bedürfnis, diesen Genuß zu wiederholen. Der ausübende Künstler aber ist, wenn sichergestellt ist, daß seine Darbietungen nur denjenigen Kreis erreichen, für den er sie bestimmt hat, in der Lage, die Nachfrage nach einer erneuten Darbietung dieser Lejistung dadurch für sich auszunutzen, daß er sich hierzu nur gegen Zahlung einer angemessenen Vergütung bereit findet. Die Möglichkeit, die Höhe der Vergütung von der jeweiligen Reichweite seiner Leistung abhängig zu machen, wird dem ausübenden Künstler jedoch genommen, wenn er es hinnehmen müßte, daß sein Vertragspartner oder gar Dritte, zu denen er in keinem Vertragsverhältnis steht, seine Leistungen, die üblicherweise honoriert werden, ohne ihm ein Entgelt zu zahlen, einem sehr viel umfassenderen Kreis zugänglich machen, als er selbst es bei der Darbietung gewollt hat und bei Ausbedingung der Vergütung für diese Darbietung in Betracht ziehen konnte. Dies würde nicht nur einen Eingriff in persönlichkeitsrechtliche, sondern auch in wirtschaftliche Interessen des ausübenden Künstlens bedeuten, weil damit das 
Gleichgewicht zwischen Leistung und Gegenleistung gestört wird, das normalerweise Vertragsgrundlage ist. Einen besonders einschneidenden Eingriff in die Erwerbsmöglichkeiten des ausübenden Künstlers aber stellt es dar, wenn seine Leistungen gegen seinen Willen auf Ton- oder Bildträger festgelegt und damit ohne seine erneute persönliche Inanspruchnahme beliebig oft wiederholbar und einem theoretisch unbegrenzten Hörerkreis zugänglich gemacht werden. Das gleiche Problem stellt sich bei allen stofflich nicht gebundenen, ihrer Natur nach vergänglichen Darbietungen, bei denen eine Nachfrage nach ihrer Wiederholung besteht, wie beispielsweise bei Darbietungen von Artisten oder Sportlern. Ihrer eigenmächtigen Ausnutzung außerhalb des vertraglich vorgesehenen Rahmens, der in der Regel für die Höhe des Leistungsentgeltes maßgebend ist, stehen nicht nur persönlichkeitsrechtliche, sondern auch allgemein bürgerlichrechtliche Grundsätze entgegen.

Es stellt eine sittenwidrige Vermögensschädigung dar (§826 BGB), eine fremde Leistung, die üblicherweise nur gegen Zahlung einer angemessenen Vergütung erbracht wird, sich kostenlos unter Zuhilfenahme der technischen Errungenschaften zunutze zu machen, die es dem Leistenden verwehren, Wirkungsbereich und Art der Auswertung seiner Leistung in tatsächlicher Beziehung zu beherrschen und durch entsprechende Verträge auch Dritten gegenüber rechtswirksam abzugrenzen. Soweit nichtgestattete gewerbliche Nutzungen der Leistung in Frage stehen, liegt zugleich auch ein Verstoß gegen die Grundsätze des lauteren Wettbewerbs ( $\begin{array}{ll}( & 1\end{array}$ UWG) vor. Es widerspricht dem Anstandsgefühl des verständigen Gewerbetreibenden, Leistungen Dritter, die erfahrungsgemäß nur gegen eine angemessene Vergütung zur Verfügung gestellt werden, sich ohne Erlaubnis des Leistenden anzueignen und kostenlos zur Förderung des eigenen gewerblichen Gewinnstrebens auszunutzen. Für die Anwendung von § 1 UWG ist nicht erforderlich, daß der Leistende - hier der ausübende Künstler — zu dem Verwerter seiner Leistung in einem unmittelbaren Wettbewerbsverhältnis steht. Auch die Gefahr der nur mittelbaren Beeinträchtigung der Erwerbsaussichten des ausübenden Künstlers durch die nichtgenehmigte Ausnutzung seiner Leistung zu gewerblichen Zwecken reicht zur Anwendung dieser Gesetzesbestimmung aus, weil die erforderliche Wechselbeziehung zwischen dem dem Verletzten zugefügten Nachteil - dem Wegfall einer Vergütung für seine persönliche Inanspruchnahme oder für die Benutzung von mit seiner Erlaubnis hergestellten Tonträgern - und dem von dem gewerblichen Verwerter seiner Leistung erstrebten Vorteil - der Förderung seines Gewerbebetriebs durch die Ausnutzung dieser Leistung - gegeben ist.

Zwar ist die "Nachbilldung" von nicht unter Sonderschutz stehenden Leistungen grundsätzlich gestattet, soweit nicht aus besonderen Umständen des Einzelfalles auf ein sittenwidriges Verhalten zu schließen ist. Im Streitfall aber geht es nicht um eine "Nachahmung" der Leistungen der Orchestermitglieder, sondern um ideren unmittelbare Ausnutzung in unveränderter Form. Eine solche Verwer- tung geldwerter Leistungen Dritter zur Förderung des eigenen gewerblichen Gewinnstrebens verstößt, wenn es an einer Einverständniserklärung des Leistenden fehlt und hierdurch dessen eigene Erwerbsaussichten gemindert werden, gegen die Gebote des lauteren Wettbewerbs.

Hiernach ist im Grundsatz davon auszugehen, daß die Festlegung einer Opernaufführung auf Tonband zu Sendezwecken ider Zustimmung jedes einzelnen ausübenden Künstlers bedarf, der unmittelbar an ider Aufführung mitwirkt. Fehlt es an der erforderlichen Zustimmung, handelt es sich also um rechtswidrig hergestellte Tonbänder, so ist aus iden gleichen rechtlichen Enwägungen, auf denen das $\mathrm{Zu}-$ stimmungserfordernis beruht, auch ein Anspruch der an der Aufführung mitwirkenden Künstler begründet, ıdie Benutzung der Tonbänder zu Sendeoder zu Vervielfältigungszwecken durch Uberspielung auf andere Tonbänder zu untersagen (Klagantrag zu Ziff. $1 \mathrm{~b}$ und $\mathrm{c}$ ). Ob diese Ansprüche auch auf eine entsprechende Anwendung von § 2 Albs. 2 LitUrhG gestützt werden können oder ob diese Gesetzesbestimmung auch insoweit als Klaggrundlage ausscheiden muB, weil sie nur Schallvorrichtungen betrifft, auf die der persönliche Vortrag eines Künstlers $\mathrm{m}$ it s e in e m Wille n festgelegt ist, kann bei dieser Sachlage dahinstehen (vgl, hierzu BGHZ 17, 266).

III. Eine andere Frage ist, wer bei Gruppenleistungen, wie Orchesterdarbietungen, zur W a h r$\mathrm{n}$ e $\mathrm{h} \mathrm{m}$ u $\mathrm{n} \mathrm{g}$ des jedem einzelnen Mitwirkenden zustehenden Zustimmungsrechtes befugt ist. Nach Ansicht des Berufungsgerichts soll für die Erstfixierung ebenso wie für weitere Verfügungen über die Tonbandaufnahme regelmäßig eine einstimmige Erlaubnis sämtlicher Mitwirkender erforderlich sein; denn die Rechtsbeziehungen zwischen den Beteiligten seien in entsprechender Anwendung des $\S 6$ LitUrhG nach den Vorschriften über die Bruchteilsgemeinschaft des Bürgerlichen Gesetzbuches (BGB $\S 741 \mathrm{ff}) \mathrm{zu}$ beurteilen. Sollten einzelne Mitberechtigte ihre Zustimmung willkürlich verweigern, so sei es Sache der übrigen Beteiligten, notfalls auf Erteilung der Zustimmung zu klagen.

Dieser Ansicht kann, jedenfalls soweit idie einzelnen Orchestermitglieder in Frage stehen, nicht beigepflichtet werden. $\mathrm{Ob}$ die Vorschriften über die Bruchteilsgemeinschaft, deren Anwendung bereits für den Miturheber im Hinblick auf die Natur der Miturheberschaft als einer in der Regel auf gewolltem Zusammenwirken beruhenden besonders engen Gemeinschaft als verfehlt bezeichnet wird (vgl. Ministerialentwurf zur Urheberrechtsreform zu $\$ 7$ S. $30 \mathrm{ff}$ ), dann entsprechend herangezogen werden können, wenn es sich um $\mathrm{r}$ e c h t mä Big hergestellte Tonträger handelt, braucht im Streitfall nicht entschieden zu werden. Denn hier geht es zunächst nicht um die Rechte an bereits vorhandenen Tonträgern, sondern um die Befugnisse bei erstmaliger Festlegung der gemeinsamen Leistung. Solange diese Leistung aber noch nicht festgelegt ist, fehlt es an einem gemeinsamen "Vermögensgegenstand". Schon aus diesem Grunde ist das Recht eines jeden Mitwirkenden an einer Orchesterdarbietung, über Art und Umfang der Ausnutzung dieser Leistung zu 
bestimmen, nicht mit den Anteilsrechten an einer Bruchteilsgemeinschaft vergleichbar. Solange ein bereits vorhandener gemeinschaftlicher Vermögensgegenstand fehlt, ist aber auch die Interessenlage zwangsläufig eine andere. Denn die Einwilligung in die Erstfixierung gemeinschaftlicher Darbietungen erfordert zumeist rasche Entscheidungen. Die Notwendigkeit, einzelne Orchestermitglieder bei Verweigerung der Einverständniserklärung zunächst auf Zustimmung verklagen $\mathrm{zu}$ müssen, würde praktisch zu dem unhaltbaren Ergebnis führen, daß jedes einzelne Orchestermitglied und sogar ein Ersatzspieler eine von allen übrigen Mitwirkenden gewünschte Verwertung der Aufführung durch Bandaufnahmen oder Funksendungen durch willkürliches Versagen seines Einverständnisses vereiteln und sein Zustimmungsrecht als Druckmittel für u n a n gemessen e Vergütungsansprüche verwenden könnte.

Wenn somit eine entsprechende Anwendung der Vorschriften über die Bruchteilsgemeinschaft ausscheidet, bleibt zu prüfen, nach welchen sonstigen Rechtsgrundsätzen die Wahrnehmung des Zustimmungsrechtes bei derartigen Gruppenleistungen zu beurteilen ist. Ublicherweise werden, wenn sich mehrere zu gemeinschaftlichem Handeln zusammenfinden, aus dem ihnen Rechte erwachsen können, auch Bestimmungen über die Wahrnehmung dieser Rechte im Innen- und Außenverhältnis getroffen. Soweit dies bei Orchester- oder Chordarbietungen bislang unterblieben ist, dürfte dies auf die noch ungeklärte Rechtslage in Ansehung der Rechte der einzelnen Orchester- und Chormitglieder zurückzuführen sein. In Erkenntnis der Notwendigkeit einer klaren Regelung sehen die einschlägigen Gesetzesentwürfe für die Zukunft Bestimmungen darüber vor, wer die den einzelnen Mitwirkenden zustehenden Rechte in deren Namen ausüben und wahrnehmen darf. Erwogen wird insbesondere die Ermächtigung einer oder mehrerer von der Mehrheit der Beteiligten bestimmter Personen, namentlich des Orchestervorstandes (vgl. § 79 des Referentenentwurfs 1954, § 87 des Ministerialentwurfs 1959; s. ferner Rom-Entwurf Art. 5 und Monaco-Entwurf Art. 2 Abs. 8, abgedruckt bei Möhring/Elsässer, Die internationale Regelung des Rechts der ausübenden Künstler und andere sog. Nachbarrechte). So heißt es in der Amtlichen Begründung zu $\S 87$ des Ministerialentwurfes, daB sich der Einzelne bei Ensemble-Aufführungen im Interesse der Gesamtheit der Mitwirkenden gewisse Beschränkungen gefallen lassen müsse und daB auch Rechtssicherheit und Erleichterung des Rechtsverkehrs in diesen Fällen eine einheitliche Wahrnehmung der Rechte aller Mitwirkenden durch wenige Repiräsentanten des Ensembles erforderten.

Diese gesetzgeberischen Bestrebungen stehen im Einklang mit allgemeinen Rechtsgrundsätzen, die dann heranzuziehen sind, wenn aus der besonderen Rechtsform des Orchesters oder aus einschlägigen Regelungen in der Orchestersatzung nichts herzuleiten ist. Gemeinschaftsverhältnisse der fraglichen Art sind im besonderen Maße durch den Grundsatz von Treu und Glauben beherrscht. Wer sich in eine solche Gemeinschaft hineinbegibt, nimmt eine Be- grenzung in der Ausübung seiner bei gemeinschaftlichen Leistungen entstehenden Rechte durch die Interessen der Mitbeteiligten in Kauf. Regelmäßig hat er sich bei Entscheidungen über die Gesamtleistung entweder dem Willen der Mehrheit oder, falls ein Organ zur Vertretung der gemeinschaftlichen Interessen von der Mehrheit oder kraft Satzung bestellt ist, dessen Entschließungen unterzuordnen. Hierbei fällt ins Gewicht, daß bei Orchesterdarbietungen der individuelle Beitrag des Einzelnen weitgehend in der Gesamtleistung aufgeht und aus diesem Grunde die Stellung eines Orchestermitgliedes eine andere ist als die des Dirigenten oder von Solisten. Dem steht nicht entgegen, daß es sich um persönlichkeitsgebundene Rechte handelt. Denn auch solche Rechte eröffnen nicht die Möglichkeit zur schrankenlosen Durchsetzung eigener Interessen, ihre Ausübung findet vielmehr ihre Grenze in den Belangen anderer, und zur Abgrenzung bedarf es sogar im besonderen Maße einer Güterabwägung (BGHZ 13, 334, 338 - Leserbriefe, BGHZ $24,72,79 \mathrm{f}$ ). Eine solche Güterabwägung gebietet freilich nur, daß lediglich die $A$ u sübung der grundsätzlich jedem der Beteiligten zustehenden Rechte vom Entschluß der Mehrheit oder eines berufenen Organes abhängig gemacht wird. Auf die Frage, ob in Ausnahmefällen den einzelnen Mitberechtigten bei miBbräuchlicher Wahrnehmung ihres Rechtes entsprechend dem Rechtsgedanken in $\S 711$ BGB, § $115 \mathrm{HGB}$, $198 \mathrm{AktG}$ ein Widerspruchsrecht zuzubilligen ist, braucht nicht eingegangen zu werden, da ein mißbräuchliches Handeln des Orchestervorstandes im Streitfall nicht zur Erörterung steht.

Zusammenfassend ergibt sich somit, daß dem Unterlassungsbegehren allenfalls mit der Maßgabe entsprochen werden könnte, dem Beklagten Tonbandaufnahmen ohne Einwilligung des Orchester vorstandes (Hilfsantrag zu Ziff. 1 a) sowie die Verwertung solcher vom Orchestervorstand nicht genehmigter Tonbandaufnahmen zu Sendezwecken zu verbieten (Antrag zu Ziff. 1 b und c).

IV. Nach Ansicht des Beklagten stellt sich in diesem Zusammenhang noch die weitere Frage, ob der Orchestervorstand die Rechte der Orchestermitglieder ohne Rücksicht auf die Interessen der übrigen Mitwirkenden an der Opernaufführung, also des Dirigenten, der Solisten und des Chores, wahrnehmen kann. Bejahendenfalls hätte dies nach Meinung der Revision zur Folge, daß sich das Orchester einseitig über Wünsche der übrigen Beteiligten hinwegsetzen könnte, die womöglich ein berechtigtes Interesse daran hätten, durch Rundfunksendungen bekannt zu werden. Das Berufungsgericht nimmt auch insoweit eine Mitberechtigung an, die nach den Regeln der Bruchteilsgemeinschaft Einstimmigkeit und notfalls eine Klage auf Zustimmung erfordere.

Dieser Ansicht des Berufungsgerichts ist im Ergebnis beizutreten. Zwar kommt auch hier eine Anwendung der Regeln über die Bruchteilsgemeinschaft nicht in Betracht, da es bei der Entscheidung über die Erstfixierung an einem gemeinsamen Vermögensgegenstand fehlt. Andererseits besteht zwischen Orchester, Chor, Solisten und Dirigent aber auch keine so enge soziale Gebundenheit wie zwischen den Orchestermitgliedern untereinander. Da- 
her muß es insoweit nach geltendem Recht regelmäBig dabei bewenden, daß jeder dieser einzelnen Beteiligten oder die jeweilig beteiligten Gruppen wie Chor, Ballett, zur selbständigen Wahrnehmung ihres Zustimmungsrechtes befugt bleiben. Aus der engen Interessenverbundenheit, die zwischen den einzelnen Gruppen besteht, läßt sich lediglich herleiten, daß sich niemand $w$ ill $\mathrm{k}$ ü $\mathrm{r} l \mathbf{i} \mathrm{c}$ h über die Interessen und den Willen der Mitberechtigten hinwegsetzen darf und daher regelmäßig zur Zustimmung verpflichtet sein wird. Dafür, daß sich im Streitfall die Zedenten der Klägerin willkürlich den Wünschen der übrigen Berechtigten verschlossen haben, ist indessen nichts ersichtlich. Sie beanstanden lediglich, daß sie überhaupt nicht gefragt worden sind, und mutmaßen, daß die weiteren Beteiligten, wie Chor und Solisten, ebenfalls übergangen worden seien. $\mathrm{Da}$ auch die Revision nicht rügt, das Berufungsgericht habe substantilerte Behauptungen über eine willkürliche Versagung der Zustimmung unbeachtet gelassen, können aus den a $11 \mathrm{~g} \mathrm{e} \mathrm{m} \mathrm{e} \mathrm{i} \mathrm{-}$ n e n Erwägungen der Beklagten über Interessen anderer Mitwirkender keine durchgreifenden Bedenken gegen das Klagebegehren hergeleitet werden. Im übrigen dürfte die Revision die Schwierigkeiten überschätzen, die sich aus dem befürchteten Interessenwiderstreit ergeben könnten, da sich ihnen weitgehend durch rechtzeitige vertragliche Abmachungen zwischen den Berechtigten und durch Bestellung von Wahrnehmungsberechtigten durch alle Beteiligten vorbeugen läßt.

V. Die bisherigen Ausführungen betrafen die Rechtslage für Orchester ganz allgemein, ohne den Einfluß des Arbeitsverhältnisses bei Orchestermitgliedern zu berücksiçhtigen, die bei Theater- oder Orchesterunternehmen der öffentlichen Hand fest angestellt sind. Es bleibt daher zu prüfen, ob in solchen Fällen, soweit es um die Orchestermitglieder geht, die Zustimmung des Arbeitgebers zu Tonbandaufnahmen für Rundfunkzwedke ausreicht. DaB aus dem Dienstverhältnis nicht ohne weiteres eine stillschweigende $\mathrm{U}$ bertragung der Rechte der Orchestermitglieder in Ansehung von Tonbandaufnahmen ihrer Leistungen auf die Nebenintervenientin als Arbeitgeberin hergeleitet werden kann, hat das Berufungsgericht ohne Rechtsirrtum angenommen. Das Reichsgericht ist zwar davon ausgegangen, daß die im Auftrage von Schallplattenherstellern tätigen ausübenden Künstler in der Regel ihre Rechte an der von ihnen besungenen oder bespielten Schallplatte stillschweigend in vollem Umfang - einschließlich der Verwertung der Schallplatten bei Rundfunksendungen - an den Hersteller übertragen und dafür durch die Vergütung voll entschädigt werden ( $R G Z$ 153, 1, $8 \mathrm{ff}$ ). In dem vom Reichsgericht entschiedenen Fall war indessen unmittelbarer Gegenstand der Arbeitsverpflichtung die Herstellung von Schallplatten zugunsten der Plattenfirma, und die Verwendung dieser Platten auch zu Sendezwecken lag nicht außerhalb ihrer natürlichen Verwertungsmöglichkeiten. Ahnlich war die Rechtslage in der von der Revision angeführten unveröffentlichten Entscheidung des erkennenden Senats vom 8. Februar 1957 (I ZR 167/55), in der eine stillschweigende Ubertragung der Rechte des Verfassers eines Fillmdrehbuches zur "Auswertung des Filmes im üblichen Rahmen" angenommen wurde (vigl. auch den Beschluß des Senats in dem diesem Urteil vorangegangenen Armenrechtsverfahren, GRUR 1955, 596 - Lied der Wildbahn, ferner GRUR 1957, 611 - Bel ami). Im Streitfall ist hingegen unmittelbarer Gegenstand des Dienstvertrages nur die Pflicht zur Mitwirkung bei Opernaufführungen für das dabei anwesende Publikum. Eine stillschweigende Ubertragung von Rechten der Orchestermitglieder auf ihren Arbeitgeber könnte daher allenfalls in dem Umfang angenommen werden, in dem dieser der Rechte zur Durchführung von Opernaufführungien bedarf. Dazu gehört aber nicht das Recht, diese Aufführungen mittels Tonbandaufnahmen Sendeunternehmen zur Zweitverwertung zur Verfügung zu stellen.

Wenn somit auch eine vertragliche Ubertragung des hier strittigen Zustimmungsrechtes nicht anzunehmen ist, so bleibt doch weiter zu untersuchen, ob das Orchester nicht kraft des durch den Dienstvertrag begründeten Treueverhältnisses gehindert ist, sein an sich bestehendes Entscheidungsrecht geltend zu machen, d. h. ob es, falls im Vertrag keine ausdrücklich entgegenstehende Abrede getroffen ist, verpflichtet ist, einen Mitschnitt der Opernaufführung zu Sendezwecken jedenfalls dann zu dulden, wenn eine angemessene Vergütung angeboten wird und wenn keine Gründe ersichtlich sind, die eine solche Duldung im Einzelfall als unzumutbar erscheinen lassen. In der amtlichen Begründung zu \$87 des Ministerialentwurfs wird eine solche Duldungspflicht nicht angenommen, wenn nicht die ausübenden Künstler im Anstellungsvertrag ihre Zustimmung ausdrücklich erteilt haben. Auch für die derzeitige Rechtslage folgt nach Ansicht des Berufungsgerichts eine solche Verpflichtung weder aus den Bestimmungen der Verträge noch aus den bisherigen Gepflogenheiten. Dem kann jedoch angesichts des Umstandes, daß diese Frage erst durch die fortschreitende Entwicklung der Technik ihre gegenwärtige Bedeutung erlangt hat, nicht beigetreten werden, mag es auch im Interesse klarer Rechtsverhältnisse wünschenswert erscheinen, die Duldungspflicht des Orchesters ausdrücklich in die Vertragsregelung aufzunehmen.

Zwar kann eine solche Duldungspflicht schwerlich aus der bisherigien Ubung hergeleitet wenden. Denn wenn auch bereits seit 1948 wiederholt Rundfunkübertragungen von Opernaufführungen stattgefunden haben, ohne daß das an den Erträgen dieser Ubertragung beteiligte Orchester dagegen Einspruch eingelegt hat, so ist doch $\mathrm{zu}$ berücksichtigen, daß sich die Einsicht in die Rechte eines Orchesters bei Tonbandaufnahmen überhaupt erst allmählich entwickelt hat. Bedeutsam ist darüber hinaus, daß nach den tatsächlichen Feststellungen des Berufungsgerichts der Orchestervorstand stets vorher gefragt worden ist. Daher.mag zwar aus der bisherigen Uibung folgen, daß der Orchestervorstand seine Zustimmung auch künftig nicht willkürlich bei Zahlung einer angemessenen Vergütung verweigern darf, nicht jedoch beantwortet sich daraus die hier zur Entscheidung stehende Frage, ob sich eine solche Zustimmung zur Zweitverwertung überhaupt erübrigt, das Orchester also zur Duldung des Mit- 
schnittes auch verpflichtet ist, wenn es nicht um sein Einverständnis befragt worden ist.

Mit Recht geht das Berufungsgericht ferner davon aus, daß weder aus den Bestimmungen des Tarifvertrages vom 14. Juli 1950 und der Orchestersatzung noch aus der Tarifordnung für die deutschen Kulturorchester vom 30. März 1958 unmittelbar eine Verpflichtung der Orchestermitglieder gefolgert werden kann, Bandaufnahmen und deren Sendung durch Rundfunk zu dulden. Bedenklich aber ist, wenn das Berufungsgericht aus $\S 3$ des Normalvertrages für Solisten, Chor und Tanz, der eine Sondervergütung für Lifesendungen vorsieht, entnehmen will, daß es sich insoweit um "außervertragliche" Leistungen handele, und hieraus folgert, daß auch die Duldung des Mitschnittes von Opernaufführungen für Sendezwecke durch die Orchestermitglieder nicht in den Rahmen der Vertragspflichten des Orchesters fallen könne. Eine solche Betrachtungsweise verkennt, daß der Dienstverpflichtete kraft seiner Treuepflicht gehalten sein kann, auch andere als die vertraglich vereinbarten Leistungen im Rahmen des Vertrages als Sonderleistungen zu übernehmen, wenn besondere Umstände des Betriebes es erfordern, insbesondere dann, wenn der Dienstverpflichtete eine beamtenähnliche Stellung mit Altersversorgung erlangt, wie dies für die Orchestermitglieder von der Nebenintervenientin unwidersprochen behauptet wird. In der Regel steht ihm dann für solche Leistungen neben dem festen Gehalt, bei dem diese Leistungen nicht einberechnet sind, ähnlich wie bei Uberstunden eine Sondervergütung zu (vgl. über den zusätzlichen Vergütungsanspruch eines Chormitgliedes für die Rundfunkübertragung einer Bühnenaufführung die Entscheidung des Bühnenoberschiedsgerichtes Frankfurt vom 7. Juni 1957 in Schulze, Rechtsprechung zum Urheberrecht Bd. IV SchG 1).

Wenn sich hiernach auch im Streitfall die Pflicht der Orchestermitglieder zur Duldung von Tonbandaufnahmen zu Sendezwecken nicht aus ausdrücklichen Vertragsbestimmungen entnehmen läßt, ergibt sich dies doch im Wege ergänzender Vertragsauslegung, die auch durch das Revisionsgericht erfolgen kann, sofern der Sachverhalt in tatsächlicher Hinsicht ausreichend geklärt ist (BGH GRUR 1959, 384, 387 - Postkalender). Dabei ist zu berücksichtigen, daß es weitgehende Ubung geworden ist, Bühnenaufführungen für Rundfunk- und Fernsehsendungen $\mathrm{zu}$ verwerten, und $\mathrm{daB}$ an einer solchen Verwertung außer dem Theaterunternehmer auch die ausübenden Künstler zur Förderung ihres künstlerischen Rufes und im Hinblick auf die sich damit eröffnenden zusätzlichen Einnahmequellen ein schutzwürdiges Interesse haben können. Jeder, der als Orchestermitglied einem solchen Unternehmen beitritt, muß unter den gegenwärtigen Verhältnissen in der Regel mit einer solchen Verwertung seiner Leistungen rechnen, zumal diese Zweitverwertung keine Mehrleistung von ihm erfordert, sondern auf Grund seiner ohnehin zu erfüllenden Verpflichtungen erbracht werden kann. Will er eine solche Verwertung, die sich mehr und mehr in den allgemeinen Betriebsablauf eines größeren Bühnenunternehmens einfügt und im allgemeinen den Interessen sowohl des Unternehmens als auch der ausübenden Künstler dient, nicht durch stillschweigende Unterwerfung hinnehmen, hat er dies jedenfalls, solange es an einer anderweiten gesetzlichen Regelung fehlt - in der Regel durch entsprechende Vertragsvorbehalte klarzustellen (vgl. auch BAG 1, 241). Hierbei fällt auch ins Gewicht, daß es sich im Streitfall um Aufführungen der Städtischen Oper Berlin handelt, die wie alle städtischen oder staatlichen Theaterunternehmen wesentlich auf Subventionen der öffentlichen Hand angewiesen ist und der es deshalb ein besonderes Anliegen sein muB, den Rundfunk- und Fernsehanstalten geeignetes Sendegut zur Verfügung zu stellen, die als Körperschaften des öffentlichen Rechts ihrerseits die Aufgabe zu erfüllen haben, die Allgemeinheit in möglichst weitreichendem Umfange an kulturellen Leistungen teilnehmen zu lassen.

Unter diesem rechtlichen Blickpunkt hat das Berufungsgericht das Klagebegehren nicht geprüft. Er führt zu dem Ergebnis, daß die Orchestermitglieder auf Grund ihrer mit der Städtischen Oper Berlin geschlossenen Verträge in Ermangelung entsprechender Vorbehalte regelmäßig verpflichtet sind, Tonbandaufnahmen ihrer Darbietungen durch Sendeunternehmen anläßlich von Opernaufführungen und deren Verwendung für Rundfunksendezwecke $\mathrm{zu}$ dulden, soweit dem nicht gewichtige Gründe, insbesondere ernsthafte künstlerische Bedenken entgegenstehen, für diese Zweitverwertung ihrer Leistung aber eine angemessene Sondervergütung von ihrem Arbeitgeber beanspruchen können, für deren Höhe in der Regel der Umfang der Auswertung (Wiederholungssendungen, Ubernahme der Sendung durch andere Sendeanstalten) maßgebend sein dürfte.

Da im vorliegenden Fall die Zahlung einer angemessenen Sondervergütung nicht im Streit steht und auch keine Bedenken vorgetragen worden sind, welche die Duldungspflicht des Orchesters als unzumutbar erscheinen lassen, war das angefochtene Urteil aufzuheben und die Klage abzuweisen. . . . 
Anlage 9

\section{Auszug aus dém Urteil des Bundesgerichtshofs vom 31. Mai 1960}

$$
\text { - I ZR 87/58 - (BGHZ 33, S. 38) }
$$

\section{Leitsätze}

Die öffentliche Hörbarmachung von Rundfunkmusik in Gaststätten bedarf der Erlaubnis der ausübenden Künstler, deren Wiedergabeleistung dargeboten wird. Dies gilt sowohl für Tonträger- wie für Direktübertragungen (sog. Livesendungen).

\section{T a tbestand:}

Die Klägerin ist ein eingetragener Verein, tdessen Zweck nach ider Vereinssatzung u. a. tdarauf gerichtet ist, die kulturellen und wirtschaftlichen Interessen seiner Mitglieder zu vertreten. Ihr sind als Mitglieder dals Sinfonie-Orchester des Westdeutschen Rundfunks (WDR) Köln, das Orchester Hermann Hagestedt, das Tanz- und Unterhaltungsorchester des Westdeutschen Rundfunks (WDR) Köln, das Orchester Hans Bund, der Chor ides Westdeutschen Rundfunks (WDR) Köln, das Sinfonie-Orchester des Norddeutschen Rundfunks (NDR) Hamburg, das Rundfunkorchester und das Kleine Unterhaltungsorchester sorwie der Chor und das Radio-, Tanz- und Unterhaltungsorchester des Norddeutschen Rundfunks (NDR) Hamburg angeschlossen.

Die genannten Klangkörper stehen im Dienste der ibei ihnen angegebenen Rundfunkanstalten. Darbietungen der Klangkörper im Hör- oder Bildfunk erfolgen im Wege der Direktübertragung (sogenannte "live"-Musik) oder von zuvor aufgenommenen Tonbändern. Soweit für die Uibertragung auch Industrie-Schallplatten Verwendung finden, bildet dies nicht Gegenstand des vorliegenden Rechtsstreits. Zwischen der Klägerin und dem Nordwestdeutschen Rundfunk (NWDR), dem Rechtsvorgänger der oben genannten Rundfunkanstalten, ist am 9. Oktolber 1954 eine Tonbändervereinigung getroffen worden, in ider es in Ziff. 7 heißt: "Der NWDR verpflichtet sich, im Falle einer gewerblichen Nutzung seiner Sendungen z. B. durch Gastwirte oder ähnliche Interessenten die Rechte nicht $\mathrm{zu}$ beeinträchtigen, idie den Musikern (Chorsängern) des NWDR gegenüber den Unternehmen zustehen, die die Sendungen des NWDR gewerblich nutzen."

Die Beklagten betreiben in Düsselidorf Gaststätten, in denen sie für ihre Gäste Rundfunkmusik durch Lautsprecher hörbar machen. Sie haben nicht bestritten, daß sich unter der hörbar gemachten Musik auch Darbietungen der genannten Klangkörper vom WDR, NDR und NWRV befunden haben. Die Klägerin ist der Auffassung, daß die Beklagten ou der Hörbarmachung Idieser Musik in ihren Gaststätten nicht ohne Zustimmung der betreffenden Klangkörper und deren Mitgliedern befugt seien. Sie hat sich von idiesen Klangkörpern sowie von sämtlichen Angehörigen derselben die Unterlassungs- ansprüche gegen gewerbliche Musikverbraucher abtreten lassen. ...

Die Beklagten . . . sind . . . der Auffassung, daB die geltenld gemachten Ansprüche nicht bestehen.

-...

Entscheidungsigründe :

I. . .

II. Das Berufunǵsgericht hat das Unterlassungsbegehren der Klägerin auf Grund von $\S 2$ Abs. 2 LitUrhG als begründet erachtet. Dies ist rechtlich nicht $\mathrm{zu}$ beanstanden, soweit die Rundfunksendung mit Hilfe von rechtmäßig hergestellten Tonträgern durchgeführt wird. Dagegen kann diese Gesetzesbestimmung für Direktübertragungen (sog. Livesendungen) nicht als Klagegrundlage herangezogen werden. Jedoch ist idem Berufungsgericht auch insoweit im Ergebnis, wenn auch aus anderen rechtlichen Gesichtspunkten beizutreten.

1. Für die Rechtslage hinsichtlich der öffentlichen Hörbarmachung von Rundfunksendungen, die mittels Tonträgern idurchgeführt werden, gilt folgendes:

Die von den Zedenten der Klägerin bespielten Tonbänder stellen durch persönlichen Vortrag bewirkte, zur mechanischen Wiedergabe für das Gehör bestimmte Schallvorrichtungen dar, die gemäß § 2 Abs. 2 LitUrhG der Bearbeitung eines Werkes der Literatur oder Tonkunst gleichgestellt sind. Das hiernach an der Schallvorrichtung bestehende Bearbeiterurheberrecht entsteht nach Satz 3 idieser Bestimmung in der Person des "Vortragenden", also des ausübenden Künstlers, tdessen "Vortrag" auf der Schallvorrichtung festgelegt ist. Bei Orchesterdarbietungen ist originärer Träger dieses Bearbeiterurheberrechtes an der Schallvorrichtung neben dem Dirigenten und etwaigen Solisten jedes einzelne Orchestermitglied, das an der festgelegten Darbietung mitgewirkt hat (v.gl. Urteile des Senats vom 31. Mai 1960 - I ZR 71/58 und I ZR 64/58). Dieses Ausschließlichkeitsrecht umfaßt auch die Befugnis, über die Nutzung der Schallvorrichtung zu öffentlichen Auffühhrungen zu bestimmen (vgl. Urt. des Senats vom 31. Mai 1960 - I ZR 53/58). Unstreitig haben die Zedenten der Klägerin die Verwendung der von ihnen bespielten Tonbänder für Rundfunksendungen gestattet. Nach den rechtlich nicht angreifbaren tatsächlichen Feststellungen des Berufungsgerichts haben dagegen die Zedenten ider Klägerin weder den Beklagten erlaubt, solche Rundfunksendungen in ihren Gaststätten öffentlich hörbar $\mathrm{zu}$ machen, noch haben sie ihre im vorliegenden Rechtsstreit geltend gemachten Ansprüche an die Rundfunkanstalten abgetreten, in deren Dienst sie die Tonbänder besungen oder ibespielt haben (vgl. 
hierzu die Tonträgervereinbarung mit dem NWDR vom 9. Oktober 1954 Ziff. 4). Auch sind nach den Feststellungen, die das Berufungsgericht in Ubereinstimmung mit dem Landgericht getroffen hat, keine vertraglichen Gesichtspunkte irgendwelcher Art ersichtlich, die die Beklagten im Verhältnis zu den Rundfunkanstalten berechtigen könnten, Tonbandmusik des Rundfunks ohne Rücksicht auf etwaige Rechte der ausübenden Künstler allein gegen Zahlung der für iden privaten Rundfunkempfang erhobenen Rundfunkgebühr gewerblich zu nutzen (vgl. hierzu auch RGZ 136, 377).

Wie der Senat in seinem Urteil vom 6. November 1953 (BGHZ 11, 135) entschieden hat, kann für die öffentliche Wiedergabe von Tonträgermusik mittels der modernen, auf dem elektroakustischen Prinzip beruhenden Plattenspieler keine Aufführungsfreiheit aus $\S 22$ a LitUrhG in Anspruch genommen werden. Das gleiche muß für die öffentliche Lautsprecherwiedergabe ider Sendung von Tonträgermusik idurch den Rundfunk gelten, da hier im Prinzip von ider gleichen Wiedergabetechnik Gebrauch gemacht wird (so schon für die Rundfunksendung von Industrieschallplatten RGZ 153, 1 ff). Ist hiernach durch $\S 22$ a LitUrhG idie öffentliche Wiedergabe von Tonträgersendungen des Rundfunks nicht von einer Erlaubniserteilung seitens ider Urheberberechtigten freigestellt, so bleibt zu prüfen, ob den Erwägungen beigepflichtet wenden kann, aus denen das Reichsgericht es in seiner Entscheidung vom 11. Juni 1932 (RGZ 136, 377 - Lautsprecherentscheidung) abgelehnt hat, die öffentliche, gewerblichen Zwecken dienende Lautsprecherwiedergabe erlaubterweise durchgeführter Rundfunksendungen an eine Erlaubnis der Urheber der gesendeten Werke zu binden. Das Reichsgericht ist zu diesem Ergebnis gelangt, weil es in der öffentlichen Hörbarmachung des gesendeten Werkes durch den Lautsprecher des Empfangsgerätes keine selbständige Handlung, sondern nur die Vollendung des eine Einheit bildenden Sendevorganges erblickt, den es als öffentliche Aufführung und zugleich als Verbreitungshandlung wertet. Da die Sendeerlaubnis ihrer Natur nach eine öffentliche Verbreitung in unbegrenzte Weite und an eine unbestimmt große Zahl von Menschen decke, könne eine dergestalt einmal freigegebene Offentlichkeit durch gewerbsmäßige Lautsprecheridarbietungen nicht mehr gesteigert, nicht "noch öffentlicher" gemacht werden.

Dieser Entscheidung des Reichsgerichts, die im Schrifttum überwiegend abgelehnt worden ist (vgl. u. a. de Boor, JW 1933, 1649; Ulmer, Urheber- und Verlagsrecht 2. Aufl., S. $207 \mathrm{ff}$; Schulze, Rechtsprechung zum Urheberrecht, Anm. zu RGZ 2; Runge, Urheber- und Verlagsrecht S. 95; Voigtländer-ElsterKleine, Urheber- und Verlagsrecht 4. Aufl. S. 85; Schollwek GRUR 1949, 283; Baum GRUR 1949, 19; Hirsch-Ballin GRUR 1949, 408; Erffa GRUR 1950, 542), und gegen die der erkennende Senat bereits in einer früheren Entscheidung Bedenken erhoben hat (BGHZ 11, 135, 149), kann nicht gefolgt werden. Der Senat vermag bereits ider Einordnung ider Rundfunksendung in den Begriff der Verbreitung oder der öffentlichen Aufführung im Sinne von $\S 11$
LitUrhG nicht zuzustimmen. Der Verbreitungsbegriff umfaßt nach der gegenwärtig wohl als herrschend anzusehenden Auffassung nur idie Verbreitung körperlicher Werkstücke, nicht dagegen unkörperliche'Werkwiedergaben, wie sie die Rundfunksendung darstellt (vgl. BGHZ 11, 144). Die "Aufführung" eines Tonkunstwerkes setzt voraus, daß Töne hörbar gemacht werden. Die Rundfunksendung als solche ist aber von der Hörbarmachung der Töne beim Empfang der Sendung zu unterscheiden. Ihr für die urheberrechtliche Betrachtungsweise bedeutsames Element liegt in dem Ausstrahlen der Wellen. Infolge dieser Besonderheit, die die Rundfunksendung von einer bloßen Aufführung unterscheidet, ist der Senat in Ubereinstimmung mit der Behandlung, die idas Senderecht in Art. 1.1 bis der Rom- sowie der Brüsseler Fassung der Revidierten Berner Ubereinkunft (vgl. Bappert-Wagner Internationales Urheberrecht $1956 \mathrm{~S}$. $116 \mathrm{ff}$ ) und in neuen ausländischen Urhebergesetzen sowie den deutschen Entwürfen zur Urheberrechtsreform gefunden hat, der Auffassung, daß es sich bei der Rundfunksendung um eine Nutzung eigener Art von Urhebergut handelt, die im Wege einer erweiterten Gesetzesanalogie in die gemäß § 11 LitUrhG dem Urheber ohne Rücksicht auf das Erscheinen des Werkes eingeräumten Ausschließlichkeitsrechte einzubeziehen ist (vgl. Schiedsspmuch vom 9. Mai 1958, Schulze a. a. O. IV SchG 2 - Ufita Bd. 28, 372). Dies gilt unabhängig davon, ob die Sendung aufgefangen und mit Hilfe von Empfangsgeräten hörbar gemacht wird, da allein schon die ungenehmigte Ausstrahlung der Sendung mit ihrem in der Regel weitreichenden Wirkungsbereich und die damit verbundene $\mathrm{Möglichkeit} \mathrm{der} \mathrm{Hörbarmachung} \mathrm{für}$ eine unbegrenzte Hörerzahl aus dem gleichen Rechtsgedanken, nach dem das Recht zur geweribsmäBigen Verbreitung körperlicher Werkstücke in den Ausschließlichkeitsbereich des Urhebers fällt einen unzulässigen Eingriff in das Ausschließlichkeitsrecht des Urhebers darstellt (vgl. auch Ulmer a. a. O. S. $203 \mathrm{ff}$ ).

Wird die Rundfunkmusiksendung über ein Empfangsgerät hörbar gemacht, so erfolgt nunmehr eine Aufführung als ein neuer Akt der unkörperlichen Werkwiedergabe. Dies gilt auch, wenn eine Aufführung aus dem Konzert- oder Theatersaal durch den Rundfunk übernommen wird. Denn es liegt eine selibständige Zweitverwertung der Aufführung vor, wenn sie außerhalb des Veranstaltungsraumes durch Emplfang der Rundfunksendung an anderen Orten wiedergegeben wird. Für den Aufführungsbegriff ist auch rechtlich unerheblich, ob die Wiedergabe für das Gehör unter Benutzung von Schallvorrichtungen im Sinne von $\S 2$ Abs. 2 LitUrhG durchgeführt wird; denn das Gesetz unterscheidet nicht zwischen unmittelbar durch Menschen oder unter Zuhilfenahme von Tonträgern bewirkten Musikaufführungen (v.gl. RGZ 140, 231 - Tonfilm RGZ 153, 1; - Rundfunk- und Schallplatte; Ulmer a. a. O. S. 199; Urteil ides Senates vom 31. Mai 1960 - I ZR 53/58). Geschieht die Hörbarmachung der Rundfunksendung im privaten Bereich, so ist dies urheberrechtlich ohne Belang, weil dem Urheber 
nur die öffentliche Aufführung vorbehalten ist. Wird dagegen die Rundfunksendung, wie im Streitfall, in einer öffentlichen Gaststätte zu Gehör gebracht, so stellt dies eine von ider Rundfunksendung als solcher zu unterscheidende Veranstaltung einer öffentlichen, gewerblichen Zwecken dienenden Aufführung dar, die der Erlaubnis der Urheberberechtigten bedauff ( so im Ergebnis auch ıdas rechtskräftige Urteil des Landgerichts Berlin vom 16. Juni 1955 für Fernsehmusik, albgedruckt Ufita Bd. 21, 359; Schulze a. a. O. LGZ 36, sowie das Urteil des Kassationshofes Paris vom 28. April 1947, Schulze a. a. O. Bd. III Frankreich Nr. 1). Das bedeutet praktisch, $\mathrm{da} B$ die öffentliche Wiedergabe von Rundfunk-Musiksendungen in Gaststätten in gleicher Weise wie öffentliche Schallplattenaufführungen (BGHZ 11, 135) einer Vergütungspflicht den Urheberberechtigten gegenüber unterliegt. $\mathrm{Da}$ der Gastwirt in beiden Fällen aus den fraglichen Musikdarbietungen gewerblichen Nutzen zieht, ist auch, rein wirtschaftlich betrachtet, kein Grund ersichtlich, der es zu rechtfertigen vermöchte, die beiden Aufführungsarten hinsichtlich der Urhebervergütung unterschiedlich zu behandeln. Auf Grund eines 1954 geschlossenen Abkommens mit ider GEMA, die die Aufführungsrechte der Komponisten wahrnimmt, entrichten die Gastwirte auch bereits für die öffentliche Darbietung von Rundfunkmusik an die Werkschöpfer Aufführungsgebü.hren.

Im Streitfall geht es nun aber nicht um die Rechte der Werkschöpfer, sondern der ausübenden Künstler, deren Wiedergabeleistungen in den Gaststätten der Beklagten über Rundfunkempfangsgeräte öffentlich zu Gehör gebracht werden. Soweit für die Rundfunksendung Tonträger benutzt werden, die von den Zedenten der Klägerin bespielt oder besungen worden sind, ist es jedoch nur eine zwangsläufige Folge der in $\S 2$ Abs. 2 LitUrhG vorgesehenen Gleichstellung der Rechte der ausübenden Künstler an der Schallvorrichtung mit dem Recht eines Werkschöpfers, daß die von den Beklagten veranstalteten öffentlichen Rundfunkdarbietungen nicht nur der Erlaubnis der Komponisten der dargebotenen Musikwerke, sondern auch derjenigen Interpreten bedürfen, deren Wiedergabeleistung auf den für die Sendung benutzten Tonträgern festgelegt ist. Da entgegen der vom Reichsgericht vertretenen Ansicht in der Sendeerlaubnis nicht zugleich auch die Freigabe des Sendegutes für eine gewerbliche Nutzung zu öffentlichen Aufführungen einbeschlossen ist, den Werkschöpfern deshalb zu Recht bereits seit 1954 auf Grund des zwischen der GEMA und der Vereinigung der Musikveranstalter abgeschlossenen Tarifvertrages Aufführungsgebühren zufließen, muß das gleiche auch für die Inhaber der Bearbeiterurheberrechte an den Schallvorrichtungen gelten, die erlaubterweise für die fraglichen Rundfunksendungen benutzt werden.

Abzulehnen ist die vom Landgericht vertretene Auffassung, wonach bei der öffentlichen Wahrnehmbarmachung von Tonträgerdarbietungen durch Rundfunkempfangsgeräte ein Unterschied zwischen dem Recht der Werkschöpfer und der ausübenden Künstler aus dem Grunde gemacht werden müsse, weil die Rechte der ausübenden Künstler gemäß $\S 2$
Aibs. 2 LitUrhG nicht an ein Geisteswerk, sondern an ein stoffliches Erzeugnis, den Tonträger, anknüpfen, dieser "Leistungsträger" aber in seiner körperlichen Gestalt nur für den Sendeakt, nicht dagegen beim Empfang der Rundfunksendung „unmittelbar” benutzt werde. Diese Betrachtungsweise wird der vom Gesetz gewollten rechtlichen Gleichstellung der auf eine Schallvorrichtung festgelegten Wiedergabeleistung - also eines körperlichen Werkstückes mit einer Werkbearbeitung im Sinne des $\S 2$ Abs. 1 LitUrhG - also einem geistigen Gut - nicht gerecht. Denn aus idieser Gleichstellung folgt, daß es für die $R$ echts folge n belanglos sein muB, ob der Tonträger von dem Veranstalter der Aufführung unmittelbar als stoffliches Erzeugnis oder nur unter Zwischenschaltung eines Rundfunkempfangsgerätes oder sonstiger technischer Ubertragungswege zur öffentlichen Hörbarmachung der auf inm festgelegten Wiedergabeleistungen verwendet wird. Es muß vielmehr insoweit das gleiche wie für Werkbearbeitungen im Sinne von $\S 2$ Abs. 1 LitUrhG gelten. Wird aber beispielsweise idie geschützte Bearbeitung eines gemeinfreien Werkes durch Funk gesendet und in Gaststätten hörbar gemacht, so kann nicht zweifelhaft sein, ldaß hienfür Aufführungsgebühren an iden Bearbeiter zu entrichten sind.

Entscheidend für die Frage, ob für eine öffentliche Aufführung ein gemäß $\S 2$ Albs. 2 LitUrhG geschützter Tonträger benutzt wird, ist hiernach allein, ob ohne den Tonträger die Aufführung nicht zustande kommen könnte. Dies aber ist auch dann der Fall, wenn die auf dem Tonträger festgelegte Wiedergabeleistung über eine Rundfunksende- und Empfangsanlage entfernt vom Sendeort hörbar gemacht wird. Die abweichende Auffassung des Landgerichts würde zu dem Ergebnis führen, daß beispielsweise auch durch das Uberspielen von Tonträgermusik, die durch Rundfunk gesendet wind, auf Schallplatten oder Tonband nicht in die Rechte der ausübenden Künstler, die den gesendeten Tonträger bespielt haben, eingegriffen würde, weil auch bei einem solchen Uberspielen unter Ausnutzung des Sendevorgangs der gemäß $\S 2$ Abs. 2 LitUrhG geschützte Tonträger nicht "unmittelbar" in seiner Eigenschaft als stoffliches Erzeugnis benutzt würde. Dieses Ergebnis aber wäre unvereinbar mit dem Schutzgedanken des § 2 Abs. 2 LitUrhG, der vor allem die Tonträgerhersteller vor unbefugten Vervielfältigungen sichern wollte. Aber auch soweit das Aufführungsrecht infrage steht, wäre es nach der geltenden gesetzlichen Regelung nicht zu rechtfertigen, den ausübenden Künstlern oder ihren Rechtsnachfolgern bei öffentlichen Tonträgerkonzerten einen Anspruch auf Urhebergebühr zwar zuzusprechen, wenn der Tonträger unmittelbar im Veranstaltungsraum abgespielt wird, einen solchen Anspruch aber zu verneinen, wenn 'die Tonträgermusik von Dritten, die den eigentlichen Abspielvorgang nicht veranlassen, durch seine Hörbarmachung in Gaststätten oder anderen öffentlichen Veranstaltungsräumen gewerblich genutzt wird.

2. Die Klage kann jedoch, soweit Direktübertragungen des Rundfunks (Livesendungen) infrage 
stehen, nicht auf $\S 2$ Abs. 2 LitUrhG gestützt werden. Die abiweichende Auffassung des Berufungsgerichts beruht darauf, daB es den Rundfunk als eine "Tonträgervorrichtung" im Sinne dieser Gesetzesbestimmung ansieht. Dem kann nicht beigepflichtet werden. Wortlaut, Entstehungsgeschichte und Zwedk des $\S 2$ Aibs. 2 LitUrhG ergeben eindeutig, daß durch diese Bestimmung nur Schallvorrichtungen erfaßt werden sollten, die die Klangquelle in sich selbst tragen und deshallb eine Wiederholung der durch sie körperhaft festgelegten Wiedergabeleistung beliebig oft und zu beliebiger Zeit gestatten. Allein in einer solchen Festlegung der an sich vergänglichen, an den Ablauf ides Wiedergabeaktes gebundenen Leistung des ausübenden Künstlers, die dieser Leistung ein von ider Person des Künstlers und dem flüchtigen Schaffensvorgang selbständiges Dasein verleiht, erblickte der Gesetzgeber die Rechtfertigung für eine rechtliche Gleichstellung der fixierten Wiedergabeleistung mit einer Werkbearbeitung (vgl. hierzu auch Kohler "Autorschutz des reproduzierenden Künstlers" GRUR 1909 S. 230 ff, auf dessen Gedankengänge in dem Bericht der Kommission über den Entwurf eines Gesetzes zur Ausführung der Revidierten Berner Uibereinkunft zum Schutze von Werken der Literatur und Kunst vom 13. Novomber 1908 ausdrücklich Bezug genommen wird; Verhandlungen des Reichstags XII. Legislaturperiode, II. Session Bd. 276, Drucksache Nr. 341 S. 2315). Die Rundfunkanlage aber dient nur der unkörperhaften Uibermittlung von Tönen, ohne sich bei Direktübertragungen irgendwelcher Vorrichtungen zu bedienen, die die Töne festhalten und damit eine Wiederholung der Darbietung ermöglichen. Das Reichsgericht hat es deshalb zu Recht stets abgelehnt, den Rundfunk als ein „zur mechanischen Wiedergabe für das Gehör dienendes Instrument" im Sinne von $\S 2$ Abs. 2 oder von $\S 12$ Abs. 2 Nr. 5 oder § 14 Nr. 4 LitUrhG anzusehen (vigl. RGZ 113, 413 - Tor und Tod; RGZ 136, 377 - Lautsprecher). Dies entspricht auch der im Schrifttum herrschenden Meinung (Smoschewer, JR 1925, 455; Hoffmann, GRUR 19.25, 71; Opet, DJZ 1925, 807; Schmidt di Simoni, Studien zum Fernseh- und Urheberrecht 1956, S. $77 \mathrm{ff}$ ). Hieran ist festzuhalten (BGHZ 8, 88, 91; vgl. auch Urteil des Senats vom 31. Mai 1960 - I ZR 64/58 - Rundfunksendung "Figaros Hochzeit").

Das aber bedeutet nicht, daß die ausüibenden Künstler gegen die gewerbliche Nutzung ihrer erlaubterweise durch Funk gesendeten unmittelbaren Leistungen schutzlos wären. Wie der Senat in seiner bereits angeführten Entscheidung I ZR 64/58, die die ungenehmigte Erstfestlegung von Orchesterdarbietungen auf Tonträger betrifft, näher dargelegt hat, steht dem ausübenden Künstler nach allgemein bürgerlich-rechtlichen wie auch persönlichkeits- und wettbewerbsrechtlichen Grundsätzen das freie Entscheidungsrecht über Art und Umfang der Auswertung seiner Leistung zu. Fraglich kann nur sein, ob er sich dieses Entscheidungsrechtes hinsichtlich der Nutzung.seiner Leistung durch öffentliche gewerbliche Aufführungen begeben hat, wenn er in ihre Sendung idurch Rundfunk willigte. Dies kann nicht angenommen werden. Bei der öffentlichen Darbie- tung von Rundfunksendungen, beispielsweise in Gaststätten, handelt es sich um eine vom privaten Rundfunkempfang, für den der ausübende Künstler nach seinen Abmachungen mit den Rundfunkanstalten seine Leistung allein zur Verfügung gestellt hat wesensverschiediene Nutzungsart, die sehr viel weitreichender als der Rundfunkempfang im privaten Bereich in die Interessen des ausübenden Künstlers eingreift, und zwar sowohl in persönlichkeitsrechtlicher wie in vermögensrechtlicher Beziehung. Denn wenn auch der ausübende Künstler, indem er die Runfunksendung erlaubte, seine Leistung einem nahezu unbegrenzten und unkontrollierbaren Hörerkreis zugänglich gemacht hat, so kann es doch gleichwohl auch vom künstlerischen Standpunkt aus für ihn einen ins Gewicht fallenden Unterschied bedeuten, ob seine Leistung nur einem privaten Hörerkreis hörbar gemacht wird oder ob sie auch für öffentliche Darbietungen, tbeispielsweise als $\mathrm{Ge}$ räuschkulisse in Gaststätten benutzt wird. Abgesehen hiervon werden durch solche öffentlichen Darbietungen seiner durch den Rundfunk vermittelten Leistungen die wirtschaftlichen Interessen des ausübenden Künstlers in einschneiddenderer Weise als durch einen privaten Rundfunkempfang berührt. Zwar kann in der Regel kaum angenommen werden, daß er zur persönlichen Leistung herangezogen würde, falls die öffentliche Hörbarmachung der Rundfunksendung unterbleiben müßte, weil er seine Zustimmung versagt oder diese von ider Zahlung einer angemessenen Vergütung abhängig macht. Nach der Lebenserfahrung ist aber angesichts der stetig wachsenden Nachfrage nach mechanischen Musikdarbietungen anzunehmen, daß dann an die Stelle der strittigen Rundfunkdarbietungen Schallplatten oder Tonbandaufführungen treten würden, für die auf Grund von § 2 Abs. 2 LitUrhG Aufführungsgebühren auch an den ausübenden Künstler zu zahlen sind, und zwar unabhängig davon, ob diese Tonträger über Plattenspieler oder über eine Rundfunkanlage öffentlich hörbar gemacht werden (vgl. Urteil des Senats vom 31. Mai 1960 - I ZR 53/58 - Künstlerlizenz bei öffentlicher Wiedergabe von Schallplatten). Es widerspricht aber den guten Sitten des lauteren Wettbewerbs ( $\begin{array}{lll}\text { U } & \text { UWG) und }\end{array}$ stellt eine sittenwidrige Vermögensbeschädigung dar (§ 826 BGB), eine fremde Leistung, die enfahrungsgemäß nur gegen eine angemessene Vergütung erbracht wird, kostenlos zur Förderung des eigenen gewerblichen Gewinnstrebens auszunutzen und hierdurch dem Leistenden einen wirtschaftlichen Schaden zuzufügen, weil ihm auf diese Weise ein Entgelt für seine etwaige persönliche Heranziehung oder aber für die Benutzung von Tonträgern entgeht, auf die seine Leistung übertragen worden ist. Die besonderen Umstände, die $\mathrm{zu}$ der unentgeltlichen und ungenehmigten Ausnutzung fremder Arbeit in der Regel hinzutreten müssen, um sie unerlaubt zu machen, liegen hier darin, daß die Leistungen der ausübenden Künstler nicht etwa "nachgebildet", sondern unmittelbar "angefaßt" und unverändert als Vorspann zur Steigerung der eigenen Erwerbschancen verwendet werden, indem sie mit Hilfe des Rundfunkempfangsgerätes aus dem Ather entnommen werden. Hierzu aber sind die Beklagten 
überhaupt nur deshalib in der Lage, weil die Errungenschaften der Technik die ausübenden Künstler weitgehend der Möglichkeit beraubt haben, Wirkungsbereich und Art der Ausnutzung ihrer Leistung in tatsächlicher Beziehung zu ibeherrschen und rechtlich durch entsprechende Verträge auch Dritten gegenüber wirksam abzugrenzen. Aus ähnlichen Erwägungen, aus denen das Reichsgericht bereits am 7. April 1910, also bevor $\S 2$ Abs. 2 LitUrhG in das Urhebergesetz eingefügt wurde, in dem Nachpressen von Schallplatten einen Verstoß gegen
$\S 826$ BGB erblickt hat (RGZ 73, 294), muß auch im Streitfall den Zedenten der Klägerin aus dem Gesichtspunkt des "Schmarotzens" an fremder Leistung ein Unterlassungsanspruch gegen die Beklagten auch insoweit zugebilligt werden, als die öffentliche Hörbarmachung von Direktsendungen des Rundfunks infrage steht (vgl. auch Urteil des Senats vom 31. Mai 1960 - I ZR 64/58 - Rundfunksendung "Figaros Hochzeit"). 


\section{Auszug aus dem Urteil des Bundesgerichtshofs vom 31. Mai 1960}

$$
\text { -I ZR 71/58 - (BGHZ 33, S. 48) }
$$

\section{Leitsätze}

Werden Orchesterdarbietungen erlaubterweise auf einem Tonträger festgelegt, so wird originärer Träger des Bearbeiterurheberrechts an dem Tonträger neben dem Dirigenten und etwaigen Solisten jedes einzelne Orchestermitglied. Wer zur Wahrnehmung dieses Rechtes befugt ist, richtet sich, falls ausdrückliche Abmachungen fehlen, nach dem sozialen Gefüge des Orchesters.

Besteht das Orchester aus freiberuflich tätigen Musikern, die sich nur gelegentlich mit wechselndem Mitgliederbestand unter einem bestimmten künstlerischen und kaufmännischen Lelter für Direktübertragungen im Rundfunk zusammenfinden, so ist den Umständen des Einzelfalles zu entnehmen, ob dieser Leiter zur Wahrnehmung des Rechtes der einzelnen Orchestermitglieder befugt ist, über die Festlegung ihrer Leistung auf Tonträger $\mathrm{zu}$ Sendezwecken zu entscheiden, und ob Ihm die Orchestermitglieder ihre Rechte aus $\$ 2$ Abs. 2 LitUrhG an den Tonträgern, soweit Wiederholungssendungen des Rundfunks infrage stehen, zur Auswertung für eigene Rechnung oder nur zur treuhänderischen Verwaltung für Rechnung aller Mitwirkenden übertragen haben.

\section{Tatbestand:}

Der Beklagte hatte 1945 ein Orchester gegründet, dessen Dirigent er war und mit dem er in wechselnder Stärke und Besetzung auch wiederholt für Direktübertnagungen (sog. Live-Sendungen) des Bayerischen Rundfunks spielte. Das geschah jeweils auf Grund von Vereinbarungen, die lediglich er mit dem Rundfunk traf und die in jedem Einzelfall in einem "Verpflichtungsschein" niedergelegt wurden. In Ziff. 3 'dieses Scheines war vorgesehen, daß der Rundfunk befugt sein sollte, die Sendungen mitzuschneiden und sie gegen ein'e Entschädigung in Höhe von $10 \%$ des urspnünglich vereinbarten Honorars, das stets 1800 , DM für jede Sendung betrug, zu wiederholen. In der Folge kam es mehrfach $\mathrm{zu}$ solchen Wiederholungssendungen. Dabei wurden auch Titel gesendet, die in der Zeit vom 13. November 1948 bis zum 24. September 1949 mitgeschnitten worden waren. Die dafür angefallenen Wiederholungsgebühren im Betrage von insgesamt 8959,80 DM zahlte der Rundfunk erst auf Vorstellungen des Beklagten, und zwar Ende Juni 1952.

28 frühere Mitglieder des von dem Beklagten gegründeten Orchesters, die inzwischen zum größten Teil vom Rundfunk übernommen worden sind, behaupten, daß ihnen an dem bezeichneten Betrag Anteile in der Gesamthöhe von 6047,73 DM zustehen. Sie haben ihre hierauf gerichteten An- sprüche zum Zwecke der Einziehung an die Klägerin als ihre Berufsvereinigung abgetreten. Diese hat nach fruchtlosem Schriftwechsel Klage mit dem Antriag erhoben, den Beklagten zur Zahlung von 6047,73 DM nebst 4\% Zinsen seit 'dem 18. März 1955 zu verurteilen. . . . Zur Begründung beruft sich die Klägerin in erster Linie auf das Bearbeiterurheberrecht des $\S 2$ Abs. 2 LitUrhG an den von dem Orchester bespielten Tonbändern, das, wie sie meint, nicht nur in der Person des Beklagten, sondern auch aller Mitglieder seines Orchesters entstanden und das vom Rundfunk entweder durch die Wiederholungssendungen verletzt oder für diese Sendungen doch nur gegen eine Wiederholungsgebühr von $10 \%$ erworben worden sei. . . .

Entscheidungsgründe:

\section{. .}

IV. Die Klägerin hat . . . ihre Klage im wesentlichen auf $\S 2$ Abs. 2 LitUrhG gestützt. Diesen Klagegrund hat das Berufungsgericht mit der Begründung nicht als durchgreifend angesehen, daß das Bearbeiterurheberrecht an einem Tonträger, der Orchesteraufführungen festhalte, nur in der Person des Dirigenten und etwa mitwirkender Solisten entstehe, während ein solches Recht an der auf dem Tonträger festgelegten Wiedergabeleistung für die einzelnen Orchestermitglieder nicht in Betracht komme. Das Berufungsgericht folgert dies daraus, daß die Rechte der ausübenden Künstler an ihrer auf einer Schallvorrichtung festgehaltenen Leistung in einem Urheberrechtsgesetz geregelt und nach urheberrechtlichen Gesichtspunkten ausgestaltet sind. Deshalb lasse sich auch der Begriffsinhalt des Merkmals "persönlicher Vortrag" in $\S 2$ Abs. 2 LitUrhG lediglich vom Urheberrecht her ibestimmen. Hiernach aber könne $\S 2$ Abs. 2 LitUrhG nur dahin ausgelegt werden, daß nicht jeder beliebige Vortrag, sondern nur derjenige Vortrag, der eine individuelle geistige Leistung idarstelle, zur Begründung eines Schutzes aus $\S 2$ A.bs. 2 LitUrhG geeignet sei. Da es aber bei Orchesteraufführungen allein die persönliche Auffassung des Dirigenten sei, die sich in dem Vortrag auspräge, könne auch nur er als Urheber im Sinne dieser Vorschrift angesehen werden. Denn nur seine Tätigkeit, nicht dagegen die der einzelnen Orchestermitglieder, die dem Dirigenten bei der Aufführung wie auch schon bei iden Proben zum "Gehorsam" verpflichtet seien, biete genug Raum für eine individuelle geistige Leistung, wie sie $\S 2$ Abs. 2 LitUrhG voraussetze.

Dieser Auslegung des $\S 2$ Aibs, 2 LitUrhG durch das Berufungsgericht kann nicht beigetreten werden. Sie läßt sich rweder mit dem Wortlaut noch 
mit der Entstehungsgeschichte und dem Zweck dieser Gesetzesbestimmung vereinbaren und wünde zu unlösbaren Abgrenzungsschwierigkeiten führen. Zunächst ist, worauf die Revision zutreffend hinweist, zu beachten, daß die Tonübertragung auf eine Schallvorrichtung durch "persönlichen Vortrag" im Sinne des Satzes 1 des $\S 2$ Abs. 2 LitUrhG der Tonübertragung durch eine "mechanische" Tätigkeit durch Lochen, Stanzen, Anordnen von Stiften gegenübergestellt ist und nach dem Gesetzeswortlaut nur bei diesem mechanischen Ubertragungsvorgang der Schutz von einer "künstlerischen" Leistung abhängig ist. Auch die Gesetzesmaterialien ergeben mit aller Deutlichkeit, daß durch das Merkmal "persönlicher Vortrag" nur der Gegensatz zu einer nicht durch den Vortrag eines lebenden Menschen, sondern durch technische - also unpersönliche - Mittel berwirkten Tonübertragung herausgestellt weriden sollte (vgl. Begründung zum Entwurf eines Gesetzes zur Ausführung der Revidierten Berner Ubereinkunft vom 13. Dezember 1908, Verhandlungen des Reichstags XII. Legislaturperiode II. Session Bd. 275 Nr. 341 S. 1793; erste Beratung dieses Entwurfes, Verhandlungen des Reichstags Bd. 261, S. 2278 sowie Kommissionsbericht Bd. 276, S. 2340). Der Gesetzgeber, der mit $\S 2$ Abs. 2 LitUrhG in erster Linie nicht einen Schutz der ausübenden Künstler, sondern der Tonträgerindustrie gegen eine unbefugte Nachbildung ihrer Erzeugnisse anstrebte, war sich im klaren darüber, daß es insoweit in Wahrheit um ein Anliegen des gewerblichen Rechtsschutzes oder des unerlaubten Wettbewerbs ging (vgl. Entwurfsbegründung zu Art. 1 Nr. 2). Man glaubte aber, einen solchen Schutz auch im Rahmen des Urheberrechtes verwirklichen zu können, wenn man ihn in der Person des ausübenden Künstlers entstehen ließ, weil seine Wiedergabe eines Werkes der Literatur oder Tonkunst eine individuelle Leistung darstelle und deshalb im Fall ihrer Festlegung auf einer Schallvorrichtung einer Werkbearbeitung gleichgeachtet werden könne.

In der Begründung der Gesetzesnovelle von 1910, ldurch die \& 2 Abs. 2 in das Gesetz eingefügt wurde, heißt es:

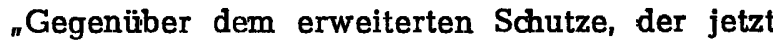
den Urhebern gegen die mechanische Wiedergabe ihrer Werke gewährt wird, ist von Seiten der Industrie der mechanischen Musikinstrumente und Sprechmaschinen der lebhafte Wunsch geäußert worden, auch ihrerseits einen Schutz für die von ihr hergestellten Wialzen, Bänder, Platten usw. gegen unbefugte Nachbildung zu erhalten. Diesem Wunsche wollen die Vorschriften der Nr. 2 entgegenkommen. Bereits in den Verhandlungen der Berliner Urheberrechtskonferenz ist die Fnage zur Sprache gekommen, dort aber nicht weiter verfolgt worden, weil sie nicht sowohl dem Gebiete des Urheberrechts als vielmehr tem des gewerblichen Rechtsschutzes angehöre (vgl. die Denkschrift zur revidierten Berner Ubereinkunft S. 37). Immerhin erscheint es, wenn jetzt das Rechtsverhältnis zwischen den Urhebern und der mechanischen Industrie neu geordnet wird, erwünscht, hierbei, soweit tunlich, auch diese Frage zu regeln. Es entspricht nur der Billigkeit, der Industrie, die sich Beschränkungen ihrer bisherigen Freiheit unterwerfen muß, einen Schutz gegen unberechtigte Nachbildung ihrer oft mit großen Kosten erworbenen Vorrichtungen $\mathrm{zu}$ bewilligen. Ein solcher Schutz läßt sich jedenfalls insoweit, als er sich auf einen persönlichen Vortrag des Werkes gründet, ohne Zwang im Rahmen des Urheberrechts verwirklichen. Denn die individuelle Leistung, die in dem persönlichen Vortrag liegt, kann, wie sie durch das Herstellen einer Vorrichtung festgelegt ist, sehr wohl einer Bearbeitung des literarischen oder musikalischen Werkes gleichgeachtet werden. Als Urheber schützt der Entwurf ( $\$ 2$ Abs. 2 Satz 1,3) demgemäß nicht den Hersteller der den Vortrag fixierenden Vorrichtung, sondern den Vortragenden, der aber in der Praxis sein Recht regelmäßig dem industriellen Unternehmen übertragen wird. Inhalt und Umfang der hiernach begründeten urheberrechtlichen Befugnisse sowie die Dauer ides Schutzes und die Folgen einer Verletzung ergeben sich ohne weiteres daraus, daß der Vortragende in Ansehung der den Vortrag fixierenden Vorrichtung in der gleichen Weise geschützt wird wie der Bearbeiter eines Werkes in Ansehung seiner Bearbeitung (§ 2 Satz 2 des Gesetzes vom 19. Juni 1901); daB das Originalwerk als solches geschützt sei, ist für den Schutz der Bearbeitung nicht erforderlich." (Verhandlung des Reichstags XII. Legislaturperiode II. Session Bd 275 S. 1793).

Danach ist der Gesetzgeber ersichtlich davon ausgegangen, daß die Voraussetzung der Ubertragung eines Werkes auf Tonträger durch einen "persönlichen Vortnag" im .Sinne dieser Gesetzesbestimmung stets gegeben sei, wenn der Tonträger die unmittelbare Wiedergabeleistung eines ausübenden Künstlers festhält, und daß es des besonderen Nach"weises einer "künstlerischen" Leistung nur bedürfe, wenn die Ubertragung allein auf eine technische Tätigkeit zurückgeht. Dem steht nicht entgegen, daB in der Gesetzesbegründung von der "individuellen Leistung" gesprochen wird, die in dem persönlichen Vortra.g liegt. Denn wie der Senat in seinem Urteil vom 31. Mai 1960 - I ZR 64/58 (Rundfunksendung „Figaros Hochzeit") näher dargelegt hat, ist jede lautliche Wiedergabe eines Tonkunstwerkes, gleichgültig, ob das Werk durch die menschliche Stimme oder das Spielen eines Instrumentes zum Erklingen kommt, mit der Person des sie vermittelnden Künstlers unlösbar verbunden, da sie von seinen höchstpersönlichen Eigenschaften und Fähigkeiten abhängig ist. Die Wiedergabeleistung eines ausübenden Künstlers gehört somit seiner in ihrer Eigenart einmaligen Individualsphäre an und ist deshalb stets zwangsläufig eine "individuelle" Leistung. $\mathrm{Ob}$ bei Gruppenleistungen wie beispielsweise Chor- oder Orchesterdarbietungen der Hörer in der Lage ist, die jeweilige Eigenart der durch die Person des einzelnen Mitwirkenden geprägten Einzelleistung herauszuhören, ist hierbei ohne Belang, weil der Gesetzgeber hierauf nicht abgestellt hat. Aus ähnlichen persönlichkeitsrechtlichen Erwägungen hat deshalb auch lder erkennende Senat in dem vorerwähnten Urteil im Grundsatz jedem einzelnen Mitglied eines 
Opernorchesters das Recht zugesprochen, über Art und Umfang der Verwertung seiner unmittelbaren Wiedergabeleistungen selbst zu entscheiden, insbesondere über die Festlegung seiner Leistung auf einen Tonträger zu bestimmen.

Die vom Berufungsgericht vertretene Auffassung, wonach Vortragender im Sinne des $\S 2$ Abs. 2 Satz 3 LitUrhG nur derjenige sein soll, dessen "persönliche Auffassung" sich in dem Vortrag auspräge, findet hiernach weder im Gesetzeswortlaut noch in seiner Entstehungsgeschichte eine Stütze. $\mathrm{Zu}$ Unrecht meint idas Berufungsgericht, die Einordnung der fraglichen Bestimmung in das Urheberrecht zwinge dazu, dem Begriff "persönlicher Vortrag" alles an Urheberrechtsgehalt zu belassen, was nicht notwendig weggedacht werden müsse. Denn es ist $z$. B. auch die Regelung des Rechtes am eigenen Bilde in ein Urheberrechtsgesetz aufgenommen ( $\S 22$ ff KunstUrhG) und dieses Recht mit urheberrechtsähnlichen Befugnissen ausgestattet worden, obwohl es sich zweifellos um ein reines Persönlichkeitsrecht und nicht um ein Urheberrecht handelt.

Gerade weil die Wiedergabeleistung des ausübenden Künstlers in der Regel keine eigentümliche Schöpfung darstellt, wird die Gleichstellung der auf einem Tonträger festgelegten Leistung mit einer Werkbearbeitung in Rechtsprechung und Schrifttum zu Recht als eine „Fiktion" gekennzeichnet. Von einer Fiktion kann nur gesprochen werden, wenn an $\mathrm{u} \mathrm{n} \mathrm{g} \mathrm{l} \mathrm{e} \mathrm{i} \mathrm{c} \mathrm{h} \mathrm{e} \mathrm{Tatbestände} \mathrm{nach} \mathrm{dem} \mathrm{Willen} \mathrm{des}$ Gesetzgebers gleiche Rechtsfolgen geknüpft werden (vgl. Urteil des Senats vom 31. Mai 1960 - I ZR $53 / 58$ - Künstlerlizenz bei öffentlicher Wiedergabe von Schallplatten). Die Auslegung des Berufungsgerichts würde zudem, wie die Revision zu Recht hervorhebt, zu untragbaren Schwierigkeiten bei der Anwendung des $\$ 2$ Abs. 2 LitUrhG führen, weil sie stets eine Feststellung erforderte, wessen persönliche Auffassung sich bei der auf einer Schallvor- richtung festgelegten Aufführung durchgesetzt hat. Schon der Ausgangspunkt der Uberlegungen des Berufungsgerichts, wonach sich die einzelnen Orchestermitglieder mehr oder weniger mechanisch als Organe ohne eigenen Willen der Leitung des Dirigenten fügen, wird nach Ansicht des Senats dem Zusammenspiel der künstlerischen Elemente bei einer Orchesterdarbietung nicht gerecht. Wie aber soll, abgesehen hiervon, die Rechtslage beurteilt werden, wenn beispielsweise ein bekanntes Orchester infolge Erkrankung des Dirigenten, der die Proben durchgeführt hat, unter einem Gastdirigenten spielt? Und in wessen Person soll das Bearbeiterurheberrecht bei Orchesterdarbietungen entstehen, die ohne Dirigenten durchgeführt werden, wie dies bei Tanzorchestern sogar der Regelfall ist?

Schon diese Fragen zeigen, welche Fülle von Einzelproblemen sich der Rechtsanwendung nach der vom Berufungsgericht vertretenen Gesetzesauslegung stellen würden. In Wahrheit erbringt auch bei Gruppenleistungen wie Chor- und Orchesteraufführungen jeder der Mitwirkenden eine individuelle, mit anderen Worten von den Bedingtheiten seiner Person abhängige Leistung, wobei sich die Einzelleistungen gegenseitig zu einer Gesamtwirkung ergänzen. Damit aber ist in der Person eines jeden Mitwirkenden die gesetzliche Voraussetzung eines "persönlichen Vortrages" erfüllt. Hieraus folgt, daß bei Festlegung einer Orchesteraufführung auf Tonträger in der Person jedes unmittelbar an der Aufführung Mitwirkenden gemäß § 2 Abs. 2 LitUrhG ein Bearbeiterurheberrecht an dem Tonträger entsteht. Dieses Recht schließt die ausschließliche Befugnis ein, die Benutzung des Tonträgers für Sendezwecke $\mathrm{zu}$ brewilligen oder $\mathrm{zu}$ untersagen (RGZ 153, $1 \mathrm{ff}_{;}$vgl. auch Entscheidung des Senats vom 31. Mai 1960 - I ZR 64/58 - Rundfunksendung "Figaros Hochzeit").

V. . . 



\section{Gegenüberstellungen}

I.

Gegenüberstellung der Vorschriften des Entwurfs zu den Vorschriften des Gesetzes betreffend das Urheberrecht an Werken der Literatur und der Tonkunst (LUG), den Vorschriften des Gesetzes betreffend das Urheberrecht an Werken der bildenden Künste und der Photographie (KUG) sowie den sonstigen Vorschriften, deren Aufhebung der Entwurf vorsieht.

II.

Gegenüberstellung der Vorschriften des Gesetzes betreffend das Urheberrecht an Werken der Literatur und der Tonkunst (LUG) zu den Vorschriften des Entwurfs.

III.

Gegenüberstellung der Vorschriften des Gesetzes betreffend das Urheberrecht an Werken der bildenden Künste und der Photographie (KUG) zu den Vorschriften des Entwurfs. 
I.

Gegenüberstellung der Vorschriften des Entwurfs zu den Vorschriften des Gesetzes betreffend das Urheberrecht an Werken der Literatur und der Tonkunst (LUG), den Vorschriften des Gesetzes betreffend das Urheberrecht an Werken der bildenden Künste und der Photographie (KUG) sowie den sonstigen Vorschriften, deren Aufhebung der Entwurf vorsieht.

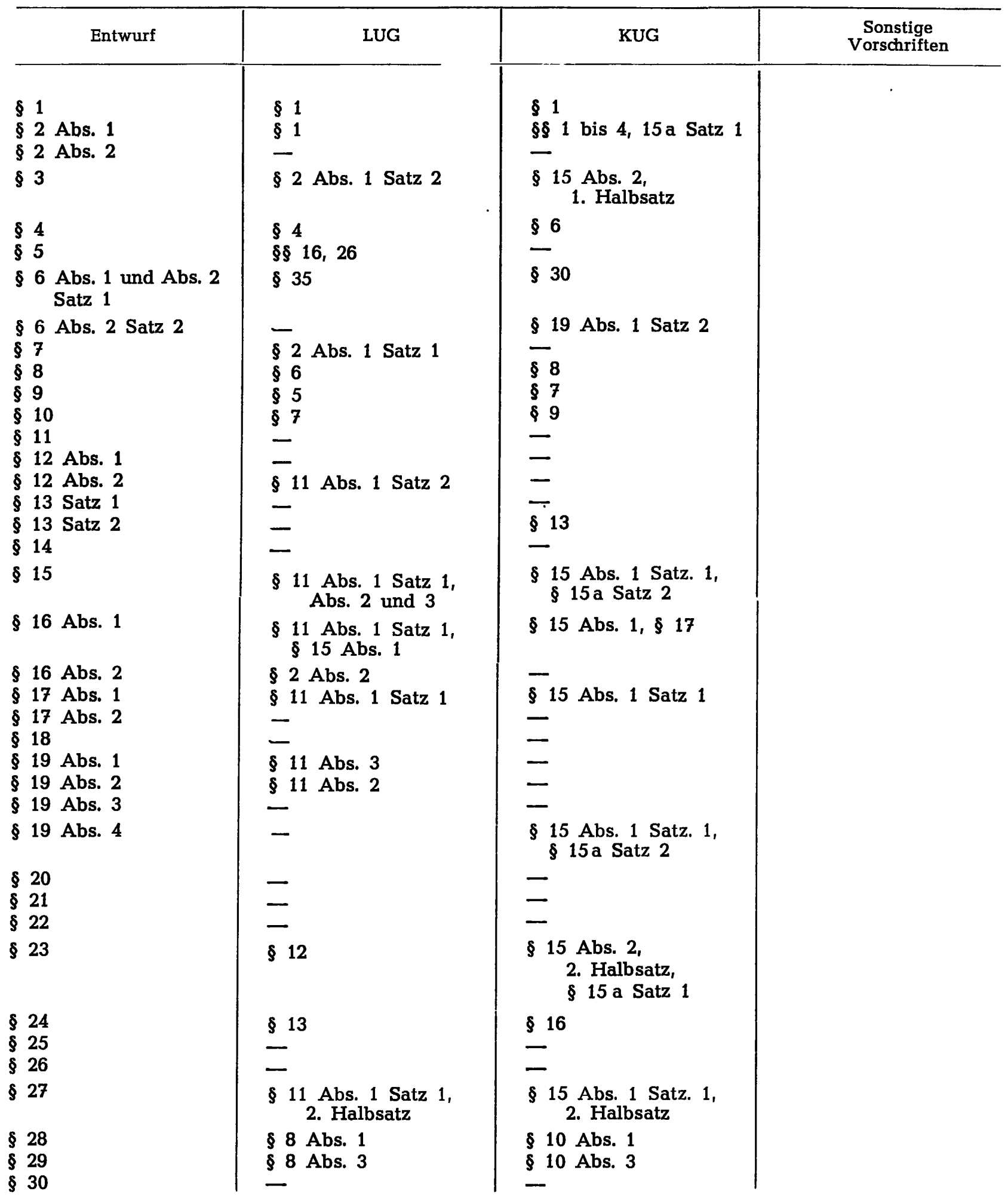




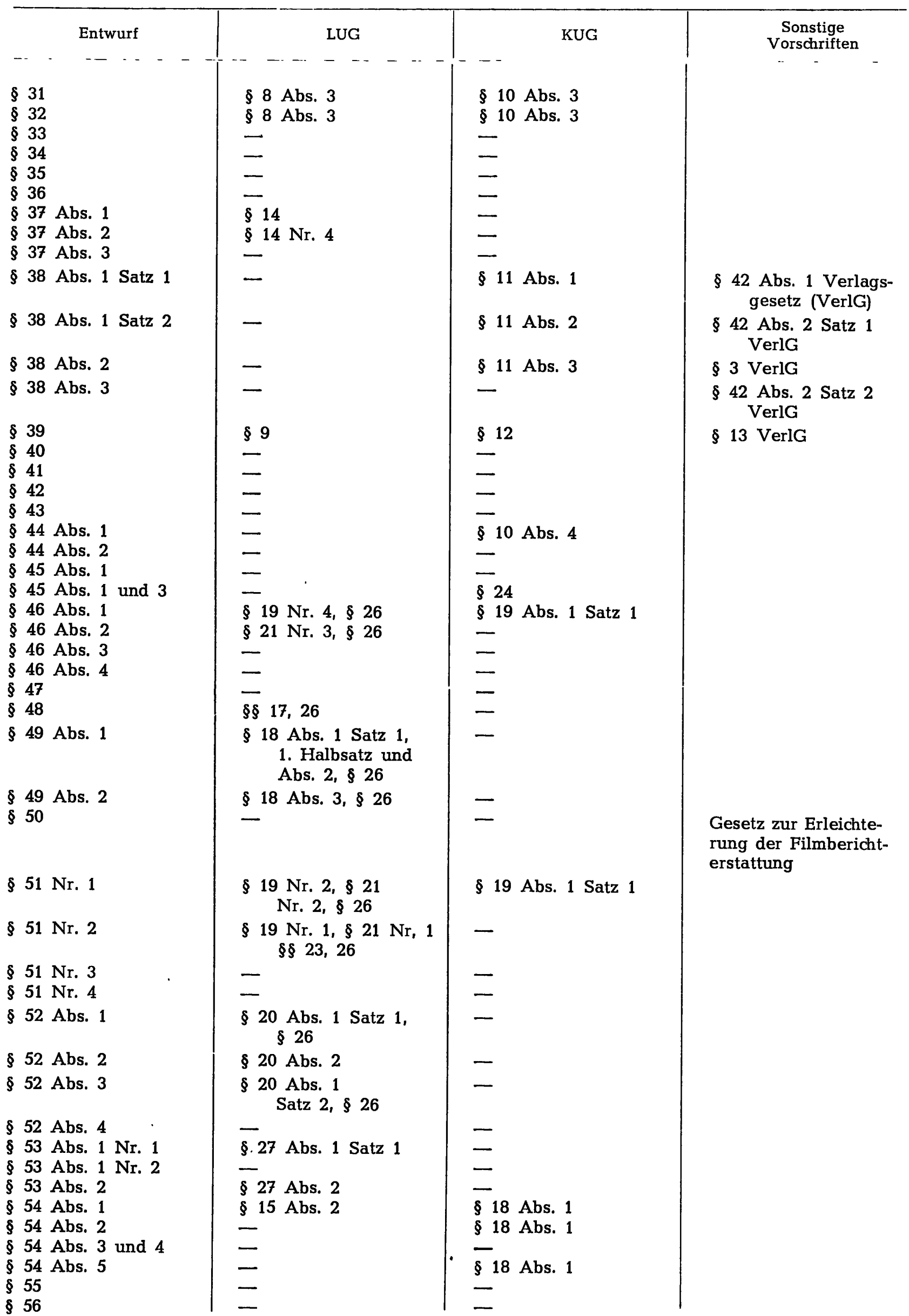




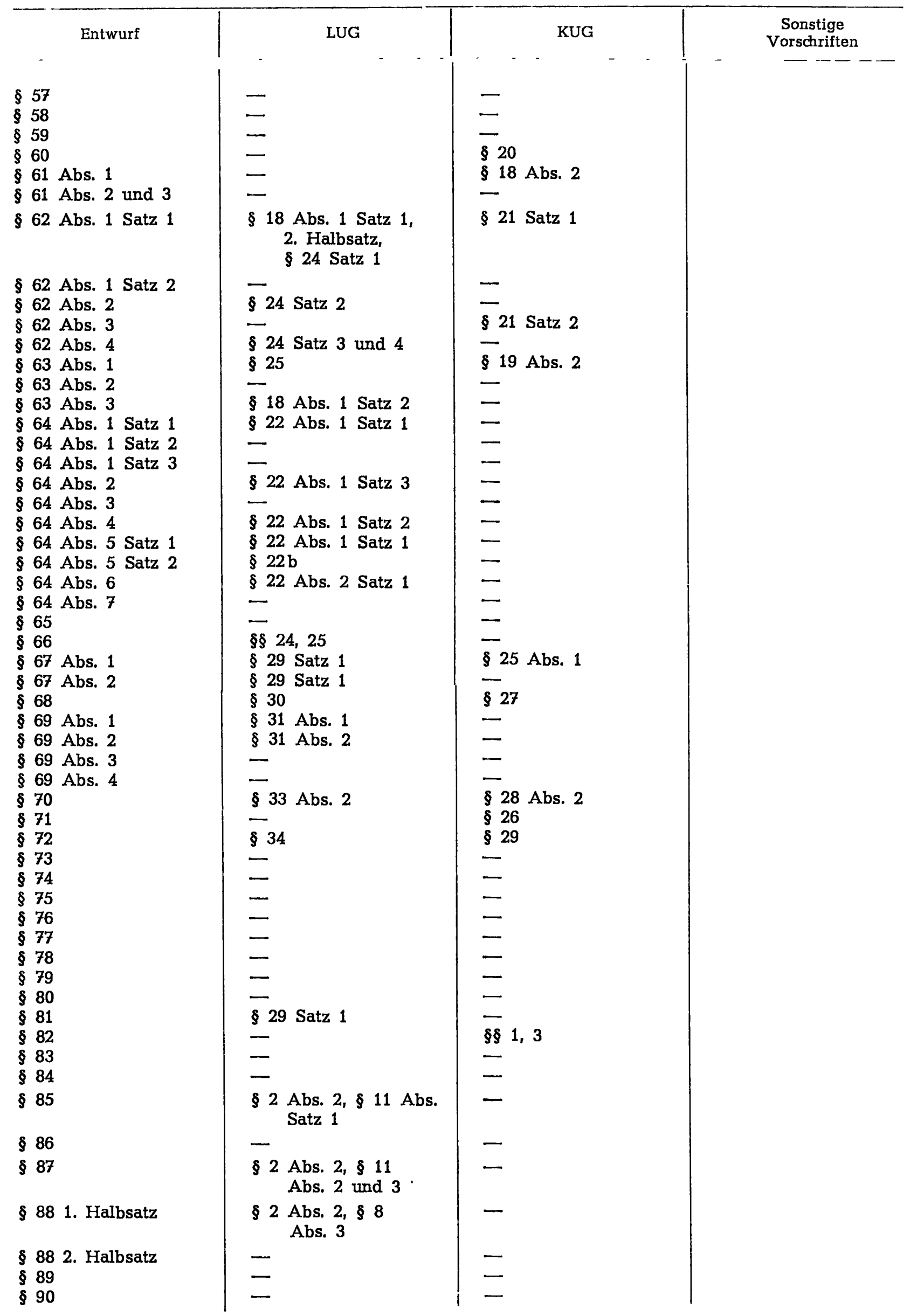




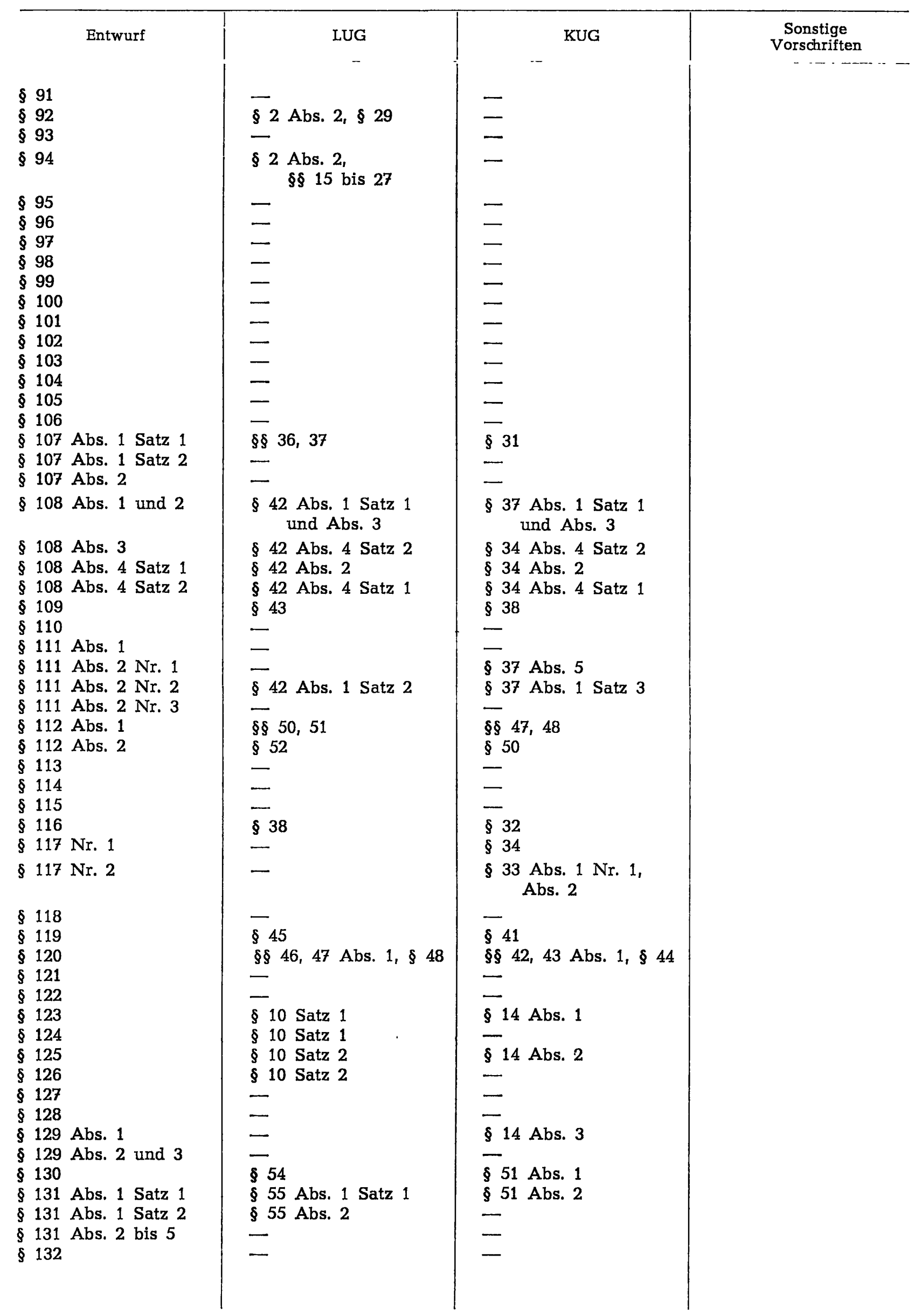




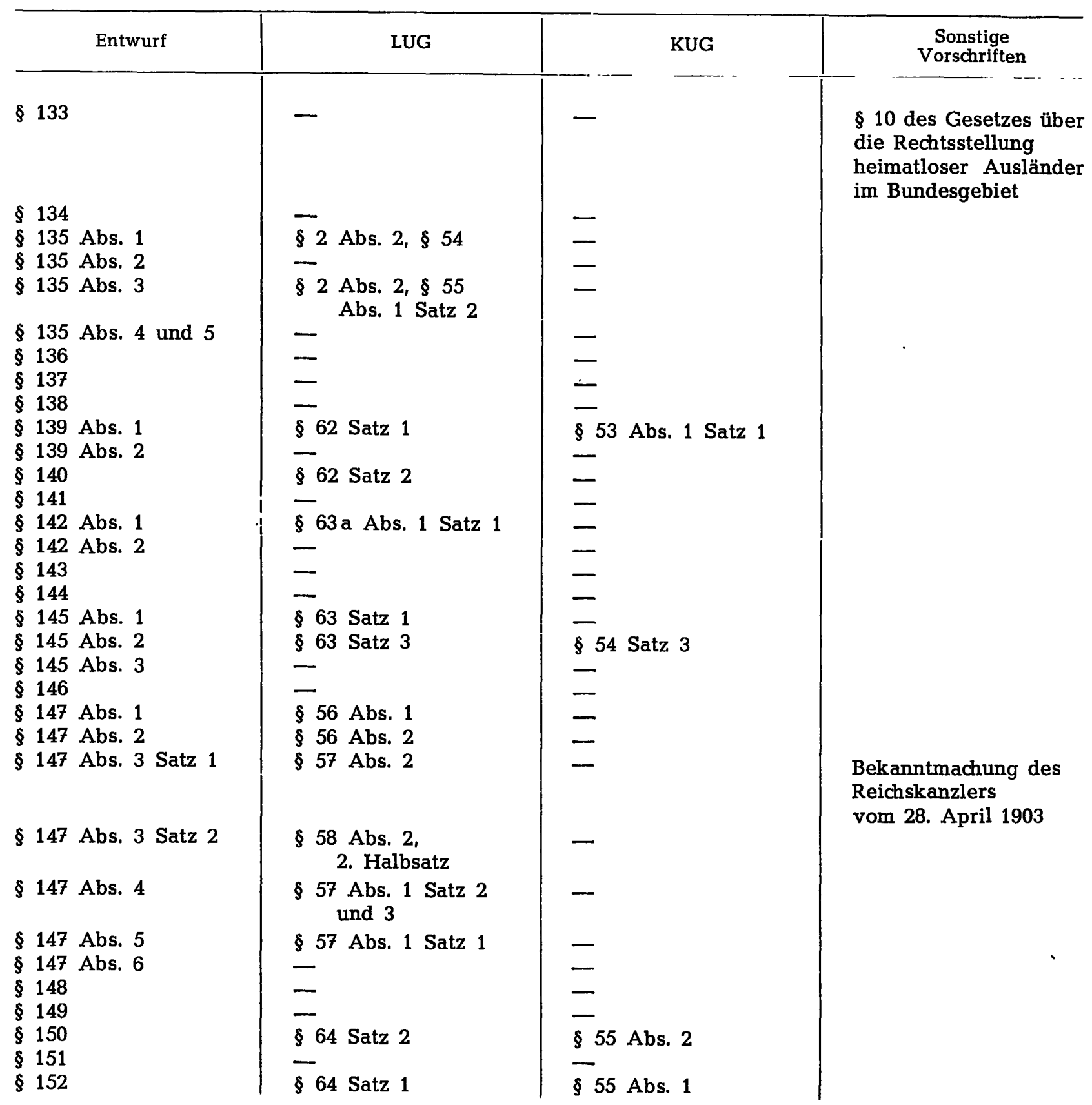


II.

Gegenüberstellung der Vorschriften des Gesetzes betreffend das Urheberrecht an Werken der Literatur und der Tonkunst (LUG) zu den Vorschriften des Entwurfs.

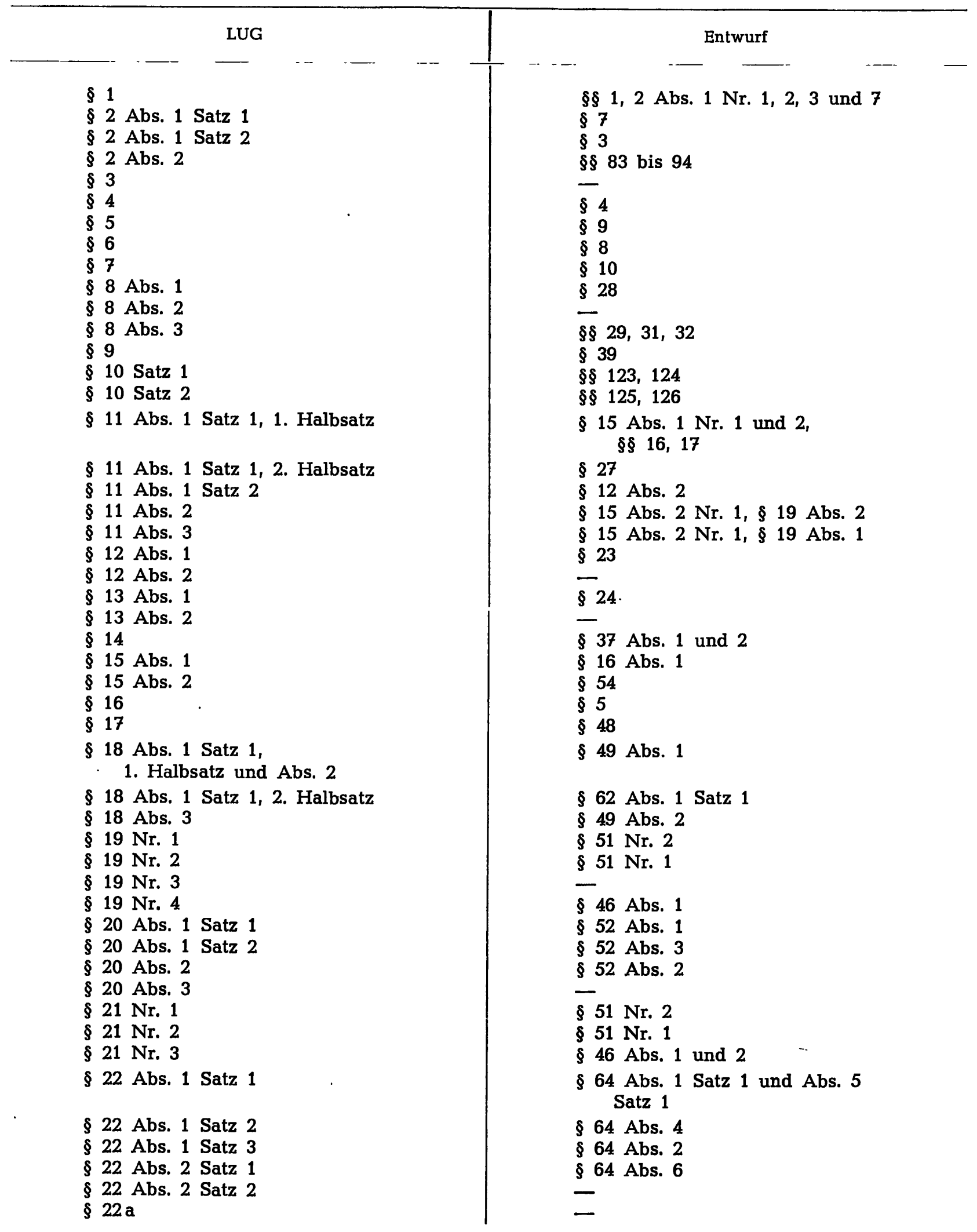




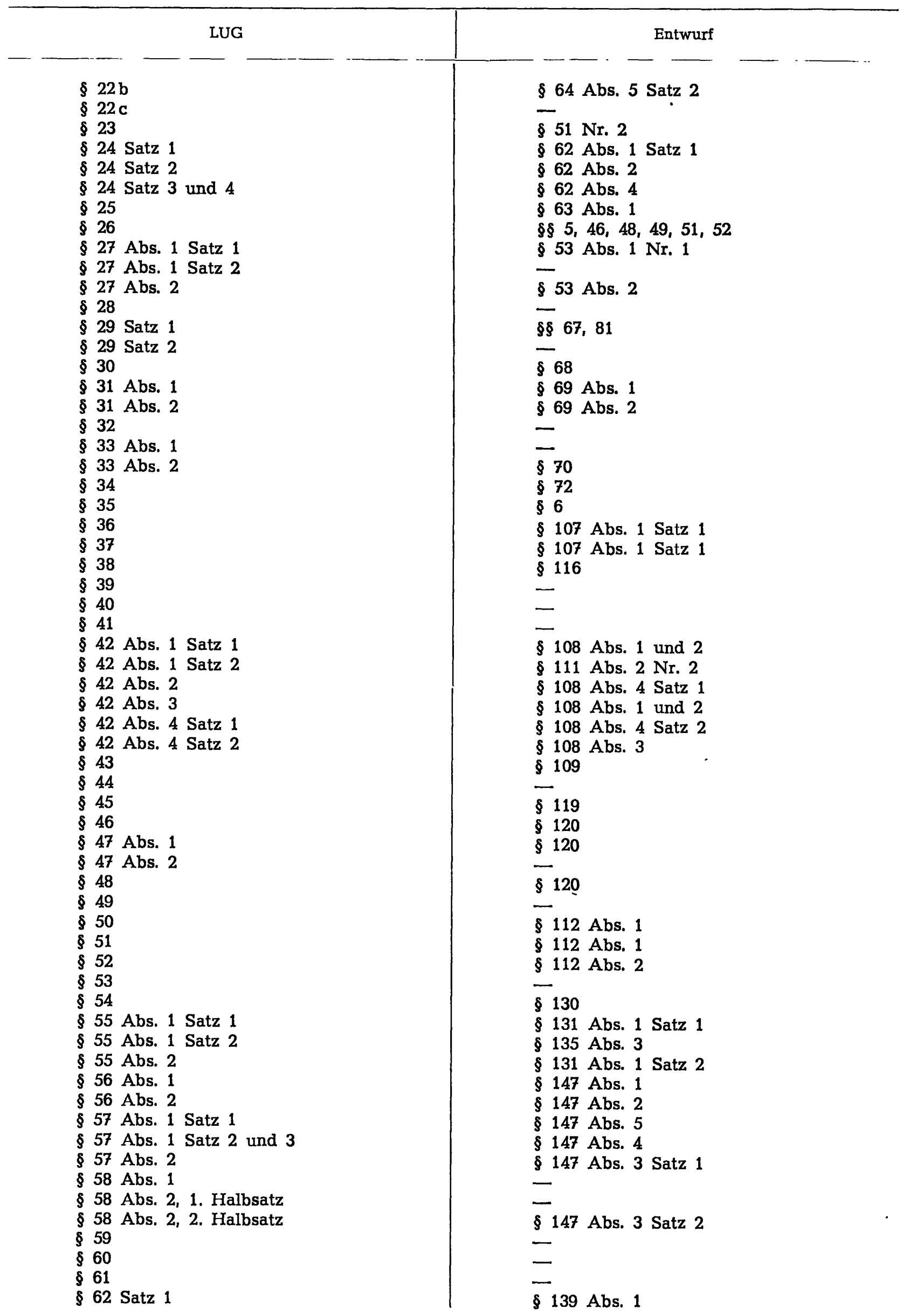


§ 62 Satz 2

$\S 63$ Satz 1

$\S 63$ Satz 2

$\S 63$ Satz 3

§ 63a Abs. 1 Satz 1

$\S 63$ a Abs. 1 Satz 2

$\S 63$ a Abs. 2

§ 64 Satz 1

$\S 64$ Satz 2

$\S 64$ Satz 3
Entwurf

LUG

$\mid \begin{gathered}\text { Entwurf } \\ \S 140 \\ \S 145 \text { Abs. } 1 \\ \S 145 \text { Abs. } 2 \\ \S 142 \text { Abs. } 1 \\ - \\ \S 152 \\ \S 150\end{gathered}$


III.

Gegenüberstellung der Vorschriften des Gesetzes betreffend das Urheberrecht an Werken der bildenden Künste und der Photographie (KUG) zu den Vorschriften des Entwurfs.

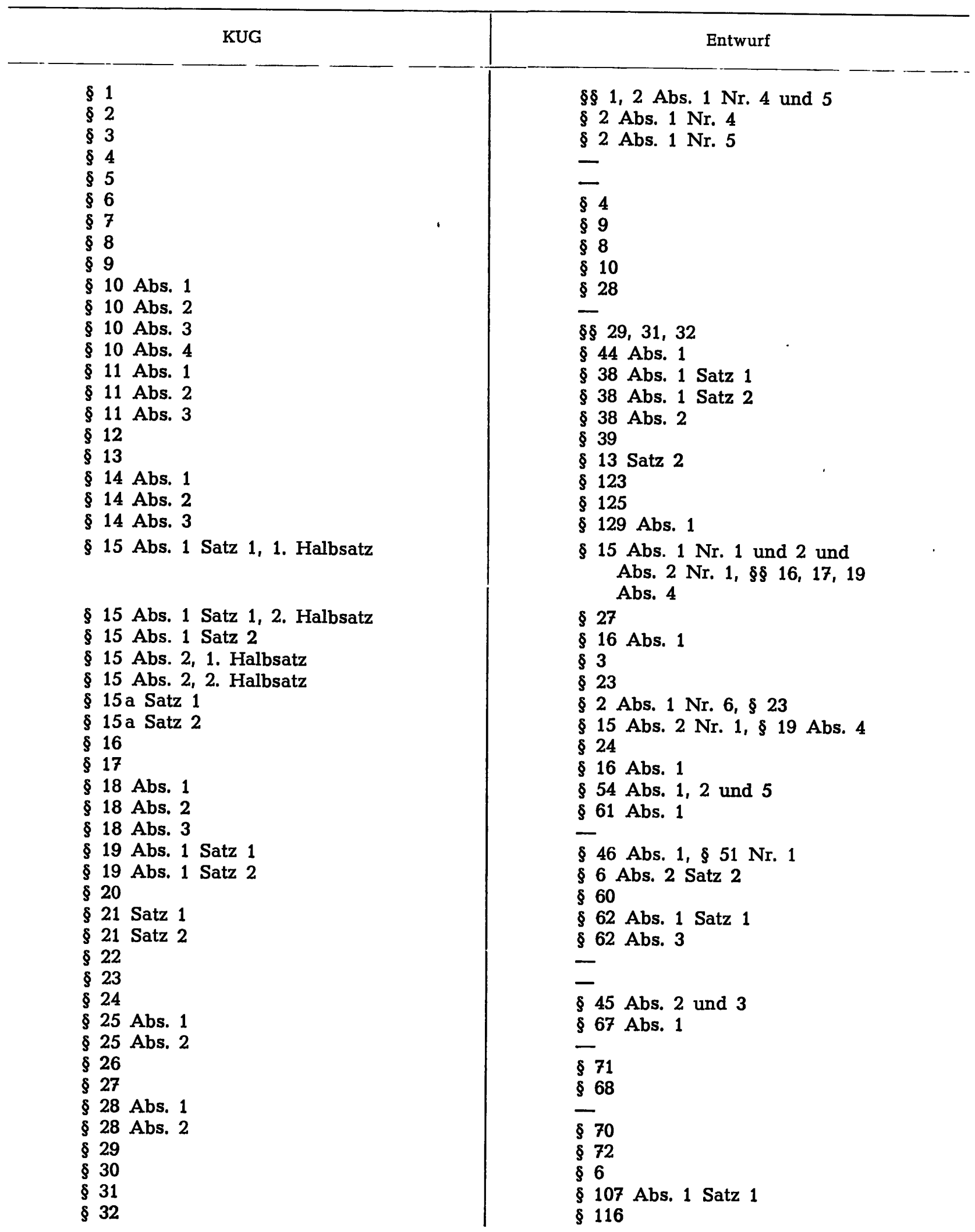




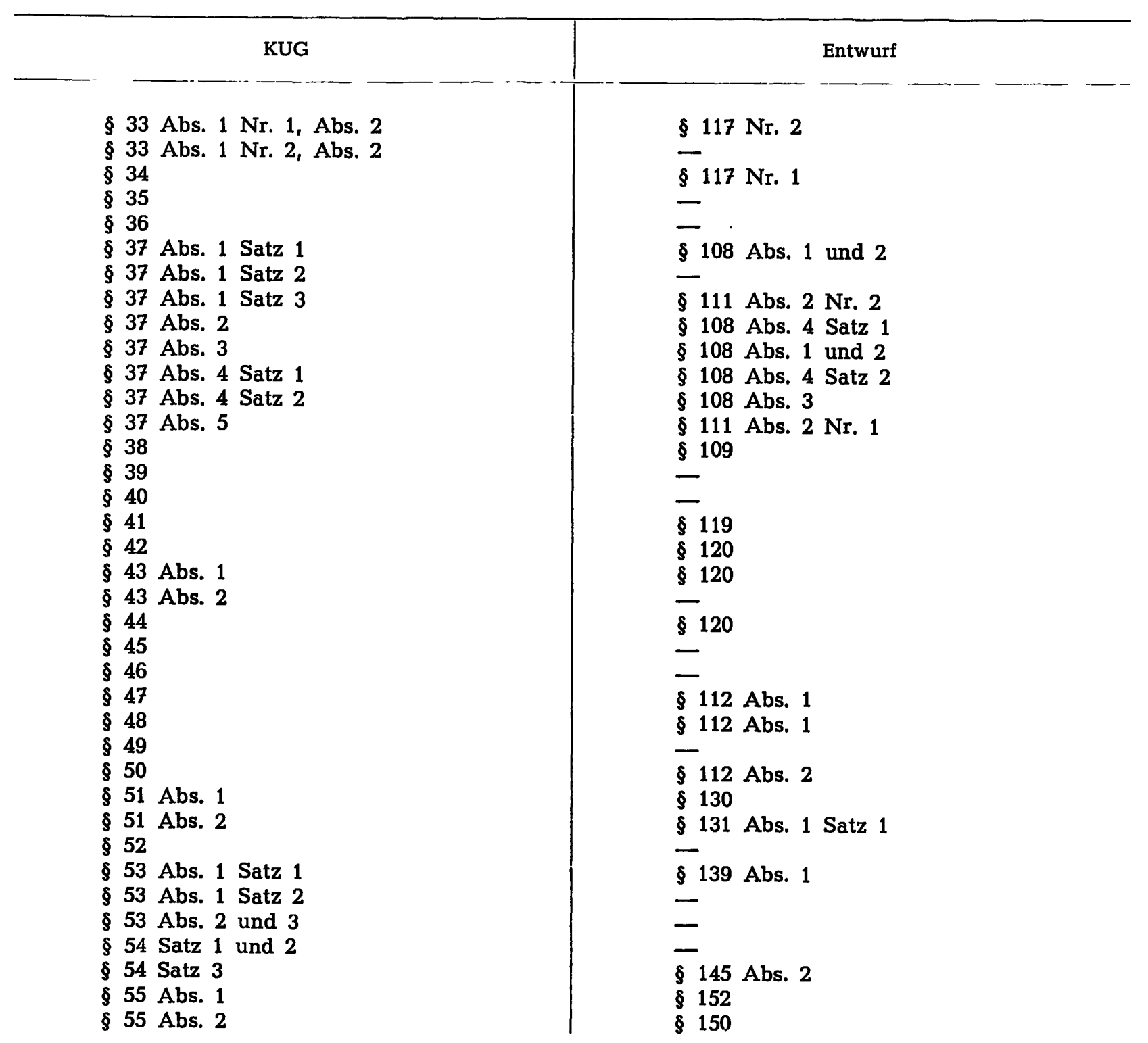


Anlage 2

\section{Stellungnahme des Bundesrates}

1. Die Eingangsworte sind wie folgt $\mathrm{zu}$ fassen:

"Der Bundestag hat mit Zustimmung des Bundesrates das folgende Gesetz beschlossen:"

B e gr ü n d u n g

Das im Entwurf vorliegende Gesetz bedarf der Zustimmung des Bundesrates, da durch $\S 148$ die Strafprozeßordnung geändert wird, die ein Zustimmungsgesetz ist.

\section{Zu $§ 19$ Abs. 3}

Die Eingangsworte des $\S 19$ Abs. 3 sind wie folgt zu fassen:

"(3) Das Vertrags- und das Aufführungsrecht umfassen ..."

B e gr ü nd u ng

Redaktionelle Verbesserung.

\section{Zu § 26 Abs. 1 Satz 2}

In $\S 26$ Abs. 1 sind in Satz 2 die Worte "fünfhundert Deutsche Mark" durch die Worte "zweitausend Deutsche Mark" zu ersetzen.

B e gr ündung

Die Mindestgrenze für den Veräußerungserlös sollte erhöht werden, damit Bagatellfälle ausgeschlossen werden.

\section{Zu $\S 44$ Abs. 2}

In $\S 44$ Abs. 2 sind nach dem Wort "Künste" die Worte "oder eines Lichtbildwerks" einzufügen.

B e g r ü n d u n g

Notwendige Ergänzung im Hinblick auf $\S 18$.

\section{Zu $\S 45$ Abs. 2}

In $\S 45$ Abs. 2 ist das Wort „Behörden" durch die Worte "Gerichte und Behörden" zu ersetzen.

B e gr ündung

Angleichung an die Terminologie in Absatz 1.

\section{Zu $\S 46$ Abs. 4}

$\S 46$ Abs. 4 ist zu streichen.

$\mathrm{B}$ e g r ündung

Dic Vergütungspflicht führt $\mathrm{zu}$ einer unerwünschten Verteuerung der Schulbücher. Die Vermögensinteressen der Urheber sollten hier gegenüber den Interessen der Allgemeinheit an der Volksbildung zurücktreten. Es ist $\mathrm{zu}$ berücksichtigen, daß kein Urheber ganz allein aus sich heraus schafft, sondern auf dem geistigen Gesamtbesitz des Volkes aufbaut. Hier, bei den Interessen der Volksbildung, sollte der Urheber als Dank für das ihm überkommene Kulturgut mit einer unentgeltlichen Weitergabe der von ihm geschaffenen Werke an die folgenden Generationen einverstanden sein.

\section{Zu § 47 Abs. 1}

a) In $\S 47$ Abs. 1 sind nach dem Wort "Schulen" die Worte "sowie Einrichtungen der Lehrerbildung und der Lehrerfortbildung" einzufügen.

\section{B e $\mathrm{g} r \ddot{\mathrm{u}} \mathrm{n} \mathrm{d} u \mathrm{n} \mathrm{g}$}

Die Ergänzung erscheint notwendig im Interesse der Vertrautheit der Lehrer mit den Schulfunksendungen und weil es die Ausbildungspläne der genannten Einrichtungen ebensowenig wie die Lehrpläne der Schulen zulassen, daß Schulfunksendungen $\mathrm{zu}$ der Zeit abgehört werden, zu der sie gesendet werden.

b) $\S 47$ Abs. 1 ist durch folgenden Satz zu ergänzen:

„Das gleiche gilt für Erziehungsheime der Jugendfürsorge."

\section{B e gr ü n d ung}

Die vorgeschlagene Erweiterung erscheint erforderlich, weil in den Erziehungsheimen der Jugendfürsorge das gleiche Bedürfnis für die Vervielfältigung besteht wie in den Schulen.

8. Zu $§ 53$ Abs. 1 Nr. 1

$\S 53$ Abs. 1 Nr. 1 ist eingangs wie folgt zu fassen:

"1. wenn die Wiedergabe keinem Erwerbszweck des Veranstalters dient, die Teilnehmer ohne Entgelt zugelassen werden oder bei öffentlichen Schulveranstaltungen lediglich ein Beitrag zur Deckung der Unkosten erhoben wird und im Falle..."

B e g r ündu n g

Schulveranstaltungen dienen in erster Linie dazu, cinem interessierten Personenkreis (Eltern, Erzieher usw.), also der erweiterten Schulgemeinde, einen Ubberblick über den Leistungsstand der Schule auf bestimmten Gebieten zu 
geben. Zur Durchführung der Veranstaltungen ist es häufig erforderlich, gewisse Materialien käuflich zu beschaffen. Ebenso bedingt eine würdige und wirksame Ausgestaltung von Schulfeiern in vielen Fällen Kosten für einfache Dekorationen, Miete usw. Letzteres trifft insbesondere bei Schulen $\mathrm{zu}$, die nicht in der Lage sind, eigene Räume für solche Veranstaltungen zu benützen. Sofern lediglich diese Kosten durch Beiträge der Teilnehmer gedeckt werden, müssen solche Veranstaltungen jenen gleichstehen, bei denen die Teilnehmer ohne Entgelt zugelassen werden.

\section{Zu § 54 Abs. 3}

$\S 54$ Abs. 3 ist zu streichen.

B e gründ ung

Es kann zwar die Möglichkeit nicht ausgeschlossen werden, daß dem Urheber durch private Tonbandaufnahmen wirtschaftliche Einbußen entstehen. Der zur Abwendung solcher Einbußen vorgesehene Vergütungsanspruch erscheint, da sich die Aufnahmen im privaten Bereich vollziehen, jedoch nicht durchsetzbar.

Weder kann damit gerechnet werden, daß die Verpflichteten infolge einer Wandlung der Rechtsüberzeugung den Vergütungsanspruch künftig freiwillig erfüllen, noch besteht eine ausreichende Gewähr dafür, daß etwa die Gerätehersteller den Vergütungsanspruch ablösen.

$\mathrm{Zu}$ diescn rechtspolitischen Erwägungen treten noch solche aus kulturpolitischer Sicht, da das Tonband geeignet ist, sich zu einem kulturpolitischen Faktor zu entwickeln. Die Bereitwilligkeit, den Vergütungsanspruch freiwillig zu erfüllen, wird daher unter Umständen auch deswegen zweifelhaft sein, weil unklar ist, ob bei der Bemessung der Vergütung den kulturpolitischen Uberlegungen Rechnung getragen würde und die Möglichkeit einer Häufung von Ansprüchen mehrerer Verwertungsgesellschaften ausgeschlossen wäre.

10. Zu § 60 Abs. 1

In $\S 60$ Abs. 1 ist das Wort "wiederzugeben" durch das Wort "vorzuführen" zu ersetzen.

B e gründung

Klarstellung des Gewollten.

11. Zu § 64 Abs. 1

$\S 64$ Abs. 1 ist eingangs wie folgt $\mathrm{zu}$ fassen:

"(1) Ist einem Hersteller von Tonträgern ein Nutzungsrecht an einem Werk der Musik eingeräumt worden mit dem Inhalt, ..."

B e gr ündung

Die Vorschrift muß ihrem Sinne nach auch dann zum Zuge kommen, wenn das Nutzungsrecht nicht von dem Urheber, sondern von einem sonstigen Berechtigten eingeräumt worden ist.

\section{2. $\mathrm{Zu} \S 64$ Abs. 6}

$\S 64$ Abs. 6 ist wie folgt zu fassen:

"(6) Auf ein Sprachwerk, das als Text mit einem Werk der Musik verbunden ist, sind die vorstehenden Bestimmungen entsprechend anzuwenden, wenn einem Hersteller von Tonträgern ein Nutzungsrecht eingeräumt worden ist mit dem Inhalt, das Sprachwerk in Verbindung mit dem Werk der Musik auf Tonträger $\mathrm{zu}$ übertragen und diese $\mathrm{zu}$ vervielfältigen und zu verbreiten."

B e gr ündu ng

wie zu $\S 64$ Abs. 1.

\section{3. $\mathrm{Zu} \$ \$ 73$ bis 79}

Die $\S \S 73$ bis 79 sind zu streichen.

B e g r ü ndu $\mathrm{ng}$

Der Grundgedanke des Entwurfs, zusätzliche Mittel für eine Förderung und Unterstützung der Urheber bereitzustellen, ist zu begrüßen. Für die Einführung einer Urhebernachfolgevergütung fehlt jedoch dem Bund die Gesetzgebungskompetenz. Die zur Streichung vorgeschlagenen Vorschriften sind nicht durch Artikel 73 Nr. 9 GG gedeckt. Sie schen vor, daß für die Verwertung eines urheberrechtlich nicht mehr geschützten oder nie geschützt gewesenen Werkes eine Vergütung an einen Urheberfonds zu entrichten ist. Die dadurch aufgebrachten Mittel sollen für Ehrensolde an verdiente Urheber, zur Hinterbliebenenversorgung sowie für Förderungsbeihilfen lür begabte Urheber verwandt werden. Die für das Urheberrecht wesentliche Verbindung zwischen dem Urheber und seinem Werk wird bei einer Regelung, die an den Untergang des Urheberrechts anknüpft, eindeutig verlassen. Eine Kompetenz des Bundes für eine solche Regelung kann auch nicht aus dem Gesichtspunkt eines notwendigen Sachzusammenhangs mit Artikel $73 \mathrm{Nr} .9$ GG hergeleitet werden; denn die Regelung des Urheberrechts setzt nicht notwendig voraus, daß solche Maßnahmen zur Kulturförderung getroffen werden. Eine Gesetzgebungskompetenz des Bundes aus Artikel 105 GG kommt nicht in Betracht, weil die Urhebernachfolgevergütung keine Steuer im Sinne dieser Bestimmung ist. Sie stellt eine Abgabe zur Kulturförderung dar. An ihrem öffentlich-rechtlichen Charakter vermag die privatrechtliche Ausgestaltung im Entwurf nichts zu ändern, so daß eine Gesetzgebungskompetenz des Bundes auch aus Artikel 74 Nr. 1 GG nicht hergeleitet werden kann.

14. Zu § 115 Abs. 2

In $\S 115$ Abs. 2 sind nach dem Wort "ermächtigt," die Worte "durch Rechtsverordnung" einzufügen.

B e gr ü nd ung

Notwendige Ergänzung. 


\section{Zu $§ 119$}

Die Bundesregierung wird gebeten, im weiteren Verlauf des Gesetzgebungsverfahrens $\S \S 119,30$ dahin zu überprüfen, ob der Rechtsnachfolger auch dann antragsberechtigt sein soll, wenn sich die Tat noch gegen seinen Rechtsvorgänger gerichtet hat.

16. Zu $\S 121$ Abs. 1

In $\S 121$ Abs. 1 sind die Sätze 2 und 3 wie folgt zu fassen:

„Dem Verletzten ist auf Kosten des Angeklagten eine Ausfertigung des rechtskräftigen Urteils zuzustellen. Die Befugnis zur Bekanntmachung erlischt, wenn die Verurteilung nicht innerhalb von sechs Monaten nach der Zustellung bekanntgemacht wird."

\section{B e gr ündung}

Beginnt die Frist mit der Rechtskraft, so kann die Fristwahrung für den Verletzten, besonders bei mehreren Angeklagten, mit Schwierigkeiten verbunden sein. Diese entfallen, wenn auf die Zustellung des rechtskräftigen Urteils abgestellt wird. Außerdem stehen Beginn und Ende der Frist für alle Beteiligten zweifelsfrei fest.

\section{Zu $§ 141$ Abs. 1 letzter Satz}

$\S 141$ Abs. 1 letzter Satz ist zu streichen.

B e gr ü ndung

Es ist zumindest rechtspolitisch bedenklich, einen so schweren Eingriff in die Vertragsfreiheit auf bereits bestehende Vertragsverhältnisse auszudehnen.

\section{Zu $\S 147$ Abs. 2}

Die in $\S 147$ Abs. 2 vorgesehene Zuständigkeit des Patentgerichts hat keine verfassungsrechtliche Grundlage. Artikel 96 a Abs. 1 GG beschränkt die Zuständigkeit des Patentgerichts auf Angelegenheiten des gewerblichen Rechtsschutzes. Urheberrechtliche Angelegenheiten rechnen, wie sich auch aus Artikel 73 Nr. 9 GG ergibt, nicht dazu.

Im weiteren Gesetzgebungsverfahren ist daher $\S 147$ Abs. 2 dahin umzugestalten, daß an Stelle des Patentgerichts das für den Sitz des Patentamts zuständige Oberlandesgericht in einem Verfahren der freiwilligen Gerichtsbarkeit entscheidet.

\section{9. $\mathrm{Zu} \S \S 147$ bis 152}

In die Schlußbestimmungen ist folgende Vorschrift aufzunehmen:

$$
\text { "§... }
$$

Die auf Grund dieses Gesetzes ergehenden Rechtsverordnungen des Bundesministers der Justiz bedürfen nicht der Zustimmung des Bundesrates."

\section{B e gründung}

Da es sich bei dem vorliegenden Gesetzentwurf um ein Zustimmungsgesetz handelt, bedürften die Rechtsverordnungen nach Artikel 80 Abs. 2 GG der Zustimmung des Bundesrates. Die Mitwirkung des Bundesrates beim Erlaß dieser Rechtsverordnungen erscheint jedoch nicht erforderlich.

20. Zu § 152 Abs. 2 (neu)

Dem $\S 152$ ist folgender neuer Absatz 2 anzufügen:

"(2) $\S 115$ Abs. 1 bis 3 und $\S 147$ Abs. 5 treten am Tage nach der Verkündung in Kraft."

\section{B e gr ündu n g}

Es muß sichergestellt werden, daß die in den genannten Vorschriften erwähnten Rechtsverordnungen bei Inkrafttreten des Gesetzes vorliegen können. 


\section{Auffassung der Bundesregierung zu der Stellungnahme des Bundesrates}

Die Bundesregierung nimmt zu den Änderungsvorschlägen des Bundesrates wie folgt Stellung:

\section{Zu 1.}

Dem Vorschlag wind nicht zugestimmt.

Die Auffassung des Bundesrates, daß das Gesetz der Zustimmung des Bundesrates bedürfe, weil $\S 148$ des Entwurfs ein Gesetz, das mit Zustimmung des Bun'desrates ergangen ist - nämlich die Strafprozeßordnung - förmlich ändert, wird von ider Bundesregierung nicht geteilt. Nach Auffassung ider Bundesregierung bedarf die Änderung eines mit Zustimmung ides Burdesrates erlassenen Gesetzes nur dann wiederum Ider Zustimmung, wenn sich die Änderung auf solche Normen bezieht, die entweder die $\mathrm{Zu}$ stimmungsbedürftigkeit des zu ändernden Gesetzes selbst begründet haben oder mit zustimmungsbedürftigen Normen in einem untrennbaren Zusammenhang stehen. Dies ist hinsichtlich ides durch $\S 148$ des Entwurfs geänderten $\S 374$ der Strafprozeßordnung nicht der Fall.

\section{Zu 2.}

Dem Vorschlag wind zugastimmt.

\section{Zu 3.}

Dem Vorschlag wird nicht zugestimmt.

Die vorgeschlagene Erhöhung der Mindestgrenze für ddie vom Folgerecht erfaßten Verkaufsfälle von $500 \mathrm{DM}$ auf $2000 \mathrm{DM}$ würde den Anwendungsbereich der Vorschrift insbesondere für das bedeutende Gebiet der graphischen Kunst ungerechtfertigt einschränken, auf dem nur selten Preise über 2000 DM, vielfach jedoch Preise über $500 \mathrm{DM}$ erzielt werden.

\section{Zu 4. und 5 .}

Den Vorschlägen wird zugestimmt.

\section{Zu 6.}

Dem Vorschlag wind nicht zugestimmt.

Dem Interesse tder Allgemeinheit an einer Erleichterung des Schulunterrichts wird dadurch ausreichend Rechnung getragen, daß der Urheber die Aufnahme seines Werkes in Sammlungen für den Schulgebrauch nicht verbieten kann. Darüber hinaus dem Urheber den vorgesehenen Vergütungsanspruch für eine solche Nutzung seines Werkes zu versagen, würde der Grundlinie des Entwurfs widersprechen, nach der ider Urheber nicht verpflichtet werden soll, seine Werke für Zwecke, deren Erfüllung Aufgabe der Allgemeinheit ist, unentgeltlich zur Verfügung zu stellen. Finanzielle Opfer zu Gunsten der Allgemeinheit sollten nach Auffassung der Bundesregierung gerade Idem Urheber, Ider in Ider Regel auf die Einnahmen aus seinen Werken angewiesen ist, nicht zugemutet werden.

\section{$\mathrm{Zu} \mathrm{7.} \mathrm{a)} \mathrm{und} \mathrm{b)}$}

Den Vorschlägen wird nicht zugestimmt.

Zwe,ck der Ausnahmebestimmung ides $\S 47$ ist es, den Schulen idie richtige Einfügung von Schulfunksendungen in den jährlichen Unterrichtsplan $\mathrm{zu}$ ermöglichen. Nur diese enge Zweckbestimmung, bei der Idavon ausgegangen wenden kann, idaß ıdie Bandaufnahme einer Schulfunksendung grundsätzlich nur jeweils einmal zur Wiedergalbe in iden Schulklassen benutzt wird, für die die Sendung bestimmt ist, rechtfertigt es hier, eine Vervielfältigung ohne $\mathrm{Ge}$ nehmigung des Urhebers und darüber hinaus vergütungsfrei zuzulassen. Im Falle der vorgeschlagenen Erstreckung der Vorschrift auf Einrichtungen der Lehrerbildung und Lehrerfortbilldung sowie auf Erziehungsheime der Jugendfürsorge würde diese Zweckbestimmung verlassen, zumal da bei solchen Einrichtungen im Gegensatz zu den allgemeinbildenden Schulen kein an einen jährlichen Turnus gebundener Unterrichtsplan besteht.

\section{Zu 8.}

Dem Vorschlag wird nicht zugestimmt.

Nach Auffassung der Bundesregierung ist es nicht gerechtfertigt, für öffentliche Schulveranstaltungen über die allgemeine Ausnahmebestimmung des $\S 53$ Abs. 1 Nr. 1 hinaus eine Sonderregelung zu treffen. Die ıdort für ddie Wiedergabefreiheit allgemein vorgesehene Voraussetzung, Idaß die Teilnehmer der Veranstaltung ohne Entgelt zugelassen sein müssen, beruht auf der Erwägung, Idaß bei Erhebung eines Entgelts, sei es auch nur zur Deckung ider Unkosten, dieses unschwer so bemessen werden kann, daß es die im Verhältnis zu den übrigen Unkosten geringe Urhebervergütung mit ıdeckt. Diese Enwägung trifft für öffentliche Schulveranstaltungen ebenso zu wie für andere öffentliche Veranstaltungen. Zu einer Einschränkung ider Rechte ides Urhebers bei öffentlichen Schulveranstaltungen, für ıdie ein Unkostenbeitrag erhoben wind, besteht um so weniger Veranlassung, als die Schulverwaltungen mit iden Verwertungsgesellschaften der Urheber Pauschalverträge für derartige Veranstaltungen abschließen können.

Zu 9.

Dem Vorschlag wird zugestimmt. 


\section{Zu 10.}

Dem Änderungsvorschlag stimmt die Bundesregierung insofern $\mathrm{zu}$, als auch sie eine Klarstellung des Gewollten für enforderlich hält. Sie ist jedoch der Auffassung, daß die erforderliche Klarstellung besser durch Streichung der Worte "sowie solche Werke durch Fernsehfunk zu senden" unter Beibehaltung des Wortes "wiederzugeben“ erreicht werden kann. Sie schlägt dementsprechend folgende Neufassung ides $\S 60$ Abs. 1 vor:

"(1) Zulässig ist, Werke, die sich bleibend an öffentlichen Wegen, Straßen oder Plätzen befinden, mit Mitteln der Malerei oder Graphik, durch Lichtbild oder durch Film zu vervielfältigen, zu verbreiten und öffentlich wiederzugeben. Bei Bauwerken erstrecken sich diese Befugnisse nur auf die äußere Ansicht."

\section{Zu 11. und 12.}

Den Vorschlägen wird zugestimmt. Die Bundesregierung weist jedoch darauf hin, Idaß bei Annahme der Anderungsvorschläge $\S 64$ Abs. 7 an die Neufassung von $\S 64$ Abs. 1 und 6 idurch folgende Neufiassung angepaßt werden muß:

"(7) Die vorstehenden Bestimmungen sind nicht anzuwenden, wenn das in Absatz 1 bezeichnete Nutzungsrecht lediglich für die Herstellung eines Tonfilms eingeräumt worden ist."

\section{Zu 13.}

Dem Vorschlag wird nicht zugestimmt.

Die Bundesregierung hält an ihrer Auffassung fest, daß die Gesetzgebungskompetenz des Bundes für die Urhebernachfolgevergütung aus Artikel 73 Nr. 9 GG folgt, der die ausschließliche Gesetzgebung über das Urheberrecht dem Bund zuweist. Für eine einschränkende Auslegung dieser Vorschrift dahingehend, daß der Bundesgesetzgeber nur zu einer Regelung der Rechte des einzelnen Urhebers an seinem Werk befugt sein soll, besteht kein Anlaß. Zum Urheberrecht im Sinne von Artikel 73 Nr. 9 GG können vielmehr alle Regelungen gerechnet wenden, die, wie es bei der Urhebernachfolgevergütung der Fall ist, an Idie Nutzung von Werken anknüpfen. Ob hierbei die Gesetzgebungskompetenz des Bundes auf privatrechtliche Regelungen beschränkt ist oder auch solche öffentlich-rechtlicher Art umfaßt, kann dahinstehen, da es sich ibei der vorgeschlagenen Urhebernachfolgevergütung entgegen ider Auffassung des Bundesrates nicht um eine öffentlich-rechtliche Abgabe, sondern um einen privatrechtlichen Anspruch handelt, der zudem nicht idem Staat, sondern einer Stiftung des bürgerlichen Rechts zustehen soll.

\section{Zu 14.}

Dem Vorschlag wird zugestimmt.

\section{Zu 15.}

Die Bundesregierung wird die angeregte Prüfung vornehmen.
Zu 16.

Dem Vorschlag wird zugestimmt.

Zu 17.

Dem Vorschlag wird nicht zugestimmt.

Die in $\S 141$ Abs. 1 Satz 3 vorgesehene Anwendung des $\S 36$ auf bestehende Verträge mit der Maßgabe, daß eine Beteiligung an vor Inkrafttreten des Gesetzes gezogenen Nutzungserträgnissen nicht verlangt werden kann, erscheint rechtspolitisch nicht bedenklich. § 36 sieht einen Beteiligungsanspruch für ıdie Fälle vor, in denen nach Abschluß des Vertrages unerwartet ein auffälliges Mißverhältnis zwischen den Nutzungserträgnissen und der dem Urheber gezahlten Vergütung entsteht. Die Vertragsgestaltung kann daher nicht davon beeinflußt worden sein, idaß zur Zeit des Vertragsabschlusses eine solche Vorschrift noch nicht bestand. Daraus folgt, daß es hinsichtlich des Beteiligungsanspruchs für bestehende Vertragsverhältnisse keines Vertrauensschutzes bedarf. Lediglich soweit bei bestehenden Vertragsverhältnissen die Voraussetzungen des Beteiligungsanspruchs schon vor Inkrafttreten des Gesetzes eingetreten sind, war eine Rückwirkung auszuschließen.

\section{Zu 18.}

Die Bundesregierung teilt die Auffassung des Bundesrates. Sie schlägt unter Berücksichtigung der Anregungen des Bundesrates folgende Neufassung des $\S 147$ Abs. 2 vor:

"(2) Wird die Eintragung abgelehnt, so kann der Antragsteller gerichtliche Entscheidung beantragen. Ubber den Antrag entscheidet das für iden Sitz des Patentamts zuständige Oberlandesgericht durch einen mit Gründen versehenen Beschluß. Der Antrag ist schriftlich bei dem Oberlandesgericht einzureichen. Die Entscheidung des Oberlandesgerichts ist endgültig. Im übrigen gelten für das gerichtliche Verfahren die Vorschriften des Reichsgesetzes über die freiwillige Gerichtsbarkeit entsprechend. Für die Gerichtskosten gilt die Kostenondnung; die Gebühren richten sich nach $\S 131$ 'der Kostenordnung. ${ }^{\prime \prime}$

\section{Zu 19.}

Dem Vorschlag wind nicht zugestimmt.

Nach Auffassung der Bundesregierung bedarf das Gesetz nicht der Zustimmung des Bundesrates (vgl. zu 1.). Die angeregte Ergànzung erübrigt sich daher.

\section{Zu 20.}

Dem Vorschlag wind zugestimmt, jedoch hält es die Bundesregierung für richtiger, die angeregte Ergänzung als Absatz 1 des $\S 152$ einzufügen. Dementsprechend wird folgende Neufassung ides $\S 152$ vorgeschlagen:

$$
\text { "§ } 152
$$

\section{Inkrafttreten}

(1) $\S 115$ Abs. 1 bis 3 und $\S 147$ Abs. 5 treten am Tage nach der Verkündung dieses Gesetzes in Kraft.

(2) Im übrigen tritt dieses Gesetz am ....... in Kraft." 